\title{
L'animal symbole
}

Marianne Besseyre,

Pierre-Yves Le Pogam,

Florian Meunier (dir.)

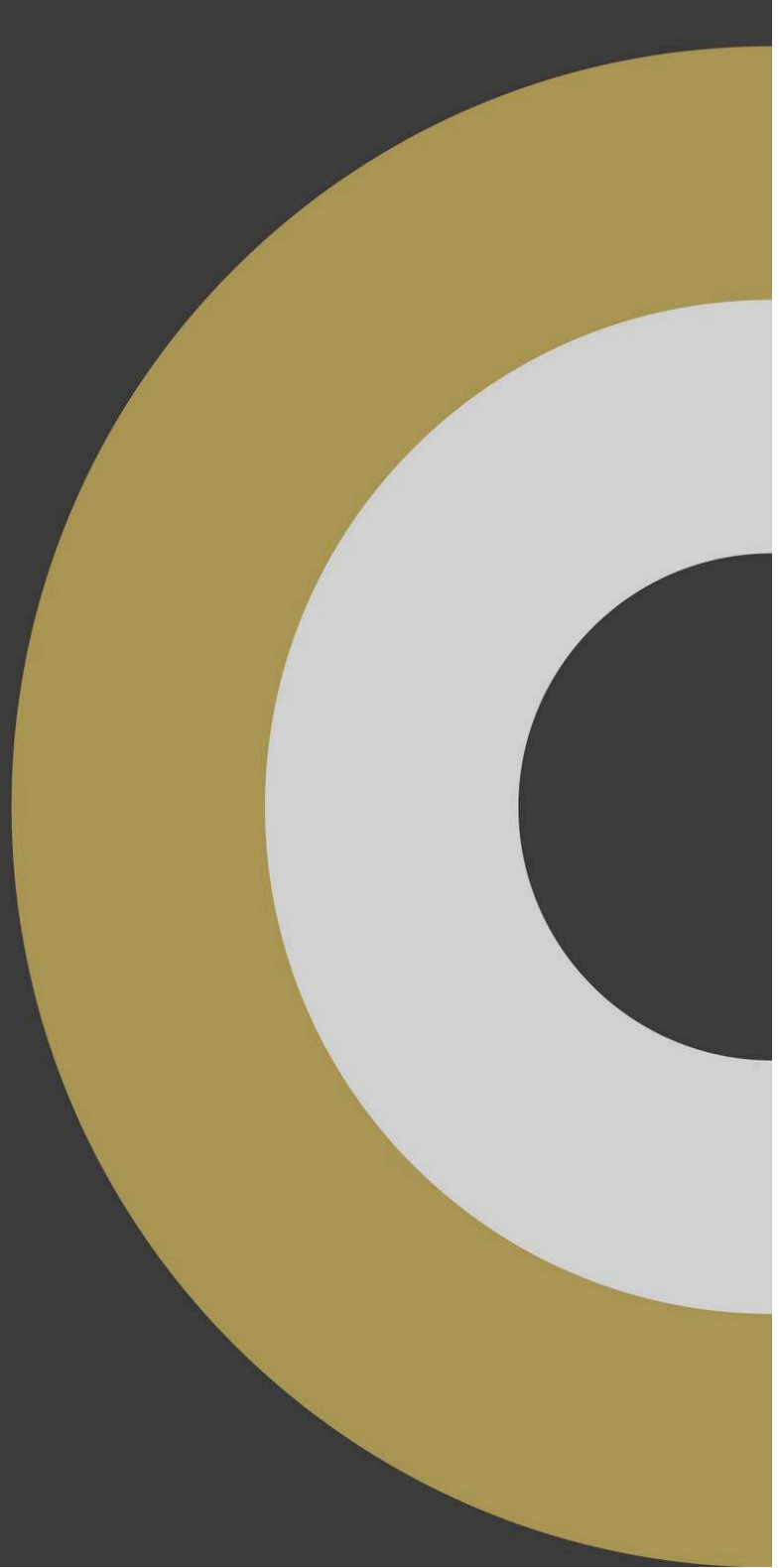




\section{L'animal symbole}

\section{Marianne Besseyre, Pierre-Yves Le Pogam et Florian Meunier (dir.)}

DOI : $10.4000 /$ books.cths. 5008

Éditeur : Éditions du Comité des travaux historiques et scientifiques

Lieu d'édition : Paris

Année d'édition : 2019

Date de mise en ligne : 30 avril 2019

Collection : Actes des congrès nationaux des sociétés historiques et scientifiques

EAN électronique : 9782735508839

\section{Q OpenEdition}

Books

https://books.openedition.org

Référence électronique

BESSEYRE, Marianne (dir.) ; LE POGAM, Pierre-Yves (dir.) ; et MEUNIER, Florian (dir.). L'animal symbole. Nouvelle édition [en ligne]. Paris : Éditions du Comité des travaux historiques et scientifiques, 2019 (généré le 15 février 2023). Disponible sur Internet : <http://books.openedition.org/cths/5008>. ISBN : 9782735508839. DOI : https://doi.org/10.4000/books.cths.5008.

Ce document a été généré automatiquement le 15 février 2023.

(C) Éditions du Comité des travaux historiques et scientifiques, 2019

Licence OpenEdition Books 


\section{RÉSUMÉS}

Religions et mythes antiques ont souvent encouragé une vision fusionnelle entre animal et homme qui semble avoir servi de repoussoir, en tant que symbole du mal ou du diable, aux religions monothéistes : des indices laissés par les vases et les textes grecs jusqu'aux sculptures médiévales en passant par l'Orient, les enquêtes sont toutes complexes et finalement révélatrices des rapports symboliques entre l'animal et l'homme.

Le Congrès national des sociétés historiques et scientifiques rassemble chaque année universitaires, membres de sociétés savantes et jeunes chercheurs. Ce recueil est issu de travaux présentés lors du $141^{\mathrm{e}}$ Congrès sur le thème « L'animal et l'homme »

\section{MARIANNE BESSEYRE (DIR.)}

Conservatrice des bibliothèques, Ciham UMR 5648

\section{PIERRE-YVES LE POGAM (DIR.)}

Conservateur en chef au département des Sculptures du musée du Louvre

FLORIAN MEUNIER (DIR.)

Conservateur en chef département des Objets d'art du musée du Louvre 


\section{NOTE DE L'ÉDITEUR}

Les articles de cet ouvrage ont été validés par le comité de lecture des Éditions du Comité des travaux historiques et scientifiques dans le cadre de la publication des actes du $141^{\mathrm{e}}$ Congrès national des sociétés historiques et scientifiques tenu à Rouen en 2016. 
SOMMAIRE

Introduction

Marianne Besseyre, Pierre-Yves Le Pogam et Florian Meunier

Aux origines des symboles de l'Occident : métamorphoses et hybridations dans les mythes et les religions

L'animal vivant et mort dans les religions : l'animal de sacrifice

Imitations et appropriations symboliques : l'animal comique et l'animal-signe

\section{Ouverture}

Du démon ambivalent à l'héroïne compatissante : la sirène entre monde antique et médiéval Jacqueline Leclercq-Marx

\section{Aux origines des symboles de l'Occident : métamorphoses et hybridations}

\section{dans les mythes et les religions}

L’homme-animal : hybridité et monstruosité dans l'iconographie des vases grecs

François Boudin

Les hybrides simples

Les hybrides multiples

Construction d'images

Les métamorphoses animales de Fintan et Tuán: les hommes primordiaux témoins de l'histoire mythique de l'Irlande

Cindy Cadoret

Tuán : le témoin désigné par Dieu

Fintan : le témoignage juridique

Énoch et Élie

À la recherche des plus vieux animaux du monde

Le bestiaire celtique

Des traces de l'eschatologie des anciens Celtes?

Passages. De l'homme à l'animal dans les mythes gréco-romains : trace des mythes dans la science

Catherine Lochin

Le rossignol

Plusieurs personnages pour un seul animal

La femme-génisse et l'homme-oiseau ou l'art de la métamorphose

Cyril Maré

L'art de la métamorphose ou le champ des possibles

L'art de la métamorphose comme rappel à l'ordre naturel 
La « sirène » d'Orient en Occident comme exemple de la sélection culturelle des hybrides féminins en Méditerranée orientalisante (VIII ${ }^{e}-\mathrm{VI}^{e}$ siècle av. J.-C.)

Christian Mazet

De la Sirène homérique à l'oiseau anthropocéphale chtonien

Origines orientales et antécédents égéens

Sur quelques « sirènes » d'Occident : les cas de Pithécusses et Cerveteri

De l'Ionie à Vulci : la « sirène » du Peintre des Hirondelles

Remarques conclusives

Les loups-garous devant la justice (XVI ${ }^{e}-\mathrm{XVII} I^{e}$ siècle) : l'hybridité comme mobile du crime "inhumain»

Philippe Nieto

Chronologie et contexte intellectuel des procès en lycanthropie

La lycanthropie sous les angles théologique et philosophique

La lycanthropie sous l'angle médical

La lycanthropie du point de vue criminologique

L'hybridité de l'homme sauvage dans l'art médiéval

Florent Pouvreau

L'excès de poil, une véritable hybridité ?

L'humanisation du motif et de nouvelles formes d'hybridité

L'animal nourricier d'enfants dans la mythologie grecque

Liliane Romy-Regent

La chèvre

Le symbolisme de la chèvre en Grèce

L'ourse

Le symbolisme de l'ourse en Grèce

La biche

La jument

Symbolisme du cheval dans l'imaginaire grec

\section{L'animal vivant et mort dans les religions : l'animal de sacrifice}

Noms d'animaux et allusions divines dans l'anthroponymie égyptienne de l'époque grécoromaine

Ana Isabel Blasco Torres

La typologie des anthroponymes à noms d'animaux

Anthroponymes à noms d'animaux et fréquence géographique

Le rôle de l'animal dans la religion romaine : la spécificité des rites et mythes féminins Nicole Boëls-Janssen

Les animaux dans la religion masculine

Les animaux dans la religion féminine

Bona Dea et le serpent

Junon et la chèvre aux Nones Caprotines

La louve nourricière et le pivert

L'animal de sacrifice à Briga («Bois l'Abbé», Eu, Seine-Maritime) : les dépôts de moutons du sanctuaire gallo-romain et de ses alentours

Alice Bourgois, Étienne Mantel, Sébastien Lepetz et Marie-Laurence Haack

Les dépôts du centre monumental

Les structures 3 et 13 : de possibles favissae?

Les caprinés des autres quartiers

Analyse et comparaisons : la place du mouton 
D'une culture à l'autre : l'acclimatation des « animaux sacrés » d'Égypte dans les temples isiaques de Rome

Marie-Christine Budischovsky

Les « métamorphoses »

Localisation des formes animales dans l'espace sacré isiaque

Divinités à forme animale et dévotion à Pompéi

Le serpent et le glaive: animaux et mise à mort dans les pratiques « magiques » de l'époque romaine

Thomas Galoppin

Sacrifices « magiques »?

Mises à mort rituelles

Ritualisation de la matière animale

Entre hommes et dieux : le statut de l'animal et la notion d'hybride dans l'Égypte ancienne Nadine Guilhou

La création des êtres vivants

Modes de création

Le troupeau de Dieu

L'image de Dieu

La bête dans l'homme: péché originel ou origine de la moralité?

Antonello La Vergata

"Ce sont les principaux maîtres des maîtres du monde "(Pline l'Ancien X, 24): le coq dans les religions romaine, grecque et gauloise

Michaël Seigle

Le coq vivant : devin ou oiseau sacré ?

Le coq est-il un oiseau sacré en Gaule?

L'oiseau sacrifié

Rituels domestiques, privés et magiques

Animaux du désert et moines en Égypte au IV siècle : une sociabilité ambiguë

Françoise Thelamon

Les animaux : des êtres dangereux rusés ou dénués de raison

Quand les démons se présentent sous l'aspect de bêtes sauvages

«Les bêtes sauvages seront en paix avec toi » $(\mathrm{Jb} 5,23)$ : une sociabilité réconciliée

Le sanglier et le bœuf entre hommes et dieux : chasser l'animal sauvage, sacrifier l'animal domestique en Grèce ancienne

Françoise Thelamon

Le sanglier et le bœuf : animal sauvage, animal domestique

Montrer ou occulter la violence

Le sanglier et le bœuf : deux animaux symboliques pour délimiter la place des humains dans le

monde

Les manifestations des animaux dans les espaces propres à l'homme comme signe augural dans les collections de présages de Mésopotamie ( ${ }^{e r}$ millénaire av. J.-C.) Andréa Vilela

La structuration de l'espace et ses subdivisions

Les irruptions animales à valeur augurale collective

Les irruptions animales à valeur augurale individuelle ou familiale 


\section{Imitations et appropriations symboliques : l'animal comique et l'animal-signe}

Le déni des apparences : bestiaire et dérision dans l'illustration marginale d'un pontifical de Guillaume Durand (Paris, Bibliothèque Sainte-Geneviève, ms. 143)

Marianne Besseyre

Les animaux imitateurs au XVIII siècle : miroir d'une animalité humaine ou d'une humanité conquérante?

Clotilde Boitard

Une réalité diverse, un amusement multiforme

Un panel étendu d'espèces

Le double mouvement de l'imitation : entre aptitude naturelle et dressage

Un reflet de l'homme ou une marque de différence? Double mouvement de fascination et

domination de la nature

Les jetons « au lion attaquant un loup » en France (fin XVI - -début XVII siècle)

Jérôme Jambu

La lecture de la scène

Plusieurs utilisations, plusieurs interprétations

La seconde série de 1598 : célébrer la victoire d'un roi belliqueux

La dernière série de 1635 : une incantation

Catalogue

La revanche des animaux couards. Lièvres, lapins et escargots dans l'art médiéval : aspects moraux et comiques

Florian Meunier

Le chasseur ligoté par deux lièvres à Königslutter am Elm

Les reliefs des cathédrales, du lapin à l'escargot

Loi salique et exempla

Essai sur la valeur symbolique de la genette dans la littérature et l'art médiéval occidental Virginie Muxart 


\title{
Introduction
}

\author{
Marianne Besseyre, Pierre-Yves Le Pogam et Florian Meunier
}

1 Religions et mythes antiques ont souvent encouragé une vision fusionnelle entre animal et homme qui semble avoir servi de repoussoir, en tant que symbole du mal ou du diable, aux religions monothéistes: des indices laissés par les vases et les textes grecs jusqu'aux sculptures médiévales en passant par l'Orient, les enquêtes sont toutes complexes et finalement révélatrices des rapports symboliques entre l'animal et l'homme.

2 Prenant racine dans le christianisme, une grande partie de la philosophie moderne a poursuivi dans la voie d'une opposition irréductible, par nature, entre l'être humain, doué de langage et jugé rationnel, et l'animal réduit à une machine que l'on peut exploiter, puisque dénué de passion voire de souffrance (selon Descartes). Dans la Bible, les conflits entre l'animal et l'homme et entre les animaux eux-mêmes remontent à la perte de l'harmonie originelle régnant au sein de la Création, suite à l'épisode punitif du Déluge ; ils devraient perdurer jusqu'à la fin des temps selon le prophète Isaïe $(11,6)$ qui prédit qu'alors seulement « le loup habitera avec l'agneau, le léopard gîtera avec le chevreau ». C'est à un autre prophète, Ézéchiel, que l'on doit la vision du tétramorphe, d'abord compris comme un chérubin avec une tête d'ange et trois têtes d'animaux, puis adapté dans les arts du Moyen Âge sous la forme d'un ange et de trois animaux ailés distincts.

Dans le judaïsme et le christianisme, la différenciation des espèces vivantes au début du monde résulte d'une parole "en actes» $(G n 2,19-20)$ : c'est Adam qui, en Éden, a nommé les animaux. Le cinquième jour du livre de la Genèse voit la création des animaux puis de l'homme fait à l'image et comme à la ressemblance de Dieu (Gn 1, 24-28), ce qui induit de fait un rapport de soumission des animaux à l'homme dont témoignent souvent les représentations occidentales figurées. Cependant, les échanges du monde chrétien avec d'autres civilisations, abordés par les auteurs de ce volume des actes du congrès de Rouen, montrent toute l'utilité de confronter les différentes traditions qui ont enrichi les arts.

4 Les métamorphoses des mythologies antiques, conçues comme des châtiments, se rapprochent ainsi de la métempsychose qui consiste en des renaissances successives, dans l'esprit des religions hindouistes. Dans le chamanisme, au contraire, l'ethnologie 
occidentale a reconnu une capacité universelle du cerveau humain à entrer en transe et communiquer ainsi avec les esprits, en particulier ceux des animaux. La question de l'interprétation des peintures pariétales des différents continents a pu être abordée à partir de ce thème sans cependant prétendre généraliser cette interprétation aux différentes représentations animales de la préhistoire, tandis que le masque animal porté dans les cérémonies revêt parfois une importance majeure. Dans un autre domaine, l'assimilation des qualités d'un individu à celles d'un animal privilégié a conduit certains peuples d'Amérique du Nord et d'Afrique à placer des clans ou familles sous la protection de totems animaux, tandis qu'en général et de façon moins sacrée, les noms de personnes sont souvent associés à des noms d'animaux dont ils reprennent les qualités symboliques.

\section{Aux origines des symboles de l'Occident: métamorphoses et hybridations dans les mythes et les religions}

5 La transformation d'un homme en animal est placée sous un jour le plus souvent négatif et menaçant, qu'elle soit complète chez les compagnons d'Ulysse, partielle et peut-être inachevée avec les sirènes (Chr. Mazet), centaures, sphinx et sphinges, ou encore temporaire avec le loup-garou, qui ressort de façon étonnante des sources juridiques (Ph. Nieto). Selon qu'on aborde l'odyssée ou bien les Métamorphoses d'Ovide, par exemple en lien avec l'apparition des espèces (C. Lochin), les « monstres » - tels que le français les nomme - peuvent être regardés, d'un autre point de vue, comme la conséquence des amours des dieux. Les Métamorphoses sont aussi, du XIV au XVII siècle, des textes moraux (Ovide moralisé).

Grâce à la qualité et au nombre des sources historiques et figurées, en particulier les vases grecs (Fr. Boudin), plusieurs communications des actes du présent congrès sont consacrées aux métamorphoses dans les religions de l'Antiquité classique et orientale (C. Mare), sans oublier le cas de l'adoption abordé par le thème des animaux servant de nourrices aux nouveau-nés, à commencer par la chèvre Amalthée dans la mythologie grecque (L. Romy-Regent). Moins connus peut-être, les mythes irlandais témoignent également du thème des métamorphoses (C. Cadoret).

\section{L'animal vivant et mort dans les religions : l'animal de sacrifice}

7 La notion de règne animal, en relation avec le monde divin et la création, semble bien se répartir de part et d'autre de la frontière entre les religions issues de la Bible d'une part et les autres religions d'autre part. Ce n'est qu'à l'époque de Darwin que la notion de création, intimement liée à celle du péché originel qui la suit, est remise en cause (A. La Vergata).

8 Le rapport entre la civilisation et le monde animal peut être au centre de la vie de la communauté. L'Égypte semble en résumer à elle seule plusieurs facettes : le statut de l'animal en Égypte ancienne devait être évoqué (N. Guilhou), et à sa suite les noms de personnes tirés de noms d'animaux en Égypte romaine (A. I. Blasco Torres), lesquels dessinent une géographie des cultes divins; le lien entre animaux et espaces sacrés 
n'est pas absent non plus des temples d'Isis à Rome (M.-Chr. Budischovsky), tandis que les animaux du désert font face aux premiers moines chrétiens (Fr. Thelamon). En changeant de région, l'on découvre que la Mésopotamie opposait, contrairement à la fable, l'animal des villes à l'animal des montagnes, lieu hostile par excellence (A. Vilela).

9 À la lecture des actes de ce congrès, la réflexion se poursuit à propos de la question de savoir si le mal en général et les vices en particulier, vus au travers du prisme des animaux, relèvent de thèmes antiques revisités ou de phénomènes fondamentalement différents, en partie l'arrivée des peuples germaniques dits «barbares». Il reste de toute façon des cas à discuter et qui pourront faire l'objet d'études ultérieures comme ceux où la vox populi prédomine : ainsi en est-il dans le culte non autorisé du saint lévrier appelé Guinefort.

10 À la limite du thème de la nourriture, qui était exclu des sujets étudiés dans ce présent congrès, l'animal objet de sacrifices rituels peut être approché grâce à l'archéologie et l'étude des textes, enrichissant ainsi la connaissance des religions en Gaule romaine (A. Bourgois, É. Mantel, S. Lepetz et M.-L. Haack), ou éclairant les pouvoirs magiques associés à la mise à mort d'animaux fortement symboliques comme les serpents (Th. Galoppin), ou encore par l'interrogation portant sur la spécificité des rites féminins (N. Boëls-Janssen). Confronter les symboliques respectives des animaux sauvages et domestiques est également permis par les sources relatives au sacrifice des bœufs, opposé à la chasse au sanglier (Fr. Thelamon) qui revêt une fonction de défense de la civilisation contre la destruction. Mais nombre d'animaux relèvent à la fois du sacrifice et de la représentation d'animaux vivants. Le coq est l'un des plus célèbres, présent dans les religions romaine, grecque et gauloise (M. Seigle).

\section{Imitations et appropriations symboliques : I'animal comique et l'animal-signe}

11 La fable et le fabliau font figure de répertoire de base où puisent auteurs, caricaturistes et artistes. Outre la littérature (Roman de Renart), les arts figurés - depuis les enluminures et décors muraux jusqu'aux personnages de dessins animés et de films en passant par les petits objets comme les jetons (J. Jambu) - et la publicité ont accordé une grande importance à l'animal comique, devenu un motif incontournable pour les secteurs de l'industrie et du commerce concernant les enfants. Pour autant, les "grotesques " figurés dans les marges enluminées des XIII et ${ }^{e}$ XIV $^{e}$ siècles ne sont pas que des adjonctions burlesques mais font bel et bien partie intégrante du message délivré par le livre en contre-point du texte, comme en témoignent par exemple les «drôleries » d'un pontifical en usage à la curie du temps de la papauté avignonnaise (M. Besseyre). Nombre de marginalia et fantaisies animalières gothiques peintes ou sculptées ont ainsi, en plus de leur irréductible qualité artistique, valeur de pictogrammes sémantiques restant à décrypter, ainsi que l'ont mis en valeur des travaux récents à la suite de ceux de Michael Camille.

12 En étudiant les postures animales et en les confrontant aux expressions humaines, certains artistes ont su provoquer des confrontations fertiles, qu'il s'agisse des costumes et déguisements subversifs des charivaris et carnavals du Roman de Fauvel ou des singeries du $\mathrm{XVIII}^{\mathrm{e}}$ siècle, pour aboutir aux assimilations comiques puis aux 
"portraits-charge" ou caricatures qui se développent particulièrement sous la Révolution et durant le XIX ${ }^{\mathrm{e}}$ siècle. Plus courte mais très frappante, l'étonnante mode des animaux chanteurs (les serins) a marqué la seconde moitié du xviII siècle (Cl. Boitard).

13 Selon saint Augustin, «Il est des choses qui ne sont que des choses et d'autres qui sont aussi des signes» (De Dialectica, V) : c'est le cas de l'animal au Moyen Âge, dont la relation à l'homme est premièrement définie par la hiérarchie de la Création, les attributs et qualités propres à chaque espèce ne venant qu'ensuite, comme autant de marqueurs ou repoussoirs du divin. Le genre littéraire du Bestiaire, dont la diffusion se répand massivement en Europe septentrionale à la fin $\mathrm{du} \mathrm{XII}^{\mathrm{e}}$ siècle, décline cette théorie de l'animal-signe en des recueils d'exempla farcis d'explications étymologiques (Isidore de Séville) et exégétiques (Raban Maur), où la créature vivante perd de son épaisseur charnelle pour se muer en support didactique et moral. Dans le cadre d'idées préconçues simples (le monde animal synonyme de sauvagerie et de lutte pour la survie), assimiler les qualités animales permet avant tout d'acquérir ou de faire montre de bravoure et de force.

14 L'héraldique, les surnoms, les légendes et mythes fondateurs des grands lignages renvoient à l'envi à ce type d'exaltation par association: on connait les aigles des armoiries impériales et les armoiries parlantes fondées sur une origine ou une étymologie véritables ou sur une association de mots : ours des villes de Bern et Berlin qui en contiennent le nom en allemand, coq gaulois (très présent sur les monuments aux morts de 1914-1918, mais qui est utilisé aussi par d'autres pays, tel le Portugal) ou encore la couleuvre de Colbert ; mais on peut citer aussi les qualificatifs accordés aux princes, comme Henri le Lion, duc de Saxe, ou Richard Cœur de Lion. Les animaux personnifient également certains idéaux (le chien ou le lion sont ainsi représentés aux pieds de la figuration des défunts et deviennent l'attribut de la fidélité ou de la force). Enfin, l'homme sauvage, dont la pilosité symbolisait la nature brutale et animale, tend à devenir un simple porte-écu ou du moins un motif plaisant et courant au cours du $\mathrm{Xv}^{\mathrm{e}}$ siècle (Fl. Pouvreau).

15 Encore plus remarquables sont les cas inverses de valeurs négatives. Les animaux symbolisant les vices sont bien connus dans le domaine de la luxure ; c'est moins le cas de ceux qui s'attachent à la couardise (Fl. Meunier). De façon remarquable, il peut même y avoir renversement, comme dans Peau d'âne, où le fait de revêtir la dépouille répugnante de l'animal est en fait le moyen trouvé par l'héroïne pour échapper à la bestialité morale de son père. Moins courants dans nos villes actuelles, certains animaux autrefois domestiqués comme la genette peuvent être interprétés comme des remparts symboliques contre les animaux négatifs et redoutés (V. Muxart).

16 Mais aucun thème ne peut être réduit à une seule interprétation : quelle meilleure démonstration de cette variété et de cette richesse que l'étude d'un motif d'une longévité exceptionnelle et représenté sur tous les supports, celui de la sirène médiévale que propose Jacqueline Leclercq-Marx en ouverture de ce volume? 


\section{AUTEURS}

\section{MARIANNE BESSEYRE}

Conservatrice des bibliothèques, Ciham UMR 5648

\section{PIERRE-YVES LE POGAM}

Conservateur en chef au département des Sculptures du musée du Louvre

\section{FLORIAN MEUNIER}

Conservateur en chef département des Objets d'art du musée du Louvre 


\section{Ouverture}




\title{
Du démon ambivalent à l'héroïne compatissante : la sirène entre monde antique et médiéval
}

\author{
Jacqueline Leclercq-Marx
}

1 Les sirènes ont toujours été des êtres ambigus présentant une part d'ombre et de mystère que l'on ne peut comprendre qu'en saisissant leur lien ancestral avec la Mort. Ce lien sera donc notre fil d'Ariane dans le labyrinthe de sens où elles nous entraîneront. C'est vers la Mort, en effet, que convergent les symboles dont les sirènes se sont chargées au cours des temps. L'archéologie et la littérature l'attestent suffisamment, même si parfois l'accumulation de significations qui assureront leur permanence tend à occulter cette unité fondamentale. Mais qui dit «Mort» dit également son antithèse, "Vie », en vertu du sentiment ambivalent que provoque le sacré. Et également «Amour », puisque depuis toujours Eros rime avec Thanatos. C'est donc à la découverte d'un certain nombre de ces représentations mentales que le lecteur est convié, à travers l'art et la littérature de l'Antiquité, du haut Moyen Âge et du Moyen Âge central ${ }^{1}$.

Dans les passages de l'Odyssée où les sirènes sont le plus anciennement évoquées et dont il est fait écho sur plusieurs vases grecs d'époque classique, la mort est déjà omniprésente. En effet, la séduction des sirènes apparait fatale aux hommes, et leur voix ensorcelante et douce, comme un instrument de mort :

«[...] bien fou qui relâche pour entendre leurs chants! Jamais en son logis, sa

femme et ses enfants ne fêteront son retour [...] »

Et le pré, leur séjour, est présenté comme «bordé d'un rivage, tout blanchi d'ossements et de débris humains [...] $\rrbracket^{2}$, comme on le voit figuré sur certains fragments de peinture pompéienne. Les sirènes sont donc à l'évidence des puissances magiques, malgré les efforts manifestes que fait Homère pour rendre autant que possible sa mythologie rationalisée et humaine. Le lien qui rattache les sirènes à l'au-delà est encore accentué par le contexte même dans lequel elles figurent. Ainsi leur apparition est-elle située parmi d'autres épreuves qui encadrent la scène de la Nekya - l'évocation des morts - ce qui l'inclut dans les épisodes qui soit annoncent soit prolongent cette traversée de 
l'Outre tombe. À cet égard, leur prairie en fleurs n'est pas sans rappeler le pré de l'asphodèle situé aux Enfers. Par ailleurs, conformément à l'impossibilité bien attestée des figures mythiques à survivre à la moindre défaite - comme celle infligée par Ulysse dans l'Odyssée, ou par Orphée dans les Argonautiques orphiques - l'histoire des sirènes est jalonnée de récits évoquant leur suicide. Cet épisode ferait même parfois l'objet de représentations, comme cela semble être le cas sur un fragment de vase réalisé vers 600 (fig. 1) $)^{3}$. Si c'est exact, il s'agirait de la plus ancienne évocation connue de cet épisode adventice issu, sans doute, d'une tradition orale et populaire. Mais ce que l'on en retiendra surtout est que le suicide des sirènes servit essentiellement à expliquer le culte qu'on leur rendait en Campanie, près du lieu de leur ensevelissement supposé. À cet égard, une place importante fut réservée à l'évocation de Parthénopè - l'une des sirènes, d'après certains - éponyme de la ville qui allait être rebaptisée Neapolis/ Napoli/Naples plus tard. Le tombeau à proximité duquel elle était honorée et les jeux rituels qu'on lui dédiait sont manifestement à l'origine de cette légende de fondation, alors que le culte des sirènes avait été en fait introduit par une très ancienne colonie grecque originaire de Rhodes ou de Chalcis en Eubée.

Fig. 1. - Fragment de vase provenant de Naucratis (C. 600 av. J.-C.).

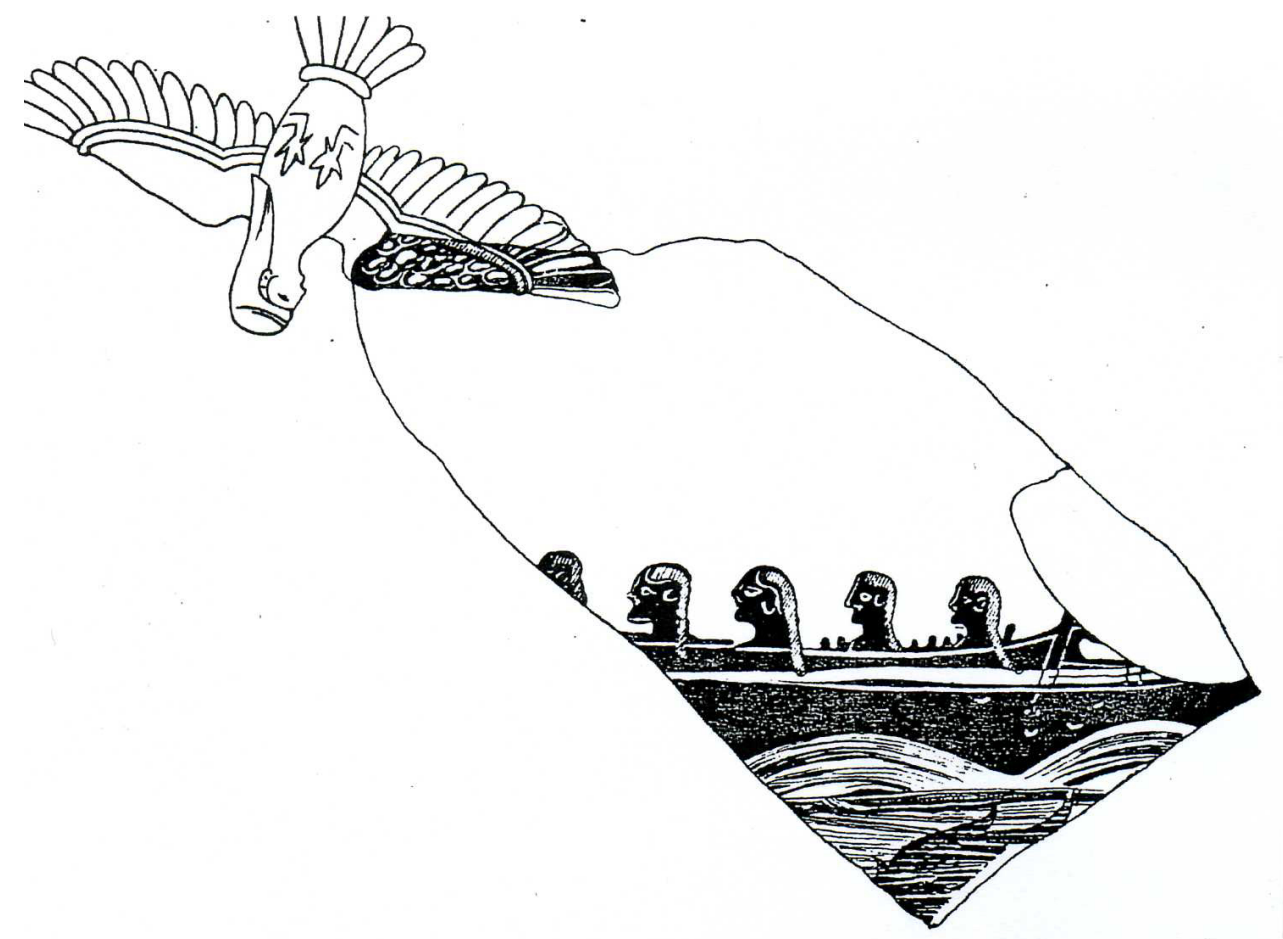

Londres, British Museum. (D'après G. Weicker, Der Seelenvogel in der alten Literatur und Kunst..., fig. 18).

Ce culte rendu aux sirènes en tant que divinités de la mort, qui était répandu dans le monde antique et qui s'exprimait notamment par l'offrande dans les tombes de petites sirènes en terre cuite, nous rappelle que, dans ce cas du moins, le mythe ne cesse pas où commence la littérature. On ne peut, en effet, approcher la réalité des sirènes antiques qu'en admettant l'interpénétration étroite et synchronique d'expériences religieuses même mystiques, parfois - et de spéculations intellectuelles rationalisantes. La difficulté majeure consiste précisément à débrouiller l'écheveau où se mêlent croyances vécues - mythe en perpétuelle genèse - et pensées abstraites - réflexion sur 
une matière morte - pour en suivre l'évolution parfois concomitante, parfois indépendante, au gré capricieux des influences et des interactions. Même les passages homériques consacrés aux sirènes recèlent en eux une réelle ambiguïté : on y devine en effet un substrat religieux que le traitement poétique a estompé, mais n'a pas occulté entièrement. C'est sûrement une des raisons pour lesquelles les sirènes de l'Odyssée constituent toujours une référence essentielle, même s'il est impossible d'apprécier de manière exacte leurs rapports avec les sirènes-oiseaux quelque peu postérieures, que les Grecs ont craintes et invoquées.

5 En fait, l'origine homérique de l'entité «sirène-oiseau » conçue comme Seelenvogel/ âme ailée, avide de sang et de sperme, que prônait Georg Weicker au début du $\mathrm{xx}^{\mathrm{e}}$ siècle ${ }^{4}$, paraitt peu vraisemblable. Cette conception ne peut en tout cas se fonder sur ce que nous savons avec certitude de la croyance aux âmes chez les Grecs. Ainsi est-il quasi certain que la sirène-oiseau n'a pas été imaginée primitivement comme une âme, même si certains indices suggèrent qu'elle a pu l'être incidemment. Parmi ceux-ci, figure une scène peinte sur un vase attique, où une femme - Procris en l'occurrence semble exhaler en mourant un oiseau à tête humaine. Mais on ne peut en aucun cas généraliser cette fonction peu et mal documentée. Il n'est pas question non plus de faire dériver la sirène-oiseau de l'oiseau Bâ égyptien, auxiliaire dévoué du mort et symbole de l'âme individuelle, malgré leur ressemblance formelle, puisqu'une telle identification ne peut s'effectuer que sur la base de l'équation Sirènes = oiseaux de l'âme/âme ailée, dont on vient de dire qu'elle est en grande partie erronée. En fait, il semble bien qu'il faille dissocier le concept « Sirène » d'origine homérique du Mischbild oriental qui fut son support au plus tard à la fin du vil ${ }^{e}$ siècle, époque des plus anciennes représentations des sirènes odysséennes.

6 Tout porte à croire, en effet, que le Menschenvogel ne relevait guère à l'origine de la sphère mythique, mais était bienvenu là où il s'agissait de représenter des êtres démoniaques. Ce Kunsttypus aurait ainsi été emprunté tel quel pour représenter les sirènes d'Ulysse dont Homère avait négligé de fixer les traits, et dont le caractère sombre rappelait en outre celui de la Babylonienne Lilith, la déesse de la mort, figurée comme une femme nue aux ailes et aux pieds d'oiseaux. Une telle hypothèse permet en tout cas d'insérer sans difficulté les sirènes parmi les autres démons de la mort, les Kères, dont elles apparaissent comme une simple spécialisation à l'instar des harpyes, des sphynx et des Gorgones, et rend en même temps compte des contextes variés dans lesquels elles apparaissent aux époques pré-classiques. En fait, l'appellation « sirène » ne nous parait justifiée qu'à partir de la fin du viI siècle avant notre ère, époque où les sirènes, définitivement dissociées de l'odyssée, ont acquis une spécificité qui les distingue des autres démons ailés. L'inscription qui accompagne l'amusante femmeoiseau qui est peinte sur une hydrie attique un peu postérieure est significative à cet égard. En effet, elle proclame CIPHN EIMI « Je suis une sirène $»^{5}$ ! On peut supposer que si la reconnaissance avait été si aisée, on n'eût guère ressenti le besoin d'identifier la silhouette par une légende explicative.

7 Ce processus de différenciation fut sans doute favorisé par l'association des sirènes à un culte chthonien et plus particulièrement funéraire, apparenté à celui des mânes et des héros, auquel il a déjà été fait allusion tout à l'heure. Ce culte, de type populaire, s'opposait en fait à la religion olympienne dont il constituait l'aspect antithétique et complémentaire. Que les sirènes soient devenues des déités secourables a évidemment de quoi surprendre lorsqu'on a à l'esprit la redoutable famille de démons dont elles 
sont issues. Toutefois, cette évolution sémantique n'est guère unique ou sans précédent en mythologie: elle procède simplement de la crainte superstitieuse dont les sirènes étaient l'objet. Ainsi, de même qu'on appela les Érinyes " Euménides ", par antiphrase, dans le but de se les rendre favorables, on associa probablement les sirènes au culte des morts pour se les concilier. De démons maléfiques, elles se transformèrent ainsi en démons secourables et leur silhouette, figurée sur la stèle ou le lécythe funéraires devint un puissant apotropaïon. Sans qu'on en soit outre mesure surpris, les témoignages littéraires confirment abondamment ces connexions avec l'au-delà et les divinités de la Mort, même si les textes concernent le plus souvent les sirènes homériques. Il faut noter à ce propos l'insistance avec laquelle tant d'écrivains les ont mises en rapport avec Perséphone. Les témoignages écrits les plus éclairants - ceux de Sophocle et d'Euripide - sont toutefois indépendants du contexte homérique. Le premier, conservé dans un fragment non identifié de tragédie, fait état de leurs accents "venant de l'Hadès» (tous Aidou nomous) ${ }^{6}$. Quant au second, il contient une longue prière adressée aux sirènes par Hélène, au moment de préluder au thrène, et qui semble avoir inspiré le décor de plusieurs stèles, en ce qui concerne du moins leur attitude empathique :

«Jouvencelles ailées, ô vierges filles de la terre, Sirènes, puissiez-vous venir à mes plaintes faire écho sur le lotos de Libye ou la syrinx, apportant à mes cris funèbres des larmes bien à l'unisson, des accompagnements de peines à mes peines, et de chants à mes chants. Que Perséphone, afin de s'unir à mes thrènes, fasse monter vers nous de lugubres concerts, et reçoive en retour, dans son palais nocturne, le péan tout mouillé de pleurs que je dédie aux misérables morts. " ${ }^{7}$

8 À l'époque hellénistique, on multiplia l'image des sirènes funéraires. Ainsi, plus de vingt statuettes de terre cuite à leur image étaient-elles parfois déposées dans une même sépulture. On en vint aussi à placer sur les tombes des sirènes monumentales, comme celle qu'on a trouvé dans le Serapeion de Memphis (fig. 2). C'est à ce type de représentation que fait écho une épigramme funéraire où la parole est précisément donnée aux sirènes de pierre :

«[...] pleurant sur toi, les joues ravagées de larmes, nous nous tenons ici près de ton tertre, belles statues de sirènes. $»^{8}$ 
Fig. 2. - Statue funéraire provenant du Serapeion de Memphis (340-330 av. J.-C.).

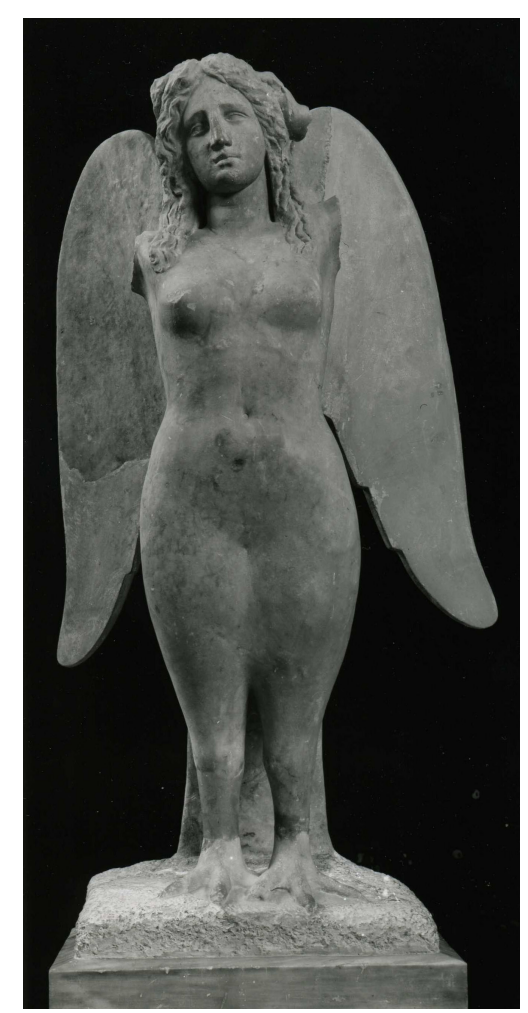

Athènes, Musée national d'archéologie. (c) Bildarchiv Foto Marburg.

9 Cette compassion attribuée aux sirènes s'accompagna aussi d'une fonction bien attestée dans l'art comme dans les textes: celle de psychopompe. C'est pourquoi certaines sirènes funéraires portent dans les bras une âme représentée sous forme d'une petite figure humaine (fig. 3). C'est aussi pourquoi on les représenta parfois dans un contexte funéraire en train de chanter, de jouer de la double flûte ou du tambourin, et de danser. Dans ce cas, elles apparaissent tout à la joie d'accompagner les âmes vers les prairies de Perséphone, dans les Îles des Bienheureux ou bien encore vers le Soleil et la Lune, tenues pour les "véritables îles des Bienheureux ${ }^{9}$ dans l'eschatologie pythagoricienne. À cet égard, il semble bien que la doctrine de l'harmonie des sphères, dont la découverte était attribuée à Pythagore et à laquelle les sirènes furent associées très anciennement, soit à l'origine de cette fonction de psychopompe : un acousma rapporté par Jamblique mais vraisemblablement d'origine très ancienne faisait déjà le lien entre Sirènes et harmonie ${ }^{10}$, avant d'être relayé par Platon, dans le célèbre mythe $\mathrm{d}^{\prime} \mathrm{Er}^{11}$. En tout cas, ce qui est certain est qu'on attribua parfois à cette musique céleste une influence bienfaisante sur les âmes errant dans le ciel après la mort. Et qu'on associa les sirènes à cette action, comme l'atteste un fragment de commentaire pythagoricien de l'Odyssée, conservé par Plutarque dans ses Propos de table:

«(...) lorsqu'après le trépas elles [les âmes] deviennent errantes, les sirènes leur inspirent l'amour de ce qui est céleste et divin, en même temps qu'elles leur versent l'oubli des misères mortelles. Elles les maintiennent, les charment, les consolent ; et ces âmes, par reconnaissance, les suivent et s'attachent à elles. Ici-bas il arrive jusqu'à nous un écho affaibli de cette musique... ${ }^{12}$ 
Fig. 3. - Terre cuite (Italie, $11 \mathrm{e}^{\mathrm{e}}-\mathrm{II}^{\mathrm{e}}$ siècle av. J.-C.).

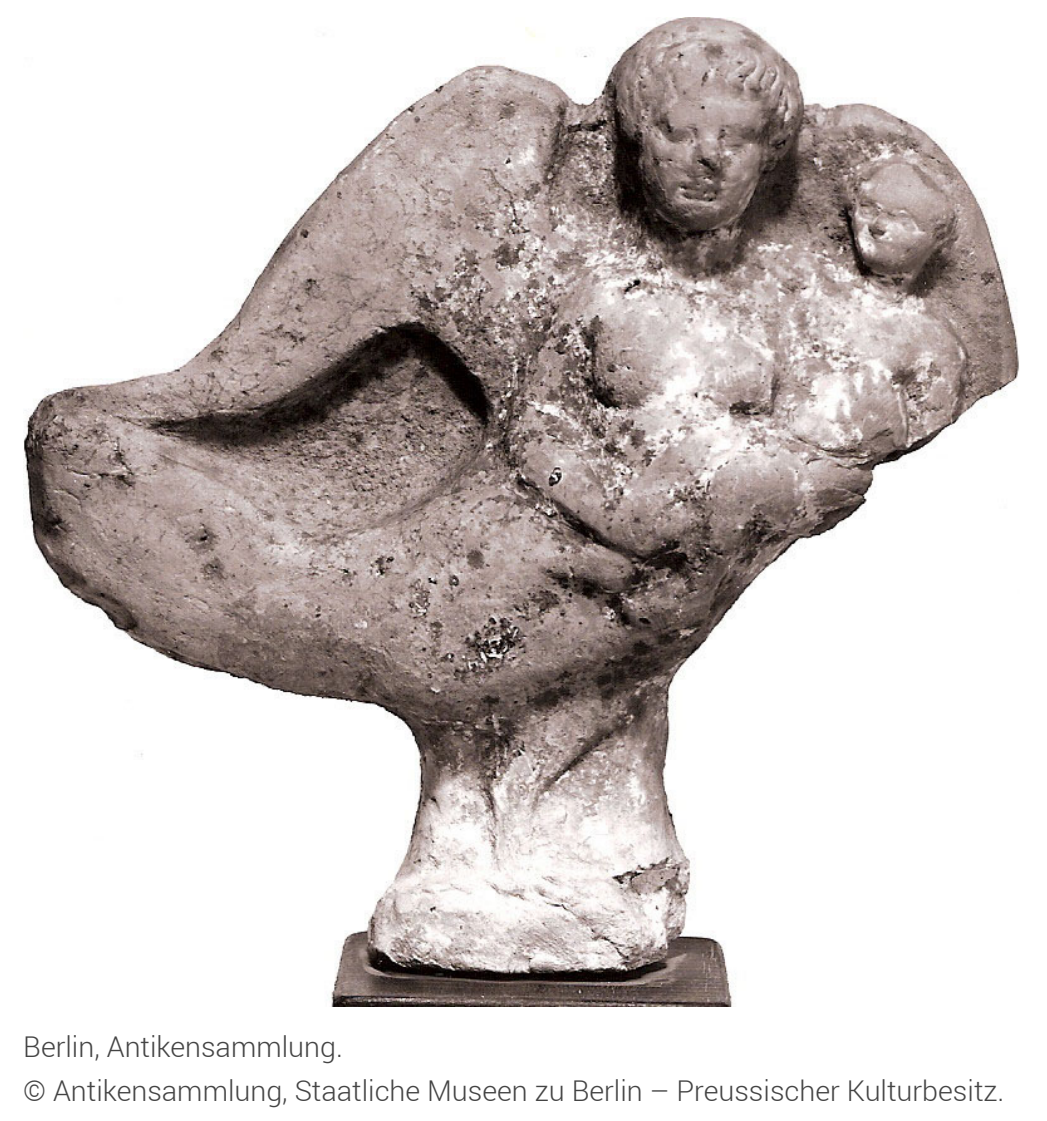

10 Expliquées par la croyance en l'immortalité céleste de l'âme, ces conceptions nouvelles surent facilement s'imposer. Par contre, l'attribution aux sirènes d'une fonction aussi prestigieuse que celle de psychopompe, dut provoquer de vives réactions : le contexte dans lequel se situe le dialogue précité de Plutarque y fait écho de même sans doute qu'une légende tardive narrant la victoire musicale des Muses sur les sirènes ${ }^{13}$, et leur substitution à ces dernières comme gardiennes de l'harmonie des sphères. C'est en constatant que Platon s'était référé tantôt aux sirènes célestes, tantôt à celles de $l^{\prime}$ Hadès $^{14}$ et que ce qu'il en avait dit ne s'accordait guère avec le mythe d'Ulysse, que Proclus estima qu'il existait trois sortes de sirènes : célestes, qui sont soumises à Zeus, génératrices, qui dépendent de Poséidon, et infernales qui obéissent à Pluton ${ }^{15}$. Sa distinction se fondait sur l'opposition entre leur harmonie charnelle et celle, intellectuelle, des Muses. Toutefois, ses théories, que le texte de Plutarque contredisait, ne furent pas adoptées unanimement : l'assimilation Muses-sirènes est encore attestée dans le Songe de Scipion, de Macrobe ${ }^{16}$. Ainsi, la doctrine qui éleva les sirènes dans les cieux pour leur faire présider l'harmonie cosmique contribua paradoxalement au maintien de leur caractère ambivalent, en rendant nécessaire leur différenciation en plusieurs catégories aux fonctions contradictoires. Les «bonnes » et les «mauvaises » sirènes coexistèrent donc, les premières - parfois identifiées aux Muses - ayant comme rôle de sauver les âmes en les attirant vers les astres, les secondes, de les perdre en les inclinant vers la génération. À la tentation de l'Immortalité s'opposait en quelque sorte la séduction de la Mort.

11 L'omniprésence de la mort dans la sphère symbolique des sirènes - jusque dans la notion même d'immortalité, puisque l'immortalité n'est rien d'autre que sa négation - 
allait encore engendrer d'autres interprétations, et notamment une interprétation violemment misogynique, antiféministe. Tout laisse en effet supposer qu'après avoir symbolisé l'angoisse devant la Mort, l'image de la sirène en vint progressivement à exprimer, par euphémisation, la peur de la Femme. Ce glissement progressif du mal métaphysique au mal moral, impliquant un infléchissement vers la sexualité, apparaît comme conséquence d'un courant ascétique pessimiste venu d'Orient qui marqua toute la civilisation gréco-romaine, et qui n'est sûrement pas étranger à la représentation de sirènes habillées et parées, dont le plus ancien exemple connu se trouve dans le décor d'un cratère campanien du IV siècle (fig. 4). Cette référence au charme physique et à la coquetterie des sirènes, et partant, à la nature érotique de leur séduction, absente chez Homère, trouva parfois un large écho auprès des poètes comiques et des moralistes qui comparèrent les courtisanes aux sirènes. Par ailleurs, dès le $\mathrm{I}^{\mathrm{er}}$ siècle apr. J.-C., elles furent fréquemment présentées comme symboles de vices, voire plus précisément comme symboles des plaisirs des sens, sans qu'on puisse toutefois attribuer précisément la paternité de cette interprétation à l'une ou l'autre école philosophique ayant pratiqué l'exégèse allégorique d'Homère, quoi qu'en ait dit Porphyre :

« Pythagore comparaît déjà aux chants meurtriers des sirènes le plaisir qui, au prix

de dépenses insensées, est agréable au ventre. $\gg^{17}$

Fig. 4. - Cratère lucanien à figures rouges (340-320 av. J.-C.), Berlin, Antikensammlung.

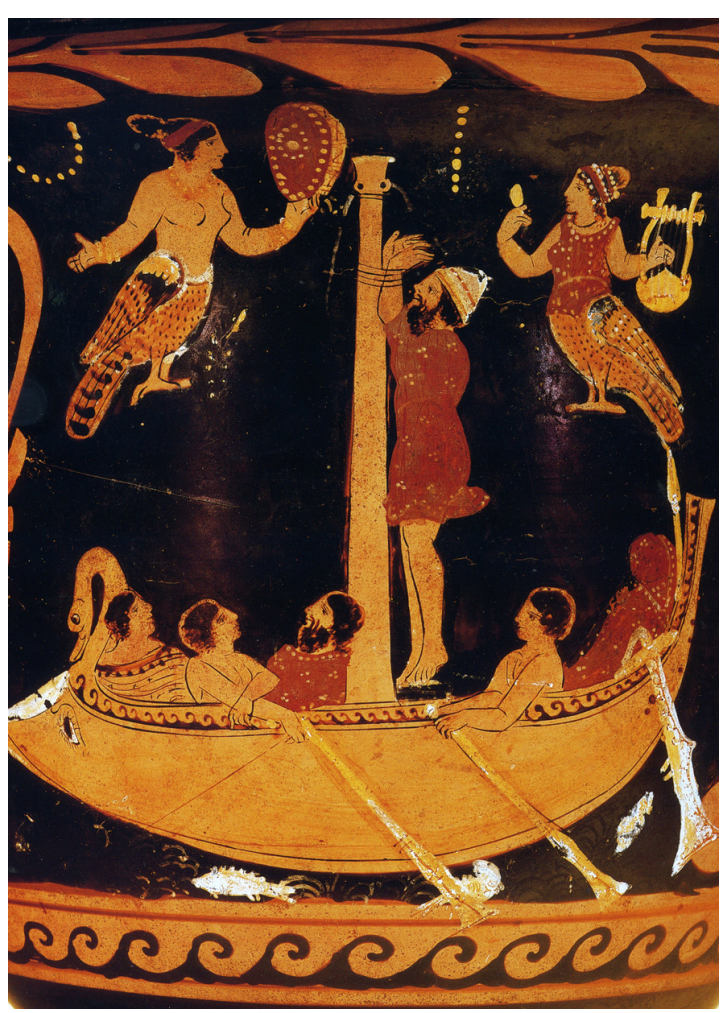

(c) Antikensammlung, Staatliche Museen zu Berlin - Preussischer Kulturbesitz. Photo J. Tietz-Glagow.

Parallèlement, leurs connotations érotiques s'exprimèrent dans la croyance aux sirènes incubes, apparentées au daemones meridiani - les démons méridiens - et aux vampires lascifs comme les lamies, fréquemment confondues d'ailleurs avec elles. Valorisées à la fois négativement et positivement, les sirènes furent donc, simultanément, craintes et vénérées par le peuple. De même leur nom fut autant utilisé comme image de séduction 
physique ou intellectuelle dans un contexte positif, que comme celle de séduction pernicieuse et funeste. Ainsi pour Plutarque encore, était-ce le charme dangereux de la poésie que symbolisaient les sirènes. Il préconisait à cet égard de les affronter « lié au mât ", le jugement "affermi et enchaîné " avec de bons et solides principes ${ }^{18}$. Il n'en reste pas moins que c'est surtout comme image de courtisane et comme symbole de luxure qu'on évoqua les sirènes dans les milieux païens du début de notre ère. Et on est en droit de se demander si ce ne fut pas sous l'influence de l'exégèse allégorique chrétienne! Quoi qu'il en soit, la morale chrétienne s'accommoda fort bien de ce symbolisme souvent révélateur d'un antiféminisme acharné. En effet, les sirènes qui provoquaient la mort par la volupté même qu'elles procuraient - mortem dabat ipsa voluptas lit-on dans l'Anthologie latine ${ }^{19}$ - pouvaient en effet symboliser sans difficulté les dangereuses séductions féminines que le chrétien, tel Ulysse, avait à fuir.

13 À vrai dire, ce fut autant par l'intermédiaire des auteurs païens que par celui de l'Ancien Testament que les Pères de l'Église eurent l'attention attirée sur les sirènes. Confrontés en effet à des mots hébreux dont il n'existait pas d'équivalents en grec ou en latin, les traducteurs de la Bible n'ont pas hésité à utiliser les vocables $\Sigma \varepsilon i \rho \eta v \varepsilon s /$ Sirenae/es quand il était question d'animaux, de monstres ou même d'esprits cruels et voluptueux habitant soit les lieux déserts, soit à proximité de la mer ${ }^{20}$. En outre, la parenté de la sirène populaire grecque avec le démon féminin juif Lilith, favorisa encore la contamination. Habituellement figurées toutes deux comme des femmesoiseaux fortement sexuées, elles étaient redoutées par le peuple pour les mêmes raisons : leur vampirisme et leur lascivité de démons incubes. Et c'est sans surprise qu'on les voit d'ailleurs associées chez Isaïe $(E s .34,14)$ et dans l'Apocalypse apocryphe de Baruch (Bar. 10, 8). Évoquées de façon récurrente dans la Bible, il était logique que les sirènes suscitent des commentaires de la part des saints exégètes. De ce point de vue, ceux-ci se situèrent volens nolens dans la tradition de l'exégèse païenne d'Homère. Au sage stoïcien en route vers l'élysée, fut substitué le chrétien voguant vers le Port du Salut. Et au mât du navire succéda le bois de la Croix de la Passion - ce qui explique l'impossibilité de savoir parfois si on a affaire à un sarcophage chrétien ou païen, sur la base de la présence de la rencontre d'Ulysse et des sirènes dans son décor (fig. 5) ! C'est Clément d'Alexandrie, à qui sa culture poétique suggéra sans cesse des analogies entre les attitudes chrétiennes et les mythes grecs, qui utilisa le premier ces antiques images en les chargeant d'un sens nouveau:

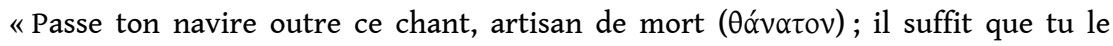
veuilles et te voilà vainqueur de la perdition; attaché au bois, tu seras délivré de toute corruption, le Logos de Dieu sera ton pilote, et l'Esprit Saint, te fera aborder aux ports célestes. $»^{21}$

Fig. 5. - Sarcophage romain (230-240 après J.-C.).

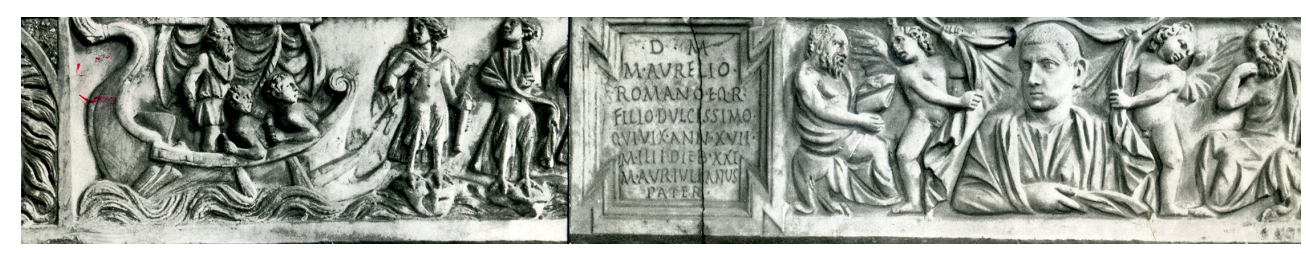

Rome, Museo Nazionale Romano. (c) Soprintendenza archeologica di Roma.

L'image du mât du navire comme antenna crucis à laquelle le chrétien doit s'attacher pendant la traversée de la vie fut fréquemment reprise après lui. Hippolyte de Rome, 
Paulin de Nole et Maxime de Turin en firent notamment de longs développements parfois très originaux. Dans tous les cas, la métaphore accompagne l'interprétation morale des sirènes, comme dans un des sermons de Maxime de Turin :

"Chacun se fera donc lier à l'arbre de la croix dans ce navire [l'Église] ou se bouchera les oreilles avec les divines Écritures, ainsi il ne craindra pas la douce tempête de la luxure. En effet, la suave figure des sirènes représente la molle concupiscence des voluptés, qui affaiblit la constance de l'esprit qui leur est soumis, par de coupables flatteries. $»^{22}$

Si l'interprétation symbolique que les Pères donnèrent des sirènes fut rarement originale, il semble toutefois qu'on leur doive d'avoir superposé à la notion de sirènecourtisane celle de femme sensu lato, au point d'en avoir rendu souvent les trois termes à peu près synonymes. Ce n'est guère un hasard en effet si Clément d'Alexandrie accompagna une évocation conjointe des sirènes et des courtisanes d'une citation particulièrement misogyne d'Hésiode :

«Qu'une femme n'aille pas non plus, avec sa croupe attifée, te faire perdre le sens, son babil flatteur n'en veut qu'à ta grange. $»^{23}$

16 Environ trois siècles plus tard, Léandre, frère d'Isidore de Séville, le dernier Père latin, recommandait encore aux religieuses de fuir la compagnie des femmes mariées, qu'il comparaît expressément aux sirènes :

«Instrument de Satan (organum Satanae), la femme mariée chantera des mélodies qui éveillent les concupiscences du siècle et qui te jettent dans les sentiers du diable. Fuis le chant des sirènes, ma sœur, de peur de quitter le droit chemin, les oreilles pleines du désir de goûter aux divertissements du monde, de te heurter à droite à un rocher ou d'être engloutie à gauche, par la gueule béante de Charybde... ${ }^{24}$ »

Toutefois, l'attrait pernicieux des femmes et de l'amour charnel ne fut pas le seul à être comparé métaphoriquement aux sirènes. Celui de la culture profane le fut également comme l'atteste notamment un passage des Stromates, du même Clément d'Alexandrie :

«Les matelots qui se bouchent les oreilles de peur d'être séduits par le chant des sirènes, et de ne pouvoir revenir, sont une image des chrétiens qui craignent, s'ils s'adonnent à la philosophie grecque, d'être gagnés par elle. $»^{25}$

Dans un même ordre d'idées, les sirènes ont également symbolisé la séduction funeste des hérésies ${ }^{26}$. Ainsi chez Hippolyte de Rome, par exemple, les enseignements des hérétiques sont comparés à leur chant séduisant et fatal ${ }^{27}$. C'est donc par deux voies différentes - l'exégèse biblique et l'utilisation comme symbole ou comme pôle métaphorique - que les sirènes pénétrèrent dans la littérature patristique. Et si l'interprétation chrétienne d'Homère se constitua principalement chez clément d'Alexandrie et chez Justin, aux $\mathrm{II}^{\mathrm{e}}$ et au $\mathrm{III}^{\mathrm{e}}$ siècles, elle s'intégra par la suite à la culture chrétienne. C'est ainsi que l'épisode d'Ulysse et les sirènes fut évoqué sans discontinuité jusqu'au Moyen Âge, tant dans la sphère culturelle grecque que latine.

Sans qu'on puisse vraiment s'en étonner, le caractère fatal des sirènes-oiseaux s'appliqua intégralement aux sirènes-poissons dont il est pour la première fois question dans le Liber monstrorum, un texte de la fin du VII ${ }^{\mathrm{e}}$ ou du début du VIII ${ }^{\mathrm{e}}$ siècle, d'origine sans doute insulaire ${ }^{28}$. C'est qu'il semble bien qu'à cette période, la sirène fut progressivement confondue avec des déités antiques, germaniques et même celtiques des eaux, l'adoption du latin comme langue savante et celle des auteurs antiques comme modèles littéraires ayant rendu en quelque sorte cette assimilation inévitable ${ }^{29}$. C'est ainsi qu'à partir du $\mathrm{IX}^{\mathrm{e}}$ siècle, il est question soit de sirènes-oiseaux, soit de 
sirènes-poissons dans les textes, avec parfois une incroyable incohérence entre ceux-ci et leurs propres illustrations. Ainsi trouve-t-on dans un manuscrit carolingien - le Physiologus de Berne - la description d'une sirène-oiseau accompagnée d'une miniature figurant une sirène-poisson (fig. 6) - ce qui tendrait à prouver l'existence de traditions différentes, littéraire et artistique, encore indépendantes l'une de l'autre au Ix siècle. À noter quand même que la métamorphose des sirènes, qui peut apparaître en un sens comme le fruit d'une attention nouvelle portée à leur morphologie, ne s'accompagna guère d'une revitalisation de leur fonction symbolique. Au contraire, les allégories dans lesquelles les sirènes interviennent témoignent d'un réel appauvrissement de sens par rapport à la tradition patristique dans laquelle elles se situent très - trop fidèlement. Cet appauvrissement sur le plan sémantique se traduit notamment par un glissement, plus accusé encore qu'à la période précédente, de la métaphysique à la morale par l'utilisation presque exclusive de la sirène comme symbole sexuel. Cessant de promettre les fruits défendus de la Connaissance ou du Savoir profane, la sirène n'offrait plus, désormais, que ceux, tout aussi redoutables de la Chair.

Fig. 6. - Ms. Berne, Burgerbibliothek, cod. 318, fol. 13 v $^{\circ}$, dit Physiologus de Berne (Hautvillers école de Reims, c. 830).

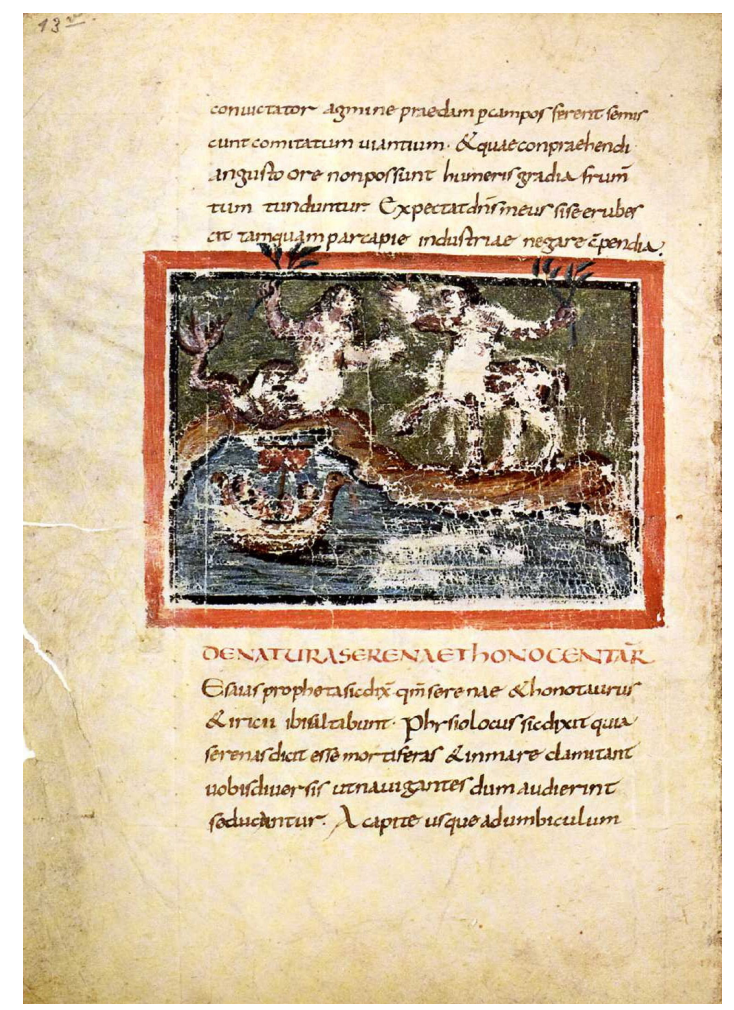

(c) Burgerbibliothek Bern.

Les traditions littéraires montraient donc certains signes d'essoufflement; l'iconographie, hésitante, était partagée entre les anciennes et les nouvelles tendances. Il appartenait $\mathrm{au} \mathrm{XI}^{\mathrm{e}}$ et surtout au XII ${ }^{\mathrm{e}}$ siècle, d'assurer la suprématie de la sirènepoisson sur la sirène-oiseau, à la fois comme symbole de la femme fatale et comme élément essentiel de la stylistique ornementale romane. Comme leurs prédécesseurs carolingiens, les lettrés et les artistes des $\mathrm{XI}^{\mathrm{e}}$ et $\mathrm{XII}^{\mathrm{e}}$ siècles n'optèrent pas définitivement pour un type de sirènes à l'exclusion de l'autre: les deux traditions se perpétuèrent 
parallèlement, et trouvèrent un même écho dans l'art et dans la littérature. Ainsi Ulysse est-il confronté soit à des sirènes-poissons, soit à des sirènes-oiseaux, tantôt pour illustrer le passage consacré aux sirènes dans les Bestiaires ${ }^{30}$, tantôt pour illustrer le combat allégorique des Vices et des Vertus, comme dans le célèbre Hortus deliciarum ( Jardin des délices ») de l'abbesse Herrade de Landsberg. Par ailleurs, les deux types de sirènes voisinent parfois au sein d'une même composition, ainsi qu'on le voit sur un chapiteau du cloître de la cathédrale d'Elne (Roussillon) (fig. 7).

Fig. 7. - Elne (Pyrénées-Orientales), cathédrale Sainte-Eulalie. Cloître, chapiteau de colonnes jumelées, fin du XII ${ }^{\mathrm{e}}$ siècle.

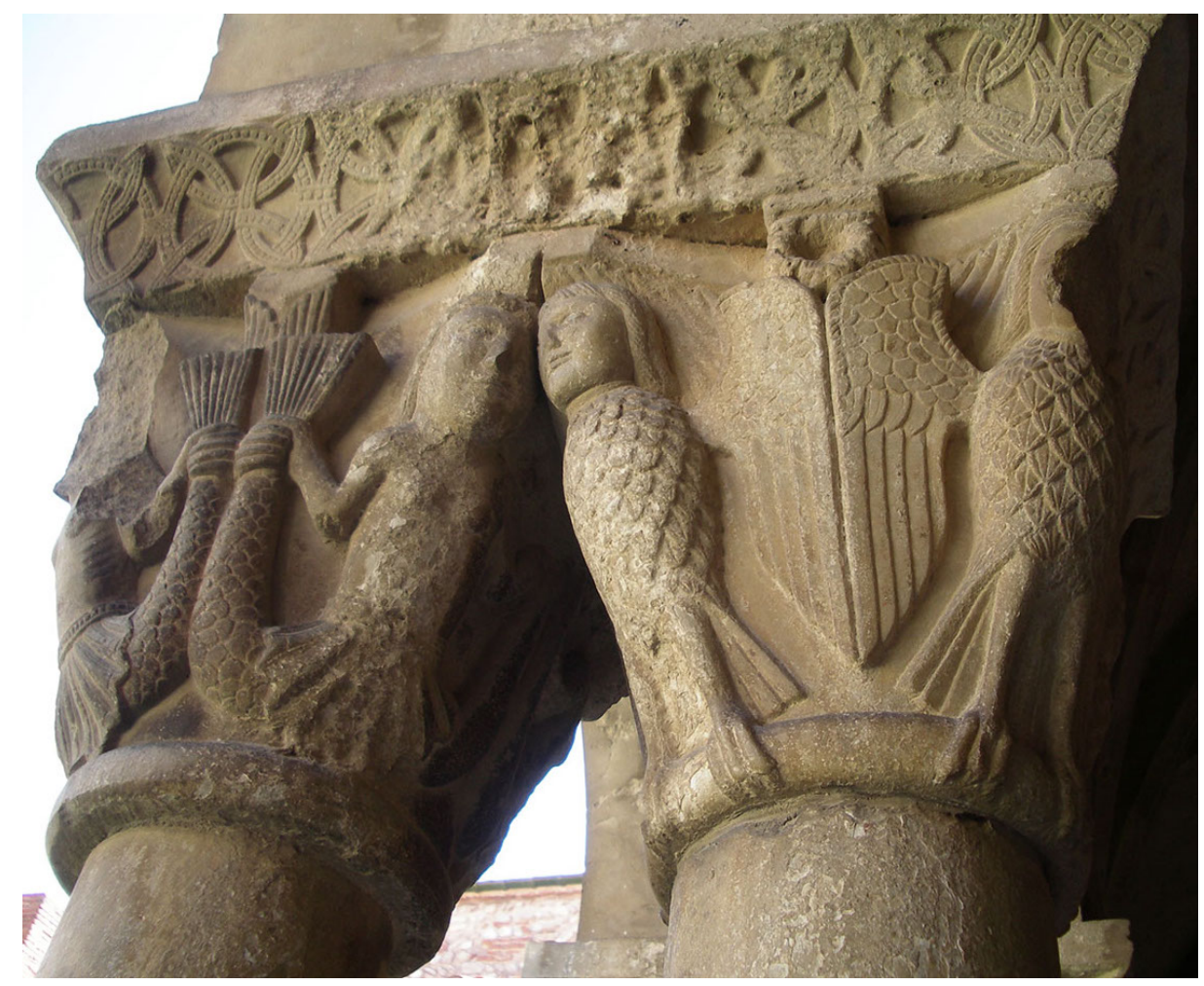

(c) J. Leclercq-Marx.

21 Eu égard au fait que le Moyen Âge n'a pas toujours distingué les vices de leur inspirateur, Satan, les sirènes devinrent très logiquement une incarnation satanique ou un symbole du monde infernal. C'est donc sans étonnement qu'on les voit peintes aux côtés d'autres monstres, au-dessous des apôtres dans le chœur de l'église de Termeno, dans le Haut-Adige (fig. 8). 
Fig. 8. - Termeno (Trentin), San Giacomo in Castellaccio. Abside, peinture murale, première moitié du XIII ${ }^{\mathrm{e}}$ siècle.

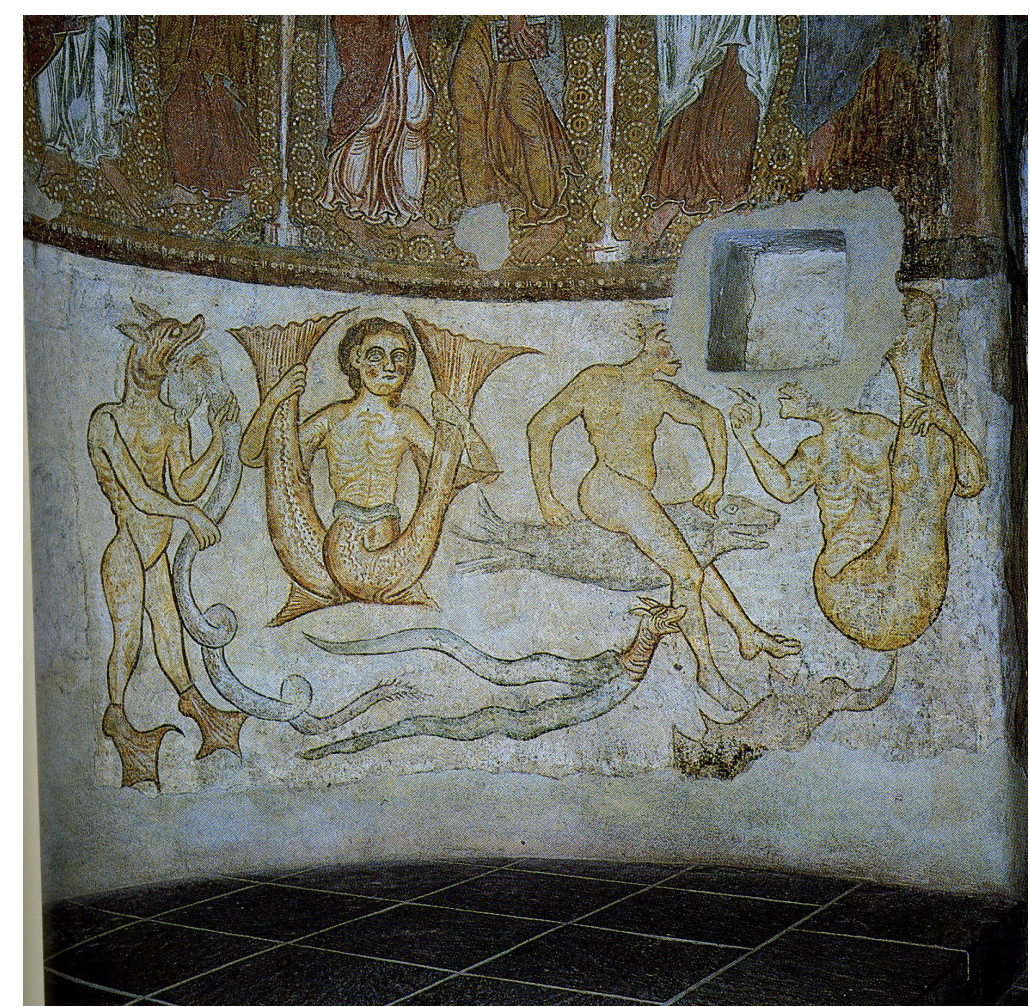

D’après O. Demus et M. Hirmer, Romanische Wandmalerei, pl. XXXIII.

22 À cet égard, Sirènes-oiseaux comme sirènes-poissons symbolisèrent souvent le monde infernal, individuellement et en dehors de tout contexte particulier. Leur accointance avec le diable s'exprime alors le plus généralement par la présence d'appendices serpentiformes ou encore de serpents comme attributs, associés éventuellement à des sabots fendus et à des cornes, comme sur un des chapiteaux du cloître de Santo Domingo de Silos, en Vieille Castille. Toutefois, quand les serpents s'accrochent aux seins de la sirène, le symbolisme se précise par analogie avec la « femme aux serpents » livrée au même supplice, qui est un symbole de luxure très répandu. Par ailleurs, sirènes et « femmes aux serpents » ou « aux crapauds » voisinent fréquemment (fig. 9). 
Fig. 9. - Montoñedo (Galice), San Martin, Nef, côté sud, chapiteau, xII siècle.

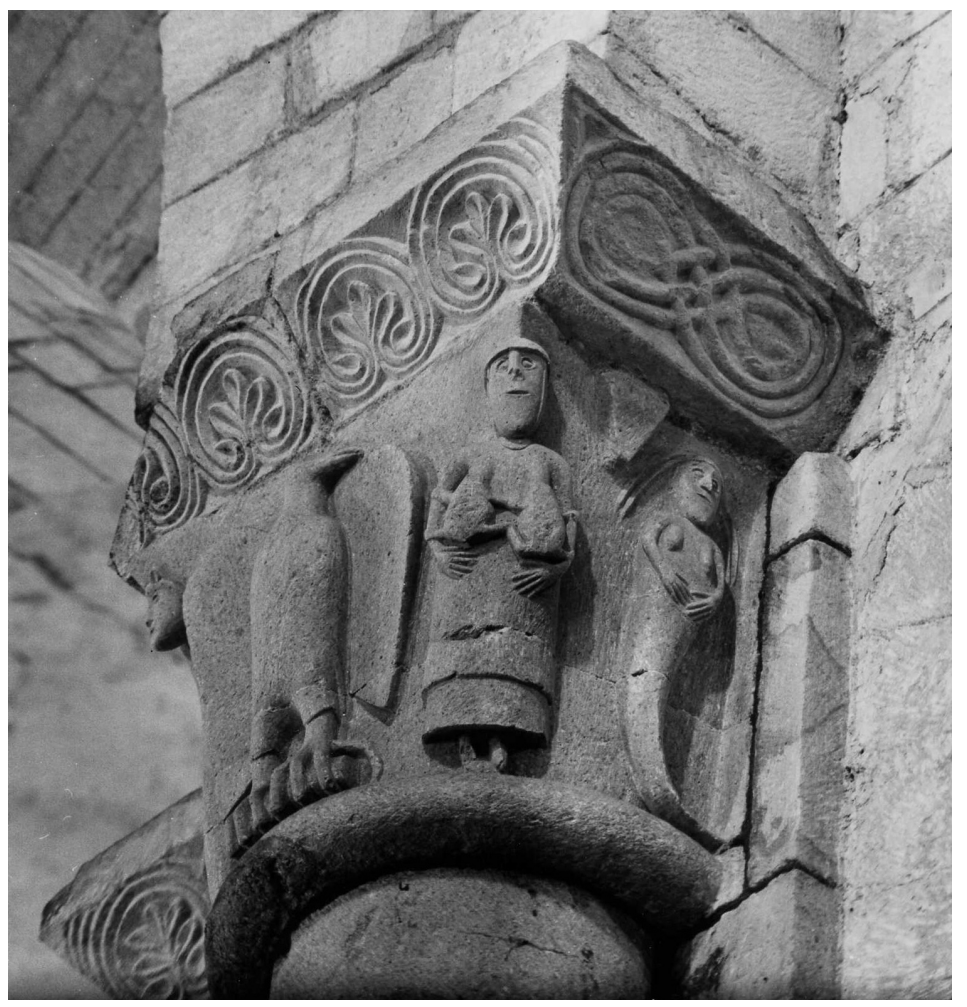

(c) J.-Cl. Vinourd, Rouen.

Une même interprétation s'impose quand la sirène est associée au centaure, traditionnel symbole de stupre au Moyen Âge ${ }^{31}$. Parfois encore la sirène se peigne d'une main et tient un miroir de l'autre ou apparaît habillée à la mode du temps (fig. 10). Le symbolisme de telles mises en scène est patent : à l'évidence la sirène incarne dans ce cas la femme frivole et séductrice, ou bien encore l'éternel féminin. Ce rapport à la Femme est encore renforcé par la présence d'une sirène tenant une quenouille aux côtés d'une sirène coquette, dans la sculpture d'une voussure du portail nord de NotreDame de Vouvant (Vendée). On ne peut rêver mieux en effet, comme association, pour signifier que la sirène doit être comprise comme une figure emblématique de la Femme. Mais contrairement à ce qu'on pourrait penser en voyant de telles images, force est de constater que ce symbolisme se retrouve de manière moins récurrente dans l'art que dans la littérature - ce qui n'a finalement rien de surprenant. En effet, la critique de la femme au Moyen Âge est d'abord un topos littéraire qui doit davantage à la tradition antique qu'à l'observation des mœurs contemporaines, et qui s'insère plus particulièrement dans la thématique du contemptus mundi. Il n'en reste pas moins que la sirène, à laquelle la femme médiévale a été si souvent comparée, illustre bien son image publique. 
Fig. 10. - Plaimpied-Givaudins (Cher), ancienne abbatiale Saint-Martin. Abside, fenêtre d'axe, après 1125.

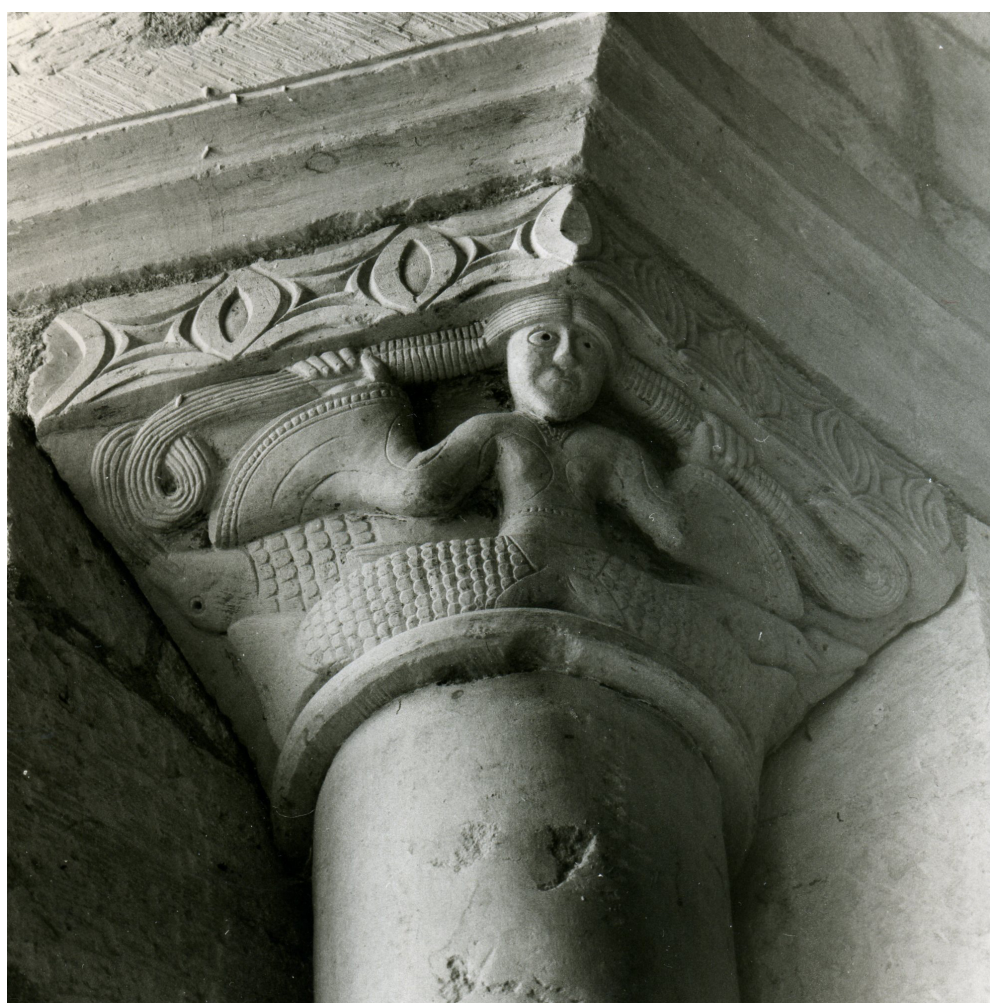

(C) J.-Cl. Vinourd, Rouen.

En dépit de cette évidence, ce n'est pas sans étonnement que l'on découvre des sirènes maternelles sur quelques chapiteaux de la fin de la période romane, en Espagne, en France et surtout dans les régions alémaniques - à Bâle (fig. 11), à Strasbourg, ou encore à Fribourg-en-Brisgau - où elles ont même des jambes humaines en plus de leurs queues. Ce type de représentation est d'autant plus déconcertant qu'il rompt avec la tradition antique qui semblait avoir figé la sirène pour toujours dans son rôle de femme fatale! Cette création authentiquement médiévale s'explique sans doute en partie par l'influence de la légende de Mélusine, fée maternelle par excellence, ayant en commun avec les sirènes la souveraineté des eaux, même si Mélusine et les sirènes appartiennent à des sphères mythiques totalement différentes, du moins à l'origine. L'apparition tardive du thème de la sirène allaitante va dans le sens de cette hypothèse, comme d'ailleurs l'attribution fréquente à Mélusine d'un appendice caudal et/ou d'ailes manifestement empruntées aux «sirènes" au sens strict. Mais il est d'autres explications. Ainsi, la scène d'allaitement est manifestement à mettre en parallèle avec plusieurs allusions à la réalité des sirènes, et plus particulièrement à leur instinct maternel, comme le laisse supposer Thomas de Cantimpré :

« Nous croyons que les sirènes sont de véritables monstres marins, dépourvus de raison [...]. En vérité, ce sont des êtres qui crient, comme le dit le Physiologue, et qui, de la tête au nombril, ont un aspect féminin : elles sont grandes; leurs visages sont effrayants et leur chevelure est longue et négligée. Elles se montrent avec leurs petits, qu'elles portent dans les bras. Elles les nourrissent en effet de leurs mamelles, qu'elles ont opulentes sur le torse. [et un peu plus loin] C'est ce qu'ont affirmé ceux qui déclarent les avoir vues... $»^{32}$ 
Fig. 11. - Bâle, cathédrale Notre-Dame. Avant-chœur, côté sud, chapiteau, c. 1200.

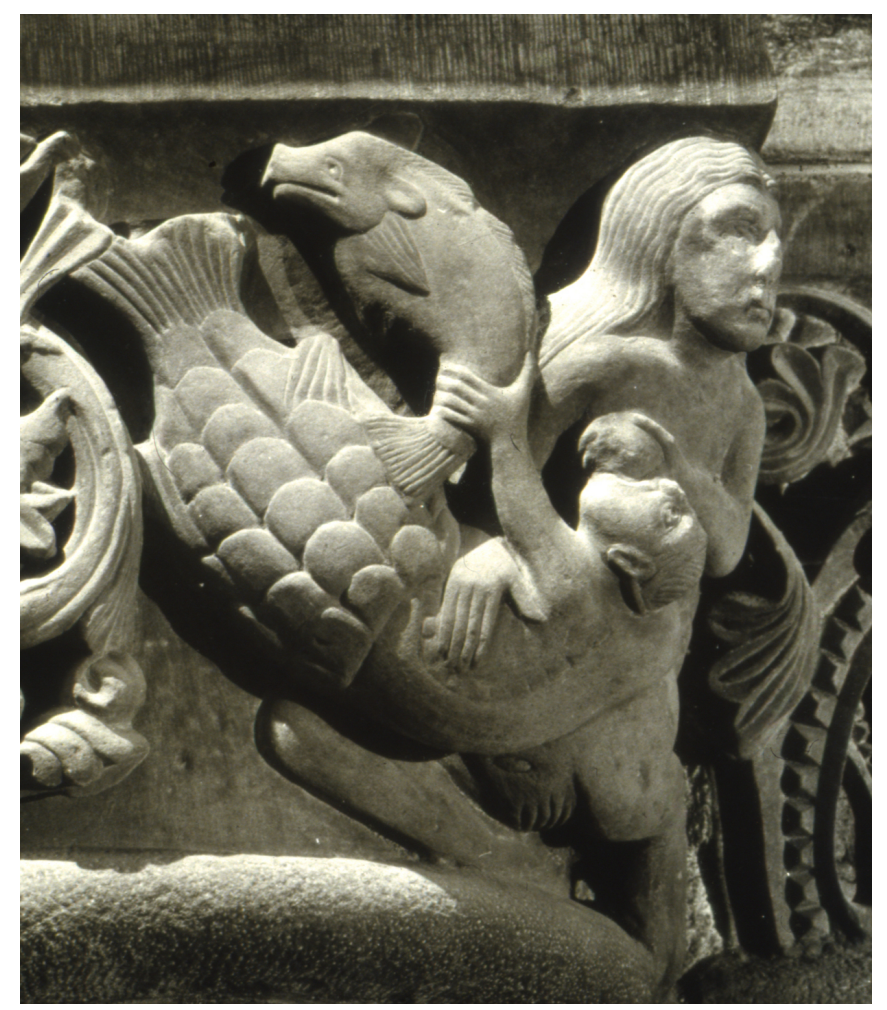

(c) Foto Basel, P. Heman.

25 À vrai dire, cet auteur n'est pas le premier à avoir fait allusion à la rencontre de marins bien contemporains et de sirènes. Ainsi, le plus ancien texte conservé qui aborde ce sujet remonte à la fin du XI ${ }^{e}$ siècle. Il s'agit de la Vie de saint Servais de Tongres ${ }^{33}$. Et ce qu'on y lit est encore plus surprenant puisqu'on y apprend que les sirènes prédisent aux marins la tempête et secourent les naufragés. Une sirène compatissante aux humains est également évoquée dans une interpolation de La bataille Loquifer, postérieure d'environ un siècle ${ }^{34}$. Et il est même question d'une sirène qui sauve un nouveau-né de la mort et le nourrit au sein dans le Tristan de Nanteuil :
«Mais Dieu lui envoya par grace une seraine
Qui moitié femme estoit et ly aultre racine
Estoit sy c'uns poissons, mais la vertu divine
Y ouvra tellement que toute estoit encline
La seraine de mer qui de Dieu estoit digne,
Qui l'enfant gouvernoit qui fut de franche orine,
Et de son propre let l'aletoit sans haÿne $»^{35}$

Cette intrusion soudaine de bonnes sirènes dans l'art (fig. 12) et dans la littérature ne peut évidemment que déconcerter celui qui en a suivi toute l'histoire mythique. Et pourtant, la conclusion s'impose d'elle-même: un nouveau type - celui de la sirène secourable, parfois victime de l'ingratitude humaine - s'est progressivement formé parallèlement à celui que l'Antiquité avait conçu et transmis à l'Occident médiéval par l'intermédiaire des Pères ${ }^{36}$. Cette réhabilitation des démones s'explique, on l'a vu, par l'émergence au sein des épopées savantes d'une matière populaire dans laquelle les sirènes apparaissent - à la fin $\mathrm{du} \mathrm{XI}^{\mathrm{e}}$ siècle au plus tard - comme des êtres réels, compatissants et pleins de sollicitude pour les marins en détresse. Mais elle peut être aussi être considérée comme la conséquence d'une ouverture certaine au surnaturel, en 
même temps que celle d'une préoccupation des chances de salut d'une créature participant de la nature humaine. Très significativement, cette tradition est exclusivement liée à la sirène sous forme d'ondine - ce qui nous incite à en voir l'origine dans un syncrétisme qui les mêle à d'autres divinités des eaux d'origine germanique ou celtique, connotées positivement ou du moins ambivalentes.

Fig. 12. - Trèves-Cunault (Maine-et-Loire), ancienne priorale Notre-Dame de Cunault. Portail nord, chapiteau, seconde moitié du XII ${ }^{\mathrm{e}}$ siècle.

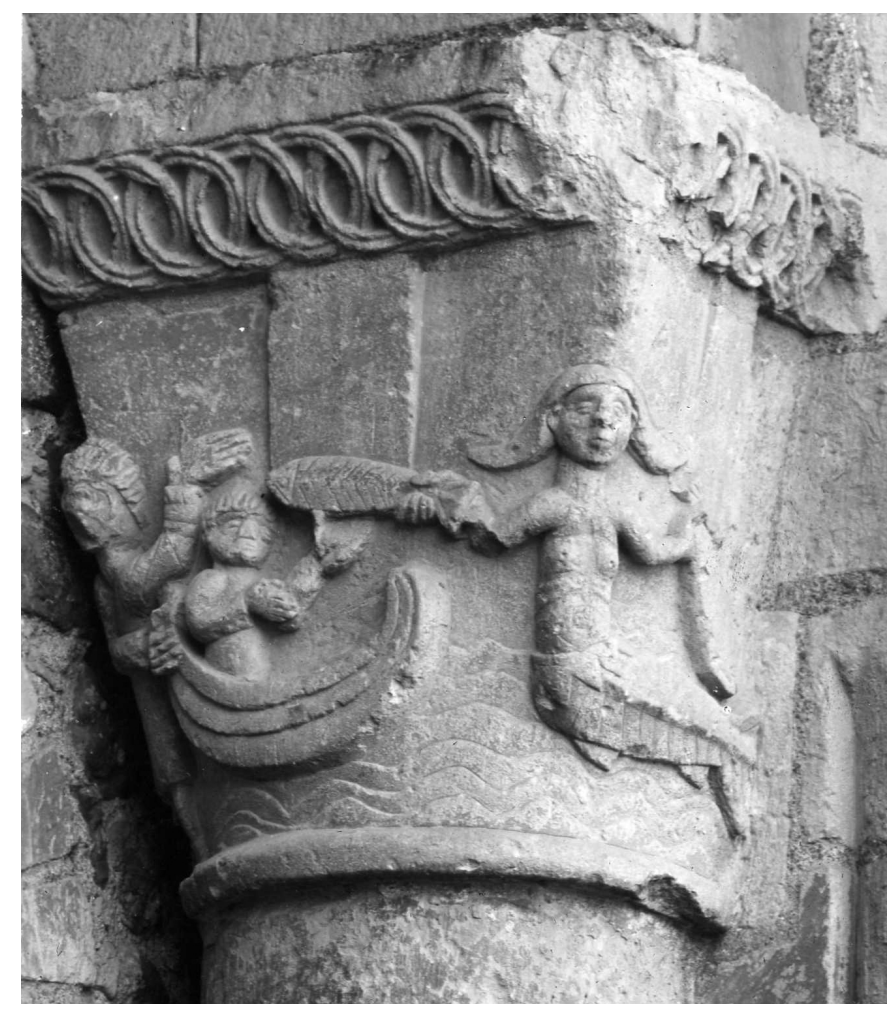

(C) Bildarchiv Foto Marburg.

L'existence parallèle d'une autre tradition populaire qui considérait au contraire les sirènes comme des êtres vampiriques proches des lamies, mène à d'autres conclusions. Exclusivement mise en rapport avec les sirènes-oiseaux, cette tradition n'est en fait que le prolongement de celle qui, dans la Basse Antiquité déjà, confondait entre eux tous les daemones meridiani auxquels se rattachent les sirènes. On notera à cet égard qu'une mosaïque de pavement de la cathédrale de Pesaro, disparue aujourd'hui, mais dont on conserve une copie, présentait deux femmes-oiseaux de type « sirènes » accompagnées de l'inscription Lamiae ${ }^{37}$.

D'une manière générale, ces valorisations contradictoires témoignent aussi de la permanence, jusqu'au Moyen Âge, de deux systèmes de valeur tout à fait opposés. L'un étant l'expression de l'idéologie dominante - celle de la religion chrétienne - l'autre étant celle de la masse populaire illettrée vivant encore dans un monde hanté de bons et de mauvais esprits, et proche des forces de la nature. Cette évidence explique notamment le parallélisme des différents discours médiévaux, leurs niveaux se superposant davantage qu'ils ne se mêlent, suivant le milieu dont ils sont l'expression. Tout le monde trouvait en fait ce qu'il cherchait dans cette figure d'ombre qu'on pouvait à la fois craindre et prendre en pitié, et dont l'ultime métamorphose - celle qui 
avait fait d'elle une mère féconde - symbolisait en quelque sorte la victoire de la Vie sur la Mort.

\section{BIBLIOGRAPHIE}

ADHÉMAR Jean, Influences antiques dans l'art du Moyen Âge français. Recherches sur les sources et les thèmes d'inspiration, Londres, The Warburg Institute, 1939, réimp. Paris, Éditions du CTHS, 2005 (Format 21).

ANGELINI Anna, «Les sirènes du Physiologos et le savoir hérétique : les périls de l'hybridité entre Antiquité et Moyen Âge ", dans Hélène VIAL (dir.), Les Sirènes ou le Savoir périlleux. D'Homère au XXI siècle, Rennes, Presses universitaires de Rennes, 2014, p. 179-192 (Interférences).

ANTIN Paul, « Les Sirènes et Ulysse dans l'œuvre de saint Jérôme », Recueil sur saint Jérôme, Bruxelles, éd. Latomus, 1968, p. 59-70 (Latomus, 95).

BETTINI Maurizio et SPINA Luigi, Il Mito delle Sirene. Immagini e racconti dalla Grecia a oggi, Turin, Einaudi, 2007 (tr. fr., Le Mythe des Sirènes, Paris, Belin, 2010).

CONSOLI Silla, La candeur d'un monstre. Essai psychanalytique sur le mythe de la Sirène, Paris, Le Centurion, 1980.

DANIELOU Jean, Message évangélique et culture hellénistique aux II $^{e}$ et III ${ }^{e}$ siècles, Paris, Desclée et Cie, 1961 (Bibliothèque de Théologie. Histoire des doctrines chrétiennes avant Nicée, 2).

DE RACHELWILTZ Siegfried, De Sirenibus : An Inquiry into Sirens from Homer to Shakespeare, New York, Garland, 1987.

DOIGNON Jean, «Le symbolisme des Sirènes dans les premiers dialogues de saint Augustin », dans MARTIN Paul M. et TERNES Charles M. (éd.), La mythologie. Clef de lecture du monde classique. Hommage à Raymond Chevalier, Tours, Centre de recherches André Piganiol, 1986, t. 1 (Caesarodunum XXI bis).

FARAL Edmond, « La queue de poisson des Sirènes », Romania, 74, 1953, p. 433-506.

HOFSTETTER Eva, KRAUSKOPF Ingrid, S.v. « Seirenes » dans Lexicon iconographicum mythologiae classicae (LIMC), Zurich - Düsseldorf, Artemis Verlag, 1997, p. 1093-1105 (Illustrations correspondantes dans le t. VIII 2, p. 734-744).

LECLERCQ-MARX Jacqueline, La Sirènes dans la pensée et dans l'art de l'Antiquité et du Moyen Âge. Du mythe païn au symbole chrétien, Bruxelles, Académie royale de Belgique, 1997 (Publications de la Classe des Beaux-Arts. Coll. In- $4^{\circ}, 3^{\text {e }}$ sér., t. 2). Consultation libre : http://www.koregos.org/fr/ jacqueline-leclercq-marx_la-sirene-dans-la-pensee-et-dans-l-art-de-l-antiquite-et-du-moyenage/4389/

LECLERCQ-MARX Jacqueline, « Du monstre androcéphale au monstre humanisé. À propos des sirènes et des centaures, et de leurs familles dans le haut Moyen Âge et à l'époque romane ", Cahiers de civilisation médiévale, 45, janvier-mars 2002, p. 55-67. 
LECLERCQ-MARX Jacqueline, « La sirène et l'onocentaure dans le Physiologus grec et latin, et dans quelques Bestiaires. Le texte et l'image », dans VAN DEN ABEELE Baudouin (dir.), Bestiaires médiévaux. Nouvelles perspectives sur les manuscrits et les traditions textuelles, Louvain-La-Neuve, 2005 (Université Catholique de Louvain. Publications de l'Institut d'études médiévales, 21). LECLERCQ-MARX Jacqueline, « De la Terre-mère à la Luxure. À propos de la Migration des Symboles », Cahiers de Civilisation Médiévale, 18, 1, 1975, p. 37-43.

LECLERCQ-MARX Jacqueline, « Femme-enfant, femme-femme, matrone et mère. La sirène dans tous ses états à l'époque romane ", dans REGOND Annie (dir.), La femme à l'époque romane, Revue d'Auvergne, 122, fasc. 586, 2008, p. 63-76.

LECLERCQ-MARX Jacqueline, « Prototypes antiques et re-créations médiévales. Le cas de quelques monstres anthropomorphes », dans SANSTERRE Jean-Marie et LENAIN Thierry (dir.), Image et Prototype, Degrés, 145-146, 2011, § G, p. 1-17.

LECLERCQ-MARX Jacqueline, « Quand le monstre se fait homme. Centaures et Sirènes dans l'art du haut Moyen Âge et du Moyen Âge central ", dans LINANT DE BELLEFONDS Pascale et ROUVERET Anne (dir.), L'homme-animal dans les arts visuels, Paris, Les Belles Lettres, Collection « Les passés dans le présent », série " Arts et mémoire », 2017, p. 62-73.

LECLERCQ-MARX Jacqueline, « Entre tradition classique et imaginaire germano-celtique. Les monstres anthropomorphes des mers septentrionales, au Moyen Âge et au début de l'époque moderne ", dans BUQUET Thierry, GAUVIN Brigitte, LUCAS-AVENEL Marie Agnès (dir.), Animaux aquatiques et monstres des mers septentrionales, Anthropozoologica, 58, 2018, art. 53,3, p. 53-65. TOUCHEFEU MEYNIER Odette, Thèmes odysséens dans l'art antique, Paris, de Boccard, 1968.

VIEILLARD-TROIËKOUROFF May, « Sirènes-poissons carolingiennes ", Cahiers archéologiques, 19, 1969, p. 61-82.

VIAL Hélène (dir.), Les Sirènes ou le Savoir périlleux. D'Homère au XX siècle, Rennes, Presses universitaires de Rennes, 2014 (Interférences).

VOISENET Jacques, Bestiaire chrétien. L’imagerie animale des auteurs du haut Moyen Âge ( $V^{e}$-XI ${ }^{e}$ siècle), Toulouse, Presses universitaires du Mirail, 1994.

WEDNER Sabine, Tradition und Wandel im allegorischen Verständnis des Sirenenmythos. Ein Beitrag zur Rezeptiongeschichte Homers, Francfort, 1994 (Studien zur klassischen Philologie, 86).

WILLIAMs David, Deformed Discourse. The Function of the Monster in Medieval Thought and Literature, Exeter, University of Exeter Press, 1996.

\section{NOTES}

1. Cet article contient un certain nombre d'idées qui sont développées et illustrées dans J. Leclercq-Marx, La Sirènes dans la pensée et dans l'art de l'Antiquité et du Moyen Âge. Du mythe païen au symbole chrétien. On ajoutera principalement à la bibliographie qui y est contenue : E. Hofstetter, I. Krauskopf, s. v."Seirenes", dans Lexicon iconographicum mythologiae classicae, p. 1093-1105 (illustrations correspondantes dans le t. VIII 2, p.734-744); Sabine Wedner, Tradition und Wandel im allegorischen Verständnis des Sirenenmythos. Ein Beitrag zur Rezeptiongeschichte Homers, et aussi Maurizio Bettini et Luigi Spina, Il Mito delle Sirene. Immagini e racconti dalla Grecia a oggi, tr. française, Le 
Mythe des Sirènes; Hélène Vial(dir.), Les Sirènes ou le Savoir périlleux. D’Homère au $\mathrm{XXI}^{e}$ siècle. Voir aussi infra, passim.

2. La rencontre d'Ulysse et les sirènes est d'abord prédite par Circé en Od. XII, 37-57 puis décrite en Od. XII, 165-200.

3. 0 . Touchefeu Meynier, Thèmes odysséens dans l'art antique, p. 145.

4. G. Weicker, Der Seelenvogel in der alten Literatur und Kunst. Eine mythologischarchäeologische Untersuchung.

5. Hydrie attique à figures noires, Paris, Louvre (inv. $\left.\mathrm{N}^{\circ} \mathrm{E} 869, \mathrm{c} .550\right)$.

6. Soph., fr. 861 (éd. A. C. Pearson, Cambridge, Univ. Press, 1917, t. III, p. 66).

7. Eur., Hel., 1, 167-178 (éd. et tr. H. Grégoire \& L. Méridier, C. U. F., I, 1950, p. 56-57).

8. Anthol. Pal., 7, 491 (éd. p. Waltz; tr. E. des Places, M. Dumitrescu, H. Lemaître \&

G. Soury, Paris, C. U. F., V, 1941, p. 65).

9. Iambl., V. P., 18, 82 (éd. L. Deubner, B. T., 1975, p. 47).

10. Iambl., V. P., 18, 22 (ibid.).

11. Plat., Rep., 10, 617 a-d (éd. É. Chambry, C. U. F., VII, 2, 1934, p. XXX).

12. Plut., Quaest. Conv., 9, 14, 6, 745 D et F (éd. C. Hubert, B. T., Plut. Mor., IV, 1971, p. 328 ; tr. U. Betolaud, Paris, Hachette, 1870, t. III, p. 490).

13. C'est dans Steph. Byz., Ethn., s. v. Aptera qu'on trouve le passage le plus explicite à cet égard.

14. Plat., Crat., $403 \mathrm{C}$.

15. Procl., In Crat., $403 \mathrm{C}$ et id., In Remp., 617.

16. Macrob., Somn. Scip. 2, 3, 1.

17. Porph., Vit. Pyth., 39 (éd. A. Nauck, B. T., 1963, p. 37).

18. Plut., De aud. Poet., 1,15 (éd. W. R. Paton, I. Wegehaupt \& H. Gartner, B. T., Plut. Mor., I, 1974, p. 30).

19. Anthol. lat., 494 a (In Sirenas) (éd. F. Buecheler et A. Riese, B. T., 1906, p. 51-52).

20. Toute cette question est amplement étudiée dans J. Leclercq-Marx, La sirène dans la pensée et dans l'art...SII (Des origines juives aux conceptions chrétiennes des six premiers siècles. Du démon du désert au symbole de la tentation).

21. Clem., Protr., 12, 118, 4 (éd. et tr. Cl. Mondésert \& A. Plassart, S. C., 2b, 1949, p. 187-188).

22. Max. Taur., Serm. 37, 1-2 (éd. A. Mutzenbecher, C. C., 23, 1962, p. 145-146).

23. Hes., Erg., 373 sq., dans Clem., Protr., 12, 118 (éd. et tr. Cl. Mondésert \& A. Plassart, S. C., 2b, 1949, p. 187-188).

24. Leander., Reg., 1 (éd. A. C. Vega, Escorial, 1948 (Scriptores ecclesiastici hispano-latini veteris et medii aevi ; fasc. 16-17), p. 100-101).

25. J. Daniélou, Message évangélique et culture hellénistique aux II et III' siècles, p. 92 à propos de Clem., Strom., 6, 11, 89, 1 (éd. O. Stählin \& L. Fruchtel, G. C. S., 52, 1960, p. 476).

26. A. Angelini, «Les sirènes du Physiologos et le savoir hérétique: les périls de l'hybridité entre Antiquité et Moyen Âge ", dans H. Vial (dir.), Les Sirènes ou le Savoir périlleux..., p. 179-192 (Interférences).

27. Hippol., Philos., 7, 13. 
28. Liber monstrorum, 1.14 (éd. A. Orchard, dans Pride and Prodigies. Studies in the Monsters of the Beowulf-Manuscripts, Cambridge, 1995, p. 262-263).

29. Voir plus particulièrement J. Leclercq-Marx, La sirène dans la pensée et dans l'art..., § III. (Du VII ${ }^{\mathrm{e}}$ au Xe siècles. Concepts anciens. Formes nouvelles).

30. Par exemple dans le manuscrit London, Brit. Lib., Harley 4751, fol. 47v (Angleterre, fin du XII ${ }^{e}$ siècle). Reproduction ibid., ill. 58, p. 122. Sur les Bestiaires médiévaux, on verra essentiellement Baudouin van den Abeele (dir.), Bestiaires médiévaux. Nouvelles perspectives sur les manuscrits et les traditions textuelles, Louvain-la-Neuve, 2005 (Université Catholique de Louvain. Publications de l'Institut d'études médiévales, 21) ainsi que, d'une manière générale, les excellentes études de Xénia Muratova.

31. On trouvera l'illustration de tous les exemples cités ici et plus bas dans J. Leclercq-

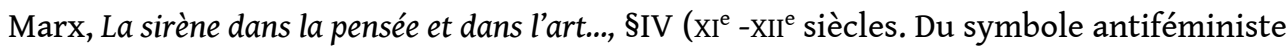
à l'héroïne compatissante). Sur le monstrueux médiéval, voir notamment D. Williams, Deformed Discourse. The Function of the Monster in Medieval Thought and Literature, Exeter, University of Exeter Press, 1996.

32. Thomas de Cantimpré, Nat. rer., 6, 46 (éd. H. Boese, Berlin / New York, De Gruyter, t. I, 1973, p. 246).

33. Gesta Sancti Servatii, 3 (éd. F. Wilhelm, Munich, Beck, 1910, p. 125).

34. La bataille Loquifer, vers 3965-3996 et 4185-4210 (éd. M. Barnett, Oxford, B. Blackwell, 1975, p. 138-139 et p. 144-145).

35. Tristan de Nanteuil, X, v. 420-426 (éd. K. V. Sinclair, Assen, Van Gorcum, 1971, p. 92).

36. Pour ce qui est de l'humanisation des sirènes, on se reportera essentiellement à mes articles « Du monstre androcéphale au monstre humanisé. À propos des sirènes et des centaures, et de leur famille dans le haut Moyen Âge et à l'époque romane », p. 55-67, et "Quand le monstre se fait homme. Centaures et Sirènes dans l'art du haut Moyen Âge et du Moyen Âge central ", dans L'homme-animal dans les arts visuels, P. Linant de Bellefonds et A. Rouveret (dir.), p. 62-73.

37. Reproduction dans J. Leclercq-Marx, La sirène dans la pensée et dans l'art..., ill. 55, p. 102.

\section{RÉSUMÉS}

Durant l'Antiquité, les sirènes ont été étroitement associées à la mort et ce, depuis Homère qui les a évoquées le plus anciennement. Redoutées par ailleurs comme démons maléfiques de la famille des Kères, elles se sont toutefois muées en démons secourables, dans le but évident de se les concilier. Leur présence sculptée ou peinte dans la tombe devint ainsi un puissant apotropaïon. Parallèlement, l'angoisse de la mort qu'elles suscitaient à l'origine en vint à exprimer, par euphémisation, la peur de la femme. La sirène devint dès lors une image de la courtisane à laquelle se superposa celle de l'éternel féminin - conception qui fut reprise par le christianisme. Symbole de la femme frivole dont la séduction peut mener à la mort, elle fut fréquemment présentée comme une figure emblématique de la femme fatale que le chrétien, tel Ulysse, doit 
fuir. Toutefois, sa métamorphose en femme-poisson lui permit d'acquérir certaines valeurs positives liées aux déités celtiques et germaniques des eaux dont elle empruntait la morphologie. C'est ainsi qu'à partir de la fin du $\mathrm{XII}^{\mathrm{e}}$ siècle, la sirène-poisson est parfois figurée ou décrite comme une mère attentionnée, allaitant indifféremment son siréneau ou un petit d'homme qu'elle aurait sauvé - étonnante victoire de la Vie sur la Mort.

\section{AUTEUR}

\section{JACQUELINE LECLERCQ-MARX}

Docteur en philosophie et lettres (Histoire de l'art et archéologie), professeur honoraire à l'Université Libre de Bruxelles, membre du Groupe de recherche en histoire médiévale et du laboratoire Histoire, arts, cultures des sociétés anciennes, médiévales et modernes (SOCIAMM) 
Aux origines des symboles de l'Occident : métamorphoses et hybridations dans les mythes et les religions 


\title{
L'homme-animal : hybridité et monstruosité dans l'iconographie des vases grecs
}

\author{
François Boudin
}

1 Les monstres interviennent le plus souvent dans un temps mythique, celui du mûthos, le récit légendaire transmis par les poètes. En Grèce, le monstre s'inscrit dans ce discours particulier. Dans la mythologie grecque, l'hybridité représente la forme la plus visible de la monstruosité. Les Grecs ne possèdent pas de mots dans leur langue qui puisse rendre compte de l'hybridité. Pour cela, ils utilisent différents mots composés tels diphuês ${ }^{1}$ (d'une double nature), dimorphos ${ }^{2}$ (d'une double forme) ou mixothêr (à moitié une bête sauvage) $)^{3}$.

2 Ces hybrides constituent une famille particulièrement importante de monstres mythologiques. Ils ont souvent une histoire. Ils sont parfois le fruit d'une transgression sexuelle entre l'homme et l'animal ou bien furent créés lorsque le monde n'était pas encore structuré par les dieux. Leur présence montre qu'il existe toujours le risque d'un retour au chaos originel. Ils marquent ce désordre des origines et leur existence est un constant rappel du fait que celui-ci peut encore revenir.

3 À travers textes et images se dresse toute une histoire de la monstruosité et de ses représentations. Dans le cadre de cet article, les images que nous ont laissées les peintres sur les vases grecs, plus d'une centaine de milliers, constituent une source de documentation importante et incontournable. Avec quelques exemples présentés ici, nous verrons comment les Grecs ont transcrit les récits des poètes par l'image pour leur donner une réalité palpable, et quelle part fut laissée à leur imagination, celle-ci se concrétisant parfois par des images d'hybrides inconnus de nos sources écrites.

\section{Les hybrides simples}

4 Les centaures sont les hybrides les plus anciennement représentés sur les vases grecs mais ce sont aussi les plus nombreux. Apparus dès le viII ${ }^{\mathrm{e}}$ siècle av. J.-C., ils ont la 
particularité de bénéficier d'une imagerie plus complexe que celle des autres hybrides. En effet, les centaures constituent une race entière composée de personnalités différentes tels Chiron, Pholos ou Nessos pour les plus connus, et non un unique individu. Le peintre se trouve donc devant un problème inédit, à savoir comment représenter la monstruosité des centaures tout en montrant les valeurs morales qui en caractérisent certains.

\section{Les centaures « sauvages »}

5 Nous ne possédons pas de description des centaures chez Homère qui utilise des périphrases pour en parler: monstres velus ou monstres de la montagne ${ }^{4}$. Sur une hydrie proto-attique datée du début du viI ${ }^{e}$ siècle av. J.-C., nous avons deux centaures sur une face du vase $\mathrm{f}^{5}$ (fig. 1). Les deux hybrides sont représentés de manière très géométrique. Ils avancent vers la droite, ressemblent à des hommes au corps épais et grossier, avec des jambes humaines, mais sur leur corps est collé celui, plus fin, d'un quadrupède. Sur les deux corps sont rattachées des sortes d'ailes très primitives qui pourraient nous inciter à $\mathrm{y}$ voir des espèces de sphinx ou de sirènes. Seulement leur faciès est celui d'un homme et rien n'est sûr pour identifier comme « ailes » les grands traits qui dessinent des formes géométriques. Le visage est très sommaire avec une tête et un œil énorme qui occupe près de la moitié du visage. La morphologie humaine du centaure nous conforte dans l'hypothèse selon laquelle ces derniers représenteraient globalement la monstruosité à une haute époque. L'arrière-train chevalin est la plus ancienne figuration des centaures, mais aussi de la monstruosité en général. Rapidement, en moins d'un siècle, les centaures perdent cette caractéristique physique pour se métamorphoser en chevaux à tronc humain.

Fig. 1. - Centaures.

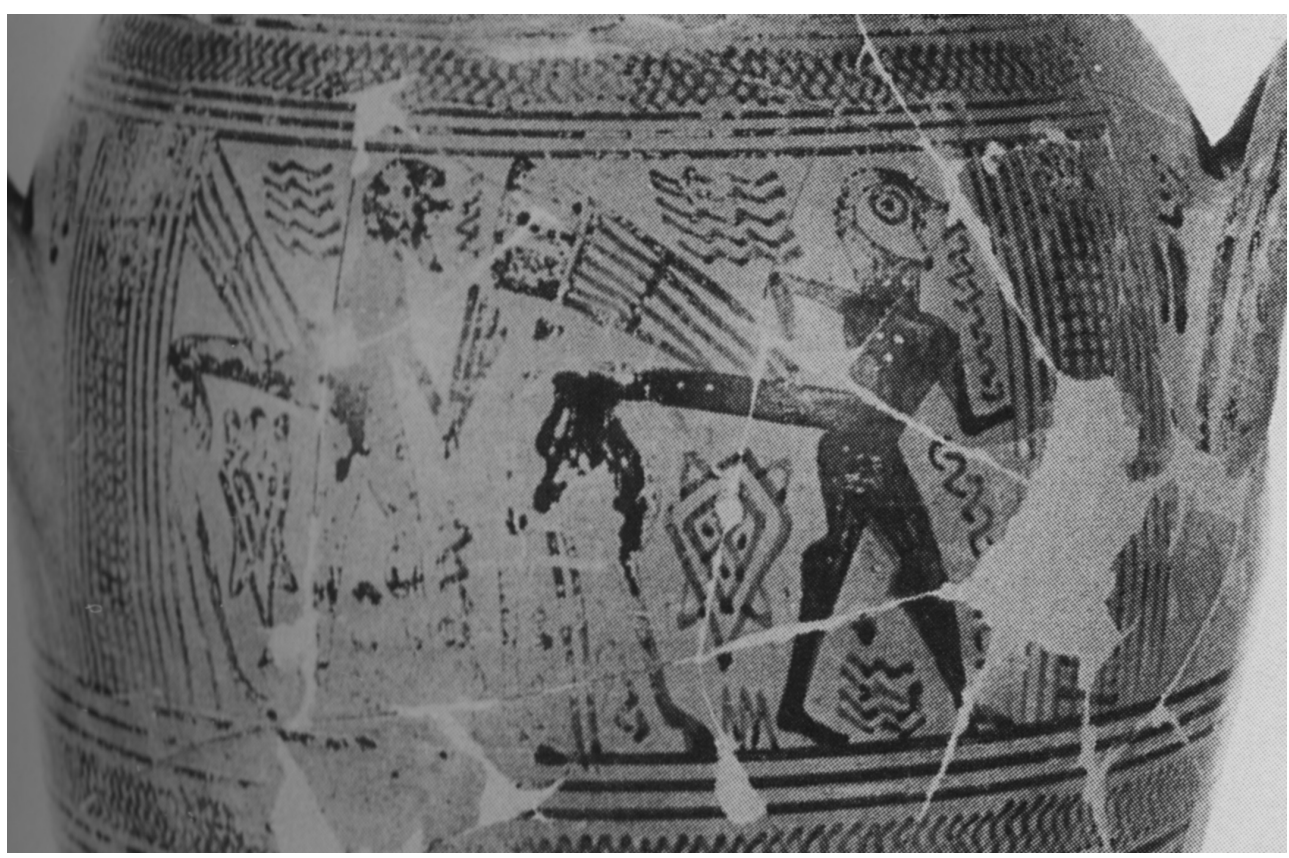

D’après LIMC, Kentauroi, Kentaurides. Musée National, Athènes. 
6 L'aventure du centaure Nessos contre Héraclès est l'une des légendes les plus populaires de l'art grec $^{6}$. Un vase proto-attique du milieu du viI ${ }^{\mathrm{e}}$ siècle offre une figuration de ce combat ${ }^{7}$ (fig. 2). Comme sur de nombreuses images anciennes de centaures, il a un corps humain, porte une longue barbe et des cheveux très longs. Il se penche vers l'avant comme un suppliant ${ }^{8}$ ou comme s'il était frappé d'un coup d'épée. Celle-ci est tenue par le personnage de droite. C'est un guerrier qui se tient devant un char sur lequel figure une femme. L'homme n'a pas d'attributs particuliers. Il est vêtu d'une tunique courte, il a les cheveux bouclés et une barbe. Nous reconnaissons dans cette scène Héraclès face à Nessos. La chouette, animal emblématique d'Athéna semble protéger le héros. Le combat d'Héraclès contre Nessos avec son épée est une tradition très répandue dans l'art attique depuis les premières images sur ce thème ${ }^{9}$.

Fig. 2. - Nessos.

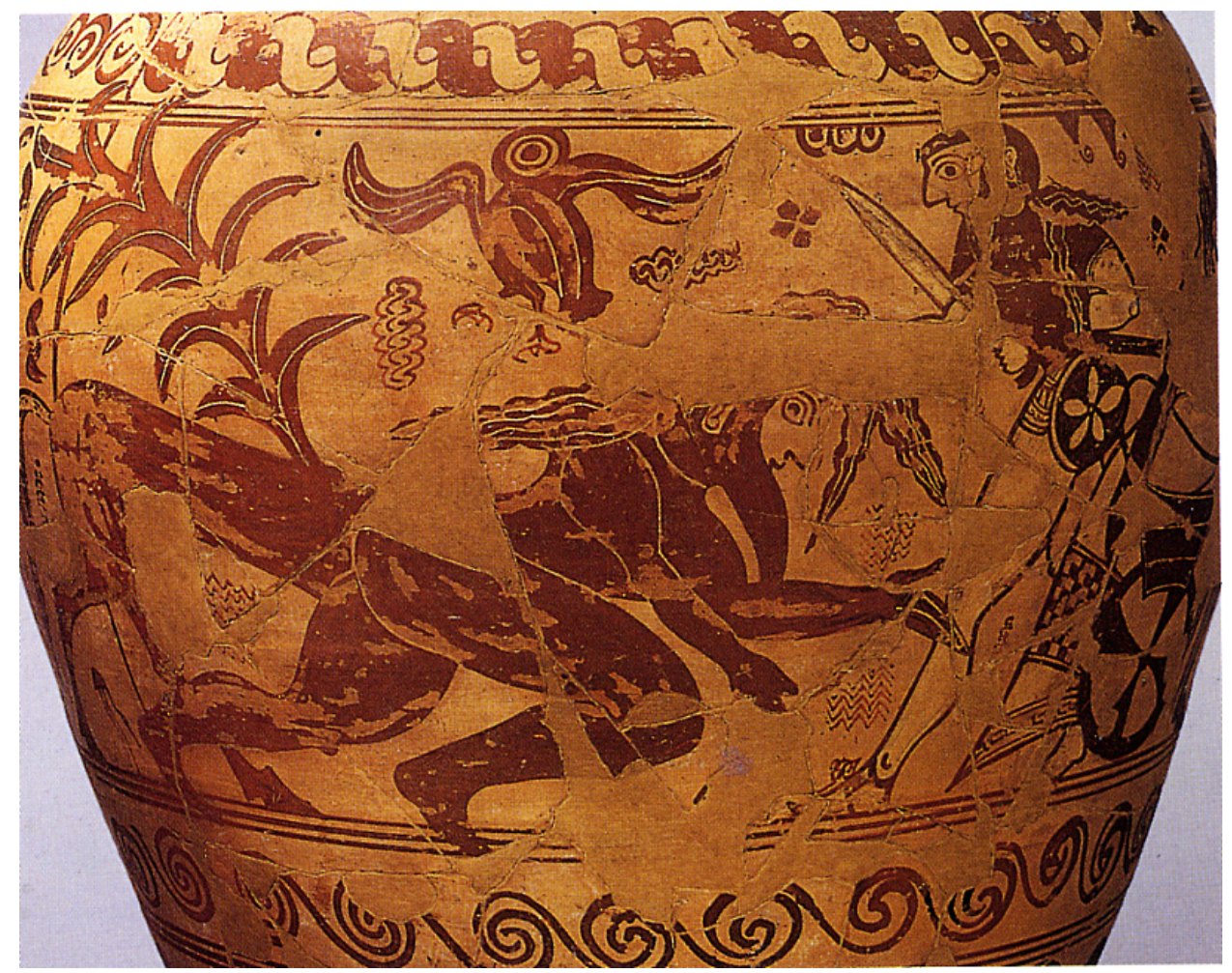

D’après J. M. Padgett, Centaur's smile. Metropolitan Museum, New York.

7 Mais très rapidement, le centaure perd ses caractéristiques originelles pour atteindre une image plus "classique ", à savoir un corps chevalin, des oreilles animales, une barbe hirsute qui correspondent mieux à l'image des centaures qualifiés de « sauvages $»^{10}$.

\section{Les « bons » centaures}

8 Les «bons » centaures que sont Chiron et Pholos sont les amis de l'humanité, et les peintres de vases vont essayer par divers moyens de rendre cet aspect. L'application du terme "bon » centaure à Chiron et Pholos transparaît dans toutes nos sources anciennes. Leur attitude d'hospitalité qui les différencie de leurs congénères fait d'eux des créatures monstrueuses uniquement dans leur forme. Leur filiation, distincte 
également de celle des autres hybrides, est aussi un signe de cette différence. Ils brouillent toutes les catégories et les frontières entre l'animalité, l'humanité et la divinité. Ainsi Chiron est un immortel. Les peintres ont tenté de produire une image d'eux qui correspondait à cette réalité tout en conservant leurs caractéristiques physiques principales. Chiron et Pholos se placent donc à part et l'iconographie rend compte de cette différence. Les peintres ont humanisé autant qu'ils le pouvaient leurs traits. Leur faciès est souvent différent de celui des autres centaures mais, aussi et surtout, les peintres ont repris cette idée d'un corps humain auquel est "collé » un corps de cheval. Chiron est le plus célèbre. Il apparaît sur les vases grecs de façon récurrente à partir du début du $\mathrm{VI}^{\mathrm{e}}$ siècle av. $\mathrm{J} .-\mathrm{C} .{ }^{11}$ comme participant au mariage de Pélée et Thétis. Sophilos ${ }^{12}$ a imaginé cette scène (fig. 3) racontée par Pindare.

Fig. 3. - Chiron.

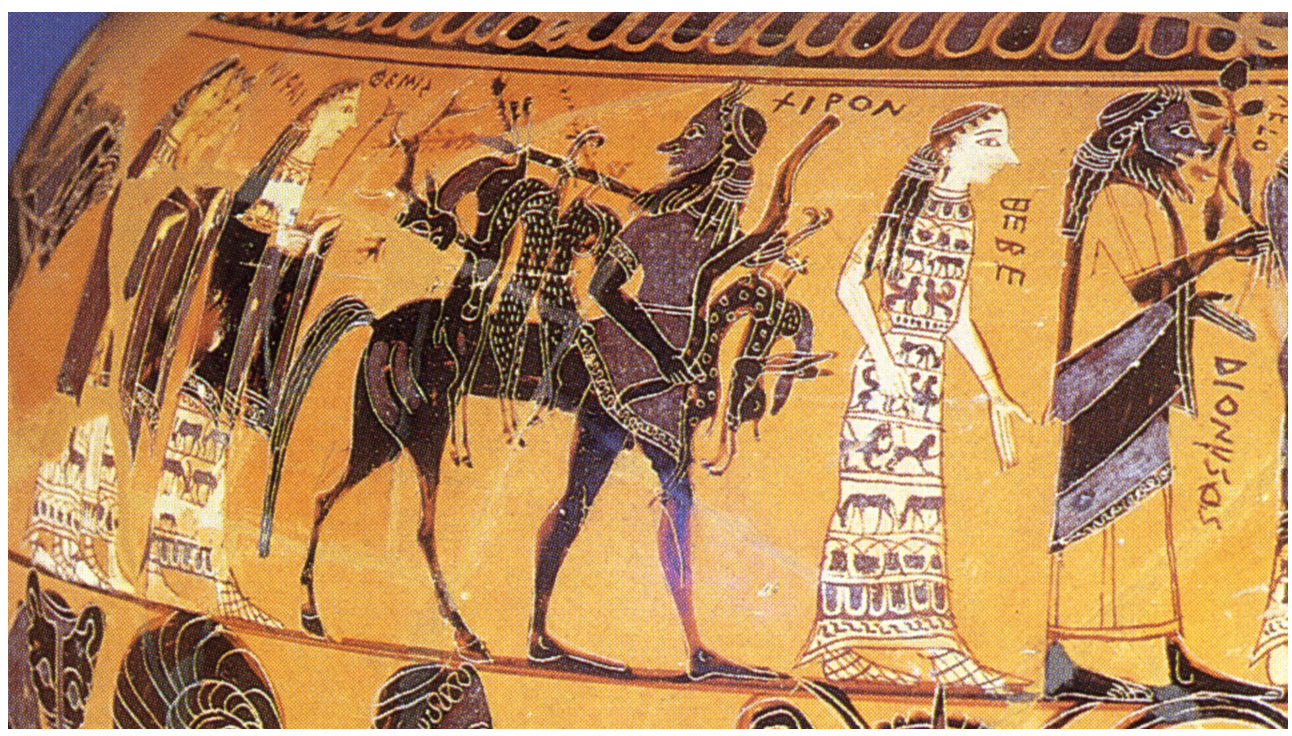

D'après D. Williams, Greek vases. Musée National, Athènes.

9 Le peintre est un artiste du début du $\mathrm{VI}^{\mathrm{e}}$ siècle, le premier dont nous connaissons le nom par une signature de vase. Il a utilisé un vase d'assez grandes dimensions, un dinos, sur lequel il a déroulé tout le cortège nuptial dans une longue bande horizontale ${ }^{13}$ : nous assistons à la procession du mariage. Tous les participants de ces noces sont nommés et la procession se déroule selon un ordre bien établi : les personnages les plus importants cheminant en char, tandis que les autres suivent à pied. Iris ouvre la marche des divinités, suivie de différentes déesses, puis de Chiron.

Le centaure est vêtu d'une tunique courte. Celle-ci couvre son corps humain qui est rattaché à celui du cheval. Sur ce vase, ses jambes antérieures sont humaines et son arrière-train est celui d'un cheval. Hormis ce « détail », Chiron se différencie peu des autres personnages. C'est un homme barbu, à la barbe longue et drue, portant également des cheveux longs retenus par un bandeau. Les oreilles du centaure sont parfaitement humaines. Ces particularités anatomiques marquent sa distinction par rapport aux autres centaures.

11 Le centaure porte une branche sur laquelle sont suspendus des animaux sauvages: lièvres et daims. Cette branche a une double fonction. Elle rappelle le rapport étroit qu'entretient le Centaure avec le monde sauvage auquel il appartient, mais aussi et 
surtout elle rappelle sa fonction d'éducateur ${ }^{14}$. Chiron est aussi un chasseur ${ }^{15}$ et la branche avec des animaux est un attribut de Chiron permettant de l'identifier ${ }^{16}$. Il a une apparence très humaine qu'il ne perdra quasiment jamais dans les décennies à venir. Les codes iconographiques qui permettent de l'identifier sont donc clairement mis en place bien avant le début $\mathrm{du} \mathrm{VI}^{\mathrm{e}}$ siècle av. J.-C. Sa présence dans un tel cortège s'explique parce qu'il est l'ami de Pélée, mais sa présence peut également avoir une autre fonction. Dans cette procession où nous ne trouvons que des divinités de l'olympe, est présent un mortel, Pélée. Chiron qui appartient aux deux mondes, celui des dieux et des hommes, ferait ainsi la transition entre ces deux univers. Sa nature mixte suggère le rapprochement entre les hommes et les dieux à travers ce mariage ${ }^{17}$.

Plus d'un siècle plus tard, le peintre d'Eupolis ${ }^{18}$ (fig. 4) peint le centaure avec une femme à ses côtés et une autre derrière eux ${ }^{19}$ vêtue d'un chiton et d'un himation, tenant deux torches dans ses mains. Ces torches rappellent celles des scènes nuptiales comme sur le vase contemporain du peintre de Copenhague où nous assistons à la procession du mariage de Thétis et Pélée ${ }^{20}$. Si Philyra tient les torches nuptiales, cela signifie que le personnage qui se tient aux côtés du centaure est Chariclô, sa femme. Celle-ci est vêtue comme la femme de gauche, mais son manteau est posé sur sa tête en partie cachée. Le centaure qui se retourne a sa main posée sur son épaule et l'accompagne par son geste. Toute la scène est empreinte de calme et de sérénité. Le centaure avance d'un pas très lent. Chiron est ici très différent des images sur les vases de la même époque. La barbe et la chevelure du centaure ne sont pas taillées et lui donnent un air plus sauvage que sur les autres vases contemporains. Le peintre n'a pas jugé utile de nous montrer ses oreilles sous cette épaisse chevelure. Dans sa main gauche, il tient une branche d'arbre, tel un bâton et non sur son épaule. Une peau de bête est jetée sur celle-ci et pend sur son bras gauche, ne cachant que partiellement le raccord entre les parties animales et humaines du centaure. Contrairement aux autres images, ses jambes sont celles d'un cheval. Nous n'avons donc plus une figuration verticale mais horizontale du centaure, celle où la partie animale est la plus importante, comme pour les autres centaures. 
Fig. 4. - Chiron et Chariclô.

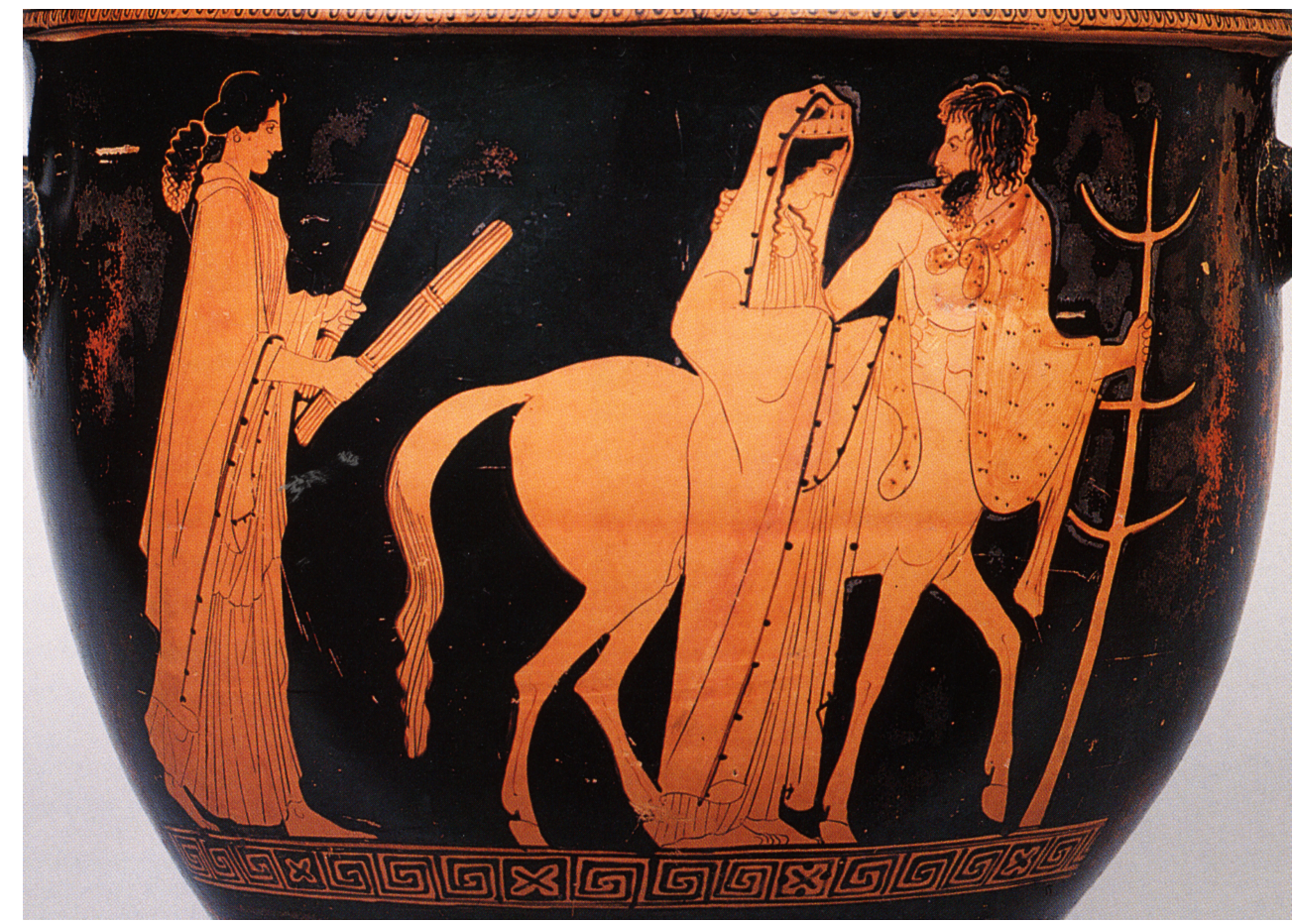

D’après J. M. Padgett, Centaur's smile. Collection privée, New York. d'identification pouvait se poser et, même si les deux centaures se ressemblent, ils sont très différents dans leur fonction. Il faut donc les montrer différemment. Pholos conserve ainsi des caractéristiques physiques de ses congénères alors que d'autres sont atténuées.

La scène du peintre d'Antiménès ${ }^{21}$ (fig. 5) met en scène l'accueil d'Héraclès par le centaure. Pholos est à gauche de l'image avec seulement le haut du corps humain, il ressemble donc plus à ses congénères qu'à Chiron ${ }^{22}$. Ses cheveux sont plus longs ainsi que sa barbe. Il a des oreilles animales. Le héros et le centaure se saluent en se serrant la main. Pholos tient une branche sur laquelle sont attachés deux lièvres. Une biche est à ses pieds. Derrière Héraclès, Hermès est assis sur un rocher et il regarde la scène. Ici, cet avant-train chevalin marque sa différence par rapport à Chiron. Dans cette scène nous pouvons noter l'absence d'éléments annexes qui identifient le centaure, tel le pithos, source de tous ses malheurs et de sa mort. Toute allusion à la centauromachie est ici gommée par le peintre qui focalise l'attention du lecteur sur la poignée de main des deux personnages. Pholos est très fortement humanisé. Héraclès, représenté sans sa peau de lion qui lui donne un aspect « sauvage », paraît plus humain également. 
Fig. 5. - Héraclès et Pholos.

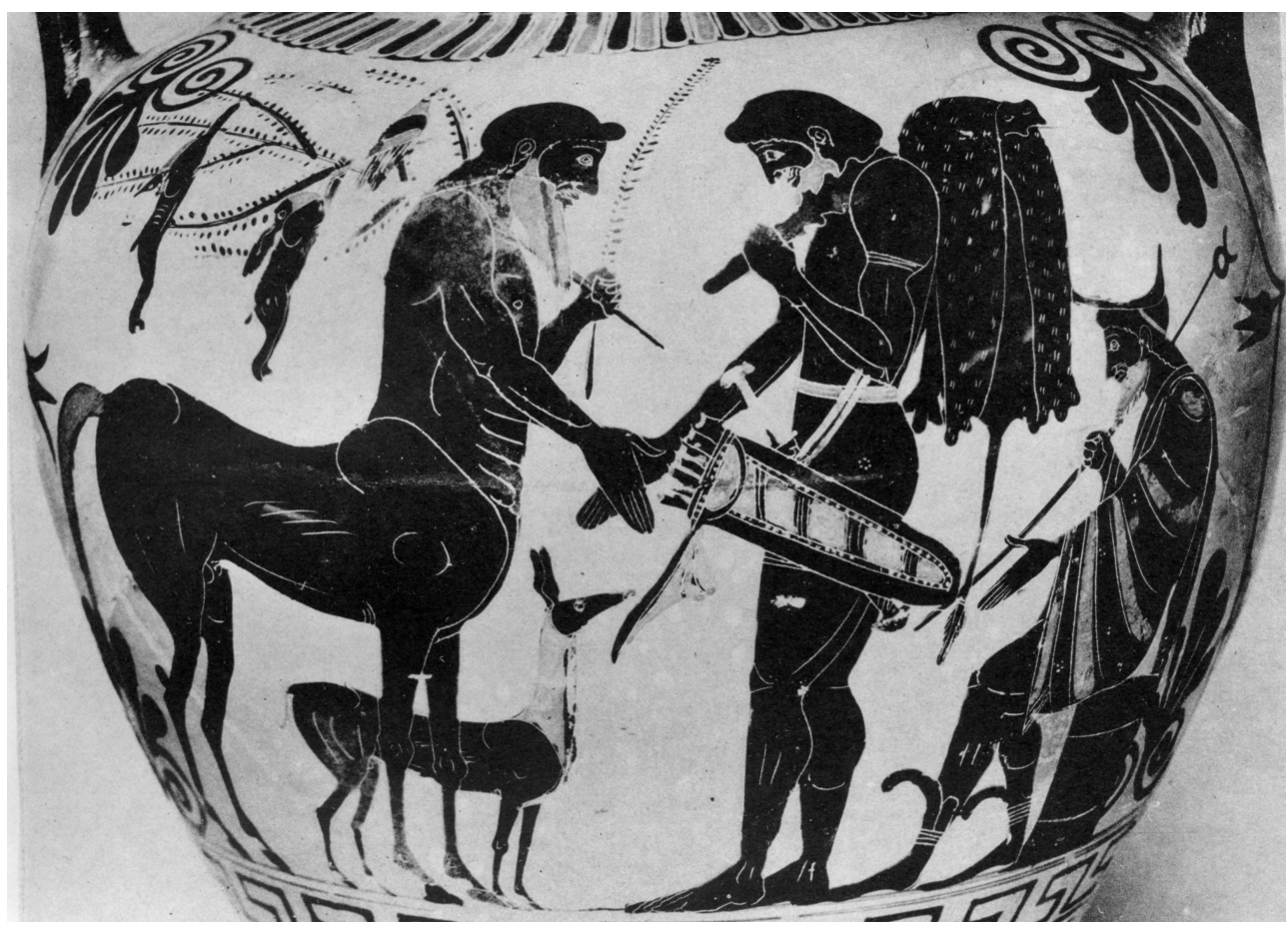

D’après Corpus vasorum antiquorum. British Museum, Londres.

Le héros est souvent secondé par Athéna ou Hermès, mais les deux divinités ont souvent une fonction dans l'image. Athéna protège ou seconde Héraclès dans ses exploits tandis qu'Hermès accompagne le héros dans ses pérégrinations et lui sert de guide. Héraclès rencontre Pholos alors qu'il poursuit le sanglier d'Érymanthe. Hermès le guide dans cette poursuite qui dure un an et c'est lui qui amène le héros chez Pholos où il se repose avant de reprendre sa route.

\section{Le Minotaure}

Contrairement aux nombreux monstres de la mythologie, le Minotaure naît dans un espace civilisé et non un espace extérieur. Par sa présence au cœur de la cité, il apporte la sauvagerie à l'intérieur de la ville, ce qui est dangereux ${ }^{23}$. Le Minotaure symbolise la bestialité de l'adultère de Pasiphaé qui est aussi une transgression entre les hommes et les animaux, ce qui dérange l'ordre cosmique.

Sur une amphore datée du milieu du $\mathrm{VI}^{\mathrm{e}}$ siècle av. J.-C., le peintre Lydos a repris la scène du combat final avec Thésée et des spectateurs ${ }^{24}$ (fig. 6). De chaque côté des adversaires se trouvent deux personnages qui entourent les combattants et regardent l'affrontement. Thésée est à gauche, vêtu d'une tunique. Le héros, imberbe, tient le bras droit du monstre et lui enfonce son épée au niveau du cou. Le Minotaure, dont la tête est de profil, s'écroule au sol sous le coup d'épée, son genou droit touchant presque le bord inférieur de l'image. De sa main droite, que tient Thésée, il brandit une pierre, inutile car le héros l'empêche de s'en servir. Le monstre hybride est nu, mais il est couvert de poils; des incisions qui représentent ceux-ci couvrent tout son corps et sa tête. Pour accentuer l'aspect sauvage que lui donne cette pilosité, le Minotaure est pourvu d'une queue ${ }^{25}$. Ces deux éléments iconographiques se retrouvent par la suite 
dans la plupart des représentations du Minotaure et vont permettre aux différents artistes de souligner l'aspect sauvage du monstre. La pilosité, bien que rare chez les bovidés, se retrouve sur plusieurs autres créatures liées au monde animal ${ }^{26}$. Elle apparaît surtout sur des animaux sauvages, plus rarement sur des animaux domestiques et elle fut employée par les peintres pour souligner la sauvagerie des monstres mythologiques.

Fig. 6. - Thésée et le Minotaure.

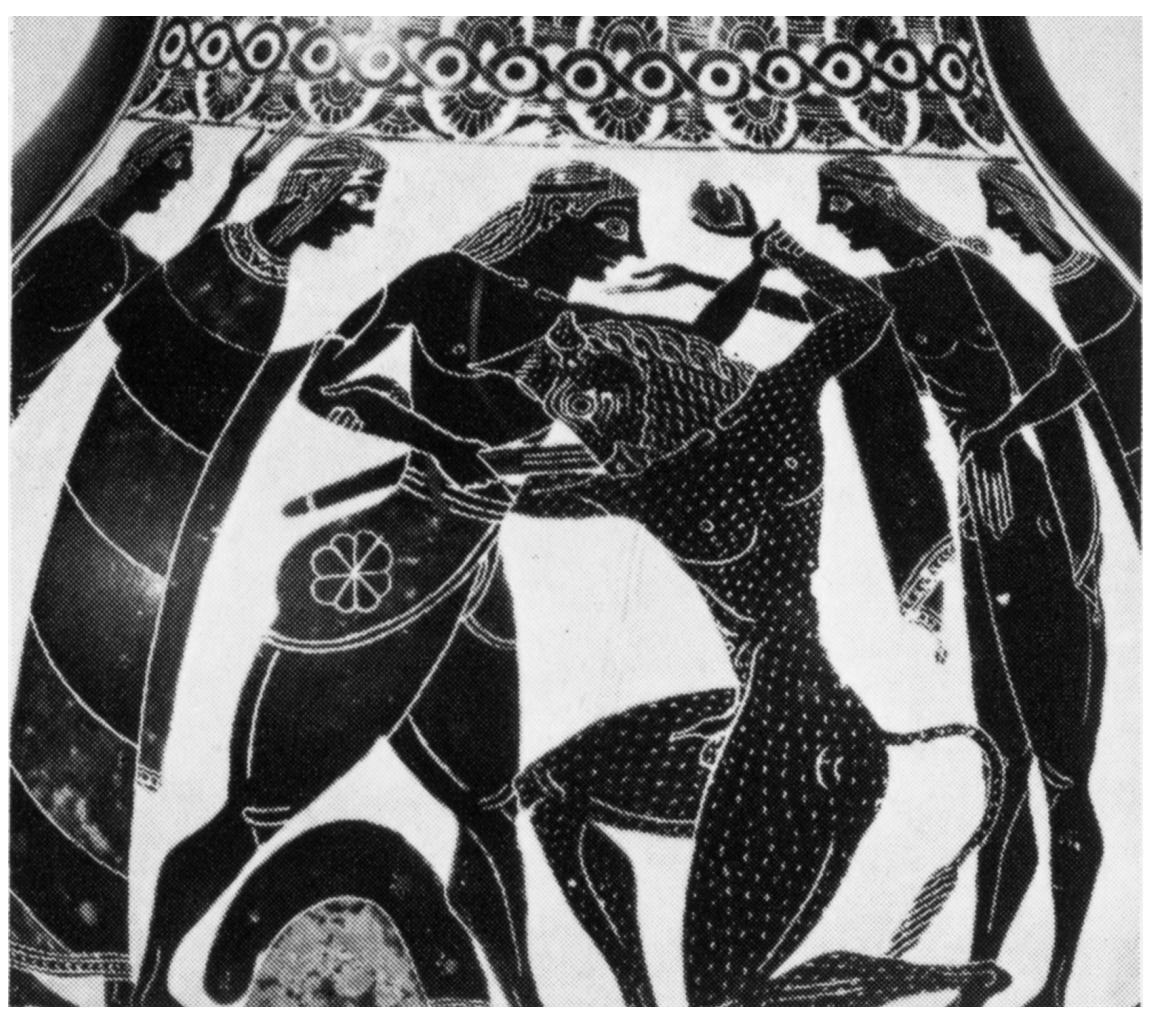

D'après D. von Bothmer, The Amasis Painter. British Museum, Londres.

La violence des images à figures rouges est caractéristique. Les peintres montrent la force, le sang, ce qui est l'inverse du sacrifice dans lequel on ne montre jamais l'acte de tuer. Mais le Minotaure est l'anti-bovin. On peut donc montrer cette violence, presque sacrificielle que l'on ne représente pas habituellement sur les vases.

\section{Les hybrides multiples}

\section{Les Gorgones}

Les Gorgones, et plus particulièrement Méduse, sont des monstres multiples dont les peintres, et avant eux les sculpteurs, ont visualisé toute l'horreur de leur forme en combinant différents animaux et en rendant leur pouvoir mortifère par la facialité de leur visage. Dents de sanglier, barbe, visage féminin, cheveux de serpents, ailes d'oiseaux, corps de cheval ${ }^{27}$ combinent animaux divers et antinomie masculin/féminin.

Sur un stamnos, le peintre de Nausicaa ${ }^{28}$ (fig. 7) a utilisé des éléments connus auxquels il en a ajouté d'autres. De gauche à droite de cette scène nous avons un homme barbu assis sur un rocher, Athéna, Méduse endormie, Persée et Hermès. La composition du 
peintre de Nausicaa est originale pour plusieurs raisons. Persée y apparaît hors de tout élément iconographique qui permette de l'identifier : pas de casque ou de chapeau, ni de bottes ailées. Il tient une arme dans sa main droite et sa sacoche de la main gauche. L'action se déroule avant la mort de Méduse puisque le héros, courbé comme pour ne pas faire de bruit, se dirige vers Méduse. Nous sommes quelques instants avant le coup fatal. Si Athéna et Hermès ne surprennent guère par leur présence, le personnage à gauche est beaucoup plus problématique. En effet, cet homme assis sur un rocher semble faire un mouvement d'étonnement en direction de l'action. Sa présence n'étant attestée par aucune de nos sources littéraires, il convient alors d'émettre l'hypothèse d'un personnage ajouté par le peintre, soit pour équilibrer sa composition (il répond à Hermès à l'extrême droite) soit pour mettre en scène un autre intervenant de l'histoire : Atlas ou Polydectès qui vont subir le terrible pouvoir de la tête de Méduse ${ }^{29}$.

Fig. 7. - Persée et Méduse.

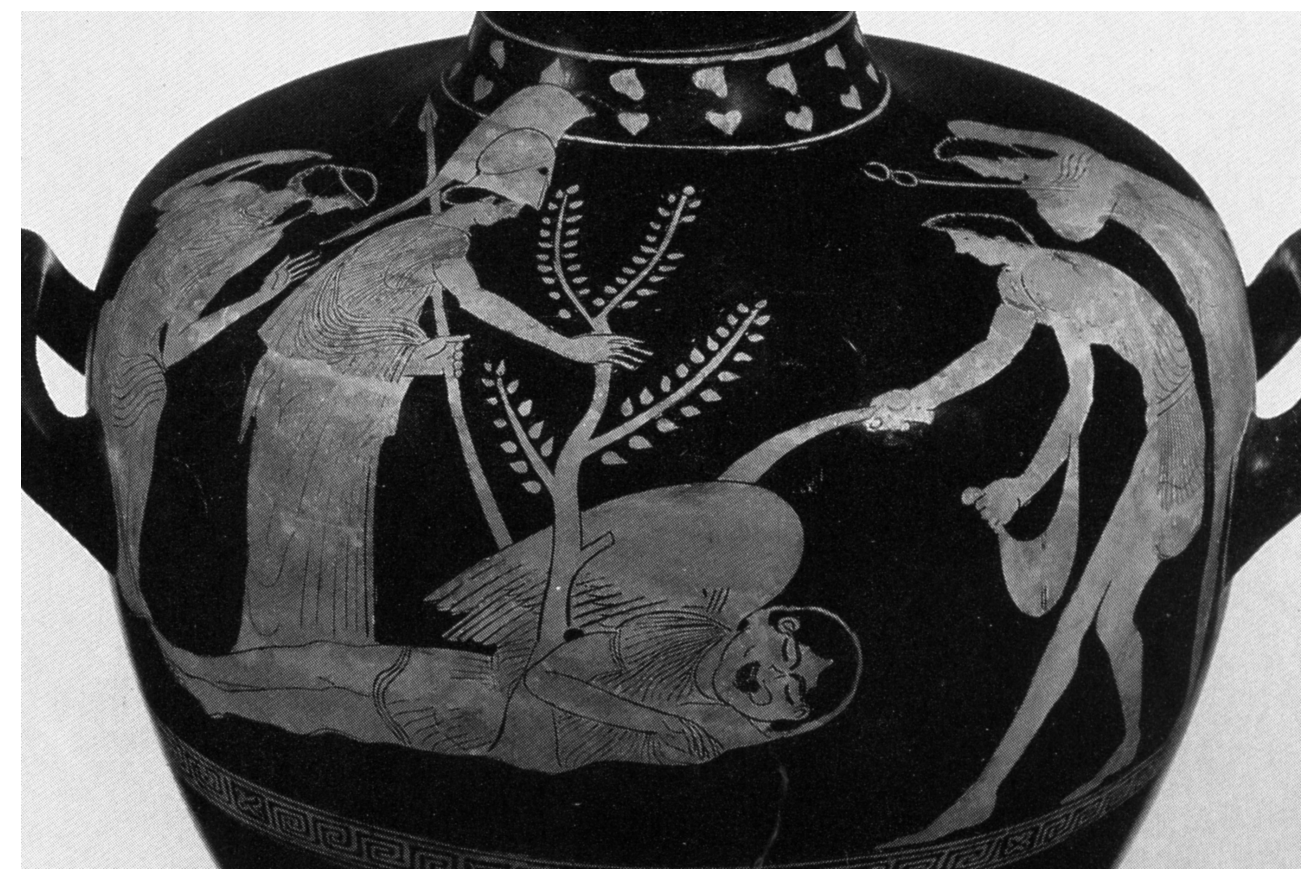

D'après J. Boardman, ARFV². Museum of Fine Arts, Richmond.

Cendant, l'élément le plus original de l'image est sans doute le fait que Persée s'approche de Méduse sans détourner la tête. Alors qu'il s'agit d'une constante dans l'iconographie, due à l'interdit visuel à propos de Méduse, le peintre n'a pas respecté ce modèle de l'image. En se penchant vers sa victime, le jeune héros la regarde. L'interdit visuel est néanmoins fortement atténué par la quasi-absence de tout élément monstrueux dans la figuration de Méduse. Celle-ci est montrée comme une femme ailée, dormant, les yeux fermés neutralisant son pouvoir. Il n'y a donc pas croisement des regards et donc dangerosité malgré la facialité. Méduse est ainsi vulnérable et cela est accentué par sa figuration en belle jeune fille. Hormis une langue pendante et un visage légèrement grimaçant aux dents non apparentes, le visage n'est guère monstrueux $^{30}$.

La Gorgone, comme tous les hybrides, dérange un esprit grec car elle symbolise - ou permet de penser - le désordre de la nature avec ses transgressions diverses. Pour rendre la monstruosité, les artistes brouillent toutes les catégories: bestiales et 
humaines. La Gorgone apparaît comme un mélange d'humanité et d'animalité et de sexe mâle et femelle. La Gorgone joue sur toutes les transgressions, mais aussi sur les antinomies : elle est jeune/vieille, belle/laide, masculine/féminine, humaine/bestiale, mortelle/immortelle. Elle représente une forme de quintessence du mal. Les hommes ne peuvent soutenir son regard qui constitue le paroxysme de la malfaisance.

\section{Typhée}

Le vase chalcidien à figures noires du musée de Munich, daté des années 540 av. J.-C. (fig. 8), est l'image la plus emblématique du conflit qui oppose Zeus à Typhée ${ }^{31}$. Le peintre des Inscriptions y a clairement identifié au moins l'un des combattants en le nommant; le souverain des dieux a son nom inscrit devant son visage. Le peintre l'a représenté sous les traits d'un homme barbu aux cheveux longs et bouclés. Couvert d'une chlamyde, il tient la foudre de sa main droite qu'il brandit en direction de Typhée. La jambe gauche est pliée en avant, dans un mouvement volontaire en direction du monstre.

Fig. 8 - Zeus et Typhée.

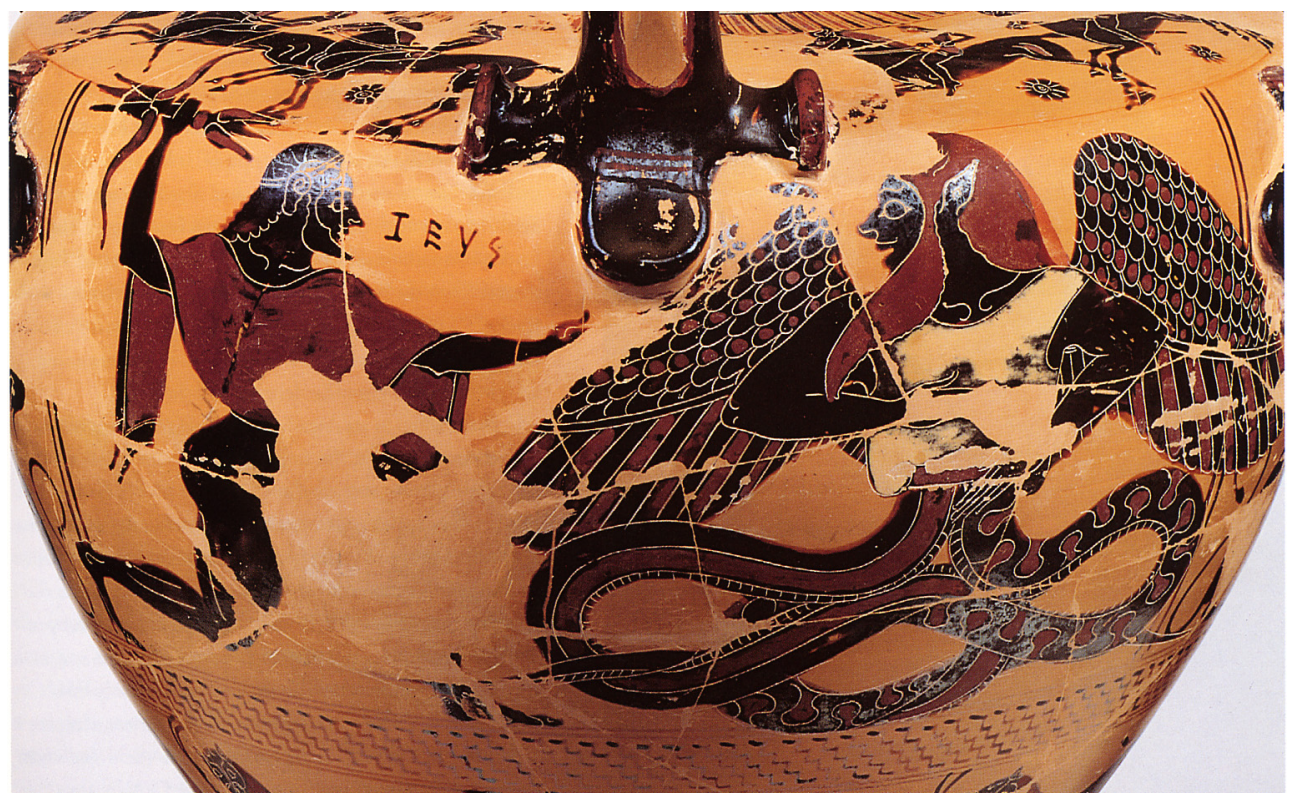

D'après P. E. Arias, A history of Greek vase painting. Museum Antiker Kleinkunst, Munich.

Typhée lui fait face. C'est un monstre au sens iconographique du terme, il concentre en lui tous les éléments du monstrueux qu'utilisent les peintres grecs pour visualiser l'innommable. Typhée a un corps humain, couvert d'une tunique. La tête du monstre ressemble à celle des centaures, car le peintre a utilisé les mêmes éléments iconographiques qui servent à montrer la sauvagerie : les traits du visage sont plus grossiers que ceux de Zeus, la barbe est longue ainsi que les cheveux et ses oreilles pointues ressemblent à celles des animaux. Deux grandes ailes à écailles rouges et noires, et à plumes de mêmes couleurs, couvrent son dos. Au buste humain se rattachent deux jambes anguipèdes sinueuses sur lesquelles repose le corps du monstre. Il tient ses deux mains devant lui mais ne semble pas tenir une arme quelconque. Toutefois, il ne paraît pas apeuré par Zeus et ne montre aucun signe 
d'hostilité ou de défense. À l'inverse de Zeus, dont la chlamyde est rouge, Typhée nous apparaît dans une grande diversité de couleurs. En effet, cheveux et barbe du monstre sont rouges tandis que sa tunique est rehaussée de blanc. Mais ce sont ses ailes où alternent les rangées d'écailles et de plumes rouges et noires qui suggèrent la profusion morphologique du monstre. De même, les jambes anguipèdes montrent un souci de réalisme, non seulement dans le dessin des anneaux, mais également dans l'alternance des couleurs. Face à un Zeus bicolore, la succession des couleurs de Typhée marque non seulement sa différence morphologique mais nous donne aussi une vision de la multiplicité de Typhée, ce qui le rend d'autant plus inquiétant.

Sur cette hydrie, le monstre compte uniquement sur sa morphologie hybride, multiple et gigantesque pour soutenir l'assaut de Zeus, un assaut qui semble toutefois prendre au dépourvu le monstre.

\section{Construction d'images}

\section{Hommes transformés par Circé}

L'épisode de Circé est rapporté dans le chant $\mathrm{X}$ de l'odyssée. Après avoir échappé aux Lestrygons, Ulysse aborde sur une île et sépare ses compagnons en deux groupes pour reconnaître le terrain et ses ressources ${ }^{32}$. Euryloque part avec le premier groupe et se retrouve face à la maison de Circé entourée de lions et de loups dociles. Là, ils boivent un breuvage magique et d'un coup de sa baguette, Circé les transforme en porcs ${ }^{33}$.

Nous avons plusieurs vases montrant les hommes d'Ulysse transformés en pourceaux par la magicienne. Le mythe est aussi populaire dans la figure noire que dans la figure rouge mais ce n'est pas un thème majeur de l'iconographie. Les peintres représentent souvent un homme avec une tête de sanglier ou de porc et une femme tenant une baguette ou un bâton. C'est le moment où Circé les frappe de cette baguette et, sous l'action de son pharmakon, ils se transforment en porcs. Les peintres ont innové en introduisant des animaux qui ne sont pas mentionnés par Homère. C'est le cas par exemple chez le peintre du Polyphème de Boston ${ }^{34}$ (fig. 9) qui représente plusieurs animaux. Un tel florilège de bêtes sauvages et domestiques permet aux peintres, à travers la diversité animale, de montrer la puissance de Circé. 
Fig. 9. - Circé et les compagnons d'Ulysse.

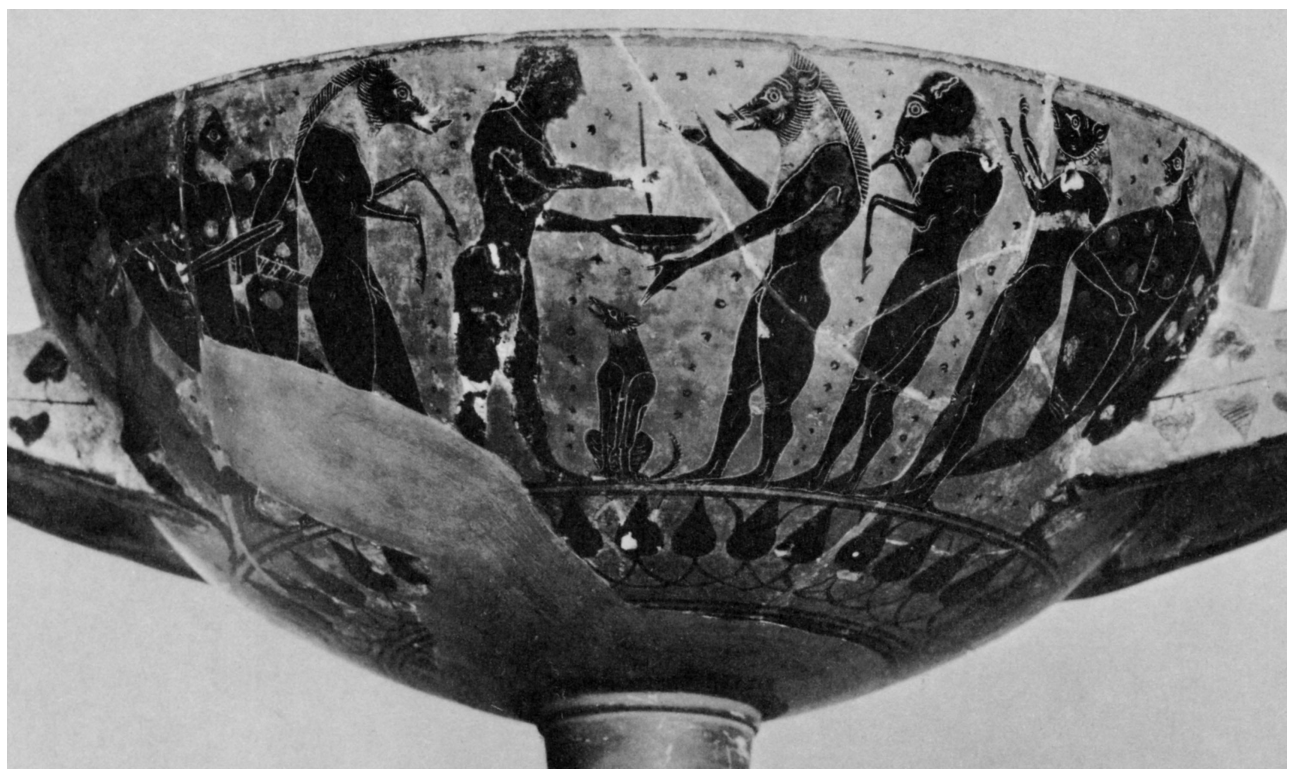

D'après Corpus vasorum antiquorum. Museum of Fine Arts, Boston.

Non seulement les compagnons d'Ulysse sont transformés en porcs mais sur la coupe de Boston, une progression dans la métamorphose est également visible. Le peintre évoque l'évolution de la métamorphose des compagnons d'Ulysse en montrant les phases de cette transformation. Dans une même scène, les différentes étapes chronologiques se succèdent. Ainsi, l'homme de gauche est entièrement humain alors que son vis-à-vis possède déjà une tête animale, à savoir celle d'un sanglier. Les autres personnages ont également des têtes animales distinctes mais plusieurs d'entre eux, en deuxième et troisième position, possèdent plusieurs caractéristiques animales telles des pattes avant, des pattes arrière, voire une queue ${ }^{35}$. En une seule image nous avons la progression du mal qui transforme les compagnons d'Ulysse en animaux à travers différents hybrides qui se succèdent dans l'espace.

\section{Les hommes-animaux}

29 Les derniers exemples d'association homme-animal que nous retrouvons sur les vases grecs et qui ne figurent pas dans un contexte mythologique posent de ce fait de nombreuses interrogations. La première d'entre elles concerne leur origine géographique, ils sont à part dans notre corpus, essentiellement constitué de vases attiques. Leur origine induit certainement des influences que nous ne pouvons peutêtre pas totalement appréhender et, faute d'autres sources, ces images demeurent un peu mystérieuses.

Il en est ainsi de l'homme-lièvre sur une amphore milésienne ${ }^{36}$ (fig. 10) où il figure sur les deux côtés du vase. Il s'agit d'un homme, courant, vêtu d'un chiton court, avec une tête de lièvre. Certains ont cru y avoir un danseur masqué, mais la plupart des commentateurs pensent qu'il pourrait s'agir d'un des compagnons d'Ulysse transformé par Circé. Même si nous avons peu d'autres exemples d'une telle transformation et si Homère ne parle que de porcs, voire de lions et de loups pour de malencontreux voyageurs antérieurs, le personnage ne possède qu'une seule partie animale, sa tête. Il 
n'est donc pas un hybride " ordinaire » qui possède souvent plusieurs caractéristiques de l'animal, mais il pourrait bien évidemment s'agir d'un des compagnons d'Ulysse surpris dans sa phase de métamorphose.

Fig. 10. - Homme-lièvre.

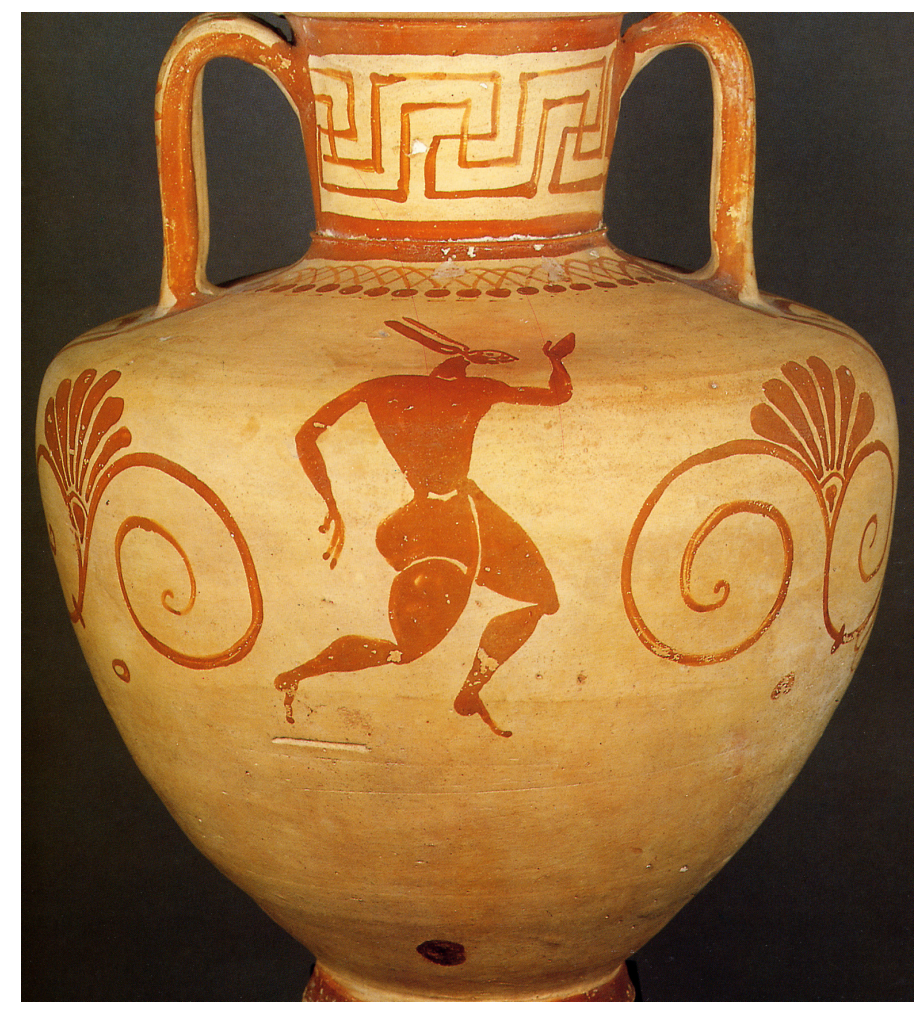

D’après M. Denoyelle, Chefs-d'œuvre. Louvre, Paris.

L'animal est utilisé pour ses vertus et vices, intrinsèques et imaginaires. Cependant, ces qualités sont des projections anthropomorphiques, on prête à des animaux des sentiments humains qui sont définis par rapport à l'homme. L'animal est utilisé dans un rapport métaphorique incomplet, car si l'on prête des caractéristiques humaines aux animaux, leur identité animale n'est pas totalement niée. La notion de bestialité est paradoxale, ses attributs et les notions qui sont mises sous ce terme recouvrent des réalités avant tout humaines (gourmandise, cruauté, etc.). On traduit l'inconnu par des termes connus: les monstres sont inconnus et leur puissance, taille, démesure, animalité sont référées à des normes humaines, or ils sont justement hors du domaine de l'humain.

Les autres hybrides, dans leur majorité, sont des composés, de parties plus ou moins importantes, d'animaux sauvages. Ce sont ces éléments qui les rendent monstrueux. Leur généalogie et leur place dans un ensemble mythique ont également un sens. Le monstre hybride est parfois le fruit d'une transgression homme/animal. Il faut repousser ce qui est inacceptable. Les centaures sont nés d'un viol, le Minotaure est issu d'un accouplement zoophile, les Gorgones sont nées de parents eux-mêmes monstrueux. 
brides effraient, ils montrent ce qu'il ne faut pas faire. La transgression sexuelle ou alimentaire est du même ordre dans le cas du Minotaure. Ainsi, Pasiphaé « consomme » de la bête pour en avoir un fils, et le fruit de cette transgression sexuelle zoophile, va consommer de la chair humaine. Il existe des hybrides connus uniquement par des images mais ils sont très rares. En l'absence de textes de référence, nous n'avons pas toutes les clés pour pouvoir les «lire » correctement, ce qui est une source d'interprétations, et peut-être même d'erreurs... ${ }^{37}$

Enfin, l'aspect physique n'est pas le seul critère de la monstruosité. Les actes sont aussi révélateurs d'un comportement hors norme qui rabaisse l'homme ou la créature à un stade intermédiaire entre les dieux, l'homme et l'animal. Les Grecs se sont attachés très tôt à structurer le monde en ces trois catégories bien définies par leur vocabulaire propre. Le monstre est un transgresseur qui est en dehors de ces catégories. La transgression des normes est la caractéristique de la monstruosité. Il est «bon à penser " que l'adversaire, l'autre, le barbare, le monstre, possède des qualités reconnues, qui confèrent ensuite une supériorité à celui qui le vainc. Le monstrueux est lié au mal, il est aux franges de l'humanité. Sa fonction est d'exorciser la peur de l'inconnu, de mettre un visage sur ce qu'on ne connaît pas. Il pose les limites du monde civilisé, du rationnel et de l'irrationnel et donc celles de l'humanité.

\section{BIBLIOGRAPHIE}

\section{Liste des abréviations}

ABV BEAZLEY, Attic black-figure vase-painters, Oxford, Clarendon

Press

ARV² BEAZLEY, Attic red-figure vase-painters, Oxford, Clarendon Press, $2^{\mathrm{e}}$ éd.

CVA Corpus Vasorum Antiquorum, Paris, Champion (à ce jour près de 320 volumes parus)

LIMC Lexicon Iconographicum Mythologiae Classicae, Zurich, Artemis

$\mathrm{n}^{\circ}$ Beazley Cette annotation dans les références iconographiques se rapporte au code des archives Beazley consultables sur internet à l'adresse : www.beazley.ox.ac.uk

Para. BEAZLEY, Paralipomena, Additions to Attic black-figure vase-painters and to Attic red-figure vasepainters, Oxford, Clarendon Press

\section{Bibliographie}

ARIAS Paolo Enrico, A history of Greek vase painting, Londres, Thames and Hudson, 1962 (traduction, Le vase grec, Paris, Flammarion, 1962). 
BAKIR Güven, Sophilos. Ein Beitrag zu seinem Stil, Mayence, Philip von Zabern, 1981, collec. Kemarikforschungen $n^{\circ} 4$.

BAUR Paul V. C., Centaurs in ancient art. The archaic period, Berlin, K. Curtius, 1912.

BEAZLEY John Davidson, The development of attic black-figure, Berkeley and Los Angeles, University of California Press, 1951.

BEAZLEY John Davidson, Attic black-figure vase-painting, Oxford, Clarendon Press, 1956.

BEAZLEY John Davidson, Attic red-figure vase-painters, Oxford, Clarendon Press, 1963.

BEAZLEY John Davidson, Paralipomena. Additions to Attic black-figure vase-painters and to Attic redfigure vase-painters, Oxford, Clarendon Press, 1971.

BOARDMAN John, Athenian red figure vases. The classical period, Londres, Thames and Hudson, 1989 (trad. 2000).

BOTHMER Dietrich von, The Amasis painter and his world, Londres, Thames and Hudson, 1985. BOUDIN François, « Monstres sans image. Images de monstres. Représentations et non représentations des monstres sur les vases », dans CROGIEZ-PÉTREQUIN Sylvie (dir.), Dieu(x) et hommes. Histoire et iconographie des sociétés païennes et chrétiennes de l'Antiquité à nos jours, Rouen, PURH, 2005, p. 537-568.

CARPENTER Thomas H., Art and Myth in Ancient Greece, Londres, Thames and Hudson, 1991 (trad. 2000).

DENOYELLE Martine, Chefs-d'œuvre de la céramique grecque dans les collections du Louvre, Paris, Réunion des Musées Nationaux, 1994.

DUGAS Charles, «La mort du Centaure Nessos », dans Revue des études anciennes, 1943, t. XLV, p. 18-26.

HURWIT Jeffrey, « Image and Frame in Greek Art », dans American Journal of Archaeology, 1977, $\mathrm{n}^{\circ} 81-1$, p. 1-30.

MANNACK Thomas, The Late Mannerists in Athenian Vase-painting, Oxford, Oxford Universit Press, 2001.

OAKLEY John H., « Perseus, the Graiai, and Aeschylus Phorkides », dans American Journal of Archaeology, 1988, n 92-3, p. 383-391.

OSBORNE Robin, Archaic and Classical Greek Art, Oxford, Oxford University Press, 1998.

PADGETT J. Michaël, « Horse men : Centaurs and Satyrs in Early Greek Art », dans J. M. PADGETT, Centaur's Smile, New Haven-Londres, Princeton University Art Museum, 2003, p. 3-48.

PADGETT J. Michael (dir.), Centaur's smile. The Human Animal in Early Greek Art, New Haven-Londres, Princeton University Art Museum, 2003.

SCHEFOLD Karl, Götter und Heldensagen der Griechen in der Spätarchaïschen Kunst, Munich, Hirmer, 1978 (trad. Gods and Heroes in Late Archaic Greek Art, Cambridge, Cambridge University Press, 1992). SCHNAPP Alain, Le chasseur et la cité. Chasse et érotique dans la Grèce ancienne, Paris, Albin Michel, 1997.

SHAPIRO HARVEY Alan, Art, myth and culture. Greek vases from Southern Collections, New Orleans, New Orleans Museum of Art, 1981. 
SHAPIRO HARVEY Alan, Personnification in Greek Art. The representation of Abstract concepts $600-400$ b.c., Zurich, Akanthus, 1993.

SOURVINOU-INWOOD Christiane, « Le Minotaure et les autres. Images et perceptions », dans Métis, 1994-1995, nº IX-X, p. 227-235.

STEWART Andrew, «Stesichoros and the Francois Vase », dans MOON W. G. éd., Ancient Greek Art and Iconography, Madison, University of Wisconsin Press, 1983, p. 53-74.

TOUCHEFEU-MEYNIER Odette, Thèmes odysséens dans l'art antique, Paris, De Boccard, 1968.

VERBANCK-PIÉRARD Annie, « La rencontre d'Héraclès et de Pholos : variantes iconographiques du peintre d'Antiménès », dans HADERMPANN-MISGUICH Lydie, RAEPSAET Georges, CAMBIER Guy, Rayonnement grec. Hommages à Charles Delvoye, Bruxelles, Éditions de l'Université de Bruxelles, 1982, p. 143-154.

WILliams Dyfri, Greek vases, Londres, British Museum Publications, 1985 ( $2^{\text {nde }}$ éd. 1999).

\section{NOTES}

1. Sophocle, Trachiniennes, 1095 (les centaures); Platon, Cratyle, 408d (Kékrops).

2. Euripide, Méléagre, fgt 19 : le Minotaure.

3. Euripide, Ion, 1161 : des centaures.

4. Homère, Iliade, I, 269 et II, 743.

5. Hydrie proto-attique à figures noires. Athènes, Musée National, BS 179, vers 700 av. J.-C., centaures : LIMC, Kentauroi et Kentaurides, 345.

6. Plus de 180 vases existent sur ce mythe, dont 170 produits en Grèce. Il existe 90 vases avec Chiron et 117 avec Pholos. «Mais Héraclès combat de nombreux Centaures dans l'art, c'est pourquoi à moins qu'il soit nommé, qu'il porte Déjanire sur son dos ou dans ses bras, ou qu'elle se tienne à côté de lui, il est difficile de s'assurer qu'il s'agit bien de Nessos ». Cette réflexion de T. H. Carpenter, Art and Myth, p.132-133, illustre parfaitement les problèmes que nous pouvons rencontrer quant à l'interprétation de certaines scènes sur les vases attiques. Il y a plus d'un demi-siècle, C. Dugas, « La mort du Centaure Nessos ", p. 18-19 soulevait déjà le problème.

7. Amphore à col proto-attique à figures noires, New York, Metropolitan Museum, 11.210.1, vers 660 peintre de Nessos; Baur, Centaurs, n² 213, J. M. Padgett, Centaur's smile, fig. 19, LIMC, Nessos, 36. Commentaire de ce vase par J. Hurwitt, "Image and Frame in Greek Art », p. 25-27.

8. Ce geste de supplication est noté par J. M. Padgett, «Horse Men », p. 24 et ressemble au geste de Nessos se retournant en levant les mains vers Héraclès sur le vase d'Athènes MN 1002.

9. C'est avec une épée qu'Héraclès attaque Nessos sur le vase d'Athènes MN 1002 et d'autres vases plus anciens : fragment de vase proto-attique à figures noires, Athènes, Musée National, vers 660 av. J.-C.; LIMC, Nessos, 89 ; cratère proto-attique à figures noires, Berlin, Antikenmuseum, A 21, vers 660 av. J.-C., peintre du jeu d'échec ; Eilmann, Gebauer, CVA n 2, pl.10-11; LIMC, Nessos, 114. L'épée est l'arme la plus ancienne utilisée par le héros. 
10. Voir par exemple la coupe de Siana attique à figures noires, Tarente, Musée National, IG 4408, vers 540 av. J.-C., peintre d'Heidelberg; Beazley, ABV, 65(43) ; Drago, CVA n 35, pl. 28-29; LIMC, Nessos, 39 ; Beazley n 300586.

11. Nous avons un fragment de vase grec plus ancien, du milieu du vII siècle av. J.-C., mais l'état très fragmentaire du vase ne nous permet pas d'avoir une image précise de la figuration du centaure. Amphore à col fragmentaire proto-attique à figures noires. Berlin, Antiquarium, A 9 (31573), vers 660 av. J.-C. peintre de la cruche au bélier; Eilmann, Gebauer, CVA nº 2, pl. 5 ; LIMC, Cheiron, 44.

12. Sophilos a peint un autre vase avec le cortège des noces Pélée. Malheureusement nous n'avons qu'un petit fragment de celui-ci. (dinos attique fragmentaire à figures noires, Athènes, Musée National, 1.587 (15165), vers 580 Sophilos ; Beazley, ABV, 39(15), 681 ; Stewart, «Stesichoros », fig. 4.4a-j; Beazley $\left.n^{\circ} 305074\right)$. Le fait que ce vase existe montre l'importance de la scène à cette époque, non seulement dans la littérature mais aussi dans les représentations sur vases.

13. Dinos attique à figures noires. Londres, British Museum, 1971.11-1.1, vers 590 av. J.C., Sophilos, Bakir, Sophilos, pl. 1 ; Beazley, Para., 19(16bis) ; LIMC, Cheiron, 41 ; Beazley $\mathrm{n}^{\circ} 350099$.

14. A. Stewart, «Stesichoros ", p. 65, pense que cette branche est du frêne. À partir de cette branche, Athéna et Héphaistos vont fabriquer la célèbre lance de Pélée.

15. Xénophon nous le rappelle dans son Art de la chasse puisqu'il commence son ouvrage en rappelant cette fonction de Chiron et le nom de tous les héros qui ont suivi auprès de lui cette formation.

16. Sur le vase de Sophilos, Chiron possède même un bâton de chasseur, le lagobolon. Sur ce détail, voir A. Schnapp, Le chasseur et la cité, p. 437.

17. R. Osborne, Archaic and Classical Greek art, p. 93.

18. Cratère en cloche attique à figures rouges. New York, collection privée, vers 460 av. J.-C., peintre d'Eupolis, J. M. Padgett, Centaur's smile, $\mathrm{n}^{\circ} 38$; LIMC, Philyra, 3 ; Beazley $\mathrm{n}^{\circ} 44049$.

19. Il existe peut-être un seul autre vase montrant Chiron et sa femme Chariclô : alabastre corinthien à figures noires, Rhodes, Archaeological Museum, 11550, vers 570 av. J.-C., J. M. Padgett, Centaur's smile, fig. 13 ; Jacopi, CVA n 9 ; pl. 2(9), LIMC, Nessos, 110.

20. Tous les intervenants de la procession sont nommés par des inscriptions. C'est ainsi que nous avons le nom de Philyra, une des très rares représentations de la déesse qui ne possède pas d'attributs particuliers. Amphore à col attique à figures noires, New York, The Metropolitan Museum of Art, SL 1990.1.21, vers 460 av. J.-C., peintre de Copenhague, LIMC, Peleus, 210 ; Beazley n 43937.

21. Amphore à col attique à figures noires. Londres, British Museum, B 226 (1837.6-9.42), vers 520 av. J.-C., peintre d'Antiménès, Beazley, ABV, 273(116) ; LIMC, Kentauroi et Kentaurides, 350 ; A. Verbanck-Piérard, "La rencontre d'Héraclès et Pholos », pl. 15(1); Walters, CVA n 5, pl. 55(4a); Beazley n 320127.

22. C'est certainement intentionnellement que l'image de Pholos recevant Héraclès ressemble à celles de Chiron accueillant Pélée, les deux centaures étant très proches par leur fonction dans la mythologie. Les traits du centaure sont très humains malgré 
ses oreilles animales. A. Verbanck-Piérard, "La rencontre d'Héraclès et de Pholos ", p. $150-151$.

23. C. Sourvinou-Inwood, «Le Minotaure et les autres», p. 233, parle de « la métaphore de l'intérieur de la maison corrompue dont le désordre est représenté par le Minotaure».

24. Lydos, ou des peintres proches de lui, ont produit sept vases avec le Minotaure dont la majorité sont des amphores. Amphore attique à figures noires. Londres, British Museum, B 148 (1848.6-19.5), vers 550 av. J.-C., Lydos, Beazley, ABV, 109(29) ; Walters, CVA n ${ }^{\circ}$ 4, pl. 25(5); Beazley n 310175.

25. Sur un fond de coupe, le Minotaure est également couvert de poils. Sa position, tourné vers la droite, suggère peut-être, qu'il tentait de s'échapper. Coupe de Siana attique à figures noires, Tarente, Musée national, 52146, vers 540 av. J.-C., Lydos, Drago, CVA n 35, pl. 16 ; Beazley n 25157.

26. Parfois les satyres sont poilus: amphore-psykter chalcidienne à figures noires, Vatican, Museo Gregoriano Etrusco, 50401, vers 540 av. J.-C., peintre des inscriptions, Boardman, Early Greek, pl. 477.1 Il en va de même pour les centaures.

27. Paris, musée du Louvre CA 795, J. M. Padgett, "The Horse Men", la figure 5 présente un sceau où figure une Gorgone ailée au corps chevalin.

28. Hydrie attique à figures rouges. Richmond, Museum of Fine Arts, 62.1.1, vers $450 \mathrm{av}$. J.-C., peintre de Nausicaa, Beazley, ARV 21683 (48bis) ; LIMC, Gorgo, Gorgones, 299 ; Beazley $n^{\circ} 275462$.

29. Le premier nom est celui le plus couramment admis mais les hypothèses sont nombreuses. T.H. Carpenter, Art and Myth, p. 112 pense à Acrisios, J.H. Oakley, «Perseus, the Graiai», p. 389 reprend l'hypothèse d'Atlas, le LIMC dans l'article des Gorgones propose également Atlas, mais celui sur Perseus avance le nom de Phorkys. T. Mannack, The Late Mannerists, p. 140, suggère Polydectès, rappelant néanmoins qu'il pourrait s'agir de Poséidon, sachant que le dieu n'a pas toujours un trident. Se référant à un vase conservé à Bologne, T. Mannack, Id., p. 94, propose Polydectès, oubliant qu'il s'agit d'un autre moment de la légende où Polydectès a plus sa place. Quant à H.A. Shapiro, Art, myth and culture, p. 98, il reprend l'hypothèse de Schauenburg, Atlas, tout en émettant l'avis qu'il pourrait également s'agir d'une divinité locale.

30. Méduse endormie occupe le centre de l'image et toute l'attention du spectateur se focalise sur elle. Elle dort paisiblement, H. A. Shapiro, Art, myth and culture, p. 98. L'auteur note cependant que ses traits sont encore déterminés par la monstruosité ; sa transformation en belle jeune fille n'est pas encore complète.

31. K. Schefold, Gods and Heroes, p. 54 qualifie même le peintre de grand artiste. Hydrie chalcidienne à figures noires, Munich, Museum Antiker Kleinkunst, 596 (J 125), vers 540 av. J.-C., peintre des Inscriptions, J. Boardman, Early Greek, fig. 473 ; LIMC, Typhon, 14 ; Walter-Katydid, CVA n ${ }^{\circ}$ 28, pl. 281(2).

32. Homère, Odyssée, X, 203-209.

33. Ibidem, $\mathrm{X}, 235-243$.

34. Coupe attique à figures noires, 99.518, Museum of Fine Arts, Boston, vers 550 av. J.C., peintre du Polyphème de Boston, Beazley, ABV, 198 ; Banks, Von Bothmer, Comstock, Truitt, Vermeule, CVA n 19, pl. 88; O. Touchefeu-Meynier, Thèmes Odysséens, pl. 3(5); LIMC, Odysseus, 68 ; Beazley n 302569. 
35. Une queue est ainsi visible sur le compagnon d'Ulysse, sur un cratère en cloche à Varsovie. Cratère en cloche à figures rouges, Varsovie, Musée National, 7653, vers 420 av. J.-C., LIMC, Kirke, 26; Beazley $n^{\circ} 4339$ ou péliké attique à figures rouges, Dresde, Antikensammlungen, 323, vers 450 av. J.-C., peintre des Ethiopiens; Beazley, $A R V^{2}$, 665(4) ; LIMC, Kirke, 8 ; Beazley n² 207775.

36. Amphore à col milésienne dite «style de Fikellura » à figures rouges sur fond blanc, A 330, Paris, Louvre, vers 530 av. J.-C., groupe de l'homme courant, Pottier, Corpus vasorum antiquorum $\mathrm{n}^{\circ} 1$, pl. 2(11); M. Denoyelle, Chefs-d'œuvres, $\mathrm{n}^{\circ} 9$; O. TouchefeuMeynier, Thèmes odysséens, p. 115. Le style de "Fikellura " a été attribué à des ateliers rhodiens en raison du grand nombre de vases trouvés à Rhodes. Cependant, les récentes découvertes ont confirmé que la cité de Milet était le centre de production de ce style de poterie.

37. F. Boudin, «Monstres sans image. Images de monstres. Représentations et non représentations des monstres sur les vases ", p. 537-568.

\section{RÉSUMÉS}

Les hybrides homme-animal donnent à penser l'humanité et posent les limites du monde. Ils peuvent être classés en deux catégories : les hybrides simples avec une partie humaine et une partie animale et les hybrides multiples avec plusieurs parties animales. L'hybridité simple représente une forme de la monstruosité; centaures et Minotaure sont encore proches des hommes avec lesquels ils vivent et sont plutôt la marque de l'interactivité qui existe entre le monde des hommes et celui des animaux. Quelques-uns sont des constructions imaginées uniquement par les peintres de vases ce qui permet ainsi de nuancer la monstruosité animale de certains d'entre eux. Les hybrides multiples, quant à eux, représentent le summum de la sauvagerie, les éléments animaux s'additionnant entre eux pour donner une créature encore plus sauvage, souvent issue des forces primordiales et née à l'aube de la création. Les relations entre les hommes et les animaux sont très ténues; l'hybridité montre que l'homme peut basculer rapidement dans le monde de cette sauvagerie animale qu'il côtoie, puisque ces hybrides vivent tous aux marges de la cité, de l'espace civilisé.

\section{AUTEUR}

\section{FRANÇOIS BOUDIN}

Docteur en histoire, université de Rouen-Normandie 


\title{
Les métamorphoses animales de Fintan et Tuán : les hommes primordiaux témoins de l'histoire mythique de l'Irlande
}

\author{
Cindy Cadoret
}

1 Dans la littérature mythologique irlandaise, il existe deux personnages, Fintan Mac Bóchra et Tuán Mac Cairill, qui jouissent d'une longévité surhumaine, rythmée par des métamorphoses animales. C'est ce qui, précisément, assure leur longévité. Tous deux ont la mission, donnée par Dieu, de raconter les antiquités d'Irlande. En cela les personnages sont similaires, mais ils diffèrent par leur fonction et le contexte de leurs interventions.

2 Il convient au préalable d'expliciter la notion de "textes mythologiques celtiques", (majoritairement irlandais et gallois). Il s'agit de récits rédigés en langue vernaculaire et composés à la période médiévale - pour la plupart entre le VIII ${ }^{\mathrm{e}}$ et le XII ${ }^{\mathrm{e}}$ siècle - par les ecclésiastiques lettrés dans les scriptoria des monastères. Au sein d'un même manuscrit, ces textes côtoient des écrits exégétiques. Ils correspondent en partie à la retranscription de traditions anciennes, préchrétiennes et orales, et sont donc les seules sources textuelles concernant la mythologie des anciens Celtes - mis à part les témoignages parfois peu précis et énigmatiques des auteurs classiques. Ils sont aussi à considérer comme une littérature à caractère identitaire, dans son contexte, proprement insulaire, et de manière inévitable, christianisée : la narration est replacée dans la chronologie biblique, les saints irlandais font de récurrentes apparitions et les personnages issus des épopées sont baptisés. Les textes qui vont nous intéresser ici présentent un autre aspect à souligner : plus que des récits mythologiques, il s'agit de l'histoire mythique de l'Irlande dont on retrouve des passages dans les annales des époques médiévale et moderne. 


\section{Tuán : le témoin désigné par Dieu}

3 Le principal récit concernant Tuán, L'histoire de Tuán fils de Cairell [racontée] à Finnén de Mag Bile ${ }^{1}$ (Scél Tuáin Meic Chairill di Fhinnén Maighe Bile inso inis), est le plus christianisé. Tuán, alors chrétien et ermite, intervient auprès de saint Finnén, fondateur $\mathrm{au} \mathrm{vi}{ }^{\mathrm{e}}$ siècle du monastère de Maigh Bile (comté de Down). À la demande du saint, il raconte de mémoire toute l'histoire de l'Irlande. Sa vie personnelle est mise en parallèle avec les différents peuplements de l'île relatés dans Le livre des conquêtes de l'Irlande ${ }^{2}$ (Lebor gabála Érenn). Il y eut une première colonisation avant le déluge, puis cinq conquêtes après la descente des eaux diluviennes. Tuán appartient au peuple qui, le premier, investit l'Irlande après le déluge et vécut donc jusqu'au temps de saint Finnén. Après avoir été homme, il changea de forme sous chaque peuple suivant et fut ainsi cerf, sanglier, faucon et saumon ${ }^{3}$.

4 C'est explicitement Dieu qui lui fait subir ses métamorphoses. Sous ces différentes formes, il n'est pas épargné par la vieillesse. Chaque fois qu'il sent son corps décrépir, il se rend au même endroit de manière rituelle et sait qu'une nouvelle forme lui sera attribuée. À cela s'ajoute la régénérescence de son corps: il recouvre une nouvelle jeunesse à chaque métamorphose. Au temps du dernier peuple arrivé sur l'île - les Goidels -, Tuán recouvre sa forme humaine : alors qu'il est saumon de rivière - sa dernière forme animale - il est pêché et mangé par une reine. Il reste en gestation en son sein pour qu'elle lui donne de nouveau naissance. Durant ce processus, l'âge de son âme ne change pas et il est capable de restituer tout ce qui fut dit durant les neuf mois qui se sont écoulés entre le repas de la reine et sa seconde naissance. Il deviendra devin puis sera baptisé par saint Patrick. Sa fonction est de transmettre l'histoire ancienne de l'île au début des temps chrétiens, auprès de la nouvelle autorité religieuse ${ }^{4}$. Mettre en scène un saint écoutant l'histoire païenne de l'île manifeste le besoin profond que l'Irlande a eu de conserver ses traditions et de forger son identité après sa christianisation $^{5}$.

\section{Fintan : le témoignage juridique}

5 Fintan est quant à lui beaucoup plus proche de la figure druidique et assure une fonction juridique. La fondation du domaine de Tara ${ }^{6}$ (Suidigud Tellaig Temra) raconte que, sous le roi Diarmait, les nobles d'Irlande voulurent redéfinir les frontières du territoire de Tara, considéré comme trop vaste, vide et sans profit, bien qu'il faille y tenir tous les trois ans un festin et nourrir tous les hommes d'Irlande durant sept jours et sept nuits. Le roi refuse d'accomplir cet acte sans le conseil d'un ancien. Après avoir fait rechercher plusieurs d'entre eux, dont Tuán, Fintan est finalement reconnu comme leur aîné de manière incontestable. Antédiluvien, arrivé en Irlande lors de la première colonisation de la reine Cessair, Fintan explique qu'il fut juge durant toute l'histoire de l'île. C'est l'aspect juridique et politique, dont le but est de légitimer l'existence du royaume suprême de Tara, qui prime dans ce texte ${ }^{7}$. La vie personnelle de Fintan est secondaire et ses métamorphoses ne sont pas précisées, seulement évoquées par des phrases allusives :

"Je ne changerai désormais plus de forme ${ }^{8}$ »; «Dieu estimait qu'il était temps que sa mort vînt, sans plus aucun changement de forme. $»^{9}$ 
Il convient d'ajouter un autre texte, Le dialogue de Fintan et du Faucon d'Aichill ${ }^{10}$, qui explique clairement :

«[...] lors de l'averse noire du déluge le seigneur me mit pour mon malheur sous la

forme d'un saumon à chaque printemps. $\|^{11}$

Cela justifie probablement sa survie à la submersion ${ }^{12}$. Il resta sous cette forme cinq cents ans puis devint aigle pendant cinquante ans et durant cent ans faucon à l'œil bleu. Il s'avère que le faucon à qui il raconte son histoire, et qui raconte la sienne en retour, est aussi vieux que lui et qu'ils se sont en fait déjà rencontrés : c'est lui qui, alors que Fintan fut changé en poisson durant le déluge, lui arracha son œil, ce qui lui valut le surnom de "Borgne d'Ess Ruadh ${ }^{13}$ ». Sans aller plus loin ici, Grigory Bondarenko a consacré un riche article à Fintan et à son rôle de « gardien de la tradition » ${ }^{14}$.

8 Les vies extraordinaires de ces personnages peuvent être rattachées à deux traditions. Celle des plus vieux animaux du monde, relatée dans les littératures médiévales irlandaise et galloise, et les traditions apocryphe et exégétique relatives aux prophètes vétérotestamentaires Énoch et Élie.

\section{Énoch et Élie}

9 Fondée sur des versets obscurs de la Bible, semblant expliquer qu'ils ne subirent pas la mort mais ont plutôt été enlevés de terre par Dieu ${ }^{15}$, la tradition apocryphe a retenu Énoch et Élie comme étant les « deux témoins » cités dans l'Apocalypse ${ }^{16}$.

Cette tradition est en tout cas bien attestée dans l'Irlande médiévale. C'est ce que content Les deux chagrins du Royaume du $\mathrm{Ciel}^{17}$ (Da brón Flatha Nime). Énoch et Élie demandèrent à Dieu de ne pas quitter leurs enveloppes corporelles. Au vu de leur mérite, Dieu leur accorda ce souhait et ils furent placés au paradis terrestre. Incapables de suivre les anges vers le Seigneur, ils furent contraints à y attendre l'antéchrist. La référence aux deux prophètes est explicite à la fin de la Fondation du domaine de Tara. Fintan meurt en la présence des esprits de saint Patrick et sainte Brigitte. On ignore où se trouve sa sépulture :

«Mais plusieurs estiment que sa dépouille mortelle a été transportée dans un endroit secret et divin, de même qu'Élie et Énoch ont été emmenés au paradis. C'est

là qu'ils attendent la résurrection de ce sage vieillard, à savoir Fintan, fils de Bóchra $[\ldots] »^{18}$

Après sa longue vie terrestre, Fintan aurait-il subi un sort similaire ? L'allusion révèle en tout cas les liens entre les personnages quant à leur fonction : vivre et être témoin.

\section{À la recherche des plus vieux animaux du monde}

Les animaux en lesquels sont changés Tuán et Fintan sont concernés par la tradition des plus vieux animaux du monde, thème littéraire gallois et irlandais. Le conte gallois Kulhwch et Olwen $^{19}$ raconte que Gwrhyr, chevalier du roi Arthur, capable de communiquer avec les animaux, a pour mission de rechercher un certain Mabon qui fut enlevé trois jours après sa naissance et dont personne n'a de nouvelle. Seul le plus vieil animal peut savoir où se trouve l'homme. Il s'adresse à plusieurs animaux qui chacun lui assure qu'il ne sait rien de Mabon, mais lui indique lequel est plus vieux que lui et est susceptible d'en savoir plus. Gwrhyr s'adresse successivement au merle de Cilgwri, 
au cerf de Rhedynfre, au hibou de Cwm, à l'aigle de Gwernabwy qui l'envoie enfin vers le saumon de Llyn Llyw, dont il avait essayé de manger la chair. Finalement le plus ancien, le saumon, indique l'endroit où Mabon est tenu captif ${ }^{20}$. Ainsi se répète le schéma narratif déjà décrit plus haut, lorsqu'il s'est agi pour le roi Diarmait de chercher l'homme le plus ancien d'Irlande.

13 Un autre texte irlandais, Les aventures de Léithin ${ }^{21}$, rapporte un schéma similaire. L'Irlande a subi une tempête extraordinaire. Il s'agit de savoir si l'île en a déjà connu auparavant. Le petit de Léithin, un aigle femelle, lui conseille d'aller voir le Dubhchosach, le cerf au pied noir. Bien que très vieux, celui-ci n'a pas connaissance d'un tel fait et Léithin revient auprès du nid. Un autre oiseau lui indique le Dubhgoire, un oiseau noir. Il se trouve aussi ignorant que le cerf et, agacée, Léithin revient à son nid. En dernier lieu, le même oiseau l'envoie auprès de Goll, saumon que l'on nomme «l'Aveugle d'Ess Ruadh». Ce surnom est fortement analogue à celui qui fut donné à Fintan lorsqu'il était saumon et il semble bien qu'il s'agisse de lui : il lui avoue que l'oiseau qui l'a envoyée vers lui n'est autre que le vieux faucon d'Aichill qui lui a arraché son œil il y a fort longtemps et qui va certainement manger ses petits. Quant à la tempête, il lui raconte le déluge qu'il a connu et auquel il a survécu.

14 Ainsi, entre les métamorphoses des personnages qui nous occupent et cette tradition littéraire, nous avons affaire au même bestiaire : cerf, oiseau - principalement rapace -, saumon. Le sanglier est une particularité de l'histoire de Tuán. C'est aussi ce bestiaire que présente le bol suspendu de Lullingstone (Angleterre) ${ }^{22}$, de la fin $\mathrm{du} \mathrm{vi}^{\mathrm{e}}$ ou du début du vII siècle : deux cerfs paraissent marcher autour d'un poisson, lui-même positionné sur une colonne, au-dessus duquel vole un oiseau. Encore au-dessus, deux oiseaux sur des petites colonnes posées sur une barre horizontale se regardent. Le sanglier est manquant. L'hypothèse de la symbolique christique a été soulevée et n'est pas exclue. Mais il semble envisageable que l'iconographie se réfère également à cette tradition liée à l'acquisition de la connaissance.

Un autre thème iconographique, celui de l'oiseau arrachant les yeux du saumon ou voulant le manger, pourrait trouver sa source dans trois des textes vus précédemment: Le dialogue de Fintan et du faucon d'Aichill, Les aventures de Léithin et Kulhwch et Olwen, l'aigle racontant lui-même dans ce dernier récit ses déboires dans la chasse au poisson. C'est ce que Claude Sterckx a appelé « la dispute primordiale ${ }^{23}$ », dispute entre les deux animaux primordiaux que sont le rapace et le saumon, dont Fintan et Tuán prirent les formes. La scène de l'oiseau au-dessus d'un poisson, l'agrippant ou penchant sa tête vers lui, est représentée plusieurs fois dans la production insulaire médiévale: sur plusieurs pierres pictes ${ }^{24}$, comme l'avait rappelé Sterckx et traité C. Thomas en évoquant "The bird/Fish cult scene $»^{25}$ - la Drosten Stone (Saint Vigeans, comté d'Angus) ${ }^{26}$, la pierre de Gairloch (comté de Ross and Cromarty) ${ }^{27}$ et la pierre de Latheron (comté de Caithness) ${ }^{28}$-, ainsi que sur le bol de Lullingstone et sur la page du tétramorphe du Livre d'Armagh ${ }^{29}$, où l'aigle de saint Jean saisit le poisson de ses serres. Le saumon représentant plus spécifiquement la connaissance et la sagesse ${ }^{30}$, et sans contradiction avec le contexte chrétien de la création de ces images, il est tentant de voir dans le poisson le symbole de l'acquisition du savoir plutôt qu'une image christique ou, plus simplement, l'image paléochrétienne de l'ichtus qui a été adaptée à l'animal avatar de la connaissance ${ }^{31}$. 


\section{Le bestiaire celtique}

16 Cerf, sanglier, rapace et saumon font partie des animaux les plus importants du bestiaire des Celtes de l'Âge du Fer et de l'iconographie insulaire médiévale. Chacun est pourvu d'une symbolique particulière à associer aux textes mythologiques. Le cerf possède très majoritairement des aspects positifs. Ainsi s'exprime Tuán :

«Après cela je fus le prince des cerfs d'Irlande puisque j'étais sous la forme d'un cerf. Il y avait autour de moi un grand troupeau de faons, quelle que fût la route que je prisse. $»^{32}$

Il symbolise le temps cyclique, la longévité et la renaissance mais aussi la noblesse et la royauté $^{33}$. Il est l'avatar du dieu celte Cernunnos, lié à la terre et à la fertilité, bien connu par sa représentation sur le bassin de Gundestrup (Danemark) ${ }^{34} \mathrm{du}^{\mathrm{er}}$ siècle av. J.-C., sur lequel on le voit anthropomorphe, coiffé de bois et accompagné du cervidé. Le cerf est chargé d'une symbolique saisonnière et marque la saison sombre. Celle-ci commence, dans le calendrier celtique, le $1^{\mathrm{er}}$ novembre, célébré par la cérémonie de Samhain. C'est à cette période que les bois du cerf sont à l'apogée de leur pousse et c'est également le moment du rut. Il est le maître de la forêt jusqu'à la chute de ses bois, à l'approche du printemps ${ }^{35}$. Au début de la saison sombre, le cerf a pu faire l'objet de sacrifices. C'est peut-être ce qui est visible sur le char cultuel de Strettweg (Autriche) ${ }^{36}$ daté du VII siècle av. J.-C. Le cerf est entouré de deux personnages qui tiennent ses bois. Derrière, deux cavaliers brandissent des lances et entre eux est placé un couple de personnages dont l'un tient une hache. La scène est représentée deux fois de manière symétrique autour d'une figure féminine centrale tenant un bassin. Il peut s'agir d'une scène de chasse ou d'une scène de sacrifice. Retrouvé dans une tombe de guerrier, le char accompagne le défunt dans l'Autre Monde ${ }^{37}$. Le cerf est aussi symbole de noblesse, sa chasse étant réservée à la haute société, et restreinte à la saison sombre - il est indigne de chasser un cerf dépourvu de bois durant la saison claire. Les chasses aux cerfs sont figurées de nombreuses fois sur les hautes croix irlandaises comme sur les pierres pictes entre le viII ${ }^{e}$ et le $\mathrm{x}^{\mathrm{e}}$ siècle. Chez Tuán, une troupe de faons suit le cerf en tout endroit, il revêt donc également un caractère paternel. Le sanglier est peut-être l'animal le plus représenté de l'Âge du Fer à la période romaine en tant qu'animal divin lié à la force et à la guerre :

«Je sus que je passais d'une forme à l'autre. J'allais sous la forme d'un sanglier, je dis alors :

Je suis un sanglier parmi les troupeaux :

je suis le puissant seigneur aux grands triomphes

Il m'a mis dans un sombre souci,

le roi de tous, dans de nombreuses apparences. $»^{38}$

On le trouve en de nombreux exemplaires sous forme de figurines en ronde-bosse - la fonction de ces figurines est mal identifiée, d'autant qu'elles n'ont peut-être pas toutes eu la même fonction. La statue d'Euffigneix (Haute-Marne) ${ }^{39} \mathrm{du} \mathrm{I}^{\mathrm{er}}$ siècle av. J.C. représente un homme portant un torque, sur le buste duquel est sculpté un sanglier positionné verticalement. Peut-être s'agit-il d'un dieu protecteur des sangliers, dieu sanglier lui-même, ou d'un dieu de la chasse ou de la guerre. En effet, le suidé est intimement lié au combat et incarne la force et la brutalité. Son image est fréquente dans l'iconographie du mobilier guerrier. Il orne ainsi le bouclier de River Witham (Angleterre) $)^{40}$; la hure du sanglier est l'extrémité du carnyx - trompette de guerre écossais de Deskford ${ }^{41}$; une plaque du bassin de Gundestrup le montre comme ayant 
servi de crête de casque ${ }^{42}$ et il fut brandi comme enseigne militaire, telle que sculptée en relief sur l'arc d'Orange (Vaucluse) ${ }^{43}$. Il est par excellence l'image apotropaïque du guerrier ${ }^{44}$. L'histoire de Tuán est probablement le seul texte dans lequel le sanglier n'est pas chassé. Le christianisme l'a retenu comme l'animal violent et ravageur. Outre quelques pierres pictes, il est rare dans l'iconographie du haut Moyen Âge insulaire. La Drosten Stone $e^{45}$, montre un archer doté d'un large capuchon, posé sur un de ses genoux, visant de son arc un sanglier qui lui fait face.

Comme le sanglier, les rapaces (mais aussi les corbeaux) sont les oiseaux des champs de bataille. C'est d'ailleurs ce que rapporte le faucon d'Aichill à Fintan: il est non seulement l'oiseau qui lui a arraché un œil lorsqu'il était saumon, mais il lui avoue également avoir mutilé le corps de ses enfants morts au combat ${ }^{46}$. Le thème du rapace concerne à la fois Fintan et Tuán. Ce dernier explique :

«J'allais ensuite sous la forme d'un grand faucon. J'eus alors l'esprit dispos. J'étais capable de tout faire. Je fus alors vif et joyeux. J'allais voler à travers toute l'Irlande et je découvrais [...] tout. $\|^{47}$

Quant à Fintan :

« Pendant cinquante ans j'ai été aigle :

il y avait peu d'oiseaux pour tenir ma place.

Pendant cent ans, heureusement,

j'ai été un beau faucon à l'œil bleu. $»^{48}$

21 Il est également présent dans l'iconographie des accessoires guerriers ${ }^{49}$. Il est remarquable en tant que crête sur le casque de Ciumesti (Roumanie) ${ }^{50} \mathrm{du} \mathrm{IV}^{\mathrm{e}}$ ou III ${ }^{\mathrm{e}}$ siècle av. J.-C., ou sur l'ombos du bouclier de Wandsworth (Angleterre) ${ }^{51}$ daté entre le $\mathrm{IV}^{\mathrm{e}}$ et le $\mathrm{II}^{\mathrm{e}}$ siècle av. J.-C. Dans l'Irlande médiévale, sur la cloche-reliquaire du Corp $\mathrm{Naomh}^{52} \mathrm{du} \mathrm{x}^{\mathrm{e}}$ siècle, deux grands oiseaux mènent des cavaliers, peut-être des guerriers, vers un personnage central, probablement le Christ, saint Patrick, ou le saint auquel fut dédié le reliquaire et dont on ignore le nom. Il est aussi l'oiseau céleste par excellence, diurne, associé à la lumière et au soleil ${ }^{53}$. Sur un détail de la crosse de Kells ${ }^{54}$, du $\mathrm{IX}^{\mathrm{e}}$ siècle, un oiseau au bec aquilin est opposé à un cerf, maître de la saison sombre. La crête de la partie incurvée du XI ${ }^{e}$ siècle est aussi constituée de paires de têtes d'oiseaux qui s'entrecroisent. Enfin, le saumon est l'animal transmetteur de la connaissance, sage et omniscient ${ }^{55}$. Il est le plus ancien, celui qui détient la réponse à la question posée. Le dialogue de Fintan et du Faucon d'Aichill semble nous faire comprendre que c'est grâce à cette métamorphose que Fintan survécut au déluge. Quant à Tuán, il explique :

«Le sommeil tomba sur moi et j'allais sous la forme d'un saumon de rivière. Puis

Dieu me mit dans la rivière et j'y fus à mon aise. J'étais vigoureux et bien nourri. Ma

nage était bonne et j'échappais à tous les dangers et à tous les pièges. $»^{56}$

Un récit du Cycle du Leinster, Les exploits d'enfance de Finn (Macgnímartha Finn), narre comment le protagoniste acquit le savoir absolu grâce au saumon de la connaissance. Encore jeune, il s'adonnait à son apprentissage poétique auprès d'un druide. Une prophétie racontait que celui qui mangerait le saumon de la Boyne obtiendrait le savoir illimité. Sept ans durant, le druide essaya de pêcher le poisson. C'est finalement son élève qui y parvint. Le druide lui confia la cuisson du saumon et lui défendit d'en manger. Mais alors que le poisson était au-dessus de la braise, pour vérifier s'il était cuit, Finn le toucha de son pouce et se brûla. Par réflexe, il mit son pouce dans sa bouche. Le druide demanda donc si le saumon était prêt et si Finn n'en avait rien mangé. Le garçon lui raconta sa brûlure. Il comprit que c'était Finn que désignait la 
prophétie et lui offrit le saumon. Pour avoir connaissance de ce qu'il ignore, Finn n'a désormais plus qu'à porter son pouce à sa bouche ${ }^{57}$.

$\mathrm{Au}$ fond du grand bol suspendu de Sutton-Hoo (Angleterre) ${ }^{58}$, de la fin $\mathrm{du} \mathrm{VI}^{\mathrm{e}}$ ou du début du VII siècle, un poisson rotatif était placé sur un petit piédestal. Le bol fut mis au jour dans une sépulture anglo-saxonne. Si la fonction de ces artefacts - de manière générale - reste une question ouverte, on admet aujourd'hui pour eux une manufacture brittonique, malgré une forte parenté stylistique avec l'art irlandais ${ }^{59}$. Le bol rempli, on imagine le poisson tourner dans l'eau. Dans le cadre d'un rite de purification, de libation, peut-être du baptême, ou même dans un contexte non liturgique, il est possible que la présence de ce poisson soit liée à l'idée de transmission de la connaissance mais aussi d'éternité. Le récipient matérialiserait par conséquent la " source cosmique ${ }^{60}$ ", détentrice de la science, dans laquelle tombent les noisettes des coudriers de la connaissance dont s'alimentent les saumons ${ }^{61}$.

\section{Des traces de l'eschatologie des anciens Celtes?} selon laquelle non seulement l'âme est immortelle mais revit après la mort dans un autre corps. Ainsi Diodore de Sicile :

«[...] le propos de Pythagore est valable chez eux, qui dit que l'âme humaine se trouve immortelle et qu'elle revit pour un temps déterminée en s'introduisant dans un autre corps. " $^{62}$

Jules César rapporte également :

«Le point essentiel de leur enseignement, c'est que les âmes ne périssent pas, mais qu'après la mort elles passent d'un corps dans un autre; ils pensent que cette croyance est le meilleur stimulant du courage, parce qu'on a plus peur de la mort. $»^{63}$

On a pu penser que les métamorphoses de Fintan et Tuán se rapportaient aux croyances décrites par les auteurs classiques. Ces passages gardent cependant une certaine opacité et les interprétations sont malaisées. Diodore et César semblent plutôt parler de réincarnation. Aucune précision n'est apportée quant aux nouveaux réceptacles des âmes après la mort du premier corps : homme, animal voire plante.

Il est assez vain d'essayer de comprendre dans le détail par l'intermédiaire des textes classiques les croyances dictées par les druides et il est peu probable que les mythes de Tuán et Fintan correspondent à la doctrine eschatologique des anciens Celtes, comme le souligne Philippe Jouët :

«La longévité des deux figures mythiques n'illustre pas une doctrine réincarnationniste mais repose sur une certaine idée de la tradition nationale vivante. $»^{64}$

Leur sort est celui d'êtres exceptionnels désignés par Dieu. Les deux personnages étant christianisés, on peut percevoir dans leurs vies un aspect hagiographique. Ils ont été choisis par Dieu - Tuán attend ses changements de formes de l'action divine et Fintan est comparé aux prophètes vétérotestamentaires et son histoire adaptée du mythe biblique du déluge - pour que survive dans les mémoires l'histoire de l'Irlande. Ils révèlent un lien fort entre les animaux, auxquels on reconnaît une longévité extraordinaire, le temps cyclique et la transmission de la tradition et de la connaissance. 


\section{Bibliographie}

BOEKHOORN Dimitri Nikolai, «Bestiaire mythique, légendaire et merveilleux dans la tradition celtique : de la littérature orale à la littérature écrite. Étude comparée de l'évolution du rôle et de la fonction des animaux dans les traditions écrites et orales ayant trait à la mythologie en Irlande, Écosse, Pays de Galles, Cornouailles et Bretagne à partir du Haut Moyen Âge, appuyée sur les sources écrites, iconographiques et toreutiques chez les Celtes anciens continentaux ", thèse de doctorat en littérature, Université Rennes II, University College Cork, 2008.

BONDARENKO Grigory, «Fintan mac Bóchra: Irish synthetic history revisited », dans FOMIN Maxim, Václav BLAŽEK, et Piotr STALMASZCZYK (éd.), Transforming traditions: studies in archaeology, comparative linguistics and narrative: proceedings of the Fifth International Colloquium of Societas Celto-Slavica, held at Př́bram, 26 - 29 July 2010, Studia Celto-Slavica 6, Łódź, Łódź University Press, 2012, p. 129 - 147. BRUCE-MITFORD Robert, The Corpus of Late Celtic Hanging-bowls with an Account of the Bowls Found in Scandinavia, Oxford, University Press, 2005.

César, La guerre des Gaules, t. II, livres V-VIII, trad. Léopold-Albert constANS, Paris, Les Belles Lettres, PUF, 1964.

DOTTIN Georges (trad.), « Les deux chagrins du royaume du ciel (Da brón Flatha Nime) », Revue Celtique, vol. XXI, 1900, p. 349-388.

DOUÉTIL Jennifer, « Le sanglier : la guerre et la force », L'archéologue, n 113, avril-mai 2001, p. 23-25.

Diodore de Sicile, Bibliothèque historique, t. V, livre V, trad. Michel CASEvitz, Paris, Les Belles Lettres, PUF, 2015.

FARLEY Julia, HUNTER Fraser (éd.), Celts : art and identity, cat. expo., 24 septembre 2015 - 31 janvier 2016, Londres, British Museum et 10 mars - 25 septembre 2016, Edimbourg, National Museum of Scotland, Londres, British Museum Press, 2015.

GREEN Miranda, Animals in Celtic Life and Myth, $3^{\mathrm{e}}$ éd., Londres, Taylors \& Francis, 2002.

GRICOURT Daniel, HOLLARD Dominique, Cernunnos le dioscure sauvage : recherche comparative sur la divinité dionysiaque des Celtes, Paris, L'Harmattan, 2010.

GUYONVARC'H Christian-Joseph (éd.), Textes mythologiques irlandais, vol. I, Rennes, Ogam-Celticum $11,1980$.

HENRY Françoise, L'art irlandais, La Pierre-qui-Vire, Zodiaque, 1963-1965, 3 vol.

HYDE Douglas, « The adventures of Léithin », The Celtic Review, vol. X, décembre 1914-juin 1916, p. 116-143.

JOUËT Philippe, Dictionnaire de la mythologie et de la religion celtique, Fouesnant, Yoann Embanner, 2012.

LAMBERT Pierre-Yves, Les quatre branches du Mabinogi et autres contes gallois du Moyen Âge, Paris, Gallimard, 1993. 
MEYER Kuno (trad.), « The Boyish exploits of Finn », Eriu, 1, 1904, p. 180-190.

STERCKX Claude, « Les deux bœufs du déluge et la submersion de la ville d'Is », Annales de Bretagne et des Pays de l'Ouest, 115-1, 2008, p. 15-53.

STOKES Whitley, «The prose tales in the Rennes dindshenchas ", Revue Celtique, 15, 1894, p. 272-336 et p. 418-484.

THOMAs Charles, « The Interpretation of the Pictish Symbols », Archaeological Journal, vol. 120, 1963, p. 31-97.

YOUNGS Susan, "Anglo-Saxon, Irish and British relations: hanging-bowls reconsidered », dans GRAHAM-CAMPBELL James, Michael RYAN (éd.), Anglo-Saxon/Irish relations before the Vikings, Oxford, Oxford University Press, 2009, p. 205-230.

\section{Ressources numériques}

CANMORE : base de données des sites archéologiques écossais : https://canmore.org.uk/

\section{NOTES}

1. C.-J. Guyonvarc'h, Textes mythologiques irlandais, p. 146-148.

2. Ibid, p. 1-19. Le Livre des conquêtes de l'Irlande relate l'histoire des différents peuples qui conquirent l'île et y vécurent. Il y eut une première colonisation avant le déluge, menée par la reine Cessair, première reine d'Irlande. Trois-cent douze ans après que se sont retirées les eaux diluviennes, se sont succédés le peuple du roi Partholon, avec lequel arrive Tuán, le peuple du roi Nemed, les Fir Bolg, les Tuatha Dé Dannan et les Goidels. Fintan et Tuán ont donc connu chaque peuplement -Tuán seulement à partir de Partholon.

3. P. Jouët, Dictionnaire de la mythologie et de la religion celtique, p. 997.

4. Ibid., p. 998.

5. Ce cas n'est pas isolé. Dans le Cycle du Leinster, le Livre des lais de Finn (Duanaire Finn) et le Dialogue des anciens (Acallam na Senórach) présentent le même aspect. Oisín et Caílte, personnages mythologiques, sont alors les hommes les plus vieux d'Irlande et racontent l'histoire passée des guerriers Fíanna à saint Patrick qui les convertit. Patrick se trouve fasciné par la bravoure des héros (dont les histoires donnent naissance aux toponymes d'Irlande). Il prend soin de les faire mettre par écrit à son scribe.

6. C.-J. Guyonvarc'h, Textes mythologiques irlandais, p. 157-166.

7. P. Jouët, Dictionnaire de la mythologie et de la religion celtique, p. 458-459.

8. C.-J. Guyonvarc'h, Textes mythologiques irlandais, p. 164.

9. Ibid., p. 165.

10. Ibid., p. 169-174.

11. Ibid., p. 170.

12. Le texte de La fondation du domaine de Tara montre plutôt Fintan réfugié, durant le déluge, dans le fort de Tul Tuinde, sous les vagues.

13. Ibid., p. 170. 
14. Gr. Bondarenko, «Fintan mac Bóchra: Irish synthetic history revisited ».

15. Pour Énoch : Genèse, V, 24 et Hébreux, XI, 5. Pour Élie : II Rois, II, 11 et Malachie IV, 5.

16. Apocalypse, XI, 3-7.

17. G. Dottin, « Les deux chagrins du royaume du ciel », p. 349-388.

18. C.-J. Guyonvarc'h, Textes mythologiques irlandais, p. 166.

19. P.-Y. Lambert, Les quatre branches du Mabinogi et autres contes gallois du Moyen Âge, p. 121-164.

20. Ibid., p. 151-154.

21. D. Hyde, «The adventures of Léithin », p. 116-143.

22. Londres, British Museum: 1967, 1004.1; J. Farley, F. Huntern, Celts: art and identity, fig. 162, p. 170 ; R. Bruce-Mitford, The Corpus of Late Celtic Hanging-bowls with an Account of the Bowls Found in Scandinavia, $\mathrm{n}^{\circ}$ 43, p. 174-178.

23. Cl. Sterckx, « Les deux bœufs du déluge et la submersion de la ville d'Is », p. 49.

24. Pour les pierres pictes voir le site Canmore, base de données des sites archéologiques écossais : https://canmore.org.uk/

25. Cl. Sterckx, «Les deux bœufs du déluge et la submersion de la ville d'Is », p. 49. Thomas Charles, « The Interpretation of the Pictish Symbols », p. 70-7, fig. 11.

26. Site Canmore, $\mathrm{n}^{\circ} 35560$.

27. Site Canmore, $\mathrm{n}^{\circ} 11962$.

28. Site Canmore, $\mathrm{n}^{\circ} 8144$.

29. MS52 01, Dublin, Trinity College: IE TCD MS 52, folio 32v.

30. P. Jouët, Dictionnaire de la mythologie et de la religion celtique, p. 887-888.

31. Le thème est aussi associé au cycle de la vie de l'aigle tel que représenté dans les bestiaires médiévaux à partir du texte du Physiologos.

32. C.-J. Guyonvarc'h, Textes mythologiques irlandais, p. 146.

33. D.-N. Boekhoorn, «Bestiaire mythique, légendaire et merveilleux dans la tradition celtique ", p. 279-287.

34. Copenhague, Nationalmuseet: C 6562-6576; J. Farley, F. Hunter, Celts: art and identity, fig. 258, p. 269 ; C. Eluère, L'art des Celtes, fig. 363, p. 347.

35. D. Gricourt, D. Hollard, Cernunnos le dioscure sauvage : recherche comparative sur la divinité dionysiaque des Celtes, p. 179-183.

36. Graz, Landesmuseum Joanneum : 2000 ; C. Eluère, L'art des Celtes, fig. 51, p. 38.

37. M. Green, Animals in Celtic Life and Myth, p. 149-150.

38. C.-J. Guyonvarc'h, Textes mythologiques irlandais, p. 146.

39. Saint-Germain-en-Laye, Musée d'Archéologie National : MAN-78243; C. Eluère, L'art des Celtes, fig. 389, p. 381.

40. Londres, British Museum: 1872,1213.1; J. Farley, F. Hunter, Celts: art and identity, fig. 67, p. 84 .

41. Edimbourg, National Museum of Scotland: IL.2011.1.1; J. Farley, F. Hunter, Celts: art and identity, fig. 76 p. 90-91 ; C. Eluère, L'art des Celtes, fig. 384, p. 378.

42. Copenhague, Nationalmuse-et C 6562-6576; J. Farley, F. Hunter, Celts: art and identity, fig. 258, p. 268 ; C. Eluère, L'art des Celtes, fig. 364, p. 347. 
43. J. Douétil, « Le sanglier : la guerre et la force », p. 23-25.

44. M. Green, Animals in Celtic Life and Myth, p. 89-91 et p. 132-133.

45. Site Canmore, $\mathrm{n}^{\circ} 35560$.

46. C.-J. Guyonvarc'h, Textes mythologiques irlandais, p. 171.

47. Ibid., p. 147.

48. Ibid., p. 170.

49. M. Green, Animals in Celtic Life and Myth, p. 87-88 et p. 133-134.

50. Bucarest, Muzeul National de Istorie ; C. Eluère, L'art des Celtes, fig. 219, p. 223.

51. Londres, British Museum: 1858,1116.2 ; J. Farley, F. Hunter, Celts : art and identity, fig. 31, p. 49 ; C. Eluère, L'art des Celtes, fig. 326, p. 317.

52. Dublin, National Museum of Ireland: 1887: 145 ; F. Henry, L'art irlandais, vol. 2, pl. 55, p. 188.

53. D.-N. Boekhoorn, «Bestiaire mythique, légendaire et merveilleux dans la tradition celtique », p. 220.

54. Londres, British Museum: 1859,0221.1 ; J. Farley, F. Hunter, Celts : art and identity, fig. 14, p. 33 ; F. Henry, L'art irlandais, vol. 2, pl. 52, p. 182-183.

55. M. Green, Animals in Celtic Life and Myth, p. 191-192 ; D.-N. Boekhoorn, «Bestiaire mythique, légendaire et merveilleux dans la tradition celtique », p. 261-262.

56. C.-J. Guyonvarc'h, Textes Mythologiques irlandais, p. 148.

57. K. Meyer, « The Boyish exploits of Finn », p. 185-186.

58. Londres, British Museum: 1939,1010.110; J. Farley, F. Hunter, Celts: art and identity, fig. 28, p. 47; R. Bruce-Mitford, The Corpus of Late Celtic Hanging-bowls with an Account of the Bowls Found in Scandinavia, $\mathrm{n}^{\circ}$ 88, p. 258-265.

59. Voir S. Youngs, «Anglo-Saxon, Irish and British relations: hanging-bowls reconsidered ».

60. Cl. Sterckx, « Les deux bœufs du déluge et la submersion de la ville d'Is », p. 10.

61. Dindshenchas de Rennes 59, dans W. Stokes, "The prose tales in the Rennes dindshenchas », p. 456.

62. Diodore de Sicile, Bibliothèque historique, livre V, 28.

63. Jules César, La guerre des Gaules, livre VI, 14.

64. P. Jouët, Dictionnaire de la mythologie et de la religion celtique, p. 459.

\section{RÉSUMÉS}

Fintan et Tuán ont connu une longévité surhumaine rythmée par des métamorphoses animales, ce qui, précisément, assure cette longévité. Tous deux ont la mission, donnée par Dieu, de raconter les antiquités d'Irlande. Le témoignage de l'antédiluvien Fintan a une fonction juridique dans l'acte de définition des frontières du royaume de Tara. Tuán, quant à lui, narre l'histoire de l'Irlande à saint Finnén et perpétue ainsi le savoir à l'arrivée de la nouvelle religion. L'histoire de 
ces personnages peut être mise en liens avec deux traditions : la tradition apocryphe concernant les prophètes Énoch et Élie et la tradition littéraire des plus vieux animaux du monde. Leurs métamorphoses constituent un bestiaire spécifique : Fintan fut saumon, aigle et faucon à l'œil bleu et Tuán fut cerf, sanglier, faucon et saumon. Au regard des sources iconographiques, ce bestiaire se rapproche en effet de celui des anciens Celtes.

\section{AUTEUR}

\section{CINDY CADORET}

Doctorante en histoire de l'art, université Paris-Sorbonne 


\title{
Passages. De l'homme à l'animal dans les mythes gréco-romains : trace des mythes dans la science
}

\author{
Catherine Lochin
}

1 La métamorphose est un ressort fréquent des mythes gréco-romains; elle peut être provisoire, les dieux apparaissent aux mortels sous une forme familière afin de leur prodiguer des conseils, les égarer ou favoriser leurs amours; ils transforment des humains afin de les protéger d'une divinité jalouse ou les perdre.

2 Définitive, elle prive l'homme de son humanité ; elle est le châtiment des coupables rabaissés à une condition inférieure, ou la protection d'une victime ou du favori d'un dieu contre un sort tragique au travers d'une nature rendant inopérante la menace. Dans ces récits aitiologiques, les métamorphoses en végétal revêtent généralement un aspect positif ; certaines en arbre, statue de culte, rivière ou source sont proches d'une apothéose, la pétrification s'apparente à un châtiment. La métamorphose en animal oscille entre clémence et châtiment ${ }^{1}$. Au fil des récits des espèces variées apparaissent (fauves, cheval, dauphin, belette, animal marin, insecte...), mais ce sont les oiseaux qui sont majoritairement représentés ; cette disproportion reflète probablement l'intérêt particulier que les Anciens leur portaient.

3 Les métamorphoses font partie du fond ancien de la légende. Homère, dans l'odyssée, fait une brève allusion à celle d'Aédon témoignant de la familiarité de son auditoire avec ce thème; Hésiode multiplie les exemples dans le Catalogue des Femmes, les Tragiques l'évoquent ou en font le sujet principal de leurs œuvres². Mais ces légendes apparaissent aussi dans des domaines éloignés de la littérature chez les historiens et les naturalistes.

4 À l'époque hellénistique, ces légendes connaissent une popularité grandissante et font l'objet d'ouvrages d'érudition, scientifiques ou poétiques. Une partie des ouvrages scientifiques ne sont plus connus que par des mentions ou des fragments; au IV siècle av. J.-C. Dans l'Ornithogonie, Boios érige ces légendes en système en attribuant une origine humaine à chaque espèce d'oiseau comme au II $^{\mathrm{e}}$ siècle av. J.-C. comme Nicandre 
- et son traducteur latin Aemilius Macer - avec l'Ornithogonia et les Thériaca ${ }^{3}$. Dans le monde romain, Ovide rassemble ces récits dans les Métamorphoses, se limitant parfois à une simple allusion. Les scholies, considérées comme des œuvres scientifiques au milieu du $\mathrm{I}^{\mathrm{er}}$ siècle après $\mathrm{J}$.-C. développent ces thèmes ${ }^{4}$. Au cours du II siècle Antoninos Liberalis raconte quarante et une légendes et un papyrus fragmentaire anonyme du $\mathrm{II}^{\mathrm{e}}$ ou $\mathrm{III}^{\mathrm{e}}$ siècle regroupe des récits sous la forme d'un dictionnaire ${ }^{5}$.

Dans ces textes, on retrouve l'écho de croyances scientifiques qui ont influencé le choix de la nouvelle forme des protagonistes. La comparaison entre les légendes et les écrits de naturalistes sur le comportement des animaux met en lumière leurs liens, le mythe est parfois modifié pour s'adapter à leurs particularités.

Parmi cette foule, quelques personnages et leur nouvelle forme animale: Procné/ Philomèle/Térée; Galinthia, Anthoss et Anthos et sa famille, sont particulièrement représentatifs des liens tissés entre mythe et zoologie.

\section{Le rossignol}

\section{La légende}

7 Une des métamorphoses les plus anciennement connues et qui a été largement répandue est celle du rossignol ${ }^{6}$ - elle a aussi suscité un très grand nombre d'études et d'interprétations ${ }^{7}$. Homère fait allusion à une première version (Od. 19, 518-524) que Phérécyde (FGH 3 F 124) développe au ve siècle av. J.-C. : Aédon (le rossignol), jalouse de la fécondité de Niobé, sa belle-sœur, voulant tuer un fils de celle-ci tue par erreur l'un des siens ; elle implore alors la pitié des dieux qui la transforment en rossignol.

La légende évolue et des témoignages plus récents font intervenir un second personnage : l'hirondelle. La «reine rossignol » devient le personnage central d'une légende largement répandue avec de nombreuses variantes régionales suivant ce canevas. Une épouse demande à son mari d'aller chercher sa sœur restée chez leur père, pendant le voyage de retour, l'homme viole la jeune fille, lui coupe la langue et l'enferme, celle-ci parvient grâce à une broderie à informer sa sœur de son sort ; ensemble, elles tuent le fils de l'époux et le servent en repas à son père, celui-ci poursuit les deux femmes qui sont transformées en oiseaux : l'épouse en rossignol et la sœur en hirondelle. Dans la région thébaine l'héroïne se nomme Aédon et à Athènes, Procné.

9 Dans un fragment issu de l'Ornithomancie (fr. 132 Merkelbach), Hésiode décrit les conséquences du crime sur les oiseaux nés des métamorphoses et fait allusion à l'hirondelle en l'appelant «fille de Pandion" (Les Travaux et les Jours 568, voir aussi Sappho, fr 135 Lobel-Page) supposant donc la généalogie de l'héroïne connue. Dans les deux cas, il montre la popularité d'une légende déjà bien établie. Une fable d'Ésope (Fab. 9) $\mathrm{au} \mathrm{vi}^{\mathrm{e}}$ siècle av. J.-C., s'en fait aussi l'écho au travers d'un dialogue entre les deux oiseaux ; là encore ce sont les noms des oiseaux et non pas ceux des héroïnes qui sont cités. Une métope peinte du temple de Thermon en Étolie datée du troisième quart du $\mathrm{VII}^{\mathrm{e}}$ siècle ${ }^{8}$, représente deux femmes se faisant face. Une des femmes est désignée par l'inscription Cheilidon (l'hirondelle), du nom de la seconde il ne reste que le A initial, mais entre elles la tête d'un enfant ne laisse pas de doute quant à la légende figurée, il s'agit bien du meurtre d'Itys. Sur un vase attique du début du $v^{e}$ siècle, deux femmes 
fuient devant un homme, chacune d'elles portant sur la tête un oiseau préfigurant leur transformation. Les inscriptions qui sont placées autour d'elles ont été lues comme la notation des chants des oiseaux 9 . Un autre vase montre de nouveau deux femmes portant sur leur coiffure un oiseau, toujours indéterminé, poursuivies par un homme menaçant ${ }^{10}$. La métamorphose du troisième protagoniste, l'époux Térée, est rapportée plus tardivement. En 464-3, le chœur des Danaïdes (Eschyle, Suppl. 57-62) déclare :

«S'il se trouve à proximité quelque devin d'ici qui entende ma plainte, il croira entendre la voix de l'épouse de Térée, à la ruse pitoyable, rossignol poursuivi par un faucon.»

C'est la première allusion connue à cette transformation, où certains n'ont vu qu'une métaphore. Sur un fragment de vase un peu postérieur, Térée, désigné par une inscription, seul personnage conservé de la représentation, est figuré portant sur la tête un oiseau caractérisé comme une huppe, préfigurant sa métamorphose ${ }^{11}$. Sophocle, avec Tereus, pièce jouée après 431, est le premier à rapporter la transformation de Térée en huppe ${ }^{12}$. Ce récit est développé par Ovide (Met. 6, 426-674) et enrichi de plusieurs personnages et épisodes annexes chez Antoninus Liberalis (XI) qui a probablement réuni diverses traditions locales. Des versions encore plus tardives rapportent la métamorphose d'Itys en oiseau: une fassa (une palombe, Serv. ad Buc. 6,78 ) ou un phasianus (un faisan, Myth. Vat. I, 4). Cependant, la mention de ces deux oiseaux pour un même personnage peut s'expliquer par une confusion de l'auteur du second texte, due à l'assonance des deux mots.

\section{La zoologie}

\section{Le chant}

11 Des textes relient les personnages aux particularités des oiseaux; en premier lieu, ils reconnaissent dans leur chant des paroles en lien avec leur histoire humaine; tardivement Eusthate ( $a d .0 d .11$, p. 215) résume cet ensemble de traditions :

«Philomèle s'envole changée en hirondelle et Procné en rossignol. C'est pourquoi l'hirondelle a la voix rauque et un chant désagréable à cause de sa langue coupée et, en bégayant constamment, profère le nom de Térée, et c'est pourquoi le rossignol émet "Itys" dans son chant. Et Térée métamorphosé en huppe ne fait que s'exclamer "où sont-elles". $»^{13}$

Il transmet ainsi cette recherche de paroles intelligibles dans le chant des oiseaux. Le chant du rossignol, où l'on reconnaît le nom d'Itys, l'enfant sacrifié ${ }^{14}$, est généralement ressenti par les anciens comme plaintif ${ }^{15}$, et décrit par des termes liés aux manifestations du deuil. Le chant de l'hirondelle est vu, de son côté, comme rauque et incompréhensible, langage barbare dû à sa langue coupée ${ }^{16}$.

\section{Le comportement}

13 Les croyances sur les particularités du sommeil du rossignol et de l'hirondelle qui sont réputés vivre sans dormir ou seulement somnoler sont expliquées par le mythe. Elien (Varia Historia 12, 20: Du rossignol et de l'hirondelle) s'appuyant sur l'autorité d'Hésiode (fr 132 Merkelbach) rapporte ce fait en précisant que c'est la conséquence de leur crime :

«Le rossignol est le seul des oiseaux qui veille toujours et ne dort jamais : il ajoute que l'hirondelle ne dort jamais tout à fait, et qu'elle n'a qu'un demi-sommeil. Ils 
subissent ainsi la peine due au crime atroce qui fut commis dans l'abominable repas

dont la Thrace fut témoin. » châtiment que prend la métamorphose. Cet oiseau a en effet la réputation de vivre près des excréments, d'en tirer sa nourriture ${ }^{17}$ et de les utiliser pour construire son nid comme le rapporte Aristote ${ }^{18}$. Pline mentionne aussi ces mœurs $(10,44)$. La huppe est pour Isidore de Séville, qui renchérit sur ces textes (Étymologies 12, 7, 66), un oiseau immonde vivant dans les sépulcres. À propos de la puanteur dégagée par le nid de ces oiseaux, il faut aussi souligner la portée symbolique des odeurs, bonnes et mauvaises. De même que les premières sont des manifestations de la présence de la divinité et de la bénédiction des dieux, la mauvaise odeur dont sont affligés certains personnages mythologiques est la marque d'une malédiction infligée par une divinité.

\section{L'habitat}

L'habitat de ces oiseaux découle aussi de leur vie antérieure: la tradition la plus courante veut que les hirondelles choisissent l'emplacement de leurs nids près des hommes par peur du retour de Térée et d'une nouvelle tragédie. C'est ce qu'explique Elien (N. A. II, 3 « Sur les dons naturels de l'hirondelle ») comme un autre texte tardif, la Paraphrase de l'Ixieutique de Denys (I, 21). Cette particularité est limitée pour certains auteurs à la région où s'est déroulé le crime, en l'occurrence la région de Daulis pour Pausanias $(10,4,9)$ :

«Une chose très surprenante, c'est que les hirondelles ne pondent ni ne font éclore leurs œufs dans tout ce canton; elles n'y font même jamais leurs nids contre le toit des maisons."

Pline (H. N. IV , 18, 47) rapporte l'absence des hirondelles dans la citadelle des rois de Thrace de Byzé (actuellement Vizé en Turquie) et lui donne une cause un peu différente : la haine de ces oiseaux pour les crimes de Térée. Pour les mêmes raisons, le rossignol fuit les régions habitées. Oiseau discret dans la nature, il voit sa discrétion attribuée au désir de fuir les dangers représentés par la proximité des humains, en souvenir du crime de Térée et de son désir de vengeance (Ésope, Fab. 9) :

«Le rossignol répondit: "Je ne veux point raviver le souvenir de mes anciens malheurs : voilà pourquoi j'habite les lieux déserts". »

\section{Térée}

17 Les souvenirs de sa vie antérieure justifient aussi pour Élien (N.A. III, 26) le choix de l'habitat de Térée/la huppe :

«Caractère farouche de la huppe. Les huppes sont les plus farouches des oiseaux, et c'est à mon avis à cause du souvenir de leur humanité antérieure et en particulier de leur haine pour le sexe féminin qu'ils confectionnent leur nid dans des lieux déserts et sur des pics élevés. »

La première forme sous laquelle Térée apparaît est un rapace (Eschyle, Suppl. 57-62) et elle reparaitt dans la littérature latine chez Hygin (Fab. 45 : accipiter). Cette forme semble particulièrement adaptée puisque des espèces de petits rapaces sont prédateurs de petits oiseaux ${ }^{19}$. Puis elle disparait en faveur de la huppe. Cette substitution n'est, semble-t-il, pas aussi surprenante aux yeux des Anciens. Aristote (H.A. IX, 51, 633a), 
citant un fragment du Tereus de Sophocle (fr. 297 Nauck), explique que huppe et épervier sont en fait deux formes d'un même oiseau :

«Cet oiseau, la huppe, témoin de ses propres malheurs, il l'a bariolé de multiples couleurs et a dévoilé un fier oiseau des rochers armé de toutes ses armes, qui le printemps venu, déploie l'aile d'un épervier (kirkos). Car il révélera ainsi les deux formes, de la jeunesse et de la maturité, bien qu'issu d'un seul sein. Au début de la saison des récoltes, au moment où jaunit l'épi, de nouveau une aile tachetée l'enveloppera. Mais toujours habité par la haine, il partira d'ici pour un autre domaine, et s'en ira vers les forêts et les sommets déserts. »

19 La citation évoque la présence du rapace pendant le séjour des hirondelles en Grèce et celle de la huppe dans les régions sauvages au moment de leur départ. Pline aussi évoque le changement de forme de la huppe $(H . N .10,44)^{20}$. En mentionnant comme référence Eschyle, il fait probablement allusion au vers des Suppliantes (57-62) où la première forme de Térée après sa métamorphose est un rapace.

Selon certains chercheurs ${ }^{21}$, dans une fable animalière, origine de cette légende anthropomorphisée par la suite, le coucou serait la première forme du troisième personnage et aurait été choisi lui aussi en raison de son cri évoquant la question que le personnage pose sans fin "Pou, pou » (Où, où). Le glissement entre le coucou et l'épervier s'est fait par la croyance en une métamorphose du coucou en épervier évoquée et rejetée par Aristote (H. A. VI, 7, 563b) :

"Le coucou, dit-on parfois, n'est qu'un épervier métamorphosé, pour la raison que le temps où le coucou fait son apparition est celui où l'épervier auquel il ressemble cesse de se faire voir. [Suit la description des différences qui montrent que ce sont bien deux espèces, mais l'auteur reconnaît la ressemblance entre les plumages]... on peut admettre cependant que par sa taille et son vol, le coucou est voisin du plus petit représentant du genre épervier. »

21 Il conclut par un argument irréfutable :

«On a vu un coucou dévoré par un épervier, ce qui ne se produit jamais entre animaux de la même espèce. »

Cependant Pline (H. N. 10,11 [9]) se fait de nouveau l'écho de ce fait, contredisant mot à mot son prédécesseur jusque dans l'affirmation que l'épervier dévore un oiseau de sa propre espèce; il classe donc le coucou parmi les rapaces et en fait le produit de l'épervier. La confusion visuelle entre ces deux espèces est cependant possible, comme des études récentes l'ont souligné22.

Les Anciens étaient particulièrement friands de ces relations sur les inimitiés ou amour entre les espèces animales les plus diverses. Aristote (H. A. X, 1 [609]) et à sa suite Pline, qui leur consacre toute la fin du livre $\mathrm{X}$ de l'Histoire Naturelle (95-98) où il développe en particulier les étonnantes relations entre les pigeons et les crécerelles (10, 52 [38]), ces derniers les protégeant des éperviers; Elien les décrit dans un paragraphe entier ( $N$. A. V, 48) et dans la Paraphrase de l'Ixieutique de Denys ces liens sont exploités dans des techniques de chasse (amitié entre les perdrix et les chevaux [1,11], les perdrix et les cerfs [III, 7], les outardes et les chevaux [III, 8]).

\section{Plusieurs personnages pour un seul animal}

Dans le cas de la complexe légende que nous venons de voir, chaque personnage donne naissance à un animal et n'intervient pas dans une autre légende. Dans d'autres mythes, plusieurs personnages peuvent être cités comme origine d'un même animal. Il 
est possible de retrouver des constantes qui expliquent cette communauté de forme dans les légendes qui les touchent.

\section{La belette}

\section{Galinthias $^{23}$}

La légende la plus répandue concernant la belette est la transformation de Galinthias, victime de la vengeance d'Héra. La déesse, jalouse de la puissance promise à l'enfant de Zeus, le futur Héraclès, demande aux Ilithyes de garder les mains croisées pour empêcher l'accouchement d'Alcmène. Mais Galinthias, la servante ou amie, annonce la délivrance de sa maîtresse, les déesses indignées se lèvent, défaisant involontairement le nœud, et s'enfuient permettant la venue au monde d'Héraclès et d'Eurysthée ; pour se venger, elles métamorphosent Galinthias en belette. Ovide (Met. IX, 319-323) précise son devenir et la sanction infligée par les divinités. Non seulement elle devient un animal, mais :

«Pour avoir aidé une femme en couches d'une bouche menteuse elle enfante par la

bouche ; et comme avant elle hante nos maisons. »

Antoninus Liberalis (Métamorphoses XXIX) en citant Nicandre comme source est encore plus précis, selon lui la belette "conçoit par l'oreille et enfante par la bouche ». Le châtiment exprimé par la métamorphose est souligné par les caractéristiques « hors normes » de son mode de reproduction, largement diffusées, hors de toute référence au mythe, par les écrits des naturalistes ${ }^{24}$.

Élien (N. A., 12, 5 Cultes rendus à des animaux par les Grecs) rapporte la même légende, mais il la lie à un autre personnage portant un nom similaire (XV, 11, Sur la belette, terrestre et aquatique) :

"J'ai appris que la belette terrestre était autrefois un être humain; il est également parvenu à ma connaissance que cet être s'appelait "belette" (galé), qu'elle était sorcière et magicienne et particulièrement débauchée et souffrait de nymphomanie ; et je ne suis pas sans savoir non plus que c'est la colère de la déesse Hécate - que la déesse ne m'en veuille pas - qui la transforma en cette créature nuisible, les testicules en pendentifs empêchent de devenir mère et détournent la femme des rapports sexuels."

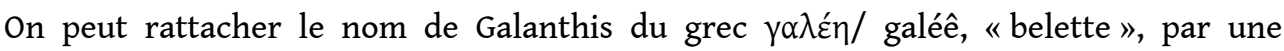
étymologie fantaisiste ${ }^{25}$. Ce lien avec le monde de la magie rappelle les bas-reliefs en mauvais état que Pausanias a vus à Thèbes (IX, 11, 3). Ils montraient la servante Historis (la savante) qui aurait trompé non plus des déesses mais des sorcières envoyées par Héra. Le mot grec employé par Pausanias est pharmakídas. Cette appellation implique le recours à une pratique liée aux drogues et à l'usage de la magie et non plus aux pouvoirs divins, rapprochant le mythe de la sorcière d'Elien ${ }^{26}$.

La proximité des domaines où agissent les deux personnages victimes d'une même métamorphose rend le lien entre eux assez évident; le choix de la forme de Galinthias se justifie par l'existence de croyances magiques liant la belette au monde de la maternité ou à son refus. Nous nous trouvons ici en présence d'une métamorphose où les liens entre le mythe et la zoologie sont évidents.

Mais d'autres personnages sans rapport les uns avec les autres se voient attribuer une même forme animale sans que l'on puisse établir de rapport pour chacun entre les causes et la forme de la métamorphose et avec la littérature scientifique. Des espèces 
animales aux origines mythiques multiples sont spécialement concernées, en particulier les cygnes, les alcyons et les colombes. Il n'y a parfois de commun entre l'animal et le personnage que l'assonance entre leurs noms. Un fils de Poséidon, Cycnos, tué par Achille lors de la guerre de Troie, est métamorphosé par son père avant d'être dépouillé de ses armes par celui-ci (Ovide, met. XII, 143-145; Pausanias, X, 14, 1); les filles d'Alkyoneus après la mort de leur père tué par Héraklès (Suidas, s.v. Akvovídrc

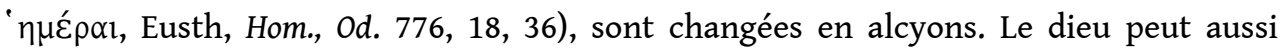
choisir la forme de son animal favori pour illustrer sa colère, comme Cycnos fils d'Apollon, abandonné par son ami Phylios lassé par les épreuves qu'il lui impose, qui se jette avec sa mère dans le lac (Antoninus Liberalis, 12 ; Ovide, Met. VII, 344-382). Dans ces cas, seuls un ou deux personnages ont donné à l'animal une caractéristique qui était le reflet de leur vie humaine : la voix mélodieuse dont Apollon avait doté Cycnos fils de Sthénélos, ami de Phaéton, explique le chant du cygne au moment de sa mort (Ovide, Met. II, 367 et suiv.; Pausanias, I, 30, 3; Virgile, Énéide X, 186 et Serv. ad. loc.), une croyance bien établie par les textes; ou les alcyons (ou les alcyons et les kéryles) qui forment des couples particulièrement unis reflétant leur union humaine comme celle d'Alcyoné et Ceyx, veuf inconsolable (Ov., Met. 11, 410- 748, Hyg., Fab.154). L'on peut ajouter à ces origines multiples celles des abeilles à propos desquelles Columelle (XI, 2, 3-5) ne réunit qu'une partie des textes, puisqu'il faut y ajouter au moins la version transmise par Servius (Aen. 1, 430), entre lesquelles on ne peut pas définir de point commun.

\section{Anthos}

31 Une dernière légende apporte un éclairage sur les liens entre la zoologie dans l'Antiquité et les mythes. Antoninus Liberalis (VII) rapporte une légende à multiples personnages dont l'origine est attribuée à Boios dans son livre I de l'Ornithogonie ${ }^{27}$. Anthos que sa mère tente de sauver, est tué par les chevaux de son père. Les héros de l'histoire sont tous métamorphosés en divers oiseaux dont ils portaient déjà le nom, sauf le père Autonoos qui devient un butor, en grec oknos : le paresseux, le craintif, dont le nouveau nom fait allusion à son attitude. Anthos, devenu oiseau, craint bien sûr les chevaux. C'est ce qu'Aristote (H. A. IX, 1 [609 b]) rapporte sans faire allusion à la légende dans son chapitre consacré à la bonne ou mauvaise entente entre les espèces :

«L'anthus [dont l'identification exacte de l'espèce reste à discuter] est l'ennemi du cheval car le cheval le chasse du pâturage ; l'anthus se repaît d'herbe, il a une taie sur l'œil et sa vue manque d'acuité ; il imite le hennissement du cheval, et il l'effraie en volant près de lui ; mais le cheval le chasse à son tour, et quand il l'attrape il le tue. L'anthus habite près des rivières et des marais, il a une belle couleur et se procure aisément sa nourriture.»

Elien se fait aussi l'écho de cet antagonisme (N. A. VI, 19), tout comme Pline (N. H. 10, 42 [116]). Il faut souligner les incertitudes sur l'identification de cet oiseau, Aristote le décrit comme un petit oiseau (H. A., VIII, 3 [592b]) :

"L'anthus : cet oiseau a la taille d'un pinson. »

En se basant sur son lieu de vie en milieu humide, certains l'ont identifié au héron pique-bœuf ; pour d'autres, se rapprochant du texte d'Aristote il s'agit du bruant ${ }^{28}$. La correspondance entre la description des relations entre les chevaux et de l'anthus et le récit d'Antoninus, bien que le lien ne soit pas exprimé par les zoologues, est cependant frappante et rien dans la réalité ne semble justifier un tel conflit entre un oiseau et les 
chevaux. Elle rejoint les réflexions déjà faites sur les relations réelles ou fantasmées entre les espèces dont on trouve d'autres échos dans les ouvrages de zoologie qui expliquent certaines particularités d'espèces animales, par exemple la métamorphose de Boulis (Antoninus Liberalis V) en un poynx, un oiseau lui aussi à l'identification incertaine, condamné à se nourrir des yeux des animaux dont on retrouve le nom chez Aristote (H. A., IX, 17 [617 a]) et qui est suivant cet auteur une sorte de héron, peut être le butor ${ }^{29}$, « le plus enclin à s'attaquer aux yeux de son adversaire».

La zoologie n'est pas la seule science à entretenir des rapports avec les mythes: l'étymologie fait aussi fréquemment appel à ce corpus et aurait aussi pu servir de base à cette étude, soit que le personnage porte déjà le nom de l'animal qui sera sa nouvelle forme, soit que son nouveau nom reflète sa nouvelle activité (Térée: le guetteur, Philomèle: celle qui aime les troupeaux et Procné: la tachetée, allusion à son plumage $)^{30}$ ou Ortygios qui avait voulu empêcher le sacrifice d'ânes à la place de chèvres demandées par Apollon, métamorphosée en la mésange (aigithallos) dont le nom est rapproché par les Anciens de celui de la chèvre ${ }^{31}$. Ces différentes métamorphoses nous amènent à nous interroger sur le degré de "croyance " que l'on accordait à ces récits. Si certains auteurs sont apparemment critiques, leur attitude n'est pas toujours totalement cohérente. Ainsi, nombre de mythes n'ont pas laissé de trace chez Pline qui en rejette une bonne partie comme des fables $(10,70)$, tout en en acceptant certains, comme le combat des Pygmées contre les grues (VII, 26;10,30), de même que l'absence d'animaux dans certains endroits, absence que seuls des mythes ou des légendes locales justifient (Pline, N.H. 10, 28 - 30). Aristote, malgré son sens critique, ne semble pas vraiment mettre en doute l'origine du surnom du héron étoilé (IX, 17 [617 a]) :

«Le héron étoilé, surnommé le lâche (doulon) passe, suivant la légende, pour être né jadis d'un esclave, et, comme son nom l'indique, c'est le plus paresseux de tous.»

L'on peut enfin conclure, pour illustrer la frontière ténue entre science et mythe, en rappelant la réflexion d'Élien qui veut, de façon rationnelle, laisser à d'autres les mythes (N. A.15, 11), mais émaille son ouvrage d'allusions à la mythologie et aux mirabilia. En revanche, Columelle à propos de l'origine des abeilles (XI, 2, 3- 5) trace une limite entre les besoins des "campagnards » et ceux des poètes et des naturalistes. Après avoir évoqué plusieurs légendes sur l'apparition des abeilles, il conclut en ces termes (XI, 2,5):

«La recherche de ces secrets, et d'autres semblables, intéresse plus particulièrement les naturalistes que les campagnards ; ils plaisent aussi plus à ceux qui cultivent les lettres et qui ont du loisir à donner à la lecture, qu'aux agriculteurs, qui sont très occupés, et auxquels ils ne seraient d'aucune utilité ni dans leur travail, ni dans leurs affaires domestiques. » 


\section{BIBLIOGRAPHIE}

BERNAND André, «Les animaux dans la tragédie grecque », Dialogues d'histoire ancienne 12, 1986, p. 241-269.

BIRAUD Michèle et DELBEY Evrard, «Philomèle : du mythe aitiologique au début du mythe littéraire » Rursus 1, 2006, http :/rursus/ revues.org/45.

BODSON Liliane, «L'apport de la tradition gréco-latine à la connaissance du coucou gris (Cuculus canorus L.) » History an Philosophy oh the Sciences 4/1, 1982, p. 99-123.

BORTHWICK E. K., « Seeing Weasels: The Superstitious Background of the Empusa Scene in the Frogs », The Classical Quarterly, New Series, vol. 18, Nº 2 (Nov. 1968), p. 200-206.

CHAZALON Ludi et VILGAUX Jérôme, «Violences et transgressions dans le mythe de Térée » Annali di Archeologia e Storia antica. Napoli, Dipartimento di studi del mondo classico e del mediterraneo antico, nuova serie n. 15 - 16, 2008-2009, p. 167-189.

ChazAlon Ludi, « Le mythe de Térée, Procnè et Philomèle dans les images attiques ", Mètis n. s. 1, 2003, p. 119-148.

CRUGNOLA Annunciata, Scholia in Nicandri Theriaka cum glosis, Milan, Istituto Editoriale Cisalpino, 1971.

FORBES Irving Paul M. C., Metamorphosis in greek Myths, Oxford Clarendon press, The Oxford classical monographs, 1990.

GOURMELEN Laurent, « Bestiaire et mythologie en Grèce ancienne : l'hirondelle, images, métaphores et métamorphoses » dans LE NAN Frédérique et TRIVISANI-MOREAU Isabelle (dir.), Bestiaires : mélanges en l'honneur d'Arlette Bouloumié, Angers, Presses universitaires d'Angers, Nouvelles recherches sur l'imaginaire, Cahier 36, 2014, p. 83-95.

Lexicon iconographicum mythologiae classicae (LIMC), Fondation pour le lexicon iconographicum mythologiae classicae, Zürich, München, Düsseldorf, Artemis Verlag, 1981-1999. LOCHIN Catherine, « Punir ou récompenser : un aspect particulier de la métamorphose dans l'Antiquité » dans AUFÈRE Sydney H. et MAZOYER Michel (éd.), Clémence et châtiment, Paris, L'Harmattan, 2009, p. 151-168.

MYERS K. Sara, «The Lizard and the Owl: an etymological Pair in Ovid », Metamorphoses Book 5, American Journal of Philology 113, 1992, p. 63-68.

MYERS K. Sara, Ovid's Causes: Cosmogony and Aetiology in the Metamorphoses, Ann Arbor, University of Michigan Press, 1994.

papathomopoulos Manolis (ed.), Antonios Liberalis, Les métamorphoses, Paris, Les Belles Lettres, Collection des Universités de France, 1968.

PITCHER Seymour M., « The Anthus of Agathon », American Journal of Philology 60/2, 1939, p. $145-169$.

RENNER Timothy, « A papyrus dictionary of metamorphoses », Harvard studies in classical philology 82, 1978, p. 277- 293.

THOMPSON D'ARCY Wenthworth, A glossary of greek birds, Oxford, The Clarendon press, 1895. 
WELBERGEN Justin A. et DAVIES NICHOLAS B., « A parasite in wolf's clothing: hawk mimicry reduces mobbing of cuckoos by hosts », Behavioral Ecology 22 mars, 2011, p. 574-579.

\section{NOTES}

1. C. Lochin, «Punir ou récompenser : un aspect particulier de la métamorphose dans l'antiquité ", passim.

2. Le mythe d'Actéon dans les Toxotides, les légendes de Callisto ou des filles de Mynias (Eschyle), Térée et Méléagre (Sophocle) Actéon, Térée, Callisto, Taygète, Hippé et les Méléagrides, et Ceyx (Euripide). Pour ces pièces perdues, voir P. M. C. Forbes Irving, Metamorphosis in greek Myths, p. 13-19

3. Pour l'historique de ces ouvrages, voir M. Papathomopoulos (ed.), Antonios Liberalis, Les métamorphoses, $\mathrm{p}$. X-XIX.

4. A. Crugnola, Scholia in Nicandri Theriaka cum glosis, p. 31.

5. T. Renner, «A papyrus dictionary of metamorphoses ", passim.

6. Apollodore. Bibliothèque III, 14; Ovide, Metamorphoses. 6, 426-674; Antoninus Liberalis,Transformationes XI ; Pausanias 1,5,4. 1,41,.8-10. 10,4,8-9 ; Achille Tatius, Histoire de Leucippe et Clitophon,. 5, 3. 5, 5 ; Servius, ad Verg. Ecl. 6, 78 ; Hygin, Fabulae. 45 ; Zenobius, Proverbes 3, 14; Conon, Narrationes 31; Tzetzes, Chiliades 7, 459-465 ; Eustathius, on Hom. Od. 19, 518, p. 1875 ; Lactantius Placidus, on Statius, Theb. V, 120 ; Scriptores rerum mythicarum Latini, ed. Bode, I. p. 2, 147 (First Vatican Mythographer 8 ; Second Vatican Mythographer 217).

7. Pour les différents oiseaux évoqués dans cette légende, voir W. Thompson d'Arcy, A glossary of greek birds, p. 16-22, 95-100 et 314-324. Pour une bibliographie sur ce sujet voir L. Gourmelen, «Bestiaire et mythologie en Grèce ancienne : l'hirondelle, images, métaphores et métamorphoses ", note 1 .

8. Atelier corinthien, Athènes, Mus. Nat. 13140, troisième quart du viI ${ }^{\mathrm{e}}$ siècle, Lexicon iconographicum mythologiae classicae, vol. 7, s.v. Prokne et Philomela ${ }^{\circ}{ }^{1}$, pl. 418 avec bibliographie.

9. Amphore à figures noires, vers 490-480 av. J.-C., Naples, Mus. Naz. 145468, du Peintre de Diosphos, L. Chazalon, "Le mythe de Térée, Procnè et Philomèle dans les images attiques", p. 130-132, fig. 8 ; L. Chazalon et J. Vilgaux, "Violences et transgressions dans le mythe de Térée », p. 177, fig. 8 et pour les inscriptions, p. 177.

10. Cratère attique à figures rouges, Agrigente, Mus. Arch. Naz., collection Pirandello, relié au peintre de Syracuse. Vers 470 av. J.-C; L. Chazalon, Ibid., p. 132-134, fig. 9; L. Chazlon et J. Vilgaux, Ibid., p. 178, fig. 9.

11. Hydrie attique à figures rouges, Reggio Calabria 27202, vers 470-460, groupe des Niobides, provenant de Locres, collection Candida, L. Chazalon, Ibid., p. 135, fig. 10 ; L. Chazalon et J. Vilgaux, Ibid., p. 179, fig. 10.

12. L. Chazalon, Ibid., p. 120. La métamorphose est rapportée dans un fragment d'une pièce perdue de Philoclès dans la seconde moitié du ve siècle, voir P. Oxy. XLII, 3013.

13. Voir aussi la scholie à Aristophane, Oiseaux 212 et à Hesiode, Trav. 566.

14. M. Biraud et E. Delbey, «Philomèle: du mythe aitiologique au début du mythe littéraire », p. 9. Pour le côté harmonieux du chant, voir Pline, H.N. 10, 43. 
15. Par exemple Pausanias $1,41,9$; B. André, «Les animaux dans la tragédie grecque », p. 247-248 (pour Eschyle), p. 250 (pour Sophocle), p. 258-259 (pour Euripide).

16. L. Gourmelen, «Bestiaire et mythologie en Grèce ancienne : l'hirondelle, images, métaphores et métamorphoses ", p. 88.

17. L. Chazalon, "Le mythe de Térée, Procnè et Philomèle dans les images attiques ", p. 147-148.

18. H. A. IX, 15, 616 b : « construit surtout son nid avec des excréments humains. Elle change d'aspect en été en hiver » et aussi Ael., N. A. 3,26; Plin. H. N. 10, 86 ; Eus. Hier. In Zach. 1, 819-20 (PL 25, 1451).

19. M. Biraud et E. Delbey, «Philomèle: du mythe aitiologique au début du mythe littéraire ", 2.2.1.

20. Pour d'autres métamorphoses saisonnières d'un oiseau en une autre espèce, voir Pline $(10,44)$ qui évoque le rouge-gorge qui devient le rouge-queue en été.

21. M. Biraud et E. Delbey, «Philomèle: du mythe aitiologique au début du mythe littéraire ", 2.3.1.

22. M. Biraud et E. Delbey, «Philomèle: du mythe aitiologique au début du mythe littéraire " 2. 2. 4 avec fig.; L. Bodson, "L'apport de la tradition gréco-latine à la connaissance du coucou gris (Cuculus canorus L.)», p.103-105; J. Welbergen et N. B. Davies, «A parasite in wolf's clothing: hawk mimicry reduces mobbing of cuckoos by hosts ", p. 574-579.

23. Ov., Met. 9, 306- 323 ; Ant. Lib. 39 ; Pline, N. H. XXVIII, 6 (17) 59 ; Clem. Alex, Protr. II, 39. Pour une étude de sa métamorphose, voir P. M. C. Forbes Irving, Metamorphosis in greek Myths, p. 205-207.

24. Plutarque, Sur Isis et Osiris, 74 ; Aristote (De la génération des animaux, III, 6) rapporte la croyance tout en s'y opposant, sans succès; elle est encore rapportée dans le Physiologus à l'époque médiévale ; Élien, N. A, XII, 5.

25. K. S. Myers, Ovid's Causes: Cosmogony and Aetiology in the Metamorphoses, p. 33.

26. E. K. Borthwick, «Seeing Weasels: The Superstitious Background of the Empusa Scene in the Frogs ", p. 203, particulièrement pour les rapports de cet animal avec la magie.

27. Pour une étude de l'origine de cette légende, voir S. M. Pitcher («The Anthus of Agathon ", p. 149-164), qui fait aussi de cette légende le sujet d'une pièce d'Agathon dont il ne reste que quelques fragments; P. M. C. Forbes Irving, Metamorphosis in greek Myths, p. 224-225.

28. W. Thompson d'Arcy, A glossary of greek birds, p. 51-52.

29. W. Thompson d'Arcy, A glossary of greek birds, p. 253.

30. M. Biraud et E. Delbey, «Philomèle : du mythe aitiologique au début du mythe littéraire », 2. 1. 1; L. Gourmelen, "Bestiaire et mythologie en Grèce ancienne: l'hirondelle, images, métaphores et métamorphoses ", p. 86.

31. Antoninus Liberalis XX. 


\section{RÉSUMÉS}

Les métamorphoses apparaissent fréquemment dans les mythes gréco-romains, mais elles sont aussi présentes dans les textes des naturalistes pour expliquer l'apparition d'une espèce. Elles servent aussi à justifier le comportement particulier d'animaux, comportement qui reflète les relations qu'ils entretenaient du temps de leur existence humaine. Quelques légendes (Procné/ Cheilidon/Térée, Galinthias, Anthos) illustrent particulièrement les liens tissés au fil du temps entre les sciences naturelles, la magie et la littérature. Les réflexions de certains auteurs nous éclairent aussi sur le degré de croyance des Anciens envers ces traditions.

\section{AUTEUR}

\section{CATHERINE LOCHIN}

Ingénieur de Recherche, CNRS ARSCAN/ESPRI-LIMC 


\title{
La femme-génisse et l'homme- oiseau ou l'art de la métamorphose
}

\author{
Cyril Maré
}

1 Des dieux, des animaux et des hommes. La mythologie grecque regroupe différentes catégories d'êtres dont la séparation est fragilisée par le phénomène de métamorphose. Il s'entend généralement comme le passage d'une apparence divine ou humaine vers celle d'un animal. D'une forme à l'autre, le changement survient comme une péripétie essentielle ou une conclusion au sein d'un récit, assumant différentes fonctions métaphoriques. Alors que la transformation est habituellement la conséquence d'un pouvoir divin ou magique, celle qui concerne Pasiphaé et Icare présente la particularité d'être permise par l'ingéniosité d'un homme, Dédale. Leurs mésaventures ont également pour caractéristique de se suivre, mettant en scène les mêmes personnages. La difficulté de leur analyse, comme souvent dans la mythologie grecque, est que les sources littéraires et iconographiques sont multiples et parcellaires: beaucoup d'auteurs, quelques fragments sauvegardés et certaines divergences de version. L'étude de leur récit, qui se métamorphose donc lui aussi et dont l'étrangeté peut déconcerter l'esprit rationnel, permet néanmoins d'interroger symboliquement les liens interespèces.

2 Pasiphaé est l'épouse de Minos, fils adoptif d'Astérios, roi de Crète. L'homme est ambitieux. À la mort de son père, il cherche à faire valoir ses droits de successions. Pour asseoir sa légitimité, il souhaite montrer au peuple son accointance avec l'Olympe. Il prie l'un de ses plus éminents représentants, Poséidon, de lui envoyer un magnifique taureau, qu'il lui sacrifiera en retour. Le dieu des océans accède à la demande. Ébahi par la majesté et la blancheur éclatante de l'animal sorti des eaux, Minos choisit de le préserver et d'immoler un autre taureau de son troupeau. Il obtient le trône, mais Poséidon découvre la supercherie ${ }^{1}$. Son courroux est à la mesure de l'imposture. Il inspire à Pasiphaé une passion pour l'animal préservé. La reine se confie alors à Dédale, artisan athénien qui vit exilé à Cnossos et qui se trouve être au service de Minos. Il lui fabrique une vache en bois, creuse et recouverte de cuir, afin qu'elle puisse s'y dissimuler et approcher l'objet de son amour. Il l'emmène ensuite dans le pré où le 
taureau se trouve, à proximité de Gortyne. De cette union naît Astérion, mi-homme, mitaureau, plus connu sous le nom de Minotaure.

3 Minos tente immédiatement de le cacher. La honte que représente cet enfant pour un roi est trop importante. Il craint que son image soit dégradée, et avec elle, la force exceptionnelle du Minotaure lui permettant de briser les liens censés le tenir à l'abri des regards, Minos se résout à consulter un oracle pour trouver une solution. La réponse est une invitation à demander à Dédale de construire une demeure à Cnossos où il se cacherait. L'architecte imagine donc un lieu insulaire doté de nombreux couloirs, multipliant les risques de s'égarer, et au centre duquel le Minotaure est placé. L'ensemble est conçu de telle sorte que quiconque y pénètre ne puisse en ressortir. Le labyrinthe, étymologiquement " palais de la double hache ", est ainsi érigé.

exige alors d'Athènes, l'ennemi défait, un tribut annuel de jeunes gens afin de les envoyer dans l'énigmatique édifice. Un jour, Thésée, prince d'Athènes, fut tiré au sort. Avec l'aide d'une des filles de Minos éprise de lui, Ariane, elle-même conseillée par Dédale qui lui révèle l'astuce du fameux fil, il parvint à s'échapper et à tuer le monstre. Excédé par une telle trahison ${ }^{2}$, Minos enferme l'architecte avec son fils dans le piège qu'il a construit. Leur fuite est organisée par les airs grâce à la fabrication d'ailes de plumes et de cire. Pendant qu'ils survolent la mer, Icare s'approche des rayons du soleil en dépit des instructions de son père. La cire se liquéfie, Icare tombe et se noie. Dédale, abattu, recueille son corps et l'enterre, avant de gagner la Sicile.

5 L'analyse comparée des mythes de Pasiphaé et d'Icare montre que la métamorphose, lorsqu'elle relève de l'art, c'est-à-dire à la fois de l'artistique et de l'artisanal, permet de dompter la nature et, concomitamment, d'éliminer l'intervention du surnaturel. Elle cherche ainsi à réécrire le rapport de l'homme au monde et au vivant. Mais en dérangeant ainsi l'ordre établi, la métamorphose expose à la difformité et à la confusion. Donnant l'illusion de réunir, la métamorphose rompt en réalité ce qui fait lien, ce qui fait corps.

\section{L'art de la métamorphose ou le champ des possibles}

Lorsqu'elle est façonnée par l'homme, la métamorphose repose sur ses propres capacités, notamment deux d'entre elles, la mètis et la technè. Elles lui permettent d'imiter la nature et de tenter de dépasser, un instant, le poids du kairos, la condition humaine. Mais ce projet, porteur d'une hubris, ne se conçoit et ne se réalise pas sans risque ou contrepartie.

\section{L'imitation de la nature par la mètis et la technè}

7 Bien que l'appartenance de Dédale à la maison royale d'Athènes soit majoritairement admise, son ascendance reste confuse. Sa mère? Alcippé, Mérope ou Iphinoé. Son père? Métion, Palamaon ou Eupalamos. Certains récits plus tardifs en font un descendant d'Athéna, vraisemblablement pour souligner son importance et justifier ses talents dans les domaines techniques. L'étymologie grecque daïdalos renvoie en effet, selon le contexte, à " artiste », " artistement travaillé » ou encore " astucieux ». Dédale incarne l'artisan par excellence, alliant le sens de l'esthétique à l'ingéniosité technique. Son habileté et son inventivité sont si exceptionnelles qu'elles franchissent la mythologie pour imprégner la philosophie. Dans le Ménon, Platon rapporte que Socrate, 
désireux d'illustrer le concept d'« opinions vraies ", évoque le réalisme des nombreuses statues façonnées par le maître, précisant qu'il était, selon la légende, nécessaire de les attacher pour les empêcher de fuir ${ }^{3}$. Aristote mentionne ces mêmes statues dans sa Politique, en compagnie des trépieds d'Héphaïstos, également autonomes dans leurs déplacements, dans le but de faire entrevoir un monde où les automates se substitueraient aux ouvriers et aux esclaves ${ }^{4}$.

8 Le penseur réunit à cette occasion les deux plus célèbres démiurges que compte la mythologie grecque : Héphaïstos, le dieu du feu et de la métallurgie, et Dédale, le père de l'architecture et de la sculpture. La proximité de leur art est telle que certains Anciens en déduisent un lien de filiation et considèrent le mortel comme un « doublet fonctionnel $»^{5}$ de l'olympien. Les deux personnages possèdent la mètis, cette intelligence rusée permettant de s'adapter dont fait également preuve Ulysse, ainsi que la technè qui " désigne à la fois le savoir et le savoir-faire mais pas le travail $»^{6}$. Ces facultés les poussent à innover, à créer et à bâtir. Ils recourent dans ce but, non pas à des sorts qu'ils énonceraient sans effort, mais à des matériaux qu'ils assemblent à l'aide d'outils. Les thérianthropies de Pasiphaé et d'Icare sont ainsi fabriquées à partir d'éléments disponibles dans la nature, dont certains proviennent directement des animaux censés être imités, le cuir de la vache et le plumage de l'oiseau. Elles possèdent les propriétés physiques de leurs composants. Les roues de la génisse permettent de la déplacer, la cire de maintenir les plumes des ailes, tant que la chaleur ne la fait pas fondre. C'est une conception mécanique et physique du vivant.

9 L'art de Dédale se distingue ainsi du pouvoir surnaturel que possèdent les dieux de modifier leurs propres apparences ou celle d'un autre être vivant, et de la magie qu'emploie la sorcière Circé7. Aucune force extérieure n'est impliquée dans le travail de l'artisan. Son œuvre s'inscrit dans un mouvement de rationalisation et de sécularisation. Toutefois, en tant que simple mortel, Dédale ne peut rivaliser avec le forgeron divin, qui jouit non seulement d'une ingéniosité et d'une habileté exceptionnelles, mais aussi de la capacité d'insuffler la vie d'une manière merveilleuse. En effet, Héphaïstos a le don d'animer ce qui est inerte. Suivant la description homérique, en donnant une voix humaine, une force et un visage de déesse à de la glaise et de l'eau pétries, il crée Pandore, la première femme. Il lui est donc possible de reproduire le vivant ${ }^{8}$, là où Dédale doit se contenter de l'imiter.

Dédale conçoit des automates en bois ou en métal, qui usent de mécanismes secrets pour donner l'illusion du vivant. C'est un travail qui nécessite des efforts : alors que la magie opère de façon statique, la technè introduit la cinétique. Le temps devient une composante de la transformation puisque l'action humaine, contrairement à la parole divine, y est soumise. Il encadre sa conception, son usage et sa fin. Un terme peut en effet lui être mis, volontairement telle Pasiphaé se dégageant de la génisse factice, ou involontairement tel Icare subissant les contraintes matérielles de ses ailes. Il est possible d'interrompre la transformation et de la renouveler à sa guise, conformément à sa fin utilitariste. Cette particularité confirme l'idée de subterfuge qui en émane, une modification de l'apparence, et non de l'essence ${ }^{9}$. Le préfixe grec meta signifie «audelà » ou «ce qui vient après » et renvoie donc à la succession des formes pour un même individu, qui reste cependant identique à lui-même.

11 Le corps change, qu'il soit dissimulé sous une seconde peau pour Pasiphaé ou équipé d'ailes pour Icare, mais la personne demeure, malgré une influence sur le comportement. En effet, mélangeant ce qui relève de l'animalité et de la nature 
humaine, Ovide raconte comment Pasiphaé perçoit les autres génisses comme des rivales et les tue par jalousie ${ }^{10}$ ou comment Dédale s'inquiète pour son fils avant son envol «comme un oiseau qui emmène sa jeune couvée dans les airs " ${ }^{11}$. Dans ces moments-là, homme et animal ne semblent faire qu'un. Ce rapprochement fait écho à la lycanthropie clinique, trouble de la personnalité à travers lequel le sujet se croit transformé en animal, mais surtout à l'étymologie voisine des mots natura, «ce qui donne naissance " en latin, et technè (d'où technica en latin) dont la racine indoeuropéenne tik signifie «engendrer ». Technique et vivant ne s'opposent donc pas et obéissent aux mêmes principes qui régissent le kosmos. Ils forment, avec le pouvoir divin, les différentes facettes d'un même monde.

Pour autant, la métamorphose artistique reste un processus dual qui permet la continuité de l'être tout en lui faisant subir une mutation. Elle diffère du changement total d'état qu'entraîne généralement la métamorphose des humains lorsqu'elle est provoquée par les dieux. Si la personnalité demeure, c'est davantage une sanction. Les cas comme celui de Io qui, par l'action de Zeus, a vécu plusieurs années en génisse, avant de retrouver son apparence initiale, sont rares. Le sort d'Actéon est plus représentatif. Transformé en cerf par Artémis pour l'avoir vu nue, il est conscient d'être dévoré par les chiens qu'il avait dressés pour l'aider à chasser. De même, Callisto, la femme changée en ours par Héra, jalouse de sa relation avec Zeus, est condamnée à se cacher dans les montagnes avant de succomber à une flèche de la même Artémis. Les métamorphoses divines sont ainsi largement les condamnations d'une hubris, d'une démesure, quand celles de Dédale sont des entreprises.

\section{Le dépassement de la condition humaine par le kairos et l'hubris}

13 Envoûtée, Pasiphaé cherche à assouvir son désir. Enfermé, Icare cherche à retrouver la liberté. Tous les deux connaissent un châtiment, alors qu'ils ne sont pas initialement fautifs. La reine est l'objet de la vengeance de Poséidon à l'encontre de son mari ${ }^{12}$, le fils est condamné par Minos car son père a aidé Thésée. La métamorphose que Dédale leur propose représente le moyen de mettre un terme à la situation dans laquelle ils se trouvent. En devenant génisse, Pasiphaé peut s'accoupler avec le taureau blanc (symbole de fécondation en Égypte ${ }^{13}$ ) et voir disparaitre la folie qui s'était emparée d'elle. En devenant oiseau, Icare peut s'évader du labyrinthe et fuir la Crète où il risquerait d'être repris.

14 Pour chacun, l'opportunité de la métamorphose désigne le temps du kairos, la saisie d'une occasion permettant d'inverser pour le meilleur ou pour le pire le cours des événements et, littéralement ici, des apparences. Faire appel à la mètis et la technè de Dédale, c'est atteindre une ambition a priori inatteignable. La métamorphose, comme le soulignent les récits d'Ovide, rend possible ce que la forme initiale ne permet pas. Ces limites, posées par la nature, renvoient plus largement à celles de la condition humaine. Pour Homère et Hésiode, cette dernière était empreinte d'une relative noirceur, de nombreuses épreuves, souvent douloureuses, parsemant le chemin de la vie. Pour compenser ce quotidien difficile, la charis, terme communément traduit par "grâce ", se manifestait parfois pour embellir les apparences, rehaussant les corps de façon éclatante, et assouvir les désirs. Habituellement procurée par les dieux pourvus de mètis, la charis peut également rayonner depuis des fabrications humaines, dont celles de Dédale. Comme Pandore, la première femme, fabriquée de toutes pièces par 
les dieux et qui possédait une boîte contenant tous les maux de l'humanité, la femmegénisse et l'homme-oiseau cachent en leur sein un danger. Le passage de la charis constitue un moment aussi exceptionnel qu'éphémère, et se trouve à la fois réjouissant et trompeur ${ }^{14}$.

La génisse de Dédale est un piège, au même titre que le cheval de Troie d'Ulysse. Deux coquilles trompeuses, qui renferment la secrète intention de conquérir l'autre, qu'il s'agisse d'un simple taureau ou d'une ville entière. Pasiphaé est la reine qui abdique son souverain statut et rejette la cité, pour se livrer au désir le plus brut et le plus primaire que seul l'artifice peut lui offrir. Le drame d'une âme qui désire un autre corps, renonçant au destin, la moïra, qui lui était naturellement tracé. Elle n'est plus debout, mais à quatre pattes. Elle commet une faute fondamentale: Thanatos écarte Éros, l'interdit est transgressé, la limite franchie.

De son côté, Icare est symbole de l'aspiration à voler, à toucher le ciel. Les ailes sont l'attribut de l'élévation vers le sublime, de l'affranchissement de la contrainte terrestre, du passage entre les mondes. Hermès, messager des dieux et gardien des voyageurs, est représenté dans l'iconographie grecque avec de petites ailes aux talons ou à la tête pour signifier sa capacité à se mouvoir partout et souligner sa fonction psychopompe. C'est pourquoi, Platon écrit dans Phèdre que :

«La vertu des ailes est de porter ce qui est pesant vers les régions supérieures habitées par les dieux, et elles participent plus que toutes les choses corporelles à ce qui est divin. $»^{15}$

Cela fait du mythe d'Icare un avertissement contre l'orgueil humain. L'hubris, d'ailleurs considérée comme un défaut caractéristique de la jeunesse, trouve sa nemesis, rappelant à l'être humain sa place dans le monde.

\section{L'art de la métamorphose comme rappel à l'ordre naturel}

Tentant de déjouer les lois de la nature, la métamorphose est rapidement rappelée par la réalité d'un monde ordonné, au sein duquel chaque espèce possède une place bien définie, et qui ne goûte guère le chaos. Dans ce contexte, l'hybridité est trop subversive pour être tolérée.

\section{La séparation verticale des règnes animal, humain et divin}

Les mythes de Pasiphaé et d'Icare interrogent les rapports entre la science et le vivant, entre l'artifice et la nature. L'art de Dédale y puise son inspiration pour proposer la solution de la métamorphose. La femme-génisse et l'homme-oiseau demeurent des humains et leur animalité un simulacre. Cette dernière n'est qu'un moyen, non une fin en soi ni un changement identitaire. De la même façon, Zeus ne devient pas mortel en se changeant en taureau pour approcher Europe, fille du roi de Tyr, sur laquelle il a jeté son dévolu. La transformation vise à éveiller l'ardeur de la jeune femme, à travers des attributs de puissance et de pureté que décrit Ovide dans les Métamorphoses ${ }^{16}$. Les thérianthropies humaines semblent singer celles des dieux.

Elles sont moins efficaces, comme en atteste un petit oiseau qui assiste à la chute d'Icare. Il n'est pas là par hasard, il est lui aussi le fruit d'une métamorphose. Celle de 
Talos, le neveu de Dédale et cousin d'Icare. Comme son oncle, c'est un inventeur de génie. Comme son cousin, il a chuté; littéralement, mais pour une autre raison. Apprenti confié à Dédale, Talos fait rapidement ses preuves. Il invente la scie, le compas et le tour de potier. Jaloux de ce talent et d'une potentielle concurrence qu'elle représentera à terme, le maître pousse son élève du haut de l'Acropole. Athéna, émue par son sort, le change en perdrix avant qu'il ne touche terre et le sauve de son cruel destin. Dédale est banni de l'Aréopage et se réfugie en Crète, chez Minos. Puis Icare est puni, quand Talos a été sauvé. La métamorphose est funeste pour le premier, salvatrice pour le second. Récompense du génie et de l'innocence contre sanction de l'artifice fragile et de l'impudence.

21 Mais c'est aussi l'indication que l'humain ne peut changer de statut sans aval divin. La technè a des limites que la puissance divine, et derrière elle la nature, ne connaît pas. L'humain n'est pas né pour voler. Dédale n'y parvient qu'en se soumettant à des règles de prudence qui obéissent elles-mêmes aux lois de la nature. Au contraire, l'oiseau est conçu pour vivre dans les airs. Pour que Talos soit sauvé de la mort, il devient animal et perd son humanité. Athéna ne lui a pas donné des ailes, ne l'a pas augmenté d'un attribut psychopompe. Elle l'a réduit à l'état de perdrix, oiseau de proie. Le génie de Talos ne suffit pas à lui ouvrir les portes de l'Olympe. Sa transformation n'est pas une apothéose, mais un moyen de poursuivre son séjour sur terre autrement et d'assister à ce qui s'apparente à une vengeance. La perdrix, terme vernaculaire désignant plusieurs espèces de petits oiseaux aux caractéristiques similaires, s'oppose à la puissance et la fierté, qualités liées aux grands rapaces, en particulier à l'aigle de Zeus. C'est une métamorphose ordinaire, qui n'a pas de continuité dans le récit mythique.

Les personnages ne sont pas les seuls éléments indiquant, dans les deux mythes étudiés, la distinction entre les espèces. Les lieux aussi, notamment le labyrinthe. La littérature grecque ancienne, qui s'embarrassait peu de détailler le décor des événements mythologiques, ne livre aucune information concernant son agencement. L'architecture du lieu se déduit donc de l'action qui s'y déroule et des protagonistes. En l'occurrence, le labyrinthe peut s'apparenter à une forêt, dense. Ses couloirs sont tels les chemins que l'on croit déceler à travers les arbres: alambiqués, trompeurs et sans assurance d'atteindre l'endroit voulu. Dans la cité, l'homme ne connaît pas de prédateur. Dans la forêt, il est une proie. Son intelligence demeure, mais elle ne compense pas ses faiblesses physiques. Il n'est plus protégé par la loi sociale, il est soumis à la loi naturelle. La loi du Minotaure. Mieux adapté à ce milieu de vie, le monstre y règne en maître, malgré lui. Au contraire, l'homme, qui est sorti de son état de nature en tant qu'animal social, n'y est plus habitué. L'être humain se distingue ainsi des animaux, comme être et comme habitant.

\section{La transgression stérile de l'hybride}

Les hybrides sont nombreux dans la mythologie grecque. Ils forment des peuples, comme les sirènes et les centaures, ou sont des êtres uniques, tels le Sphinx ou Echidna ${ }^{17}$. Comme le souligne Françoise Frontisi-Ducroux, l'hybridation dans le mythe grec permet de " penser la différence et le contact, la séparation et le mélange ${ }^{18}$. Les frontières qu'elle trace ne sont pas des murs infranchissables. Le fait que Dédale et Icare s'envolent par-dessus ceux du labyrinthe souligne la présence inévitable de passages, même lorsque cela semble impossible. Il existe toujours une issue, qu'elle soit prévue ou à créer. Mais cette issue semble être un leurre, car elle conduit au tragique et 
s'avère souvent fatale. L'une des rares exceptions est Pégase, le cheval ailé. Or, il est moins présenté comme un assemblage que comme une entité à part entière. Fils de Poséidon, il est l'instrument de Zeus, qu'il finit par rejoindre sur le Mont Olympe. Changé ensuite en constellation, il devient immortel. Il est même celui qui, avec Bellérophon, vainc la Chimère (représentation à la fois la plus aboutie et la plus invraisemblable de l'hybridité), avant de réussir son ascension, laissant son cavalier chuter du ciel, parodiant Icare.

À cause de son caractère monstrueux, l'hybride paraît condamné à un sort funeste dès sa naissance, surtout Astérion en tant que fils d'un amour improbable et illusoire. Le taureau blanc n'a pas d'attrait naturel pour l'humaine qu'est Pasiphaé. Le déguisement est nécessaire pour faire naître chez lui le désir. Parallèlement, l'amour de l'infortunée reine n'est pas de son fait, mais provoqué par un sort divin. Pour chacun, un élément externe, trompeur, prend le pas sur le comportement normal. Leur accouplement est un viol réciproque et l'enfant qui en résulte constitue une aberration, une terrifiante transgression de toutes les frontières. Par la technè, la nature a été forcée, inversant l'humain et l'animal, Éros et Thanatos. Pasiphaé l'anticipe, lorsqu'en quête du taureau à la fin du Chant de Silène, elle implore l'aide des Nymphes :

«Fermez, Nymphes, Nymphes du Dictè, fermez maintenant les clairières des bois. $»^{19}$

Mais, paradoxalement, le Minotaure est aussi celui qui rétablit la limite, en tant qu'erreur, non seulement à ne pas reproduire, mais à supprimer. Ce rôle éminent revient à Thésée, qui, sous l'œil complice d'Athéna, parvient à s'échapper du labyrinthe après avoir terrassé son gardien. Le geste a un double sens : psychique d'une part, c'est l'accomplissement initiatique d'un humain face à la part sombre et tortueuse de son inconscient, politique d'autre part, c'est un acte civilisateur face à un état de nature. Le héros tranche de son glaive le lien symbolique que représente le Minotaure entre l'humain et l'animal, entre le citoyen et le barbare, entre Athènes et les autres cités. C'est aussi grâce au fil d'Ariane, donné par Dédale, qu'il réussit à s'enfuir. La technè déjoue l'hybridité qu'elle avait contribué à créer. Elle est un outil de domestication et une démonstration de la supériorité de l'intelligence, caractéristique humaine, sur la force brute, attribut plutôt animal.

Le Minotaure est largement étudié dans son rapport à l'humanité, moins dans son rapport à l'animalité. Souvent considéré comme une forme monstrueuse de l'être, comme une part sombre des pulsions de mort, le Minotaure est aussi une aberration du point de vue animal. Dans son hybridité certes, mais aussi dans son mode de vie. Il est présenté comme un carnivore, alors que sa mâchoire de taureau, puisqu'il est majoritairement représenté comme un homme à tête de bovidé et non le contraire, devrait en faire un herbivore. Superprédateur au sommet de la chaîne alimentaire, puisque l'humain figure à son menu, et la proie d'aucune autre espèce, le Minotaure s'oppose, par son positionnement et son comportement, à son père, qui broute tranquillement l'herbe des prés. Violence contre pacifisme, voracité contre frugalité, difformité contre pureté.

Astérion est de surcroît l'exacerbation de la territorialité du taureau, qui n'autorise aucun empiétement dans son enclos, le labyrinthe. Sa nature le place ainsi en dehors de l'humanité et de l'animalité. Être à part, dans un monde à part. Animal et humain à la fois, homme à tête de taureau ou taureau à corps d'homme, il n'est ni l'un ni l'autre. C'est un entre-deux inadapté à ce monde, qui ne peut engendrer une descendance. 
Désordonnant le kosmos, il est la manifestation d'un interdit, la zoophilie, qui fonde la notion d'humanité en la détachant du reste du règne animal. Zeus, en comparaison, avait choisi de reprendre son apparence normale pour s'accoupler avec Europe, délaissant la forme du séduisant taureau ${ }^{20}$. Autrement dit, l'homme s'est permis de commettre une transgression, ce que le maître de l'olympe s'était lui-même refusé.

La mythologie illustre l'anthropocentrisme et le spécisme de la culture grecque antique. Les dieux ont l'apparence et le comportement des humains, seuls leur pouvoir et leur immortalité les distinguent. Les animaux, quant à eux, sont réduits à des êtres accessoires, dont la présence dans les récits sert de faire-valoir aux héros. Le bestiaire, qu'il soit réaliste ou fantastique, n'a pas d'existence propre et sert de projection des qualités et défauts des personnages qui peuplent les récits.

En évoquant cependant le mélange des règnes, par la métamorphose et par l'hybridité, les parcours de Pasiphaé et d'Icare sont porteurs de sens, tant pour les Anciens que pour les Modernes. Contrairement à ceux à qui il fait don de son art, Dédale emploie ce dernier dans des limites raisonnables, cherchant la juste proportion platonicienne. Il soutient l'harmonie avec la nature tandis que la passion monstrueuse le fragilise. Son comportement et sa prudence interrogent le risque d'une science sans conscience, alors que les biotechnologies se développent et que les perspectives de transhumanisme ne relèvent plus ni du mythe, ni de la science-fiction.

\section{BIBLIOGRAPHIE}

APOLLODORE, La Bibliothèque, traduction sous la direction de Paul SCHUBERT, Paris, L'Aire (Le chant du monde), 2014.

ARISTOTE, La Politique, traduction de Jules TRICOT, Paris, Vrin, 1995.

CAMILLONI Maria Teresa, « Su la leggenda di Pasifae », RCCM, nº 28, 1986, p. 53-66.

DINGREMONT François, «Jeu et enjeux de la charis dans la poésie d'Homère et d'Hésiode ", Annuaire de l'École pratique des hautes études (EPHE), Section des sciences religieuses, vol. 122, 2015, p. 43-48.

EURIPIDE, Les Crétois in Tragédies, tome VIII, $2^{\mathrm{e}}$ partie, traduction de JOUAN François et VAN LOOY Herman, Paris, Les Belles Lettres (Collection des Universités de France), 1998, p. 329-332.

FRONTISI-DUCROUX Françoise, Dédale. Mythologie de l'artisan en Grèce ancienne, nouv. éd., Paris, La Découverte (Sciences humaines et sociales, 95), 2000.

FRONTISI-DUCROUX Françoise, L'homme-cerf et la femme-araignée. Figures grecques de la métamorphose, Paris, Gallimard (Le Temps des images), 2003. 
HYGIN, Fables, traduction de Véronique MERLIER-ESPÉNEL, Nanterre, Presses universitaires de Paris Nanterre (Fictions), 2016.

HOMÈre, L'Odyssée, traduction de Philippe JAccotTeT, Paris, La Découverte (Poche/Littérature et voyages, 87), 2004.

MARCINKOWSKI Alexandre et WILGAUX Jérôme, « Automates et créatures artificielles d'Héphaïstos : entre science et fiction » dans Techniques \& Culture, $\mathrm{n}^{\circ}$ 43-44, 2004, p. 163-190. [URL : http:// tc.revues.org/1164] ovide, L'art d'aimer, traduction de Henri BORNECQUE, Paris, Librio (Librio Philosophie), 2018. OVIDE, Les Métamorphoses, traduction nouvelle de Joseph CHAMONARD, Paris, Garnier frère, 1936, 2 vol.

PLATON, Ménon, traduction de Monique CANTO-SPERBER, Paris, Flammarion, (Garnier Flammarion/ Philosophie), 1999.

PLATON, Phèdre, Euvres, tome VI, traduction de Victor cousin, Paris, Rey et Belhatte, 1849, p. 1-134; [URL : http://remacle.org/bloodwolf/philosophes/platon/cousin/phedre.htm] VIRGILE, Les Bucoliques, Euvres, traduction de Sainte-Beuve, nouvelle éd., Paris, Garnier frères, 1859 , p. 61-112.

\section{NOTES}

1. Apollodore, La Bibliothèque, III, 1.3 et 1.4. Dans les fables d'Hygin, la divinité offensée n'est pas Poséidon mais Aphrodite.

2. Dans certaines versions, la vengeance de Minos est liée au seul fait qu'il apprend que Dédale a aidé non pas Ariane mais Pasiphaé.

3. Platon, Ménon, 97d et 97e.

4. Aristote, La Politique, p. 34, I, 4, 1253-1254.

5. F. Frontisi-Ducroux, Dédale. Mythologie de l'artisan en Grèce ancienne, p. 94.

6. «Anthropologie historique et spécificité grecque. Entretien avec Jean-Pierre Vernant », L'Âne, vol. 29, 1987, p. 25-28.

7. Homère, L'Odyssée, X, 234-236.

8. Voir à ce sujet : A. Marcinkowski et J. Wilgaux, « Automates et créatures artificielles d'Héphaïstos : entre science et fiction », p. 170-171.

9. Le mythe d'Iphis montre cette limite : jeune crétoise qui voudrait être un homme, elle estime que c'est hors de portée de l'art de Dédale et est finalement exaucée par la déesse Isis (Ovide, Les Métamorphoses, IX,674-797).

10. Ovide, L'art d'aimer, VIII, 210.

11. Ovide, Les Métamorphoses, VIII, 210.

12. Dans Les Crétois d'Euripide, Pasiphaé juge d'ailleurs Minos responsable de son mal.

13. M. T. Camilloni, « Su la leggenda di Pasifae », p. 60.

14. Voir sur le sujet: F. Dingremont, «Jeu et enjeux de la charis dans la poésie d'Homère et d'Hésiode », p. 43-48.

15. Platon, Phèdre, 246d, p. 49. 
16. Ovide, Les Métamorphoses, II, 836-875.

17. Il convient de noter que la part humaine est le plus souvent féminine, soulignant le danger que représente la femme dans la mythologie et sa position dans la cité.

18. F. Frontisi-Ducroux, L'homme-cerf et la femme-araignée. Figures grecques de la métamorphose, p. 53.

19. Virgile, Les Bucoliques, VI, 55-56.

20. Europe enfanta Minos avant d'être donnée en épouse au roi de Crète Astérion, le grand-père du Minotaure, auquel il donna son nom, sans qu'il n'y ait de lien de sang entre les deux. Cette famille est donc placée sous le signe du taureau qui intervient jusque dans sa généalogie.

\section{RÉSUMÉS}

L'art de Dédale donne un corps de génisse à Pasiphaé et des ailes à Icare. L'animalité est un moyen librement choisi, grâce à la mètis et la technè, et non une fin subie émanant d'une divinité. Ce mode de création permet à chacun d'entreprendre un projet inaccessible sous sa forme initiale : pour l'une, aimer un taureau, pour l'autre, s'évader du labyrinthe. La condition humaine est élargie, l'interdit brisé. La transformation, momentanée, n'est ni illusoire, ni réelle, mais un entre-deux, transcendant nature et culture, perçu comme condamnable. Pasiphaé, reine rendue à l'état sauvage, engendre le Minotaure, monstre barbare tué par un Thésée civilisateur. Icare, homme augmenté d'un attribut divin, chute par imprudence ou impudence, sans obtenir la même clémence que son cousin Talos, changé en oiseau par Athéna. Les mythes soulignent donc la séparation, verticale, des règnes animal, humain et divin, tout en entrouvrant un passage, risqué, de l'un à l'autre.

\section{AUTEUR}

\section{CYRIL MARÉ}

Doctorant en études psychanalytiques, université Paul-Valéry - Montpellier III 


\title{
La « sirène » d'Orient en Occident
} comme exemple de la sélection culturelle des hybrides féminins en Méditerranée orientalisante ( $\mathrm{VIII}^{\mathrm{e}}$ $\mathrm{VI}^{\mathrm{e}}$ siècle av. J.-C.)

\author{
Christian Mazet
}

1 L'hybride, considéré comme une composition imaginaire formée par la combinaison ou la fusion d'éléments de diverses espèces connues, humaine, animales ou végétales, constitue une création de l'esprit. En tant qu'aberration de l'ordre naturel, il outrepasse les règles de la taxonomie des espèces tout en témoignant d'un processus créatif de "bricolage ", associé dans les sociétés anciennes à une " pensée mythique ", tel que le définissait l'anthropologue Claude Lévi-Strauss en 1962 dans son essai La pensée sauvage. Une exceptionnelle variété de ces créatures fantastiques peuple les écrits et les représentations de l'Antiquité. En Méditerranée, au cours des $\mathrm{VIII}^{\mathrm{e}}, \mathrm{VII}^{\mathrm{e}}$ et $\mathrm{VI}^{\mathrm{e}}$ siècles avant notre ère, un processus de sélection et de recréation de l'image de l'hybride est attesté dans différentes aires culturelles qui sont interconnectées, en particulier au sein des cultures de la Grèce ancienne, de la péninsule italique et de la péninsule ibérique. Ce processus se situe à un moment particulier de l'histoire méditerranéenne où les contacts, les échanges et les influences inter et transculturelles entre l'Orient et l'Occident se sont exercés avec une grande intensité. De leur foyer oriental, lui-même multiple, puis égéen, les figures fantastiques de l'homme et de la femme ailée, du Minotaure, d'Achéloos, de Typhon, du centaure, de la gorgone, de la sphinx ou de la sirène, parmi les créatures mi-humaines et mi-animales les plus représentées, sont diffusées et réinventées en suivant majoritairement les routes commerciales et «coloniales » méditerranéennes, des premières expériences phéniciennes et grecques en Occident aux multiples mouvements de biens et de personnes, notamment d'artisans. Elles caractérisent ainsi un processus d'appropriation et de réinterprétation à intensité variable, tant artistique qu'idéologique, que les historiens de l'art et les 
archéologues ont nommé, depuis la fin du XIX ${ }^{\mathrm{e}}$ siècle, le "phénomène orientalisant " $^{1}$. Les hybrides féminins constituent une catégorie spécifique de ces êtres hybrides à michemin entre l'humain et l'animal. La femme ailée, la gorgone, la sphinx et la sirène comptent parmi les images les plus diffusées, tandis que d'autres iconographies, plus originales et plus rares, sont attestées comme la gorgone-centaure, la femme-abeille ou la femme-poisson. En les replaçant dans leur contexte de création et de réception, il convient d'étudier leur diffusion, en retraçant leurs origines iconographiques et en mettant en lumière leurs particularités au sein de différentes cultures, puis d'identifier leur signification en se fondant à la fois sur l'étude de l'image elle-même, en les situant au sein $\mathrm{du}$ répertoire dont elles font partie, enfin en analysant leur contexte archéologique. L'étude non exhaustive de quelques représentations grecques et étrusco-italiques de la sirène, ou plutôt de l'oiseau anthropocéphale, être hybride composé d'un corps d'oiseau et d'une tête humaine, permet d'illustrer cette démarche par un cas concret de diffusion iconographique ${ }^{2}$.

\section{De la Sirène homérique à l'oiseau anthropocéphale chtonien}

2 Dans la Grèce du vII ${ }^{e}$ siècle av. J.-C., la cité de Corinthe (Péloponnèse), la Grèce de l'Est, l'Attique et les Cyclades jouèrent un rôle prépondérant dans la diffusion des différents types d'oiseaux anthropocéphales. L'image se retrouve également dans la péninsule italique, probablement introduite par le biais d'installations d'artisans grecs au cours des entreprises coloniales en Occident, ainsi que dans la péninsule ibérique, où toutefois les images d'oiseaux à tête de femme semblent être directement inspirées des représentations proche-orientales sans nécessairement être dépendantes d'une influence grecque ${ }^{3}$.

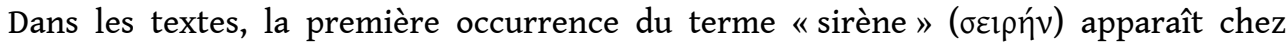
Homère dans les aventures d'Ulysse ${ }^{4}$. Homère ne donne aucune description de l'apparence de cette créature: il parle seulement de deux ou plusieurs sirènes, en employant le cas du duel. Au viI ${ }^{\mathrm{e}}$ siècle, dans l'iconographie grecque et étrusco-italique, aucune inscription ne permet d'associer les premières images d'oiseaux anthropocéphales avec ce terme homérique. Il faut attendre le $\mathrm{vl}^{\mathrm{e}}$ siècle pour que la première mention du terme "sirène" afin de désigner le motif apparaisse sur la céramique attique et pour que l'épisode bien connu du navire d'Ulysse et des deux sirènes sur leur rocher soit représenté sur la céramique de la cité de Corinthe. Un aryballe du Corinthien Moyen, conservé au Museum of Fine Arts de Boston représente sur sa panse l'épisode du passage du navire d'Ulysse près du rocher des Sirènes (fig. 1a et fig. 1b) ${ }^{5}$. Le vaisseau d'Ulysse est représenté, avec cinq de ses compagnons ramant dans le sens inverse de la proue du navire en forme de tête de sanglier, ainsi qu'Ulysse casqué, attaché au mât, attaqué par deux grands oiseaux de proie. La scène est expressive, on perçoit même le mouvement des rames dans l'eau, avec les vagues qui grandissent au fur et à mesure de l'effort engagé dans la fuite. Dans une direction opposée à celle de ses compagnons d'infortune, Ulysse est tourné vers le rocher des Sirènes où se tiennent, conformément au mythe homérique, les deux créatures ouvrant leur bouche pour faire entendre leur chant mélodieux et envoûtant. Ces dernières sont accompagnées d'une figure féminine assise, dont l'identification est incertaine. En suivant une hypothèse généralement non retenue de John Pollard, il serait possible d'y 
voir la magicienne Circé, dont la présence serait corroborée, à droite de la composition, par la représentation schématique de son palais ${ }^{6}$. Ainsi, le peintre exerce son talent de narrateur en recréant, peut-être à partir de deux épisodes différents de l'Odyssée, mais qui se suivent, une même scène, où lors de l'épisode du passage du rocher des Sirènes, l'épisode de Circé et de l'aide qu'elle apporte à Ulysse est mis en abyme : chez Homère, c'est Circé qui parle des Sirènes à Ulysse, et qui l'aide à échapper au sort terrible qui lui était destiné, en montant le stratagème bien connu qui consiste à boucher les oreilles de ses compagnons avec de la cire et à se faire attacher au mât du bateau.

Fig. 1. - a : Aryballe globulaire corinthien. Corinthien Moyen, vers 600-580 av. J.-C. H. 10, 2 cm, Diam. 9,5 cm. Boston, Museum of Fine Arts, inv. 01.8100.

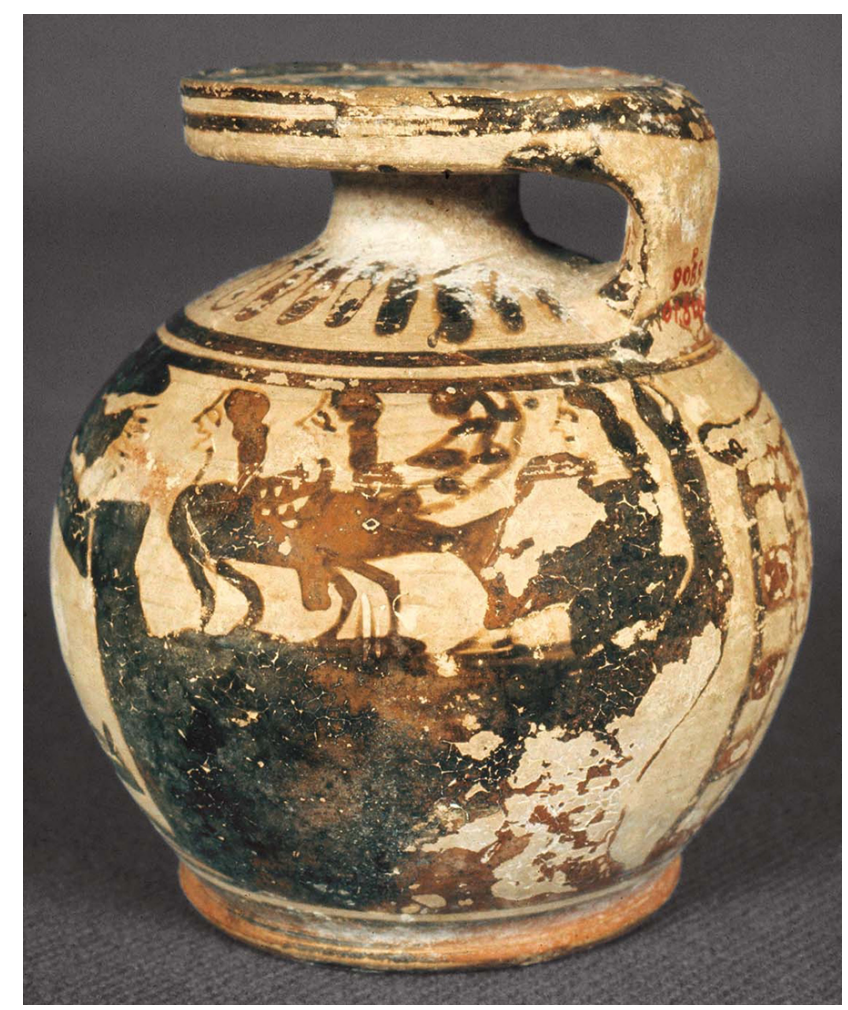

(c) Boston, Museum of Fine Arts.

Fig. 1. - b : L'épisode du passage du navire d'Ulysse près du rocher des Sirènes.

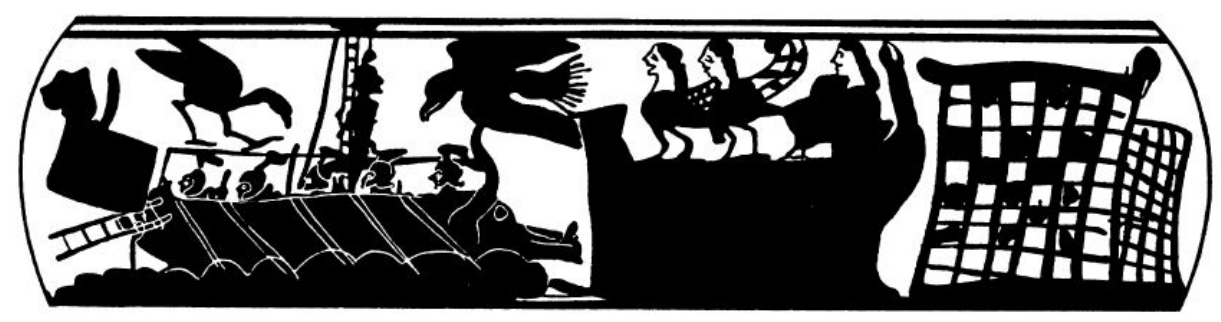

Dessin d'après Pollard 1949

4 À l'époque orientalisante, les premières images d'un oiseau anthropocéphale sont représentées pour la plupart isolées, sans contexte narratif, et ne correspondent pas au caractère féminin des Sirènes homériques, car certaines d'entre elles, représentées barbues, sont dites masculines. À titre d'exemple, sur une œnochoé rhodienne 
découverte à Camiros, conservée au British Museum et datée du début du vil ${ }^{\mathrm{e}}$ siècle, deux de ces oiseaux dotés de barbes figurent sur la panse ${ }^{7}$. Un fragment protoattique souvent oublié des études sur le sujet, trouvé sur l'Agora d'Athènes et récemment republié par Giulia Rocco, associe l'image de l'oiseau androcéphale barbu et une inscription sur laquelle il est écrit en caractère sinistroverse « Nyktopaidias ». Traduite par «fils ou filles de la Nuit", elle pourrait être une référence à la cosmogonie d'Hésiode, indiquant ainsi une relation entre ces premiers oiseaux anthropocéphales et les divinités chtoniennes (fig. 2) ${ }^{8}$. En effet, située en contexte hésiodique, cette appellation désigne la descendance de Nyx, la Nuit personnifiée (Théogonie, V. 115-153 : la Cosmogonie, id., V. 211-232: la descendance de la Nuit), l'une de ces anciennes divinités issues du Chaos primordial et qui renvoient au monde souterrain, en opposition aux divinités célestes, dites ouraniennes9. C'est d'ailleurs cet aspect chtonien qui permet à Giulia Rocco de répondre à une interrogation jusqu'alors laissée en suspens, celle du passage, au terme de l'époque orientalisante, du masculin au féminin. Au cours de l'évolution de l'image de la sirène, la barbe tend en effet à disparaître des représentations et l'on ne trouve plus que des images féminines à la fin $\mathrm{du} \mathrm{VI} \mathrm{I}^{\mathrm{e}}$ siècle. En s'appuyant sur une analyse minutieuse de quelques cas d'études, Giulia Rocco a su démontrer de manière convaincante qu'en parallèle à leur agrégation progressive au mythe homérique, ces créatures ont été associées aux divinités féminines de l'au-delà en Grèce ancienne, comme Artémis, Perséphone, Némésis ou Héra.

Fig. 2. - Fragment de cratère protoattique, élève du Peintre de l'Amphore du Cinosarges, vers 670-660 av. J.-C. Trouvé dans l'Agora d'Athènes. Athènes, musée de l'Agora, inv. p. 13323.

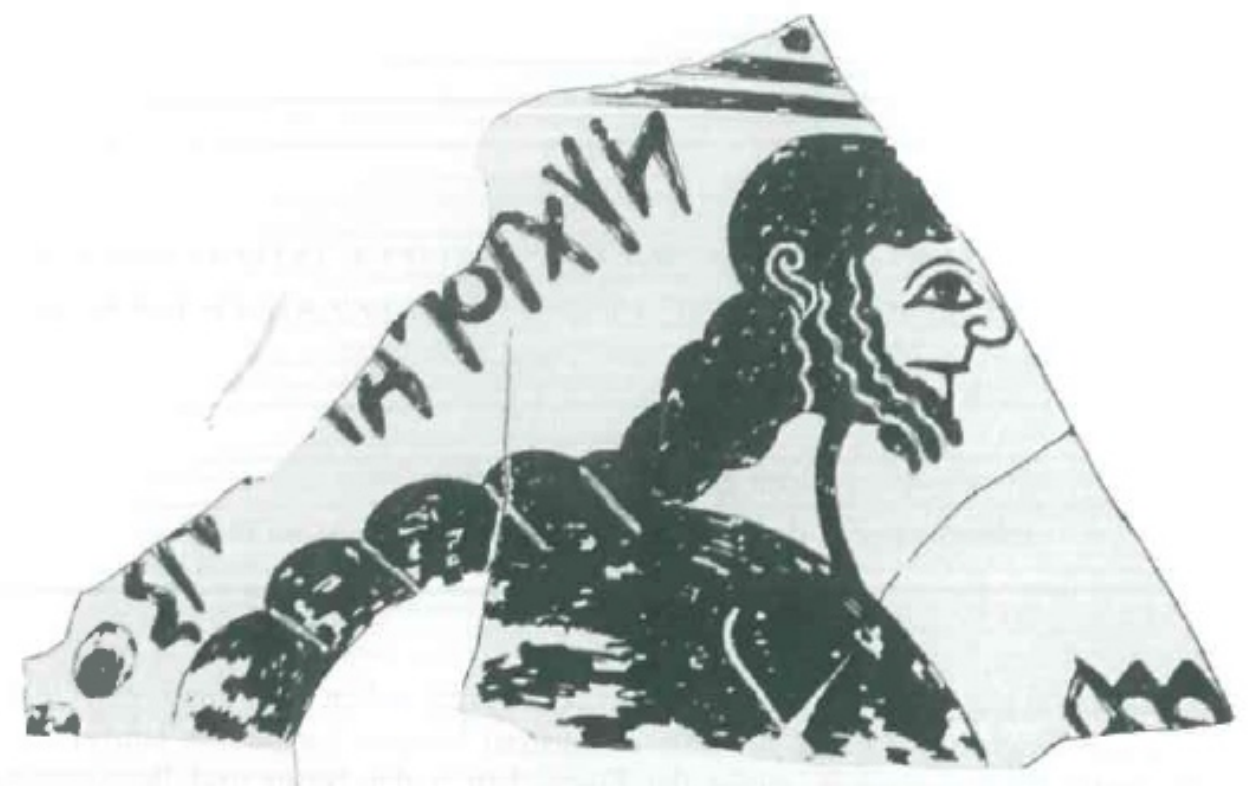

D’après Rocco G. 2014, p. 90, fig. 1

\section{Origines orientales et antécédents égéens}

5 L'ambivalence de l'image entre masculin et féminin, également fréquente dans la céramique corinthienne, demeure une question généralement non résolue, mais elle 
peut être expliquée d'un point de vue iconographique. Dans ces premières représentations, la présence de la barbe pourrait être due à l'influence d'un de leurs modèles iconographiques, à savoir l'ombre ou le bâ égyptiens, représentés sous la forme d'oiseaux à tête humaine avec ou sans barbe, et censés constituer les formes de l'esprit du défunt qui survivent après la mort. La présence de la barbe n'induit pas forcément une distinction sexuelle puisqu'au Proche-Orient et en Grèce, la barbe est aussi un attribut des démons féminins, comme Lamasthu, la sphinx ou la gorgone ${ }^{10}$. L'image de l'oiseau à tête humaine a aussi été associée à un couple de démons féminins égyptiens liés à l'au-delà, à la fois médiatrices et destructrices à l'instar des Harpies, ces autres femmes ailées et maléfiques dont la tradition littéraire remonte à Homère et à Hésiode ${ }^{11}$.

6 L'étude de l'origine des modèles iconographiques a suscité un débat académique qui a duré plus d'un siècle, opposant les partisans de l'influence égyptienne à ceux de l'influence proche-orientale. Dans un article récapitulatif, Christine Walter notait à juste titre que les antécédents égéens de l'image, minoens et mycéniens, restaient à explorer ${ }^{12}$. Les récentes publications synthétiques sur la glyptique égéenne permettent de démontrer que le concept de l'hybridité femme-oiseau existait dans le répertoire égéen de l'âge du bronze, mais ces attestations ne correspondent pas aux hybrides méditerranéens des $\mathrm{VIII}^{\mathrm{e}}$-VII ${ }^{\mathrm{e}}$ siècles car elles présentent généralement un corps féminin ailé et une tête d'oiseau ou de femme ${ }^{13}$. À la lumière de ces nouvelles données, on peut avancer l'hypothèse que l'image orientalisante tire son origine d'une fusion entre des éléments iconographiques de la tradition égyptienne, qui avaient déjà été assimilés au Proche-Orient (principalement en Assyrie et au Levant) dans certaines figures de monstres et de démons, et que son introduction était favorisée par une tradition égéenne préexistante. Un ivoire syrien de Nimrud, daté du viII ${ }^{\mathrm{e}}$ siècle, représente ce type d'oiseau anthropocéphale au caractère démoniaque, associé à la maîtrise de deux rapaces qui dévorent une gazelle (fig. 3$)^{14}$ : il semble constituer, avec d'autres images attestées sur la glyptique assyrienne et babylonienne des $\mathrm{IX}^{\mathrm{e}}$-VII ${ }^{\mathrm{e}}$ siècle ${ }^{15}$, l'antécédent direct des oiseaux anthropocéphales orientalisants, notamment corinthiens. Dès l'âge du bronze puis aux $\mathrm{IX}^{\mathrm{e}}$ et $\mathrm{VIII}^{\mathrm{e}}$ siècles av.J.-C., les représentations levantines et anatoliennes ont aussi influencé les artisans méditerranéens : pour preuve, l'hommeoiseau-scorpion nord-syrien de Tell Halaf ${ }^{16}$, les tridacnes gravés de production syrolevantine ${ }^{17}$ ou encore les appliques de chaudrons nord-syriennes (les Sirenenattaschen) qui dérivent de modèles ourartéens et assyriens, connues en Grèce à la fois par des importations et des imitations, majoritairement à Olympie ${ }^{18}$. C'est ce type oriental qui est diffusé à Rhodes dans l'orfèvrerie orientalisante du dernier quart du $\mathrm{VII}^{\mathrm{e}}$ siècle $^{19}$, dans de rares images protocorinthiennes et laconiennes ${ }^{20}$, mais également jusqu'en Méditerranée occidentale, probablement par des artisans grecs. 
Fig. 3. - Élément de mobilier en ivoire. Production nord-syrienne, fin VIII ${ }^{\mathrm{e}}$ siècle av. J.-C. De Nimrud, Palais Nord-Ouest. Bagdad, Iraq Museum, inv. 79225-7ND.21.

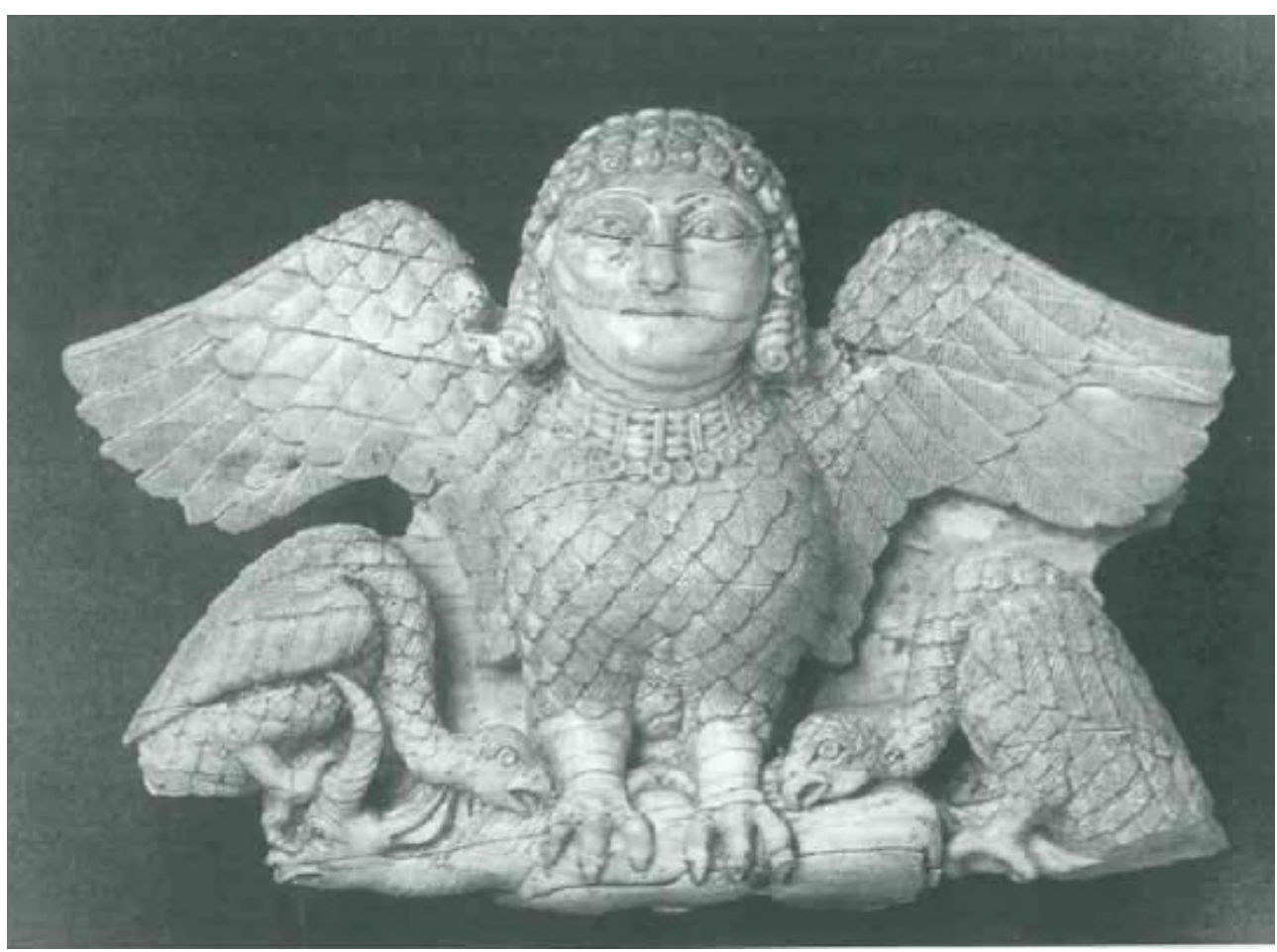

D’après Caubet 2014, p. 164, fig. 3.55.

Fig. 4. - Fragment de cratère tardo-géometrique, dernier tiers VIII siécle av. J.-C. De Pithécusses (Ischia), localité Mazzola (Lacco Ameno).
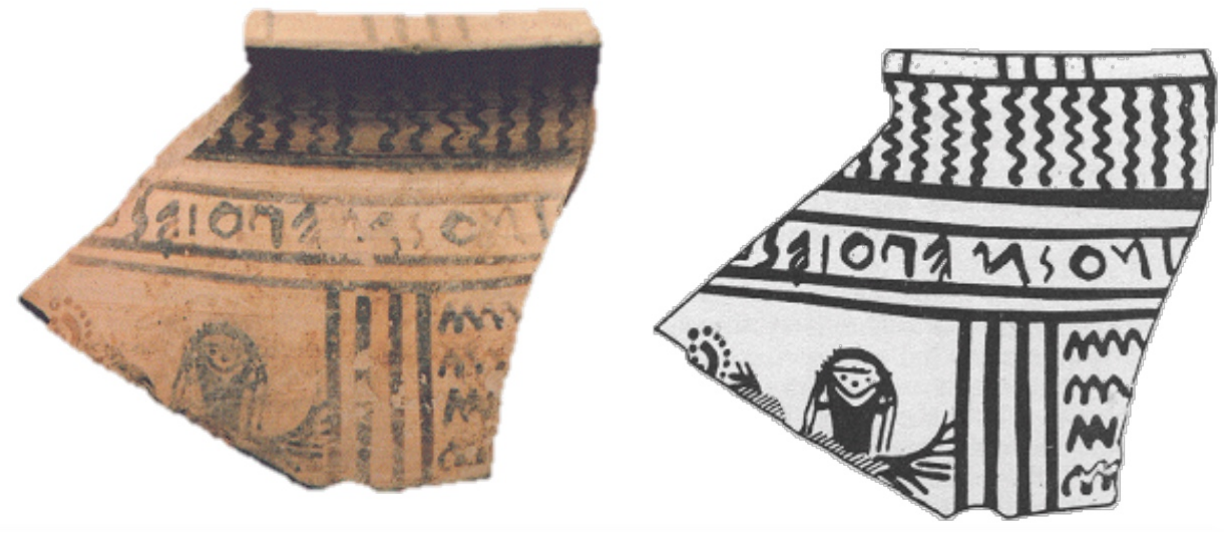

D’après Denoyelle, lozzo 2009.

\section{Sur quelques « sirènes » d'Occident : les cas de Pithécusses et Cerveteri}

Dans le golfe de Naples, le motif de l'oiseau androcéphale est représenté dès le troisième tiers du viII siècle av. J.-C. sur un fragment de cratère découvert à Pithécusses, sur l'île d'Ischia (fig. 4) 4) $^{21}$ Le cratère de Pithécusses, d'ascendance eubéenne mais de production locale, est célèbre pour la signature en alphabet eubéen d'un 
artisan grec qu'il porte, peinte en sinistroverse sous la lèvre du vase: «[...] INO $\Sigma$ M'EПOIELE », c'est-à-dire « [...] inos m'a fait ». Dans une métope sous l'inscription, on distingue une figure ailée vue de face, caractérisée par ses deux ailes déployées et un visage à la barbe quadrangulaire, qui fait écho aux attaches de chaudrons prochesorientales et grecques. L'identification de la figure varie entre la sphinx et la sirène, mais le rapprochement iconographique avec les attaches de chaudrons favorise la deuxième solution. En resituant le fragment au sein du corpus des productions contemporaines de Pithécusses, comme le fameux cratère dit du «Naufrage de Pithécusses $»^{22}$, l'image pourrait se comprendre dans un contexte iconographique aujourd'hui perdu qui ferait écho aux traversées périlleuses liées à l'entreprise coloniale. Faut-il alors y voir la plus ancienne représentation du mythe d'Ulysse et des Sirènes $?^{23}$ Ce courant d'influences est ensuite perceptible dans d'autres images d'oiseaux anthropocéphales de la première moitié du VII siècle, par exemple sur deux bandeaux funéraires provenant de Cumes (fig. 5) et Palestrina ${ }^{24}$. La position des ailes en vue faciale et la queue constituée de plumes verticales et parallèles rappellent les attaches de chaudrons, comme pour l'image du cratère fragmentaire de Pithécusses, mais les créatures ne sont plus barbues. En Étrurie, ce type est également attesté sur les ivoires orientalisants de Palestrina et Quinto Fiorentino ${ }^{25}$ ainsi que dans la céramique en white-on-red.

Fig. 5. - Plaque funéraire. Production de Pithécusses ou Tarquinia, première moitié du vile siècle av. J.-C. L. 17,5 cm, De Cumes, collection Guilhou (Vente Drouot 1905-1906).

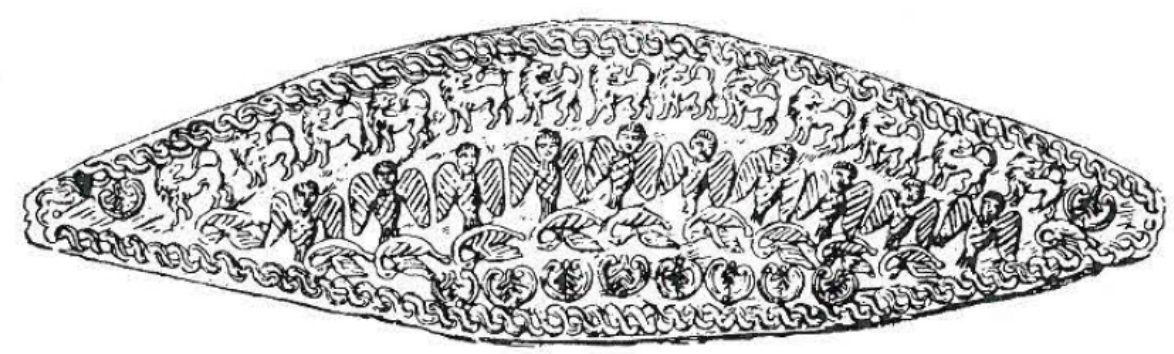


Fig. 6. - Amphore en white-on-red du Peintre de la Sirène ourartéenne (Production de la cité de Cerveteri), vers 630 av. J.-C. De Cerveteri, nécropole de la Banditaccia, tombe 17 . $\mathrm{Ht} .56 \mathrm{~cm} \emptyset \mathrm{col}$ 15,5. Milan, Civiche raccolte Archeologiche, inv. A17786.
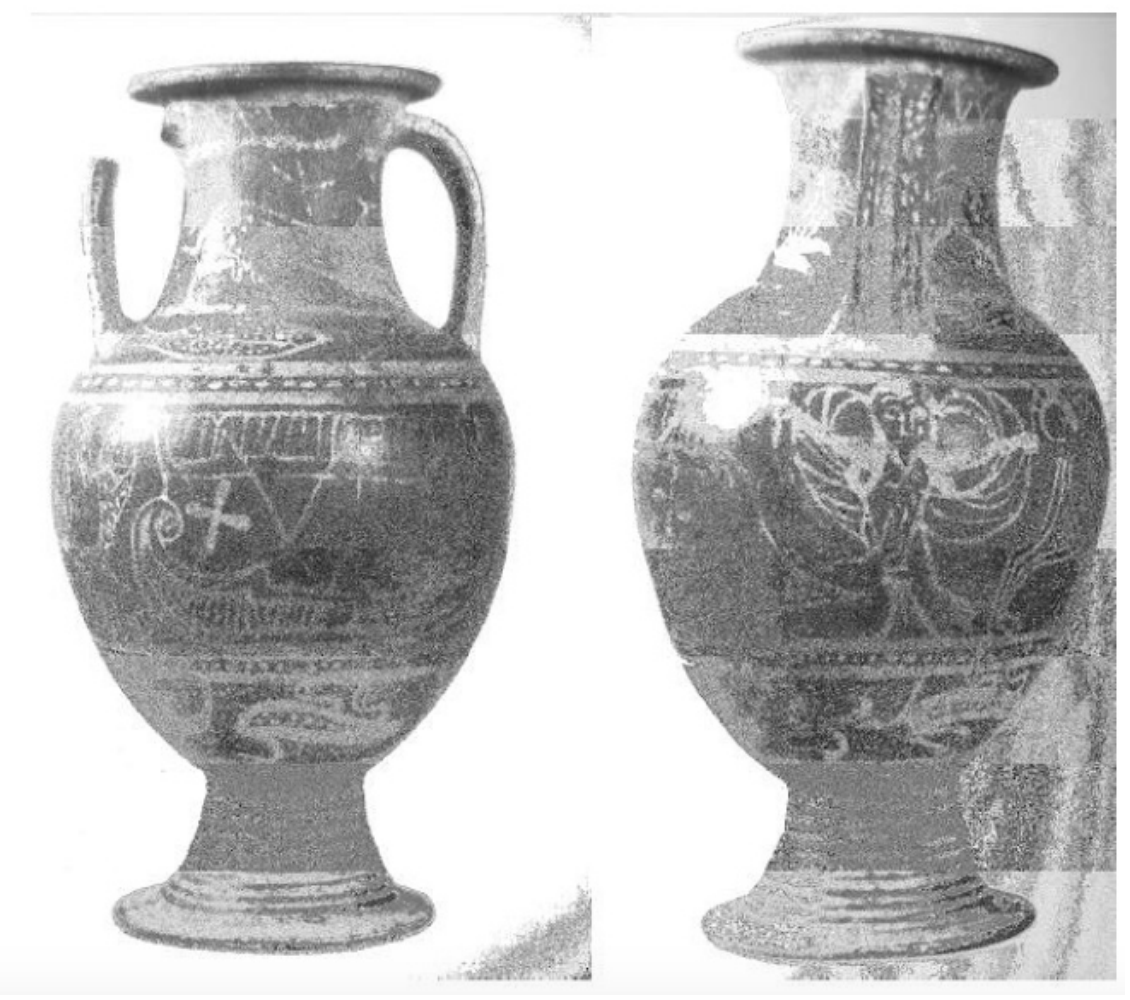

D'après Martelli 1987, fig. 17-18.

Fig. 7. - Kylix du Peintre des Hirondelles (Production de la cité de Vulci), vers 630-600 av. J.- C. De Vulci. Rome, Villa Giulia, inv. 65455.

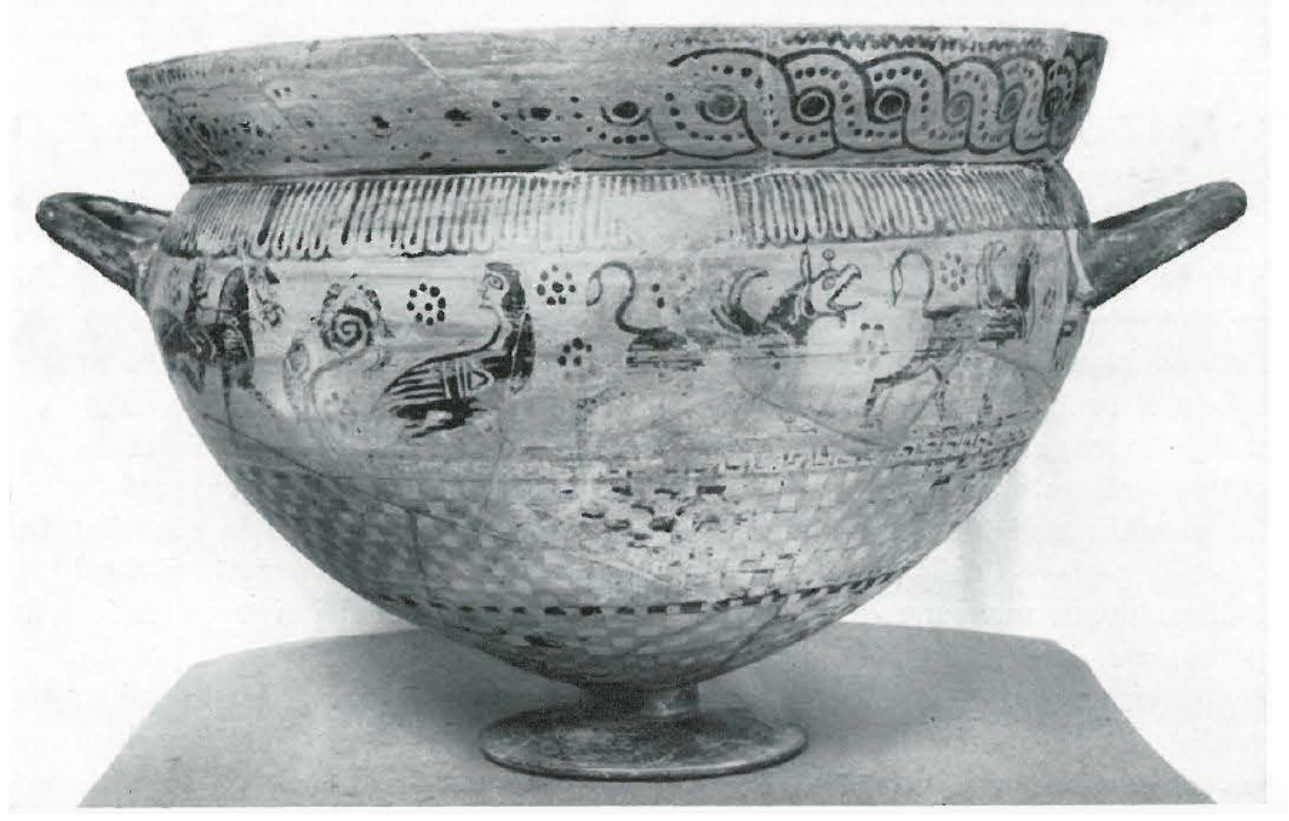

D’après Giuliano 1963 
Dans ce dernier domaine, la « sirène » peinte sur une amphore en white-on-red, datée du troisième quart du $\mathrm{VII}^{\mathrm{e}}$ siècle et provenant de la nécropole de la Banditaccia à Cerveteri, est accompagnée sur le vase d'un cheval ailé, d'un lion ainsi que d'un navire et de poissons (fig. 6 ${ }^{26}$. Ces deux derniers éléments marins ont conduit à penser à une intention narrative visant à illustrer l'épisode bien connu de l'odyssée ${ }^{27}$. En effet, certaines représentations isolées d'oiseaux à tête humaine évoquent le thème homérique par associations d'images génériques ou descriptives au sein de leur contexte figuratif, dans lequel la frontière avec le narratif est tangible. Ces images, que nous pourrions qualifier de polysémiques, sont alors autant susceptibles de véhiculer une signification mythologique originelle que d'être resémantisées en fonctions de traditions, de sélections ou d'interprétations propres aux cultures qui les utilisent. Dans le cas de la scène peinte sur l'amphore de Milan, les citations marines ne semblent effectivement pas anodines, appelant à un imaginaire visuel qui possède ses propres modes de fonctionnement, indépendants de ceux de la littérature homérique. Elles rendraient compte du danger représenté par l'image de la sirène en un "système évocateur des dangers de la mer ", défini par les études de Bruno d'Agostino et Luca Cerchiai $^{28}$, qui projetterait la scène dans un contexte odysséen. Cependant, certains chercheurs ont, encore récemment, remis en cause cette interprétation en faisant remarquer que le lion et le cheval ailé, exclus du récit homérique, reléguaient ces thèmes marins au rang de simples citations ${ }^{29}$. Elles se comprennent pourtant par le contexte funéraire du vase et par un réseau d'images, un système visuel qui associe les représentations du lion, du cheval ailé et de l'oiseau anthropocéphale, qui sont représentés dans la même frise sur la panse, à une conception plus vaste du thème marin dans l'imaginaire étrusque. L'image du lion pourrait aussi constituer une évocation implicite du défunt ${ }^{30}$. La " sirène ", qui ferait alors la jonction entre le navire et le défunt personnifié, devrait être comprise comme un intercesseur facilitant le passage de la vie à la mort. Si l'on admet cette hypothèse, l'intention narrative et la référence homérique ne doivent pas être pour autant réfutées : dans l'Odyssée c'est la rencontre avec les Sirènes qui constitue une étape fondamentale dans le parcours héroïque puisqu'en résistant à leur chant et en rentrant ainsi dans la mémoire épique, Ulysse acquiert aux yeux des hommes l'immortalité du héros.

\section{De l'Ionie à Vulci : la « sirène » du Peintre des Hirondelles}

9 Pour cette période couvrant le dernier quart du vile siècle av. J.-C., l'insertion de la figure de l'oiseau anthropocéphale au sein d'un contexte à vocation narrative est attestée en Étrurie méridionale sur une grande kylix découverte à Vulci (fig. 7) ${ }^{31}$, attribuée à un artisan de la cité originaire de Grèce de l'Est mais dont l'œuvre s'est enrichie d'expériences diverses, tant cycladiques que locales: le Peintre des Hirondelles ${ }^{32}$. L'image de l'oiseau à tête humaine, non barbue, aux ailes non déployées et à la tête retournée, est unique en Étrurie. Les plus proches parallèles résident dans les images d'oiseaux du style milésien de la chèvre sauvage, et en particulier celles du Peintre de l'œnochoé Lévy et de ses successeurs ${ }^{33}$. En contexte micrasiatique, l'image de l'oiseau anthropocéphale n'est attestée qu'à de rares occasions, à la différence de la sphinx ou du griffon dont les représentations sont plus fréquentes. Elle existe sur la céramique d'Éolide, dans les productions de Chios et d'Ionie du Nord mais les types les 
plus utilisés, témoins d'une veine corinthianisante au début $\mathrm{du} \mathrm{VI}^{\mathrm{e}}$ siècle, ne correspondent pas à l'image vulcienne (fig. 8) ) $^{34}$. Deux oenochoés milésiennes découvertes à Vroulia (Rhodes) présentent un type similaire d'oiseau à tête humaine et aux ailes non déployées, mais qui ne tourne pas la tête (fig. 9) ${ }^{35}$. Cette composition si particulière est utilisée de manière presque contemporaine par les peintres du corinthien ancien ${ }^{36}$ et se retrouve aussi dans le tondo d'un plat nord-ionien, découvert à Syracuse en contexte funéraire et daté vers le début du vi ${ }^{e}$ siècle av. J.-C. ${ }^{37}$. Ces attestations constituent à ce jour les parallèles les plus probants pour l'hybride de Vulci. On peut dès lors émettre l'hypothèse que le Peintre des Hirondelles aurait créé à Vulci, à partir du répertoire connu des oiseaux à tête féminine dans sa cité (sans doute Milet) et dans sa région d'origine, mais aussi à partir, peut-être, du répertoire corinthien contemporain ${ }^{38}$, une iconographie originale de l'oiseau à tête féminine. De plus, cette image s'insère dans une scène qui fait référence à l'univers aristocratique et funéraire étrusque, témoignant de l'intégration culturelle du peintre immigré. La face principale du vase se compose, de gauche à droite, d'un cavalier se dirigeant vers la droite, d'un motif floral sous forme de volute où sont regroupées six hirondelles, ayant donné son nom au peintre, de la "sirène " à la tête retournée, enfin de deux autres animaux fantastiques se dirigeant vers la droite, un griffon et une sphinx. Par cette succession d'images, il convient de reconstituer deux parties dans la frise, séparées par l'élément végétal : celle du cavalier et celle des animaux fantastiques. La "sirène ", placée au centre de la composition et tournant la tête vers le cavalier, pourrait constituer un intercesseur. La scène de la coupe, fixant l'image sociale du défunt représenté par le cavalier, figure par excellence de la jeunesse aristocratique, pourrait être interprétée comme son dernier voyage vers l'au-delà ${ }^{39}$.

Fig. 8. - Fragment de col de dinos, production d'lonie du Nord (Smyrne ?), vers 600 av. J.-C. Du temple d'Athéna à Bayraklı.

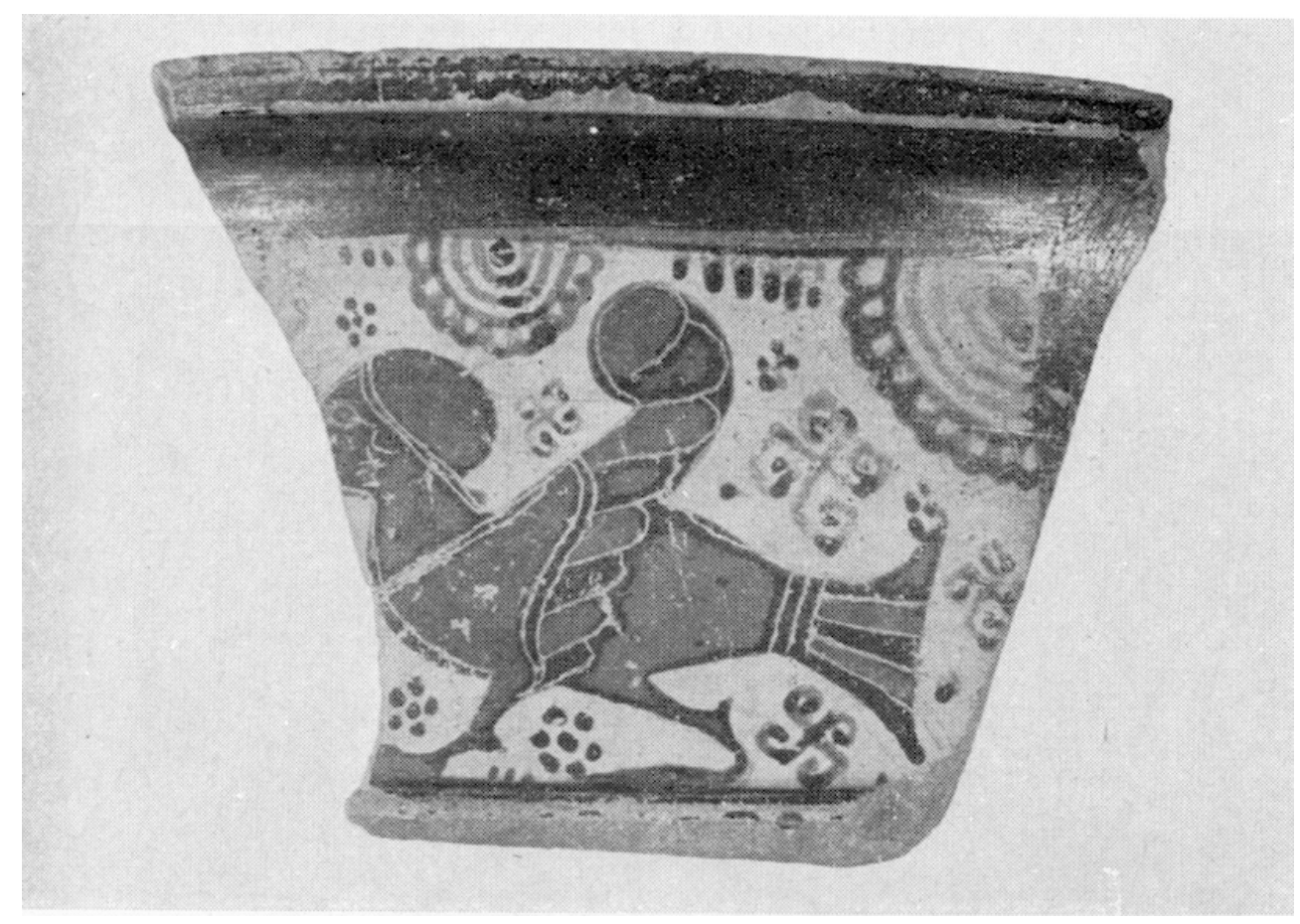

D'après Akurgal 1983, pl. 37a. 
Fig. 9. - Enochoai milésiennes, dernier tiers du VII siècle av. J.-C. De Vroulia. Londres, British Museum, inv.1867.5-8.927 (A 683) ; Leyde, Rikjmuseum van Oudheden, inv. I 1908/4.2.

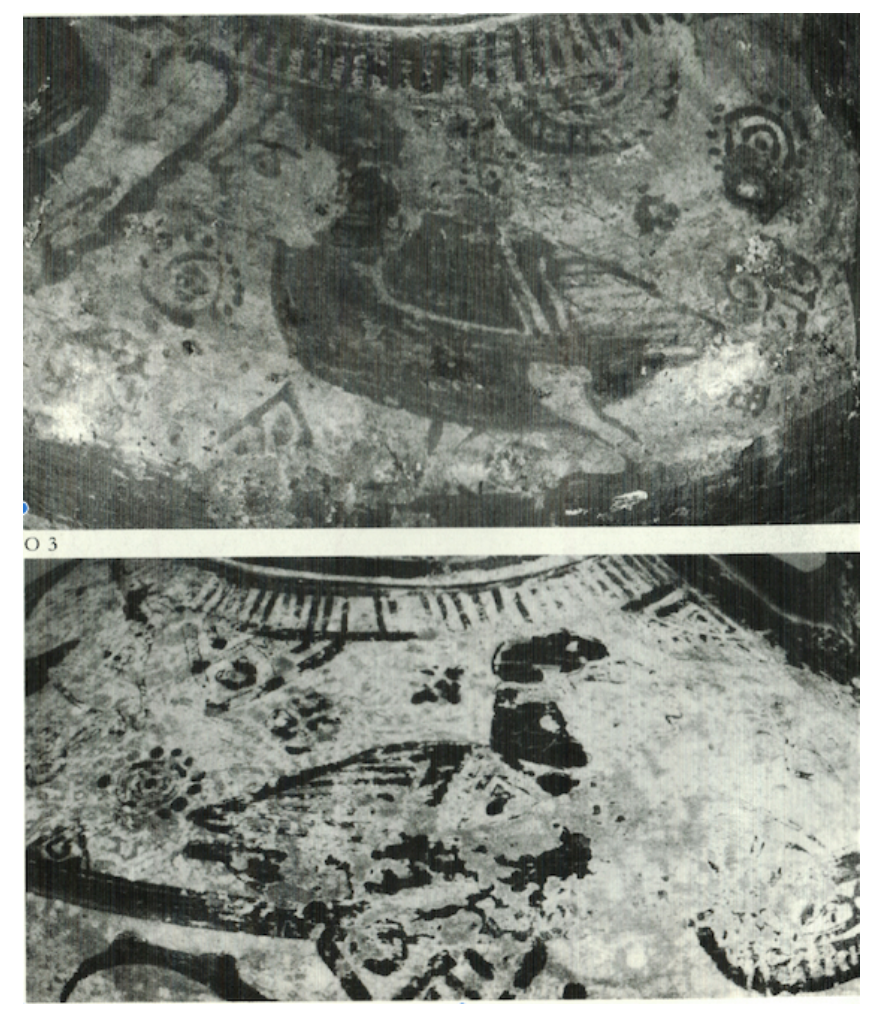

D'après Hofstetter 1990, pl. 18, 2-3.

\section{Remarques conclusives}

10 L'analyse de ces quelques exemples attestés de l'image de l'oiseau à tête humaine permet de percevoir comment une figure hybride, à l'iconographie d'inspiration égéoorientale, est réutilisée, réinventée, et peut être interprétée à la lumière de son contexte de création, de réception et d'utilisation. Si le concept de l'hybride femmeoiseau préexiste en Grèce ancienne dans l'imagerie égéenne du II millénaire, l'image orientalisante de l'oiseau anthropocéphale tire ses origines iconographiques du monde proche-oriental, en particulier de la Syrie du Nord. L'importance des réseaux de diffusions de la Méditerranée orientale et de quelques centres de l'« orientalisation » grecque (la Grèce de l'Est, Rhodes, Athènes, Corinthe, Sparte, Olympie) mérite d'être mise en valeur, au même titre que le rôle crucial joué par la mobilité des artisans eubéens, corinthiens et micrasiatiques dans la circulation du motif de la Grèce à l'Italie. En effet, la présence du type « ourartéen » de l'oiseau anthropocéphale dans le golfe de Naples, le Latium ou l'Étrurie méridionale et septentrionale illustre la diffusion d'une imagerie orientale adoptée par les artisans grecs et réinventée en Occident par des artisans immigrés ou autochtones, qui l'insèrent dans des systèmes visuels propres à leurs environnements culturels. Dans cette même optique de la réception de l'image en Occident, le cas vulcien de la "sirène » du Peintre des Hirondelles constitue une création iconographique unique, témoin du parcours personnel d'un artisan immigré de Grèce de l'Est dont la technè s'est enrichie d'expériences diverses. Dans certains cas présentés ici (les bandeaux funéraires de Cumes ou de Palestrina, l'amphore de 
Cerveteri, la coupe de Vulci) il semble bien que l'oiseau anthropocéphale, au cours de son transfert d'Orient en Occident, ait maintenu dans l'imaginaire des cultures réceptrices sa nature originelle de créature démoniaque liée au monde de l'au-delà. Néanmoins, il faut garder à l'esprit que ces images d'êtres hybrides, souvent représentées isolées à l'époque orientalisante, sont interprétables de différentes manières: dans la recherche moderne de leur sens, les propositions d'interprétation ont été nombreuses et suscitent encore bien des interrogations. Ces images de l'anormalité ont dû revêtir de nombreuses attributions, ou bien être parfois même simplement décoratives; mais on ne peut guère nier la connotation symbolique s'attachant à leur représentation - surtout lorsqu'elles font partie d'un programme figuratif complexe, d'un système visuel qu'il s'agit de déchiffrer et d'interpréter.

\section{BIBLIOGRAPHIE}

AKURGAL Ekrem, Alt-Smyrna I. Wohnschichten und Athenatempel, Ankara, Türk Tarih Kurumu Basımevi, 1983.

ARUZ Joan, LAPÉROUSE Jean-François, « Cauldrons », dans ARUZ Joan, GRAFF Sarah B. et RAKIC Yelena (éds.), Assyria to Iberia at the Dawn of the Classical Age, New York, The Metropolitan Museum of Art, 2014, p. 272-281.

ASTON Emma, Mixanthropoi: animal-human hybrid deities in Greek religion, Liège, Centre international d'Étude de la Religion Grecque Antique, (Kernos, Supplément 25), 2011.

AUBET Maria Eugenia, Los marfiles orientalizantes de Praeneste, Barcelone, Universidad de Barcelona, 1971.

BONAUDO Rafaella, «Eroi in viaggio: Odisseo dalla Grecia in Etruria », Bollettino di Archeologia on line, I, 2010, p. 15-28.

CAMPOREALE Giovannangelo, « Odysseus/Uthuze », dans LIMC VI, 1992, p. 970-983.

CAUBET Annie, « Tridacna Shell », dans ARUZ Joan, GRAFF Sarah B. et RAKIC Yelena (éds.), Assyria to

Iberia at the Dawn of the Classical Age, New York, The Metropolitan Museum of Art, 2014 p. 163-166.

CERCHIAI LuCa, «L'immaginario del mare nel mondo etrusco », dans GIANNATTASIO Bianca Maria, CANEPA Cristina et GRASSO Luisa (éds.), Aequora, pontos iam, mare... Mare, uomini e merci nel Mediterraneo antico : atti del Convegno Internazionale (Genova 9-10 dicembre 2004), Borgo S. Lorenzo, All'insegna del giglio, 2006, p. 174-181.

COLDSTREAM John Nicolas, « Some Unusual Geometric Scenes from Euboean Pithekoussai », dans BERLINGò Irène et alii (éd.), Damarato. Studi di Antichità classica offerti a Paola Pelagatti, Milan, Electa, 2000, p. 92-98.

COOK Robert Manuel, « The Swallow Painter and the Bearded Sphinx Painter », dans Archäologischer Anzeiger, 1981, p. 454-461.

COOK Robert Manuel, DUPONT Pierre, East Greek Pottery, Londres-New York, Routledge, 1998. 
CoUlié Anne, La céramique grecque aux époques géométrique et orientalisante ( $\mathrm{XI} \mathrm{e}^{e}-\mathrm{VI}{ }^{e}$ siècle av. J.-C.), Paris, Picard (La céramique grecques 1), 2013.

CROISSANT Francis, « Sociétés, styles et identités : pour une relecture archéologique du "phénomène orientalisant" ", dans ETIENNE Roland (éd.), La Méditerranée au VII siècle av. J.-C. : Essais d'analyses archéologiques, Paris, De Boccard (Travaux de la Maison René-Ginouvès 7), 2010, p. 311-368.

CROWLEY Janice L., The Iconography of Aegean Seals, Leuven-Liège, Peeters (AEGAEUM 34), 2013. CULTRERA Giuseppe, « Siracusa-Scoperte nel Giardino Spagna », dans Notizie di Scavi, 1943, p. 33-126.

DAWKINS, Richard MCGILLIVRAY, The Sanctuary of Artemis Orthia : excavated and Described by Members of the British School at Athens, 1906-1910, Londres, Macmillan and C० 1929.

D’Agostino Bruno, CERCHIAI Luca, Il Mare, la Morte, L'Amore. Gli Etruschi, i Greci e l'immagine, Rome, Donzelli, 1999.

DENOYELLE Martine, IOZzo Mario, La céramique grecque d'Italie méridionale et de Sicile. Productions coloniales et apparentées du VIII ${ }^{e}$ au III ${ }^{e}$ siècle av. J.-C., Paris, Picard (La céramique grecque 4), 2009. FREIHERRN VON OPPENHEIM Max, Der Tell Halaf. Eine neue Kultur im ältesten Mesopotamien, Leipzig, F.A. Brockhaus, 1931.

GIOVANELLI Enrico, « Esseri fantastici alle origini della glittica preromana: spunti preliminari su alcuni intagli », dans BIELLA Maria Cristina, GIOVANELLI Enrico et PEREGO Lucio Giuseppe (éds.), Il bestiario fantastico di età orientalizzante nella penisola italiana, Trento, Tangram (Aristhonotos. Quaderni 1), 2012, p. 189-206.

GIULIANO Antonio, « Un pittore a Vulci nella II metà del VII secolo a.c. », JdI, 78, 1963, p. 183-199.

GIULIANO Antonio, «Il Pittore delle Rondini », Prospettiva, 3, 1975, p. 4-8.

GIULIANO Antonio, « Ancora sul “pittore delle Rondini” ", dans BERLINGò Irene et alii (éd.), Damarato. Studi di Antichità classica offerti a Paola Pelagatti, Milan, Electa, 2000, p. 126-129.

GUZzo Pier Giovanni, Oreficerie dalla Magna Grecia. Ornamenti in oro e argento dall'Italia Meridionale tra l'VIII ed il I secolo, Tarente, la Colomba, 1993.

HERRMANN Georgina, LAIDLAW Stuart, Ivories from Nimrud (1949-1963). Fasc. 6, Ivories from the North West Palace (1845-1992), Londres, British School of Archaeology in Irak, 2009.

HOFSTETTER Eva, Sirenen im archaïschen und klassichen Griechenland, Würzburg, K. Triltsch, 1990.

HOFSTETTER Eva, « Seirenes », dans LIMC VIII, Zurich-Munich, 1997, p. 1093-1104.

HOGHART David George, Excavations at Ephesus. The archaic Artemisia, Londres, Printed by order of the Trustees, 1908.

IREN Kaan, Aiolische orientalisierende Keramik, Istanbul, Ege Yayinlari, 2003.

KAHIL Lily, « Harpyiai », dans LIMC IV, Zurich-Munich, 1988, p. 445-450.

KARAGIORGA Theodora G., Gorgeiè kephalé, Athènes, Archaiologikī etaireia, 1970.

KARDARA Chrysoula, Rodiaki aggeiographia, Athènes, Archaiologikī Etaireia, 1963.

KOPF-WENDLING Ursula, Die Darstellungen der Sirene in der griechischen Vasenmalerei des 7., 6. Und 5. Jhs. V. Chr., Fribourg, Meier Druck \& Verlag, 1989. 
KRAUSKOPF Ingrid, « Gorg, Gorgones. Katalog », dans LIMC IV, 1, 1988, p. 288-345 ; IV, 2 1988, p. 163-195.

KUNZE Emil, « Sirenen », Mitteilungen des Deustchen Archäologischen Instituts. Athenische Abteilung, 57,1932, p. 124-141.

LAFFINEUR Robert, L'orfèvrerie rhodienne orientalisante, Paris, De Boccard (Travaux et Mémoires de l'École française d'Athènes, 21), 1978.

LE MEAUX Hélène, L'iconographie orientalisante de la péninsule ibérique : questions de styles et d'échanges (VIII $-V^{e}{ }^{e}$ siècles av. J.-C.), Madrid, Casa de Velásquez (Bibliothèque de la Casa de Velázquez, 47), 2010.

LECLERCQ-MARX Jacqueline, La Sirène dans la pensée et dans l'art de l'Antiquité et du Moyen Âge. Du mythe païen au symbole chrétien, Bruxelles, Académie royale de Belgique, 1997.

LEMos Anna A., Archaic Pottery of Chios, The Decorated Styles, Oxford, Oxford University Committee for Archaeology, 1991.

LENTINI MARIA Costanza (éd.), Vasi del Wild Goat Style dalla Sicilia e dai Musei Europei, Catalogo della Mostra Gela, Museo Archeologico Regionale 27 Aprile-21 Maggio 2006, Syracuse, Lombardi, 2006. LUBTCHANSKY Natacha, Le cavalier tyrrhénien : représentations équestres dans l'Italie archaïque, Rome, École française de Rome (BEFAR 320), 2005.

MARANGOU Lila, Lakonische Elfenbein und Beinschnitzereien, Tübingen, Ernst Wasmuth, 1969.

MARTELLI Marina, La ceramica degli Etruschi : la pittura vascolare, Novara, Instituto geografico de Agostini, 1987.

MARTELl Marina, «Del Pittore di Amsterdam e di un episodio del nostos odissiaco. Ricerche di ceramografia etrusca orientalizzante », Prospettiva, 50, 1987, p. 4-14.

MEDORI Lucilla, «Il Bestiario fantastico nella white-on-red in Etruria e nell'Agro falisco », dans BIELla Maria Cristina, GIOVANELli Enrico et PEREGo Lucio Giuseppe (éds.), Il bestiario fantastico di età orientalizzante nella penisola italiana, Trento, Tangram (Aristhonotos. Quaderni 1), 2012, p. 76-116.

MICOzZI Marina, “White-on-red ”. Una produzione vascolare dell'Orientalizzante etrusco, Rome, GEI (Terra Italia 2), 1994.

MICOZZI Marina, « White-on-red. Miti greci nell'Orientalizzante etrusco », dans BENEDETTA Adembri (éd.), AEIMNESTOS. Miscellanea di studi per Mauro Cristofani, 2005, p. 256-266.

NASO Alessandro, « Nuovi dati sulla pittura funeraria di età orientalizzante in Etruria meridionale », dans MINETTI Alessandra (éd.), Pittura etrusca: problemi e prospettive, Atti del Convegno (Sarteano-Chiusi 2001), Sienne, Amministrazione provinciale di Siena, 2003, p. 13-35.

NERI Sara « Il bestiario nella ceramica italo-geometrica di età orientalizzante in Etruria Meridionale », dans BIELla Maria Cristina, GIOVANELl Enrico et PEREGo Lucio Giuseppe (éds.), Il bestiario fantastico di età orientalizzante nella penisola italiana, Trento, Tangram (Aristhonotos. Quaderni 1), 2012, p. 55-76.

PAYNE Humfry, Necrocorinthia: A study of corinthian art in the archaic period, Oxford, Clarendon press, 1931.

POLLARD John R. T., «The Boston Siren Aryballos », American Journal of Archaeology, vol. 53, $\mathrm{N}^{\circ} 4$, Oct.-Dec. 1949 , p. 357-359. 
RAMNOUX Clémence, La Nuit et les enfants de la Nuit dans la tradition grecque, Paris, Flammarion (Symboles), 1959.

Rocco Giulia, « Nyktopaidias: considerazioni sulle immagini di uccelli androcefali nell'Orientalizzante greco », Atti della Accademia Nazionale dei Lincei. Anno 2013. Rendiconti, Serie IX, vol. XXIV, Rome, 2014, p. 289-325.

SCHIERING Wolfgang, «Eine Amphora des Schwalbenmalers im Louvre », Revue Archéologique, I, 1974, p. 3-14.

STRøM Ingrid, Problems Concerning the Origin and Early Devlopment of the Etruscan Orientalizing Style, Odense, Odense University Press, 1971.

STUCKY Rolf A., " The Engraved Tridacna Shells », Dédalo (São Paulo) 10, nº 19, juin 1974, p. 1-170.

TOUCHEFEU-MEYNIER Odette, Thèmes odysséens dans l'art antique, Paris, de Boccard, 1968.

VERNANT Jean-Pierre, La mort dans les yeux. Figures de l'Autre en Grèce ancienne, Paris, Hachette, 1985.

WALTER Christine, «Sur les origines iconographiques de la Sirène en Grèce ancienne : des

hypothèses avancées depuis un siècle aux dernières découvertes ", dans ISABEL Izquierdo, LE MEAUX Hélène (éds.), Seres Híbridos. Apropiación de motivos míticos mediterràneos, Actas del Seminario, Casa De Velázquez, 7-8 Marzo 2002, Madrid, Casa de Velázquez, 2003, p. 143-163.

WALTER-KARYDI Elena, Samische Gefässe des 6. Jahrhunderts v. Chr. Landschaftsstile. Ostgriechischer Gefässe, Bonn, Kommission bei R. Habelt (Samos VI), 1973.

WEICKER Georg, Der Seelenvogel in der alten Litteratur und Kunst. Eine Mythologisch-Archaeologische Untersuchung, Leipzig, B. G. Teubner, 1902.

WINKLER-HORAČEK Lorenz, Monster in der frühgriechischen Kunst. Die Überwindung des Unfassbaren, Berlin-Boston, De Gruyter (Image \& context 4), 2015.

zouzoula Evgenia, «The fantastic creatures of Bronze age Crete », PhD thesis, Nottingham, University of Nottingham, 2007, 2 vol.

\section{NOTES}

1. Sur la notion du "phénomène orientalisant", voir en particulier Fr. Croissant, "Sociétés, styles et identités : pour une relecture archéologique du "phénomène orientalisant" ", et A.Coulié, La céramique grecque aux époques géométrique et orientalisante (XI ${ }^{e}-\mathrm{VI}^{e}$ siècle av. J.-C.), p. 105-107 (avec bibliographie).

2. Sur l'image de la Sirène en Grèce ancienne, G. Weicker, Der Seelenvögel in der alten Litteratur und Kunst ; E. Kunze « Sirenen »; O. Touchefeu-Meynier, Thèmes odysséens dans l'art antique ; U.Kopf-Wendling, Die Darstellungen der Sirene in der griechischen Vasenmalerei des 7., 6. und 5. Jhs. v. [idem] Chr. ; E. Hofstetter, Sirenen im archaïschen und klassichen Griechenland ; E. Hofstetter, "Seirenes "; J. Leclercq-Marx, La Sirène dans la pensée et dans l'art de l'Antiquité et du Moyen Âge. Du mythe païen au symbole chrétien; Ch. Walter, "Sur les origines iconographiques de la Sirène en Grèce ancienne : des hypothèses avancées depuis un siècle aux dernières découvertes "; G. Rocco, « Nyktopaidias: considerazioni sulle immagini di uccelli androcefali nell'Orientalizzante greco ». 
3. H. Le Meaux, L'iconographie orientalisante de la péninsule ibérique, p.65-67. Dans le corpus péninsulaire d'époque orientalisante, les oiseaux à têtes féminines sont surtout identifiés comme une transposition et une réélaboration de l'imagerie hathorique levantine. L'image de la « sirène » de modèle grec apparaît à proprement parler à partir de la fin du v siècle (id. p. 154).

4. Odyssée, $12.39-46 ; 12.158-160 ; 12.197-200 ; 23.326$

5. Vers 570-550 av. J.-C. MFA Boston, inv. 01.8100 : H. Payne, Necrocorinthia: a study of Corinthian art in the Archaic period, p. 321, $\mathrm{n}^{\circ} 1282$, pl. 36.5 .

6. J. R. T. Pollard, « The Boston Siren Aryballos ». Pour une autre interprétation de cet élément, identifié aux portes de l'Hadès ou aux Planktai petrai de l'Odyssée (hypothèse non retenue), voir B. D’Agostino, L. Cerchiai, Il Mare, la Morte, L'Amore. Gli Etruschi, i Greci e l'immagine, p. 53-60, 73-80.

7. G. Weicker, Der Seelenvögel in der alten Litteratur und Kunst, fig. 38. Les sirènes de l'Enochoé du British Museum sont considérées comme les plus anciennes images du monde grec avec un ivoire d'Éphèse, un sceau du sanctuaire d'Artémis Orthia de Sparte, une amphore de Théra et un fragment de situle crétoise de Praisos (Ch. Walter, "Sur les origines iconographiques de la Sirène en Grèce ancienne : des hypothèses avancées depuis un siècle aux dernières découvertes ", p. 145, fig. 3-6).

8. G. Rocco, «Nyktopaidias: considerazioni sulle immagini di uccelli androcefali nell'Orientalizzante greco ».

9. Sur la figure de la Nuit chez Hésiode, voir Cl. Ramnoux, La Nuit et les enfants de la Nuit dans la tradition grecque.

10. Sur l'image de la Gorgone, voir en particulier G. Karagiorga, Gorgeiè kephalé; J.P. Vernant, La mort dans les yeux. Figures de l'Autre en Grèce ancienne ; I. Krauskopf, « Gorg, Gorgones. Katalog ».

11. L. Kahil, « Harpyiai », p. 450.

12. Ch. Walter, «Sur les origines iconographiques de la Sirène en Grèce ancienne : des hypothèses avancées depuis un siècle aux dernières découvertes ", p. 150-151 (avec bibliographie).

13. Voir en dernier lieu E. Zouzoula, "The fantastic creatures of Bronze age Crete ", vol. 1, p. 169-177, vol. 2, no 572-618, p. 149-158 ; J. L. Crowley, The Iconography of Aegean Seals, p. 52 (Thème 11), 168 (E77a, Potnia ailée), 231 (E 203, femme-oiseau).

14. Bagdad, Irak Museum, inv. IM 79523. De Nimrud, Palais Nord-Ouest, aile résidentielle : G. Herrmann, S. Laidlaw, Ivories from Nimrud (1949-1963). Fasc. 6, Ivories from the North West Palace (1845-1992), p. 191, n 240, pl. 67.

15. L. Winkler-Horaček, Monster in der frühgriechischen Kunst, p. 187-188, fig. 138-139.

16. M. Freiherrn von Oppenheim, Der Tell Halaf. Eine neue Kultur im ältesten Mesopotamien, p. 153 ; Ch. Walter, «Sur les origines iconographiques de la Sirène en Grèce ancienne : des hypothèses avancées depuis un siècle aux dernières découvertes ", p. 162, fig. 14.

17. Voir R. Stucky, "The Engraved Tridacna Shells", et en dernier lieu A. Caubet, « Tridacna Shell » (avec bibliographie).

18. En dernier lieu, voir J. Aruz, J.-F. de Lapérouse, « Cauldrons » (avec bibliographie).

19. Musée National de Copenhague, inv. 861-R. Laffineur, L'orfêvrerie rhodienne orientalisante, $\mathrm{n}^{\circ} 193, \mathrm{p} .123-125$. 
20. Oenochoé protocorinthienne à fond plat de Perachora (L. Winkler-Horaček, Monster in der frühgriechischen Kunst, p. 184, fig. 135) ; peigne laconien en ivoire du sanctuaire d'Artémis Orthia à Sparte (Athènes, Musée archéologique national, inv. 13328. R. M. Dawkins, The Sanctuary of Artemis Orthia, Excavated and Described by Members of the British School at Athens 1906-1910, p. 223, pl. CXXX, n 3 ; L. Marangou, Lakonische Elfenbein und Beinschnitzereien, p. 96-97, $\mathrm{n}^{\circ}$ 45, pl. 75a-b).

21. Ischia, Lacco Ameno, Contrada Mazzola, Museo di Pitecussa, inv. 239083. Voir entre autres J. N. Coldstream, "Some Unusual Geometric Scenes from Euboean Pithekoussai », p. 94, note 40, fig. 7 ; M. Denoyelle, M. Iozzo, La céramique grecque d'Italie méridionale et de Sicile. Productions coloniales et apparentées du VIII au III siècle av. J.-C., p. 37-38, pl. III (avec bibliographie complémentaire).

22. Ibid., p. 36-38, fig. 13 (avec bibliographie complémentaire).

23. Sur la localisation du rocher des Sirènes dans la péninsule de Sorrente, mentionnée par le Pseudo-Aristote, Lycophron et Strabon, E. Aston, Mixanthropoi: animal-human hybrid deities in Greek religion, p. 68-70.

24. Exemplaire provenant de Cumes, ancienne collection Guilhou, production de Pithécusses? (I. Strøm, Problems Concerning the Origin and Early Devlopment of the Etruscan Orientalizing Style, p. 60, ${ }^{\circ}$ S7, 81-82, S III 2, fig. 47 ; P. G. Guzzo, Oreficerie dalla Magna Grecia. Ornamenti in oro e argento dall'Italia Meridionale tra l'VIII ed il I secolo, p. 265, IA2). [Idem] De Palestrina, Tombe Bernardini, production d'Étrurie méridionale (Palestrina ?), Rome, Museo di Villa Giulia inv. 61549 (I. Strøm, Problems Concerning the Origin and Early Devlopment of the Etruscan Orientalizing Style, p. 61, $\mathrm{n}^{\circ}$ S11, 81-82, S III 6, fig. 48).

25. M. E. Aubet, Los marfiles orientalizantes de Praeneste, pl. XXIb, fig. 21-22 ; E. Giovanelli, «Esseri fantastici alle origini della glittica preromana: spunti preliminari su alcuni intagli », p. 201, fig. 6.

26. M. Martelli, «Del Pittore di Amsterdam e di un episodio del nostos odissiaco. Ricerche di ceramografia etrusca orientalizzante "; M. Micozzi, "White-on-red”. Una produzione vascolare dell'Orientalizzante etrusco, p. 101, pl. XXXIId ; M. Micozzi, «Whiteon-red. Miti greci nell'Orientalizzante etrusco »; L. Medori, «Il Bestiario fantastico nella white-on-red in Etruria e nell'Agro falisco », $\mathrm{n}^{\circ}$ 18, 20, p. 84-85, fig. 14.

27. R. Bonaudo, «Eroi in viaggio: Odisseo dalla Grecia in Etruria ».

28. B. D'Agostino, L. Cerchiai, Il Mare, la Morte, L'Amore. Gli Etruschi, i Greci e l'immagine; L. Cerchiai, « L'immaginario del mare nel mondo etrusco ».

29. G. Camporeale, "Odysseus/Uthuze », p. 981 ; L. Medori, «Il Bestiario fantastico nella white-on-red in Etruria e nell'Agro falisco », p. 95.

30. Voir en dernier lieu les réflexions de Sara Neri à ce sujet à propos des vases du Peintre de Narce et de la tombe des Lions rugissants de Véies : S. Neri « Il bestiario nella ceramica italo-geometrica di età orientalizzante in Etruria Meridionale ", p. 62-64 (avec références). Sur le lion comme une allusion sinon une référence à la mort, A. Naso, "Nuovi dati sulla pittura funeraria di età orientalizzante in Etruria meridionale ", p. 22-23.

31. Rome, Villa Giulia, inv. 65455.

32. Sur le Peintre des Hirondelles, voir A. Giuliano, « Un pittore a Vulci nella II metà del VII secolo a.C.» ; W. Schiering, "Eine Amphora des Schwalbenmalers im Louvre » ; 
A. Giuliano, «Il Pittore delle Rondini »; R. M. Cook, "The Swallow Painter and the Bearded Sphinx Painter »; M. Martelli, La ceramica degli Etruschi ; R. M. Cook, P. Dupont, East Greek Pottery, p. 68-70 ; A. Giuliano, «Ancora sul 'pittore delle Rondini' ». Antonio Giuliano fait du peintre un artisan immigré de Grèce de l'Est ayant parcouru la Méditerranée occidentale, notamment la Sicile, avant de s'installer à Vulci vers 630-625 av. J.-C.

33. Pour une synthèse récente, voir A.Coulié, $L a$ céramique grecque aux époques géométrique et orientalisante ( $\mathrm{XI}^{e}-\mathrm{VI}^{e}$ siècle av. J.-C.), p. 142-170, avec parallèles iconographiques: id., p. 162, fig. 153, Oenochoé de Camiros, Rhodes, La Résidence, inv. 14807 , vers 620 av. J.-C.

34. Voir par exemple E. Walter-Karydi, Samische Gefässe des 6. Jahrhunderts v. Chr. Landschaftsstile. Ostgriechischer Gefässe, $\mathrm{n}^{\circ}$ 704, 753, 836, 873, 939, 951, 975, 1017 ; E. Akurgal, Alt-Smyrna I. Wohnschichten und Athenatempel, pl. 37a ; E. Hofstetter, Sirenen im archaïschen und klassichen Griechenland, p. 227-249 (avec références); A. Lemos, Archaic Pottery of Chios, The Decorated Styles, p. 41-42, fig. 23, pl. 68, n ${ }^{\circ} 554,555$, pl. 71, $\mathrm{n}^{\circ} 567$, pl. 88, nº 675 ; K. Iren, Aiolische orientalisierende Keramik, pl. 44-45, nº 106, 109.

35. Londres, British Museum, inv.1867.5-8.927 (A 683) ; Leyde, Rikjmuseum van Oudheden, inv. I 1908/4.2 : - C. Kardara, Rodiaki ageiographia, p. 156, fig. 126-127 ; E. Hofstetter, Sirenen im archaïschen und klassichen Griechenland, $\mathrm{n}^{\circ}$ 01-03, p. 226-227, pl. 18, 2-3.

36. Ibid., pl. 3, K 57.

37. Syracuse, Museo Archeologico Regionale «Paolo Orsi », inv. 50988. De la nécropole Giardino Spagna, tombe 53 : G. Cultrera, "Siracusa - Scoperte nel Giardino Spagna ", p. 75-77, fig. 33 ; M.-C. Lentini (éd.), Vasi del Wild Goat Style dalla Sicilia e dai Musei Europei, p. 100-101, n 35 (avec bibliographie). Les analyses d'argile ont confirmé l'appartenance de ce plat au groupe nord-ionien.

38. Par ailleurs, en croisant les listes et les dessins présentés par Giuseppe Micali en 1844 des vases du Musée de Lucien Bonaparte dit le Prince de Canino à Musignano (G. Micali, Monumenti inediti a illustrazione della storia degli antichi popoli italiani, pl. V, 3), il faut relocaliser une olpé corinthienne portant cette iconographie particulière dans un contexte de découverte vulcien de l'époque orientalisante, peut-être la célèbre Tombe d'Isis de la nécropole de Polledara. Nous avons retrouvé sa trace au Museo Arqueológico Nacional de Madrid (inv. 10788).

39. Cette interprétation serait corroborée par la lecture de l'autre face de la coupe, pouvant être interprétée comme une scène de départ à la guerre précédant et annonçant la scène du cavalier et des créatures liminales. Sur la question de la représentation du cavalier et sa connotation sociale, aristocratique et funéraire en Étrurie archaïque, voir en particulier N. Lubtchansky, Le cavalier tyrrhénien: représentations équestres dans l'Italie archaïque, p. 172-178. 


\section{RÉSUMÉS}

Les contacts entre les mondes orientaux et méditerranéens se manifestent avec une grande intensité à l'époque dite "orientalisante", de la fin $\mathrm{du} \mathrm{vIII}^{\mathrm{e}} \mathrm{au} \mathrm{VI}^{\mathrm{e}}$ siècle avant notre ère. Ce processus de diffusion, d'adoption et d'adaptation d'innovations techniques, d'objets, d'images et d'idées, a eu un impact considérable dans l'histoire des représentations de nombreuses cultures méditerranéennes, en particulier grecques, italiques et ibériques. Perçus chez Hésiode et les philosophes présocratiques tels Empédocle d'Agrigente comme un symbole du chaos originel, les hybrides - ces êtres composites créés par l'assemblage ou la fusion d'éléments de différentes espèces, humaine, animale ou végétale - en sont l'une des manifestations les plus caractéristiques. L'étude de l'oiseau anthropocéphale, souvent nommé "Sirène " d'après l'Odyssée d'Homère, permet d'esquisser le parcours tant iconographique qu'idéologique d'une image d'hybride féminin dans la sphère des contacts interculturels, des antécédents égéoorientaux aux diverses expérimentations méditerranéennes.

\section{AUTEUR}

\section{CHRISTIAN MAZET}

Doctorant à l'École pratique des hautes études (ED 472, UMR 8546 AOrOc), boursier Jean WalterZellidja (Académie française) accueilli à l'École française de Rome 


\title{
Les loups-garous devant la justice (XVI ${ }^{\mathrm{e}}-\mathrm{XVII}{ }^{\mathrm{e}}$ siècle) : l'hybridité comme mobile du crime « inhumain »
}

\author{
Philippe Nieto
}

1 La question de la lycanthropie peut être étudiée sous de multiples facettes (fig. 1). L'idée qu'il existe des hommes-loups remonte à des temps très anciens, se nourrit de plusieurs mythes, prolifère dans de nombreuses légendes locales, plonge dans les pratiques chamaniques... On peut également l'aborder comme une catégorie de la sorcellerie et convoquer toute la littérature historique sur le sujet, ou encore en faire une pathologie à étudier sous un angle médical. On peut enfin traiter la lycanthropie comme un sujet littéraire ou cinématographique.

2 Nous avons choisi d'isoler un point précis du sujet en l'abordant sous l'angle judiciaire, et en nous focalisant, par commodité, sur les cas recensés dans l'aire francophone royaume de France et Saint-Empire. 
Fig. 1. - Homme et loup.

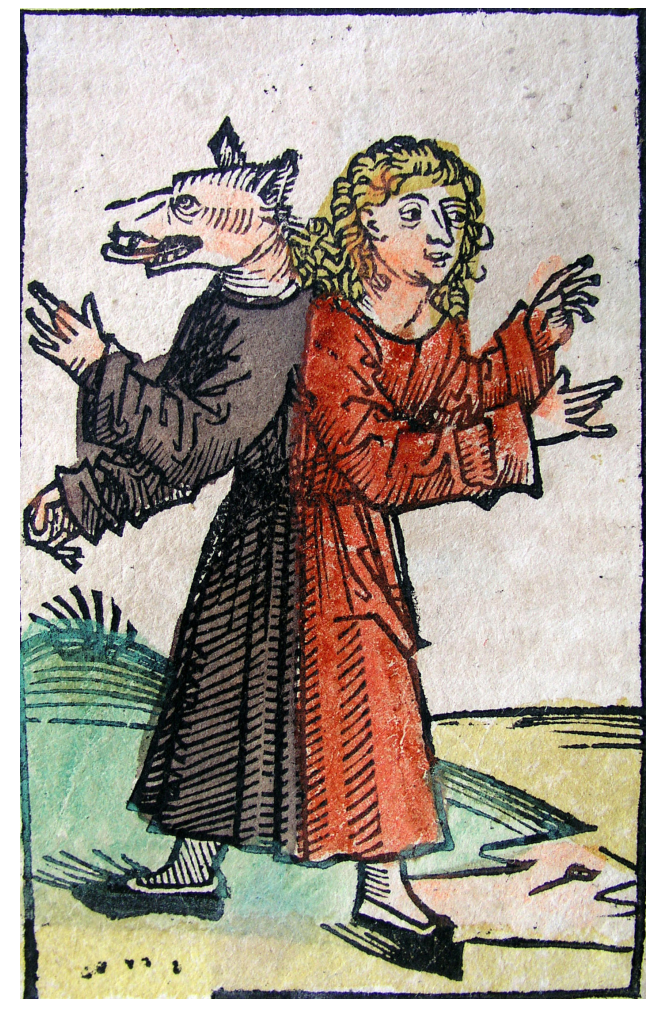

Liber Chronicarum, Nuremberg, 1493.

\section{Chronologie et contexte intellectuel des procès en lycanthropie}

3 Les grands procès en lycanthropie se tiennent entre le dernier tiers $\mathrm{du} \mathrm{XVI}^{\mathrm{e}}$ et les premières décennies du $\mathrm{XVII}^{\mathrm{e}}$ siècle. Disons que les affaires les plus anciennes, si elles existent, sont rares ou peu documentées, les procès concernant spécifiquement des loups-garous disparaissent dans le courant $\mathrm{du} \mathrm{XVII}^{\mathrm{e}}$ siècle, du moins en Europe occidentale. On remarque qu'ils se tiennent tous au cœur de la vague des grands procès en sorcellerie.

4 Les zones géographiques sur-représentées sont également celles où se déploient les plus impitoyables chasses aux sorciers - à l'échelle de l'Europe occidentale : Allemagne du sud, Suisse, Franche-Comté, Espagne... De fait, on peut, dans un premier temps, considérer les procès en lycanthropie comme un cas particulier des procès en sorcellerie. Ils suivent à peu près la même courbe, analysée notamment par Robert Mandrou $^{1}$, les accusés passant progressivement du statut de possédé du diable à celui de malade mental.

5 La première vague, qui est plutôt un raz-de-marée, submerge une région bien précise : le Jura et ses marges. En 1521, à Besançon, Pierre Burgot et Michel Verdung, les « loupsgarous de Poligny », sont brûlés ; en 1574, Gilles Garnier, "l'ermite de Saint-Bonnot » est exécuté à Dole. En 1584, à Saint-Claude, la famille Gandillon est jugée. En 1598, une véritable «meute » de loups-garous est condamnée dans une lame de fond judiciaire qui emporte également d'autres sorciers plus... ordinaires. 
6 Pour le royaume de France, on ne relève que deux cas certains de lycanthropie passés devant des juges, le troisième visant en 1598 un certain « tailleur de Chalons », n'ayant livré à la postérité aucun document fiable. La même année 1598, Jacques Roulet est jugé par le tribunal d'Angers, et, en 1603, le tribunal de Bordeaux juge Jean Grenier, un jeune « loup-garou » de quatorze ans.

7 Il est intéressant de noter que ces deux derniers «lycanthropes ", même si ils sont condamnés en première instance, voient leur peine commuée en internement par les parlements de Paris et de Bordeaux. Il est également intéressant de savoir que ces deux derniers « hommes-loups » ont été plutôt considérés comme des simples d'esprit.

Comme nous allons le voir, la lycanthropie pose un certain nombre de problèmes aux démonologues et il se dégage peu à peu un discours pré-médical qui va transformer les sorciers en "mélancoliques». Quatre ouvrages majeurs des XVI ${ }^{\mathrm{e}}$-XVII ${ }^{\mathrm{e}}$ siècles jalonnent cette mutation conceptuelle.

D'abord le livre du médecin néerlandais Jean Wier, De praestigiis daemonum² (Des illusions des démons...), qui est le premier à camper la sorcellerie sur le versant «médical». Ouvert à l'influence humaniste, ce médecin qui officia à la cour du duc Guillaume de Clèves s'oppose à ceux qui tiennent pour réel le «transport corporel» des affidés de Satan. Il argumente à partir de son expérience médicale pour faire de la sorcellerie le produit d'un dérèglement des « humeurs » et d'un « excès de bile noire ».

10 La réponse cinglante, et presque injurieuse à l'ouvrage de Wier est assénée avec verve par un éminent philosophe Jean Bodin, "économiste» avant l'heure, distingué par ailleurs pour ses Six livres de la République ${ }^{3}$. De la Démonomanie des sorciers ${ }^{4}$ est un livre brillant, érudit, d'une grande clarté, qui affirme la réalité des sabbats et de la possession, et cherche à ridiculiser les thèses de Wier en leur opposant "l'évidence » des faits rapportés lors des procès de sorcellerie.

11 Dans la première décennie du xvII ${ }^{e}$ siècle, le savant français Jean de Nynauld vient renforcer les thèses de Jean Wier en publiant le premier ouvrage traitant spécifiquement de la question des «hommes-loups »: De la lycanthropie ${ }^{5}$, dans lequel il range délibérément sorcellerie et « lycanthropie » parmi les dérèglements mentaux. La synthèse sera faite par le médecin anglais Robert Burton qui livre, six ans plus tard, la première édition de son Anatomy of melancholy 6 .

\section{La lycanthropie sous les angles théologique et philosophique}

12 L'idée qu'il puisse exister des « hommes-loups » suppose que certains sorciers aient la faculté de se métamorphoser. Ce qui, pour des esprits cultivés et rompus au raisonnement universitaire, est encore plus difficile à admettre que le simple transport au sabbat sur des balais. La première objection contestant la réalité de cette transformation des sorciers en loups - ou en autres animaux - est d'ordre théologique. Voici comment elle s'exprime sous la plume de Nynauld :

«C'est un blaspheme de dire \& de croire que reellement le Diable puisse changer la nature des choses contre l'habilité naturelle que le Createur leur a despartie, que si cela estoit il faudroit establir deux principes, qui est un autre blaspheme : il ne faut doncques pas estimer que Dieu vueille communiquer aux malins esprits [...] la puissance de créer, ou changer l'essence des choses, laquelle puissance il s'est reservée à luy seul. » 
Dole qui condamne Gilles Garnier :

«Les diables ne creent pas les natures. »

Autre problème, relié à celui-ci, citons encore Nynauld :

«Si ainsi estoit que la forme du corps humain perit, l'ame se separoit du corps, \& ne rertourneroit plus. Or l'ame ne peut se separer du corps que premierement il ne soit privé de toutes les trois facultez naturelles, assavoir Vitale, Animale, \& Naturelle, car elles perissantes, la mort s'ensuit, \& par consequent la separation de l'ame d'avec icelles, laquelle demeurant libre s'en retournerait à sa source premiere, d'où elle retournera pour prendre corps, jusques à la resurrection des morts, comme tous vrays Chrestien le croyent. »

15 Contre toute attente, même certains parmi les chauds partisans des procès en sorcellerie partagent cet argument. Ainsi, Pierre de Rostéguy de Lancres, dont le nom est indissociablement lié à l'impitoyable chasse aux sorciers qu'il dirige dans le Labourd, en terre basque, au cours de l'année 1609, pour «purger le pays de tous les sorciers et sorcières sous l'emprise des demons $"$ :

«Car le Demon n'a pas le pouvoir de separer l'ame du corps, sinon lors que Dieu lui permet de tuer. $»^{8}$

16 Viennent ensuite les linéaments d'une argumentation, disons, "philosophique ». Nous rangerons sous ce vocable ce que nous qualifierions aujourd'hui de «scientifique » ou « rationnel ». C'est Nynauld lui-même qui emploie l'adjectif dans ce sens :

«Comme ceste transformation pretenduë par les Sorciers, repugne aux maximes Theologiques, Aussi repugne elle aux maximes Philosophiques, entant que les Philosophes croyent \& tiennent d'un commun accord qu'une espece ne peut estre transformée en une autre espece. »

17 Le même Jean de Nynauld combat en ces termes l'idée d'une génération spontanée d'un loup, ou de tout autre animal :

«Cela repugne à tout ordre de la nature, puisque nature ne peut engendrer ou former un tel corps animé d'une matiere non animée par la puissance, comme disent les Philosophes, Car tout ce qui prend estre, ou naissance, naist de quelque semence...»

18 Et il ajoute :

«Quant aux Animaux, où ils sont parfaits, ou imparfaits; Les parfaits ne se peuvent engendrer que par la propre semence du masle \& de la femelle meslées par la copulation d'une mesme espece. »

Dans le commentaire de Pierre de Lancres, nous retrouvons le même argument :

«Mais les parfaicts naissent de la generation de deux sexes : \& de leur charogne \& corruption ne reviennent jamais des animaux de mesmes especes. »

20 Pierre de Lancres précise, à ce propos, ce qu'il faut entendre par animaux « imparfaicts », ce qui sonne bizarrement à nos oreilles du xxI ${ }^{\mathrm{e}}$ siècle. Ce terme désigne, pour lui :

«... les petits animaux, comme rats, grenouilles, mouches à miel, anguilles, lézards...»

21 Même un farouche inquisiteur, comme Henry Boguet, qui écume la terre de SaintClaude, dans le Jura, en qualité de grand juge de sorciers, à la fois théoricien et praticien, à l'instar d'un Pierre de Lancres, doute de la réalité des transformations... Ne se demande-t-il pas si ce n'est pas directement le diable qui dévore les victimes à la 
façon d'un loup, après avoir endormi et caché l'infortuné sorcier qualifié de lycanthrope... « derrière un buisson »?

Si les théoriciens s'accordent donc sur l'idée que le diable ne peut transformer la nature, on lui accorde cependant de redoutables pouvoirs. Selon Pierre de Lancres :

«Les Demons ayans cognoissance des secrets de nature \& des causes secondes, sont capables de faire telles transformations non d'eux mesmes, mais par la force \& operations de la mesme nature \& moyens employez d'icelle. »

En d'autres termes, les démons ayant une connaissance exhaustive du fonctionnement de la nature, et d'interactions non connues des simples humains, ils savent utiliser toutes ses ressources, sans avoir besoin d'en bouleverser les lois. Ce qu'ils peuvent faire aisément, car, ainsi que le dit Pierre de Lancres :

«[plus encore que les] hommes les plus versez aux choses naturelles [qui ne sont qu']apprentis auprès d'eux, [ils] ont une merveilleuse intelligence de toutes choses de ce monde elementaire. "

\section{La lycanthropie sous l'angle médical}

24 L'arme principale de ces démons, c'est l'illusionnisme : ils agissent de l'intérieur, en créant des illusions, des hallucinations. Car ils sont experts en drogues, potions et onguents. L'onguent est un grand classique, et une grande obsession des procès de sorcellerie : le diable donne à ses fidèles, ses « esclaves » selon les termes de Nynauld, des onguents et breuvages, lesquels, selon les interprétations, soit leur donnent des pouvoirs surnaturels, soit les plongent dans une torpeur maléfique. Ces onguents sont un point important, on y insiste particulièrement, au cours des interrogatoires, dans les perquisitions à domicile chez les sorciers et dans les traités de démonologie. Nynauld lui-même y consacre les deux tiers de son petit opuscule sur la lycanthropie, avec force détails.

L'usage d'un onguent permet de rationaliser en partie des processus contraires au sens commun, comme la transformation en animal, aux yeux d'hommes contemporains de la gestation de la science moderne, même si certains se réfugient encore dans des actes de foi. Le point sur lequel s'opposent les pourfendeurs de sorciers et les médecins, c'est la réalité des pouvoirs donnés ainsi aux sorciers. Pour Pierre de Lancres ou Boguet, ces breuvages et pommades ont des pouvoirs réels, en termes de transport aérien des sorciers ou de métamorphose. Pour Wier ou Nynauld, onguents et potions font plutôt entrer le sorcier dans un état de sommeil profond, de catalepsie dirait-on aujourd'hui, et tout le détail du sabbat provient de son imagination, comme une sorte de rêve dont il resterait des traces au réveil. C'est en amont que le diable intervient, en produisant des images fausses, selon les termes de Nynauld:

«En se glissant à cachette dedans la fantasie des hommes [...] pour esmouvoir les humeurs \& troubler les sens. »

Cela nous porte sur le terrain médical, car ce n'est pas un hasard si les contempteurs des chasseurs de sorciers sont plutôt des médecins. Le lien entre la lycanthropie et les maladies mentales est admis depuis l'Antiquité. Dès le $\mathrm{II}^{\mathrm{e}}$ siècle, le médecin grec Marcellus de Side classe la lycanthropie comme une forme clinique de mélancolie. Cette idée sera reprise par Avicenne. Il n'est donc pas étonnant que Jean Wier considère cette lycanthropie comme un phénomène imaginatif morbide, qu'il nomme: insania lupa 
(folie louvière). Ce concept sera repris encore par Robert Burton, en 1621, dans son Anatomy of melancholy.

C'est ainsi que les deux derniers loups-garous français de notre chronologie - Jacques Roulet à Angers, Jean Grenier à Bordeaux - échappent à la mort, leur état étant considéré plus comme une folie que comme un crime satanique. Jean Grenier est envoyé dans un monastère, parce que les «Iuges doyvent suppleer le defaut du tuteur $\&$ du curateur ", selon les termes de Pierre de Lancres; Jacques Roulet finit sa vie à l'hôpital de Saint-Germain-des-Prés, où l'on avait coutume de placer les fous.

Voici comment Pierre de Lancres, pourtant féroce pourfendeur de sorciers, décrit le jeune Jean Grenier, quatorze ans au moment des faits :

"C'est un enfant rustique, mal instruit, ou à vray dire, non instruit en la coignoissance \& crainte de Dieu : \& moins encore aux moyens de se defendre des subtilitez de Satan. »

Selon les termes du jugement de Bordeaux qui condamne le même Jean Grenier :

«Les furieux et les maniacles ne doivent pas être punis, pas plus que les cynanthropes et vrais lycanthropes dont le mal constitue une espèce de folie et que,

d'après la loi, leur affliction les punit assez. »

Une victime, en somme... Comme on le voit, la lycanthropie n'est pas une forme de possession comme une autre. Même quand ils sont traités pleinement comme des sorciers, même quand ils sont brûlés comme des sorciers, on concède qu'ils sont frappés d'un certain degré de folie. Déjà en 1574, Benoist Rigaud, qui rapporte et commente les termes de l'arrêt du parlement de Dole ${ }^{9}$ condamnant Gilles Garnier au bûcher, le présente plutôt comme un pauvre bougre et parle à son sujet de «mélancolie », en citant précisément Marcellus de Side.

\section{La lycanthropie du point de vue criminologique}

31 Examiner ces affaires de lycanthropie sous un angle strictement criminel se révèle plutôt difficile, les traces de la procédure étant soit inexistantes, soit lacunaires, soit non retranscrites dans les attendus du procès. L'essentiel porte sur la démonstration de la possession diabolique, non sur la matérialité des faits. Par recoupement, il est quand même possible d'extraire quelques éléments.

\section{Arrestation}

Il y a ceux qui s'accusent, et accusent des complices, spontanément, ou sous la sollicitation expresse d'un inquisiteur ou d'un juge, tels Pierre Burgot et Michel Verdung, ou la bande des sorciers de Saint-Claude - Paget, Prost, Guillaume, Boquet... Il y a ceux qui sont pris en flagrant délit: Gilles Garnier, Pernette Gandillon, Jean Grenier... ou sur le lieu du délit - Jacques Roulet, qui s'accuse immédiatement.

\section{Fondement de l'accusation}

Elle repose principalement sur les déclarations des accusés. Car le loup-garou, même quand il est pris sur le fait, n'est jamais vu sous sa forme de loup par les témoins (fig. 2 et 3). Ainsi pour Gilles Garnier, pris en flagrant délit, il est dit dans l'arrêt :

«Estant lors le dict deffendeur en forme d'homme et non de loups ». 
Fig. 2. - Le loup-garou vu comme un fou à forme humaine.

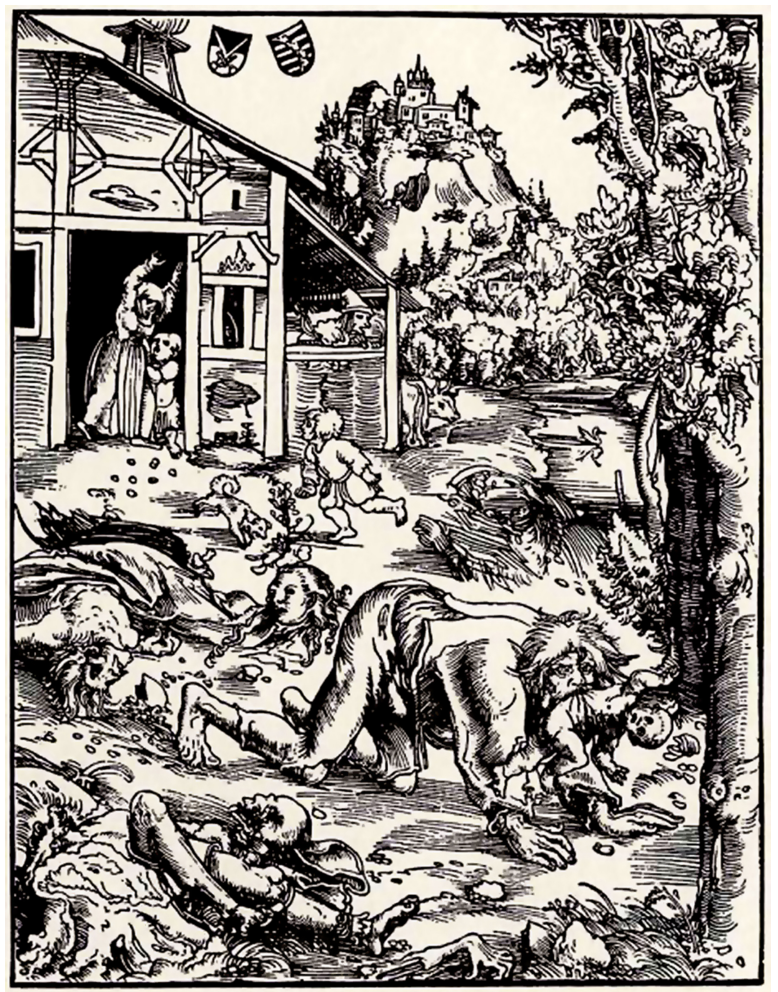

Gravure de Lucas Cranach, circa 1510-1515.

Fig. 3. - Le loup-garou vu comme un loup, jusqu'à la potence.

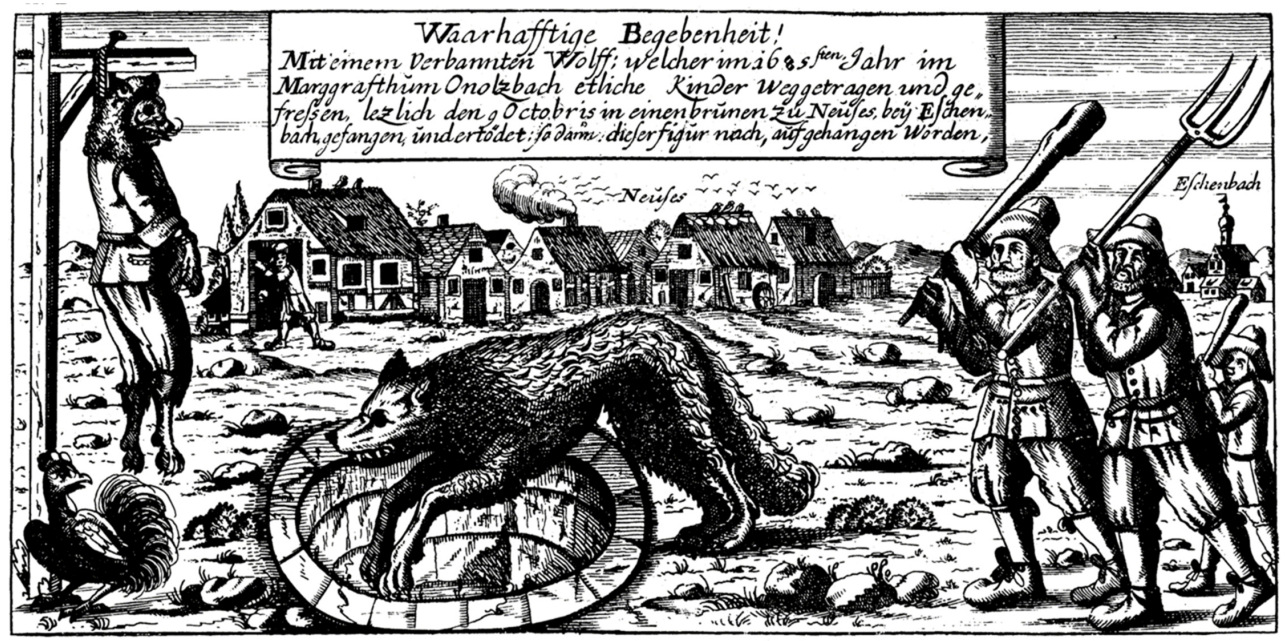

Gravure représentant le lycanthrope d'Ansbach (Bavière), 1685

34 Jacques Roulet est découvert à proximité du cadavre d'un enfant, en «homme couché sur le ventre, de son long, la face contre terre ». Ce même Jacques Roulet est ainsi décrit par Pierre de l'Estoile, dans son journal :

«Il portait les cheveux pendants jusqu'aux talons, la barbe de même, et les ongles aussi grands et longs que les mains. » 


\section{Clauda-Jean Prost, presque impotente :}

«Comment elle pouvoit suivre les autres si dispotement [...] attendu qu'elle était boiteuse et de haut âge. »

En revanche, les accusés se montrent prolixes dans les détails qu'ils fournissent, souvent, semble-t-il, plus spontanément que les sorciers ordinaires. Pierre de l'Estoile ne dit-il pas, toujours à propos de Jacques Roulet :

«Monsieur Lecoigneux conseiller en la Cour était son rapporteur qui m'a dit que par ses interrogatoires, il en confessait plus qu'on ne lui en demandait. »

Parfois, le juge lui-même doute des aveux, comme Boguet qui demande à la vieille quoi elle répondit qu'elle était portée par Satan. L'accusation ne repose donc ni sur des témoignages visuels, ni sur un flagrant délit, uniquement sur des aveux. Et c'est à partir de ces aveux que se dessine le portrait du lycanthrope. L'apparition d'un " homme noir ", dans la forêt la plupart du temps, est souvent évoquée. En revanche, la participation au sabbat est quasi inexistante. Seule exception, le procès des loupsgarous de saint-Claude, où se mêlent lycanthropes chroniques ou occasionnels, et sorciers ordinaires. Mais cette affaire est la plus confuse. Les accusés fournissent très peu de précisions sur leur métamorphose, disant juste qu'ils étaient sous forme de loup. Ce qui contraste avec le détail des sabbats sur lesquels ils sont plus prolixes. La plupart des aveux font mention d'un onguent, souvent fourni tel quel par l'homme noir, ou le diable, sans qu'il soit très clair sur les propriétés de cette pommade, ni sur les modalités de la métamorphose. Ainsi, l'enquêteur interroge Jacques Roulet, le loup-garou angevin :

«En vous frottant de cet onguent, deveniez-vous un loup?

- Non, cependant j'ai tué et mangé l'enfant Gornier, j'étais loup lorsque je l'ai dévoré.

- Étiez-vous loup lorsqu'on vous arrêta?

- J'étais loup [Nous avons vu que c'était faux]

- Étiez-vous habillé en loup?

- J'étais habillé comme à présent. »

La plupart des accusés mentionnent également une "peau de loup » dont ils se revêtaient, qui était, dans certains cas, fournie directement par le diable. Comme nous l'avons vu, Jacques Roulet se dit s'être "habillé en loup ». Gilles Garnier prétendait commettre ses crimes «par le moïen d'une peau de loup dont il se vêtait ». Notons que les arrêts ne mentionnent jamais qu'une peau d'animal ait été retrouvée.

\section{Modus operandi}

C'est sur le mode opératoire que les doutes les plus certains auraient dû apparaître pour contredire une transformation réelle en loup. Si l'usage des dents est parfois évoqué, la plupart du temps l'homicide, quand il est avéré, se commet avec les mains. Gilles Garnier dit avoir étranglé ses victimes, précisant toutefois qu'il s'agissait de «mains semblant pattes". Tout est dans le "semblant». Lorsqu'on possède des témoignages concernant ces homicides, ou tentatives d'homicide, il est toujours mentionné l'usage des mains, "et non de pattes armées de griffes ", selon les termes des enfants Bidel lorsqu'ils sont intervenus contre Pernette Gandillon au moment où elle commettait son forfait.

Que dire des armes par destination, occasionnellement utilisées par ces « loups-garous » visiblement bien démunis de crocs et de griffes... (voir le couteau manipulé par 
Pernette Gandillon ou encore l'interrogatoire de Pierre Burgot qui dit avoir tué une chèvre en se servant d'un instrument tranchant).

\section{Examen des corps}

41 Dans les aveux mêmes de ces lycanthropes, la description des plaies occasionnées (et des morceaux de corps dévorés) correspond tout à fait à celles qu'auraient pu occasionner de véritables loups prédateurs ${ }^{10}$ : les accusés disent avoir mangé les cuisses, le ventre, les bras... Mais cela ne prouve pas la véracité des faits ; les pratiques alimentaires des loups devaient être connues de tous à cette époque. Il est tout à fait normal que des hommes se prétendant des loups s'en soient souvenus au moment des aveux.

42 Pour faire bonne mesure, certains des loups-garous de Saint-Claude disent avoir épargné le côté droit des victimes, parce que c'est le côté de la main qui fait le signe de croix... c'est, à l'évidence, un indice qui confirme que nous sommes en présence de sorciers ordinaires, s'accusant de lycanthropie.

43 Mais l'examen des corps est rendu difficile, voire impossible, par l'absence, le plus souvent, du corps du délit. Il n'est pas fait mention que l'on ait trouvé la moindre trace des cinq infortunés que Burgot et Verdung disent avoir tués et dévorés en partie. Il en est de même pour les victimes introuvables des loups-garous de Saint-Claude.

Il est permis de penser que certains des corps parfois retrouvés dont la mort est attribuée à certains lycanthropes en procès ont été tout simplement ceux de victimes de véritables loups. Il est plus que probable, par exemple, que les cadavres trouvés à proximité de Jean Roulet lors de son arrestation aient été tués et déchiquetés par des loups. Dans l'affaire Pierre Grenier, on n'est pas vraiment sûr qu'il soit l'auteur des meurtres qui lui ont été attribués, même si c'est probable. Les seules victimes certaines sont celles de Gilles Garnier et de Pernette Gandillon, pris tous deux en flagrant délit.

Le tableau dressé par les affaires de lycanthropie est contrasté. Ces procès, à l'exception de celui de Burgot et Verdung - 1521 - sont tous situés dans une période allant de 1574 à 1603. Si l'on exclut l'affaire Garnier - 1574 -, ils s'échelonnent dans une période allant de 1584 à 1603. Or, c'est très précisément au cours de cette période que Jean-Marc Moriceau a noté un pic dans les attaques de loups prédateurs ${ }^{11}$. C'est comme si les procès en lycanthropie obéissaient à une double chronologie: celle de l'acmé des procès en sorcellerie, celle du pic des attaques des loups prédateurs.

Faut-il y voir une sorte de court-circuit entre deux périodes? Si l'on se réfère au cas précis des procès menés à Saint Claude par Henri Boguet à Saint-Claude, en particulier celui de l'année 1598, il est fort probable qu'il y ait eu contamination de la peur du loup sur celle des sorciers.

47 Dans les autres affaires, nous pensons immédiatement à des manifestations d'une maladie mentale connue aujourd'hui sous le vocable de lycanthropie clinique, dans laquelle les patients sont persuadés d'être transformés en loup, ou en un autre animal. Le cas de Jacques Roulet, qui vit comme un sauvageon et s'accuse lui-même spontanément, semble relever à l'évidence de cette affection. 

être aussi à Pernette Gandillon et à Gilles Garnier. Mais des homicides à répétition ayant été attestés, il se pourrait que l'on soit en présence de ce qu'on appelle aujourd'hui des tueurs en série désorganisés.

cas de crimes suivis de consommation de chair humaine sont pointés dès le $\mathrm{XIX}^{\mathrm{e}}$ siècle. On citera pour mémoire, Vincent Verzeni en Italie, l'espagnol Garrayo, le Français Joseph Vacher... Tous étranglent leurs victimes avant d'en manger des morceaux. Avouons que le modus operandi ressemble beaucoup à celui de nos «loupsgarous » des XVI et XVII ${ }^{e}$ siècles. Si le doute peut planer sur Gandillon et Grenier, Gilles Garnier répond à tous les critères permettant de le classer parmi les tueurs en série.

Un dernier point. Pourquoi le loup? Pourquoi une identification au loup plutôt qu'à tout autre prédateur? D'abord pour ses qualités symboliques. Comme le remarque l'ethnologue Sophie Bobbé dans son ouvrage L'Ours et le loup, la figure du loup est celle d'une bête anthropophage - c'est important -, d'un animal qui dévore sans retenue, une bouche dévoreuse, et, notons ce détail, un animal auquel on attribue la pratique de l'endo-cannibalisme. N'oublions pas qu'un loup-garou est, au départ, un homme. Sa transformation symbolique se doit de rester cohérente.

Pourquoi un loup ? La question a été posée à Gilles Garnier lui-même, voici sa réponse, retranscrite à partir des interrogatoires :

«Un jour où poussé par la misère il errait dans les bois, il avait rencontré un fantôme en figure d'homme, qui lui avait promis monts et merveilles s'il voulait se donner à lui et le pouvoir de se déguiser, à son choix, en figure de lion, de loup ou de léopard. Il avait choisi le loup, disait-il, parce que cet animal lui avait paru plus mondanisé que le lion ou le léopard. »

Que voulait dire exactement Gilles Garnier sous ce terme curieux de "mondanisé »? Vraisemblablement que le loup était pour lui la forme même du prédateur le plus commun à l'époque sous nos contrées. En définitive, n'est-ce pas une façon de se nommer soi-même, et de nommer une forme de crime incompréhensible, même aujourd'hui, mais plus encore, peut-être, du temps de Gilles Garnier, le crime sans mobile, le crime gratuit. Nous entendons par ce terme l'homicide qui ne provient pas d'une cause sociale acceptable, même si elle est moralement inacceptable, comme l'assassinat crapuleux, le meurtre passionnel ou le crime d'honneur. À crime «inhumain », il faut la figure d'un criminel «inhumain», ou plutôt mi-homme, mibête, l'homme-loup, le Wer-wolf, devenu le loup-garou.

\section{BIBLIOGRAPHIE}

Arrest memorable de la Cour de parlement de Dole, donné à l'encontre de Gilles Garnier, Lyonnois, pour avoir en forme de loup-garou dévoré plusieurs enfans, \& commis autres crimes : enrichy d'aucuns points recueillis de divers autheurs pour esclaircir la matiere de telle transformation. Lyon : Benoist Rigaud, 1574. 
BARATTA Alexandre, WEINER Luisa, « La lycanthropie : du mythe à la pathologie psychiatrique », L'information psychiatrique, éd. numérique, 2009 - 7 Volume 85.[http://www.cairn.info/revue-1information-psychiatrique-2009-7-page-675.htm]

BOBBE Sophie, L'ours et le loup. Essai d'anthropologie symbolique, Paris, Éd. de la MSH/INRA, 2002.

Bulletin de la Société d'Agriculture, Sciences et Arts de Poligny (Jura), $17^{\mathrm{e}}$ année, 1876, p. 203. GIBSON Dirk C., Legends, monsters or serial murderers? The real story behind an ancient crime. Westport (CT) : Praeger, 2012, $201 \mathrm{p}$.

LÉVY-BRUHL Henri, « Un loup-garou devant le parlement de Bordeaux en 1603 », Revue du Folklore français, $\mathrm{n}^{\circ}$ 4, juillet-août 1930.

MANDROU Robert, Magistrats et sorciers en France au XVII ${ }^{e}$ siècle. Une analyse de psychologie historique historique, Paris, Éditions du Seuil (coll. L'Univers historique), 1980, 576 p.

MORICEAU Jean-Marc, Histoire du méchant loup. 10000 attaques sur l'homme en France ( $\mathrm{XV}^{e}-\mathrm{XXI} I^{e}$ siècle), Paris, Fayard/Pluriel, 2016, 640 p. (réédition revue et augmentée, 1 ère édition, chez Fayard en 2007).

NYNAULD Jean (de), De la lycanthropie, transformation, et extase des Sorciers. Où les astuces du Diable sont mises tellement en evidence, qu'il est presque impossible, voire aux plus ignorants, de se laisser doresnavant séduire. Avec la refutation des argumens contraires, que Bodin allegue au 6. chap. du second livre de sa Demonomanie, pour soustenir la realité de cette pretenduë transformation d'hommes en bestes, Paris : chez Nicolas Rousset, 1615.

SUMMERs Montague, The werewolf. Londres: Kegan Paul, Trench, Trubner \& Co, 1933, 307 p.

\section{NOTES}

1. R. Mandrou, Magistrats et sorciers en France au XVII ${ }^{e}$ siècle... p. 121-133 et p. 369-478.

2. De praestigiis daemonum et incantationibus ac veneficiis, première édition publiée à Bâle, en 1563.

3. Publié à Paris en 1574.

4. Publié à Paris en 1580.

5. Jean de Nynauld, De la lycanthropie, transformation et extase des sorciers, publié à Paris en 1615 .

6. Anatomy of melancholy. What it is, with all the kinds causes, symptoms, pronostiches \& severall cures of it, publié à Oxford en 1638.

7. Arrest memorable de la Cour de parlement de Dole, donné à l'encontre de Gilles Garnier, Lyonnois, pour avoir en forme de loup garou dévoré plusieurs enfans, \& commis autres crimes: enrichy d'aucuns points recueillis de divers autheurs pour esclaircir la matiere de telle transformation, publié à Lyon, en 1574.

8. Tableau de l'inconstance des mauvais anges et demons, ou il est amplement traicté des Sorciers \& de la Sorcellerie, publié à Paris, en 1612.

9. Arrest... op. cit.

10. Pour Jean-Marc Moriceau, le « loup prédateur » est celui qui s'attaque à l'homme. 
11. J.-M. Moriceau, Histoire du méchant loup. 10000 attaques sur l'homme en France..., rééd. augm. 2016.

\section{RÉSUMÉS}

On peut considérer les procès de lycanthropes comme des cas particuliers de procès de sorcellerie. La question de la transformation d'un homme en loup rencontre cependant des contradictions, tant sous l'angle théologique que philosophique. De plus, depuis Marcellus de Side, la lycanthropie est plutôt considérée comme un dérèglement des «humeurs » et une manifestation d'un état mélancolique. Si l'on se place du point de vue criminologique, on peut distinguer plusieurs situations : procès en sorcellerie contaminés par la recrudescence parallèle des attaques de loups prédateurs, manifestation de lycanthropie clinique, homicides que l'on attribuerait aujourd'hui à des tueurs en série désorganisés. À crime « inhumain », il faut la figure d'un criminel « inhumain », mi-homme, mi-bête.

\section{AUTEUR}

PHILIPPE NIETO

Conservateur, Archives nationales 


\title{
L'hybridité de l'homme sauvage dans l'art médiéval
}

\author{
Florent Pouvreau
}

1 L'historiographie récente a montré toute l'importance de l'étude des images et de la culture folklorique pour une compréhension plus fine de la place qu'occupent les animaux dans les cultures médiévales. Michel Pastoureau a ainsi suggéré, dans le cas des procès d'animaux, de réévaluer la capacité de discernement et de responsabilité que les hommes du Moyen Âge reconnaissaient à ceux-ci ${ }^{1}$.

2 La fin du Moyen Âge est précisément le théâtre de grands bouleversements concernant ces réflexions théoriques sur le rapport entre l'animal et l'homme. La conception chrétienne d'une séparation très nette entre l'homme et les autres créatures, en raison notamment de l'immortalité de l'âme humaine ${ }^{2}$, se renforce ainsi à partir du XII ${ }^{\mathrm{e}}$ siècle. La redécouverte de la philosophie naturelle d'Aristote confirme d'abord la conception d'une chaîne des êtres allant de l'inanimé au divin selon un axe vertical reliant la terre au ciel ${ }^{3}$. Cependant, à l'intérieur de cette chaîne, l'idée d'un franchissement possible des frontières par la procréation entre espèces différentes, particulièrement présente dans la culture folklorique, mais à laquelle s'oppose Aristote, recule dans les écrits savants ${ }^{4}$. En parallèle, la différence entre la condition humaine et animale commence à être conçue de plus en plus nettement en termes naturalistes à partir du XIII ${ }^{\mathrm{e}}$ siècle, et les anciennes frontières (animaux sauvages/domestiques) se font plus discrètes au profit de celle entre l'homme et le reste des animaux ${ }^{5}$.

Dans ce contexte, la figure de l'homme sauvage qui connaît un grand succès dans l'art médiéval à partir du $\mathrm{xIII}^{\mathrm{e}}$ siècle $^{6}$, est tout à fait singulière. Ce personnage anthropomorphe et velu est en effet une invention iconographique du Moyen Âge, contrairement à d'autres figures interrogeant les frontières entre humanité et animalité comme la sirène ou le centaure hérités des cultures antiques ${ }^{7}$. Cette communication propose donc de comprendre comment le corps de l'homme sauvage questionne les limites et les relations entre humain et animal, et comment les artistes jouent, entre le début du XIV ${ }^{e}$ et la fin du Xv $v^{e}$ siècle, sur la dimension transgressive de ce corps. 
4 La réponse à ces questions peut être apportée en deux temps, en voyant d'abord pourquoi l'excès de poil peut être considéré comme une forme d'hybridité, puis de quelle manière le jeu sur la nature liminale de l'homme sauvage se déplace dans la seconde moitié $\mathrm{du} \mathrm{Xv}^{\mathrm{e}}$ siècle.

\section{L'excès de poil, une véritable hybridité ?}

5 Si le poil n'est pas le propre de l'animal, son excès est cependant très fréquemment associé à l'animalité dans les textes médiévaux, aussi bien médicaux qu'exégétiques ou littéraires. La première raison relève du rapport entre pilosité et sexualité. Le poil est en effet considéré par la médecine médiévale comme une superfluité engendrée par des humeurs chaudes qui sèchent au contact de l'air en s'échappant de la peau ${ }^{8}$. L'homme, considéré comme plus chaud que la femme, est ainsi naturellement plus velu. Utile et esthétique lorsqu'il est présent en quantité limitée, le poil est cependant fréquemment associé à l'animalité lorsqu'il est abondant.

L'analogie animale, très fréquente dans les sources antiques, est en effet reprise par bon nombre d'auteurs médiévaux. Dans le domaine médical, les Anciens considèrent ainsi l'abondance pileuse comme un signe de puissance procréatrice. Chez Aristote par exemple, la pilosité du lièvre provient de son abondance spermatique, et la même correspondance se retrouve chez les hommes velus ${ }^{9}$. La physiognomonie use également du recours fréquent aux zootype ${ }^{10}$. Pour cette proto-science qui associe des caractères physiques à des traits de personnalité, l'abondance pileuse, suivant la partie du corps où elle se trouve, peut signifier la hardiesse du lion (sur le dos) ou au contraire le caractère craintif et versatile des volatiles (épaules) ${ }^{11}$.

7 La seconde raison de l'association du poil à l'animalité est d'ordre esthétique : l'excès de poil est très fréquemment comparé au pelage animal et souligne pour les auteurs médiévaux la laideur ou la sauvagerie d'un individu. Pour saint Jérôme déjà, la nature mauvaise d'Esaü, sauvage et pécheresse, est annoncée par son poil animalisé et comparé à celui d'un bouc ${ }^{12}$. Dans la littérature également, et dans les chansons de geste en particulier, la cruauté et la sauvagerie des peuples étranges sont associées à une abondance pileuse comparée à celle des animaux : chien, porc ou ours ${ }^{13}$.

Le poil, commun aux hommes et aux bêtes, constitue ainsi un caractère physique qui se prête bien aux jeux sur l'ambiguïté dès qu'il se trouve en abondance. C'est le cas en particulier pour les premières images d'hommes sauvages, qui se diffusent à partir du $\mathrm{XIII}^{\mathrm{e}}$ siècle. Dans certaines représentations, la présence du poil jette un doute sur l'identité de la créature représentée. C'est le cas d'un chapiteau sculpté de la cathédrale de Salamanque : le haut du corps velu laisse penser à un singe, tandis que jambes et pieds ressemblent à ceux d'un homme ${ }^{14}$.

9 La pilosité participe ensuite d'une animalisation très nette dans les images de la première moitié $d u x V^{e}$ siècle où l'homme sauvage est présenté comme une bête monstrueuse. L'abondance pileuse et l'hirsutisme, associées à une stature imposante, créent ainsi une ressemblance avec l'ours dans les scènes courtoises des coffrets d'ivoire parisiens montrant des sauvages lubriques terrassés par des chevaliers (fig. 1) ${ }^{15}$. Sur d'autres supports, comme c'est le cas par exemple avec une marge du psautier de la reine Mary (fig. 2), des jeux de contrastes sont établis entre le poil du sauvage et la peau lisse de l'homme ou de la bête domestique. L'animalisation est 
renforcée dans cette dernière image par la posture à quatre pattes du personnage qui s'apparente totalement à une bête sauvage traquée.

Fig. 1. - Chevalier délivrant une dame du sauvage.

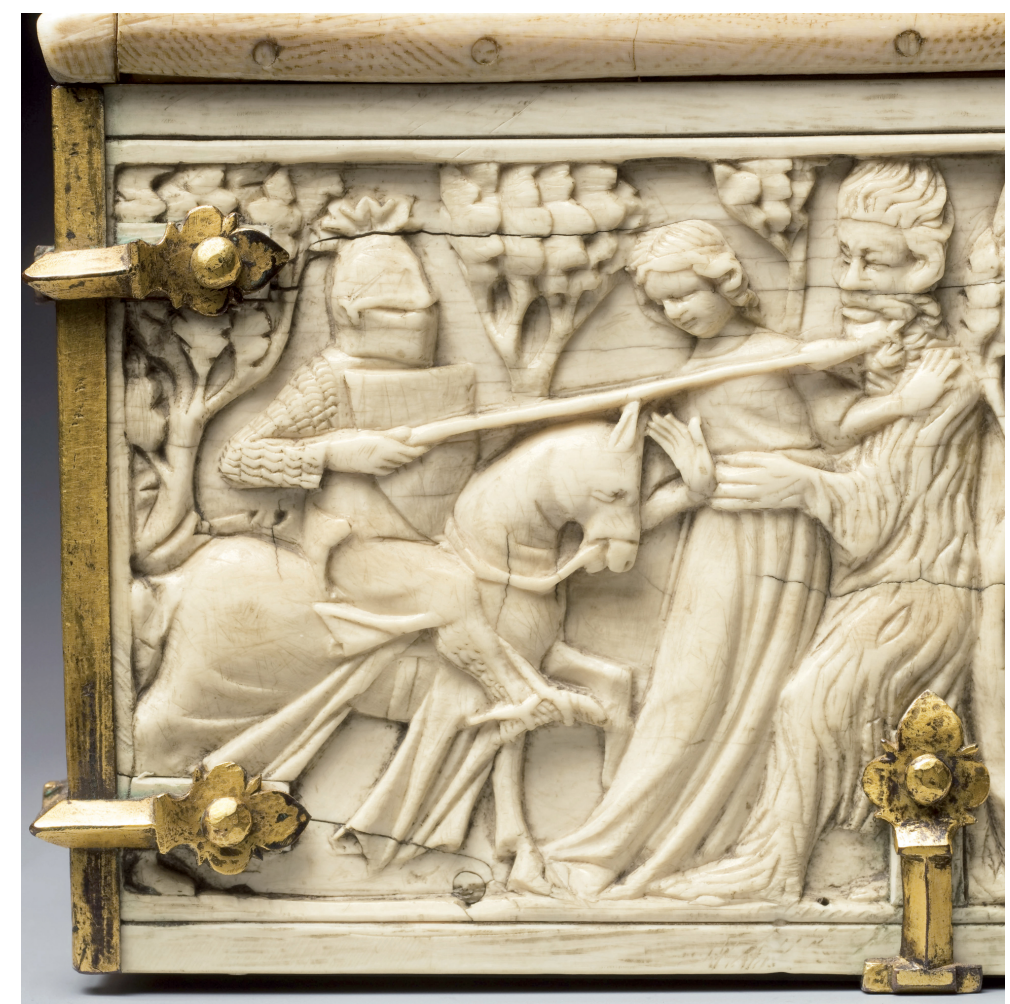

Panneau d'un coffret d'ivoire, vers 1300-1310, Paris, musée de Cluny - musée national du Moyen Âge, CL. 23840.

(c) RMN-Grand Palais (musée de Cluny - musée national du Moyen Âge)/Michel Urtado. 
Fig. 2. - Chasse de l'homme sauvage.

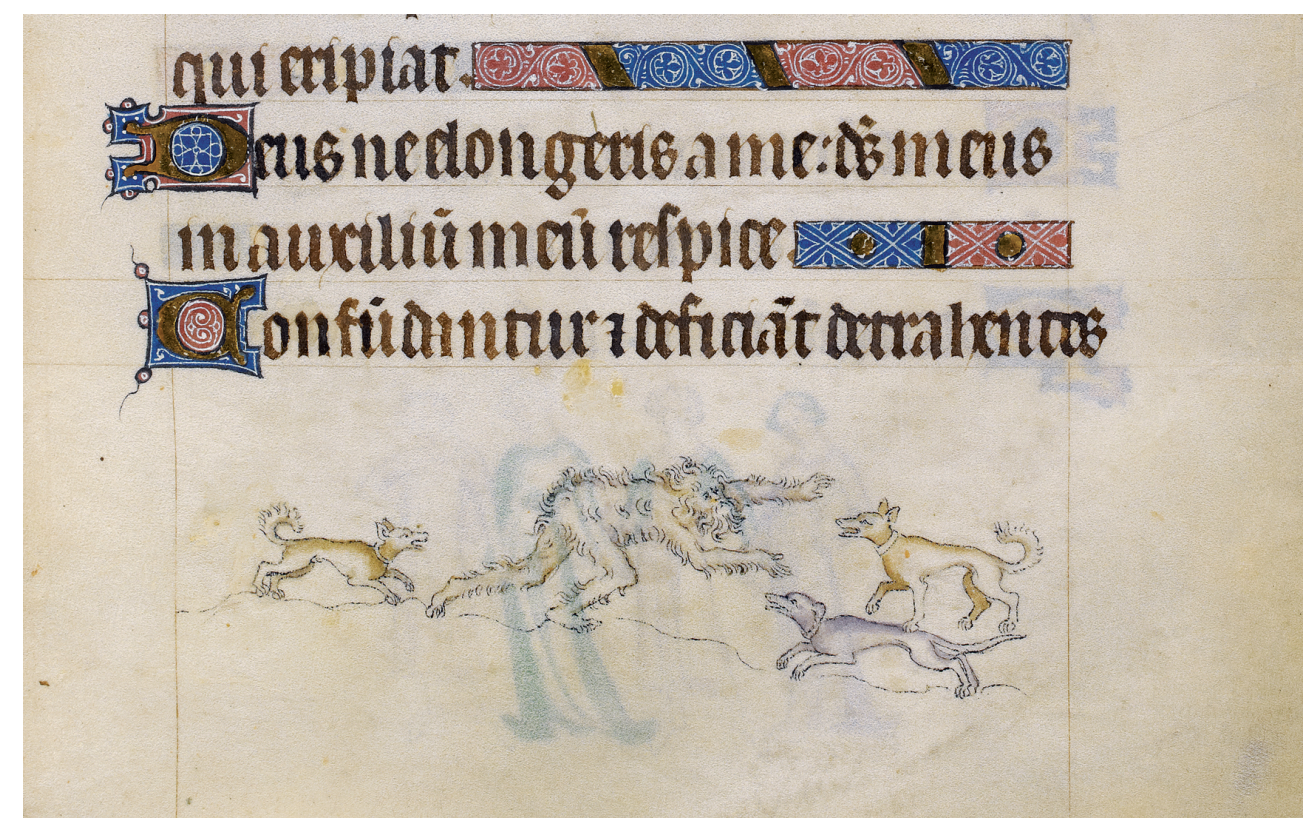

Miniature marginale du Psautier de la reine Mary, Angleterre, 1310-1320.

(Londres, British Library, ms. Royal 2 B VII), fol. 173.

Fig. 3. - Ange signant un contrat tenu par un homme sauvage, initiale historiée.

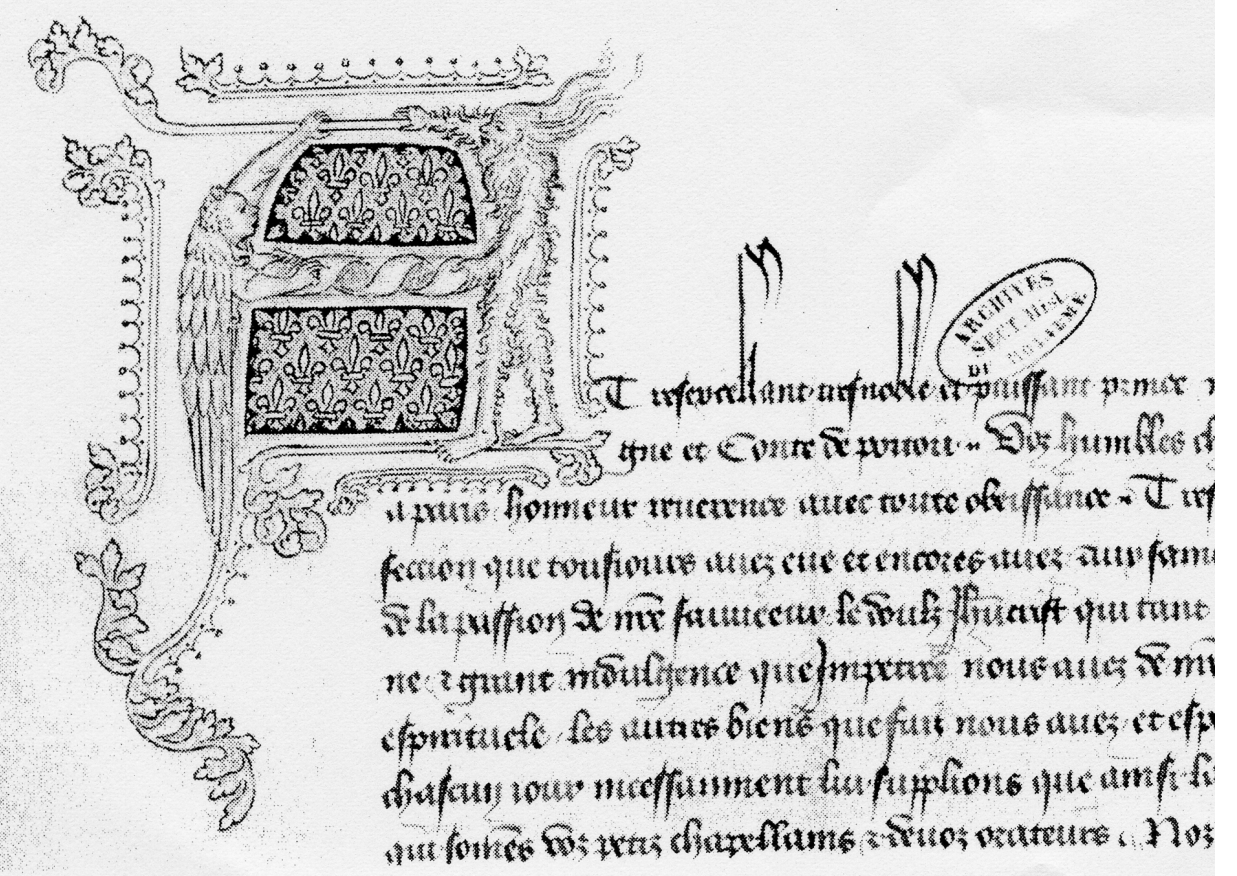

Engagement des chanoines de la Sainte-Chapelle envers Jean duc de Berry, Paris, 1386.

Paris, Centre historique des archives nationales, J 187 A - Berry.

Souvent brutaux et clairement animalisés dans les textes comme dans les images, encore relativement rares, et se distinguant de la plupart des créatures par leur dérangeante monstruosité, ces premiers hommes sauvages correspondant en tout point 
à la «merveille » médiévale ${ }^{16}$. Leur hybridité repoussante, associée à un comportement bestial, est présentée comme problématique et déroutante pour le lecteur ou le spectateur. Le succès du motif iconographique dans les décennies suivantes s'accompagne cependant d'une normalisation des formes corporelles du sauvage tendant à infléchir ce fonctionnement dans les images.

\section{L'humanisation du motif et de nouvelles formes d'hybridité}

11 L'animalisation par l'excès pileux recule en effet sensiblement dans les images à partir de la seconde moitié du XIV ${ }^{e}$ siècle. Le corps de l'homme sauvage s'humanise alors nettement, et ce par divers procédés :

- la pilosité se fait moins hirsute, la taille moins imposante et parfois le personnage est identifié symboliquement à l'homme, comme cela peut être le cas avec Samson (fig. 4);

- la pilosité est assez fréquemment absente sur les coudes et les genoux à partir de la fin du XIV ${ }^{\mathrm{e}}$ siècle, ce qui distingue le poil du sauvage de celui de la bête ${ }^{17}$;

- l'attitude du sauvage est souvent moins agressive, moins menaçante ou dirigée contre des créatures maléfiques comme les bêtes sauvages ou les dragons (fig. 4) (18 $^{18}$

- l'affirmation de la figure de la femme sauvage et la représentation de couples sauvages participent également, à travers le modèle de la famille nucléaire, à l'humanisation de la figure ${ }^{19}$;

- l'animalité du personnage recule également par l'usage de la parole : l'homme sauvage n'est plus systématiquement représenté comme une bête mutique, mais il s'adresse de plus en plus régulièrement au spectateur à partir de la fin du XIv siècle. C'est le cas dans une tapisserie réalisée à Ratisbonne en 1390 qui décline en six séquences de quatre médaillons la gamme des sentiments amoureux. Le sauvage indique ici que l'amour l'a domestiqué : il est passé de sauvage (« wild ») à docile (« zahm »)

Fig. 4. - Combat de Samson et du lion et d'un homme sauvage contre un dragon.

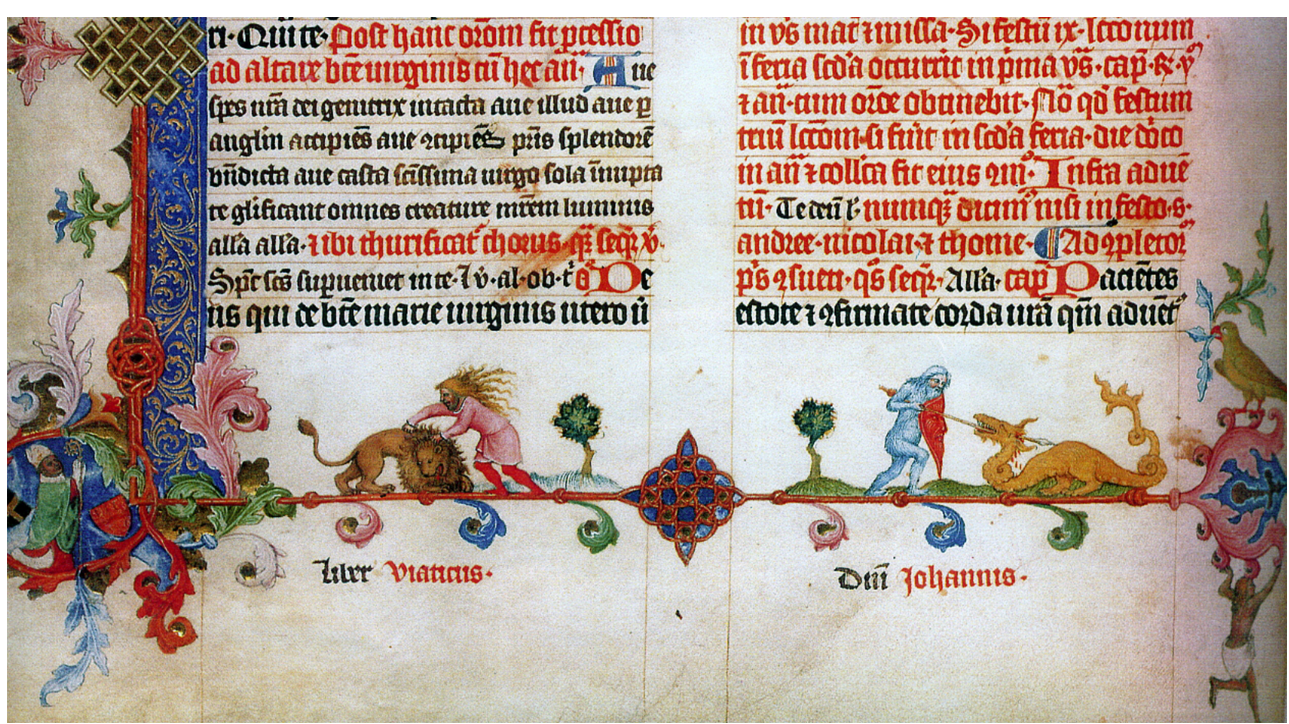

Miniature marginale du Liber Viaticus de Jean de Neumarkt, Prague, 1360-1364.

Prague, Galerie nationale, Cod. XIII A 12, fol. 69 v. 
12 À partir du troisième quart $\mathrm{du} \mathrm{xv}^{\mathrm{e}}$ siècle, la nature ambiguë de l'homme sauvage se réaffirme de nouveau, mais avec cette fois-ci de nouvelles formes d'hybridité. L'écart par rapport au modèle iconographique peut ainsi d'abord se manifester par un jeu sur les couleurs. Dans une marge de la Bible de Nicolas Rolin par exemple, le miniaturiste donne une dimension inquiétante à un homme sauvage musicien grâce à un pelage verdâtre (fig. 5) ${ }^{21}$.

Fig. 5. - Homme sauvage musicien.

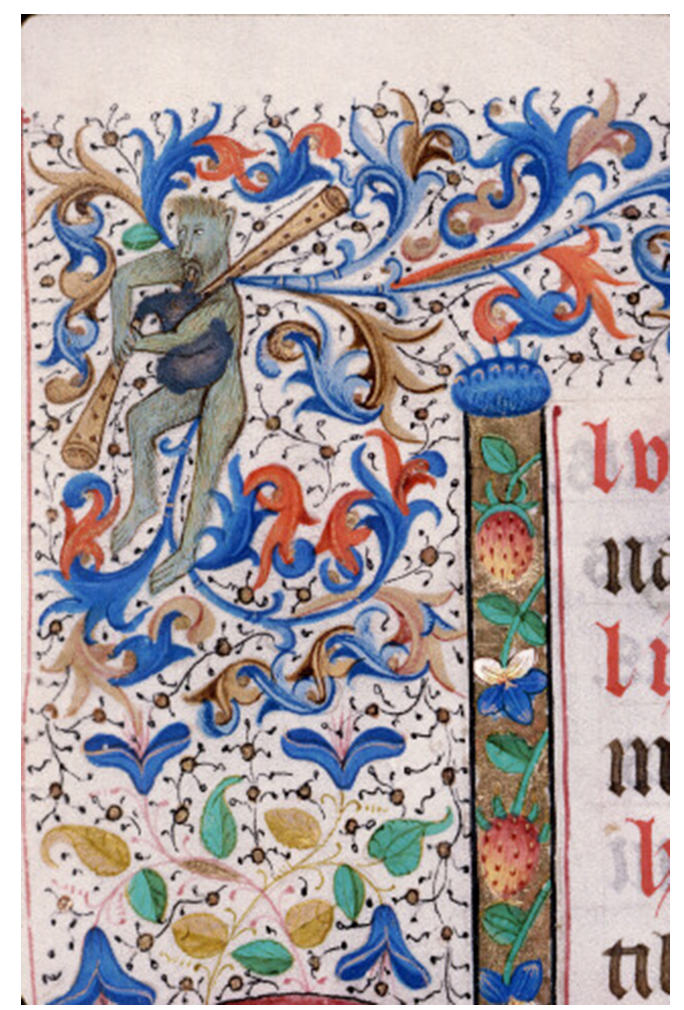

Miniature marginale de la Bible de Nicolas Rolin, France, vers 1460.

Autun, BM, ms. 275, fol. 3v.

Parfois, les artistes jouent également sur les couleurs de l'homme sauvage à l'intérieur d'un même manuscrit. En parallèle aux figures classiques, au pelage brun ou gris, certains hommes sauvages se distinguent ainsi par des couleurs étranges, comme c'est le cas dans les Heures de Marie de Bourgogne. Au folio 163 verso de ce manuscrit, un homme sauvage multicolore, doté d'une poitrine de femme, agite ostensiblement des clochettes (fig. 6) ${ }^{22}$. 
Fig. 6. - Liévin van Lathem, homme sauvage polychrome.

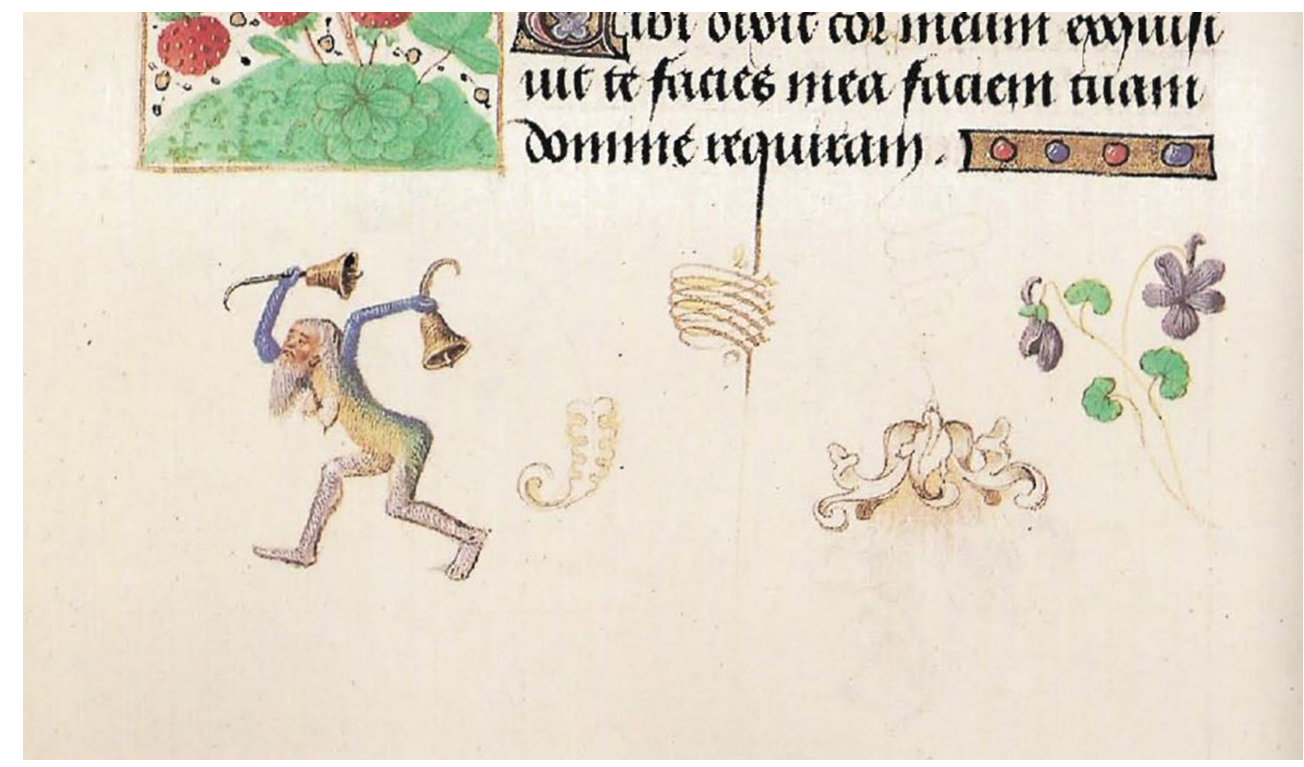

Miniature marginale des Heures de Marguerite de Bourgogne, Flandre, 1475-1480.

Vienne, Österreichische Nationalbibliothek, Codex Vindobonensis 1857, fol. 163v.

Certains hommes sauvages sont ensuite parfois représentés avec des parties animales, telles des queues de singes ${ }^{23}$, ou des cornes. Ainsi, un homme sauvage est affublé d'une corne de licorne dans un manuscrit du Maître de l'Échevinage de Rouen ${ }^{24}$. Ce jeu des artistes sur l'ambiguïté des figures est particulièrement net dans le cas de créatures à la limite entre l'homme, l'homme sauvage et le singe, dont on trouve plusieurs exemples à cette période ${ }^{25}$. Le singe constitue en effet la créature liminale par excellence. Isidore de Séville donne par exemple pour le mot « singe » (simia) une double étymologie, selon lui :

«Le nom du singe est grec et signifie "camus"; c'est pourquoi nous disons aussi simiae, parce qu'ils ont le nez plat et la face hideuse $»^{26}$.

Il rejette ensuite une seconde étymologie selon laquelle simia viendrait de similitudo, et marquerait la ressemblance avec la nature humaine. De nombreux auteurs du Moyen Âge ignorent cependant ces recommandations et insistent sur la similitude entre l'homme et la bête : le singe, trompeur, est un prétendant au statut d'homme. Dans une perspective morale et édifiante, plusieurs auteurs font ainsi du singe une figure du pécheur animalisé par ses fautes ${ }^{27}$.

L'homme sauvage est ensuite parfois confondu avec des hybrides canoniques, comme le centaure. On en trouve une illustration avec une marge d'un Miroir du monde enluminé à Paris dans le troisième quart du $\mathrm{Xv}^{\mathrm{e}}$ siècle (fig. 7). Le sauvage peut enfin se prêter à des hybridations radicales, et constituer des créatures totalement anomiques, comme cela apparaît à plusieurs reprises dans un livre d'heures de l'extrême fin du $\mathrm{XV}^{\mathrm{e}}$ siècle, dans lequel les hommes sauvages occupent la quasi-totalité des marges ${ }^{28}$. 
Fig. 7. - Femme sauvage centaure.

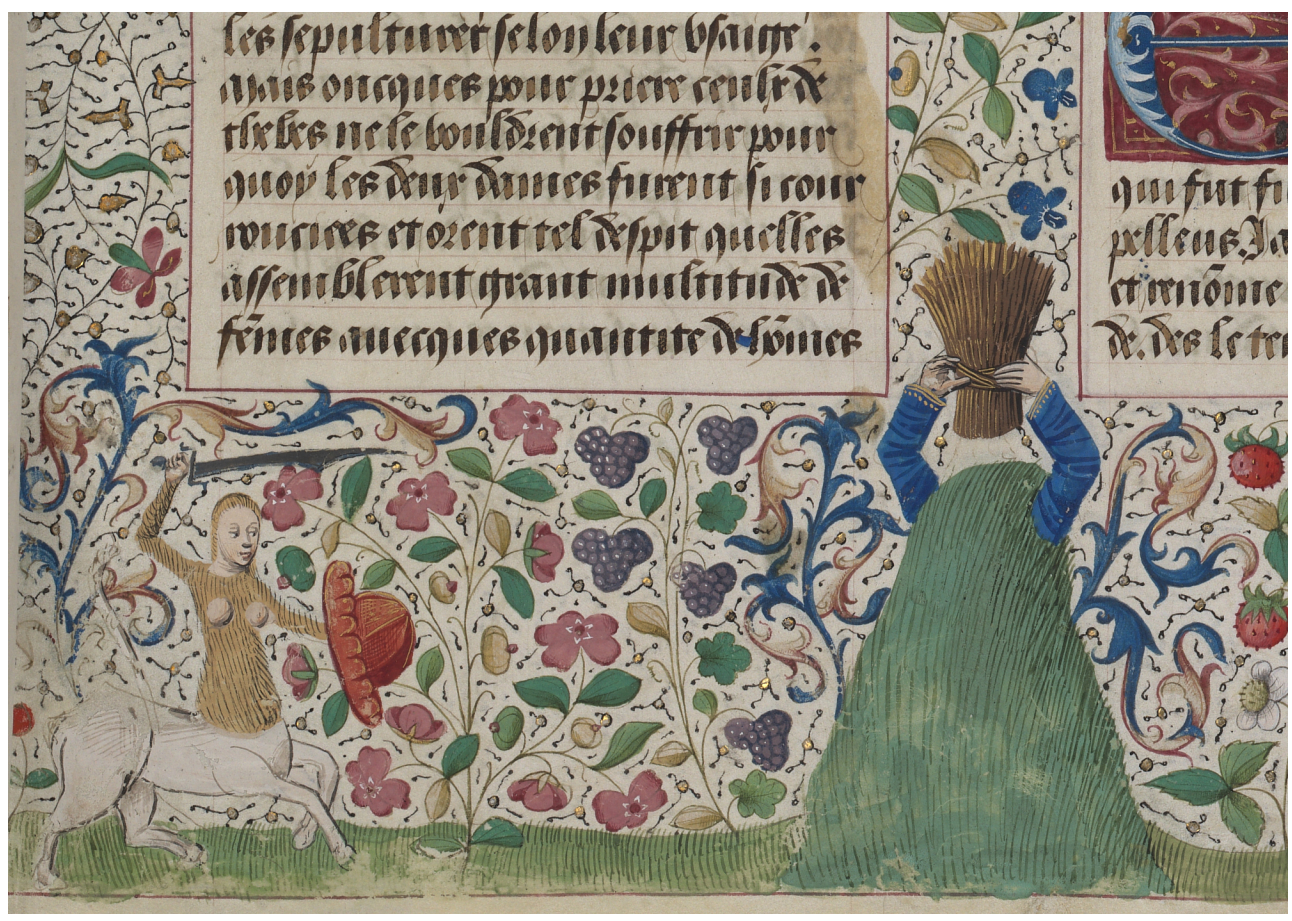

Miniature marginale d'un Miroir du monde, Paris, 1450-1475.

Paris, BnF, ms. Fr. 328, fol. 18

Cet examen rapide montre une désanimalisation assez évidente de l'homme sauvage entre le début $d u X^{e}$ et la fin $d u X V^{e}$ siècle. L'humanisation du corps et la diversification des usages de la figure sont liées à une banalisation du motif iconographique, procédant elle-même de la généralisation des images. Ainsi l'homme sauvage surprend moins au début $d u \mathrm{Xv}^{\mathrm{e}}$ siècle qu'une centaine d'années plus tôt. La nature ambiguë du personnage, sa position liminale entre l'homme et la bête n'est plus transgressive: il s'agit d'une hybridité admise, et la créature a été intégrée par la taxinomie médiévale. L'homme sauvage est nommé comme tel, et il a perdu de ce fait une partie de sa nature interstitielle ${ }^{29}$. De nouvelles formes d'hybridité s'affirment cependant dans la seconde moitié $d u \mathrm{Xv}^{\mathrm{e}}$ siècle quand l'homme sauvage humanisé est érigé en nouvelle norme anthropologique. Même s'il paraît difficile d'interpréter systématiquement les marginalia tardives, dont l'usage ornemental prime souvent sur le sens $^{30}$, ces jeux sur l'hybridité de la figure montrent à la fois la capacité des artistes à renouveler l'usage des motifs iconographiques et le foisonnement des questionnements sur l'animalité de l'homme dans cette période charnière d'affirmation de l'humanisme. 


\section{BIBLIOGRAPHIE}

Aristote, De la génération des animaux, Pierre Louis (éd. et trad.), Paris, Les Belles Lettres (Universités de France), 1961.

Albert le Grand, De Animalibus, dans Alberti Magni Ratisbonensis Episcopi, ordinis praedicatorum Opera Omnia, A. Borgnet (éd.), vol. XII, Paris, Ludovic Vivès, 1891.

BARTHOLEYNS Gil, DITTMAR Pierre-Olivier et JOLIVET Vincent, Image et transgression au Moyen Âge, Paris, Presses universitaires de France (Lignes d'art), 2008.

BERNHEIMER Richard, Wild Men in the Middle Ages. A Study in Art, Sentiment, and Demonology, Cambridge, Harvard University Press, 1952 [rééd. New York, Octagon Books, 1970].

BOUTET Dominique, « Les peuples étranges dans la chanson de geste (XII ${ }^{\mathrm{e}}-\mathrm{XIV}^{\mathrm{e}}$ siècles) », dans THOMASSET Claude et JAMES-RAOUL Danièle (dir.), En quête d'utopies, Paris, PUPS, 2005, p. 155-182.

CAAMAÑO MARTíNEZ Juan Manuel, « Un precedente romanico del "salvaje” », Boletin del Seminario de Estudios de Arte y Arqueologia Valladolid, 1984, n 50, p. 399-401.

DITTMAR Pierre-Olivier, « Naissance de la bestialité. Une anthropologie du rapport homme-animal dans les années $1300 »$, thèse de doctorat, Paris, EHESS, 2010.

DUBOST Francis, Aspects fantastiques de la littérature narrative médiévale (XII -XIII siècles) : l'Autre, l'Ailleurs, l'Autrefois, Paris, Honoré Champion, 1991, 2 vol.

GONTIER Thierry, De l'homme à l'animal. Paradoxes sur la nature des animaux. Montaigne et Descartes, Paris, Vrin, 1998.

HUSBAND Timothy, The Wild Man. Medieval Myth and Symbolism, New York, Metropolitan Museum of Art, 1980.

Isidore de SÉVILLE, Étymologies. Livre XII : Des animaux, J. André (éd., trad. et com.), Paris, les Belles Lettres (Auteurs latins du Moyen Âge, 6), 1986.

JEANJEAN Benoît, « Esaü le velu, figure biblique du réprouvé chez les Pères de l'Église », dans LANÇON Bertrand et DELAVAUD-ROUX Marie-Hélène (dir.), Anthropologie, mythologies et histoire de la chevelure et de la pilosité. Le sens du poil, Paris, L'Harmattan (Le Corps en question), 2011, p. 33-46.

LECLERC-MARX Jacqueline, La sirène dans la pensée et dans l'art de l'Antiquité et du Moyen Âge. Du mythe païn au symbole chrétien, Bruxelles, Académie royale de Belgique, 1997.

LE GOFF Jacques, « Merveilleux », dans Jacques LE GOFF et Jean-Claude schmitT (dir.), Dictionnaire raisonné de l'Occident médiéval, Paris, Fayard, 1999, p. 709-724.

LE GOFF Jacques, « Le merveilleux dans l'Occident médiéval » dans Jacques LE GOFF, L'imaginaire médiéval (1985), rééd., dans Un autre Moyen Âge, Paris, Gallimard, 1999, p. 455-475.

Les deux rédactions en vers du Moniage Guillaume, Cloetta Wilhelm (éd.), 2 vol., Paris, Firmin, Didot et Cie, 1906, vol. 1, p. 159.

Les Narbonnais, Suchier Hermann (éd.), Paris, Firmin Didot et Cie, 1898, 2 vol.

LUGT Maaike (VAN DER), Le ver, le démon et la vierge. Les théories médiévales de la génération extraordinaire. Une étude sur les rapports entre théologie, philosophie naturelle et médecine, Paris, Les Belles Lettres, 2004. 
PASTOUREAU Michel, «L'animal », dans DALARUn Jacques (dir.), Le Moyen Âge en lumière. Manuscrits enluminés des bibliothèques de France, Paris, Fayard, 2002, p. 64-105.

PASTOUREAU Michel, « L'animal et l'historien du Moyen Âge », dans BERLIOZ Jacques et POLo de BEAULIEU Marie-Anne (dir.), L’Animal exemplaire au Moyen Âge, Rennes, PUR, 1999, p. 13-26.

PASTOUREAU Michel, «Le bestiaire iconographique du diable, animaux, formes, pelages, couleurs », dans Démons et merveilles au Moyen Âge, actes du IV colloque international du Centre d'Études Médiévales de Nice (13 et 14 mars 1987), Nice, Université de Nice Sophia-Antipolis, 1990, p. 185-193.

PASTOUREAU Michel, Une histoire symbolique du Moyen Âge, Paris, Seuil (La librairie du XxI ${ }^{\mathrm{e}}$ siècle), 2004.

PELLEGRIN Pierre, La Classification des animaux chez Aristote. Statut de la biologie et unité de l'aristotélisme, Paris, Les Belles Lettres, 1982.

Pierre de ABANO, Compilationis phisonomie, édition de P. Mauser, Padoue, 1474.

POUVREAU Florent, Du poil et de la bête. Iconographie du corps sauvage en Occident à la fin du Moyen Âge (XIII $-\mathrm{XVI}^{e}$ siècle), Paris, Éd. du Comité des travaux historiques et scientifiques, 2014.

RAPP BURI Anna et STUCKY-SCHÜRER Monica, Zahm und wild. Basler und Straßburger Bildteppiche des 15. Jahrunderts, Mayence, P. von Zabern, 1990.

SCHROEDER Nicolas, « "Nature” et Moyen Âge. Quelques remarques pour l'histoire de l'environnement et l'écologie en politique », Etopia. Revue d'Écologie Politique [en ligne], 2010, n 7 (Philosophie de la nature), p. 137-148.

Trésor de la langue française informatisé [en ligne], éd. Analyse et traitement informatique de la langue française, Paris, 2004, [URL : http://atilf.atilf.fr/.]

VOISENET Jacques, Bêtes et hommes dans le monde médiéval. Le bestiaire des clercs du v $v^{e}$ au XII siècle, Turnhout, Brepols, 2000.

WILCKENS Leonie (VON), « Die Mittelalterlichen Bildteppiche aus dem Alten Rathaus », dans M. ANGERER et H. WANDERWITZ (éd.), Regensburg im Mittelalter, vol. II, Katalog der Abteilung Mittelalter im Museum der Stadt Regensburg, Ratisbonne, Universitätsverlag Regensburg, 1995, p. 147-149.

WIRTH Jean, Les Marges à drôleries des manuscrits gothiques (1250-1350), Genève, Droz (Matériaux pour l'Histoire publiés par l'École des chartes, 7), 2008.

ZUCKER Arnaud, « La physiognomonie antique et le langage animal du corps », Rursus [en ligne], éd. numérique, $\mathrm{n}^{\circ}$ 1, 2006, [URL : http://rursus.revues.org/index58.html.]

\section{NOTES}

1. M. Pastoureau, Une histoire symbolique du Moyen Âge, p. 33-39 et 45. Dans ces pages, l'auteur revient sur le procès de Falaise en Normandie, en 1386. Une truie y est jugée pour avoir tué un nourrisson. L'animal est condamné à mort et exécuté devant une foule composée d'hommes et de cochons. Les porcs ont été conviés à l'exécution par le vicomte de Falaise afin que le châtiment "leur fasse enseignement». Michel Pastoureau rappelle à propos de cet épisode qu' «au Moyen Âge, pour un certain nombre d'auteurs, l'animal est en partie responsable de ses actes ». Cet exemple, ainsi que les remarques de l'auteur, sont repris dans un article stimulant sur les conceptions 
de la nature au Moyen Âge: N. Schroeder, «"nature" et Moyen Âge. Quelques remarques pour l'histoire de l'environnement et l'écologie en politique », p. 143.

2. Saint Augustin est l'un des premiers grands penseurs chrétiens à affirmer la supériorité radicale de l'homme sur l'animal. Il reconnait aux animaux une force permettant l'exercice des sens et de la mémoire (Confessions, Livre X, chap. VII et XVII) mais leur refuse, contrairement à saint Paul, la qualité d'« âme ». Ce terme est réservé à l'âme humaine, désignant la seule pensée pure et intellectuelle ; T. Gontier, De l'homme à l'animal, p. 30. Augustin, scellant ainsi le dogme chrétien de l'immortalité de l'âme, laisse donc avec ses écrits de jeunesse un important héritage dualiste à ses successeurs, bien que lui-même s'en détache progressivement ; E.-H. Weber, La personne humaine au XIII siècle, p. 29.

3. Aristote défend l'idée d'une " unité structurelle et fonctionnelle de tous les êtres vivants ", qui, accompagnée d'une conception hiérarchique, « lui fait ranger les vivants dans un ordre de perfection croissante ", l'homme étant " le stade ultime de cette échelle des êtres »; P. Pellegrin, La Classification des animaux chez Aristote, p. 110.

4. Ainsi, si l'évêque Guillaume d'Auvergne soutient par exemple au début du xIII siècle que la proximité de l'homme et de l'ours permet un accouplement fécond, donnant naissance à de vrais hommes (veri homines), il le fait en recourant à des récits folkloriques et ne trouve aucun soutien des autorités savantes; M. Van der Lugt, Le ver, le démon et la vierge, p. 259-260.

5. C'est ce qu'a montré récemment le travail de thèse de P.-O. Dittmar, L'invention de la bestialité, dans une étude appuyée à la fois sur les textes et les images.

6. Sur l'iconographie de l'homme sauvage au Moyen Âge voir en particulier R. Bernheimer, Wild Men in the Middle Ages ; T. Husband, The Wild Man : Medieval Myth and Symbolism ; F. Pouvreau, Du poil et de la bête ; A. Rapp Buri et M. Stucky-Schürer, Zahm und wild. Basler und Straßburger Bildteppiche des 15. Jahrunderts.

7. Sur la figure de la sirène dans l'art médiéval voir le travail remarquable de J. LeclercMarx, La sirène dans la pensée et dans l'art de l'Antiquité et du Moyen Âge.

8. Albert le Grand, De Animalibus, lib.XIX, cap.6; Barthélémy l'Anglais, Liber de proprietatibus rerum, lib. V, cap. 65.

9. « Il [le lièvre] a beaucoup de sperme. Ce qui le montre, c'est l'abondance de son poil : sa fourrure est excessivement épaisse. [...] Or le développement du système pileux est l'indice d'une abondance de résidu, et c'est pourquoi, parmi les hommes eux-mêmes, ceux qui sont velus sont plus portés à l'amour et ont plus de sperme que ceux qui sont dépourvus de poils »; Aristote, De la génération des animaux, IV, 5, P. Louis (éd. et trad.), Paris, Les Belles Lettres, 1961, p. 165.

10. Pour le pseudo-Aristote, $72 \%$ des émotions et des comportements signifiés par la pilosité reposent sur une sémiologie zoologique ; A.Zucker, «La physiognomonie antique et le langage animal du corps", Rursus [En ligne], n ${ }^{\circ} 1,2006$, consulté le 22/01/2019, URL : http://rursus.revues.org/index58.html. L'analogie animale n'est pas systématique dans les traités médiévaux, mais elle se retrouve par exemple à propos de la pilosité dans l'œuvre de Pierre d'Abano, composée à la fin du XIII' siècle.

11. P. d'Abano, Liber compilationis phisonomie, édition de P. Mauser, Padoue, 1474, pars II, cap. 1 , decisio 5 . 
12. Jérôme de Stridon, In Ezechielem, 11-35, cité et traduit par B. Jeanjean, «Esaü le velu, figure biblique du réprouvé chez les Pères de l'Église », p. 44.

13. Dans Les Narbonnais, un passage remanié de la version D E évoque des païens cornus et velus : "En sa compaigne avoit paiens cornus, / Et conme chiens estoit chascun velus » (v. 7203-7204) ; Les Narbonnais, vol. 2, p. 88. De même, la version B de la seconde rédaction du Moniage Guillaume décrit un géant velu comme un ours et ressemblant au diable : «Et .i. gaiant qui fu desmesures Bien resembloit diable et uif malfe Si ert velus con ours encaenes " (v. 2483 et suiv.) ; Les deux rédactions en vers du Moniage Guillaume, vol. 1, p. 159. Voir également l'article de D. Boutet, "Les peuples étranges dans la chanson de geste (XII ${ }^{\mathrm{e}}$-XIV ${ }^{\mathrm{e}}$ siècles) », p. 164-165.

14. J. M. Caamaño Martínez a montré, en s'appuyant sur l'observation de la stature (équivalente à celle de l'homme lui faisant face) et des pieds du personnage qu'il ne s'agissait pas d'un singe ; J. M. Caamaño Martínez, " Un precedente romanico del "salvaje" ".

15. Sur la série de coffrets d'ivoire représentant des hommes sauvages tentant d'enlever de jeunes demoiselles, voir F. Pouvreau, Du poil et de la bête, p. 111-115.

16. Au Moyen Âge, une «merveille » est un élément d'une image ou d'un récit qui « se caractérise par la rareté et par l'étonnement » qu'il suscite ; J. Le Goff, « Merveilleux », p. 710. La merveille implique également une dimension visuelle (comme l'indique sa racine mir) ; J. Le Goff, «Le merveilleux dans l'Occident médiéval», p. 456. Pour la littérature, Francis Dubost définit la merveille comme "l'événement, surnaturel ou non, par lequel le récit s'écarte des représentations inscrites dans l'horizon d'attente du lecteur. Elle marque un point de rupture dans la prévisibilité narrative et rend soudain problématique la matière de la fiction ». Sont ainsi considérées comme des merveilles les évènements caractérisés par une transgression des lois de la nature (pierre qui flotte, résurrection, etc.), les capacités cognitives extraordinaires (clairvoyance, omniscience, etc.), les capacités opératives spécifiques (technique, magie), ou enfin les êtres considérés comme monstrueux (sirène, dragon, ou homme sauvage) ; F. Dubost, Aspects fantastiques de la littérature narrative médiévale, vol. 1, p. 63.

17. Sur un échantillon de 220 œuvres dans lesquelles sont représentés des hommes sauvages sur la période, ces derniers apparaissent avec les coudes ou les genoux glabres dans une quarantaine d'œuvres. Rien ne permet d'affirmer qu'il s'agit de représentations inspirées de spectacles dans lesquelles les artistes auraient reproduit les ouvertures pratiquées sur les costumes, ou que ces parties glabres correspondent à l'usure du pelage en contact avec le sol ; F. Pouvreau, Du poil et de la bête, p. 78 et 127.

18. L'homme sauvage est également fréquemment opposé à des dragons sur les tympans sculptés d'églises de l'Est de l'Angleterre au $\mathrm{Xv}^{\mathrm{e}}$ siècle. La position des représentations, à l'entrée de l'édifice sacré, ainsi que la charge symbolique de l'animal combattu donnent incontestablement au sauvage une dimension positive et protectrice ; F. Pouvreau, Du poil et de la bête, p. 141-142.

19. Un célèbre exemple de ce type de représentations est la famille sauvage gravée par le maître BXG entre 1470 et 1490; T. Husband, The Wild Man, Medieval Myth and Symbolism, fig. 11, p. 11.

20. Ratisbonne, Rathaus, tapisserie aux médaillons, médaillon 12. Cette tapisserie est absente du corpus de R. Bernheimer. Les six thèmes sont respectivement : les 
supplications, la conquête, les joies, les douleurs, la folie et la certitude de l'amour ; L. von Wilckens, « Die Mittelalterlichen Bildteppiche aus dem Alten Rathaus ", $\mathrm{n}^{\circ}$ 20.1, p. 148.

21. La couleur verte, la moins dense pour l'œil médiéval, est souvent utilisée pour les créatures étranges; M. Pastoureau, « le bestiaire iconographique du diable », p. 192.

22. Ce manuscrit comporte de nombreuses représentations d'hommes et de femmes sauvages, la plupart représentés avec un poil gris brun: Vienne, Österreichische Nationalbibliothek, Codex Vindobonensis 1857, fol.37, 57v, 108, 178v, 179v. Les sauvages multicolores des folios $160 \mathrm{v}$ et $163 \mathrm{v}$ se détachent clairement de cette série. Pour ce dernier folio, la présence d'une poitrine féminine accentue le jeu sur les limites et la volonté de brouillage, entre les espèces mais également entre les genres.

23. C'est le cas dans un livre d'heures à l'usage d'Evreux : Oxford, Bodleian Library, ms. Liturg. 59, fol. 54 (1450-1475).

24. New York, Pierpont Morgan Library, ms. M 167, fol. 40v (1465-1475).

25. Plusieurs marges de livres d'heures de la fin $d u \quad x v^{e}$ siècle offrent des représentations d'hommes sauvages simiesques: New York, Pierpont Morgan Library, ms. G 9, fol. 100 (vers 1450); Oxford, Bodleian Library, ms. Rawl. Liturg. e 17, fol. 86 (1450-1475) ; New York, Pierpont Morgan Library, ms. S 4, fol. 42v (1485); New York, Pierpont Morgan Library, ms. M 175, fol.97v (vers 1500). Ces représentations se retrouvent également dans les marges d'ouvrages profanes, comme c'est le cas d'un manuscrit de la Fleur des Histoires de Jean Mansel enluminé en France dans la seconde moitié du Xve siècle : Paris, BnF, ms. fr. 56, fol. 43v.

26. Isidore de Séville, Étymologies. Livre XII : Des animaux, p. 114.

27. J. Voisenet, Bêtes et hommes dans le monde médiéval, p. 65-66.

28. Les Heures de Vanderbilt (New Haven, Yale University, Beinecke Rare Book and Manuscript Library, Harley ms. 436) comportent 140 images marginales d'hommes sauvages. Certains subissent des hybridations radicales, comme un sauvage ailé au buste posé sur un corps de dragon au folio $46 \mathrm{v}$.

29. Sur le rapport entre taxinomie et transgression, voir M. Pastoureau, «L'animal et l'historien du Moyen Âge ", p. 21-23; id., "L'animal », p. 81 ; G. Bartholeyns, P.O. Dittmar et V. Jolivet, Image et transgression au Moyen Âge,p. 26-30.

30. Pour une tentative de synthèse récente sur l'interprétation des marges des manuscrits à peinture, voir J. Wirth, Les marges à drôleries des manuscrits gothiques.

\section{RÉSUMÉS}

L'homme sauvage, qui s'impose dans l'art occidental à partir du XIII ${ }^{\mathrm{e}}$ siècle, est un personnage éminemment hybride: il est recouvert dans les textes comme dans les images d'une pilosité surabondante dont le caractère animal est attesté dans toutes les sources écrites (littérature, encyclopédisme, médecine). Évidente dans les textes, l'animalité du sauvage est en revanche de moins en moins nette dans les images. De la seconde moitié du XIV siècle à la fin du Xve siècle, 
l'évolution de la figure est ainsi caractérisée par une fixation des formes du motif iconographique et par une humanisation du personnage. L'homme sauvage échappe ainsi progressivement au registre du fantastique pour constituer une norme anthropologique. Le pelage n'y suffisant plus, les artistes jouent désormais, lorsqu'ils veulent animaliser le personnage, sur d'autres formes d'hybridité comme la couleur, la ressemblance avec le singe ou l'addition de parties animales (cornes, queues, sauvages centaures).

\section{AUTEUR}

\section{FLORENT POUVREAU}

Docteur en histoire médiévale et professeur agrégé (académie de Grenoble) 


\title{
L'animal nourricier d'enfants dans la mythologie grecque
}

\author{
Liliane Romy-Regent
}

1 Dans la mythologie, les récits d'enfants de dieux, de héros ou d'hommes élevés ou confiés à des nourrices animales sont nombreux. Cette conception de «l'animal nourrice » est une tradition orientale que l'on retrouve pratiquement dans toutes les civilisations, et certaines légendes sont restées célèbres : comme l'image de la louve romaine allaitant Rémus et Romulus, de la vache Hathor allaitant Pharaon ou de la chienne allaitant le perse Cyrus.

2 Ce thème est également très présent dans l'imaginaire grec et je présenterai donc l'étude de quelques mythes de ces enfants élevés par un animal au travers de deux sources documentaires: les sources littéraires allant du viII siècle av. J.-C. jusqu'au II ${ }^{\mathrm{e}}$ après J.-C., et les sources iconographiques, notamment les monnaies. Ces sources iconographiques sont peu nombreuses parce que les Grecs ne représentaient que très rarement les scènes d'allaitement. L'analyse de ces allaitements mythiques montre des particularités dans le monde grec à la fois par le choix de l'animal, le statut de l'enfant et la finalité de cet allaitement. Intéressons-nous à cet animal et analysons son habilitation à la fonction nourricière. Existe-t-il en Grèce un animal nourricier par excellence? Que symbolise cet animal aux yeux des Grecs? Que va-il-apporter à l'enfant? À travers l'analyse des mythes, certains animaux se rencontrent plus fréquemment que d'autres dans ce rôle d'allaitement. C'est le cas de la chèvre.

\section{La chèvre}

\section{Zeus}

Hésiode rapporte que le titan Cronos engloutit tous ses enfants mâles de peur d'être détrôné par l'un d'eux selon la prédiction de l'oracle. Pour protéger son dernier né, Zeus, sa mère Rhéa utilise une ruse, au moment de donner son fils :

«Elle entoure de langes une grosse pierre que Cronos engloutit... ${ }^{1}$ 
Ensuite, Hésiode rapporte qu'arrivée à Lyctos en Crète, Rhéa :

«L'emporte à la faveur de la nuit rapide... puis, de ses mains, elle le cache aux creux d'un antre inaccessible, dans les profondeurs secrètes de la terre divine aux flancs du mont Égéon que recouvrent des bois épais. $»^{2}$

Apollodore précise :

«Elle le donne à élever aux Curètes et aux nymphes Adraste et Ida, filles de Mélissus qui le nourrissent du lait de la chèvre Amalthée, et du miel de l'abeille Panacris, tandis que les Curètes gardent l'antre en frappant fortement leurs lances contre leurs boucliers, pour empêcher que les cris du nouveau-né ne parviennent à Cronos. $»^{3}$

Callimaque ajoute :

"Que les Nymphes le reçurent dans leurs bras et le mirent dans un berceau d'or, où Adrastée provoqua son sommeil. $»^{4}$

7 À la mort d'Amalthée, la peau de la chèvre, l'égide, deviendra le symbole de Zeus et le symbole de la protection. Cette égide sera portée plus tard par sa fille Athéna comme une sorte de bouclier sur son bras ${ }^{5}$.

\section{Égisthe}

Fils de Thyeste et de sa fille Pélope de la maison des Atrides, il est le fils de deux mortels. Il est né d'un inceste. Thyeste voulait se venger d'Atrée, son jumeau qui l'avait dépossédé du pouvoir et lui avait fait manger ses propres enfants. Il consulta l'oracle et celui-ci lui commanda d'avoir un fils avec sa propre fille ${ }^{6}$; il engendre donc Égisthe (Aigisthos vient d'Aigos la chèvre). Il est allaité par une chèvre ${ }^{7}$, recueilli par un berger et gardé par un chien de troupeau. Là encore, cet enfant fait partie des enfants monstrueux dont il faut se défaire.

\section{Asklepios}

9 Fils d'Apollon et de Coronis. C'est le fils d'un dieu et d'une mortelle. Apollon séduit la nymphe Coronis, la fille de Phlégias. Séduire une nymphe, une vierge a quelque chose de monstrueux et cet enfant est exposé par sa mère sur une montagne appelée Myrtium. En quelque sorte, Coronis le redonne à la nature dont elle est issue. L'enfant est nourri par une chèvre nommée " Trygone ${ }^{8}$ " et gardé par le chien de troupeau". Un matin, le berger Aresthanas s'aperçoit que sa chèvre n'a plus de lait et que son chien n'est jamais là. Il découvre l'enfant abandonné, mais au moment où il veut le prendre dans ses bras, une lumière l'éblouit. Il comprend que cette naissance est divine.

\section{Philacis et Philander}

Ce sont les fils de la nymphe Acacallis, fille de Minos premier roi de Crète et d'Apollon, enfants donc d'une nymphe et d'un dieu. Leur mythe nous est connu grâce à Pausanias qui raconte qu'Apollon eut deux enfants, qui furent allaités par une chèvre. De son vivant, il y avait dans les montagnes de la Crète une ville nommée Elyros dont ses habitants avaient envoyé à Delphes une chèvre de bronze pour allaiter deux jeunes enfants, Phylacis et Phylander ${ }^{10}$. 


\section{Le symbolisme de la chèvre en Grèce}

11 En Grèce, la chèvre est un animal très fréquent à l'état sauvage. Elle vit dans les Eschatai, les confins, c'est-à-dire dans les régions montagneuses, isolées, escarpées et boisées, à la limite de la terre cultivée et du monde sauvage. Pausanias mentionne des chèvres sur les hauteurs du Taygète dans le Péloponnèse ${ }^{11}$. De nombreuses îles portent encore dans leur nom le souvenir de leur présence (Polyaigos, dans les Cyclades). C'est du gibier dont la chair est très appréciée. Homère rapporte la chasse d'Ulysse :

«L'aurore fit lever de leur gîte des chèvres montagnardes, bon repas pour mes

compagnons... ce qui leur permet de festoyer jusqu'au coucher du soleil. $»^{12}$

Les chèvres sont aussi des ennemies de la culture, elles peuvent faire des ravages dans les plantations, détruire les arbres. La chèvre peut être également un animal d'élevage. Le cheptel d'Ulysse dénombre 11 grandes hardes de chèvres qui broutent à l'extrémité de l'île d'Ithaque ${ }^{13}$. Mais c'est le caractère des chèvres qui semble très intéressant. Selon Aristote, sa nature n'est pas stable, mais vive et changeante ${ }^{14}$. Même domestiquée, elle demeure imprévisible. Ce qui fait dire à Jean-Pierre Vernant que :

«La chèvre est l'animal le moins social, le moins domestiqué des bêtes de troupeaux. $»^{15}$

13 Et à Ludovic Teillier :

«Chez la chèvre les frontières qui séparent le civilisé du sauvage ne sont jamais définitivement fixées [...] La chèvre relève de deux mondes: elle occupe une position liminale entre le monde sauvage et le monde civilisé. $»^{16}$

C'est aussi l'animal préféré d'Artémis, les Grecs sacrifient des chèvres domestiques en son honneur ou pour s'assurer de sa protection avant les combats. À Athènes, on sacrifie 300 chèvres à Artémis pour célébrer la victoire sur les Perses ${ }^{17}$. Dans cet espace intermédiaire, la chèvre a donc tout à fait sa place pour allaiter l'enfant destiné sans cela à mourir. En tant qu'animal d'Artémis, elle participe à la protection des tout-petits. De plus, en allaitant l'enfant elle prépare son passage, son retour vers le monde humain. En effet, le lait est un aliment qui n'est pas du côté du sauvage, du cru, c'est un aliment cuit à l'intérieur. Aristote le décrit comme « une matière dont dont la coction est parfaite $»^{18}$. Ce n'est donc pas un aliment ordinaire, il facilite le passage entre le cru et le cuit.

\section{L'ourse}

\section{Atalante}

C'est la fille de Iasos, roi du Péloponèse et de Clyméné, la fille de Minyas. C'est donc la fille de deux humains. Apollodore en fait le récit :

«Iasos, son père, l'a exposée tout enfant sur le Mont Pélion car il désirait des garçons. $»^{19}$

Élien décrit la scène :

«Une ourse aux mamelles gonflées et alourdies de lait, à laquelle les chasseurs avaient enlevé ses petits, arriva et mue par une inspiration divine, elle se réjouit de la découverte de l'enfant et l'allaita. La bête fut ainsi soulagée de ses souffrances et procura en même temps de la nourriture au bébé. Encore pleine et regorgeant de 
lait, puisqu'elle n'était pas restée la mère de ses petits elle devint la nourrice de cette enfant qui pourtant n'était pas sienne. $»^{20}$

à la course, ce qui est vrai car elle est la plus rapide. Atalante fait partie de l'entourage d'Artémis, C'est une chasseresse, une archère experte, c'est-à-dire qu'elle appartient au monde des combattants les plus sauvages. Dans la chasse de Calydon, c'est elle qui, la première, blesse à mort le redoutable sanglier, elle encore qui perce de ses traits les Centaures Rhoecos et Hylaeos qui veulent la violer ${ }^{22}$. Cependant la ruse de l'un de ses courtisans, Hippomenes, va l'obliger à renoncer à son statut de nùmphê (jeune fille). Et elle va alors commettre un sacrilège en ayant une union sexuelle dans un sanctuaire sacré d'Artémis, se comportant alors comme une bête sauvage. Pour la punir, Artémis la change en ourse puis Zeus la métamorphose en constellation de l'Ourse. Le couple n'a pas respecté les bonnes règles sociales. S'unir dans le domaine d'Artémis est une insulte à la déesse, c'est un mariage raté. Elle est changée en ce qu'elle était: une ourse. L'élevage par une ourse n'a pas permis à Atalante de maitriser son côté animal et le retour vers les hommes n'a pu se faire. Tout au plus, sa transformation en constellation lui confère-t-elle un destin supérieur.

\section{Pâris/Alexandre}

Pâris, né d'Hécube et de Priam, roi de Troie, est le fils de deux mortels. Enceinte, Hécube fait un rêve prémonitoire : elle enfanterait un brandon enflammé symbole de la destruction de Troie ${ }^{23}$. Hécube raconte son rêve à Priam qui fait interpréter le songe par son fils Esacos, initié à cet art divinatoire par Mérops, son grand-père maternel. Esacos recommande d'exposer cet enfant dangereux. Priam prend l'enfant, le confie à un esclave Agelaos pour qu'il l'expose sur le Mont Ida. Pendant 5 jours, le bébé exposé fut allaité par une ourse. Quand Agelaos revient, il le trouve sain et sauf, le garde avec lui dans la campagne et l'éleva comme son propre fils en lui donnant le nom de Pâris. Dans l'entourage de l'enfant, on retrouve souvent le berger, le pâtre, c'est-à-dire le moins civilisé des hommes, qui joue le rôle du père adoptif en recueillant l'enfant (en le relevant) et en lui donnant son nom (comme pour Atalante précédemment), sorte d'amphidromies dans le monde sauvage. En effet, le rite pratiqué ressemble étrangement aux cérémonies d'intégration du nouveau-né dans l'oikos. À la différence que, lors des amphidromies, c'est le père qui relève l'enfant, le fait tourner autour du foyer domestique, le nomme, lui donne cette reconnaissance sociale en l'agrégeant à l'oikos. Ici, c'est le berger, un homme des marges, qui réalise ce rite d'accueil dans le monde sauvage.

\section{Le symbolisme de l'ourse en Grèce}

D'après Otto Keller, il restait des ours en Grèce à l'époque classique dans le nord des chaînes de Thessalie, d'Épire, de Thrace ${ }^{24}$. Et Pausanias en signale en Attique ${ }^{25}$. L'ours 
est considéré comme un des animaux les plus sauvages ${ }^{26}$. C'est traditionnellement le symbole de la cruauté, de la brutalité, de la sauvagerie, de la force instinctive, de la puissance ${ }^{27}$. C'est un animal plus sauvage que la chèvre, on monte d'un cran dans le degré de sauvagerie. L'ours est un animal ambigu. D'abord par son nom même, en grec le mot ours est féminin même lorsque l'animal est de sexe masculin. Cette ambiguïté se retrouve dans son aspect physique. Il a une allure d'homme. Il peut marcher sur deux pieds comme l'homme, descendre des arbres à reculons ${ }^{28}$, Aristote et Pline l'Ancien comparent les pattes antérieures à des mains et les pattes postérieures à des pieds $\mathrm{d}^{\prime}$ homme ${ }^{29}$. Son mode alimentaire est lui aussi proche de celui de l'homme, il est omnivore ${ }^{30}$, enfin :

«Il s'accouple couché non pas à la façon ordinaire des animaux quadrupèdes mais tous les deux couchés et s'embrassant. $\|^{31}$

Mais ce qui est plus curieux encore, c'est la façon dont la femelle ourse élève ses petits :

«La femelle met bas des êtres difformes et désarticulés, mais avec sa langue, comme avec un outil, elle donne forme à leurs membres, de sorte qu'elle ne se contente pas d'enfanter et d'allaiter son ourson mais qu'elle le façonne. ${ }^{32}$

Pline décrit lui aussi les « oursons comme des masses de chair blanches et informes, un peu plus grosses que des rats, sans yeux, sans poils à qui les mères donnent forme peu à peu en les léchant ${ }^{33}$. L'ourson naît donc informe et ne devient animal reconnu que par le façonnage de la mère, un peu comme les accoucheuses de nos campagnes façonnait le crâne du nouveau-né en le massant. Cette immaturité de l'ourson rappelle celle du petit humain.

Cet animal est souvent dédié à la déesse Artémis, déesse protectrice de la fertilité. On trouve des ourses vivant dans les sanctuaires d'Artémis. Et cette présence de l'animal auprès de la déesse fait penser aux rites de Brauron ou Munichie où les jeunes filles font l'ourse. Ce rituel a été l'objet de nombreuses études et interrogations. Le mythe est le suivant: une ourse sacrée, apprivoisée, vivait dans le sanctuaire d'Artémis à Brauron; un jour en jouant, elle égratigne une jeune fille et est tuée par les frères de la parthénos. Pour expier le meurtre de l'ourse, les jeunes filles doivent faire l'arkteia, doivent mimer l'ours. Ce rituel demeure mystérieux, ce que l'on peut en dire, c'est que des petites filles dont l'âge varie entre 6 et 12 ans s'acquittent de la dette envers la déesse Artémis en mimant l'ourse. Ce rituel nous est connu d'une part par la Lysistrata d'Aristophane :

«Dès l'âge de sept ans j'étais arréphore, à dix ans je broyais le grain pour notre patronne puis revêtue de la crocote je fus ourse aux Brauronies. Enfin devenue grande et belle fille je fus canéphore et portais le collier de figues sèches. $»^{34}$

Et d'autre part, par des représentations de ces "petites » ourses sur des vases, des cratérisques, décrits par Lilly Ghali-Kahil. Sur ces vases, les petites filles font une course rituelle autour d'un autel où brûle une flamme, près d'un palmier (arbre d'Artémis) et l'ours est présent, représenté par un personnage qui porte un masque d'ours. C'est un rite d'initiation qui semble précéder la nubilité35. L'ours est donc une créature du monde sauvage mais apprivoisé et dédié à la déesse Artémis, il se définit comme un intermédiaire entre l'humain et le divin, un passeur entre les hommes et les animaux ${ }^{36}$. 


\section{La biche}

\section{Télèphe}

Resté célèbre, mais contrairement à celui de la naissance de Zeus, le mythe de Télèphe a donné lieu à une iconographie plus riche ${ }^{37}$. Cette histoire a connu une vogue dans le monde romain surtout chez les souverains de Pergame. Télèphe est le fils d'Héraklès et d'Augé, d'un dieu et d'une mortelle. Augé est la fille d'Aléos, roi de Tégée en Arcadie. Un oracle prédit qu'elle aurait un fils qui détrônera ses oncles. Pour éviter un tel malheur, Aléos consacre sa fille au service d'Athéna et institue une règle selon laquelle la prêtresse d'Athéna doit être vierge. Mais Héraklès, invité au temple, s'éprend de la jeune vierge qui va tomber enceinte. Augé cache l'enfant dans le sanctuaire d'Athéna, ce qui entraine une épidémie de peste ${ }^{38}$. C'est donc encore un enfant dangereux.

«L'enfant est exposé sur le Mont Parthénion en Arcadie, il est nourri par une biche qui vient juste de perdre son faon et recueilli par des bergers qui lui donnent le nom de Télèphe (tele $=$ mamelon et elaphos $=$ biche $/$ daine $).{ }^{39}$

\section{La biche dans l'imaginaire grec}

C'est un animal sauvage qui est chassé; la biche a un comportement différent des animaux sauvages :

«Parmi les quadrupèdes sauvages la biche n'est pas la moins intelligente, elle fait ses petits au bord du chemin de crainte des bêtes sauvages [...] elle évite moins les sentiers frayés par les hommes que les solitudes propices aux bêtes féroces. $»^{40}$

27 Car les bêtes féroces ne s'en approchent pas à cause des hommes. C'est un animal qui semble moins sauvage que l'ourse. C'est un animal maternel, qui prend soin de sa progéniture. Mais, et surtout, c'est là aussi l'animal de la déesse Artémis et l'illustration en est dans le mythe d'Iphigénie, la fille d'Agamemnon. Le roi Agamemnon tue une biche et se vante de sa supériorité d'adresse par rapport à Artémis qui, pour le punir, envoie du mauvais temps pour empêcher la flotte des Achéens de quitter Aulis et d'aller combattre à Troie. Pour lever cette sanction, en échange, la déesse demande au roi le sacrifice de sa fille. La déesse la sauve in extremis en faisant apparaitre à sa place une biche. Iphigénie devient prêtresse d'Artémis. C'est souvent une biche qui accompagne l'iconographie de la déesse. On voit que c'est un animal à la limite de deux mondes, civilisé et sauvage.

\section{La jument}

\section{Pelias et Neleus}

Pelias et Néléus sont les enfants de Tyro (la petite fille d'Éole) et de Poséidon (ou de Poséidon sous la forme du fleuve Enipeus) ${ }^{41}$. Tyro tombe amoureuse du fleuve Enipeus. Poséidon prend la forme du fleuve pour séduire la jeune fille, s'unit à elle. Elle enfante en cachette des jumeaux et les expose. Ils sont nourris par une jument, puis un des gardiens de chevaux les élève. Pélias chasse son frère du trône et Nélée se réfugie en Messénie où il fonde Pylos dont il revient roi ${ }^{42}$. 


\section{Symbolisme du cheval dans l'imaginaire grec}

29 À l'état sauvage, c'est un animal terrifiant. Il existe des chevaux sauvages qui ne connaissent pas le mors et qui sont omophages (mangeurs de viande crue). M. Détienne et J.-P. Vernant ont noté que :

«Par toute une série de comportements, par sa nervosité, ses hennissements, ses crises d'affolement, l'écume de sa bouche, la sueur de sa robe, le cheval est perçu comme un animal inquiétant, un peu possédé. $»^{43}$

C'est un animal qui est domestiqué ; la jument a un comportement très maternel :

«Quand une jument meurt celles qui vivent dans le même pâturage s'entraident pour élever le poulain... le sentiment maternel semble naturellement développé chez les chevaux. ${ }^{44}$

31 Il a donc un aspect mixte chez cet animal qui peut osciller lui aussi entre sauvagerie et civilisation. Un animal imprévisible, un animal au tempérament insaisissable. Cet animal est souvent mis en relation avec l'enfant ou l'adolescent qu'il faut éduquer en le mettant sous le joug; d'ailleurs, le terme pôlos désigne à la fois le jeune cheval et le jeune adolescent fougueux qu'il va falloir sociabiliser. De même, C.Calame met en parallèle l'image de la cavale et de la jeune fille qu'il faut apprivoiser avant le mariage ${ }^{45}$.

« Proitos, dont les filles furent rendues folles par Héra car elles étaient entrées dans son sanctuaire pour y commettre un acte d'hybris, éleva deux temples à Artémis car elle ramena ses filles de leurs courses errantes à travers les montagnes d'Azame et elle adoucit leur humeur sauvage, c'est-à-dire qu'Artémis a réussi à apprivoiser, à civiliser, à socialiser ces adolescentes. $»^{46}$

La pouliche est, là encore, proche d'Artémis. C'est elle qui peut servir d'intermédiaire, de passeur entre le monde des animaux et des humains.

Ourse, chèvre, biche, jument... L'analyse de ces animaux montre que l'animal nourricier n'est jamais un animal domestique, mais un animal sauvage. C'est un animal qui a en lui une part d'humain, cette double nature l'habilite au rôle de passeur d'un monde à l'autre, du monde animal au monde des hommes. C'est un animal avec des côtés maternels très développés. La femelle vient spontanément nourrir l'enfant de son lait et lui sauver la vie. Elle l'allaite, or en principe, c'est vraiment une prérogative maternelle ${ }^{47}$. L'animal tient donc le rôle de la mère. C'est donc une mère de substitution. Pierre-Olivier Dittmar ${ }^{48}$ montre l'importance du rôle de la mère dans l'allaitement, car c'est "par son lait que celle qui allaite pose son empreinte sur l'enfant ", transmet les vertus du génos, de la famille. Donc donner son enfant à nourrir à un animal risque de lui conférer le tempérament de cet animal, la transmission de l'identité. "Les enfants ressemblent à qui les nourrit de son lait ». Cette fois, c'est l'animal nourricier qui va jouer ce rôle. Mais alors que va-t-il transmettre? Il y a brouillage dans les repères biologiques, inévitablement, l'enfant va "hériter » des caractères de l'animal, s'ensauvager plus ou moins.

Et le degré d'ensauvagement est parfois tel que le retour vers le monde des hommes est impossible. L'animal façonne l'enfant, l'aide à prendre forme ; on est donc tout à fait dans la définition du courotrophe, «celui qui favorise le développement de ce qui est soumis à croissance». En léchant l'enfant, l'animal le rend beau, socialement 
acceptable, il n'est plus ce petit animal informe. C'est un animal toujours en rapport à Artémis, car lorsque l'animal prend en charge l'enfant exposé, c'est tout de suite après l'accouchement, alors que cet enfant est un nourrisson. Les Grecs parlent de teknon pour désigner toute sorte de petit qu'il soit humain ou animal.

Aux yeux des Grecs le nourrisson n'est pas encore un humain, c'est un être informe dont la nature humaine est encore imparfaitement développée et qu'il va falloir parfaire. Le genre neutre de teknon renforce cette idée. Il est asexué. La naissance ne lui a pas conféré le statut d'humain, l'accouchement n'en a pas fait de facto un humain. Aristote le décrit comme un être intermédiaire :

«À ce qui chez l'homme est art, sagesse, intelligence correspond chez certains animaux à quelque faculté naturelle du même genre. Cette remarque est particulièrement vraie si on considère les enfants dans leur premier âge; chez les enfants il est possible de voir comme les traces et les germes de leurs dispositions futures et l'âme ne diffère pour ainsi dire nullement de l'âme des bêtes si bien qu'il n'y a rien qui choque la raison si certains traits psychiques sont les mêmes chez l'homme et les autres animaux. Ainsi la nature passe petit à petit des êtres inanimés aux êtres doués de vie si bien que cette continuité empêche d'apercevoir la frontière qui les sépare et qu'on ne sait auquel des deux groupes appartient la forme intermédiaire. $»^{49}$

La courotrophie animale n'est jamais pensée comme un allaitement à des bébés normaux. L'animal prend en charge un enfant abandonné car dangereux, voué à la mort. Or le destin va en décider autrement puisque cet enfant reçoit une aide divine. Il subit donc une initiation et renaît à une nouvelle vie animale cette fois. Sorti de la condition humaine, il n'est plus protégé par les dieux de la famille. Il faut donc qu'il soit mis sous la protection d'une déesse si le projet doit aboutir. Et dans ce monde Artémis veille, elle prend en charge les petits nouvellement nés, les protège ${ }^{50}$. Elle est aux confins de deux univers sauvage/civilisé et va donc conduire ces enfants jusqu'au seuil, jusqu'au passage vers la cité, vers l'intégration sociale. Elle prépare l'intégration de la sexualité dans la culture. Car pour les Grecs, la puberté, tout comme l'accouchement, représentait un moment de possible introduction de la sauvagerie. Artémis va donc apprendre aux jeunes à respecter la frontière entre le monde civilisé et sauvage. À ne pas se laisser envahir par des accès de sauvagerie. Ceux qui en sortent sont vraiment humains. J.-P. Vernant montre bien que :

«Depuis les marges où elle règne, elle prépare le retour au centre. La courotrophie qu'elle exerce en zone sauvage vise à une bonne intégration au cœur de l'espace civique. $\|^{51}$

Ces êtres à l'enfance surnaturelle sont des êtres d'exception. Ces mythes expliquent leur destin réussi ou funeste selon que l'apprentissage a été bénéfique ou non car la frontière est ténue entre le monde civilisé et le monde sauvage, entre civilisé et bestialité/sauvagerie. Confronté au sauvage dans son enfance, cet enfant court un danger constant à l'âge adulte, celui de basculer à tout moment dans la sauvagerie. La transmission réside dans la possibilité de basculer à tout moment. 


\section{BIBLIOGRAPHIE}

Apollodore, Bibliothèque, Londres, Heinemann, 1921.

Aristophane, Lysistrata, Paris, Les Belles Lettres, 1928.

Aristote, De la génération des animaux, Paris, Les Belles Lettres, 1961.

Aristote, Histoire des animaux, Paris, Les Belles Lettres, 1968 (coll. des Universités de France) 3 tomes.

BRÛLÉ Pierre, « Retour à Brauron. Repentirs, avancées, mises au point », Dialogues d'histoire ancienne, 1990, vol. 16, $\mathrm{n}^{\circ} 2: 61-90$.

CALAME Claude, Chœurs de jeunes filles en Grèce archaïque, Rome, De l'Ateneo et Bizzari, 1977, 2 tomes.

CALLIMAQUe, Hymnes, Paris, Les Belles Lettres, 1922.

DÉTIENNE Marcel, VERNANT Jean-Pierre, Les ruses de l'intelligence : la métis des Grecs. Paris, Flammarion, 1978.

DITTMAR Pierre-Olivier, MAILLET Chloé, QUESTIAUX Astrée, « La chèvre ou la femme. Parentés de lait entre animaux et humains au Moyen Âge ", Images Revues, éd. numérique, 2011 : http:// imagesrevues.revues.org/1621) (consultation janvier 2019).

Élien, Histoire variée, Paris, Les Belles Lettres, 1991 (coll. des Universités de France).

Hésiode, Théogonie, Paris, Les Belles Lettres, 1993 (coll. des Universités de France).

Homère, Odyssée, Paris, Garnier, 1957.

KAHIL Lilly, « Artémis attique », Comptes-rendus des séances de l'Académie des Inscriptions et Belles lettres, 1976, vol. 120, $\mathrm{n}^{\circ} 1$ p. 126-130.

MILLIN Aubin-Louis, Galerie mythologique, tome II Paris, Soyer, 1811.

PASTOUREAU Michel, l'ours : histoire d'un roi déchu, Paris, Seuil, 2007.

Pausanias, Périégèse. Londres, Heinemann, 1965 vol. 1 et 3 ; 1966 vol. 2.

Pline l'Ancien, Histoire naturelle. Paris, Les Belles Lettres, 1952.

Plutarque, Moralia, Paris, Les Belles Lettres, 1975.

KELLER Otto, Die antike Tierwelt, Hildesheim, Geng Olms Verlag, 1963.

STELLA Luigia Achillea, La civita micenea nei documentali contemporanei, Rome, Ed. dell'Ateneo, 1955.

TEILLIER Ludovic, Écologie et image de la chèvre dans la pensée grecque (VIII siècle av. J.-C.-III ${ }^{e}$ siècle apr. J.C.), communication du 17 juin 2011. $\mathrm{V}^{\mathrm{e}}$ rencontres archéologiques de Lattes.

VERNANT Jean-Pierre, CEuvres : religions rationalités politique, Paris, Seuil, 2007 (Opus) 2 tomes.

Xénophon, L'art de la chasse, Cynégétique, Paris, Les Belles Lettres, 1970. 


\section{NOTES}

1. Hésiode, Théogonie, 485, p. 48.

2. Hésiode, Théogonie, 465-490, p. 48-49.

3. Apollodore, Bibliothèque, I, I, 4-7 + note 2 et 3, p. 7 .

4. Callimaque, Hymne à Zeus, v.13-57, p. 38.

5. Iconographie de Zeus et Amalthée : Sigillée de Cnossos 1580 av. J.-C. in L. A. Stella, La civita micenea nei documentali contemporanei, Rome, Ed. dell'Ateneo, 1955, table IV p. 240. Rhéa, Amalthée allaitant et la danse des curètes dessin d'un bas-relief romain in A.-L. Millin, Galerie mythologique, tome II Paris, Soyer, 1811, planche V.

6. Apollodore, Bibliothèque, Epitomê, II, 14, p. 169.

7. Élien, Histoire variée, Livre 12, 42, p. 128.

8. Pausanias, Périégèse, Arcadie, XXV, 11, p. 27.

9. Pausanias, Périégèse, Corinthe, XXVI, 3-7, p. 8.

10. Pausanias, Périégèse, Phocis Azolian Locri, X, 16,5, p. 455.

11. Pausanias, Périégèse, Laconie, XX, 4, p. 127.

12. Homère, Odyssée, IX, 152-163, p. 126.

13. Homère, Odyssée, XIV, 99-108, p. 205.

14. Aristote, Histoire des animaux, Livre VI, XIX v.6, p. 110.

15. J.-P. Vernant, « Figures, Idoles et masques », p. 1616.

16. L. Tellier, «Écologie et image de la chèvre dans la pensée grecque (VIII ${ }^{\mathrm{e}}$ av. J.-C.-III ${ }^{\mathrm{e}}$ apr. J.-C.) », p. 2-3.

17. Élien, Histoire variée, Livre 2, 25 p. 24.

18. Aristote, De la génération des animaux, Livre IV, 8, 777a, 7.

19. Apollodore, Bibliothèque, III, IX, 2, p. 399.

20. Élien, Histoire variée, Livre 13, 1, p. 137.

21. Élien, Histoire variée, Livre 13, 1, p. 138-139.

22. Apollodore, Bibliothèque, III, IX, 2, p. 399.

23. Apollodore, Bibliothèque,III, XII, 5, p. 47.

24. O. Keller, Die antike Tierwelt, p. 175.

25. Pausanias, Périégèse, Attique XXXII, p. 173.

26. Plutarque, Moralia, 494c, p. 187.

27. M. Pastoureau, L'ours : histoire d'un roi déchu, p. 54-59.

28. Pline l'Ancien, Histoire naturelle, Livre VIII, LIV (36) v 126-131, p. 68.

29. Aristote, Histoire des animaux, II, I, 498a, p. 36.

30. Aristote, Histoire des animaux, VIII, 5, p. 20.

31. Pline l'Ancien, Histoire naturelle, Livre VIII, LIV (36) v 126, p. 67.

32. Plutarque, Moralia, 494c, p. 187.

33. Pline l'Ancien, Histoire naturelle, Livre VIII, LIV (36) v 126, p. 67.

34. Aristophane, Lystrata v.639-646, p. 148.

35. L. Kahil, « Artémis attique », p. 126-130. 
36. P. Brûlé, « Retour à Brauron. Repentirs, avancées, mises au point », p. 63.

37. La ville de Tégée émet entre 370-250 av. J.-C. un type de monnaie représentant son héros allaité par une biche (Trichalque en cuivre 250 av. J.-C.). Cf. Monnaie Arcadie Tégée : http://gallica.bnf.fr/ark:/12148/btv1b8570053c.r=tegee\%20tegee, http:// gallica.bnf.fr/ark:/12148/btv1b85705496.r=tegee\%20tegee, http://gallica.bnf.fr/ark:/ 12148/btv1b8570548s.r=tegee\%20tegee, http://gallica.bnf.fr/ark:/12148/ btv1b103116548.r=tegee\%20tegee, http://gallica.bnf.fr/ark:/12148/ btv1b10311657m.r=tegee\%20tegee, http://gallica.bnf.fr/ark:/12148/ btv1b10311655q.r=tegee\%20tegee, http://gallica.bnf.fr/ark:/12148/ btv1b10311653t.r=tegee\%20tegee, http://gallica.bnf.fr/ark:/12148/ btv1b8570054s.r=tegee\%20tegee, http://gallica.bnf.fr/ark:/12148/ btv1b8570552p.r=tegee\%20tegee, http://gallica.bnf.fr/ark:/12148/ btv1b8570550v.r=tegee tegee, Pausanias signale une statue de Télèphe nourrisson tétant la biche sur l'Hélicon (in Pausanias, Périégèse, IX Béotie xxxi, 1-2, p. 307). Télèphe allaité par une biche. Dessin d'après une peinture antique trouvée à Herculanum in A.L. Millin, Galerie mythologique, tome II, Paris:Soyer, 1811 vue 460 p. 340. Peinture murale romaine, V. 70 apr. J.-C. (d'après modèle de Pergame). Télèphe allaité par une biche. Fresque de la basilique d'Herculanum. Inv. 9008 Référence AKG325138, Musée archéologique de Naples.

38. Apollodore, Bibliothèque, III, VIII, 2-IX,p. 397.

39. Apollodore, Bibliothèque, II, VII, 4-5, p. 257.

40. Aristote, Histoire des animaux, VI, 29, p. 124; IX,5, p. 73 ; Pline l'Ancien, Histoire naturelle, Livre VIII, L v.112.

41. Homère, Odyssée, Chant IX, v.255, p. 163.

42. Apollodore, Bibliothèque, I, IX, 8, p. 83.

43. M. Détienne, J.-P. Vernant, Les ruses de l'intelligence : la mètis des Grecs, p. 185-186.

44. Aristote, Histoire des animaux, IX, 4, p. 72.

45. C. Calame, Chœurs de jeunes filles en Grèce archaïque, p. 374-375.

46. Callimaque, Hymne à Artémis, in Hymnes, v233-236, p. 252.

47. S. Vialatte, La nourrice grecque, p. 10.

48. P. O. Dittmar, C. Maillet, A. Questiaux, « La chèvre ou la femme. Parentés de lait entre animaux et humains au Moyen Âge », p. 3.

49. Aristote, Histoire des animaux, VIII, 1, p. 1.

50. Xénophon, Cynégétique V, 14, p. 66.

51. J.-P. Vernant, «La mort dans les yeux : figures de l'autre en Grèce ancienne ", p. 1487. 


\section{RÉSUMÉS}

La mythologie grecque rapporte de très nombreuses légendes d'enfants d'hommes, de héros ou de dieux nourris par des animaux. Cette conception de l'animal nourrice est une vieille tradition orientale et certaines nourrices sont restées célèbres. Cet élevage hors de la maison familiale est cependant réservé à des enfants au destin particulier puisque le thème de l'allaitement par un animal est étroitement lié à l'abandon ou l'exposition d'enfant. Quels sont donc ces enfants? Quel est leur statut social ? Pourquoi sont-ils exposés à la naissance puisqu'ils risquent la mort? Quels sont les animaux qui les recueillent et qui sont donc habilités à cette fonction de nourrice ? Enfin quelle est l'incidence sur la vie adulte de l'enfant, de ce « passage » dans le monde animal ? Il faut noter le contraste entre la richesse des sources littéraires sur ce sujet et la pauvreté de la représentation iconographique.

\section{AUTEUR}

\section{LILIANE ROMY-REGENT}

Documentaliste 
L'animal vivant et mort dans les religions : l'animal de sacrifice 


\title{
Noms d'animaux et allusions divines dans l'anthroponymie égyptienne de l'époque gréco-romaine
}

\author{
Ana Isabel Blasco Torres
}

Je remercie l'Association de Soutien aux Congrès des Sociétés Historiques et Scientifiques de m'avoir versé une bourse d'aide au déplacement pour assister au congrès.

1 Parmi les différents types d'anthroponymes attestés dans les sources égyptiennes ${ }^{1}$, les noms de personnes contenant des noms d'animaux constituent un groupe important à toutes les époques de l'histoire de l'Égypte ancienne ${ }^{2}$. Présents dans les textes depuis l'Ancien Empire, ces noms, portés par des hommes et des femmes, sont bien attestés à l'époque gréco-romaine, où ils deviennent assez populaires. À cette période, environ une trentaine de noms d'animaux - dont plus de quinze sont des noms de mammifères ${ }^{3}$, plus de cinq appartiennent à des oiseaux ${ }^{4}$ et au moins trois sont des dénominations d'amphibiens et de reptiles ${ }^{5}$ - sont attestés dans de nombreux anthroponymes. Après examen des anthroponymes contenant des noms d'animaux attestés à la période grécoromaine dans les différentes écritures, et notamment en démotique et en transcription grecque, nous présentons ici une analyse de la typologie de ces noms de personnes et de la fréquence géographique de quelques noms d'animaux contenus dans les anthroponymes égyptiens datés de cette époque ${ }^{6}$.

\section{La typologie des anthroponymes à noms d'animaux ${ }^{7}$}

\section{Anthroponymes composés du nom d'un animal avec ou sans article}

2 Plus d'une quarantaine d'anthroponymes égyptiens datés de la période gréco-romaine sont composés uniquement du nom d'un animal, qui est souvent précédé de l'article défini masculin ou féminin. Parmi les noms personnels formés par le nom d'un animal sans article, et attestés en démotique ainsi qu'en transcription grecque, se trouvent:

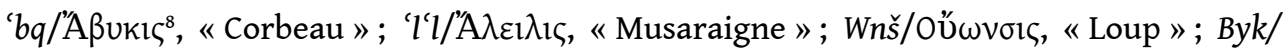




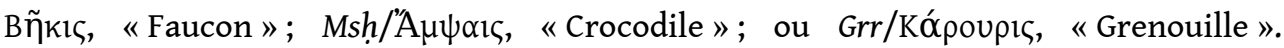
D'autres noms sont seulement attestés en transcription grecque, à partir de laquelle il est possible de reconstruire le prototype égyptien reflété. C'est notamment le cas des noms "I $\beta 1 \varsigma\left({ }^{*} \mathrm{Hb}\right)$, « Ibis », et Kı $\alpha \mu \mathrm{ou} \lambda\left({ }^{*} G m w l\right)$, « Chameau »".

Certains des anthroponymes composés du nom d'un animal sans article sont aussi attestés en démotique ou en transcription grecque avec l'article masculin (p3) ou

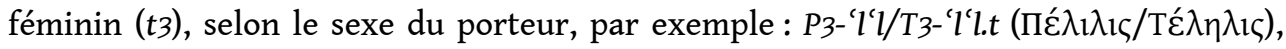

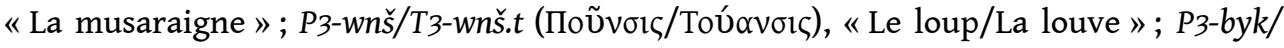

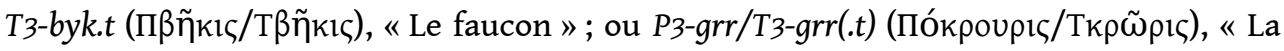
grenouille ». D’autres noms de personnes, comme P3-3b3/T3-3b3(.t) (Пع́ $\beta \omega \varsigma / T \varepsilon ́ \beta \omega \varsigma)$, « La panthère ", sont seulement attestés avec l'article défini. Finalement, quelques anthroponymes ne sont attestés qu'avec l'article défini à un genre spécifique : P3-“" $n$ / Пદ́vı

Les anthroponymes formés exclusivement sur le nom d'un animal peuvent contenir, dans quelques cas, des adjectifs qualificatifs, des épithètes ou des appositions, relatifs à certaines caractéristiques de l'animal mentionné. C'est notamment le cas des noms:

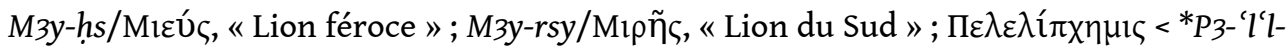

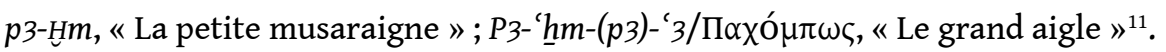

\section{Anthroponymes composés d'un pronom possessif (pa-/ta-) ou démonstratif ( $\left.p_{3} y-/ t 3 y-\right)$ plus le nom d'un animal}

Plus de vingt anthroponymes à noms d'animaux datés de l'époque gréco-romaine sont composés du pronom possessif masculin $p a$, «celui de...», et au moins une autre vingtaine de noms personnels féminins sont formés du pronom $t a$, « celle de... », suivis du nom d'un animal précédé, ou pas, d'un article défini. Ainsi, parmi les noms d'animaux attestés dans les anthroponymes commençant par $p a-/ t a-$ attestés en démotique ainsi qu'en transcription grecque, on trouve le faucon, le lion et l'ibis : $P a$ -

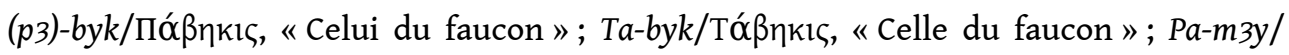

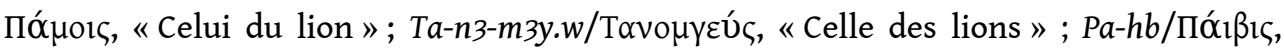
"Celui de l'ibis»; Ta-p3-hb/Tó $\varphi ı ß \varsigma$, , «Celle de l'ibis » ${ }^{12}$. En revanche, les anthroponymes commençant par le pronom démonstratif p3y-/t3y- sont moins fréquents que ceux composés par le pronom possessif $p a-/ t a-$. En effet, environ dix anthroponymes avec le pronom $p 3 y$ et quatre avec t3y au début du nom, plus le nom d'un animal, sont attestés ${ }^{13}$.

\section{Anthroponymes à noms d'animaux commençant par $P_{3}$-šr-n-/T3-šr.t-} $n-$

6 Un nombre assez élevé d'anthroponymes égyptiens (approximativement quarante) commence par P3-šr-n-, «Le fils de... », et plus de vingt par T3-šr.t-n-, «La fille de... ». Ces noms sont généralement suivis ou bien par le nom d'un animal avec ou sans article défini ou bien par les pronoms $p a-/ t a-$ ou $p 3 y-/ t 3 y$ - plus le nom d'un animal spécifique. Parmi les noms d'animaux attestés dans les anthroponymes qui commencent par P3-šr$n$-/T3-šr.t-n-, on trouve la musaraigne, l'aigle, le faucon, le lion et l'ibis : T3-šr.t-n-p3-' 'l'l/

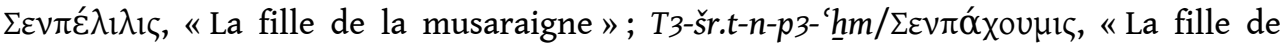




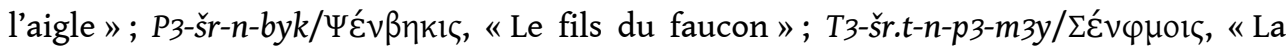

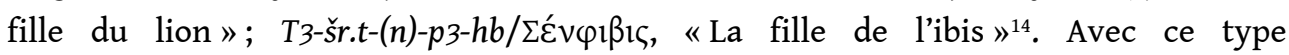
d'anthroponymes, une relation filiale est probablement établie entre l'animal mentionné et le porteur du nom ${ }^{15}$.

\section{Anthroponymes à nom d'animaux commençant par $P_{3}$-di-/T3-dí-}

7 Une dizaine de noms de personnes égyptiens contenant le nom d'un animal commencent par P3-dỉ-, "Celui qui a été donné par...", tandis que moins de dix contiennent le même début au féminin (T3-dỉ-, «Celle qui a été donnée par...»). Les noms d'animaux attestés dans les anthroponymes de ce type au masculin, en démotique ou en transcription grecque, sont - au moins - le chat, le héron, l'aigle, le faucon, le lion, le crocodile, l'ibis et le taureau gem $^{16}$. Parmi les noms féminins commençant par T3-di-, on trouve des animaux comme le chien, le faucon, le lion et le taureau gem $^{17}$. L'utilisation de P3-di-/T3-di- - une forme relative de dỉ, "donner", nominalisée -, pour la création d'anthroponymes révèle que, pour les anciens Égyptiens, l'animal mentionné, dont une divinité pouvait être l'hypostase, était considéré comme le créateur, le donneur de vie, du porteur du nom ${ }^{18}$.

\section{Anthroponymes à noms d'animaux commençant par $\underline{D} d-h \underline{r}$ -}

8 Moins de dix anthroponymes datés de l'époque gréco-romaine sont composés de $\underline{D} d-h-h r$-, «Le visage dit... », plus le nom d'un animal. Le commencement de ces noms personnels, Dd-hrr-, une expression à caractère magique et oraculaire, est censé être l'abréviation de $\underline{D} d-h r-X-i w=f / s-' n H$, « Le visage de X dit : 'Il/elle vivra' " ${ }^{19}$. Les noms des animaux attestés dans cette sorte d'anthroponymes sont - au moins - le chat, le héron, le lion, l'ibis et le taureau gem: Dd-hr-p3-imy (-ỉw=f/s-' nH), "Le visage du chat dit: ('Il/elle vivra')»;

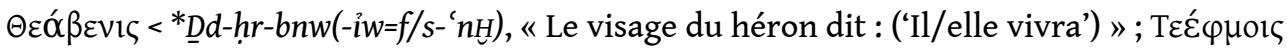
< *Dd-hrr-p3-m3y(-îw=f/s-' nH), « Le visage du lion dit : ('Il/elle vivra') »; $\underline{D} d-h r-p 3-h b(-i w=f /$

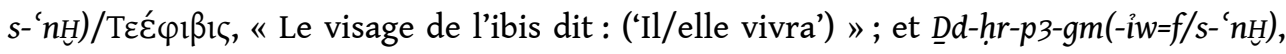
«Le visage du taureau gem dit: ('Il/elle vivra') ${ }^{20}$. Dans le cas des anthroponymes commençant par $\underline{D} d$-ḩr- et ne contenant pas le nom d'un animal, le "visage » qui prononce la prophétie appartient à une divinité spécifique, comme le dieu Bes, Ptah ou Néfertoum ${ }^{21}$.

\section{Anthroponymes contenant le nom d'une divinité et le nom d'un animal}

9 Approximativement une trentaine d'anthroponymes sont composés du nom explicite d'une divinité, suivi ou bien du nom d'un animal comme apposition ou bien d'un pronom possessif ( $p a-/ t a-)$ ou démonstratif $(p 3 y-/ t 3 y-)$ plus le nom de l'animal ${ }^{22}$. Les divinités le plus souvent mentionnées dans ce type d'anthroponymes sont : Horus, qui est lié à des animaux comme le loup, le taureau, le lion, l'ibis ou le faucon ${ }^{23}$; Marres, associé au taureau gem $^{24}$; et Khonsou, Toutou et Thot, qui sont mis en lien avec le lion ${ }^{25}$. D'autre part, environ une dizaine d'anthroponymes commencent par le nom d'un animal, généralement avec l'article défini, après lequel se trouve la mention d'une divinité. Même si dans quelques cas le nom du dieu est introduit par la préposition de 
génitif $n^{26}$, il est habituellement dépourvu de préposition. Ce manque de préposition entre le nom de l'animal et celui du dieu pose la question de savoir si le nom de la divinité mentionnée est un complément (génitif direct) ou plutôt une apposition du nom de l'animal (cf. ПovopÉvoußı < *P3-whr-İnpw, «Le chien Anoubis» ou bien «Le chien d'Anoubis » ${ }^{27}$. Cependant, la présence du pronom possessif -pa-/-ta- entre le nom

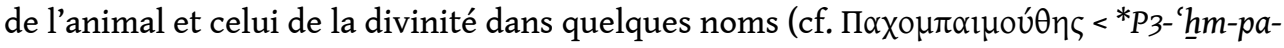

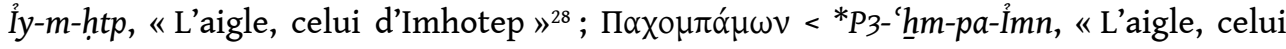

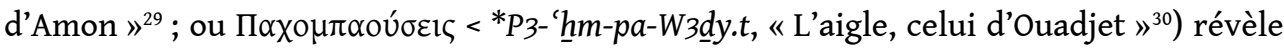
que l'animal cité est considéré comme une possession ou manifestation de la divinité. L'aigle (' $h \mathrm{hm})$ est l'animal le plus fréquent dans ce type d'anthroponymes ${ }^{31}$.

\section{Anthroponymes à noms d'animaux et fréquence géographique}

10 La plupart des noms d'animaux présents dans les anthroponymes sont attestés à travers toute l'Égypte ${ }^{32}$. Pour d'autres noms, par contre, les attestations sont peu nombreuses ${ }^{33}$. Enfin, il y a quelques noms ${ }^{34}$ pour lesquels les attestations sont concentrées presque exclusivement dans une partie de l'Égypte et, par conséquent, ils peuvent nous fournir des informations sur les lieux précis où avait lieu le culte de ces animaux. Dans le présent travail, nous présentons l'analyse de la fréquence géographique d'une sélection de noms d'animaux présents dans les anthroponymes égyptiens datés de l'époque gréco-romaine ${ }^{35}$.

\section{Le chat}

11 Le nom de (î)my(.t), "chat/chatte ", à caractère onomatopéique semble être attesté dans une dizaine d'anthroponymes datés de la période gréco-romaine (cf. tabl. 1). La majorité des attestations de ces anthroponymes provient de la Haute Égypte en général et, en particulier, de la région de Thèbes (nome IV), ainsi que des zones de Panopolis (nome IX), Pathyris (nome IVa) et Hérakléopolis (nome XX) (cf. fig. 1) ${ }^{36}$. Le nombre d'attestations en démotique (68) est similaire à celui de noms écrits en transcription grecque (63). La présence d'anthroponymes contenant le nom du chat à travers toute l'Égypte, ainsi que le grand nombre de nécropoles destinées aux chats dans plusieurs régions du pays ${ }^{37}$, montrent l'importance de cet animal en tant que manifestation de la divinité en général et de la déesse Bastet en particulier, et comme intermédiaire entre celle-ci et l'homme dans la pensée égyptienne ${ }^{38}$. 
Tabl. 1. - Anthroponymes contenant le nom (i)my(.t), « chat/chatte».

\begin{tabular}{|c|c|c|c|c|}
\hline $\begin{array}{c}\text { Numéro } \\
\text { Trismegistos }\end{array}$ & Nom égyptien & $\begin{array}{c}\text { Transcription } \\
\text { grecque }\end{array}$ & Traduction & Attestations \\
\hline 802 & P3-ỉmy & 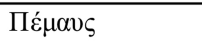 & Le chat & 46 \\
\hline 694 & P3y-my & --- & Celui du chat & 2 \\
\hline 973 & P3-šr-n-n3-ỉmy.w & --- & Le fils des chats & 1 \\
\hline 14831 & P3-dí-my & $\begin{array}{l}\Pi \tau \varepsilon \dot{\mu} \mu \alpha v \varsigma \text { (?), } \\
\Pi \tau \varepsilon \dot{\varepsilon} \mu \alpha{ }^{2}(?)\end{array}$ & $\begin{array}{l}\text { Celui que le } \\
\text { chat a donné }\end{array}$ & 3 \\
\hline 7275 & Pa-my & 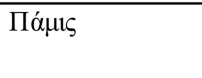 & $\begin{array}{l}\text { Celui du chat } \\
\text { (?) }\end{array}$ & 51 \\
\hline 35798 & Pa-n3-ỉmy.w & --- & Celui des chats & 1 \\
\hline 770 & Pa-tz-ỉmy.t & 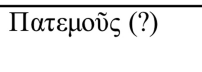 & $\begin{array}{l}\text { Celui de la } \\
\text { chatte }\end{array}$ & 10 \\
\hline 16820 & *Hrr-pa-(i)my (?) & 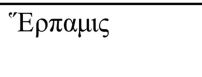 & $\begin{array}{l}\text { Horus, celui du } \\
\text { chat (?) }\end{array}$ & 1 \\
\hline 13574 & T3-ỉmy.t-špšy.t & --- & La noble chatte & 1 \\
\hline 15607 & T3-my.t & --- & La chatte & 6 \\
\hline 20953 & T3-šr.t-n-my & --- & La fille du chat & 2 \\
\hline 13857 & Ta-my & Tópus & $\begin{array}{l}\text { Celle du chat } \\
\text { (?) }\end{array}$ & 17 \\
\hline 29681 & $\begin{array}{l}\text { *Ta-pa-(i)my(.t) } \\
(?)\end{array}$ & Та́л $\alpha \mu \mu \varsigma$ & $\begin{array}{l}\text { Celle de celui } \\
\text { du chat (?) }\end{array}$ & 1 \\
\hline 1335 & $\begin{array}{l}\text { Dd-hr-p3-imy- } \\
\text { (iw=f/s-'nh) }\end{array}$ & --- & $\begin{array}{l}\text { Le visage du } \\
\text { chat dit : } \\
(« \mathrm{Il} / \mathrm{elle} \\
\text { vivra ») }\end{array}$ & 2 \\
\hline
\end{tabular}

Fig. 1. - Attestations du nom (i)my(.t), "chat/chatte ", dans l'anthroponymie égyptienne au Fayoum $(00)$ et en Basse (B) et Haute Égypte (H).

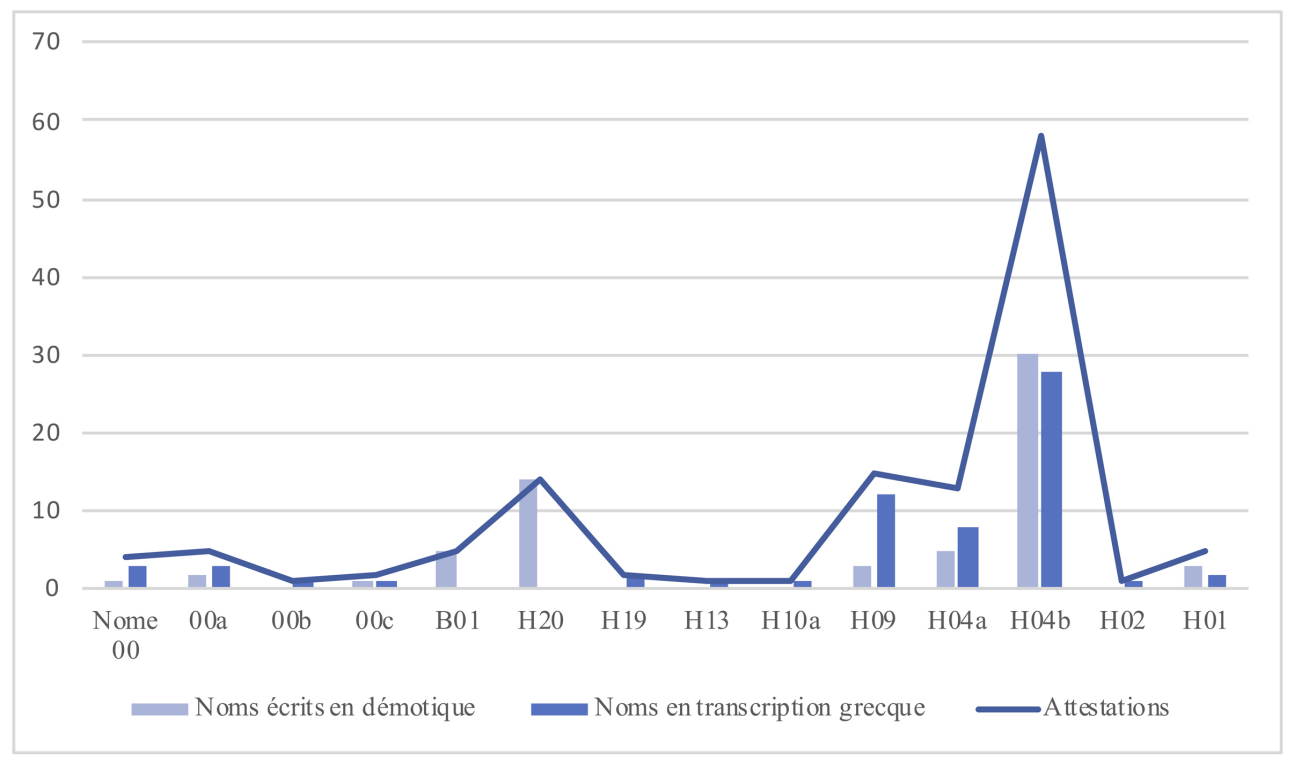

\section{Le crocodile}

Moins de dix anthroponymes attestés à la période gréco-romaine contiennent le nom $m s h(. t)$, « crocodile ». Le nom personnel contenant le nom de cet animal le plus présent dans les documents gréco-égyptiens est P3-msh, "Le crocodile», suivi de Msh, «Crocodile», et *T3-msh.t, «Le crocodile» (femelle) (cf.tabl. 2). Le nombre 
d'attestations des anthroponymes avec le mot msh..t) inclus en écriture démotique (29) est clairement inférieur à la quantité d'attestations écrites en caractères grecs (171). L'analyse de la fréquence géographique de ces anthroponymes montre que la région où ces noms personnels étaient les plus populaires était le Fayoum, suivi du nome thébain (cf. fig. 2) ${ }^{39}$. C'est en fait la zone du Fayoum où le culte au dieu Sobek - dont le crocodile était considéré comme une hypostase - était le plus répandu au moins depuis l'Ancien Empire $^{40}$, probablement à cause de la présence de cet animal due à la configuration géographique de la région ${ }^{41}$.

Tabl. 2. - Anthroponymes contenant le nom msḥ(.t), « crocodile ».

\begin{tabular}{|c|c|c|c|c|}
\hline $\begin{array}{c}\text { Numéro } \\
\text { Trismegistos }\end{array}$ & Nom égyptien & $\begin{array}{c}\begin{array}{c}\text { Transcription } \\
\text { grecque }\end{array} \\
\end{array}$ & Traduction & Attestations \\
\hline 20930 & P3y-msh & --- & $\begin{array}{l}\text { Celui du } \\
\text { crocodile }\end{array}$ & 1 \\
\hline 803 & P3-msḥ & По́ $\mu \sigma \alpha 1 \zeta$ & Le crocodile & 121 \\
\hline 20862 & $\mathrm{P}_{3}$-šr-n-p3-msḥ & --- & $\begin{array}{l}\text { Le fils du } \\
\text { crocodile }\end{array}$ & 1 \\
\hline 24355 & ${ }^{*} \mathrm{P}_{3}$-dỉ-p3-msh & 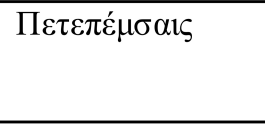 & $\begin{array}{l}\text { Celui que le } \\
\text { crocodile a } \\
\text { donné }\end{array}$ & 1 \\
\hline 24343 & ${ }^{*} P_{3}$-dî-msh & 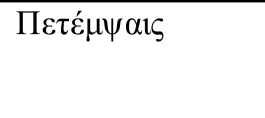 & $\begin{array}{l}\text { Celui que le } \\
\text { crocodile a } \\
\text { donné }\end{array}$ & 2 \\
\hline 35765 & Msḥ & "A $\mu \psi \alpha u s$ & Crocodile & 51 \\
\hline 13389 & Ḥr-msḥ & --- & $\begin{array}{l}\text { Horus le } \\
\text { crocodile }\end{array}$ & 1 \\
\hline 6301 & $* \mathrm{~T}_{3}$-msh.t & 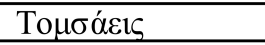 & Le crocodile & 32 \\
\hline
\end{tabular}

Fig. 2. - Attestations du nom msh.(.t), « crocodile », dans l'anthroponymie égyptienne au Fayoum $(00)$ et en Basse (B) et Haute Égypte (H).

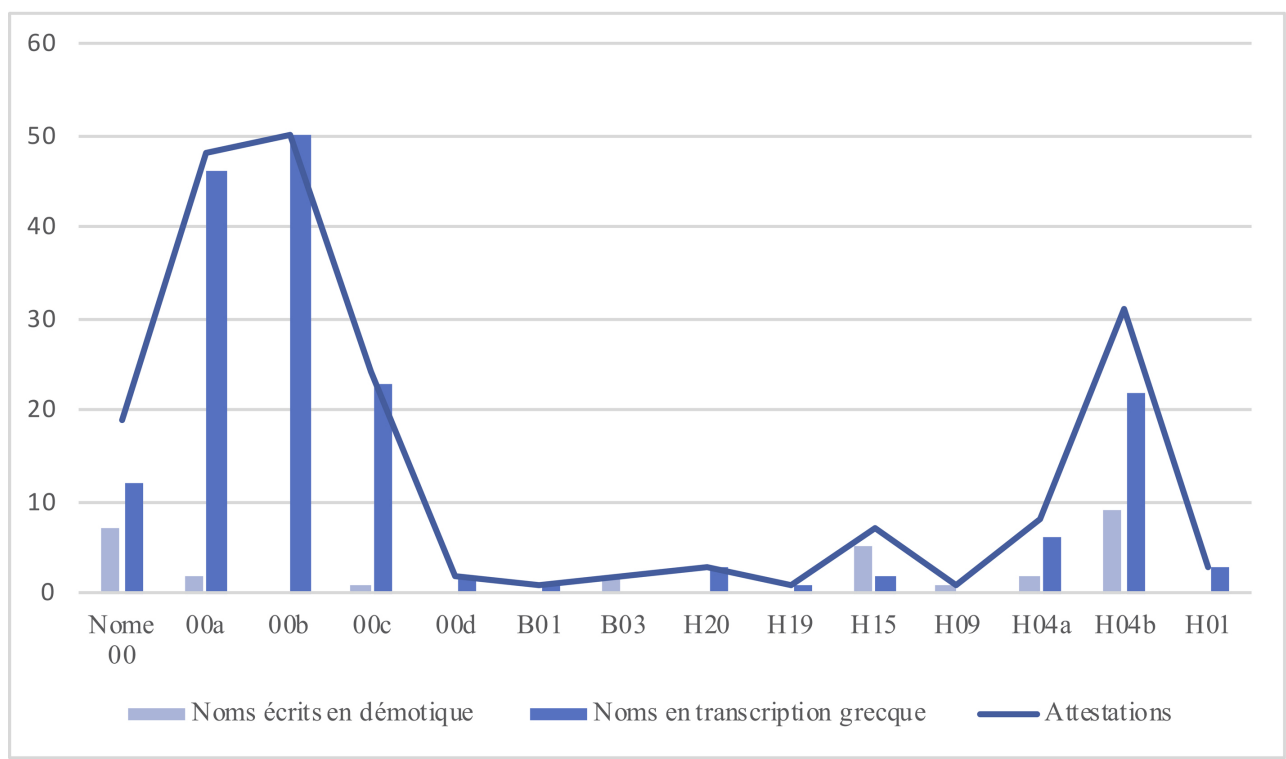




\section{Le héron ou oiseau bénou}

Le nom du héron $(b n w)$, attesté seulement dans deux anthroponymes préservés

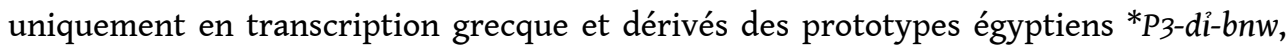
«Celui que le héron a donné » et * $D d-h r-b n w-\left(i w=f / s-{ }^{-} n H\right)$, « Le visage du héron dit : ('Il/ elle vivra')»(cf. tabl.3), était, conformément aux attestations conservées, utilisé notamment dans la région de Karanis au Fayoum à l'époque gréco-romaine. Environ $94 \%$ des attestations des anthroponymes contenant le mot bnw sont, en effet, originaires de cette zone géographique ( $\mathrm{cf}$. fig. 3$)^{42}$. Le héron, considéré comme la manifestation - le ba - du dieu Rê, est, dans la pensée égyptienne, étroitement lié à la ville d'Héliopolis étant donné son caractère solaire ${ }^{43}$. Le fait que la plupart des anthroponymes contenant le nom de cet animal proviennent de Karanis, une région proche d'Héliopolis, est, par conséquent, significatif.

Tabl. 3. - Anthroponymes contenant le nom bnw, « héron ».

\begin{tabular}{|c|c|c|c|c|}
\hline $\begin{array}{c}\text { Numéro } \\
\text { Trismegistos }\end{array}$ & Nom égyptien & $\begin{array}{c}\text { Transcription } \\
\text { grecque }\end{array}$ & Traduction & Attestations \\
\hline 33418 & $* P_{3}$-dì-bnw & 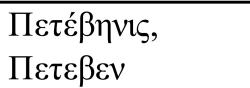 & $\begin{array}{l}\text { Celui que le } \\
\text { héron a donné }\end{array}$ & 2 \\
\hline 5434 & $\begin{array}{l}\text { *Dd-hrr-bnw- } \\
\left(\hat{i w}=\mathrm{f} / \mathrm{s}-{ }^{-} \mathrm{nh}\right)\end{array}$ & 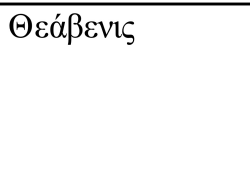 & $\begin{array}{l}\text { Le visage du } \\
\text { héron dit : } \\
\text { (« I1/elle } \\
\text { vivra ») }\end{array}$ & 134 \\
\hline
\end{tabular}

Fig. 3. - Attestations du nom bnw, « héron », dans l'anthroponymie égyptienne au Fayoum (00) et en Basse (B) et Haute Égypte (H).

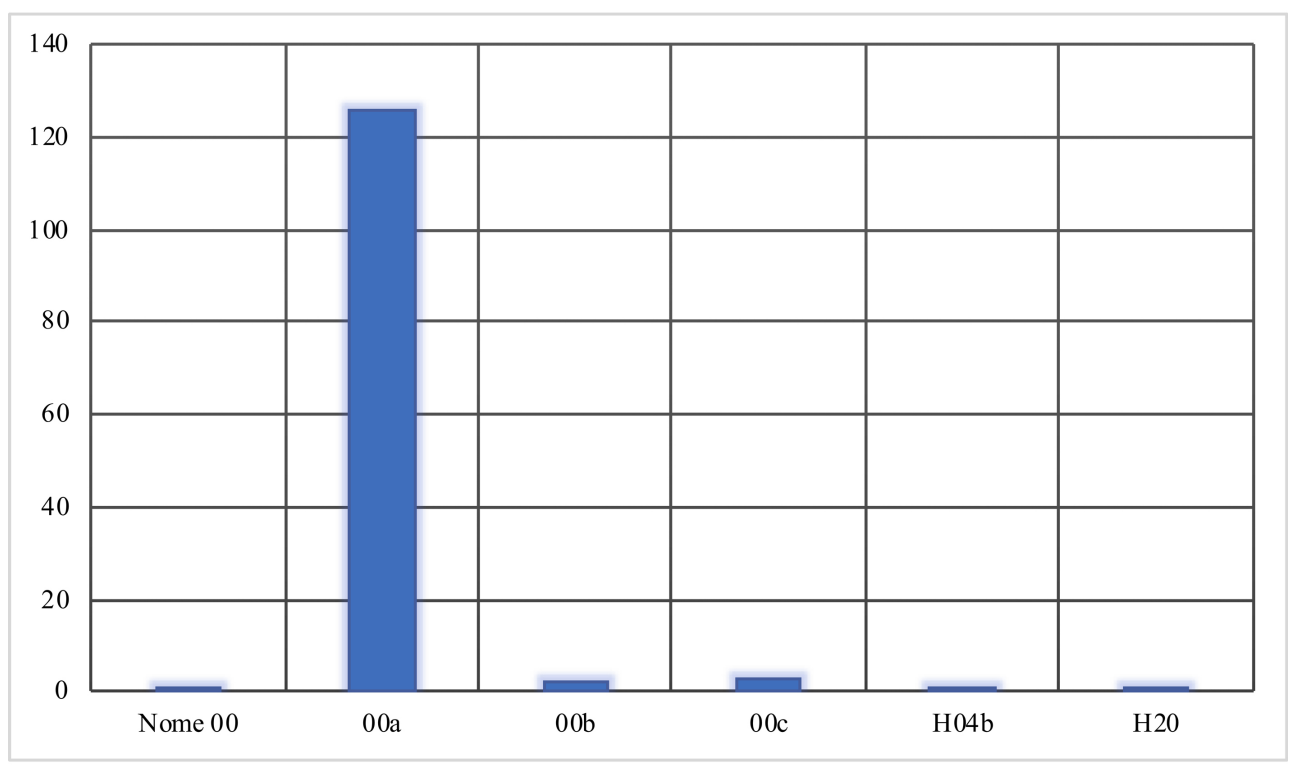

Les anthroponymes contenant des noms d'animaux, présents dans les sources égyptiennes depuis l'Ancien Empire, sont largement attestés à l'époque gréco-romaine 
en écriture démotique et, notamment, en transcription grecque. Comme H. Ranke l'a indiqué ${ }^{44}$, la présence de quelques noms d'animaux dans les anthroponymes peut être due au désir de possession de certaines caractéristiques de l'animal, comme la vitesse de la panthère ou la force du lion. Dans d'autres cas, le choix d'un animal spécifique dans un anthroponyme, comme la grenouille ou la souris, peut être dû à la comparaison des singularités de l'enfant avec les attributs de quelques animaux ou à d'autres raisons humoristiques; dans un premier temps, ces noms ont pu être, en réalité, des surnoms qui sont devenus après de véritables anthroponymes ${ }^{45}$. Cependant, l'analyse de la typologie de ces noms personnels montre qu'un bon nombre d'anthroponymes à noms d'animaux fait allusion à la divinité dont l'animal était censé être l'hypostase dans la pensée égyptienne. Quelques anthroponymes, et spécialement ceux commençant par $\mathrm{Pa}-/ \mathrm{Ta}-, \quad$ P3y-/T3y-, P3-šr-n-/T3-šr.t-n- ou P3-dï-/T3-dì-, ainsi que ceux contenant explicitement le nom d'un dieu ou d'une déesse, révèlent le lien établi entre l'individu porteur du nom et la divinité à laquelle l'animal se rapportait. Ce lien semble être confirmé par l'étude de la fréquence géographique des noms personnels contenant la mention d'un certain animal : dans les cas analysés ici, les régions géographiques où se trouvent la plupart des anthroponymes avec le nom d'un animal spécifique sont les mêmes que celles où était le plus répandu le culte à la divinité dont l'animal était considéré comme la manifestation. Ces faits montrent, encore une fois, que les anthroponymes des anciens Égyptiens constituent un reflet fidèle, non seulement de leur histoire, mais aussi de leurs croyances et de leur conception ontologique.

\section{BIBLIOGRAPHIE}

BRESCIANI Edda, « Sobek, Lord of the Land of the Lake », dans IKRAM Salima (éd.), Divine Creatures. Animal Mummies in Ancient Egypt, Cairo, The American University in Cairo Press, 2005, p. 199-206. CLARYSSE Willy, « Greek Accents on Egyptian Names », Zeitschrift für Papyrologie und Epigraphik, $\mathrm{n}^{\circ} 119,1997$, p. 177-184.

De WIT Constant, Le rôle et le sens du lion dans l'Égypte ancienne, Leiden, Brill, 1951.

IKRAM Salima (éd.), Divine Creatures. Animal Mummies in Ancient Egypt, Cairo, The American University in Cairo Press, 2005.

FRANKFORT Henri, Ancient Egyptian Religion, New York, Harper \& Row, 1948.

HART George, A Dictionary of Egyptian Gods and Goddesses, New York, Routledge \& Kegan Paul, 1986. HORNUNG Erik, El uno y los múltiples. Concepciones egipcias de la divinidad, Valladolid, Trotta, 1999.

JENNES Gwen, « P3-šr-n + Personal Name: An Expression of Genealogical Relations? », Zeitschrift für ägyptische Sprache und Altertumskunde, $\mathrm{n}^{\circ} 140,2013$, p. 132-141.

KÁKOSY Lászlo, « Phönix », dans Helck WOLFGANG, Otto EBERHARD (éds.), Lexicon der Ägyptologie, vol. IV, Wiesbaden, Otto Harrassowitz, 1982, p. 1030-1039. 
QUAEGEBEUR Jan, « Aspects de l'onomastique démotique : formes abrégées et graphies phonétiques », dans VLEEMING S. P. (éd), Aspects of Demotic Lexicography, Leuven, Peeters, 1987, p. 75-84.

RANKE Hermann, « Tiernamen als Personennamen bei den Ägyptern », Zeitschrift für ägyptische Sprache und Altertumskunde, $\mathrm{n}^{\circ} 60,1925, \mathrm{p} .76-83$.

RANKE Hermann, « Les noms propres égyptiens », Chronique d'Égypte, n 11, 1936, p. 293-323.

VERGOTE Jozef, Les noms propres du P. Bruxelles Inv. E. 7616. Essai d'interprétation, Leiden, Brill, 1954.

YOYOTTE Jean, « Une étude sur l'anthroponymie gréco-égyptienne du nome prosôpite », Bulletin de l'Institut français d'archéologie orientale, $\mathrm{n}^{\circ}$ 55, 1955, p. 125-140.

ZIVIE Alain, LICHTENBERG Roger, « The Cats of the Goddess Bastet », dans IKRAM Salima (éd.), Divine Creatures. Animal Mummies in Ancient Egypt, Cairo, The American University in Cairo Press, 2005, p. 106-119.

\section{NOTES}

1. Cf. H. Ranke, « Les noms propres égyptiens ».

2. Cf. H. Ranke, «Les noms propres égyptiens» ; H. Ranke, «Tiernamen als Personennamen bei den Ägyptern ».

3. Les noms de mammifères attestés dans les anthroponymes gréco-égyptiens sont au moins : la panthère $(3 b 3(. t))$, le chien (iwiw /whr(.t)), le chat (imy(.t)), la vache (îh.t), le mouton (isw), le babouin (" $n$ ), la musaraigne ('l'l(.t)), le loup (wnš(.t)), la souris (pyn), le lion $(m 3 y(. t) / r l w)$, le porc $(l l)$, le cheval $(h t r)$, le taureau $(k 3)$, le taureau gem $(\mathrm{gm})$ et le chameau $(g m w l)$.

4. Les noms d'oiseaux présents dans les anthroponymes égyptiens de l'époque grécoromaine sont au moins : le canard ( $3 p d)$, le corbeau ('bq), l'aigle (' $h \mathrm{hm})$, le faucon (byk(.t)), l'hirondelle (bny), le héron (bnw), l'ibis $(h b)$ et la colombe (gr-n-p.t, littéralement « oiseau du ciel »).

5. Il s'agit du nom du crocodile (msh(.t)), du serpent (hf(.t)) et de la grenouille (grr(.t)).

6. Ce travail a été réalisé grâce à la base de données Trismegistos (http:// www.trismegistos.org/), développée à l'Université de Louvain (KU Leuven). Les numéros d'identification des noms personnels, cités dans cet article pour chaque anthroponyme ou bien d'une manière explicite ou bien entre parenthèses à côté des noms, correspondent tous à ceux de Trismegistos.

7. Dans ce travail, les différents types d'anthroponymes à noms d'animaux ont été décrits seulement d'une façon générale. Il y a, d'autre part, des noms personnels qui pourraient être considérés comme appartenant à plus d'un type.

8. Dans cet article, les accents des transcriptions grecques des noms égyptiens ont été placés conformément aux critères signalés par W. Clarysse, «Greek Accents on Egyptian Names ».

9. Les numéros d'identification des différents noms mentionnés sont : $11+20970$ (' $b q$ ), 70 ('l'l), 8095 (Wnš), $9003+9018$ (Byk), 35765 (Msh), 207 (Grr), $13333+3395+3396+18502$ $+29760+32957\left({ }^{*} H b\right), 7031\left({ }^{*} \mathrm{Gmwl}\right)$. 


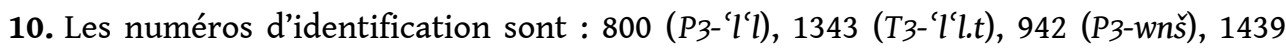

(T3-wnš.t), 787 (P3-byk), 1314 (T3-byk.t), 796 (P3-grr), 12596 (T3-grr(.t)), 794 (Р3-3b3), 6003 (Т3-363(.t)), 804 (Р3-“' $), 679+23010$ (Р3-'hm).

11. Ces anthroponymes sont identifiés par les numéros : 475 (M3y-ḥs), 10630 (M3y-rsy), 35973 (*P3-'l'l-p3-Hm), 24484 (P3-'

12. Les anthroponymes mentionnés ont les numéros d'identification suivants : $669(\mathrm{~Pa}-$ (p3)-byk), 1228 (Ta-byk), 718 (Pa-m3y); 6054 (Ta-n3-m3y.w) 689 (Pa-hb) et 12464 (Ta-p3-hb).

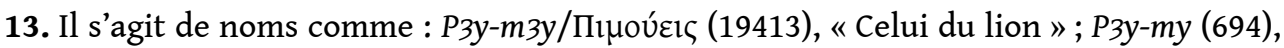

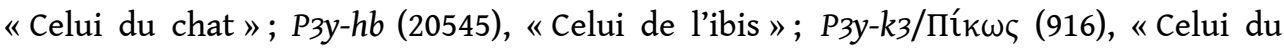
taureau "; T3y-whr (39202), "Celle du chien»; T3y-hb.t/Tíıßৎ (13922), "Celle de

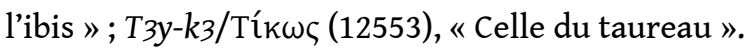

14. Les numéros d'identification des anthroponymes mentionnés sont : 5718 (T3-šr.t-np3-'l'l), 12069 (T3-šr.t-n-p3-' 'hm), 12998 (P3-šr-n-byk), 1084 (T3-šr.t-n-p3-m3y) et 13641 (Т3šr.t-(n)-p3-hb).

15. Pour plus d'informations sur le caractère généalogique possible des anthroponymes commençant par P3-šr-n-, cf. G. Jennes, « P3-šr-n + Personal Name: An Expression of Genealogical Relations?».

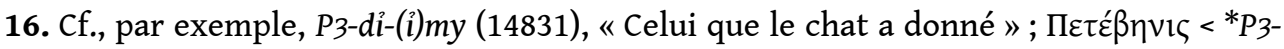

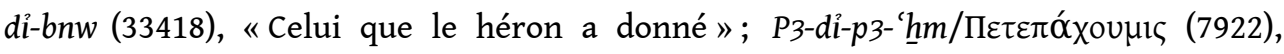

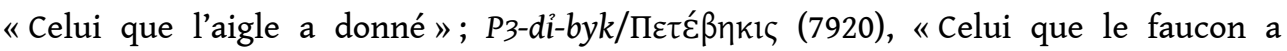

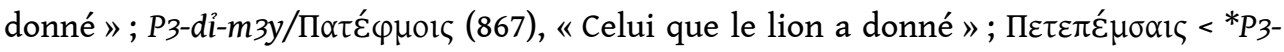

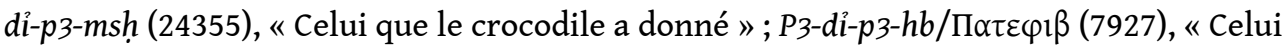
que l'ibis a donné »; P3-dî-km (824), « Celui que le taureau gem a donné ».

17. Cf. T3-dì-whr (16323), «Celle que le chien a donnée »; T3-dỉ-p3-byk (15754), «Celle

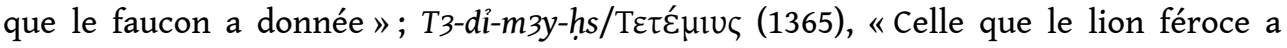

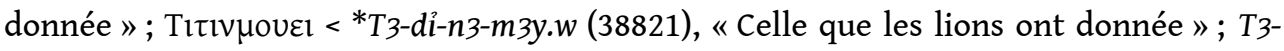
dï-p3-km (1357), «Celle que le taureau gem a donnée ».

18. Cf. aussi des anthroponymes avec cette structure mais avec le nom d'une divinité :

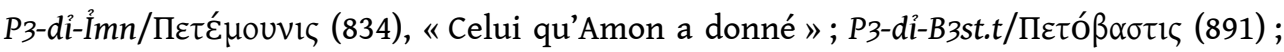

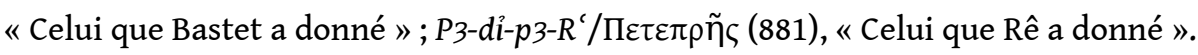

19. J. Quaegebeur, «Aspects de l'onomastique démotique : formes abrégées et graphies phonétiques », p. 78.

20. Les numéros d'identification des anthroponymes mentionnés sont, respectivement : 1335, 5434, 25776, 1338 et 36901.

21. Cf. $D d-h r-B s-\left(i w=f / s-{ }^{'} n H\right) / T \varepsilon \varepsilon \beta \tilde{\eta} \varsigma$ (1336), « Le visage de Bes dit : ('Il/elle vivra') »; $\underline{D} d$ -

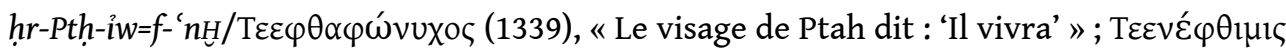
< ${ }^{*} D d-h r-N f r-T m$-(i $\left.i w=f / s-' n H\right)$ (1337), « Le visage de Néfertoum dit : ('Il/elle vivra') ».

22. Conformément à la pensée égyptienne, un même dieu pouvait se manifester sous la forme de différents animaux et vice-versa. Ainsi, par exemple, des dieux et des déesses comme Atoum, Shou, Heka, Amon, Onouris, Bes, Ptah, Horos, Thot, Khonsou, Bastet, Mout ou Rénénoutet étaient en rapport avec le lion. Cf. C. de Wit, Le rôle et le sens du lion dans l'Égypte ancienne, p.191-368. Pour plus d'informations sur le rapport entre les animaux sacrés et la divinité, cf. H. Frankfort, Ancient Egyptian Religion, p. 8-14. Cf. aussi E. Hornung, El uno y los múltiples. Concepciones egipcias de la divinidad, p. 95-124. 
23. Cf. par exemple les anthroponymes Hr-p3-wnš/ÁAтоó $\omega v \sigma ı \varsigma ~(20200)$, «Horus le

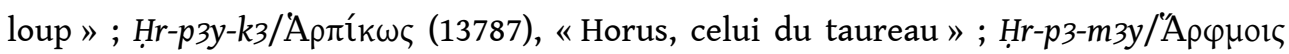
(7906) «Horus le lion»; 'А $\rho \varphi ı 1 \varsigma<{ }^{*} H r-p 3-h b$ (8811), « Horus l'ibis»; Hr-(p3)-byk/ "A $\rho \beta \chi 1 \varsigma$ (286), « Horus le faucon ».

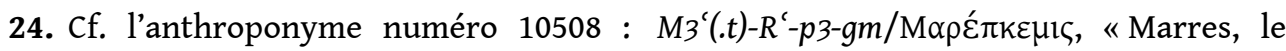
taureau gem ".

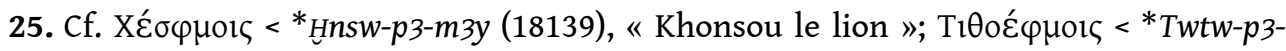

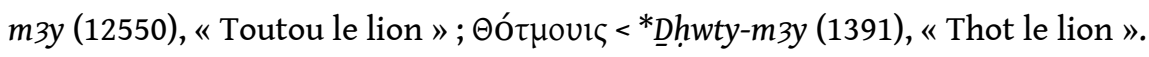

26. Cf. P3-ỉwiw-n-Hr/חívvpıৎ (918), « Le chien d'Horus ».

27. Le numéro d'identification du nom Пovopévoußıৎ est 26630. Cf. aussi d'autres noms

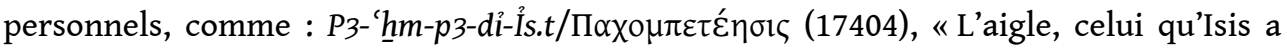
donné », plutôt que « L'aigle de celui qu'Isis a donné ».

28. Numéro d'identification 23002.

29. Numéro d'identification 24130.

30. Numéro d'identification 17401.

31. D'autres anthroponymes contenant le nom de l'aigle sont: $\Pi \alpha \chi \chi \mu \mu \pi \rho \tilde{\eta} \varsigma^{*}{ }^{*} P_{3}-{ }^{\prime} \underline{h} m-p_{3}-$

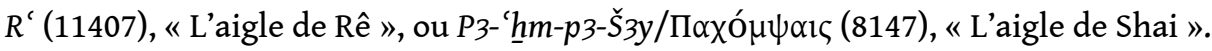

32. C'est notamment le cas des noms 3b3(.t), "panthère "; iwỉw, «chien »; ỉmy(.t), « chat »; îh.t, « vache »; 'lll(.t), « musaraigne »; ‘ 'hm, « aigle »; wnš(.t), «loup »; whr(.t), « chien »; byk(.t), «faucon»; m3y, «lion»; hb, « ibis »; k3, « taureau »; gm, « taureau gem »; gmwl, « chameau »; et grr(.t), « grenouille».

33. Il s'agit des noms isw, " mouton »; " $n$, « babouin »; bny, « hirondelle »; pyn, « souris »; rlw, «lion »; ll, « porc »; htr, « cheval »; ou gr-n-p.t, « colombe ».

34. Cf., par exemple, 'bq, « corbeau »; bnw, « héron »; ou hff.t), « serpent ».

35. Il faut néanmoins considérer que l'analyse de la fréquence géographique de certaines données, même si elle offre en effet des indices significatifs de quelques faits, n'est pas complètement fiable à cause de l'inégalité des documents préservés d'un point de vue géographique. Cf. J. Vergote, Les noms propres du P. Bruxelles Inv. E. 7616. Essai d'interprétation, p. 1-2 ; J. Yoyotte, «Une étude sur l'anthroponymie gréco-égyptienne du nome prosôpite", p. 125: "Pour une vaste partie du pays, ces matériaux [onomastiques] se révèlent assez rares : le delta du Nil est en effet beaucoup moins propice à la conservation des papyrus que la Haute Égypte et le Fayoum ».

36. En chiffres, 4 attestations, dont 1 en démotique, proviennent du nome $00 ; 5$, dont 2 en démotique, du nome $00 \mathrm{a}$; une en transcription grecque du nome $00 \mathrm{~b} ; 2$, dont une en démotique, du nome 00c; 5 en démotique du nome I de Basse Égypte (B) ; 5, dont 3 en démotique, du nome I de Haute Égypte $(\mathrm{H})$; une en transcription grecque du nome II (H) ; 13, dont 5 en démotique, du nome IVa $(\mathrm{H}) ; 58$, dont 30 en démotique, du nome IVb (H) ; 15, dont 3 en démotique, du nome IX (H) ; une en transcription grecque du nome $\mathrm{Xa}(\mathrm{H})$; une en transcription grecque du nome XIII (H) ; 2 en transcription grecque du nome XIX (H) ; et 14 en démotique du nome XX (H).

37. Pour des informations sur les endroits où ont été trouvées des nécropoles destinées aux chats, cf. S. Ikram (éd.), Divine creatures, p. XVIII-XX.

38. Cf. A. Zivie, R. Lichtenberg, « The Cats of the Goddess Bastet », p. 106-118. 
39. En chiffres, 19 attestations, dont 7 en démotique, proviennent du nome $00 ; 48$, dont 2 en démotique, du nome $00 \mathrm{a} ; 50$ en transcription grecque du nome $00 \mathrm{~b} ; 24$, dont une en démotique, du nome $00 \mathrm{c} ; 2$ en transcription grecque du nome $00 \mathrm{~d}$; une en transcription grecque du nome I (B); 2 en démotique du nome III (B); 3 en transcription grecque du nome I $(\mathrm{H}) ; 8$, dont 2 en démotique, du nome IVa $(\mathrm{H}) ; 31$, dont 9 en démotique, du nome IVb (H) ; une en démotique du nome IX (H); 7, dont 5 en démotique, du nome XV (H) ; une en transcription grecque du nome XIX (H); et 3 en transcription grecque du nome $\mathrm{XX}(\mathrm{H})$.

40. L'établissement du culte du crocodile à Shedet-Crocodilopolis est attribué au roi Ménès par Diodore de Sicile (I 89,3). Même si le culte du crocodile était spécialement répandu au Fayoum, il avait lieu également dans d'autres régions de l'Égypte: Crocodilopolis, une ville située en Haute Égypte, est mentionnée par Strabon (XVII 1, 47). Des nécropoles de crocodiles ont été, en fait, trouvées non seulement dans le Fayoum et dans différents lieux de la Basse Égypte, mais aussi dans quelques zones de la Haute Égypte. Cf. S. Ikram (éd.), Divine creatures, p. XVIII-XX.

41. Cf. E. Bresciani, «Sobek, Lord of the Land of the Lake », p. 201-202.

42. En chiffres, une attestation provient du nome $00 ; 126$ du nome $00 \mathrm{a} ; 2$ du nome $00 \mathrm{~b}$; 3 du nome 00c; une du nome IVb $(\mathrm{H})$; et une du nome XX (H).

43. Cf. L. Kákosy, Lexicon der Ägyptologie IV, p. 1030-1039; G. Hart, A Dictionary of Egyptian Gods and Goddesses, p. 57-58.

44. H. Ranke, « Les noms propres égyptiens », p. 297-298.

45. H. Ranke, « Les noms propres égyptiens », p. 298.

\section{RÉSUMÉS}

Attestés déjà à l'Ancien Empire, les anthroponymes contenant des noms d'animaux sont présents dans les sources égyptiennes à toutes les époques de l'histoire de l'ancienne Égypte. Ces anthroponymes, portés par des hommes et des femmes et écrits dans les différentes écritures égyptiennes, ainsi qu'en transcription grecque, sont composés d'une trentaine de noms de différents animaux. Même si dans quelques cas la présence du nom d'un animal spécifique dans un anthroponyme peut faire allusion au désir de possession des qualités de l'animal, l'utilisation de ce genre de noms révèle souvent la connexion du porteur de l'anthroponyme avec la divinité représentée par l'animal mentionné. Dans le présent travail, nous présentons une analyse de la typologie des différents anthroponymes contenant des noms d'animaux et de leur signification dans le contexte de la vie religieuse à l'époque gréco-romaine.

\section{AUTEUR}

\section{ANA ISABEL BLASCO TORRES}

Doctorante, université catholique de Louvain et université de Salamanque 


\title{
Le rôle de l'animal dans la religion romaine : la spécificité des rites et mythes féminins
}

\author{
Nicole Boëls-Janssen
}

1 La place des animaux dans la civilisation romaine a déjà été bien étudiée de différents points de vue ${ }^{1}$. Leur rôle n'est bien sûr pas le même dans le domaine religieux que dans la vie privée. On connaît surtout la religion masculine et l'animal y joue un rôle de premier plan puisque le sacrifice sanglant est un élément essentiel du rituel. Mais il y avait aussi des divinités féminines, des cultes célébrés par des femmes. Mon but est ici de tenter de comparer le rôle des animaux dans la religion féminine avec celui qu'ils tiennent dans la religion masculine. Nous verrons que ce parallèle révèle combien leurs conceptions des relations de l'homme avec le divin sont différentes.

\section{Les animaux dans la religion masculine}

L'une des cérémonies essentielles de la religion antique en général et de la religion romaine en particulier est le rite du sacrifice. Il consiste à donner une offrande à la divinité, produits de la terre, fleurs, fruits... Quand il s'agit d'un animal, il est préalablement consacré par la mola salsa que l'on répand sur lui avant de l'abattre. Après quoi il est partagé entre les chairs, que mangent les fidèles, et les exta (la fressure), qui constituent la part du dieu et sont brûlés sur l'autel ${ }^{3}$. L'homme entretient la puissance du dieu en le «nourrissant » et prend part à sa puissance en partageant avec lui la victime consacrée. Mais hommes et dieux restent séparés, ils ne consomment pas les mêmes morceaux et ne mangent pas ensemble: la frontière entre eux reste infranchissable. Les recherches modernes ont désormais tendance à s'attacher davantage aux modalités spécifiques qu'à une théorie générale ${ }^{4}$. Mais le mécanisme sacrificiel reste celui que Mauss a mis en lumière dès la fin du xix ${ }^{e}$ siècle ${ }^{5}$. Jean Pierre Vernant en résume clairement le principe :

«Un des traits distinctifs du sacrifice c'est donc qu'il se joue entre trois termes,

l'objet consacré servant d'intermédiaire entre le sacrifiant et la divinité. ${ }^{6}$ 
L'animal sacrificiel est un simple moyen de communication entre l'humain et le divin. Il peut servir la relation hommes-dieux d'une autre façon: il transmet à l'homme la volonté divine. Ainsi le sacrifice permet de consulter le dieu par l'observation des exta. Rome a adopté cette technique originaire d'Étrurie et ce sont toujours des spécialistes étrusques, les haruspices, qui la pratiquent. Le foie de l'animal était considéré comme une sorte de microcosme qu'ils savaient déchiffrer. En témoigne le fameux foie en bronze de Plaisance, qui est divisé en régions légendées. L'animal sacrificiel n'est alors qu'un miroir inerte de la pensée divine. Une autre technique de consultation des dieux était l'auspicine (mot formé sur la racine spec/spic, regarder et celle d'auis, l'oiseau). Cette discipline, bien romaine, elle, consistait à observer les oiseaux dans un espace céleste délimité, le templum, pour traduire les signes envoyés par les dieux en fonction de la nature des oiseaux, de leur nombre, de leurs cris et de la direction de leur vol. Un collège de prêtres, les augures, était spécialisé dans cette science, qui était soumise à des règles rigoureuses d'observation, de formulation et d'interprétation. Toute tenue du sénat, toute assemblée du peuple devait être autorisée par une prise d'auspices préalable. En campagne, le général était tenu de consulter les dieux avant de livrer bataille; pour ce faire on observait le comportement des poulets sacrés que l'on transportait dans des cages. Même si le rôle des oiseaux auspiciaux est plus actif, si j'ose dire, que celui des victimes sacrificielles, même si on peut considérer qu'ils sont des messagers des dieux, leur rôle se borne, là aussi, à être des intermédiaires chargés de transmettre aux hommes la volonté divine, comme une estafette apporte aux officiers les ordres du général.

4 Il en est de même lorsque les dieux envoient spontanément des signes aux hommes : on appelle ces événements extraordinaires des prodiges. Les animaux figurent parmi ces manifestations: un loup qui fait irruption dans un camp, un bœuf qui monte au sommet d'un immeuble, une femelle faisant ses petits dans un temple, autant d'avertissements que les hommes doivent prendre en compte; il faudra toute la compétence des prêtres spécialisés dans l'interprétation du langage des dieux, augures, haruspices et decemuiri sacris faciundis (collège de dix prêtres habilités à résoudre les problèmes religieux exceptionnels) pour inventer les rites expiatoires qui rétabliront la pax deorum (la bonne entente avec les dieux).

Dans tous les cas donc, l'animal est considéré comme un outil qui permet aux hommes de communiquer avec les dieux; il peut être utilisé par les hommes ou par les dieux mais n'a de toute façon aucune valeur sacrée en soi. Qu'en est-il dans les pratiques religieuses féminines?

\section{Les animaux dans la religion féminine}

6 Pour la consultation de la volonté divine par l'observation des oiseaux, le déchiffrement des exta de l'animal sacrificiel ou l'interprétation des prodiges fournis par des animaux, les femmes ne sont pas concernées puisque seuls des hommes, qu'ils soient augures, haruspices ou décemvirs ${ }^{7}$, sont officiellement habilités à traduire le message divin. Les rites sacrificiels étaient-ils également réservés au sexe masculin ? Certains savants ont soutenu que les femmes n'avaient pas le droit de pratiquer de sacrifices sanglants. Olivier de Cazanove $^{8}$ a été le premier à énoncer clairement cette théorie, suivi par nombre de savants; ainsi John Scheid intitule un développement de sa contribution à l'Histoire des femmes en Occident : 
"L'incapacité sacrificielle des femmes. "

7 Cette thèse a été critiquée à juste titre par Rebecca Flemming ${ }^{10}$. En effet, les occurrences de sacrifices sanglants accomplis par des femmes ne manquent pas. Outre les Vestales, qui participaient, entre autres, au sacrifice des Fordicidia en avril et à celui en l'honneur de Consus en août ${ }^{11}$, on peut citer les exemples de la Regina Sacrorum et de la Flaminica Dialis qui sacrifiaient l'une une truie à Junon à toutes les calendes ${ }^{12}$, l'autre un bélier à Jupiter à toutes les nondines ${ }^{13}$. La Flaminica utilisait, comme les flamines, les pontifes et les Vestales, le couteau sacrificiel rituel, la secespita ${ }^{14}:$ il est donc l'attribut aussi bien des prêtresses que des prêtres, sans distinction entre les sexes. Cazanove et Scheid le reconnaissent et tentent de justifier ce qu'ils considèrent comme des exceptions soit par l'origine étrangère des cultes concernés, soit par le statut des prêtresses : la Vestale a un statut sexuel ambigu et la fonction de la Flaminica Dialis n'est que le corollaire de celle de son mari. J'ai montré que ces arguments n'étaient pas valides $^{15}$. Les femmes n'étaient donc pas frappées d'interdiction concernant les sacrifices sanglants. On pouvait aussi sacrifier un animal à une déesse, par exemple à la fête de Junon à Faléries, où les victimes sacrificielles, des génisses blanches, étaient amenées en procession au bois sacré où se trouvait l'autel de la déesse ${ }^{16}$. Généralement le sexe de la victime devait être le même que celui de la divinité à laquelle s'adressait le sacrifice; et lorsqu'il s'agissait d'un rite de fécondité, on sacrifiait une femelle pleine, en vertu du principe d'analogie. Mais cette pratique du sacrifice sanglant est un rite commun à toute la société patriarcale ; les prêtresses que j'ai citées appartiennent à la religion d'État; ces sacrifices féminins n'entrent donc pas dans notre étude : c'est la religion strictement féminine qui nous intéresse. Or les offrandes consacrées à la divinité y sont le plus souvent des céréales, des fruits, des fleurs; et quand un animal figure dans le rituel, il n'est pas sacrifié, non parce que les femmes n'avaient pas le droit de sacrifier, mais parce que l'animal y est considéré de façon très différente. Les exemples sont rares mais révélateurs.

\section{Bona Dea et le serpent}

Commençons par le culte de Bona Dea ${ }^{17}$. C'est un culte mystérieux et la déesse à laquelle il s'adressait ne l'était pas moins, ne serait-ce que parce que l'on ne savait pas son vrai nom. Dans la nuit du 4 au 5 décembre les matrones ${ }^{18}$ se réunissaient dans la maison d'un consul ou d'un préteur, pour célébrer la fête. Les renseignements que nous possédons sur ce qui s'y passait sont nécessairement parcellaires, car seuls des hommes nous les ont transmis, or il leur était strictement interdit d'y assister. Ils ont surtout noté ce qui leur semblait étrange dans ce qu'on en disait. La salle était décorée de feuillage mais le myrte en était exclu; on mettait une branche de vigne au-dessus de la statue de la déesse ; il y avait un serpent dans la salle, sans doute apporté du temple où vivaient des serpents apprivoisés. Les femmes faisaient des libations de vin, alors qu'elles n'avaient pas le droit d'en boire ; le vase qui contenait ce vin était couvert d'un voile et on utilisait les noms mensongers de "lait " pour le vin et de "vase à miel » pour le récipient. Enfin il y avait de la musique et de la danse, divertissements indignes d'une bona matrona et qu'on associe au comportement des courtisanes.

9 Un mythe étiologique (destiné à donner l'origine d'un culte), où la déesse est appelée Fauna, était censé rendre compte de tous ces mystères. On en racontait deux versions. Dans la première elle est une matrone modèle mais elle boit du vin en cachette et son 
mari Faunus la châtie en la fouettant à mort avec une verge de myrte. Pris de remords, il fait d'elle une déesse. Dans l'autre version elle est la fille de Faunus. Elle résiste aux avances de son père ; il essaie en vain de l'enivrer puis de la fouetter avec une branche de myrte et n'arrive à ses fins qu'en prenant la forme d'un serpent. La conclusion n'est pas exprimée dans la seconde version, car l'auteur ne cite que les éléments qui diffèrent de la première; on doit donc présumer qu'elle est identique : après avoir bu du vin, avoir été frappée avec une branche de myrte et (uniquement dans la seconde version) pénétrée par un serpent, Fauna devient une déesse ${ }^{19}$.

10 C'est cette déification finale qui donne la clef du sens de la fête ${ }^{20}$. En réunissant les différents éléments du mythe et du rite on peut reconstituer un schéma rituel où, dans un premier temps, le vin est dissimulé et le myrte exclu. Le serpent est sans doute, lui aussi, invisible, enfermé dans un panier. Au moment crucial de la cérémonie le récipient est dévoilé en vue des libations de vin; on lui donne alors son vrai nom. Sous l'effet $\mathrm{du}$ vin, les femmes peuvent alors chanter et danser. Il y a une ressemblance évidente avec les rites dionysiaques où les Bacchantes boivent la liqueur sacrée du dieu du vin, qui les entraîne dans un délire orgiaque ; elles chantent, dansent, frappent le sol de leurs thyrses et brandissent des serpents. Elles sont "enthousiasmées »: le dieu a pénétré en elles avec le vin qu'elles ont bu ${ }^{21}$. De la même façon, à la fête de décembre la divinité prend possession des matrones sous la forme du vin qu'elles absorbent. L'identité de la déesse avec le breuvage est manifestée par la branche de vigne sur sa statue. Les faux noms qu'on donne au vin, «lait», «miel», ont un sens symbolique, qu'on retrouve dans beaucoup de civilisations: ils signifient que c'est une boisson divine, qui « nourrit » de sacré les femmes qui le consomment, un breuvage initiatique qui les fait entrer dans une vie nouvelle.

11 Puis la verge de myrte, exclue jusque-là, fait son apparition: la déesse pénètre les femmes sous la forme végétale. Mais, dira-t-on, si la déesse est la vigne, elle ne peut être aussi le myrte, d'autant plus que la première semble exclure l'autre. Pour comprendre cette apparente contradiction il faut tenir compte à la fois de la date de la fête et de la nature des deux végétaux concernés. La fête avait lieu en décembre. C'était donc une fête de fin d'année, qui célébrait la mort de l'année écoulée par un retour provisoire au chaos antérieur à la civilisation avant que naisse la nouvelle année. Comme dans les rites carnavalesques qui font revivre ce chaos, les matrones font à la fête de Bona Dea des choses qui leur sont habituellement interdites: boire du vin, pratiquer musique et danse. La fête était célébrée la nuit du 4 au 5 décembre, c'est-àdire la veille des nones; or les nones marquent l'apparition du $1^{\text {er }}$ quartier lunaire ${ }^{22}$ qui symbolise la renaissance après la mort que représente la période de la Nouvelle Lune. C'est le sens de la présence du myrte dans la légende ${ }^{23}$. Lui qui est toujours vert, donc immortel, redonne vie à la vigne qui semble morte en hiver, c'est le sens de la flagellation de Fauna qui, après sa mort symbolique (caractéristique des mythes et rites initiatiques), reçoit ainsi une nouvelle vie, divine puisque Faunus fait d'elle une déesse. Dans le rituel de décembre, le myrte est d'abord exclu de la salle où se célèbre la fête, de même que le vin est dissimulé sous un voile et appelé de noms mensongers, jusqu'au moment où, le vin ayant été dévoilé et consommé, le myrte peut, à son tour, pénétrer dans le lieu de culte et donner, lui aussi, une nouvelle vie aux célébrantes; c'est une autre forme d'enthousiasme. Je ne pense pas que les matrones procédaient à une flagellation comme dans le mythe : un simple contact devait suffire à faire pénétrer en 
elles la vie nouvelle, divine, que contenait le myrte sacré. De même la fée se contente de toucher de sa baguette magique la personne ou l'objet qu'elle va transformer.

Cette interprétation du rôle du vin et du myrte dans le mythe et dans le rite éclaire celui du serpent. Il a la même signification: sa mue fait de lui, c'est bien connu, un symbole de renaissance. Comme le vin et le myrte il est d'abord dissimulé, enfermé dans un panier, puis, comme eux, il apparait : on ouvre le panier. En pénétrant Fauna dans le mythe, il lui donne une vie nouvelle : il fait d'elle une déesse. Dans le rite, je ne crois pas qu'il y ait eu de pénétration, pas plus que de flagellation, mais sans doute des gestes symboliques comme prendre le serpent en mains ou le faire glisser le long du corps. Comme pour le myrte, un simple contact suffit à faire passer le sacré de la personne divine à la personne humaine.

On trouve un autre exemple de lien entre une divinité féminine et le serpent dans le culte de Junon à Lanuvium ${ }^{24}$. On y pratiquait une sorte d'ordalie : une jeune fille devait descendre dans la grotte où se trouvait l'animal de Junon. S'il acceptait la nourriture qu'elle lui apportait, sa virginité était prouvée et la fertilité des champs assurée pour l'année. Loin d'être une victime sacrifiée à la divinité, le serpent est la forme animale sous laquelle elle se manifeste : c'est à lui qu'est donnée l'offrande. C'est lui qui la consomme. Au lieu d'être détruit par le rite sacrificiel, comme dans le sacrifice sanglant de la religion masculine, l'animal est nourri par lui. Qu'il soit dans une grotte n'est pas sans signification non plus. Le serpent est considéré comme un animal tellurique : il vit dans les profondeurs de la terre. Il est l'animal emblématique de la Grande Déesse-Mère des temps archaïques, divinité chtonienne, car la Terre est source de fertilité et de vie. Elle se manifeste à Lanuvium sous la double forme animale et minérale ${ }^{25}$. Même si la finalité du rite n'est pas la même qu'à la fête de Bona Dea, le principe est le même : un contact direct avec le sacré. La jeune fille pénètre dans la grotte et le serpent vient en personne consommer la nourriture qu'elle lui offre. La grotte comme le serpent matérialisent la Déesse-Terre, matrice de toutes choses, seule capable de transmettre aux humains sa puissance de fécondité. La jeune fille ne peut «absorber » cette force divine que si elle est vierge. Elle n'est pas féconde elle-même : elle est une promesse de fécondité. Validée en quelque sorte par son contact avec le serpent sacré, cette promesse sera transmise par elle à toute la cité.

14 Le rituel de la fête de décembre, lui, avait une valeur initiatique : il donnait aux femmes qui le célébraient une vie nouvelle, où elles partageaient la divinité de Bona Dea grâce au contact successif de ses trois épiphanies, le vin de la vigne, le bois du myrte et le serpent régénérant. La divinité au féminin tend à se manifester dans la nature sous plusieurs apparences. Son caractère protéiforme et sa capacité à transmettre ses pouvoirs divins apparaissent aussi dans un autre culte de Junon.

\section{Junon et la chèvre aux Nones Caprotines}

Les Nones Caprotines ${ }^{26}$ étaient un rituel de fécondité. Elles tirent leur nom de la date de la fête: elle se célébrait aux nones de juillet en l'honneur de Junon Caprotine. L'épithète qui qualifie à la fois la déesse et le jour de la fête est formée sur le mot caper (le bouc) ou capra (la chèvre). Rien ne permet a priori de choisir entre les deux. Les liens de Junon avec les caprins sont nombreux. Je passe sur la fête de Faléries où les jeunes garçons chassaient rituellement une chèvre; celui qui l'atteignait gagnait l'animal. Le poète Ovide donne trop peu de détails sur le contexte et le rituel pour qu'on puisse 
interpréter celui-ci avec certitude ${ }^{27}$. Mais il suggère un lien quelconque entre la déesse et la chèvre.

Plus révélatrice est la Junon de Lanuvium. Cicéron la décrit avec précision $^{28}:$ d'aspect guerrier, elle portait un bouclier et une lance et elle était revêtue d'une peau de chèvre. Il existe d'elle des représentations figurées ${ }^{29}$ : la peau de chèvre est jetée verticalement sur ses épaules, les pattes de devant sont nouées sur sa poitrine et les autres pendent de chaque côté, la tête forme une sorte de casque au-dessus du visage de la déesse. L'ensemble donne l'impression d'une identification de la déesse à l'animal. Elle a une certaine analogie avec la déesse grecque Athéna, d'aspect guerrier, elle aussi, qui portait la fameuse égide, un bouclier fabriqué avec la peau de la chèvre Amalthée qui, selon le mythe, aurait nourri Jupiter enfant. Les deux déesses manifestent un lien entre une divinité féminine d'aspect guerrier et la race caprine, mais sans exclure les deux fonctions traditionnelles de la féminité, mettre au monde des enfants (la Junon de Lanuvium portait les épithètes à la fois de Mater, Mère, et de Sospita, protectrice) et les nourrir (allaitement de Zeus par la chèvre Amalthée), qui se trouvent associées à la fonction guerrière. Pour Junon Caprotine aussi, dont l'épithète suggère qu'elle a un lien avec la race caprine, l'aition de sa fête (récit mythologique qui en justifie les rites) est révélateur de cette double fonction de la féminité, car il raconte comment des femmes sauvèrent Rome d'un ennemi dangereux ${ }^{30}$. De même dans le monde animal les femelles nourrissent les petits qu'elles ont mis au monde et les défendent contre tous les dangers. La Junon des Nones Caprotines est donc sans doute bien une Junon à la chèvre $^{31}$ et, comme Athéna dont le bouclier est emprunté à la nourricière Amalthée, elle est une déesse à la fois maternelle et protectrice.

Un autre lien entre les caprins et Junon apparaît aussi, curieusement, dans la fête des Lupercales : le 15 février les Luperques, dont le nom évoque plutôt un dieu-loup (le loup se dit lupus en latin) parcouraient la ville, vêtus d'un simple pagne; ils brandissaient des lanières faites, comme leur pagne, de la peau de l'animal sacrificiel, bouc ou chèvre ${ }^{32}$, et en frappaient tout ce qu'ils rencontraient. En ce début d'année, le rite avait une fonction purificatrice, comme l'indique le nom du mois, februarius (mois des purifications), et celui des lanières, februa (outils de purification). Or la peau dont étaient faits le pagne et les fouets des Luperques était appelée amiculum Iunonis (vêtement de Junon) ${ }^{33}$. La déesse n'a pas à notre connaissance d'autre lien avec les Lupercales; ce nom est peut-être dû simplement à la ressemblance entre la tenue de "sauvage " des Luperques et celle de la Junon de Lanuvium; mais il suggère qu'il existait une relation de notoriété publique entre la déesse et la race caprine.

Enfin la fête des Poplifugia, qui se situe juste avant les Nones Caprotines, le 5 juillet, passait pour rappeler le souvenir de la disparition de Romulus au lieu-dit Palus Caprae (le Marais de la Chèvre) ${ }^{34}$. Ce n'est sans doute pas un hasard: la proximité des deux fêtes suggère un lien entre elles et incite à penser également que la Junon des Nones Caprotines était plutôt une Junon à la chèvre qu'une Junon au bouc.

Cependant, depuis les travaux de James Frazer, qui a étudié les Nones Caprotines dans son Commentaire aux « Fastes » d'Ovide, on a reconnu dans l'épithète de la déesse et de la fête une référence à la caprification, procédé qui consiste à favoriser la fécondation du figuier cultivé par la proximité du figuier sauvage. Celui-ci aurait donc été considéré comme l'élément mâle fécondant l'arbre femelle, d'où l'interprétation de caprificus comme formé de caper et de ficus : figuier-bouc. Junon serait donc la déesse au bouc. Mais le mot caprificus serait alors un "monstre ", car il serait à la fois masculin et 
féminin, comme ces hermaphrodites que Rome considérait comme des prodiges particulièrement menaçants, donnant lieu à des rites purificatoires exceptionnels. En réalité, caprificus est bien un mot féminin, comme tous les noms d'arbres, ce qui incite à penser qu'il associe le figuier à la chèvre et non au bouc. Le fait que sa sève blanche, que les matrones utilisaient dans le rite des Nones Caprotines, était appelé «lait du figuier » confirme qu'il était effectivement, comme tous les arbres, considéré comme féminin. Junon serait donc bien la déesse-chèvre.

Cependant, malgré le nom de la fête et l'épithète de la déesse, et quel que soit le sexe de l'animal concerné, aucun caprin ne figure dans le rituel des Nones Caprotines. Les matrones se réunissaient sous un figuier sauvage et pratiquaient des rites à l'aide d'une branche du figuier et de sa sève blanche. La chèvre est donc présente mais seulement par le biais de l'onomastique qui réunit l'arbre et l'animal en un seul mot. On ne retrouve la même solidarité entre l'animal et le végétal que dans le culte de Bona Dea. Le caprificus est présent aussi dans le mythe qui justifie le rituel des Nones Caprotines. Les ennemis assiégeant Rome ayant exigé qu'on leur envoie des Romaines comme épouses, les esclaves s'habillent en mariées et se rendent au camp des ennemis; elles les enivrent ; puis l'une d'entre elles, appelée Tutula, monte sur un figuier sauvage pour faire signe aux Romains à l'aide d'une torche qu'ils peuvent venir les massacrer ${ }^{35}$. Paul Drossart ${ }^{36}$ a montré que l'image de Tutula brandissant une torche au sommet du figuier était l'image de la déesse lunaire matérialisée dans l'Arbre Lunaire, ou Arbre de Vie, et dans la lumière de l'astre représentée par la torche. Le caprificus associe les deux fonctions de la déesse : dans le rite il transmet aux matrones la puissance fécondante de la déesse et dans le mythe il les défend comme l'indique le nom de l'esclave qui conçoit la ruse destinée à sauver les matrones du destin que leur réservent les ennemis.

21 La personnalité de cette Junon qui associe les fonctions de fécondité et de protection guerrière est très différente de celle de Bona Dea mais, comme elle, elle transmet sa puissance sacrée par une épiphanie à la fois végétale et animale : le caprificus. Dans le rituel, on devait sans doute frotter légèrement une partie du corps des femmes avec le lait du figuier sacré et les toucher avec une de ses branches. Le processus religieux est identique : la puissance de la déesse passe de la divinité aux femmes par le contact direct avec ses épiphanies végétales ou animales.

\section{La louve nourricière et le pivert}

Un dernier exemple illustrera la présence de l'animal dans le monde religieux féminin : le mythe de la naissance du fondateur de Rome ${ }^{37}$. Selon la tradition, nés du viol d'une Vestale par le dieu de la guerre, Romulus et Rémus sont exposés sur le Tibre dans une nacelle qui s'échoue sur la berge. Ils sont découverts par une louve qui les allaite ${ }^{38}$ dans une grotte appelée Lupercal, sous un figuier sacré, appelé Ficus Ruminalis. On s'aperçoit que, dans la tradition masculine des origines de Rome, intervient la structure propre aux divinités féminines : l'association d'un végétal, le figuier, et d'un animal, la louve, avec tous deux une fonction nourricière, la louve parce qu'elle allaite les jumeaux, le figuier par son épithète Ruminalis, formée sur le mot ruma, la mamelle. On constate même la présence du minéral puisque la scène est associée à la grotte du Lupercal. L'ensemble formé par la grotte, image de la Terre-Mère, le figuier nourricier et la louve allaitante suggère qu'on a affaire à une triple épiphanie de la Grande Déesse, Mère de toutes choses. Cela n'a rien d'étonnant puisque c'est Romulus qui, après avoir fondé 
Rome, est censé avoir créé la société patriarcale en instituant le mariage et la famille après l'enlèvement des Sabines: le mythe de la naissance du fondateur se situait nécessairement dans un environnement antérieur, celui où était révérée la puissance fécondante et maternelle de la Grande Déesse.

Cependant Plutarque ajoute un détail surprenant : un pivert serait venu aider la louve à nourrir et protéger les enfants ${ }^{39}$. Étrange mission pour un oiseau qui ne peut ni allaiter ni combattre; la louve n'avait certainement pas besoin d'un pivert pour nourrir ses enfants adoptifs et elle était mieux qualifiée pour les défendre. Les représentations figurées de la fameuse louve montrent d'ailleurs un animal à l'air menaçant, bien plus redoutable qu'un pivert. L'invraisemblance du rôle que cette version de la légende attribue à cet oiseau donne à réfléchir.

24 Comme dans quantité de mythes, le héros au destin exceptionnel naît miraculeusement; souvent il est enfanté par une vierge; selon les cas, la vierge est fécondée par un dieu, un animal merveilleux ou une flamme divine, c'est-à-dire que la légende introduit un élément mâle qui rend crédible qu'une vierge mette un enfant au monde. C'est à Mars qu'est attribuée la paternité des jumeaux dans la légende la plus connue des origines de Rome, mais dans une autre version, sans doute antérieure, c'est un symbole de virilité apparu dans le foyer du palais royal qui aurait fécondé la vierge. On lui préféra celle qui donnait à Romulus un père divin nommément désigné et à Rome un garant de sa puissance guerrière.

Après l'épisode de la naissance miraculeuse, qui met dès le début le héros en dehors des normes de la société, vient celui de l'allaitement. Les mythes héroïques exigent qu'il se fasse aussi, comme les rites initiatiques, en dehors de la cité, dans un contexte sauvage. Comme la naissance, l'allaitement ne peut être assumé que par le sexe féminin : c'est donc la louve qui représente l'environnement asocial dans lequel doit être nourri le héros. Mais le rôle attribué au pivert, oiseau de Mars, permet d'introduire le dieu également dans l'épisode du " nourrissage ».

Ensuite une femme, Acca Larentia, prend la relève de la louve pour élever les enfants ; la légende fait d'elle une prostituée grâce à un jeu de mots signifiant: le mot lupa, "louve ", désigne aussi une prostituée, car celle-ci vit, sur le plan sexuel, en marge de la société civilisée, comme les loups. Mais cela ne l'empêche pas d'être aussi une femme mariée ; cette situation ambiguë, socialement impossible ${ }^{40}$, permet de faire intervenir à nouveau un personnage masculin : c'est son époux, le berger Faustulus qui trouve les bébés et les lui donne à élever.

Tout se passe comme si les hommes avaient cherché à s'approprier la légende du héros né d'une vierge et élevé en marge de la société par une louve. Dans cette relecture du mythe, la vierge est fécondée par un dieu ou même par un homme : certaines versions attribuent au roi Amulius, son oncle, déguisé en Mars, le viol de la Vestale ${ }^{41}$; les jumeaux sont nourris et protégés par un pivert et élevés grâce au berger Faustulus. Ces versions plus conformes à la conception patriarcale du monde se superposent à la structure féminine du mythe du futur héros mis au monde par une vierge, nourri par une louve dans une grotte, sous le figuier Ruminalis, c'est-à-dire sous l'égide de la Grande Déesse matérialisée dans sa triple épiphanie. La double fonction maternelle nourricière et protectrice - qu'assure la Junon de Lanuvium (qui est à la fois Mater et Sospita) ou la déesse des Nones Caprotines (qui sauve Rome dans le mythe et utilise le « lait » du figuier dans le rite) se reconnaît encore dans l'image ancienne de la louve allaitant les jumeaux et les protégeant de son air menaçant. Mais dans la version 
«patriarcale » de la naissance de Romulus, cette double fonction se trouve scindée en deux figures animales : le pivert qui représente le dieu défenseur Mars et la louve, qui incarne le Déesse Mère, désormais réduite au rôle de nourrice. Mais cette réécriture du mythe en fausse la signification. Le pivert n'est pas une incarnation de la divinité ; il n'est que l'attribut de Mars. Il ne peut pas transmettre directement le sacré aux enfants comme le fait la louve en les allaitant et comme le fait le caprificus en donnant son « lait » aux matrones dans le rituel des Nones Caprotines. Il ne peut faire, si j'ose dire, que de la figuration et reste étranger au sens religieux du mythe originel. leurs déesses avaient à Rome une relation avec l'animal bien différente de celle des hommes. Pour les hommes, l'animal est un moyen de communication avec les dieux. Pour reprendre et compléter la phrase de J.-P. Vernant citée au début de cette contribution :

«Le sacrifice se démarque des formes de contact direct entre hommes et dieux.»

Dans la religion féminine au contraire le contact direct avec la divinité est privilégié, grâce aux multiples formes que peut revêtir celle-ci. L'animal fait partie d'une conception religieuse plus large où la divinité n'est pas manipulée par l'humain mais se manifeste sous des apparences diverses, tout en restant elle-même. Elle s'incarne sous forme animale comme elle habite aussi les arbres ou les grottes. Il n'est pas besoin de sacraliser l'animal en le saupoudrant de mola salsa ni de le sacrifier. Il est lui-même la divinité, qui communique ainsi directement avec ses fidèles.Le simple contact suffit pour que le sacré pénètre en elles. On peut dire que dans la conception religieuse féminine romaine l'animal a une place originale, qui correspond à une conception du rapport entre les hommes et les dieux totalement différente de la conception masculine : là où l'homme a une relation utilitaire avec l'animal comme avec le dieu, la femme a, avec les déesses et leurs épiphanies animales (ou végétales), une relation d'ordre mystique.

\section{BIBLIOGRAPHIE}

AMAT Jacqueline, Les animaux familiers dans la Rome antique, Paris, Les Belles Lettres, 2002.

BASANOFF Vsevolod, « Nonae Caprotinae », Latomus, 8, 1949, p. 209-216.

BOËLS-JANSSEN Nicole, La vie religieuse des matrones Romaines à l'époque archaïque, Rome (Collection de l'École Française de Rome nº 176), 1993.

BOËLS-JANSSEN Nicole, « Le statut religieux de la Flaminica Dialis », Revue des Études Latines, 51, 1974, p. 77-100. 
BOËLS-JANSSEN Nicole, « Le double mythe de la Bona Dea », dans OUDOT Estelle et POLI Fabrice (textes rassemblés par), Epiphania, Études orientales, grecques et latines offertes à Aline POURKIER, Nancy-Paris, A.D.R.A. Nancy éd., diffusion De Boccard, 2008, p. 273-295.

BOËLS-JANSSEN Nicole, « Matrona/meretrix : duel ou duo ? À propos du rôle social et religieux des grandes catégories féminines dans l'imaginaire romain », dans Varietates Fortunae. Religion et mythologie à Rome. Hommage à Jacqueline Champeaux, PUPS, 2010, p. 89-129.

BOËLS-JANSSEN Nicole, « Bona Dea dévoilée », Revue des Études Latines, 92, 2015, p. 35-54.

BROUWER H. H. J., Bona Dea. The sources and a description of the cult, Leyde-New York-Cologne, E. Brill éd., 1989.

CAZANOVE de Olivier, «Exesto. L'incapacité sacrificielle des femmes à Rome. À propos de Plutarque, Q.R. 85 », Phoenix, 41, 2, 1987, p. 159-173.

DÉTIENNE Marcel et VERNANT Jean-Pierre, La cuisine du sacrifice en pays grec, avec les contributions de Jean-Louis DURAND, Stella GEORGOUDI, François HARTOG et Jesper svENKO, Paris, Gallimard, Bibliothèque des Histoires, 1979.

DROSSART Paul, « Nonae Caprotinae : la fausse capture des Aurores », Revue d'Histoire des Religions, 1974, p. 129-139.

DUMÉZIL Georges, Fêtes romaines d'été et d'automne, suivi de Dix questions romaines, Paris, Gallimard, collection Bibl. Des Sciences Humaines, 1975 (« Les Nones Caprotines », p. 271-283).

FLEMMING Rebecca, «Festus and the role of women in Roman Religion », dans GLINISTER F. \& WOODS Cl. ed., Verrius, Festus and Paulus, Lexicography, Scolarity and Society, Londres, Institute of Classical Studies, 2007, p. 87-108.

GOGUEY-KERNER Dominique, Les animaux dans la mentalité romaine, Bruxelles, Latomus, coll. Latomus $\mathrm{n}^{\circ} 271,2003$.

MAUSS Marcel et HUBERT Henri, «Essai sur la nature et les fonctions du sacrifice », L'Année sociologique, 2, 1899 ; repris sous le titre « Les fonctions du sacré », dans M. MAUss, Cuvres, Paris, 1968, p. 193-307.

PESTALOZZA Umberto, «Juno Caprotina », Studi e materiali di storia delle religioni, 9, 1933, p. 38-71. POIRIER Jean-Louis, Cave canem : Hommes et bêtes dans l'Antiquité, Paris, Les Belles Lettres, coll. Signets $\mathrm{n}^{\circ} 25,2016$.

RICHARD Jean-Claude, «Pline et les myrtes du temple de Quirinus », Latomus, 45, 4, 1986, p. 783-796.

SCHEID John, «D’indispensables étrangères. Les rôles religieux des femmes à Rome ", dans schmitT-PANTEl Pauline (dir.), Histoire des femmes en Occident, t. 1, L’Antiquité, éd. fr., Paris, Plon, 1991, p. 405-435.

SCHEID John, Quand faire c'est croire. Les rites sacrificiels des Romains, Paris, éd. Flammarion (département Aubier, Collection historique), 2005.

VERNANT Jean-Pierre, "Théorie générale du sacrifice et mise à mort dans la thusia grecque », dans Fondation Hardt, Entretiens sur l'Antiquité Classique, t. 27, Genève, 1981, p. 1-39. 


\section{NOTES}

1. J. Amat s'est intéressée aux animaux familiers, D. Goguey-Kerner à la mentalité romaine vis-à-vis d'eux ; en dernier lieu J.-L. Poirier a rassemblé une centaine de textes antiques sur ce sujet.

2. La mola salsa est un mélange de farine d'épeautre et de sel, fabriqué par les Vestales. En le répandant sur l'animal, le sacrifiant consacre ce dernier à la divinité.

3. On trouvera une bonne description du rituel sacrificiel romain public dans J. Scheid, Quand faire c'est croire, p. 44-57. Pour la Grèce, voir la belle contribution de F. Thélamon à ce congrès : « Le sanglier et le bœuf entre hommes et dieux ».

4. Voir en particulier M. Détienne et J.-P. Vernant, La cuisine du sacrifice en pays grec.

5. M. Mauss, Essai sur la nature et la fonction du sacrifice.

6. J.-P. Vernant, «Théorie générale du sacrifice », p. 2.

7. Ce dernier mot est particulièrement signifiant puisque uir désigne un humain de sexe masculin (homo s'applique à tout le genre humain, hommes et femmes confondus).

8. O. de Cazanove, Exesto. L'incapacité sacrificielle des femmes à Rome.

9. J. Scheid, « D'indispensables "étrangères". Les rôles religieux des femmes ", p. 407.

10. R. Flemming, «Festus and the rôle of women in Roman Religion », p. 87-108.

11. Fordicidia: Ovide, Fastes (=Calendrier religieux) 4, 637-640; Consus: Tertullien, De spectaculis, 5 .

12. Macrobe, Saturnalia 1, 15, 18. Il s'agit de l'épouse du Rex Sacrorum, prêtre qui, depuis l'instauration de la République, assumait les fonctions religieuses de l'ancien roi, qu'il eût été sacrilège de supprimer.

13. Ibid., 1, 16, 30. La Flaminica Dialis était l'épouse du Flamen Dialis, le prêtre de Jupiter. Les nondines désignent le jour du marché, où les paysans viennent en ville et s'y instruisent des lois. Sur les sacrifices accomplis par le couple flaminial et le couple royal, voir N. Boëls-Janssen, « Le statut religieux de la Flaminica Dialis », p. 90-91.

14. Servius, Commentaire à l'Énéide de Virgile, 4, 262; Festus, De Verborum Significatione, p. 472, éd. Lindsay.

15. Voir « Bona Dea dévoilée », p. 39.

16. Ovide, Amores, 3, 13, 13.

17. On trouvera tous les témoignages épigraphiques, littéraires et archéologiques concernant Bona Dea dans le précieux ouvrage de H. H. J. Brouwer, Bona Dea.

18. Rappelons que seule une épouse de citoyen romain a droit au titre de matrone, qui lui assure un certain nombre de privilèges (par exemple nul n'a le droit de porter la main sur elle) mais lui impose aussi des devoirs : fidélité (pudicitia), soumission au mari (obsequium), tenue et comportement discrets (modestia), etc.

19. Voir N. Boëls-Janssen, « Le double mythe de Bona Dea ».

20. Voir N. Boëls-Janssen, La vie religieuse des matrones romaines, chap. intitulé « La Bona Dea », p. 429-468 et, plus récemment, «Bona Dea dévoilée ».

21. C'est le sens primitif du mot, composé de theos, « le dieu », et du préfixe en, « dans ».

22. À l'époque archaïque le calendrier latin était basé sur les phases de la lune. Les nones sont le $9^{\text {ème }}$ jour avant les ides, qui désignent le jour de la pleine lune. Les nones correspondent donc à l'apparition du premier quartier. 
23. Sur le myrte symbole de vie à Rome, voir J.-Cl. Richard, «Pline et les myrtes du temple de Quirinus ».

24. Description du rite chez Properce, Élégies, 4, 8, 3-14.

25. La scène de l'ordalie mettant face à face la vierge et le serpent est représentée sur des monnaies. Le serpent figure aussi sur les statues de la Junon de Lanuvium, sur son bouclier ou aux pieds des chevaux de son char. Sur ces représentations guerrières de Junon, voir note 29.

26. Bibliographie antique des Nones Caprotines: Varron, De lingua latina 6, 18 ; Plutarque, Vie de Romulus 29, Vie de Camille 33 ; Macrobe, Saturnales 1, 11, 35-40; Ausone, Feria Romanae 9; Polyaenos, Stratagemata, 8, 30.

27. Ovide, Amores, 3, 13, 19-22.

28. Cicéron, De natura Deorum, 1,82 .

29. Elle apparaît sur des monnaies de l'époque républicaine et du temps des empereurs Antonin le Pieux et Commode. Il existe aussi une colossale statue de marbre de la déesse ainsi accoutrée, conservée au Musée du Vatican.

30. Voir note 35.

31. Thèse soutenue par V. Basanoff dans « Nonae Caprotinae ».

32. Valère Maxime, Memorabilia, 2, 2, 9 ; Plutarque, Vie de Romulus, 21. C'est Ovide qui parle du sacrifice d'une chèvre (Fastes 2,361) mais c'est peut-être pour une raison métrique. Le bouc est plus vraisemblable puisque la fête était dédiée à une divinité masculine, Faunus.

33. Ovide, Fastes 2, 425; Juvénal, Satires 2, 142; Festus, De Verborum Significatione (abrégé de Paul Diacre), éd. Lindsay, p. 57 ; Plutarque, Vie de Romulus 21. Un amiculum est un vêtement que l'on jette autour de soi.

34. Varron, De lingua latina 6, 18 ; Macrobe, Saturnales 3, 2, 14 ; Denys d'Halicarnasse, Antiquités romaines 2, 56, 5; Plutarque, Vie de Romulus 29, Vie de Camille 33.

35. L'épisode est raconté en détail par Plutarque (Vie de Camille 33) et Macrobe (Saturnales 1, 11, 36-40).

36. P. Drossart, « Nonae Caprotinae »; repris par G. Dumézil, Questions Romaines 9 : «Les Nones Caprotines ».

37. Récits détaillés des différentes versions du mythe chez Tite-Live, Histoire Romaine, 1, 4, 1-7 ; Denys d'Halicarnasse, Antiquités Romaines, 1, 77-79; Plutarque, Vie de Romulus, 2-6.

38. Au cours de ce congrès, Liliane Régent-Romy a traité des "animaux nourriciers dans la mythologie grecque ».

39. Plutarque, Vie de Romulus, 4, 2. Même présence du pivert chez Ovide (Fastes, 3, 54); il l'introduit aussi dans le rêve prémonitoire de la Vestale où un loup et un pivert combattent pour défendre de la hache du roi Amulius, son oncle, les deux jeunes pousses, représentant les jumeaux, nées de ses bandelettes sacrées, qui symbolisent sa virginité de Vestale (v. 29-38).

40. L'opposition entre le statut de la matrone et celui de la prostituée est irréductible à Rome. Voir N. Boëls-Janssen, "Matrona/meretrix, duel ou duo?». Une épouse qui manque à la vertu matronale doit être aussitôt répudiée. Mais il fallait qu'Acca Larentia soit mariée pour que Faustulus puisse lui confier les enfants et qu'elle puisse assumer un rôle de mère. 
41. Denys d'Halicarnasse, Antiquités Romaines, 1, 77 ; Plutarque, Vie de Romulus, 4-3.

\section{RÉSUMÉS}

Il y avait dans la Rome antique des différences fondamentales entre les religions masculine et féminine. L'originalité de celle-ci se manifeste dans le rôle qu'y jouent les animaux. Dans les cultes masculins l'animal est un intermédiaire entre les hommes et les dieux. Même s'il transmet la volonté divine, il n'est qu'un moyen de communication. Dans la religion féminine au contraire il incarne le sacré. Les divinités féminines se manifestent dans ce que l'on pourrait appeler des «épiphanies » animales, végétales ou même minérales. La fête de Bona Dea, où la vigne et le serpent figurent à la fois dans le mythe et dans le culte, et celle des Nones Caprotines, qui associe la chèvre et le figuier, illustrent bien cette conception du rapport de l'animal avec le sacré. Le mythe de la naissance de Romulus pose un problème particulier en faisant intervenir un pivert à côté de la louve nourricière, associant l'animal du dieu de la guerre à la divinité maternelle incarnée par la louve.

\section{AUTEUR}

\section{NICOLE BOËLS-JANSSEN}

Professeur émérite, université de Bourgogne 


\title{
L'animal de sacrifice à Briga (« Bois l'Abbé », Eu, Seine-Maritime) : les dépôts de moutons du sanctuaire gallo-romain et de ses alentours
}

\author{
Alice Bourgois, Étienne Mantel, Sébastien Lepetz et Marie-Laurence Haack
}

1 L'identification des gestes rituels impliquant l'animal constitue une difficulté de l'approche archéozoologique dans les cas de vestiges fauniques découverts hors de lieux de culte avérés. En outre, même lorsque la présence d'un sanctuaire est assurée, il demeure des circonstances où les os, parce qu'ils ne se différencient pas des rejets alimentaires ordinaires, ne peuvent pas non plus être reconnus comme des témoignages de pratiques religieuses ${ }^{1}$. En revanche, dans d'autres cas, le contexte archéologique épaulé par des techniques de fouilles et par des études adaptées à cette problématique permet de décrire des vestiges dont la dimension rituelle semble évidente. C'est le cas de plusieurs dépôts du site de "Bois l'Abbé » à Eu. Cette agglomération gallo-romaine, d'une soixantaine d'hectares, est implantée sur un étroit plateau séparant deux vallées : la vallée de la Bresle et le vallon de Saint-Pierre-en-Val. Cette petite ville installée sur la pointe nord de l'actuelle Seine-Maritime, près de l'antique frontière entre les provinces de Gaule Belgique et de Lyonnaise, est un cheflieu de pagus, a priori dépendant des Bellovaci ${ }^{2}$. Elle est dotée de quartiers d'habitations, d'un réseau de voiries et d'au moins un centre monumental à sa périphérie nord-ouest rassemblant, au $\mathrm{III}^{\mathrm{e}}$ siècle, un complexe cultuel associant plusieurs temples et leurs portiques, une salle de conseil ainsi qu'une basilique (fig. 1$)^{3}$. Une plaque dédicatoire découverte en 2006 dans ce dernier bâtiment mentionne à la fois le dieu Mercure, divinité tutélaire de la ville, le nom de l'agglomération Briga et le peuple des Catuslougi, les habitants du pagus ${ }^{4}$.

2 La plus ancienne structure documentée sur les secteurs I et II (fig. 1) remonte au milieu $\mathrm{du} \mathrm{III}^{\mathrm{e}}$ siècle avant notre ère, elle correspond à la première aire de dépôts rituels, surnommée les "terres noires" pour la couleur sombre de son comblement, très organique et riche en mobilier ${ }^{5}$. Après quatre siècles d'occupation continue, la ville est 
massivement abandonnée à la fin du $\mathrm{III}^{\mathrm{e}}$ siècle de notre ère et le secteur du complexe monumental est transformé en carrière, exploitée pendant l'Antiquité tardive et le Haut Moyen Âge. Depuis une dizaine d'années, ce site fait l'objet de campagnes de fouilles programmées pluriannuelles, sous la direction d'Étienne Mantel du Service Régional de l'Archéologie de Normandie. Si le site est connu depuis la fin du $\mathrm{XVIII}^{\mathrm{e}}$ siècle $^{6}$, les opérations récentes ont porté sur des secteurs jusqu'alors inexplorés, en particulier la partie est du centre monumental et sa périphérie, révélant ainsi des quartiers d'habitations des $\mathrm{I}^{\mathrm{er}}$, $\mathrm{II}^{\mathrm{e}}$ et $\mathrm{III}^{\mathrm{e}}$ siècles de notre ère, au nord et à l'est du complexe monumental, mais également de nouvelles structures dont le caractère cultuel est fortement probable ${ }^{7}$.

Fig. 1. - Localisation géographique et plan général du centre monumental de « Bois l'Abbé » et de ses alentours, état des connaissances à la fin de la campagne de 2015.

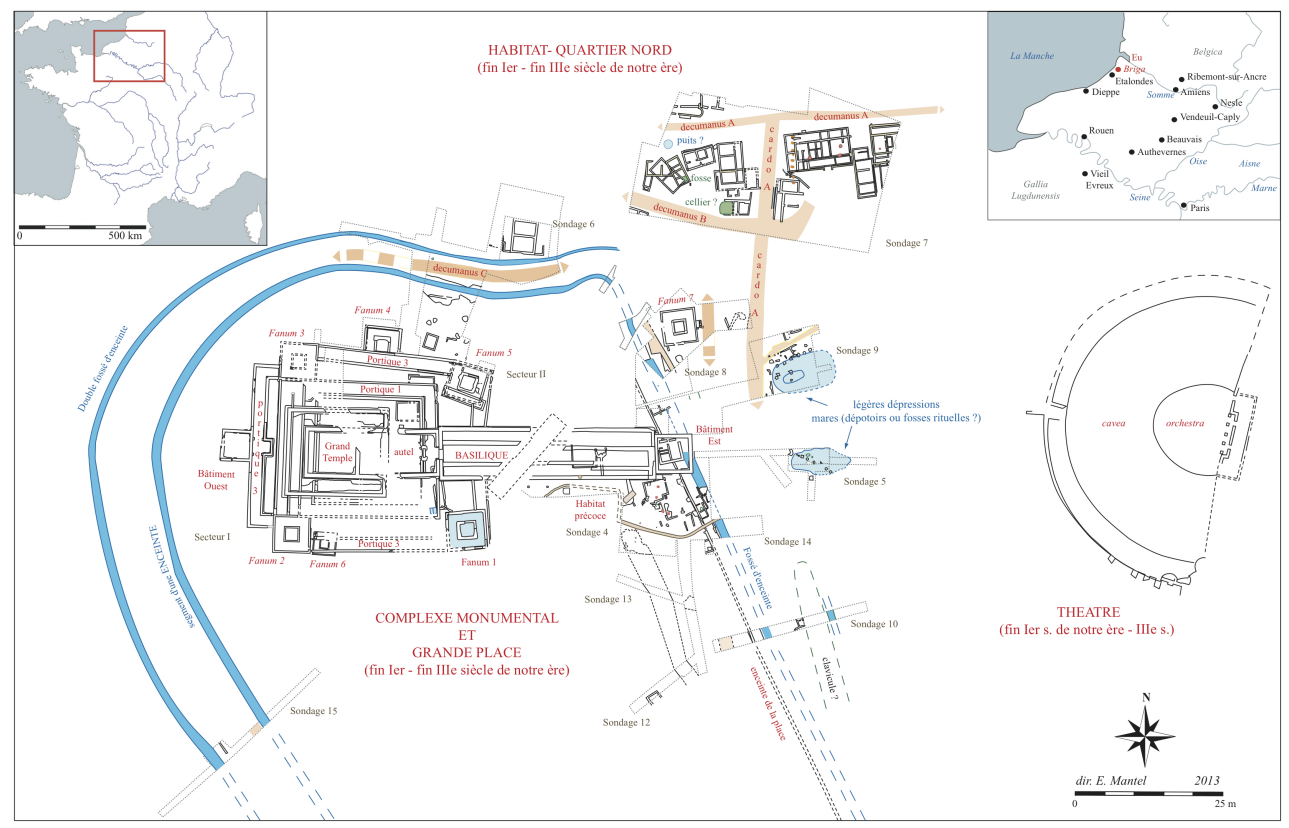

(DAO E. Mantel, S. Dubois, J. Paretias, A. Bourgois).

Parmi les éléments exhumés lors de ces fouilles, les vestiges fauniques constituent à «Bois l'Abbé » un matériel archéologique abondant, puisque les campagnes de fouille mettent au jour chaque année de 10000 à 20000 restes osseux et dentaires. Trois types de dépôts potentiellement rituels livrent des vestiges animaux : les dépôts ponctuels isolés, les dépôts ponctuels groupés et les aires de dépositions. On trouve les deux premiers dans le centre monumental (secteurs I et II) ${ }^{8}$; les aires de dépôts sont, elles, situées entre le théâtre et le fanum 7, dans les sondages 5 et 9 . Enfin, il existe d'autres exemples de dépôts ponctuels en dehors du sanctuaire. Chaque cas doit être examiné, d'abord individuellement, puis remis en perspective avec les autres structures de « Bois l'Abbé » et d'autres sites de comparaison, pour confirmer ou non le caractère rituel des différents dépôts.

Les recherches anciennes et récentes ${ }^{9}$ ont déjà montré la place privilégiée que tient le mouton (Ovis aries) dans les pratiques sacrificielles de Briga ${ }^{10}$, mais les dernières découvertes illustrent cette préférence de manière remarquable : seize dépôts d'ovins enfouis devant le fanum 7 et fouillés pour partie en 2015 (fig. 2), qui n'ont, pour l'heure, pas encore été étudiés, à l'exception du premier dépôt et de la dizaine de restes très 
abîmés qui composaient le huitième. Les vingt autres, issus des fouilles de 2006 à 2013, ont été inventoriés ${ }^{11}$.

Fig. 2. - Localisation des dépôts d'ossements animaux en périphérie du centre monumental.

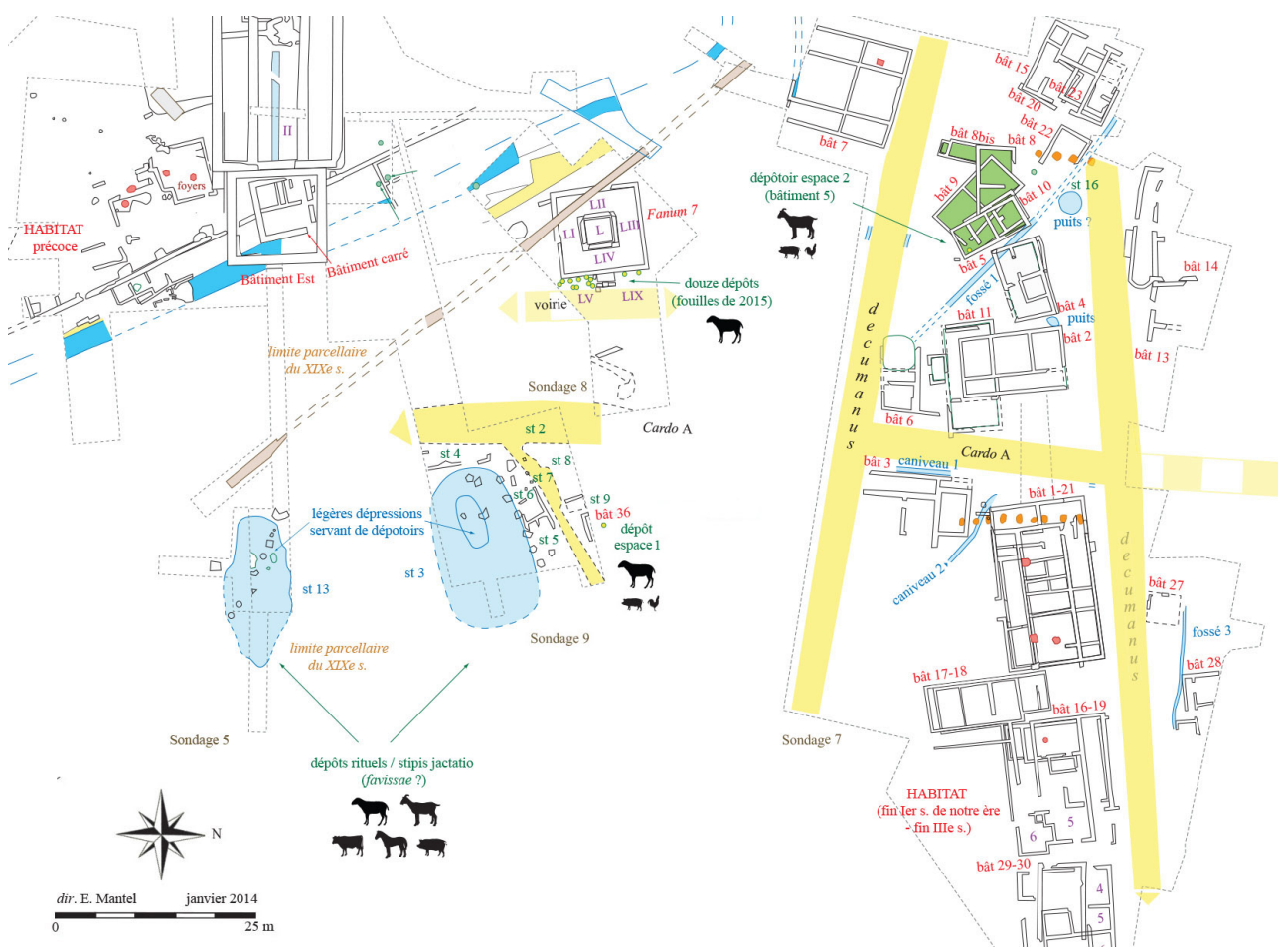

(DAO E. Mantel, A. Bourgois).

\section{Les dépôts du centre monumental}

5 Au total, pour le centre monumental, ce sont vingt-deux dépôts sur trente-six connus à ce jour qui ont été étudiés ${ }^{12}$. L'absence d'offrande complémentaire, de type céramique ou numismatique, dans la plupart de ces structures ne permet hélas pas de datation précise et il faut dans bien des cas se contenter de la chronologie relative fournie par la stratigraphie. Néanmoins, les quelques dépôts contenant monnaies et poteries comme dans les isolations ter, quater et sexies de l'espace VIII sont attribuables à la fin du $\mathrm{II}^{\mathrm{e}}$ siècle $^{13}$ ou au III $^{\mathrm{e}}$ siècle. Les autres, sans datation, sont a priori contemporains puisqu'ils sont situés immédiatement sous les couches de démolition du dernier quart $\mathrm{du} \mathrm{III}^{\mathrm{e}}$ siècle ; les cas les plus extrêmes sont les quatre isolations A, B, C et D de l'espace $\mathrm{CV}$, au sud-ouest du complexe monumental, devant le fanum 2 (fig. 3) ${ }^{14}$. 
Fig. 3. - Localisation des dépôts d'ossements animaux dans le centre monumental.

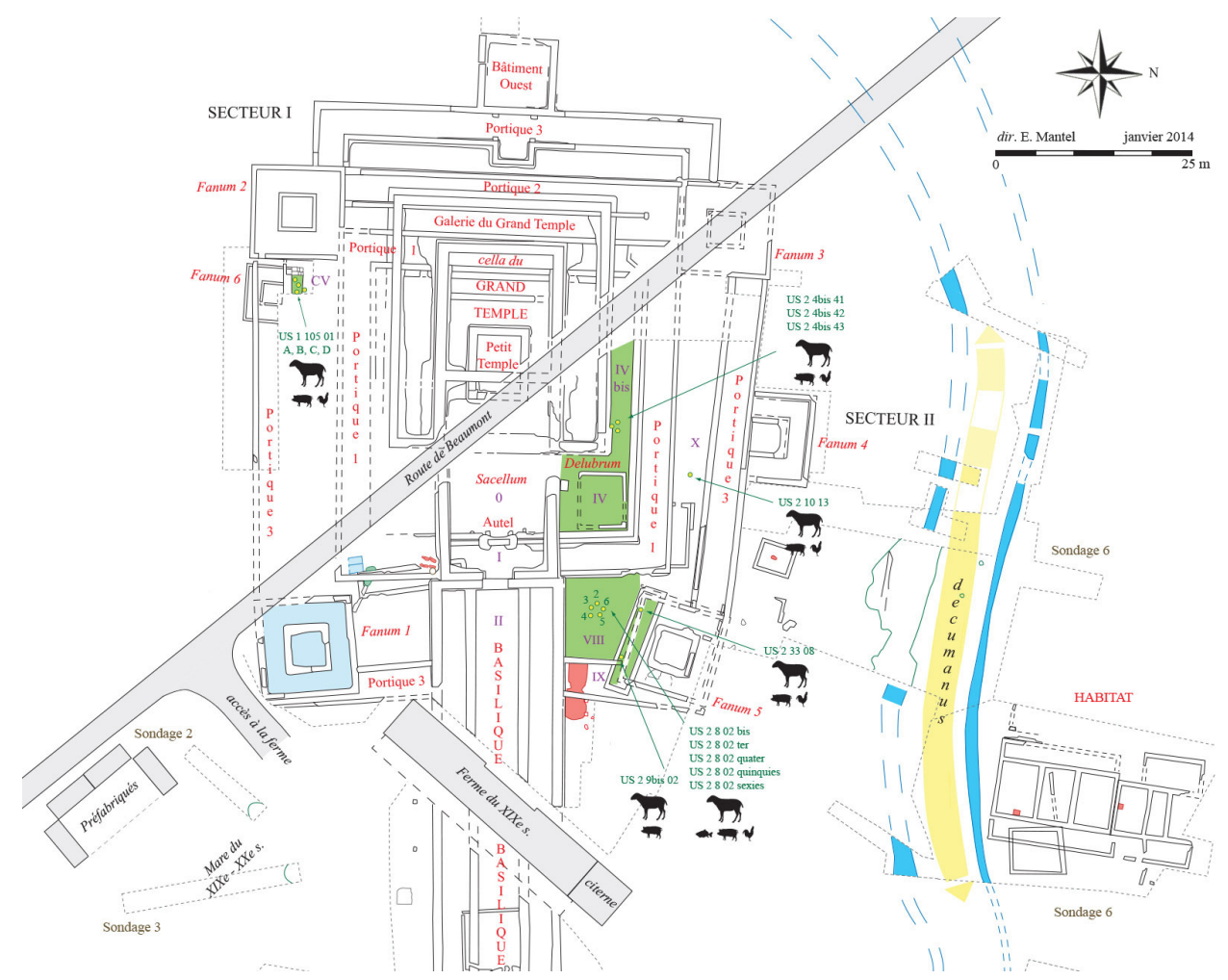

(DAO E. Mantel, A. Bourgois).

6 Les ossements semblent avoir été déposés en « fagots » (fig. 4). Leur nombre et l'état de leur conservation diffèrent grandement selon les lots. Les fosses qui les contenaient sont mal délimitées, sauf les trois cas provenant de l'espace IVbis. Quelques-uns de ces amas situés à proximité du fanum 7 avaient été matérialisés au sol par quelques tuiles et briques posées à plat. Certains dépôts ont par ailleurs probablement été remaniés dès l'Antiquité lors de travaux de réfection et de reconstructions, comme le laissent supposer les importantes quantités de restes de caprinés découvertes dans les remblais du centre monumental ${ }^{15}$. D'autres ont pu être bouleversés ou détruits par de nouvelles dépositions rituelles. En effet, on perçoit, notamment dans l'espace VIII au sud du fanum $5^{16}$ ou devant la façade du fanum 7 , que certains dépôts ont été effectués pardessus d'autres, révélant par ailleurs l'importance de certains espaces par rapport à d'autres, en l'occurrence ceux situés immédiatement devant les façades des temples (fig. 2 et 3). 
Fig. 4. - Photographie de l'isolation C en cours de fouille, située devant le fanum 6 dans l'espace CV.

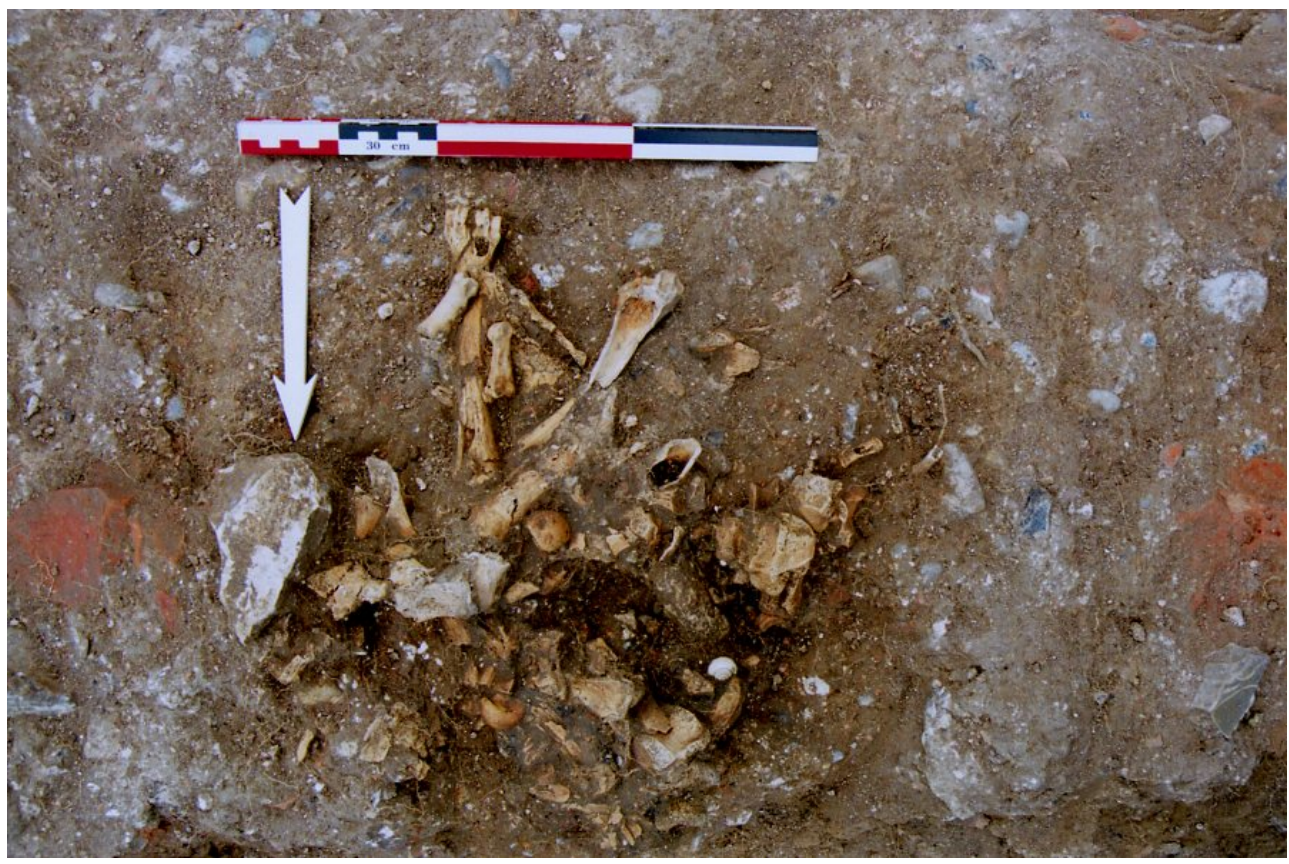

(c) Cliché E. Mantel.

7 Seuls six dépôts contenaient des squelettes de moutons complets ou quasi-complets (isolations CV B et C, 2802 ter et quater, et le dépôt 1 du fanum 7), sinon, il s'agit généralement de pièces isolées, d'os ou de segments anatomiques. Dans un tiers des cas, plusieurs individus sont rassemblés, jusqu'à trois animaux au maximum comme dans l'isolation C de l'espace CV (fig. 5). Des dépôts simples en côtoient donc d'autres plus complexes. Il n'est d'ailleurs pas impossible que ces dépôts complexes soient, au moins pour certains d'entre eux, la conséquence d'une superposition de dépôts individuels mal conservés. L'isolation $\mathrm{CV}-\mathrm{C}$ est par exemple caractérisée par la présence d'un deuxième membre postérieur droit complet, du fémur jusqu'aux phalanges, de quelques éléments issus d'une deuxième patte arrière gauche et de restes de trois crânes différents (fig.5). Absolument tous les dépôts comprennent des éléments crâniens et mandibulaires; à l'inverse, il manque régulièrement des vertèbres aux rachis, sauf dans les dépôts de squelettes complets ${ }^{17}$. Sur l'ensemble des dépôts, les répartitions anatomiques sont relativement bien équilibrées, mais révèlent toutefois une légère surreprésentation des bas de pattes, en particulier des métapodes, et un déficit des côtes (fig. 6a). Plus fragiles et donc souvent très fragmentées, voire complètement émiettées, les côtes échappent aux fouilleurs et au tamisage. 
Fig. 5. - Répartition anatomique schématique des restes ovins découverts dans les isolations $A, B$, $C$ et $D$ de l'espace $C V$, devant le fanum 6 .

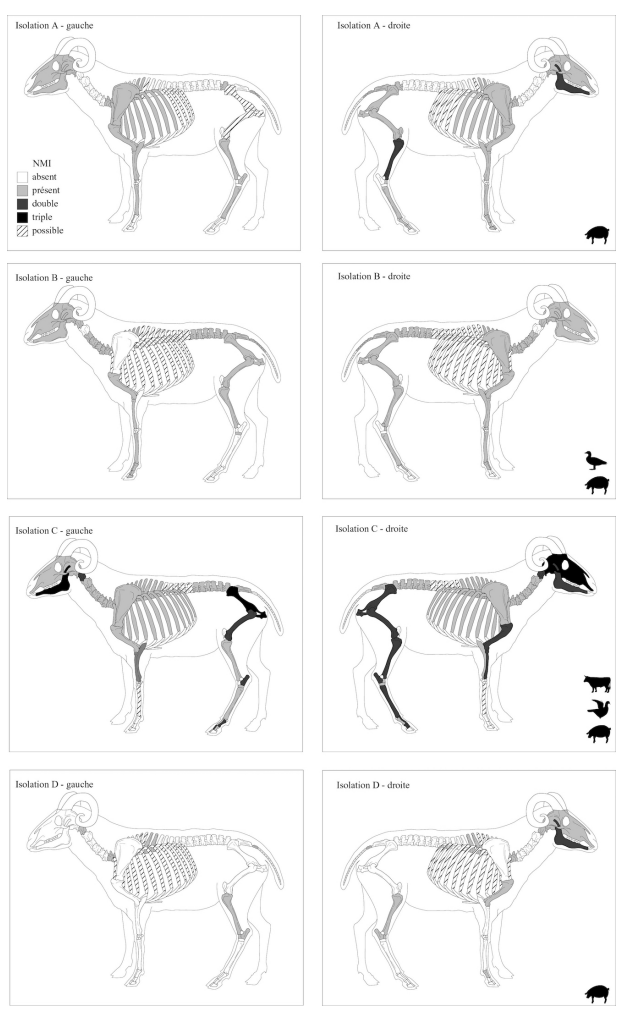

(DAO M. Coutureau, A. Bourgois).

Fig. 6. - Répartitions brute et pondérée des poids de restes des moutons dans les dépôts du sanctuaire et la structure 3 (sondage 9).

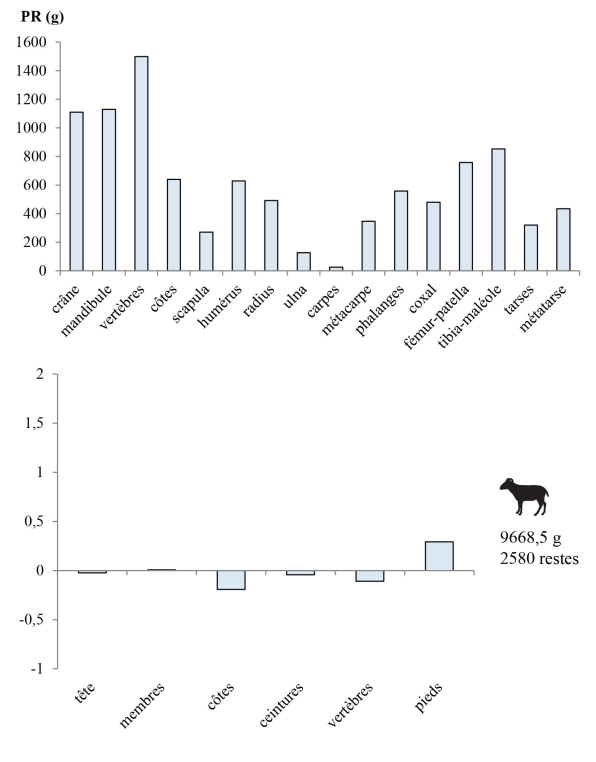

a - moutons du sanctuaire (dépôts)
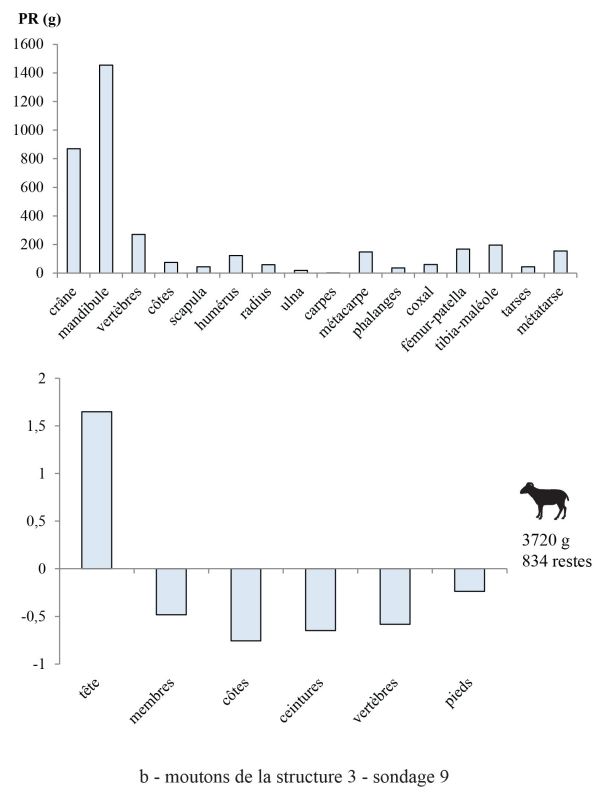

8 Il ne semble pas y avoir de critères de choix stricts des bêtes, tout au moins les restes ostéologiques ne permettent pas de le déterminer. Les moutons sont tantôt jeunes (52\% ont moins de 24 mois), tantôt adultes ( $45 \%$ ont entre 48 et 72 mois), mais 
rarement séniles ( $3 \%)$. Les animaux âgés de 24 et 48 mois sont en revanche peu nombreux (fig. 7a).

Fig. 7. - Répartitions corrigées des âges d'abattage des moutons, évalués à partir des mandibules dans les trois secteurs étudiés.

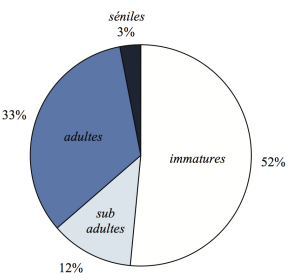

a - dépôts du sanctuaire $(n=33)$
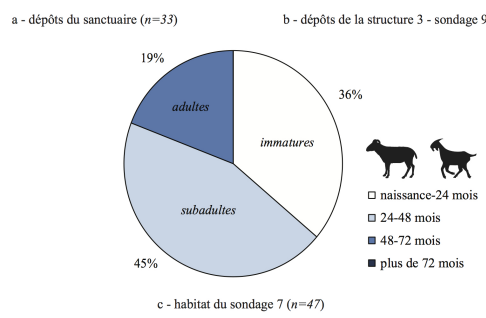

c- habitat du sondage $7(n=47)$

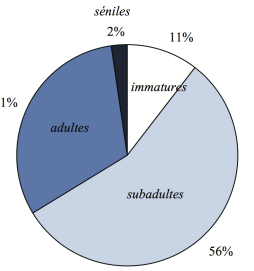

b - dépôts de la structure 3 - sondage $9(n=8 \emptyset)$

plus de $72 \mathrm{moi}$

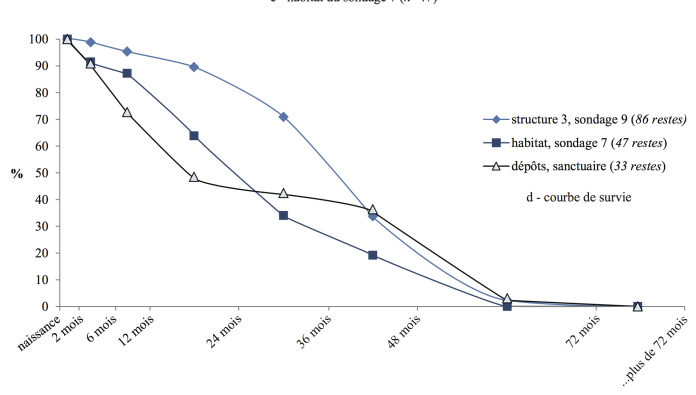

Déterminer le sexe des animaux est peu aisé, car les chevilles osseuses sont rares ou mal conservées. En outre, leur présence sur les crânes ne signifie pas obligatoirement qu'il s'agit de mâles puisqu'il existe des brebis cornues ${ }^{18}$. Quatre cas d'adultes acères ont été recensés ${ }^{19}$, il pourrait s'agir de brebis abattues entre 48 et 60 mois. Les coxaux fragmentés et découpés, bien souvent incomplets, ne peuvent pas non plus être utilisés pour les déterminations sexuelles. La quinzaine d'individus adultes, dont quelques os entiers ont permis une prise de mesure, ne présentent pas non plus de stature particulière ${ }^{20}$ : les tailles au garrot ont pu être estimées entre 60,2 et $71,3 \mathrm{~cm}$ au garrot, soit une moyenne de $66 \mathrm{~cm}$, elles constituent des valeurs typiques pour les ovins du Nord de la Gaule au Haut Empire ${ }^{21}$.

Les traces de coups liés à la désarticulation et à la décarnisation au couteau sont très fréquentes et semblent venir attester la consommation des animaux. Il faut cependant demeurer prudent, puisque les preuves de consommation ne peuvent se limiter aux stigmates de découpes qui ne révèlent que la mise en pièces des morceaux; les quartiers de viandes ont certes été divisés et fracturés, mais ni la cuisson, ni la consommation ne sont formellement attestées. Il en résulte la possibilité que ces portions ainsi préparées aient été pour partie enfouies crues ou non consommées. En dehors du lot calciné 210 13, les brûlures sont extrêmement rares sur les ossements ; il existe cependant deux cas dans le dépôt 23501 avec quelques zones noircies, carbonisées, très localisées sur un carpe et un tarse. Hormis pour le dépôt 24 bis 41 constitué exclusivement d'os ovins, les squelettes de moutons sont dans la plupart des cas associés à d'autres espèces, principalement au porc (Sus scrofa domestica) dans $86 \%$ 
des dépôts et au coq (Gallus gallus) dans $48 \%$ des dépôts. Les volailles sont préparées, sans tête et sans pieds (fig. 8). Dans de rares cas, on trouve du poisson, des pigeons ${ }^{22}$ ou bien encore du bœuf (Bos taurus).

Fig. 8. - Répartition anatomique schématique des restes de coqs découverts dans les différents dépôts du centre monumental.

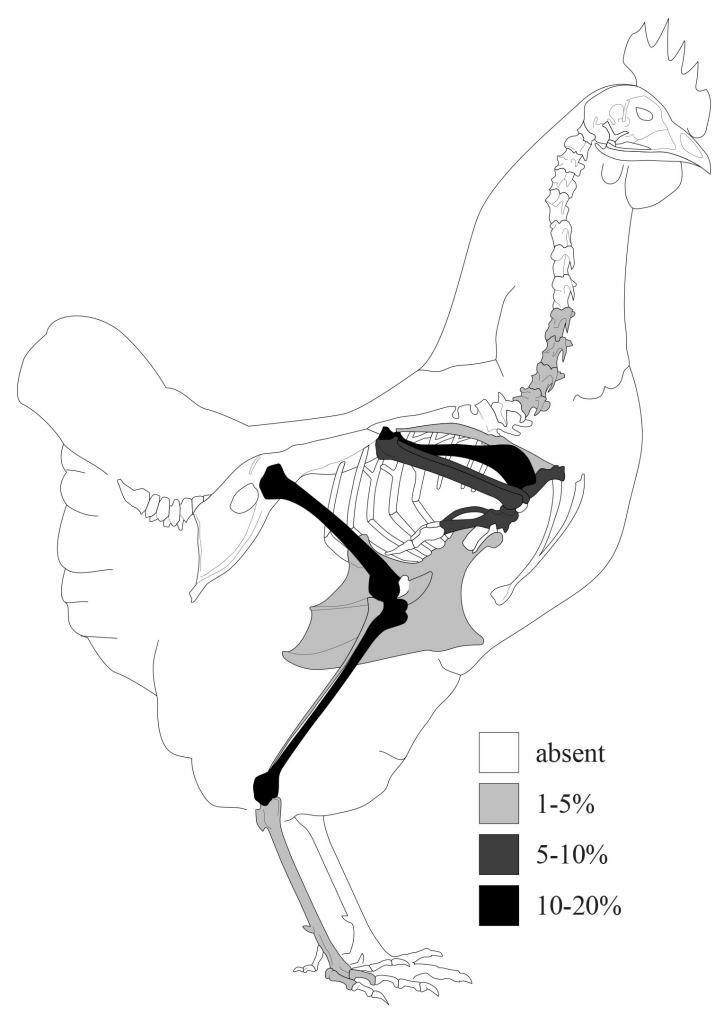

(DAO M. Coutureau, A. Bourgois).

11 La multiplicité de ces dépôts reflète la pérennité de ce type de pratiques à Briga, du début du $\mathrm{II}^{\mathrm{e}}$ siècle jusqu'à l'abandon du site à la fin du $\mathrm{III}^{\mathrm{e}}$ siècle de notre ère. Ces découvertes apparaissent comme cohérentes avec les premières observations faites par Patrice Méniel sur le matériel issu des fouilles de Michel Mangard sur la partie est du centre monumental (années 1960-1980). Il avait remarqué un accroissement du nombre de caprinés au détriment du porc, dans les niveaux des $\mathrm{II}^{\mathrm{e}}$ et $\mathrm{III}^{\mathrm{e}}$ siècles $^{23}$. Il signalait également la présence d'un autre dépôt de mouton aux alentours du fanum $2^{24}$. Une augmentation similaire des proportions de caprinés semble s'opérer dans les zones périphériques, notamment dans le quartier nord ${ }^{25}$.

12 Compte tenu de leurs emplacements, dans les cours au-devant des fana et du grand temple, à l'intérieur de la zone sacrée (fig. 2 et fig. 3), il est logique de lier ces dépôts à des pratiques religieuses (restes de repas partagés par les fidèles, parts réservées aux divinités, etc.). Il existe aussi à Briga d'autres structures particulières, situées, cette fois, à l'extérieur du centre monumental, et sur lesquelles il est nécessaire de s'interroger.

\section{Les structures 3 et 13 : de possibles favissae?}

13 Les structures atypiques dont il est question sont deux des six dépressions naturelles situées à une trentaine de mètres à l'est de la basilique, en périphérie du 
centre monumental (îlot VIII) : les structures 3 (sondage 9) et 13 (sondage 5) ${ }^{26}$. Dans un premier temps, elles furent interprétées comme des mares reconverties en dépotoir, le bâtiment situé à proximité pouvant être un "débit de boissons" ou une auberge. Cependant, l'examen d'une partie du mobilier a permis d'envisager un usage cultuel ${ }^{27}$. En premier lieu, il y a les quelques centaines de monnaies du $\mathrm{II}^{\mathrm{e}}$ siècle $^{28}$, qui renvoient probablement à une pratique de la stipis jactatio ${ }^{29}$, c'est-à-dire le jet de monnaie dans une source ou une fontaine pour l'offrir à la divinité associée à ce point d'eau. Ensuite, des gobelets miniatures, de la fin $\mathrm{du} \mathrm{I}^{\mathrm{er}}$ au milieu du $\mathrm{III}^{\mathrm{e}}$ siècle $^{30}$, ont été trouvés par milliers, et peuvent avoir été utilisés comme offrandes et/ou contenants à libations ${ }^{31}$.

Des ossements animaux sont également présents à hauteur de 1790 restes $^{32}(11,7 \mathrm{~kg})$ pour la structure 3000 et 1770 restes $(8 \mathrm{~kg})$ pour la structure 13. L'acidité du sol dans cette zone et le battement de la nappe ont considérablement altéré les vestiges. La fragmentation importante des os longs a rendu la détermination difficile dans la structure 13 : seul $32 \%$ du matériel a été déterminé dans la structure 13 , contre $75 \%$ dans la structure 3. L'analyse se concentre donc sur le contenu de la structure 3 , un peu plus fourni et surtout mieux documenté.

Le mouton constitue l'espèce majoritaire dans cette structure, au sein des caprinés qui représentent $63 \%$ des restes déterminés ${ }^{33}$, le bœuf vient en deuxième (22\%) et le porc en troisième position ( $9 \%$ ). Les équidés sont également bien représentés dans cette dépression, puisqu'ils correspondent à $6 \%$ des restes identifiés. Les autres espèces sont le chien (Canis lupus familiaris), le lièvre (Lepus capensis) et le coq, mais elles sont anecdotiques $^{34}$. L'assemblage comprenait également une diaphyse de fémur de pygargue à queue blanche (Haliaeetus albicilla), teintée de vert par le contact avec le bronze des monnaies. Il est intéressant de constater que la seule autre structure ayant révélé des restes de pygargue à Briga est l'aire de dépôts rituels du $\mathrm{I}^{\mathrm{er}}$ siècle avant notre ère ${ }^{35}$.

Les répartitions anatomiques ainsi que la courbe d'abattage des moutons de la structure 3 sont très différentes de ce que l'on observe dans les dépôts du sanctuaire. La structure 3 se caractérise par des quantités élevées de dents déchaussées et de mâchoires de moutons (fig. 6). Les mauvaises conditions de conservation évoquées pourraient expliquer, en partie, la surreprésentation des mandibules et des maxillaires de caprinés, puisque les dents sont plus solides que l'os. D'ailleurs, lors de la fouille, des empreintes d'os sous forme de matière pulvérulente ont été observées mais n'ont pas pu être prélevées. Malgré cette réalité taphonomique ${ }^{36}$, l'analyse comparée des restes de moutons et de porcs, de solidité équivalente, révèle des situations différentes; les os des membres sont majoritaires pour les suidés (en particulier une série de trente diaphyses d'humérus à la découpe standardisée), ce qui permet d'envisager des divergences dans le traitement des espèces (fig. 9). La répartition des restes de bovins est, elle, assez similaire à celle des moutons; on soulignera toutefois la présence marquée des bas de pattes ${ }^{37}$, ce qui n'était pas le cas pour les caprinés. L'état de conservation de ces restes de porcs et de bœuf est tout aussi médiocre que celui des vestiges ovins; initialement il y avait donc nettement plus de mâchoires et de crânes que d'éléments postcrâniens de caprinés. Les problèmes de conservation ne font qu'accentuer une répartition préexistante. 
Fig. 9. - Répartitions pondérées des poids de restes de porcs et de bœufs dans la structure 3 (sondage 9).
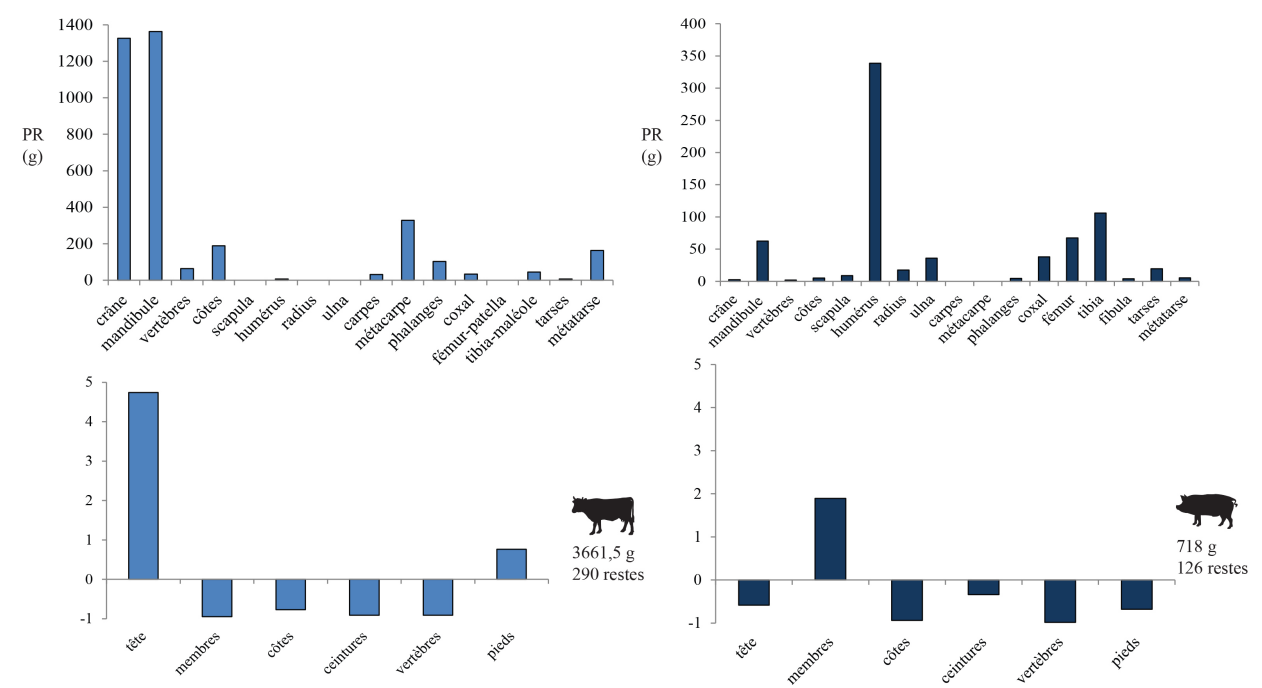

17 Un autre fait surprenant concerne l'aspect général des os des grands animaux (bœufs et équidés). Ils sont blanchis, le périoste a souvent disparu ou il s'effrite facilement. Les ossements de porcs sont eux aussi très abîmés. Cette différence marquée avec les restes de moutons (bruns, fragiles et pulvérulents) permet d'envisager deux histoires taphonomiques distinctes; si tous ces ossements se sont retrouvés dans la même structure, tous n'ont vraisemblablement pas subi le même traitement et/ou n'ont pas suivi le même parcours. Certains (notamment les os de bœufs et d'équidés) ont pu séjourner sur le sol, à l'air libre, un certain temps avant d'être balayés, d'autres ont pu faire l'objet d'un rite d'exposition, notamment les crânes des différentes espèces, tandis que la majorité des os de moutons a sans doute été rejetée directement dans les dépressions humides après leur décarnisation.

Cette surreprésentation des mâchoires de caprinés autorise une estimation des âges statistiquement fiable, basée sur 86 mandibules issues d'au moins 57 individus. La catégorie des jeunes adultes de 24 à 48 mois, sous-représentée dans les dépôts du centre monumental, est ici largement majoritaire avec $56 \%$ des effectifs étudiés. Viennent ensuite les individus adultes plus âgés de 48 à 72 mois (31\%), tandis que les immatures (moins de 2 ans) et les séniles sont rares dans cette structure 3 (fig. 7b).

L'examen des ossements animaux concorde plutôt bien avec l'hypothèse formulée sur la base du mobilier céramique et numismatique de la présence d'une nouvelle aire de dépôts rituels succédant aux "terres noires" ou de celle d'une favissa ${ }^{38}$. L'utilisation des mandibules et des crânes comme éléments de commémoration des sacrifices est d'ailleurs un fait avéré et on connaît des cas en France d'accumulations de mandibules de caprinés, notamment dans les enclos des bâtiments A et B du sanctuaire de Corent, chez les Arvernes ${ }^{39}$, même si l'époque est différente et la région éloignée.

Malgré une perception incomplète des modalités de dépôt dans la structure 3, la proximité de cette zone avec le grand sanctuaire, son emplacement dans l'axe architectural Est/Ouest qui ordonne l'organisation des bâtiments principaux du complexe monumental (grand temple et basilique), son vis-à-vis avec le fanum 7-8 et les autres dépressions, ainsi que l'association des ossements animaux aux monnaies et aux gobelets miniatures rend la dimension rituelle relativement évidente ${ }^{40}$, au moins pour 
une partie de la faune, assimilable à des restes d'animaux sacrifiés, de rejets de banquets et d'offrandes alimentaires.

\section{Les caprinés des autres quartiers}

21 Une zone résidentielle est bien connue à Briga pour les $\mathrm{II}^{\mathrm{e}}-\mathrm{III}^{\mathrm{e}}$ siècles : le quartier nord, situé au niveau des sondages 6,7 et 7bis, et l'̂llot IX dans le sondage 9, à proximité de la possible favissa de l'̂llot VIII, que nous venons de décrire. Dans ces îlots urbains furent découverts deux autres dépôts de caprinés capables de soutenir la comparaison avec les dépositions du sanctuaire.

Dans le quartier nord, un dépôt particulier est à signaler ; il s'agit d'une fosse dépotoir, datée du milieu du ${ }^{\mathrm{e}} \mathrm{e}$ siècle, associée au bâtiment 5-8 (fig. 2). Elle a été présentée lors des journées archéologiques de Haute-Normandie à Alizay en 2014 ${ }^{41}$. Par plusieurs aspects, cette fosse présente des ressemblances avec les dépôts du sanctuaire : il s'agit une fois encore d'une association de plusieurs squelettes découpés de caprinés, enterrés avec des restes de volaille (une poule, deux coqs, un chapon et un poulet immature incomplets, des pieds et des têtes ont toutefois été retrouvés), des restes de cochons (membres et mandibules provenant de cinq individus différents), ainsi qu'une céramique (fig. 10). Il demeure toutefois une différence majeure : les quatre caprinés présents dans la fosse sont des chèvres (Capra hircus) et non pas des moutons ${ }^{42}$. Les animaux, de sexe inconnu, sont respectivement âgés de 12-20 mois, 18-24 mois, 24-36 mois et d'environ $24 \mathrm{mois}^{43}$, ce sont donc des animaux relativement jeunes, comme ceux des dépôts du sanctuaire.

Fig. 10. - Photographie de la fosse dépotoir du bâtiment 5 en cours de fouille, dans l'habitat du sondage 7 .

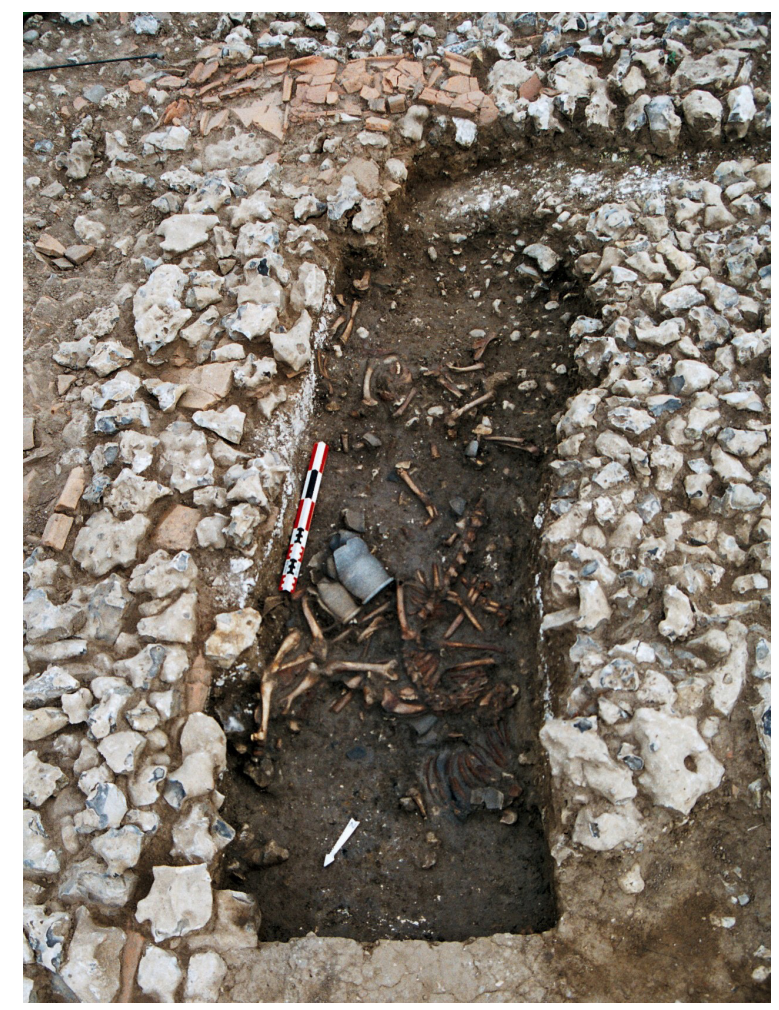

(c) Cliché E. Mantel. 
l'ensemble du sondage 7, les caprinés sont abondants : ils représentent $31 \%$ du spectre faunique en nombre de restes, mais demeurent en deuxième position derrière le porc qui domine l'échantillon avec $52 \%$ des restes déterminés ${ }^{44}$. L'importance des caprinés dans la zone résidentielle est donc à relativiser par rapport aux effectifs très élevés du sanctuaire et de la structure 3. En outre, les chèvres semblent plus nombreuses que les moutons dans ce quartier, le ratio entre les deux espèces est estimé à $84,5 \%$ de chèvres contre $15,5 \%$ de mouton (estimation obtenue à partir de vingt individus : trois moutons et dix-sept chèvres, les autres restes ont été enregistrés en tant que caprinés indéterminés). Ce cas de figure est assez exceptionnel puisque les chèvres ne représentent que $6 \%$ en moyenne dans le nord de la Gaule ${ }^{45}$.

Les animaux du quartier sont également assez jeunes (fig. 7c) : $36 \%$ des caprinés abattus ont moins de 2 ans, $45 \%$ sont de jeunes adultes (entre 2 et 4 ans) et les $19 \%$ restants ont plus de 4 ans. Les individus séniles n'apparaissent pas dans cette répartition basée sur les usures dentaires, mais quelques éléments post-crâniens attestent la présence de vieux animaux dans ce quartier ${ }^{46}$. La jeunesse de ces animaux fait écho à une production surtout axée sur la viande et le lait, peu sur la laine, la présence marquée de la chèvre dans ce sondage semble d'ailleurs corroborer ce premier constat.

Dans l'îlot IX, à proximité des structures 3 et 13, un autre dépôt a également été découvert, sous le sol de circulation, au centre de l'espace 1 du bâtiment 36 (fig. 2). Il comprenait les restes de quatre moutons, d'au moins quatre volailles et de trois cochons, ainsi que quelques éléments plus anecdotiques comme une vertèbre de poisson, une molaire supérieure de bœuf et deux os d'un tarse d'équidé ${ }^{47}$. Là encore, les ossements étaient accompagnés d'une céramique caliciforme ${ }^{48}$. Les restes de moutons exhumés de cette fosse proviennent de deux adultes, l'un de 36-48 mois, l'autre de 48-72 mois d'après l'usure des dents ${ }^{49}$ et de deux juvéniles de moins de 10 mois $^{50}$. Les deux animaux adultes présentent des caractères ostéologiques de femelle, tant au niveau du pubis que de leurs crânes acères. Quant aux restes de porcs, ils appartiennent au minimum à trois individus, dont une jeune femelle de 10-12 mois et un jeune mâle d'environ 8-10 mois. Enfin, les os de gallinacés viennent de quatre individus différents, avec au moins une poule, un coq adulte et un oiseau immature, mais les squelettes de ces volailles sont très incomplets par rapport aux moutons et aux porcelets. Au vu de ces répartitions anatomiques, il apparaît que la fosse contenait les restes concentrés mais désarticulés d'animaux presque complets qui ont été consommés.

La proximité du bâtiment 36 avec la structure 3 dans le sondage 9 laisse planer le doute sur la nature réelle de cette construction, il ne s'agit peut-être pas d'une maison ordinaire ${ }^{51}$, le contenu archéozoologique du dépôt présente en tout cas des points communs avec ceux du centre monumental et avec la fosse du bâtiment 5. Pour ces structures du quartier d'habitat, l'hypothèse de dépôts de fondation, ou de refondation dans le cas du bâtiment 5-8, composés des restes d'un repas festif (consécutif ou non d'un sacrifice) et de quelques offrandes céramiques et alimentaires peut être proposée.

\section{Analyse et comparaisons : la place du mouton}

Les moutons sont majoritaires dans les structures à caractère cultuel de Briga ; or, l'implication des caprinés dans les pratiques rituelles est courante en Gaule romaine et dans le monde occidental, notamment en Britannia. Ainsi, les sanctuaires de Bancroft, 
Brigstock, Chesterford, Harlow, Henley Wood, Lowbury, Nettleton, Witham ${ }^{52}$ et Hayling-Island ${ }^{53}$ en Grande Bretagne, d'Authevernes "Les Mureaux " dans l'Eure ${ }^{54}$, Nesle dans la Somme ${ }^{55}$ ou encore, plus au Sud, de Gergovie en Haute-Loire ${ }^{56}$ et Ménestreau dans la Nièvre ${ }^{57}$, furent les théâtres de nombreux sacrifices ovins, voire caprins dans le cas d'Uley au Royaume Uni ${ }^{58}$.

Parmi ces exemples, le sanctuaire rural d'Authevernes est celui qui présente le plus de ressemblances avec Briga dans les types de dépôts, et il reflète une forme d'unité de pratiques, sinon de croyances dans la région. Malgré sa taille modeste ( 1,2 hectare), ce site combine en effet quelques structures similaires à celles de "Bois l'Abbé » : un dépôt individuel de mouton consommé, associé au fanum du milieu du $\mathrm{I}^{\mathrm{er}}$ siècle (structure $1443)^{59}$, un fossé de la deuxième moitié du $\mathrm{I}^{\mathrm{er}}$ siècle de notre ère, voire du début du II $^{\mathrm{e}}$ siècle, délimitant le sanctuaire (structure 1323), qui contenait de nombreux crânes et des bas de pattes de caprinés peut-être exposés ${ }^{60}$, une possible favissa (structure 1254) des II $^{\mathrm{e}}$-III ${ }^{\mathrm{e}}$ siècle, comportant également du matériel un peu plus ancien ${ }^{61}$, ainsi qu'une série de dépôts dispersés dans l'enceinte associant des céramiques à des ossements de moutons ${ }^{62}$.

Cette préférence pour les caprinés, au détriment $d u$ porc $^{63}$, dans différents rituels, pourrait témoigner d'une évolution des pratiques religieuses qui débuterait aux alentours du début du $\mathrm{II}^{\mathrm{e}}$ siècle à Briga. Ce choix du mouton comme victime privilégiée peut être influencé par une préférence agro-pastorale locale ou micro-régionale, à l'instar de ce qui s'observe en Bretagne romaine ${ }^{64}$ et dans la partie méditerranéenne de $l^{\prime} E m p i r e{ }^{65}$, où restes de chèvres et de moutons se rencontrent en abondance, non seulement dans les lieux de cultes, mais également dans les zones d'habitat, rurales et urbaines. Les spectres fauniques du quartier d'habitat nord, où les caprinés talonnent le porc en tête du décompte ${ }^{66}$, et du site rural d'Etalondes "la plaine du chemin Saint Martin ", fouillé en 2013 par le service municipal d'archéologie de la ville d'Eu à quelques kilomètres de Briga, où les moutons étaient largement majoritaires ( $71 \%$ des restes déterminés), viennent renforcer cette hypothèse ${ }^{67}$. Les élevages de moutons sont d'ailleurs encore fréquents dans cette partie de la Seine-Maritime.

Cette présence marquée des caprinés à Briga peut aussi être liée au culte d'un dieu particulier, par exemple Mercure, divinité tutélaire de la ville, à qui l'on sacrifie traditionnellement des béliers et parfois des boucs ${ }^{68}$. La consultation des multiples sources littéraires et épigraphiques romaines montre aussi que, de manière générale, les ovins mâles et femelles sont les victimes les plus courantes, quelle que soit la divinité honorée ${ }^{69}$, probablement parce que le sacrifice d'un mouton est moins coûteux que celui d'un bœuf, ou pour respecter une forme de hiérarchie dans le culte impérial et entre les différentes divinités ${ }^{70}$.

31 Bien que les victimes des rituels soient plus souvent des animaux jeunes ${ }^{71}$, le sacrifice d'ovins âgés comme certains animaux du sanctuaire (espace IV, 2802 quater, dépôt 1 du fanum 7, CV C et D) n'est pas inhabituel, comme a pu le constater Maaike Groot dans le sanctuaire romain d'Empel aux Pays-Bas ${ }^{72}$. Dans le temple d'Harlow, en GrandeBretagne, les animaux sacrifiés ont tous moins de deux ans, comme plus de la moitié des ovins inhumés dans les dépôts du sanctuaire de Briga. Pour Tony King et Maaike Groot, la concentration de jeunes animaux d'une même classe d'âge restreinte (par exemple 6-8 mois et 18-20 mois) témoigne de pratiques rituelles saisonnières ${ }^{73}$. 

permet de dresser une première liste de critères spécifiques aux dépositions à caractère particulier (restes de sacrifices, de banquets, dépôts de fondation...). La victime principale du rituel, ici le mouton, peut être associée à un certain nombre d'éléments récurrents : des restes de porcs, des restes de coq, des céramiques et des monnaies. Les autres éléments ponctuels, par exemple les tarses de chevaux, les côtes ou les dents de bœufs, peuvent alors être considérés comme erratiques et intrusifs ${ }^{74}$. On ne peut toutefois pas exclure complètement l'hypothèse d'offrandes supplémentaires atypiques que l'on ne peut pas reconnaître.

Les trois assemblages étudiés (dépôts du sanctuaire, aires de dépositions dans les dépressions de l'îlot VIII et quartier d'habitat nord) reflètent trois types de sélections des animaux, probablement adaptées aux divers usages des caprinés dans la vie de la bourgade : le sacrifice (les victimes sont alors d'âges divers), la boucherie qui privilégie les jeunes adultes de 24 à 48 mois et les productions annexes comme le lait (les individus abattus sont pour moitié très jeunes et pour moitié très âgés, réformés) ou la laine qui nécessite de garder les animaux plusieurs années pour obtenir une production rentable. La pluralité de ces usages et le déplacement des ossements d'un secteur à l'autre par mouvement de remblais (notamment dans les sondages 7 et 9) rendent parfois difficile la lecture de ces résultats, mais l'analyse permet malgré tout une lecture inédite des vestiges fauniques rendant compte de quelques pratiques sacrificielles des occupants de Briga, aux II -III $^{\mathrm{e}}$ siècle de notre ère.

\section{BIBLIOGRAPHIE}

ARGANT A. et al. 2008, « De la diversité des contextes : les os animaux du sanctuaire de Ménestreau (Nièvre) et leur environnement ", dans LEPETZ S., VAN ANDRINGA W. (dir.), Archéologie du sacrifice animal en Gaule romaine. Rituels et pratiques alimentaires, Montagnac, éditions Monique Mergoil, Collection Archéologie des Plantes et des Animaux, volume II, p. 77-87.

BOESSNECK J. 1969, « Osteological differences between sheep (Ovis aries - Linné) and goat (Capra hircus - Linné) », BROTHWELL D., HIGGS E., Science in archaeology, a survey of progress and research, Cambridge, Thames and Hudson, 30, p. 331-358.

BOURGOIS A. 2015, «Consommation carnée et élevage dans le quartier d'habitat nord de Briga « Bois l'Abbé » (Eu, 76) », dans Journées archéologiques de Haute Normandie, Alizay 20 au 22 juin 2014, Rouen, PUHR, p. 33-46.

CHAIX L., MÉNIEL P., 2001, Archéozoologie, les animaux et l'archéologie, Paris, Errance.

FERNANDEZ H. 2001, « Ostéologie comparée des petits ruminants eurasiatiques sauvages et domestiques (genres Rupicapra, Ovis, Capra et Capreolus) : diagnose différentielle du squelette appendiculaire ", thèse de doctorat en science biologique, Genève, Museum d'Histoire Naturelle, Université de Genève, 2 vol. 
FOUCRAS S. 2011, Animaux domestiques et faunes sauvages en territoire arverne, Montagnac, éditions Monique Mergoil, Collection Archéologie des Plantes et des Animaux, volume III.

GROOT M. 2008, Animals in ritual and economy in a Roman frontier community. Excavations in TielPassewaaij, Amsterdam, University Press.

HALSTEAD P., COLLINS P., ISAAKIDOU V., 2002, « Sorting the Sheep from the Goats : morphological distinctions between the mandibles and mandibular teeth of adult Ovis and Capra. », Journal of Archaeological Science, vol. 29, issue 5, may, p. 545-553.

HAYDEN B. 2001, «Fabulous feasts: a prolegomenon to the importance of feasting » dans DIETLER M., HAYDEN B., Feasts, archaeological and ethnographic perspectives on food, politics and power, Washington, Smithsonian Institution Press, p. 23-64.

HUET V., PRESCENDI F., SCHEID J., VIOLA-SIEBERT A., VAN-ANDRINGA W., WYLER S., 2004, « Les sacrifices dans le monde romain » dans Thesaurus Cultus et Rituum Antiquorum, vol. I, Processions, sacrifices, libations, fumigations, dedications, The J. Paul Getty Museum, Los Angeles, p. 183-237.

KING A. 2005, « Animal remains from temples in Roman Britain », Britannia, vol. 36, novembre, p. 329-369.

KING A. 1999, «Diet in the roman world: a regional inter-site comparison of the mammal bones », Journal of Roman Archaeology, vol. 12, p. 168-202.

KING A., SOFFE G. 1994, « Recherches récentes sur les temples romano-celtiques de GrandeBretagne. L'exemple de Hayling Island » dans GOUDINEAU C., FAUDUET I. and Coulon G. (dir.), Les Sanctuaires de tradition indigène en Gaule romaine, Actes du Colloque d'Argentomagus, Paris, Errance, p. 33-48.

LEACH P., WOODWARD A. 1993, The Uley Shrines, Excavation of a ritual complex on West Hill, Uley, Gloucestershire: 1977-1979, English Heritage.

LEPETZ S. 2019, « Apports des études archéozoologiques à la connaissance des sanctuaires romains de la moitié nord de la France ", dans Apports des études environnementales à la connaissance des sanctuaires celtes et romains du nord-ouest européen, actes du colloque «Sacrée science! », 6 au 8 juin 2013, Amiens, Revue Archéologique de Picardie.

LEPETZ S., YVINEC J.-H., BOURGOIS A. 2014, « Étude archéozoologique du site de Nesle (Mesnil-SaintNicaise), fouille $40 \mathrm{du}$ Canal-Seine-Nord, Somme », rapport d'étude archéozoologique, Institut national de recherches archéologiques préventives.

LEPETZ S., VAN ANDRINGA W. (dir.) 2008, Archéologie du sacrifice animal en Gaule romaine. Rituels et pratiques alimentaires, Montagnac, Éditions Monique Mergoil, Collection Archéologie des Plantes et des Animaux, volume II.

LEPETZ S., MATTERNE V. 2003, «Élevage et agriculture dans le Nord de la Gaule durant l'époque gallo-romaine : une confrontation des données archéozoologiques et carpologiques ", Revue Archéologique de Picardie, 1/2, p. 23-35.

LEPETZ S., OUESLATI T. 2003, « La consommation de viande dans les villes romaines d'Ile-de-France au $\mathrm{I}^{\mathrm{er}}$ siècle. Les cas de Meaux et de Paris (Seine-et-Marne et Seine) », Revue archéologique du Centre de la France, 42, p. 41-59.

LEPETZ S. 1996, L'animal dans la société gallo-romaine de la France du Nord, Amiens, Revue Archéologique de Picardie, numéro spécial 12. 
MANTEL E., DUBOIS S. (dir.) 2019, L'agglomération antique de Briga. Bilan de cinquante ans de recherches sur le site du «Bois l'Abbé», (commune d'Eu, Seine-Maritime), volume I.

MANTEL E., DUbOIS S., DESCHAMPS L., JONVEl R., PARETIAS J. 2016, Agglomération antique de Briga « Bois l'Abbé ", Eu, Seine-Maritime, 76255001 AH, campagne 2015, rapport de fouille programmée, Rouen, Service Régional de l'Archéologie de Haute Normandie, volume I.

MANTEL E., DUBois S., JONVEl R., DeSCHAMPS L. 2015, Agglomération antique d'Eu Briga "Bois l'Abbé " (Seine-Maritime - 76255011 AH) - Fouille programmée pluriannuelle, campagne de fouilles 2014, rapport intermédiaire, Rouen, Service Régional de l'Archéologie de Haute Normandie.

MANTEL E., DUBOIS S. 2014, « L'agglomération gallo-romaine de Briga (Eu, « Bois l'Abbé », Seine-

Maritime) au Haut Empire : mise au jour des premiers îlots d'habitation », dans Journées archéologiques de Haute Normandie, Rouen 24 au 26 mai 2013, Rouen, PUHR, p. 109-126.

MANTEL E., DUBoIS S., BOURGoIs A. 2012, Agglomération antique d'Eu Briga « Bois l'Abbé » (Seine-Maritime - 76255011 AH) - Fouille programmée pluriannuelle 2010-2012, campagne de fouilles 2011, rapport intermédiaire, Eu, Service Régional de l'Archéologie de Haute Normandie, Service Municipal d'Archéologie de la Ville d'Eu.

MANTEL E., DUBoIS S. 2011, « Eu, Bois l'Abbé (Seine Maritime) » dans Bilan Scientifique Régional de Haute Normandie, Rouen, DRAC, p. 73-76.

MANTEL E. (dir.) 2010, Briga ou l'histoire d'une bourgade antique peu à peu dévoilée en forêt d'Eu, FATRA, $\mathrm{n}^{\circ} 3$.

MANTEl E., DeVILleRs S., DuboIS S. 2010, Agglomération antique d'Eu « Bois l'Abbé » (Seine-Maritime $76255011 \mathrm{AH}$ ) - Fouilles programmées pluriannuelles campagnes 2009-2011, campagne de fouilles 2009, Eu, Service Régional de l'Archéologie de Haute Normandie, Service Municipal d'Archéologie de la Ville d'Eu.

MANTEl E., DEVILleRS S., DuboIS S. 2009, Agglomération antique d'Eu « Bois l'Abbé » (Seine-Maritime $76255011 \mathrm{AH}$ ) - Fouilles programmées pluriannuelle campagnes 2006-2008, Document Final de Synthèse, Eu, Service Régional de l'Archéologie de Haute Normandie, Service Municipal d'Archéologie de la Ville d'Eu.

MANTEL E., DEVILLERS S., DUBOIS S. 2007, « Une agglomération antique sort de l'anonymat (Eu, « Bois l'Abbé », Seine-Maritime) : BRIGA ressuscitée », Revue Archéologique de Picardie, 3/4, p. 31-50.

MÉNIEL P. 2008, « Les restes animaux du sanctuaire du Bois l'Abbé », dans MANGARD M., Le sanctuaire gallo-romain du Bois l'Abbé à Eu (Seine Maritime), Revue du Nord, hors-série, Collection Art et Archéologie, vol. 12, p. 291-294.

MiCHEL M. (dir.) 2012, « Authevernes “Les Mureaux" (Eure) : le sanctuaire antique approche chronologique et pratiques cultuelles ", dans Journées archéologiques de Haute Normandie, Évreux 6 au 8 mai 2011, Rouen, PUHR, 2012, p. 91-106.

POUX M., DEMIERRE M. (dir.) 2015, Le sanctuaire de Corent (Puy de Dôme, Auvergne), vestiges et rituels, Paris, Gallia, $62^{\mathrm{e}}$ supplément, CNRS éditions.

poux M. (dir.) 2012, Corent. Voyage au cœur d'une ville gauloise, nouvelle édition corrigée et augmentée, Paris, Errance.

SCHEID J. 2005, Quand faire c'est croire : les rites sacrificiels des Romains, Paris, éditions AubierMontaigne. 
VAN ANDRINGA W. 2008, « La cuisine du sacrifice en pays gallo-romain » dans LEPETZ S., VAN ANDRINGA W. (dir.), Archéologie du sacrifice animal en Gaule romaine. Rituels et pratiques alimentaires, Montagnac, Éditions Monique Mergoil, Collection Archéologie des Plantes et des Animaux, volume II, p. 27-42. WOODWARD A. 1992, English Heritage book of shrines and sacrifice, London, Bastford B. T.

ZEDER M.-A., LAPHAM H.-A. 2010, « Assessing the reliability of criteria used to identify postcranial bones in sheep, Ovis, and goats, Capra », Journal of Archaeological Science, vol. 37, issue 11, novembre, p. 2887-2905.

ZEDER M.-A., PILAAR H.-A. 2010, « Assessing the reliability of criteria used to identify mandibles and mandibular teeth in sheep, Ovis, and goats, Capra », dans Journal of Archaeological Science, vol. 37, issue 2, février, p. 225-242.

\section{NOTES}

1. Lepetz, Van Andringa 2008, p. 11-12.

2. Mantel 2010, p. 16.

3. Mantel, Dubois, Jonvel, Deschamps 2015, p. 36.

4. Mantel, Dubois, Devillers 2007, p. 37.

5. Mantel, Dubois, Deschamps, Jonvel, Paretias 2016, figure 136.

6. Mantel 2010, p. 1.

7. Mantel, Dubois 2019.

8. Le complexe monumental est séparé en deux parties par la route moderne, le secteur I correspond à la partie sud-ouest, tandis que le secteur II recouvre la partie nord-est du centre monumental.

9. Méniel 2008, p. 292 et Mantel, Dubois 2019, (étude archéozoologique A. Bourgois).

10. Il ne s'agit toutefois pas de la seule victime, comme en témoignent les deux dépôts exceptionnels de bouvillons fouillés en 2010 et présentés dans la monographie de site (Mantel, Dubois 2019).

11. L'ensemble des informations concernant ces dépôts et les autres vestiges osseux sont en cours d'étude dans le cadre d'une thèse de doctorat, préparée à l'Université de Picardie Jules Verne par Alice Bourgois, sous la direction de Marie-Laurence Haack et de Sébastien Lepetz: "Approche archéozoologique des campagnes et des villes de l'Ouest septentrional, entre Seine et Somme à la période romaine ", et financée par un contrat doctoral ministériel de 2012 à 2015.

12. Les dépôts du centre monumental pris en compte dans cet article sont les suivants : 22 119, 2 4bis 41, 2 4bis 42, 2 4bis 43, 25 03, 26 06, 28 02bis, 28 02ter, 28 02quater, 28 02quinquies, 28 02sexies, 2 9bis 02, 210 13, 215 17, 233 06, 235 01, 1105 01A, 1105 01B, 1105 01C, $110501 \mathrm{D}$, dépôts 1 et 8 du fanum 7. Le premier chiffre de chaque dépôt correspond au secteur (I ou II), le deuxième nombre renvoie au numéro de l'espace ou bâtiment concerné (par exemple II basilique et CV pour l'allée devant le fanum 2) et le troisième nombre correspond au numéro de la couche dans la stratigraphie. La combinaison de ces trois informations forme l'unité stratigraphique de référence (U.S.) au « Bois l'Abbé ».

13. Mantel, Devillers, Dubois 2009, p. 53-54. 
14. Exhumés en 2009, ces dépôts se trouvaient immédiatement sous une fine couche de terre végétale. Le piétinement lors des campagnes de fouilles successives d'abord dans les années 1960, puis en 2000, les a beaucoup altérés (Mantel, Devillers, Dubois 2010, p. 42).

15. Mantel, Dubois, Jonvel, Deschamps 2015, annexe 5 (pré-inventaire de la faune).

16. Par ailleurs, l'U.S. 2802 contenait au moins quatre autres squelettes disloqués de moutons (Mantel, Dubois 2019).

17. Dans l'isolation CV A, il manque l'intégralité de la colonne vertébrale à l'exception de la dernière vertèbre cervicale, ainsi que quelques petits os du tarse et du carpe. Toutes les autres parties squelettiques sont présentes.

18. Lepetz 1996, p. 48.

19. Dans les isolations CV D, 2802 quater et les deux derniers cas dans le dépôt 1 du fanum 7.

20. Les tailles au garrot ont été estimées à partir des coefficients de Teichert (1975), disponibles dans Chaix, Méniel 2001, p. 58.

21. Lepetz 1996, p. 46.

22. Pigeon ramier (Columba palumbus) dans l'espace VIII et pigeon biset (Columba livia) dans les espaces XXXV et CV.

23. Méniel 2008, p. 292.

24. Ibid, p. 294.

25. Bourgois 2015, p. 42 et Mantel, Dubois 2019.

26. Mantel, Dubois, Deschamps, Jonvel, Paretias 2016, p. 101 et figure 93.

27. Mantel, Dubois, Bourgois 2012, p. 69.

28. Les $\mathrm{I}^{\mathrm{er}}$ et $\mathrm{III}^{\mathrm{e}}$ siècles sont aussi représentés, dans une moindre mesure.

29. Ibid., p. 70.

30. Mantel, Dubois, Deschamps, Jonvel, Paretias 2016, p. 105.

31. Mantel, Dubois 2011, p. 75.

32. Les ossements exhumés de la structure 3 en 2014 (quelques centaines de restes) n'ont pas pu être intégrés à l'étude faute de temps, mais ils présentent les mêmes caractéristiques que le matériel des campagnes de 2011 à 2013.

33. Sur les 834 restes de caprinés de la structure 3, 42 ont été attribués au mouton contre un seul à la chèvre.

34. La dépression contenait sept restes de chiens, un unique reste de lièvre et un autre de coq.

35. Mantel, Dubois 2019.

36. Pour des raisons de lisibilité, le choix a été fait d'exprimer les répartitions anatomiques des trois espèces principales (fig. 8 et 9 ) en poids des restes, plutôt qu'en nombre de restes, et de les pondérer selon la méthode proposée par Sébastien Lepetz et Tarek Oueslati en fonction d'une répartition "normale " (naturelle) d'un squelette de référence (Lepetz, Oueslati 2003, p. 54-55) suivant la formule suivante $:$ indice $=(\%$ poids des restes -\% poids de référence) /\% poids de référence.

37. Principalement des parties distales de métapodes, dont un élément scié.

38. Mantel, Dubois 2014, p. 126 et Mantel, Dubois 2019. 
39. Poux 2012, p. 154 (étude de Sylvain Foucras) et Foucras 2011, p. 169. À Corent, des centaines de mandibules de moutons ont pu être accrochées en guirlande le long d'un bâtiment (Poux, Demierre 2015, p. 474, 478-479 et 580), comme c'est encore le cas de nos jours chez certaines ethnies du Sud-Est de l'Asie (Hayden 2001, p. 56).

40. Le sanctuaire d'Uley, en Grande Bretagne, présentait la même association de ces trois types de matériel archéologique (Woodward 1992, p. 67-69).

41. Bourgois 2015, p. 39.

42. Les différents critères ostéologiques et dentaires de distinction entre moutons et chèvres sont disponibles dans Boessneck 1969, Fernandez 2001, Halstead, Collins, Isaakidou 2002, Zeder, Lapham 2010 et Zeder, Pilaar 2010.

43. Bourgois 2015, p. 41.

44. Ibid., p. 36.

45. Lepetz, Matterne 2003, p. 31.

46. Bourgois 2015, p. 42-43.

47. Le naviculaire et le talus.

48. Mantel, Dubois, Jonvel, Deschamps 2015, p. 94.

49. D’après le code de Grant de 1982 (Chaix, Méniel 2001, p. 66-67).

50. L'âge de l'un d'entre eux peut être affiné entre 2 et 6 mois, selon l'usure de la dernière prémolaire $(\mathrm{p} 4)$ déchaussée isolée retrouvée dans la fosse.

51. Mantel, Dubois 2011, p. 75.

52. King 2005, p. 330 et 332.

53. King, Soffe 1994, p. 38.

54. Lepetz 2019.

55. Lepetz, Yvinec, Bourgois 2014.

56. Foucras 2011, p. 183 et 185.

57. Argant 2008, p. 81.

58. Leach, Woodward 1993, p. 295.

59. Interprété comme un dépôt de fondation/consécration (Michel 2012, p. 98-99).

60. Ibid., p. 100-103.

61. Ibid., p. 103-104.

62. Lepetz 2016 (sous presse).

63. Le porc est en effet l'animal majoritaire dans l'ensemble des secteurs durant les deux premiers siècles d'occupation du « Bois l'Abbé » (Mantel, Dubois 2019).

64. King 1999, p. 182.

65. Notamment sur la côte africaine, en Grèce, en Asie mineure et en Narbonnaise (ibid., p. 194).

66. Bourgois 2015, p. 37.

67. Bourgois inédit.

68. Lepetz, Van Andringa 2008, p. 19.

69. Huet et alii. 2004, p. 193, 199 et 202 ; Van Andringa 2008, p. 27.

70. Scheid 2005, p. 64-66. 
71. Van Andringa 2008, p. 30.

72. Si les moutons sont très âgés à Empel, les bovins sont à l'inverse assez jeunes : entre 15 et 30 mois (Seijnen 1994, cité dans Groot 2008, p. 111).

73. King 2005, p. 357-358 et Groot 2008, p. 111-112 (plus particulièrement au printemps et en automne).

74. L'aspect général de certains ossements (taphonomie, conservation...), très différent du reste du dépôt, ne laisse d'ailleurs aucun doute sur leur nature intrusive.

\section{RÉSUMÉS}

Reconnaître les vestiges d'un sacrifice est une tâche complexe, le rituel s'accompagne de gestes et d'une spiritualité que l'archéologie ne peut documenter. Toutefois, un certain nombre de critères permettent d'identifier des dépôts d'ossements animaux particuliers. La localisation de ces dépositions joue un rôle majeur dans l'analyse : lorsque les structures sont découvertes à l'intérieur de l'enceinte sacrée d'un sanctuaire, elles méritent une attention appuyée. Le nombre de dépôts et leur organisation constituent deux indices supplémentaires, car la multiplicité des structures reflète une pratique régulière, plutôt qu'un évènement ponctuel difficilement interprétable. Ces considérations appellent un exemple concret : celui du "Bois l'Abbé » à Eu (Seine-Maritime), où une trentaine de dépôts de moutons ont été exhumés près des temples, entre 2005 et 2015. Ces enfouissements de carcasses découpées sont-ils les ultimes témoignages de sacrifices animaux pratiqués dans le sanctuaire antique?

\section{AUTEURS}

\section{ALICE BOURGOIS}

Docteure, université de Picardie Jules Verne, TRAME EA 4284, CRAVO

\section{ÉTIENNE MANTEL}

Responsable de la fouille programmée du « Bois l'Abbé », DRAC de Haute Normandie, service régional de l'Archéologie, ArScAn UMR 7041, équipe GAMA

\section{SÉBASTIEN LEPETZ}

Archéozoologie, archéobotanique, sociétés, pratiques et environnements (UMR 7209), Sorbonne Universités, Muséum national d'Histoire Naturelle, CNRS

\section{MARIE-LAURENCE HAACK}

Professeur d'histoire ancienne à l'université de Picardie Jules Verne, TRAME EA 4284 


\title{
D'une culture à l'autre :
}

l'acclimatation des « animaux

sacrés » d'Égypte dans les temples

isiaques de Rome

\author{
Marie-Christine Budischovsky
}

1 Contrairement à la Bible et à l'Antiquité classique qui avaient globalement une vision hiérarchique et dépréciative de l'animal, les Égyptiens croyaient à une communauté d'origine de tous les règnes de la création, où l'homme ne tenait pas toujours le premier rôle ${ }^{1}$. Aussi, quand l'historien Hérodote fit son voyage en Égypte, il a pu constater l'étonnante familiarité que les habitants de la Vallée du Nil entretenaient avec l'espèce animale. Surtout, il nous relate un des faits les plus curieux qu'il ait rencontrés, l'existence d'animaux «sacrés ». À sa suite, Diodore de Sicile $(\mathrm{I}, 83,1)$ déclare, à l'époque d'Auguste, que :

«Les Égyptiens vénèrent extrêmement quelques animaux, non pas seulement quand ils vivent, mais quand ils sont morts aussi, tels les chats, les ichneumons, et les chiens, et encore les faucons et les animaux appelés chez eux ibis, et aussi, les loups, les crocodiles et bien d'autres encore du même genre. »

2 En fait, une divinité peut se manifester sous une forme animale et les animaux devenir des intermédiaires avec le monde divin, sans être objet d'un culte ; aussi, l'existence de grandes nécropoles d'animaux momifiés frappait les étrangers sans qu'ils en comprissent bien l'utilisation' ${ }^{2}$.

Depuis la mort d'Alexandre, certaines croyances inspirées de l'Égypte traditionnelle s'étaient diffusées dans toute la Méditerranée, privilégiant quelques dieux dits isiaques : en tête le couple d'Isis et Sérapis, puis leur fils Harpocrate et le fidèle Anubis à tête de chien; enfin, sur un mode mineur quelques autres dont le taureau Apis, la chatte Bubastis et le faucon Horus. Bien entendu, au contact d'autres cultures, il y a eu modification de l'original égyptien et c'est principalement sous une forme hellénisée que ces dieux apparaissent en Italie à la fin de la République et se conforment aux pratiques cultuelles de Rome ${ }^{3}$. 
Comment a pu se faire l'adaptation de formes animales divines? Car quelques déités isiaques n'ont pas abandonné leur apparence première. Or, si le regard d'Hérodote est celui d'un observateur, cette particularité égyptienne n'a pas été sans provoquer de réaction hostile, réaction que l'on remarque tant dans l'Énéide de Virgile (VIII, 698) que dans les satires de Juvénal (XV, 1-8), a fortiori chez les chrétiens (Paul, Rom.1, 22-23). Cependant, nous sommes dans un univers polythéiste où les dieux d'origine égyptienne ont eu leurs adeptes, y compris parmi les empereurs de Rome.

5 C'est dans ce contexte isiaque que nous allons étudier la forme des représentations animalières dans la sculpture et la peinture italiennes du début de l'Empire romain essentiellement les $\mathrm{I}^{\mathrm{er}} \mathrm{II}^{\mathrm{e}}$ siècles de notre ère - et découvrir leur place dans un espace sacré. Pour cela, nous privilégions le temple bien documenté d'Isis à Pompéi dans la province de Campanie, celui de Bénévent fondé par Domitien et celui du Champs de Mars (Iseum Campense), rénové par les Flaviens, principal sanctuaire isiaque de Rome. On s'interrogera, enfin, sur les fidèles qui n'ont pas été rebutés par cet aspect insolite.

\section{Les « métamorphoses »}

6 Deux divinités thériomorphes se distinguent dans le cortège des isiaques, Apis et Anubis. À Memphis, capitale traditionnelle de l'Égypte, l'ancien culte du taureau Apis est lié aux forces vitales du pharaon et s'était développé à l'époque tardive : les prêtres de Ptah sélectionnaient un taureau, tel une statue divine animée où se serait manifesté ce dieu, et le présentaient à la vue de tous dans une dépendance du temple. Hérodote (III, 28) nous renseigne approximativement sur les critères du choix de l'élu :

«Ce jeune taureau que l'on appelle Apis présente les signes que voici : il est noir, il porte sur le front une marque blanche triangulaire, il a sur le dos l'image d'un aigle [faucon], les poils de la queue fourchus, sous la langue, l'image d'un scarabée.»

7 On reconnaît le modèle iconographique égyptien: disque astral (soleil flanqué d'un uræus ou lune) entre les cornes, marque triangulaire sur le front, collier large, décor d'animaux ailés sur le dos encadrant un tapis (fig. 1) ${ }^{4}$. L'image familière du taureau a pu faciliter un transfert de l'aspect animal en Italie, mais avec des simplifications ${ }^{5}$ : le taureau debout, ou en marche, est coiffé d'un disque solaire (fig. 7, en haut vers la droite) ${ }^{6}$. Mais son aspect lunaire est également souligné par un croissant soit dressé entre les cornes : sacrarium de l'Iseum de Pompéi ${ }^{7}$, petits bronzes de Campanie (fig. 2) ${ }^{8}$, soit gravé sur le flanc: temple de Bénévent ${ }^{9}$; cette sélénisation est commentée par Plutarque (De Iside, 43) :

« Apis est l'image vivante d'Osiris [dieu lunaire], il est engendré au moment où une lumière génératrice part de la lune et vient toucher la génisse en chaleur. Pour le même motif, ils [certains philosophes] ajoutent encore qu'Apis paraît offrir plusieurs traits de ressemblance avec les phases de la lune. »

Parfois, la divinité ne porte pas d'attribut, quand son identification est évidente (mosaïque du Serapeum d'Ostie). Il est à noter qu'il n'existe aucune dédicace à Apis en Italie, mais nous savons par Ovide (Amores, II, 13, 11) qu'il pouvait accompagner Isis dans les processions; sans doute, sa présence renforçait-elle l'égyptianité du sanctuaire. Les empereurs Flaviens lui ont porté une attention particulière qui peut s'expliquer par ses liens avec un pouvoir fort ${ }^{10}$ : outre la consécration d'un Apis à Memphis par Titus (Suétone, Titus, 5, 4), on remarquera que dans l'Iseum de Bénévent, 
créé en l'honneur de Domitien, dans un esprit de fidélité au modèle égyptien (y compris dans les hiéroglyphes des obélisques), ont été retrouvées trois images de ce dieu ${ }^{11}$.

Fig. 1. - Statuette d'Apis égyptien. Bronze. H. $13 \mathrm{~cm}$. Copenhague, Ny Carlsberg Glyptothek, AE.I.N. 616.

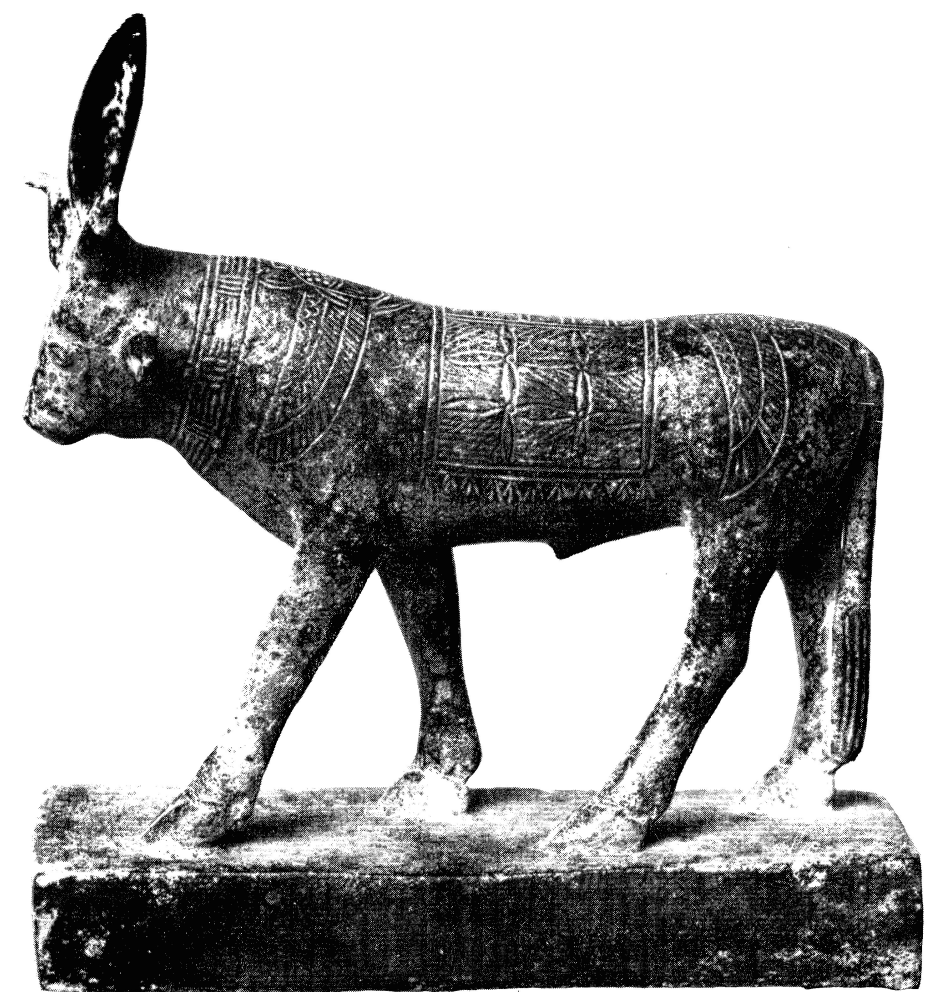

Source Kater-Sibbes et Vermaseren Martin, Apis, II, p. 49, n 403, pl. 118. 
Fig. 2. - Statuette d'Apis romain (Herculanum). Bronze. H. $13 \mathrm{~cm}$. Naples, Musée archéologique, inv. 4934.

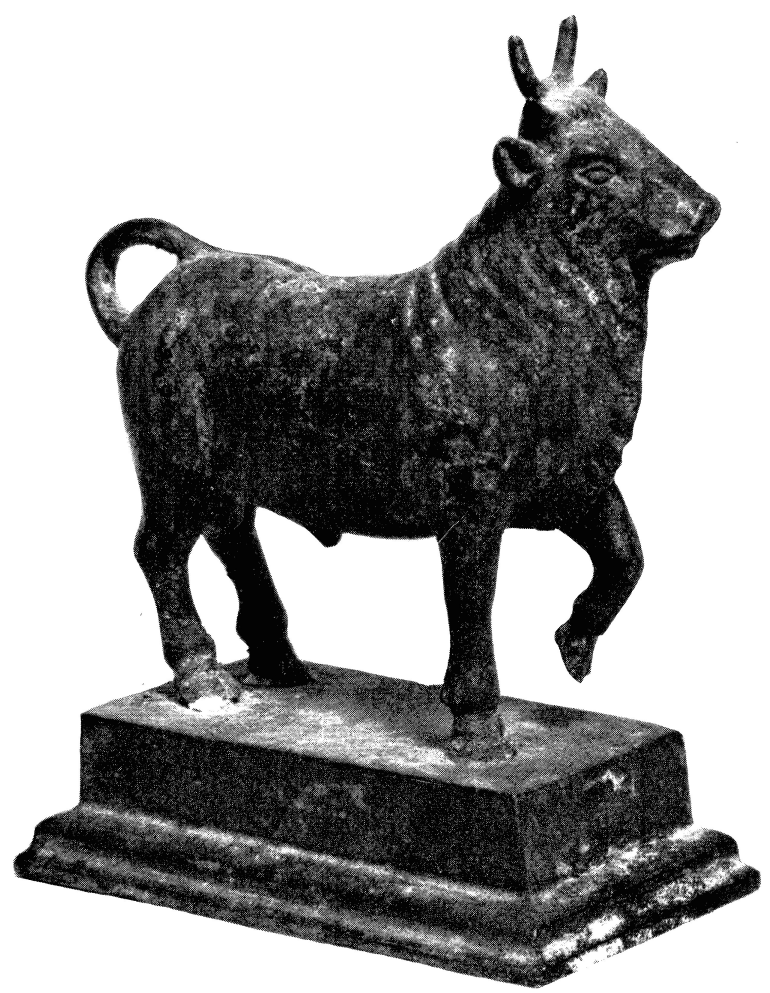

Source Kater-Sibbes et Vermaseren Martin, Apis, II, p. 24, n 305, pl. 65. 
Fig. 3. - Hermès d'Osiris-Apis (Canope de la Villa Adriana). Marbre noir. H. $50 \mathrm{~cm}$. Cité du Vatican, musée Grégorien-Egyptien, inv. 22807.

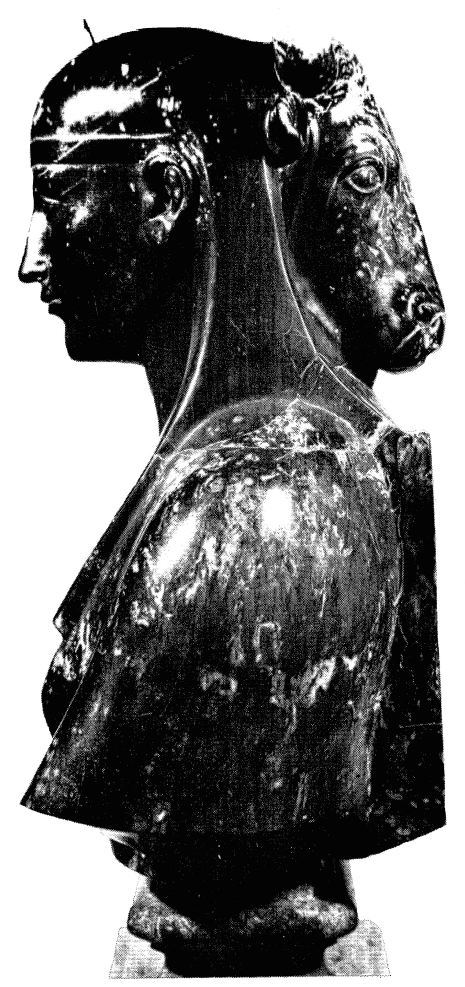

Source Kater-Sibbeset Vermaseren Martin, Apis, II, p. 20, n² 295, pl. 49.

Un autre cas de contexte impérial peut être observé dans le cadre privé du complexe de la Villa Adriana qui commémore Antinoüs, favori d'Hadrien, mort noyé et divinisé en Égypte. Un premier monument est une statue provenant sans doute de Memphis, exemple rare d'importation de la forme hybride de ce dieu à l'égyptienne: tête de taureau coiffée d'une perruque surmontée du disque entre les cornes et torse de forme humaine gravé du sceptre ouas. Le deuxième monument est encore plus intéressant, car il a fait l'objet d'une construction savante sous les directives probables d'un prêtre lettré ; il est l'expression en image de l'étymologie du nom du dieu Osiris-Apis (WsrHp.is), forme funéraire vénérée à Memphis (sa forme hellénisée, Sérapis, fut adoptée avec des fonctions enrichies par les Ptolémées). Deux têtes des entités divines Osiris (humaine) et Apis (animale) sont, donc, greffées sur le même corps (fig. 3) qui devait émerger de la fleur de lotus, symbole de renaissance solaire, trouvée au même endroit ${ }^{12}$.

À Rome, un relief de la XVIII ${ }^{\mathrm{e}}$ dynastie (daté de Horemheb, Nouvel Empire, fin du $\mathrm{XIV}^{\mathrm{e}}$ siècle av. J.-C.) n'a pas été importé sans intention politique ${ }^{13}$; il a été retrouvé dans la zone de l'Iseum Campense somptueusement rénové par les Flaviens: c'est la représentation classique de Pharaon allaité par la vache Hathor, marque d'adoption du roi par les divinités féminines. Le choix de ce monument n'est pas innocent : la forme animale permet un rapprochement avec la louve allaitant le futur roi Romulus et son frère, image familière aux Romains. En revanche, le texte hiéroglyphique de l'obélisque de Domitien dans le même lieu se réfère à l'allaitement par des déesses à forme humaine, comme dans les mammisis égyptiens ${ }^{14}$ :

«Les deux déesses ont mis leur sein dans sa bouche. $»^{15}$ 
11 Si l'obélisque apparaît aux yeux du simple promeneur comme un référent égyptien, ce texte est un moyen de légitimer et glorifier l'empereur ainsi que son destin exceptionnel de maitre du monde. Aspects humain (texte) et animal (image) alternent dans le même espace à des niveaux de lecture différents. Cela implique, en relation avec les temples, l'existence de prêtres de culture égyptienne plus ou moins spécialisés tant pour la composition des textes que pour l'adaptation des modèles iconographiques et leur insertion dans une architecture mixte; dans les ateliers, il faut envisager des artisans d'origine égyptienne ou des copistes romains plus ou moins habiles ${ }^{16}$.

Venons-en au procédé le plus habituel, celui de l'interpretatio. Il consiste en un système d'équivalence entre divinités gréco-romaines et étrangères par rapport à des caractéristiques communes ${ }^{17}$. Nous prendrons l'exemple d'Anubis ${ }^{18}$ : si le petit bronze (fig. 4) exhumé dans le laraire de la maison de C. Memmius Auctus à Pompéi est de style égyptien (allure hiératique, museau animal allongé, perruque, pagne, main tenant un sceptre disparu $)^{19}$, les peintures pompéiennes sur le thème de la réception d'Io par Isis (ecclesiasterion de l'Iseum ${ }^{20}$, maison du duc d'Aumale ${ }^{21}$ ) montrent, au contraire, un dieu totalement anthropomorphe (Hermanubis) portant le caducée de Mercure, mais aussi le sistre, «logo». isiaque par excellence. Examinons maintenant la forme la plus habituelle sur un relief romain d'un autel de l'Iseum Campense dédié à Isis (fig. 5) ${ }^{22}$ : sur le côté gauche, Anubis debout garde sa tête canine, mais romanisée avec un mufle épais; il porte palme et caducée (attribut de Mercure); il est vêtu à la romaine, vêtement court, manteau, sandales ailées. On trouve l'explication de cette création romaine dans le dernier livre des Métamorphoses (XI, 11) où Apulée, déclare qu'Anubis «sert de messager entre le monde d'en haut et le monde infernal »; comme Hermès/ Mercure, il est un dieu mobile circulant entre les différents espaces du monde. 
Fig. 4. - Statuette d'Anubis égyptien de Pompéi (laraire de la maison de M. Memmius Auctus). H. 13, 2 cm. Naples, Musée archéologique, inv. 110606 .

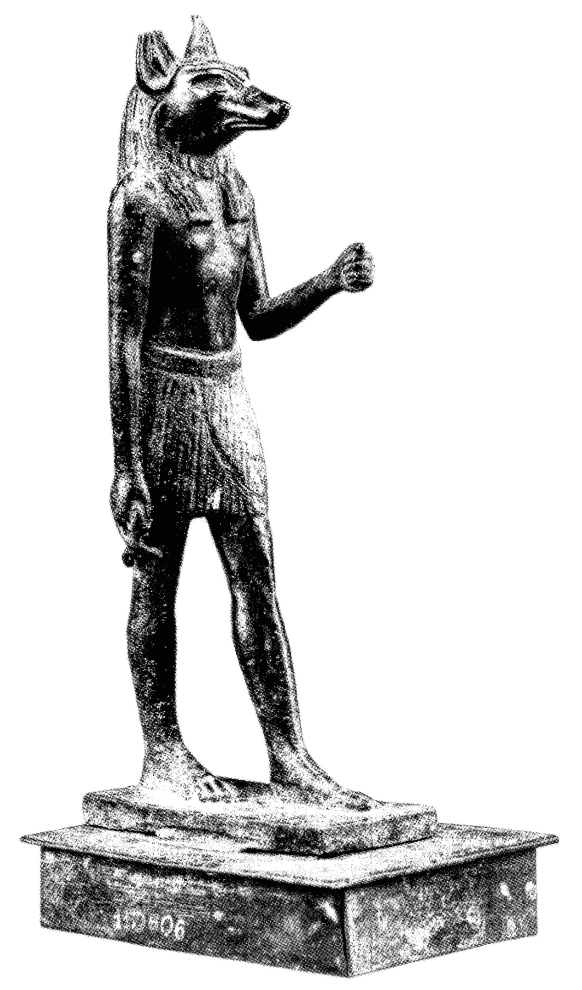

Source De Caro, Iside, p. 435, V. 58 
Fig. 5. - Relief d'Anubis romain (côté droit d'un autel de l'Iseum Campense de Rome). Marbre grec. H. $87 \mathrm{~cm}$. Rome, Musées Capitolins, salle de l'lseum Campense, inv. 21.

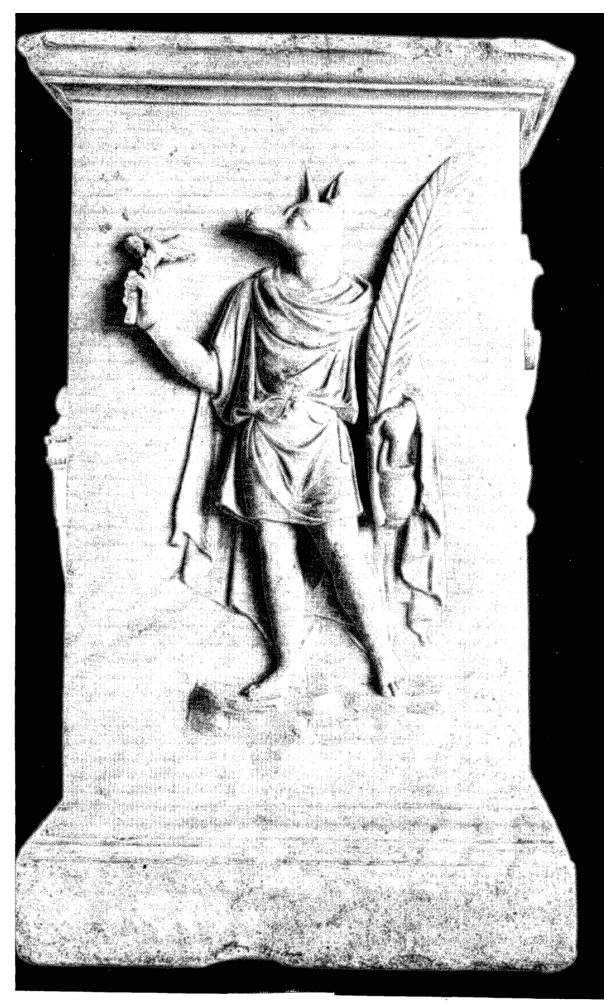

Source De Caro, Iside, p. 387, V, 2.

Une peinture du portique de l'Iseum de Pompéi montre un prêtre ou un fidèle isiaque coiffé du masque d'Anubis ${ }^{23}$; chaussé de sandales de papyrus, il est enveloppé dans un ample manteau rouge dissimulant ses bras repliés. Ces Anubophores jouent un rôle important dans les processions ${ }^{24}$ et sont évoqués dans le même texte d'Apulée (XI, 8-11), qui nous restitue l'atmosphère de la fête publique du Navigium Isidis, marquant la reprise de la navigation maritime, sous la protection d'Isis, le 5 mars. On y voit d'abord défiler des figures carnavalesques à la romaine; puis arrive le cortège sacré isiaque au son des sistres; les prêtres porteurs des sacra sont suivis des dieux liés aux manifestations animales divines: en tête, un prêtre ou un dévot porte le masque d'Anubis, un autre, une statue de la vache divine :

«Bientôt parurent les dieux, daignant, pour avancer, se servir de pieds humains. D'abord le dieu à l'aspect terrifiant qui sert de messager entre le monde d'en haut et le monde infernal, mi-parti noir et doré de visage, la tête haute et dressant son encolure de chien: Anubis qui de la main gauche tenait un caducée, de la droite agitait une palme verdoyante. Puis immédiatement, sur ses pas, une vache tout debout, symbole de fécondité, image de la déesse mère de toutes choses. Elle reposait sur les épaules d'un de ses bienheureux ministres, qui gardait en la soutenant une allure pleine de dignité (XI, 11).»

Anubis occupe le dernier rang du quatuor des grandes divinités isiaques. S'il est attesté assez fréquemment dans les inscriptions du monde grec, son rôle est plus effacé en Italie, mais dans des milieux sociaux variés; une dédicace à Aquilée par une femme d'origine servile ${ }^{25}$, une offrande de statue du dieu par un affranchi impérial à Rome ${ }^{26}$, la mention de citoyens, Anubiaques, à Ostie ${ }^{27}$. De même, il apparaît peu dans l'iconographie, généralement en compagnie et sous une forme hybride. Pour ces 
divinités " étranges », le temple est le lieu par excellence qui permet la transmission de leur image aux dévots qui le fréquentent et au-delà.

\section{Localisation des formes animales dans l'espace sacré isiaque}

15 À l'inverse de l'Égypte, les statues principales de culte dans la cella ne peuvent pas revêtir une forme animale. Peintures et sculptures de ce type occupent des espaces secondaires. Ainsi, à Pompéi, ces représentations sont concentrées dans une salle annexe du temple d'Isis, appelée sacrarium $^{28}$. Elle est décorée de fresques avec des sujets thériomorphes : sur la paroi est, un tableau regroupe des animaux égyptiens peints par une main romaine peu habile; on reconnaît sur deux niveaux, de gauche à droite : taupe (à la place de la musaraigne?), vautour, mangouste, puis, singe tenant un serpent, bélier, chien ou chacal, sans aucun attribut divin, mais ils sont susceptibles d'interprétations sacrées ${ }^{29}$. En effet, on note le voisinage dans la même pièce des représentations de divinités : Osiris trônant (paroi ouest), Bès (paroi nord), transfert du coffret osiriaque par Isis (paroi nord), mais aussi des figures isolées d'animaux (paroi nord) : vautour, lion, dont certaines coiffées du lotus, attribut divinisant : cobra, ibis cher à Thot (fig. 6) ; taureau Apis à coiffe lunaire (paroi est). Dans l'ecclesiasterion, un Hermanubis apparaît dans le tableau de la réception d'Io en Égypte ${ }^{30}$. Dans la cuisine, une grosse chatte blanche à l'affût sur son réchaud veille telle Bastet sur les provisions du temple ${ }^{31}$. On est loin des animaux exotiques de la mosaïque de Palestrina ${ }^{32}$.

Fig. 6. - Ibis (fresque du sacrarium de l'Iseum de Pompéi). H. $82 \mathrm{~cm}$. La. $56 \mathrm{~cm}$. Naples, Musée archéologique, inv. 8562.

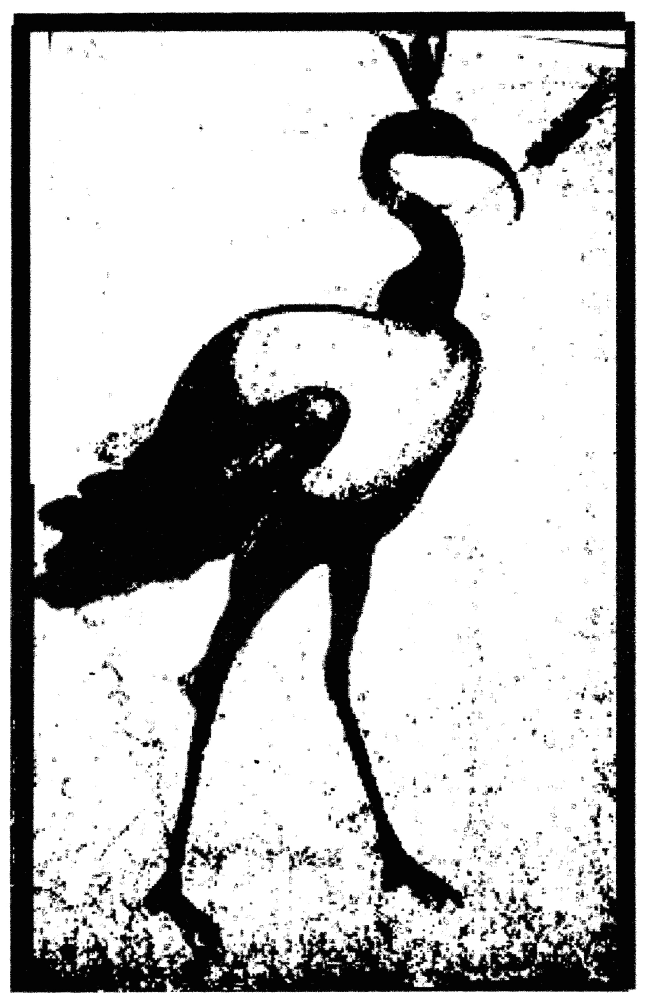

Source Tran Tam Tinh, Le culte d'Isis à Pompéi, pl. VII. 2, avec modification de l'auteure. 
Passons à l'Iseum Campense. L'emplacement de ce temple principal des dieux égyptiens apparaît dans les sources écrites: Apulée, (Met. XI, 26), Juvénal (VI, 528-529) et sur la Forma Urbis (plan antique de Rome), dans la région à l'ouest du Panthéon entre la Via del Seminario et $\mathrm{S}$. Stefano del Cacco (le macaque) ${ }^{33}$. Un relief d'Ariccia éclaire notre sujet (fig. 7) ${ }^{34}$ : un portique, formé de petites chapelles abritant des statues de divinités et de cynocéphales borde une cour cérémonielle; dans un espace ouvert, une statue $\mathrm{d}^{\prime} \mathrm{Apis}^{35}$. Des sculptures animalières ont été retrouvées dans cette zone : un crocodile à queue repliée, image de Sobek, près d'un canal ${ }^{36}$, des babouins ${ }^{37}$, des lions ${ }^{38}$, le plus souvent en paire (fig. 10, formant aujourd'hui le décor de l'escalier d'accès au Capitole), des sphin $^{39}$; ces derniers pourraient évoquer l'existence d'un dromos, allée processionnelle égyptienne. L'origine, les matériaux (surtout granit, mais aussi basalte, porphyre, pierre) et la datation de tous ces monuments sont très divers ${ }^{40}$. On note l'époque pharaonique avec des inscriptions royales: sphinx d'une épouse de Thoutmosis III ( $\left.n^{\circ} 15\right)$, d'Amasis II ( $\left.n^{\circ} 16\right)$, lions de Nectanebo I ( $\left.n^{\circ} 13-14\right)$, singes de Nectanebo II ( $\left.n^{\circ} 20-21\right)$; l'époque ptolémaïque: lions ( $\left.n^{\circ} 10-12\right)$, sphinx ( $\left.n^{\circ} 17\right)$. S'y ajoutent quelques monuments : des détails dans l'ensemble des colonnes sculptées où certaines figures de prêtres portent un canope à tête canine, l'enseigne d'un faucon ou d'un bovin couchée ${ }^{41}$, une statue d'Horus à tête de faucon ${ }^{42}$; l'Anubis d'un autel isiaque déjà mentionné ${ }^{43}$.

Fig. 7. - Relief d'Ariccia. Marbre. L. 1,12 m. H. 50 cm. Rome, Musée National Romain, inv. 77255.

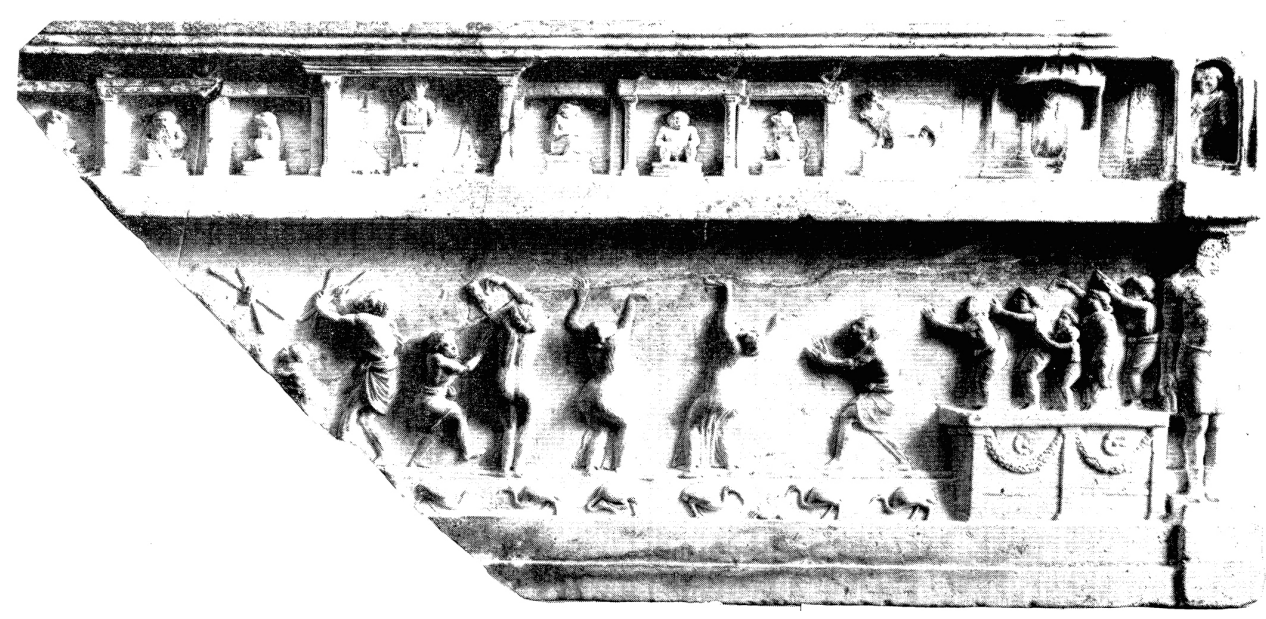

Source Kater-Sibbes et Vermaseren Martin, Apis, II, p. 17-18, n²93, pl. 45

L'Iseum de Pompéi est un bon exemple d'un temple provincial italien: son portique présente un dévot portant un masque animal d'Anubis dans une procession, mais le dieu peut être parfaitement intégré dans le tableau de la réception d'Io en Égypte dont on trouve copie dans une riche demeure; c'est dans les salles annexes que sont regroupés les animaux égyptiens dans tous leurs états. Au contraire, l'Iseum Campense est une véritable vitrine visible par tous de la forme d'origine, un musée sacré enraciné dans la tradition : la forme animale égyptienne y est privilégiée et peut devenir l'objet d'une dévotion personnelle. Emblématique nous semble le cas des cynocéphales assis, une forme rare du dieu Thot en Italie ${ }^{44}$, dont nous avons vu la représentation statuaire soulignée sur le relief d'Ariccia. Nous nous intéresserons à deux documents: un monument au passé prestigieux (fig. 8), où une paire de babouins de type hermopolitain porte une double inscription avec la titulature du pharaon Nectanebo II 
(-359-341), «aimé de Thot " $^{45}$. L'idéogramme du nom divin est un babouin, à la fois image et texte de la statue; les Égyptiens lettrés peuvent le lire dans leur langue Djéhouty, selon une tradition ancienne, les habitants cultivés de Rome liront Thot. D'autre part, une copie romaine retrouvée dans la zone de l'exèdre du Serapeum du même temple est le témoignage de piété d'un fidèle hellénisé (peut-être égyptien ?) et présente à la base une inscription bilingue (fig. 9) : à l'avant, on lit en grec Ph..., le début du nom très lacunaire du dédicant ; sur le côté droit, on lit en grec le nom des artisans : Phidias et Ammonios, tous deux fils de Phidias; sur le côté gauche, on lit en latin la permission du magistrat romain :

«(Ph a dédié ce monument) sur un emplacement assigné par Caelius [...] illianus Maximus, administrateur des bâtiments sacrés et des ouvrages publics, [...] Septimius Quintillus et Priscus étant consuls. » (159 apr. J.-C.) ${ }^{46}$

Pour d'autres exemples de singes en milieu sacré, on a celui du tableau du sacrarium de Pompéi brandissant un serpent et les deux sculptures du temple de Bénévent ${ }^{47}$. En fait, c'est l'ibis, autre forme du dieu, qui apparait le plus, tant dans le décor des temples (relief d'Ariccia, Iseum de Pompéi ${ }^{48}$, scènes de culte d'Herculanum ${ }^{49}$ ) que dans celui à tendance égyptomane des riches maisons de Rome et de Campanie ${ }^{50}$. C'est dans cette dernière mouvance que ces animaux ont connu un réel succès.

Fig. 8. - Statue égyptienne de Thot en babouin. Granit gris. H. 1, 51 m. Rome, Musées Capitolins, salle de l'Iseum Campense, inv. 26.

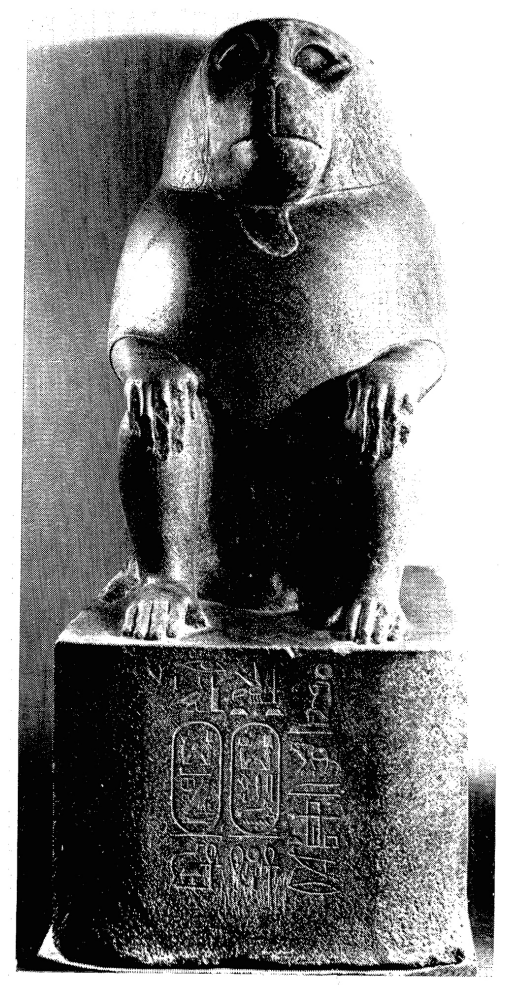


Fig. 9. - Statue romaine de Thot en babouin acéphale. Basalte bleu-gris, H. 1, $10 \mathrm{~m}$. Vatican, Musée Grégorien-Égyptien, inv. 34.S.

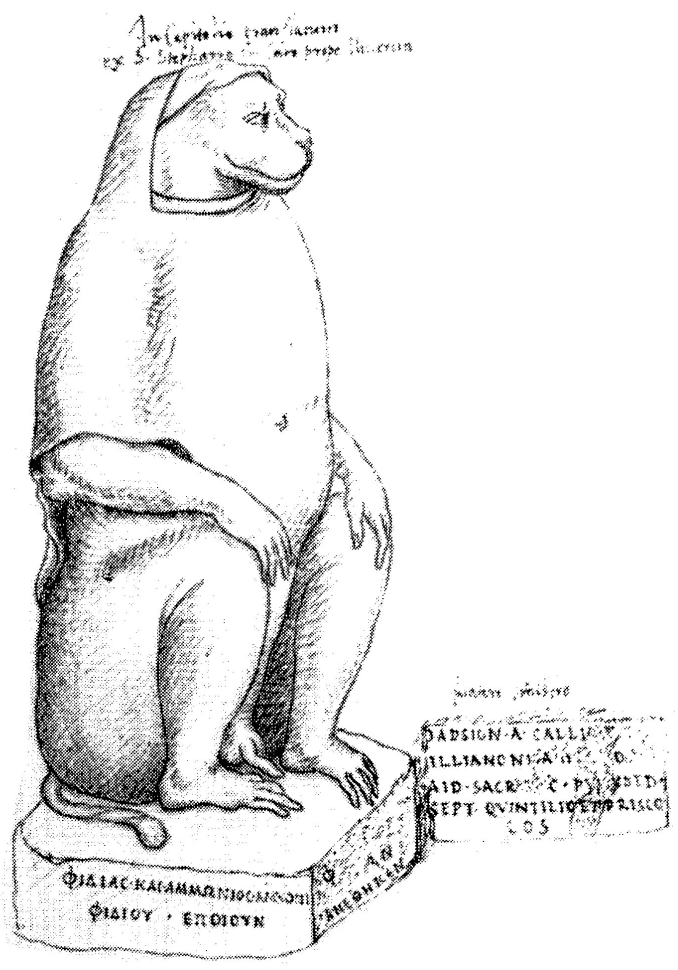

Source Roullet, Egyptian and Egyptianizing monuments, pl. 174, figure 252 = Codex Pighianus (1550-1555).

\section{Divinités à forme animale et dévotion à Pompéi}

Nous savons que la remise en état de l'Iseum de Pompéi est due aux libéralités du père de N. Popidius Celsinus, un fils d'affranchi d'une riche famille samnite reçu au sein du sénat de la cité ${ }^{51}$, un exemple parmi d'autres des liens de l'élite locale avec notre culte ${ }^{52}$. Nous reprendrons plus précisément les exemples représentatifs d'Apis (forme animale) et d'Anubis (interpretatio) dont l'image se retrouve dans les riches maisons de la sphère supérieure de la cité. Il est intéressant de croiser nos données avec celles des laraires.

Pour Apis, il convient d'essayer d'analyser le contexte. Les scènes sans référence précise isiaque peuvent relever d'une simple égyptomanie ${ }^{53}$ : peintures de la «masseria » d'Idrace ${ }^{54}$, de la maison «del Frutteto " d'Oro $»^{56}$. À l'inverse, les figures égyptisantes en procession de la maison du Centenaire (celle d'A. Rustius Verus, duumvir de la cité ?), dont l'une porte un Apis et où figure un babouin accroupi ${ }^{57}$, sont dans une maison où une statuette d'Harpocrate a été retrouvée avec celle de Jupiter (laraire ?) ${ }^{58}$. De même, dans la villa de Cn. Domitius Auctus à Scafati, le petit bronze accompagné d'un croissant lunaire en argent se rattache à un probable laraire avec une statuette d'Isis Panthée, une Vénus anadyomène, un serpent ${ }^{59}$. Sur un gobelet en argent avec des scènes du culte isiaque, on voit, à côté d'un autel, une statue du dieu taurin à croissant lunaire sur un piédestal. L'objet a été trouvé dans la Grande Palestre, près du squelette d'un jeune homme en fuite lors de l'éruption 
du Vésuve. Il pourrait provenir de deux maisonnées de dévots, à proximité : celle de Loreius Tiburtinus ou des Praedia Julia Felix ${ }^{60}$.

21 Les représentations d'Anubis se trouvent dans des maisons abritant des laraires, en compagnie d'autres divinités isiaques ou classiques. Dans le grand domaine dit Praedia Julia Felix, un édicule du portique abrite une peinture où Anubis vêtu de noir avec une palme côtoie Isis et Sérapis ${ }^{61}$. Au sud-est du péristyle de la belle maison des Amours Dorés, dans un sacellum isiaque, on voit le dieu au museau noir, vêtu d'une toge rouge et portant un caducée, accompagné d'Isis, Sérapis et Harpocrate ; à côté, une lampe au disque orné des figures d'Isis, Harpocrate et d'Anubis avec caducée et palme, sans compter une statuette en albâtre d'Horus hiéracocéphale ${ }^{62}$. Passons à une pièce de la maison dite du duc d'Aumale. Nous y avons une copie (de moins bonne qualité) de la peinture de la réception d'Io par Isis de l'Iseum de Pompéi, avec un Hermanubis portant le caducée et le sistre ${ }^{63}$. Enfin, dans le laraire de la maison de C. Memmius Auctus, une statuette du dieu au type égyptien (fig. 4) en voisine d'autres d'Isis égyptisante et des Lares dans un coffre en bois ${ }^{64}$.

Les formes animales sacrées introduites dans le cortège isiaque n'ont pas toutes connu un franc succès, face une certaine réticence romaine. L'adaptation suit des processus différents : forme animale dynamisée et fortement sélénisée pour Apis, interpretatio romaine pour la forme hybride dominante d'Anubis, interprétation savante sous protection impériale avec intervention de spécialistes pour des œuvres isolées. Peintures et sculptures occupent une situation auxiliaire dans les espaces sacrés, mais témoignent d'une égyptianité revendiquée: Anubis est présent dans le monde du temple et sa visibilité est certaine dans les processions; quant à Apis, il garde une forme taurine dans la statuaire et dans les décors égyptisants. L'archéologie pompéienne nous permet de remarquer un relatif succès d'Anubis en accompagnateur de la triade familiale divine dans les riches maisons où cohabite une dévotion aux divinités classiques et isiaques, alors que la figure d'Apis, à l'instar de la plupart des représentations thériomorphes, est davantage liée à l'égyptomanie. Quant à l'Iseum Campense, phare de l'isiacisme, il apparaît comme un véritable laboratoire avec des formes divines rares à caractère spectaculaire qui ne seront pas forcément diffusées largement dans le culte, tel le cynocéphale. Deux figures animalières égyptisantes ont perduré dans le paysage urbain romain influençant le décor architectural européen : le double sphinx et le double lion: une paire de lions en granite gris venant de l'Iseum Campense garde l'accès monumental à la colline capitoline. Lors des fêtes papales du $\mathrm{xVII}^{\mathrm{e}}$ siècle, ils fonctionnaient comme des fontaines à vin ${ }^{65}$, maintenant ils accueillent tout visiteur gravissant la montée du Capitole (fig. 10). 
Fig. 10. - Lions ptolémaïques de l'Iseum Campense.

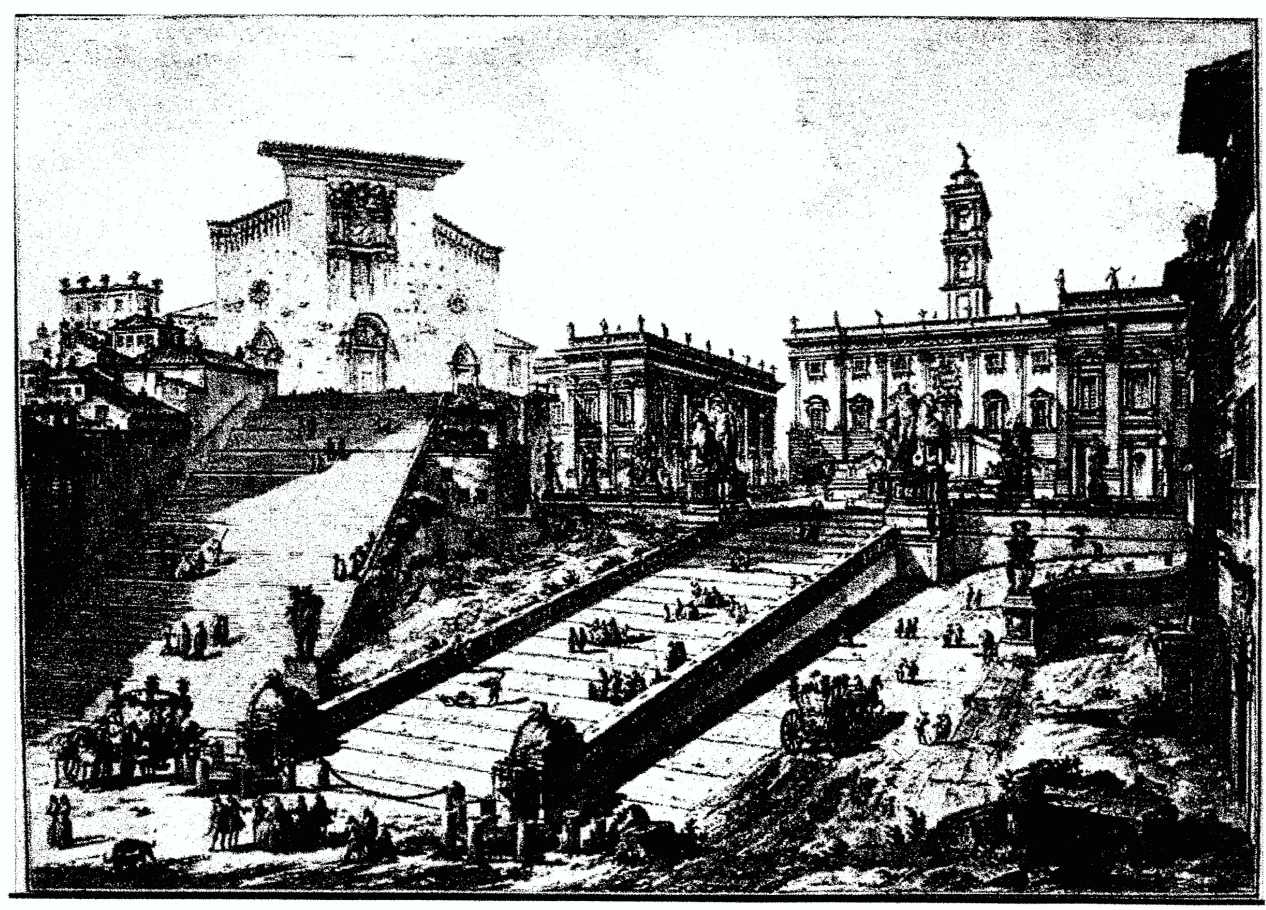

Gravure de G. B. Piranese, Vue du Capitole romain avec escalier allant à l'église de l'Araceli. Source Vues de Rome (1775).

\section{BIBLIOGRAPHIE}

ARSLAN Ermanno A. (éd.), Iside. Il mito. Il mistero. La magia, Milan, Electa, 1997.

BEAURIN Ludivine, « Les divinités isiaques dans les cultes domestiques : l'exemple de Pompei et d'Herculanum ». [URL : docslide.fr/documents/article-55c611d686252.html.]

BRICAULT Laurent, «Les Anubophores », Bulletin de la société égyptologique de Genève, édition numérique, 24, 2001, p. 29-42. [URL : https://hal.archives-ouvertes.fr/hal-00562518]

BRICAULT Laurent, Les cultes isiaques dans le monde gréco-romain, Paris, Les Belles Lettres, La Roue aux livres, 2013.

BORGEAUD Philippe, Aux origines de l'histoire des religions, Paris, Seuil, 2004.

BRAGANTINI Irena, «Il culto di Iside e l'egittomania antica in Campania », dans DE CARO Stefano (éd.), Egittomania. Iside e il mistero, Milan, Electa, 2006, p. 163-167.

BUDISCHOVsкy Marie-Christine, « La figure de Pharaon dans la Mensa Isiaca et ses avatars italiens. Du temple pharaonique au temple isiaque », dans Richard VEYMIERS (éd.), Individuals and Materials in the Greco-Roman Cults of Isis, Liège, Colloque international, 23 au 24 septembre 2013, LeydeBoston, Brill, RGRW 187, I, 2018, p. 332-339. 
CAPRIOTTI VITTOZZI Giuseppina, «The Flavians: Pharaonic Kingship between Egypt and Rome », dans BRICAULT Laurent, VERSLUYS Miguel John (éds), Power, Politics and the Cults of Isis, Proceedings of the $V^{\text {th }}$ International Conference of Isis Studies, Boulogne-sur-mer, Oct. 13-15 2011, Leyde-Boston, Brill, RGRW 180, p. 237-259.

CHARRON Alain, «Les animaux et le sacré dans l'Égypte tardive, fonctions et signification ", École pratique des hautes études, Section des sciences religieuses. Annuaire, t. 105, 1996-1997, p. 517-519. CIAMPINI Emanuele Marcello, « The Pamphili Obelisk: Two Notes on Pharaonic Elements in Domitian Ideology ", dans M. SANADER and A. R. MIOČEVIČ (éds), Religion and Myth as an impetus for the Roman Provincial Culture. The Proceeding of the 8-th International Colloquium on Problems of Roman Provincial Art, Zagreb, 2005, p. 399-402.

DE CARo Stefano, « L'Iseo di Pompei », dans ARSLAN Ermanno A. (éd.), Iside. Il mito. Il mistero. La magia, Milan, Electa, 1997, p. 338-343.

DE CARO Stefano, Il santuario di Iside a Pompei e nel museo archeologico, Naples, Electa, 2006.

DE CARo Stefano (éd.), Egittomania. Iside e il mistero, Milan, Electa, 2006.

DE VOS Mariette, L'egittomania in pitture e mosaici romani-campani della prima età imperiale, Leyde, Brill, EPRO 84, 1980.

GRENIER Jean-Claude, « Les inscriptions hiéroglyphiques de l'obélisque Pamphili », Mélanges de l'École française de Rome, Antiquité, 1987, vol. 2, p. 937-961.

GRENIER Jean-Claude, « La décoration statuaire du "Serapeum" du "Canope" de la Villa Adriana ", Mélanges de l'École française de Rome, Antiquité, 101, 1989, vol. 2, p. 925-1019.

KATER-SIBBES G. J. F., VERMASEREN MARTIN J., Apis, II. Monuments from outside Egypt, Leyde, Brill, EPRO $48,1975$.

LEMBKE Katia, Das Iseum Campense. Studie über den Isiskult unter Domitian, Archäologie und Geschichte 3, Heidelberg, 1994.

LEMBKE Katia, « Ein relief aus Ariccia und seine Geschichte », Mitteilungen des Deutschen Archäologischen Instituts, Römische Abteilung, 101, 1994, p. 97-102.

MALAISE Michel, Inventaire préliminaire des documents égyptiens découverts en Italie, Leyde, Brill, EPRO $21,1972$.

MALAISE Michel, « Anubis et Hermanubis à l'époque gréco-romaine. Who's who », dans BRICAULT Laurent et VEYMIERS Richard (dir.), Bibliotheca Isiaca, III, Bordeaux, Ausonius, 2014, p. 73-93.

MASTROROBERTO Marisa, « Le sfingi nel giardino dipinto della Casa del Bracciale d'oro a Pompei », dans DE CARo Stefano (éd.), Egittomania. Iside e il mistero, Milan, Electa, 2006, p. 188-190.

MEYвоом Paul G.P., The Nile Mosaic of Palestrina. Early Evidence of Egyptian Religion in Italy, Leyde, Brill, RGRW 121, 1995.

RICIS = BRICAULT Laurent, Recueil des Inscriptions concernant les Cultes Isiaques, 1 et 2, MAIB, 31, Paris, De Boccard, 2005.

ROULLET Anne, The Egyptian and Egyptianizing monuments of imperial Rome, Leyde, Brill, EPRO 20, 1972.

SAUNERON Serge, YOYOTTE Jean, « La naissance du monde selon l'Égypte ancienne », dans La naissance du monde, Paris, Seuil, 1959, p. 18-91. 
VERSLUYS Miguel John, « The sanctuary of Isis on the Campus Martius in Rom », Bulletin Antieke Beschaving, 72, 1997, p. 159-169.

VERSLUYS Miguel John, Aegyptiaca Romana. Nilotic Scenes and the Roman Views of Egypt, Leyde-Boston, Brill, RGRW 144, 2002.

TRAN TAM TINH Vincent, Essai sur le culte d'Isis à Pompéi, Paris, De Boccard, 1964.

\section{NOTES}

1. S. Sauneron, J. Yoyotte, «La naissance du monde selon l'Égypte ancienne », p. 69-70 et 74-76.

2. A. Charron, «Les animaux et le sacré dans l'Égypte tardive, fonctions et signification », p. 517-519.

3. L. Bricault, Les cultes isiaques dans le monde gréco-romain, p. 181-193.

4. G. J. F. Kater-Sibbes, M. J. Vermaseren, Apis II, p. 48, nº 395, pl. CXIV.

5. M. Malaise, Inventaire préliminaire des documents égyptiens découverts en Italie, p. 363, s.v. APIS.

6. Ibid., p. 58, pl. 2.

7. S. De Caro, Il santuario di Iside a Pompei e nel museo archeologico nazionale, p. 78-79, $\mathrm{n}^{\circ} 123$.

8. G. J. F. Kater-Sibbes, M. J. Vermaseren, Apis II, p. 24, nº 305, pl. LXV.

9. M. Malaise, Inventaire, p. 300-301, nº 17-19, pl. 59.

10. G. Capriotti Vittozzi, «The Flavians: Pharaonic Kingship between Egypt and Rome », p. 237-259.

11. M. Malaise, Inventaire, p. 300-301, $\mathrm{n}^{\circ} 17-19$, pl. 59.

12. J.-C. Grenier, «La décoration statuaire du 'Serapeum' du 'Canope' de la Villa Adriana », p. 938 et 977-979, pl. XVII.

13. K. Lembke, Das Iseum Campense in Rom, p. 227, $\mathrm{n}^{\circ} 18, \mathrm{pl} .36,1$.

14. E. M. Ciampini, « The Pamphili Obelisk», p. 399-400.

15. J.-C. Grenier, « Les inscriptions hiéroglyphiques de l'obélisque Pamphili », p. 945.

16. M.-Ch. Budischovsky, « La figure de Pharaon dans la Mensa Isiaca », p. 334-338.

17. Ph. Borgeaud, Aux origines de l'histoire des religions, p. 71-72. L. Bricault, Les cultes isiaques, p. 473-491.

18. M. Malaise, « Anubis et Hermanubis à l'époque gréco-romaine », p. 73-93.

19. E. A. Arslan, Iside, p. $435, \mathrm{~V}, 58$.

20. S. De Caro, Il santuario di Iside a Pompei, p. 29.

21. S. De Caro, Egittomania, p. 186, III, 55.

22. E. A. Arslan, Iside, p. 386-387, V, 2. K. Lembke, Das Iseum Campense in Rom, p. 245, $\mathrm{n}^{\circ} 49, \mathrm{pl}$. 46.3 .

23. S. De Caro, Il santuario di Iside a Pompei, p. $54, \mathrm{n}^{\circ} 60$ et p. 58 .

24. L. Bricault, « Les Anubophores », p. 29-42.

25. RICIS 515/0101 Anubis augustus. 
26. RICIS 501/0102 (dans une dédicace à Isis lydienne de la Regio III).

27. RICIS 503/1115 et 503/1118.

28. S. De Caro, Il santuario di Iside a Pompei, p. 75-80, n 117, 119-123 et no 135.

29. S. De Caro, «L'Iseo di Pompei », p. 342.

30. S. De Caro, Il santuario di Iside a Pompei, p. 29 et $70 \mathrm{n}^{\circ} 98$.

31. Ibid., p. 81, $\mathrm{n}^{\circ} 135$.

32. P. G. P. Meyboom, The Nile Mosaic of Palestrina.

33. L'ouvrage de référence est : K. Lembke, Das Iseum Campense in Rom. Voir la reconstitution, p. 25. Voir aussi M. J. Versluys, «The sanctuary of Isis on the Campus Martius in Rom ", p. 159-169.

34. K. Lembke, « Ein relief aus Ariccia und seine Geschichte », p. 97-102.

35. K. Lembke, Das Iseum Campense in Rom, p. 240, $\mathrm{n}^{\circ} 40$ (disparu).

36. Ibid., p. 239-240, n 39, pl. 43,3.

37. Ibid., p. 228-229, n' 20-21, pl. 37,2.3 ; p. 238, n 36, pl. 43,1.2.

38. Ibid., p. 221-224, no 10-11, pl. 29-30; $\mathrm{n}^{\circ} 12$, pl. $31 ; \mathrm{n}^{\circ} 13-14$, pl. 32.

39. Ibid., p. 225-227, no 15 , pl. 33,1.2; no 16 , pl. 34,$2 ; n^{\circ} 17$, pl. $35 ;$ p. $241-242, n^{\circ} 44$, pl. 45,$1 ; \mathrm{n}^{\circ} 45$, pl. 34,1 .

40. Les numéros renvoient au catalogue de K. Lembke, Das Iseum Campense in Rom.

41. Ibid., p. 186-188, $n^{\circ}$ 3, 5, 6, pl. 7.1, 3 et 8.4.

42. Ibid., p. 228, n 19 , pl. 37,1.

43. Ibid., p. $245, \mathrm{n}^{\circ} 49$, pl. 46.

44. G. Capriotti Vittozzi, «The Flavians: Pharaonic Kingship between Egypt and Rome », p. 254-257.

45. K. Lembke, Das Iseum Campense in Rom, p. 228-229, $\mathrm{n}^{\circ}$ 20-21, pl. 37, 2.3.

46. Ibid., p. 238, nº 36, pl. 43,1.2. RICIS, 501/0123.

47. S. De Caro, Egittomania, p. 137, II, 88 et p. 143.

48. Ibid., p. 108, I, 68 ; p. 112, I, 77.

49. Ibid., p. 120 et 124 .

50. Ibid., p. 192, III, 65. M. De Vos, L'egittomania in pitture e mosaici. M. J.Versluys, Aegyptiaca Romana.

51. V. Tran Tam Tinh, Le culte d'Isis à Pompéi, p. 31-32.

52. Ibid., p. 41-49.

53. M. De Vos, L'egittomania in pitture e mosaici, p. 15-21. I. Bragantini, « Il culto di Iside e l'egittomania antica in Campania », p. 163-167.

54. G. J. F. Kater-Sibbes, M. J. Vermaseren, Apis II, p. 22, nº 300, pl. LXI.

55. M. De Vos, L'egittomania in pitture e mosaici, p. 15-21, $\mathrm{n}^{\circ}$ 9, pl. XV.

56. M. Mastroroberto, «Le sfingi nel giardino dipinto della Casa del Bracciale d'oro a Pompei », p. 188-190.

57. M. De Vos, L'egittomania in pitture e mosaici, p. 35-51.

58. L. Beaurin, « Les divinités isiaques dans les cultes domestiques », $n^{\circ} 23$.

59. Ibid. $n^{\circ}$ 25. G. J. F. Kater-Sibbes, M. J. Vermaseren, Apis II, p. 24-25, $n^{\circ}$ 306, pl. LXVI. 
60. V. Tran Tam Tinh, Le culte d'Isis à Pompéi, p. 173, n 138. E. A. Arslan, Iside, p. 132, V 52 et 53.

61. L. Beaurin, « Les divinités isiaques dans les cultes domestiques », $n^{\circ} 6$.

62. Ibid., $\mathrm{n}^{\circ} 13$ ter et quater. I. Bragantini, « Il culto di Iside e l'egittomania », p. 159-160, fig. 2.

63. S. De Caro, Egittomania, p. 186, III, 55.

64. S. De Caro, Egittomania, p. 174, III, 23. L. Beaurin, «Les divinités isiaques dans les cultes domestiques ", $\mathrm{n}^{\circ} 12$ et 12 ter.

65. Mercure de France, décembre 1721, p. 127.

\section{RÉSUMÉS}

En Égypte pharaonique, les animaux ne sont pas une espèce inférieure à l'homme ; ils ne sont pas non plus des dieux, mais ils peuvent entretenir avec le monde divin des relations privilégiées. Dès la fin de la République romaine, les cultes d'origine égyptienne se sont intégrés aux pratiques de Rome sous une forme spécifique appelée culte isiaque. Pour savoir si ces communautés pieuses adoraient réellement des "animaux sacrés", comme le pensaient la plupart des Grecs et des Romains, il convient d'étudier, outre les inscriptions, les représentations zoomorphes trouvées dans les principaux temples isiaques fondés sur le sol italien en analysant les transformations morphologiques qu'ils ont subies ainsi que la place qu'ils occupaient dans l'espace sacré et dans le cœur des fidèles.

\section{AUTEUR}

\section{MARIE-CHRISTINE BUDISCHOVSKY}

Maître de conférences honoraire en histoire ancienne, université de Rennes II 


\title{
Le serpent et le glaive : animaux et mise à mort dans les pratiques «magiques » de l'époque romaine
}

\author{
Thomas Galoppin
}

1 Un ouvrage en grec connu comme le Lapidaire " orphique » et daté du $\mathrm{II}^{\mathrm{e}}$ siècle de notre ère recense différentes pierres aux propriétés merveilleuses, dites «magiques $»^{1}$. Or, l'une de ces pierres, la «liparée ", permet d'attirer un serpent (drakôn) que trois jeunes hommes doivent capturer et découper en neuf tronçons à coups de glaives ${ }^{2}$. Les chairs de l'animal tué et découpé sont plongées dans un chaudron ou un trépied avec des épices, de l'huile et du vin, et mises à mijoter tandis que le commanditaire de cette action entonne des chants performatifs. En réponse à ces chants, un souffle divin descend sur les viandes reptiliennes et, au terme de cette cuisine et de sa consommation, le «magicien» repart détenteur d'une capacité divinatoire extraordinaire : il peut comprendre le langage des animaux ${ }^{3}$.

2 Le glaive des jeunes hommes du Lapidaire « orphique » fait écho au glaive que tire Médée (stricto Medea recludit ense) lorsqu'elle doit, selon Ovide, trancher la jugulaire du vieux Aeson pour remplacer son sang par une potion de rajeunissement ${ }^{4}$. Dans le roman d'Apulée, Méroé s'avance, une éponge et un glaive dénudé (spongiam et nudum gladium) dans les mains, vers l'homme dont elle s'apprête à trancher la gorge, machinant une mort à retardement spectaculaire ${ }^{5}$. Le glaive est un instrument de rituel dans les mains d'une sorcière ou dans celles des assistants du magicien, mais ce n'est pas la machaira, le couteau de boucher-cuisinier que l'on attend lors d'un sacrifice ${ }^{6}$. Au contraire, il s'agit d'une arme, un instrument de guerre ou de meurtre, et la différence est de taille. Il existe en effet deux conceptions du rite appelé " sacrifice ", celle qui met l'accent sur la mise à mort et celle qui le définit comme une "cuisine ". Le Lapidaire "orphique " n'emploie pas le terme de sacrifice (thusia) pour désigner ce traitement du serpent, dans lequel on distingue en premier lieu la mise à mort, ensuite la cuisine et enfin la consommation. Le divin n'intervient pas comme convive, recevant les viandes en offrande, mais comme un agent supérieur de la cuisine, en donnant de la puissance aux parts de viande au moment de la cuisson ${ }^{7}$. Le glaive fait donc la différence : il ne s'agit 
pas d'un sacrifice, mais d'une mise à mort rituelle qui participe d'une étape du processus culinaire, celle qui fait passer l'animal du statut d'être vivant à celui d'ingrédient. Néanmoins, cette mise à mort fabrique un ingrédient rituel et possède donc une pertinence symbolique propre à expliquer le rôle de l'animal dans le rituel.

3 L'intérêt de cette recette est de donner à voir le rite d'une " cuisine magique » en écho à la célèbre « cuisine du sacrifice » théorisée autour du rite supposé fondamental de la religion grecque ancienne, le sacrifice d'un animal ${ }^{8}$. Les théoriciens de la «cuisine du sacrifice » ont montré l'importance symbolique de ce rituel, consistant en un partage entre hommes et dieux qui marque la place intermédiaire des premiers, supérieurs aux animaux mais inférieurs aux dieux immortels. La force des études a été, dans cette perspective, de montrer qu'un rituel ancien fait sens en lui-même ${ }^{9}$, sans doctrine préalable - ce qui n'empêche pas des cercles philosophiques ou des poètes de théoriser en parallèle ${ }^{10}$. Pourtant, la critique adressée à ce modèle de la « cuisine du sacrifice » a précisément été qu'il a établi un modèle au risque de masquer la complexité du ritualisme grec antique et la diversité des comportements rituels de type « sacrificiel " ${ }^{11}$. La dépendance étroite entre la notion même de « sacrifice » et la mise à mort rituelle d'un animal demande à être relativisée. Plantes, gâteaux ou parfums sont également "sacrifiés " ${ }^{12}$. En outre, l'acte de la mise à mort ne paraît pas être tant au cœur de l'événement rituel appelé «sacrifice » (thusia), à moins qu'un terme n'oriente le regard vers telle modalité de mise à mort, mais c'est bien le dépôt des matières consacrées dans le feu de l'autel qui constitue le sacrifice pour ce qu'il est: une offrande, un smoke signal adressé aux dieux dans un acte de communication sociale ${ }^{13}$.

4 De nombreux textes témoignent de pratiques dites "magiques" qui impliquent de mettre à mort des animaux, d'en faire des amulettes, des encens, des onguents ou des potions ${ }^{14}$, mais il paraît intéressant de se pencher plus particulièrement sur quelques exemples tirés des papyrus grecs magiques $(P G M)^{15}$. Ces documents proviennent d'Égypte, où ils ont été écrits, pour l'essentiel, en grec aux III et $\mathrm{IV}^{\mathrm{e}}$ siècles de notre ère, et sont considérés comme le témoin majeur d'une "magie gréco-égyptienne " à l'époque romaine. Il s'agit surtout d'un ensemble de rituels dont ils donnent les prescriptions, nous permettant de constater l'existence de rituels construits de manière multiculturelle ${ }^{16}$. Il faut donc, pour étudier la ritualisation de l'animal dans un contexte " magique ", à la fois décentrer le regard par rapport à des modèles culturels comme celui du sacrifice grec et envisager le dialogue qui s'opère entre différentes façons de concevoir l'animal et le divin.

5 Je reviendrai d'abord sur la question de savoir s'il existe une particularité rituelle autorisant à parler de «sacrifice magique ». Puis, j'examinerai comment les «mises à mort rituelles " d'animaux font sens dans les rites des $P G M$, avant de voir comment celles-ci produisent des ingrédients dotés d'une qualité divine.

\section{Sacrifices « magiques »?}

6 Selon F. Graf, les sacrifices «magiques » se définissent par leurs écarts par rapport au modèle sacrificiel grec: loin d'être exécutés en commun, ils sont pratiqués à petite échelle, avec des petits animaux, surtout des volailles et des pigeons ${ }^{17}$. Toutefois, le vocabulaire des PGM étudié par A. Zografou reflète une conception du sacrifice comme offrande par le feu, indépendamment de la matière concernée ${ }^{18}$. De même, le matériel utilisé pour offrir le sacrifice est alternativement un autel (bômos) ou un brûle-parfum 
(thumiaterion), les deux mots étant interchangeables ${ }^{19}$. Le " sacrifice", dans l'écriture des PGM, est donc avant tout une offrande odorante, brûlée, qu'il s'agisse d'un encens, d'un parfum, de végétaux ou d'animaux. En ce qui concerne ces derniers, la mise à mort reste implicite derrière l'impératif prescriptif «sacrifie $»^{20}$. En une seule occasion, un couteau (machaira) est évoqué, et encore n'est-il présent que pour offrir la possibilité au dieu, momentanément incarné peut-être par la personne même du praticien qui en aura absorbé le Nom, de se faire à lui-même le sacrifice de la volaille ${ }^{21}$. Mais pour tous les autres cas, le lexique du sacrifice ne dit pas l'abattage de l'animal et focalise plutôt l'attention sur l'offrande de son corps. Ce rite sacrificiel, même s'il est exécuté à domicile, avec des volailles ou des pigeons, sur un brûle-parfum - en somme, miniaturisé2 ${ }^{2}$ - n'en est pas moins le prolongement dans l'exercice rituel du «magicien » des rites sacrificiels connus dans la plupart des traditions religieuses de la Méditerranée ancienne.

7 Il y a toutefois des moments dans les PGM où le "sacrifice " surprend. En effet, en parallèle et parfois en complément de l'offrande sacrificielle de volailles et pigeons blancs, respectant les valeurs symboliques des sacrifices habituels, positifs, les rituels font parfois appel à des procédures d'epanagkos. Ce terme, formé sur l'anagkê, " nécessité » ou " contrainte ", désigne un moyen de forcer la réaction d'une puissance déterminée. Or, dans ce cadre, les « sacrifices » ne relèvent plus d'une offrande positive d'animaux entiers, blancs et purs, mais de substances issues d'animaux signifiants: cervelles, sabots, poils, ossements, graisses, excréments, peaux, œufs, cœurs, sont prélevés sur des béliers noirs, des ibis, des vautours, des chèvres tachetées, des babouins, des chiens, parfois en boulettes préparées avec des encens, ou encore des scarabées, des musaraignes, broyés avec de l'armoise, de l'ail, de l'oignon. Si dans les autres sacrifices un animal blanc et pur est accompagné de bois odorants, d'aromates, et dégage pour le dieu un fumet agréable ${ }^{23}$, ces substances brûlées sur les autels à parfums dégageraient une odeur qui déplaît à la divinité. En outre, les espèces animales sont choisies selon des critères théologiques, parmi les animaux sacrés d'Égypte notamment ${ }^{24}$, mais répondent à une inversion volontaire des valeurs théologiques dans la mesure où, en Égypte, le sacrifice est entendu comme l'offrande d'un animal qui représente le désordre et non la divinité elle-même ${ }^{25}$. L'epanagkos offre ainsi au dieu un sacrifice en négatif, propre à susciter la colère de la puissance divine, donc sa réaction.

Ce serait alors un sacrifice "magique", du moins si l'on donne à l'adjectif une acception grecque, comme Porphyre lorsqu'il critique la contrainte exercée par les Égyptiens sur les dieux ${ }^{26}$. Plus exactement, aux yeux du philosophe, cette contrainte est une superstition, inefficace et malsaine. En revanche, pour le praticien de ces rituels gréco-égyptiens, il apparaît que ces offrandes de mauvais parfums sont, à part entière, des sacrifices, puisqu'il les désigne comme tels. La particularité de ces sacrifices n'est pas dans leur caractère étrange, qui dessine seulement dans les recettes une typologie entre sacrifices bienfaisants et sacrifices malfaisants ${ }^{27}$, mais dans la réduction, de l'animal entier et dénué de symbolisme propre, à l'ingrédient prélevé sur un animal dont l'espèce est signifiante au sein d'un système théorique. Cette matière doit posséder sa propre puissance et, de la sorte, ces rituels invitent à décentrer le regard, depuis le sacrifice, vers les rites de prélèvement de la matière rituelle, dans la mesure où c'est en amont que la matière animale reçoit la puissance rituelle qui en fait un ingrédient de la fabrique du divin. 


\section{Mises à mort rituelles}

C'est précisément parmi des rites préparatoires de la matière rituelle que l'on rencontre des mises à mort explicites dans les prescriptions des PGM. Ainsi, dans une recette de fumigation de type epanagkos sont inclus des musaraignes « déifiées » dans de l'eau, des scarabées "déifiés " avec de la graisse de chèvre vierge tachetée, des matières mortes de babouins et de chiens, ainsi qu'une écrevisse ${ }^{28}$. Le parfum est brûlé pour la Lune, dont on cherche à susciter l'ire contre une femme pour que celle-ci soit attirée chez le praticien ${ }^{29}$. Or ce terme « déifié " renvoie à d'autres actions rituelles où la déification, explicite (verbes $\dot{\varepsilon} \kappa \theta \varepsilon o \tilde{v} v$, $\dot{\alpha} \pi \circ \theta \varepsilon \circ \tilde{v} v^{30}$ ), se concrétise comme une immersion de l'animal dans un liquide ${ }^{31}$. Ainsi, un gecko est ailleurs maintenu « dans de l'huile de lys jusqu'à ce qu'il soit déifié »; par la suite, l'huile sert à consacrer un anneau de fer portant l'image d'Asclépios de Memphis (Imhotep) ${ }^{32}$. Dans un autre cas, c'est un faucon qui est « déifié » dans du lait de vache noire, pour ensuite être lui-même emmailloté et installé dans un petit sanctuaire miniature - un naos en bois de genévrier ${ }^{33}$. Le faucon déifié devient lui-même une image divine, honorée comme une forme d'Horus pour être le paredros, l'assistant du praticien ${ }^{34}$. Dans les deux cas, le rite de la déification prépare une matière qui sert à la fabrique d'une représentation du divin. Dans tous les cas, la mise à mort explicite est un geste rituel qui, contrairement à son rôle implicite dans le sacrifice, possède ici sa propre pertinence, le pouvoir de créer du divin.

Or, cette modalité de mise à mort rituelle découle du ritualisme égyptien ${ }^{35}$. Sa capacité à créer du divin est compréhensible dans la pensée religieuse égyptienne, dans la mesure où les animaux "sacrés », qui ne sont pas offerts en sacrifice, peuvent être mis à mort pour faire du divin. Faucons, ibis, boucs, crocodiles, bovins, chiens, chats, et d'autres, ont été mis à mort à une échelle presque industrielle dans l'Égypte grécoromaine pour être momifiés et offerts ensuite aux dieux ${ }^{36}$. La ritualisation de la mise à mort et du cadavre participe de la notion de divin dans l'Égypte ancienne, où est " dieu » (ntr) ce qui a été créé tel par le rituel ${ }^{37}$.

11 Cette conception particulière du divin n'a pas été bien comprise par les Grecs et les Romains qui ont fait du culte des animaux sacrés une marque négative de la religion égyptienne ${ }^{38}$. Mais dans les papyrus de « magie " grecs, cette « déification » des formes animales du divin s'adapte et s'associe à des formes grecques de pouvoir rituel. Dans le Papyrus Mimaut, la noyade d'un chat est accompagnée d'une parole rituelle qui s'adresse au dieu solaire en disant que sa «forme » est mise à mort par ses ennemis ${ }^{39}$. Le chat est ainsi, du fait de la parole prononcée, assimilé à une forme du dieu solaire, sa mise à mort devenant alors un événement quasi mythique ${ }^{40}$. L'animal "assassiné» rituellement est ensuite un daimôn propre à servir le praticien dans ses envoûtements pour deux raisons : d'une part parce que, selon un principe des envoûtements connus en Grèce ancienne, il est mort de mort violente, un état privilégié pour exécuter un envoûtement ${ }^{41}$; d'autre part parce que, selon le principe égyptien, il est la forme du dieu et son $b a$, c'est-à-dire une émanation du dieu à travers laquelle est possible la communication rituelle ${ }^{42}$.

12 Ainsi, une mise à mort explicite d'un animal doit être distinguée d'un rite proprement sacrificiel. C'est un acte performatif à part entière qui dote la matière animale d'une certaine qualité divine. Le contexte multiculturel dans lequel s'inscrivent les textes des PGM entraîne à cet égard deux effets : soit une incompréhension et un rejet de la part 
des auteurs grecs, soit une adaptation des praticiens qui associent à une ritualisation égyptienne de la mise à mort une symbolisation d'origine grecque concernant l'action des puissances funèbres.

\section{Ritualisation de la matière animale}

13 L'exemple des PGM permet non seulement de dissocier "mise à mort rituelle " et "sacrifice» dans l'analyse anthropologique et historique des rituels, mais encore d'envisager la catégorie des rites de "prélèvements». Celle-ci découle d'une comparaison entre la mise à mort rituelle d'un animal et la cueillette dite " magique " d'une plante. Parmi les documents qui témoignent de la pratique, en effet, on compte des rites qui accompagnent la cueillette des plantes utilisées en remèdes et amulettes, comme des incantations, des fumigations, le tracé de cercles, parfois en relation avec des correspondances astrologiques ${ }^{43}$. Dans le cas des animaux, la parole accompagnant le prélèvement de la matière illustre au mieux la performativité attendue de celle-ci. J'ai évoqué le cas de la noyade d'un chat, qui s'accompagne d'une parole rituelle affirmant que la forme du dieu est assassinée par ses ennemis et invitant le dieu à se manifester en réaction. Dans une autre recette, pour attirer une femme, le praticien doit capturer un gecko dans un endroit où sont momifiés les morts et le brûler sur des charbons ardents en disant :

«Gecko, gecko, comme le Soleil et tous les dieux t'ont haï, de même, fais que cette

femme haïsse son mari et que son mari la déteste définitivement. ${ }^{44}$

Le gecko est ensuite gardé pour un usage ultérieur. Il s'agit donc bien d'un rite de "prélèvement ", à savoir la capture et la mise à mort d'un animal pour fabriquer une puissance efficace. La parole rituelle oriente la performativité de l'action rituelle vers sa fonction, tout en conditionnant l'existence de l'animal par rapport à un univers mythique et divin, celui du dieu Soleil et du panthéon qui déteste le reptile et par là même institue sa fonctionnalité malveillante ${ }^{45}$.

Or, c'est également ce que font les incantations accompagnant la cueillette des plantes. Le médecin Galien atteste l'existence d'ouvrages sur les plantes qui conservent des récits de métamorphoses originelles et des prélèvements rituels ${ }^{46}$. D’après les prescriptions de cueillettes rituelles qui nous sont parvenues, les plantes sont adjurées de mettre en œuvre leur puissance naturelle en invoquant le nom des dieux ou de la terre dont elles sont issues et en faisant parfois usage d'historiolae, c'est-à-dire des récits mythiques performatifs ${ }^{47}$. Parfois les incantations interpellent la plante comme une divinité, sur un mode égyptien qui en fait l'émanation corporelle des dieux, avant que le cueilleur ne récupère une matière qui, du fait du rituel, est détenteur d'une qualité divine ${ }^{48}$. Des traces de cette même modalité rituelle de prélèvement et consécration de la matière, cette fois animale, sont encore visibles dans des textes postérieurs, comme les Cyranides, un " grimoire " dont l'écriture est postérieure au IV siècle de notre ère ${ }^{49}$. Le livre III est un répertoire d'animaux aériens : l'aigle y est présenté comme un oiseau de grande puissance, dont on prescrit une découpe bien particulière de sorte que toutes les matières de l'animal soient conservées et prêtes à l'usage ${ }^{50}$. Mais avant même cette découpe, l'oiseau doit être mis à mort, et une parole accompagne le geste :

«Ô aigle, ami de l'homme, je te sacrifie maintenant ( $v \tilde{v} v \theta u ́ \omega \sigma \varepsilon$ ) pour soigner toutes les souffrances. Je t'adjure (ó $\rho \kappa i ́ \zeta \omega \sigma \varepsilon)$ par le dieu du ciel et de la terre et par les quatre éléments, agis en chaque soin auquel je t'appliquerai. ${ }^{51}$ 


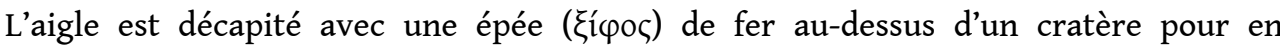
recueillir le sang, en même temps que l'on fait une fumigation de styrax et de miel. C'est ainsi que l'on retrouve le modèle de la mise à mort rituelle par l'épée, rituelle puisque créatrice de pouvoir, assimilée cette fois explicitement à un sacrifice sans pour autant être une offrande. On décèle ici un décalage du vocabulaire qui permet d'assimiler une mise à mort d'animal à un « sacrifice » païen.

Le schéma rituel était similaire dans le Lapidaire « orphique " : le serpent évoqué par une fumigation était mis à mort et découpé au moyen d'un glaive avant d'être véritablement cuisiné. Dans ce schéma, le traitement de l'animal n'est pas un sacrifice à proprement parler, mais les parts de l'animal, consacré du fait de sa mise à mort rituelle, sont cuites, assaisonnées et chargées d'un «souffle» divin que les incantations du «magicien » persuadent les dieux d'envoyer dans la viande ${ }^{52}$. Par ailleurs, le " souffle » ou pneuma est un terme très présent dans les PGM et certaines mises à mort rituelles peuvent avoir pour effet, à l'inverse, de transférer le souffle de l'animal au dieu. Ainsi, dans un rituel où le praticien fabrique l'image d'un Éros, il faut étouffer des oiseaux de sorte que leur souffle aille au dieu ${ }^{53}$. Le pneuma animal, principe vital, est ainsi l'ingrédient d'une animation de la statue divine ${ }^{54}$. C'est un exemple de la multiplicité des sens que peuvent avoir les mises à mort d'animaux, d'autant plus intéressant que ce geste rituel est explicitement distingué du sacrifice proprement dit des oiseaux, lequel n'intervient que dans un autre temps du rituel ${ }^{55}$.

Il n'était pas possible ici d'entrer dans le détail des prescriptions rituelles, des configurations symboliques et des transferts, adaptations et dialogues interculturels qu'offrent les PGM. Mais une observation des formulations prescriptives et des gestes rituels permet de proposer une règle méthodologique pour l'analyse plus générale des rituels impliquant les animaux dans l'Antiquité : distinguer «sacrifice " et «mise à mort rituelle » pour mieux tenir compte de la pertinence rituelle propre à une mise à mort, dont le caractère explicite peut être le signe d'une fonction indépendante. Celleci invite alors à considérer l'existence, à côté de la catégorie « rite de cueillette " pour les plantes, des mises à mort rituelles d'animaux qui constituent de la même manière des rites de " prélèvement » de matières dotées d'une qualité divine. La ritualisation de la mort animale, faisant débat dans un cadre interculturel, rejoint le sacrifice, autre pomme de discorde entre systèmes religieux, lorsqu'il s'agit de construire une forme de savoir rituel marginal, dit « magique ». On doit garder à l'esprit le rôle fondamental que jouent ces éléments de langage lorsqu'il s'agit de poser la question des animaux dans un système rituel qui met en jeu plus d'une altérité. 


\section{BIBLIOGRAPHIE}

ALPERS Klaus, « Untersuchungen zum griechischen Physiologus und den Kyraniden », Vestigiae Bibliae, 6, 1984, p. 13-87.

ASSMANN Jan, The Search for God in Ancient Egypt, Ithaca-Londres, Cornell University Press, 2001 (tr. de Ägypten: Theologie und Frömmigkeit einer frühen Hochkultur, 1984).

AUFRÈre Sydney H., « Le rituel de cueillette des herbes médicinales du magicien égyptien traditionnel d'après le Papyrus magique de Paris », dans Sydney H. AUfRÈrE (éd.), Encyclopédie religieuse de l'Univers végétal. Croyances phytoreligieuses de l'Égypte ancienne, vol. II, Montpellier, Publications de l'Université Montpellier III, 2001, p. 331-362.

BAIN David, « 'Trading Birds': an unnoticed use of $\pi \alpha \tau \varepsilon$ ( $\omega$ (Cyranides, 1. 10.27, 1.19.9) », dans Elizabeth M. CRAIK (éd.), Owls in Athens: essays on Classical Subjects presented to Sir Kenneth Dover, Oxford, Clarendon Press, 1990, p. 295-304.

BERTHIAUME Guy, Les rôles du mágeiros : études sur la boucherie, la cuisine et le sacrifice dans la Grèce ancienne, Leyde-Montréal, Brill-Presses Universitaires de Montréal, 1982.

BETZ Hans D. (éd.), The Greek Magical Papyrus in Translation. Including the Demotic Spells, ChicagoLondres, University of Chicago Press, 1992 (1 ère éd. 1986).

BOUANICH Catherine, « Mise à mort rituelle de l'animal, offrande carnée dans le temple égyptien », dans Stella GEORGOUDI, Renée KOCH PIETTRE, Francis SCHMIDT (dir.), La cuisine et l'autel. Les sacrifices en questions dans les sociétés de la Méditerranée ancienne, Turnhout, Brepols, p. 149-162.

CHARRON Alain, « Les animaux et le sacré dans l'Égypte tardive. Fonctions et significations », thèse de doctorat, Paris, EPHE, IV ${ }^{\mathrm{e}}$ section, 1996.

CHARRON Alain, « Les animaux sacralisés », dans F. DUNAND et R. LICHTENBERG, Des animaux et des hommes : une symbiose égyptienne, Monaco-Paris, Éd. du Rocher, 2005, p. 165-200.

CHARRON Alain, « Massacres d'animaux à la Basse Époque », Revue d'Égyptologie, 41, 1990, p. 209-213.

CIRAOlo Leda J., "Supernatural Assistants in the Greek Magical Papyri », dans Marvin MEYER, Paul MIRECKI (éd.), Ancient Magic and Ritual Power, $2^{\mathrm{e}}$ éd., Boston Leyde, Brill, 2001 (1 ${ }^{\text {ère }}$ éd. 1995), p. 279-295.

DANIEL Robert W. et MALTOMINI Franco, Supplementum Magicum, Opladen, Westdeutscher Verlag, 1990-1992, 2 vol.

DELATTE Armand, Herbarius. Recherches sur le cérémonial usité chez les Anciens pour la cueillette des simples et des plantes magiques, $3^{\mathrm{e}}$ éd., Bruxelles, Académie Royale de Belgique, $1961^{3}$.

DÉTIENNE Marcel et VERNANT Jean-Pierre (éd.), La cuisine du sacrifice en pays grec, Paris, Gallimard, 1979.

DIELEMAN JacCo, MOYER Ian, « Miniaturization and the Opening of the Mouth in a Greek Magical Text (PGM XII.270-350) », Journal of Ancient Near Eastern Religions, 3, 2003, p. 47-72.

DIELEMAN Jacco, Priests, Tongues, and Rites: The London-Leiden Magical Manuscripts and Translation in Egyptian Ritual (100-300 CE), Leyde-Boston, Brill, 2005.

DUCOURTHIAL Guy, Flore magique et astrologique de l'Antiquité, Paris, Belin, 2003. 


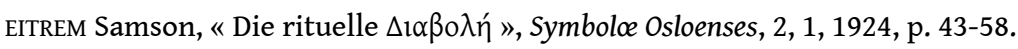

FARAONE Christopher A., " The collapse of celestial and chthonic realms in a late antique ‘Apollonian invocation' (PGM I 262-347) », dans Ra'anan BOUSTAN, Annette YOSHIKO REED (éd.), Heavenly Realms and Earthly Realities in Late Antique Religions, Cambridge, Cambridge University Press, 2004, p. 213-232.

FRANKFURTER David, « Egyptian Religion and the Problem of the Category 'Sacrifice' », dans Jennifer W. KNUST, Zsuzsanna VÁRHELYI (éd.), Ancient Mediterranean Sacrifice, Oxford, Oxford University Press, p. 75-93.

FRANKFURTER David, « Narrating Power: The Theory and Practice of the Magical Historiola in Ritual Spells », dans Marvin MEYER, Paul MIRECKI (éd.), Ancient Magic and Ritual Power, $2^{\mathrm{e}}$ éd., Boston Leyde,

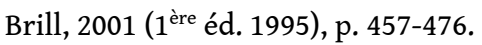

GALOPPIN Thomas, « How to understand the voices of animals? ", dans Patricia A. JOHNSTON, Attilio MASTROCINQUE, Sophia PAPAIOANNOU (éd.), The Animals in Greek and Roman Religion and Myth. Proceedings of the Symposium Grumentinum, Grumento Nova (Potenza), 5-7 June 2013, Cambridge, Cambridge Scholars Publishing, 2016, p. 141-167.

GRAF Fritz, « Magical Sacrifice (abstract) », dans Robin HÄGG, Brita ALROTH (éd.), Greek Sacrificial Ritual, Olympian and Chthonian, Stockholm, Åströms Förlag, 2005, p. 71 (avec discussion, p. 71-73).

GRAF Fritz, « One generation after Burkert and Girard: where are the great theories? », dans Christopher A. FARAONE, Fred S. NAIDEN (éd.), Greek and Roman Animal Sacrifice. Ancient Victims, Modern Observers, Cambridge-New York, Cambridge University Press, 2012, p. 32-51.

GRAF Fritz, La magie dans l'Antiquité gréco-romaine. Idéologie et pratique, Paris, Les Belles Lettres, 1994.

GRIFFITH Francis L., « Herodotus II, 90: Apotheosis by Drowning », Zeitschrift für Ägyptische Sprache und Altertumskunde, 46, 1909, p. 132-134.

HALLEUX Robert, schamP Jacques, Les lapidaires grecs, Paris, Les Belles Lettres, 1985.

HERMANN Arnold, “Ertrinken/Ertränken”, Lexikon der Ägyptologie, II, 1977, col. 17-19.

HERRERO VALDÉS Flor, « $\Delta \mathrm{l} \alpha \beta$ $\beta$ ń como recurso de la invocación en la magia greco-egipcia », MHNH, 11, 2011, p. 305-318.

HORNUNG Erik, Les dieux de l'Égypte. Le Un et le Multiple, Paris-Monaco, Éd. du Rocher, 1986.

IKRAM Salima (éd.), Divine creatures: animal mummies in Ancient Egypt, Le Caire-New York, The American University in Cairo Press, 2005.

IKRAM Salima, Choice cuts: meat production in Ancient Egypt, Louvain, Peeters, 1995.

JOHNSTON Sarah I., « Le sacrifice dans les papyrus magiques », dans Alain MOREAU, JeanClaude TURPIN (dir.), La Magie, vol. II, Montpellier, Publications de l'Université Montpellier III, 2000, p. 19-36 = « Sacrifice in the Greek Magical Papyri » dans Marvin MEYER, Paul MIRECKI (éd.), Magic and Ritual in the Ancient World, Leyde-Boston-Cologne, Brill, 2002, p. 344-358.

JOHNSTON Sarah I., Restless Dead: Encounters Between the Living and the Dead in Ancient Greece, Berkeley, University of California Press, 1999.

JOUANNA Jacques, « Médecine rationnelle et magie : le statut des amulettes et des incantations chez Galien », Revue des études grecques, 124, 1, 2011, p. 47-77.

KAIMAKIS Dimitri, Die Kyraniden, Meisenhem am Glan, Anton Hein, 1976. 
KEARNS Emily, «'O $\lambda_{1} \beta \alpha v \omega \tau o ̀ \varsigma ~ \varepsilon \dot{\sigma \varepsilon \beta \varepsilon ́ \varsigma ~ \kappa \alpha i ̀ ~ \tau o ̀ ~ \pi o ́ \pi \alpha v o v: ~ t h e ~ r a t i o n a l e ~ o f ~ c a k e s ~ a n d ~ b l o o d l e s s ~}$ offerings in Greek sacrifice », dans Vinciane PIRENNE-DELFORGE, Francesca PRESCENDI (éd.), « Nourrir les dieux? » Sacrifice et représentation du divin, Liège, CIERGA, 2011, p. 89-103.

LINCOLN Bruce, « From Bergaigne to Meuli: how animal sacrifice became a hot topic » dans Christopher A. FARAONE, Fred S. NAIDEN (éd.), Greek and Roman Animal Sacrifice. Ancient Victims, Modern Observers, Cambridge-New York, Cambridge University Press, 2012, p. 13-31.

MEEKS Dimitri, « Notion de "dieu” et structure du panthéon dans l'Égypte ancienne », Revue de l'histoire des religions, 205, 4, 1988, p. 425-446.

MEHL Véronique, « Parfums de fêtes. Usage de parfums et sacrifices sanglants », dans Véronique MEHL, Pierre BRULÉ (dir.), Le sacrifice antique. Vestiges, procédures et stratégies, Rennes, Presses Universitaires de Rennes, 2008, p. 167-186.

MORENZ Siegfried, La religion égyptienne. Essai d'interprétation, Paris, Payot, 1962 (tr. de Aegyptische Religion, Stuttgart, W. Kohlhammer, 1960).

NAIDEN Fred S., Smoke Signals for the Gods. Ancient Greek Sacrifice from the Archaic through Roman Periods, Oxford-New York, Oxford University Press, 2013.

PREISENDANZ Karl (éd.), Papyri Graecae Magicae. Die griechischen Zauberpapyrus, $2^{2}$ éd., Stuttgart, Teubner, 1973-1974 (1 ${ }^{\text {ère }}$ éd., Leipzig-Berlin, 1928-1931), 2 vol.

PRESCENDI Francesca, Décrire et comprendre le sacrifice : les réflexions des Romains sur leur propre religion à partir de la littérature antiquaire, Stuttgart, Franz Steiner, 2007.

PROST Francis, «L'odeur des dieux en Grèce ancienne. Encens, parfums et statues de culte », dans Liliane BODIOU, Dominique FRÈrE et Véronique MEHL (dir.), Parfums et odeurs dans l'Antiquité, Rennes, Presses Universitaires de Rennes, 2008, p. 97-103.

QUAEGEBEUR Jan, « L'autel-à-feu et l'abattoir en Egypte tardive », dans QUAEGEBEUR Jan (éd.), Ritual and Sacrifice in the Ancient Near East, Louvain, Peeters, 1993, p. 329-353.

QUAEGEBEUR Jan, « Notes sur l'Herêsieion d'Antinoé », Zeitschrift für Papyrologie und Epigraphik, 24, 1977, p. 246-250.

RIVES James B., « The Theology of Animal Sacrifice in the Ancient Greek World. Origins and developments ", dans Jennifer W. KNUST, Zsuzsanna VÁRHELYI (éd.), Ancient Mediterranean Sacrifice, Oxford, Oxford University Press, 2011, p. 187-202.

SCHEID John, « Roman animal sacrifice and the system of being », dans Christopher A. FARAONE, Fred S. NAIDEN (éd.), Greek and Roman Animal Sacrifice. Ancient Victims, Modern Observers, CambridgeNew York, Cambridge University Press, 2012, p. 84-95.

SCHEID John, « Les offrandes végétales dans les rites sacrificiels des Romains », dans Vincianne PIRENNE-DELFORGE, Francesca PRESCENDI (éd.), « Nourrir les dieux? » Sacrifice et représentation du divin, Liège, CIERGA, 2011, p. 105-115.

SCHEID John, Quand faire, c'est croire. Les rites sacrificiels des Romains, Paris, Aubier, 2005. SCIBILIA Anna, « Supernatural Assistance in the Greek Magical Papyri: The figure of the parhedros ", dans Jan N. BREMMER, Jan R. VEENSTRA (éd.), The Metamorphosis of Magic from Late Antiquity to the Early Modern Period, Louvain-Paris-Dudley, Peeters, 2002, p. 71-86.

SMELIK Klaas A. D. et Emily A. HEMELRIJK, " "Who knows not what monsters demented Egypt worships?" Opinions on Egyptian animal worship in Antiquity as part of the ancient conception of Egypt », Aufstieg und Niedergang der römischen Welt, II, 17, 4, 1984, p. 1852-2000. 
SMITH Jonathan Z., « Trading Places », dans Marvin MEYER et Paul MIRECKI (éd.), Ancient Magic and

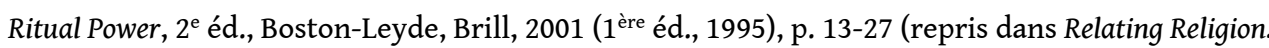
Essays on the Study of Religion, Chicago-Londres, University of Chicago Press, 2004, p. 215-229).

SPIEGELBERG Wilhelm, « Zu dem Ausdruck ḥsj 'Eøiñऽ' », Zeitschrift für Ägyptische Sprache und Altertumskunde, 53, 1917, p. 124-125.

VAN STRATEN FOLKERT T., « Ancient Greek Animal Sacrifice: Gift, Ritual Slaughter, Communion, Food Supply, or What? Some Thoughts on Simple Explanations of a Complex Ritual », dans Stella GEORGOUDI, Renée KOCH PIETTRE, Francis SCHMIDT (dir.), La cuisine et l'autel. Les sacrifices en question dans les sociétés de la Méditerranée ancienne, Turnhout, Brepols, 2005, p. 15-29.

VERBEKE Gérard, L'évolution de la doctrine du pneuma, du stoïcisme à S. Augustin. Étude philosophique, Louvain-Paris, Desclée De Brouwer, 1945.

WAEGEMAN Maryse, « The gecko, the hoopoe... and lice ", D'antiquité classique, 53, 1984, p. 218-225. WAGNER Guy, « Le concept de "hsy" à la lumière des inscriptions grecques ", dans Willy CLARYSSE, Anton SCHOOR, Harco WILLEMS (éd.), Egyptian religion. The last thousand years, II, Louvain, Peeters, 1998, p. 1073-1078.

ŽABKAR Louis V., A Study of the Ba Concept in Ancient Egytian Texts, Chicago, University of Chicago Press, 1968.

ZACCAGNINO Cristiana, Il thymiaterion nel mondo greco. Analisi delle fonti, tipologia, impieghi, Rome, «L'Erma » di Bretschneider, 1998.

ZAGO Michela, « Le nom physique du dieu », dans Michel TARDIEU, Anna VAN DEN KERCHOVE, Michela ZAGO (éd.), Noms barbares, vol. I : Formes et contextes d'une pratique magique, Turnhout, Brepols,

2013, p. 205-223.

zografou Athanassia, « Des sacrifices qui donnent des ailes : PGM XII, 15-95 », dans

Vincianne PIRENNE-DELFORGE, Francesca PRESCENDI (éd.), « Nourrir les dieux ? » Sacrifice et

représentation du divin, Liège, CIERGA, 2011, p. 158-159.

zografou Athanassia, Papyrus Magiques Grecs : le mot et le rite. Autour des rites sacrificiels, Ioannina, Université de Ioannina, 2013.

\section{NOTES}

1. Il a été édité et traduit aux Belles Lettres en 1985 par R. Halleux et J. Schamp, Les lapidaires grecs.

2. Ibid., Lapidaire " orphique», 698-744.

3. Ibid., 745-747.

4. Ovide, Les métamorphoses, 7, 285-286.

5. Apulée, Les métamorphoses, 1, 12-19.

6. G. Berthiaume, Les rôles du mágeiros.

7. T. Galoppin, « How to understand the voices of animals? ».

8. M. Détienne, J.-P. Vernant (éd.), La cuisine du sacrifice en pays grec.

9. J. Scheid, Quand faire, c'est croire. 
10. F. Prescendi, Décrire et comprendre le sacrifice ; J. B. Rives, « The Theology of Animal Sacrifice in the Ancient Greek World. Origins and developments ».

11. B. Lincoln, «From Bergaigne to Meuli: how animal sacrifice became a hot topic »;

F. Graf, « One generation after Burkert and Girard: where are the great theories? ».

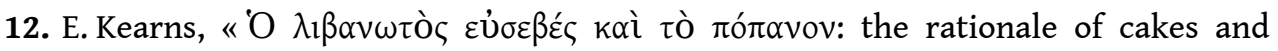
bloodless offerings in Greek sacrifice »; J. Scheid, « Les offrandes végétales dans les rites sacrificiels des Romains »; J. Scheid, "Roman animal sacrifice and the system of being ".

13. F.T.Van Straten, "Ancient Greek Animal Sacrifice: Gift, Ritual Slaughter, Communion, Food Supply, or What? Some Thoughts on Simple Explanations of a Complex Ritual »; F. S. Naiden, Smoke Signals for the Gods.

14. Voir à ce titre à l'inventaire de Pline l'Ancien, Histoire naturelle, 28-30 et 32.

15. Édition : K. Preisendanz (éd.), Papyri Graecae Magicae. Die griechischen Zauberpapyrus; R.W. Daniel et F. Maltomini, Supplementum Magicum. Traduction anglaise dans H. D. Betz (éd.), The Greek Magical Papyrus in Translation. Including the Demotic Spells.

16. J. Z. Smith, «Trading Places », p. 21; J. Dieleman, Priests, Tongues, and Rites.

17. F. Graf, « Magical Sacrifice (abstract) », p. 71 ; F. Graf, La magie dans l'Antiquité grécoromaine, p. 258-259.

18. A. Zografou, Papyrus Magiques Grecs : le mot et le rite, p. 25-54.

19. C. Zaccagnino, Il thymiaterion nel mondo greco; J. Quaegebeur, "L'autel-à-feu et l'abattoir en Égypte tardive ».

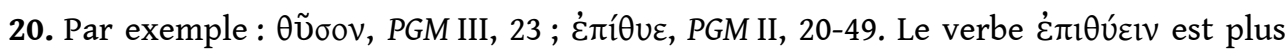
fréquent dans les $P G M$ que $\theta$ víviv.

21. PGM XIII, 372-376. M. Zago, « Le nom physique du dieu ».

22. J. Z. Smith, « Trading Places », p. 23-27 ; S.I. Johnston, « Le sacrifice dans les papyrus magiques ".

23. F. Prost, «L'odeur des dieux en Grèce ancienne. Encens, parfums et statues de culte »; V. Mehl, « Parfums de fêtes. Usage de parfums et sacrifices sanglants ».

24. A. Charron, « Les animaux sacralisés».

25. D. Frankfurter, "Egyptian Religion and the Problem of the Category 'Sacrifice' »; C. Bouanich, "Mise à mort rituelle de l'animal, offrande carnée dans le temple égyptien ».

26. Porphyre, Lettre à Anébon, fr. 64 = Eusèbe, Préparation évangélique, 5, 10.3-5.

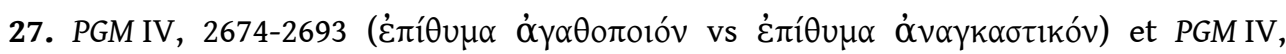

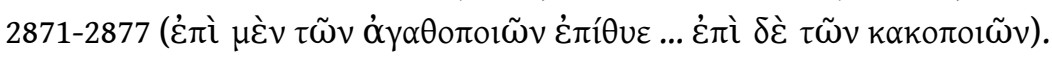

28. PGM IV, 2456-2467.

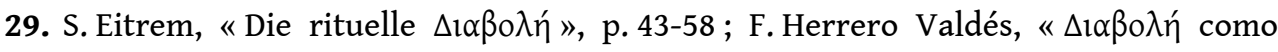
recurso de la invocación en la magia greco-egipcia ».

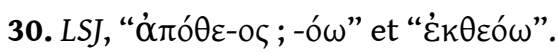

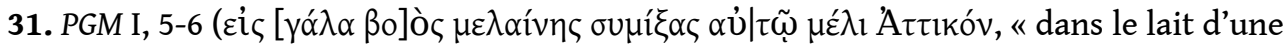

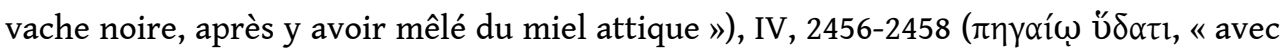

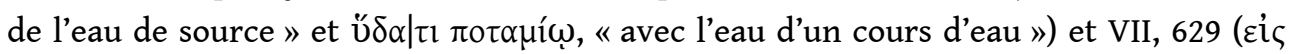
kpívivov, «dans de l'huile de lys »). D'après J. Quaegebeur, " Notes sur l'Herêsieion 
d'Antinoé ", p. 246-250, la déification dépend du séjour du corps en immersion plutôt que de la noyade elle-même.

32. PGM VII, 628-642.

33. PGM I, 3-10.

34. L. J. Ciraolo, "Supernatural Assistants in the Greek Magical Papyri », p. 279-295; A. Scibilia, "Supernatural Assistance in the Greek Magical Papyri: The figure of the parhedros".

35. F. L. Griffith, « Herodotus II, 90: Apotheosis by Drowning », p. 132-134 (haj = noyé ou victime des crocodiles); W. Spiegelberg, « Zu dem Ausdruck ḥsj 'Eøı̃̃ $\varsigma$ '», p. 124-125; A. Hermann, «Ertrinken/Ertränken », col.17-19; J. Quaegebeur, «Notes sur l'Herêsieion d'Antinoé ", p. 246-250 ; G. Wagner, « Le concept de "hsy" à la lumière des inscriptions grecques $»$.

36. A. Charron, « Massacres d'animaux à la Basse Époque »; A. Charron, «Les animaux et le sacré dans l'Égypte tardive »; S. Ikram (éd.), Divine creatures.

37. E. Hornung, Les dieux de l'Égypte, p. 53 ; D. Meeks, « Notion de "dieu" et structure du panthéon dans l'Égypte ancienne », p. 425-446.

38. K.A.D. Smelik et E.A. Hemelrijk, «"Who knows not what monsters demented Egypt worships?" Opinions on Egyptian animal worship in Antiquity as part of the ancient conception of Egypt ». Cf. Jamblique, Réponse à Porphyre, 5, 8.

39. PGM III, 1-5.

40. Sur la performativité du «mythe» dans l'incantation, cf. D. Frankfurter, « Narrating Power: The Theory and Practice of the Magical Historiola in Ritual Spells ».

41. S.I. Johnston, Restless Dead. On retrouve en PGM XII, 107-108 un « chat entièrement

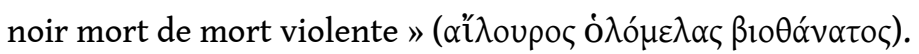

42. J. Assmann, The Search for God in Ancient Egypt, p. 43 ; S. Morenz, La religion égyptienne, p. 209-210 ; L.V. Žabkar, A Study of the Ba Concept in Ancient Egytian Texts, p. 124-143. Le Soleil est en outre un dieu qui peut établir la communication entre monde des vivants et mondes des morts dans la mesure où il passe régulièrement de l'un à l'autre: C.A. Faraone, "The collapse of celestial and chthonic realms in a late antique "Apollonian invocation" (PGM I 262-347)».

43. A. Delatte, Herbarius; G. Ducourthial, Flore magique et astrologique de l'Antiquité, p. $139-180$.

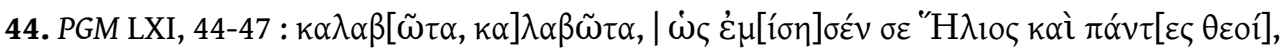

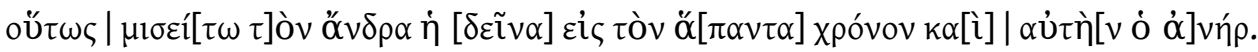

45. La mythologie grecque attribue la métamorphose originelle d'un homme en gecko à Déméter à Éleusis, en insistant sur la damnation perpétuelle de l'animal : Nicandre, ap.

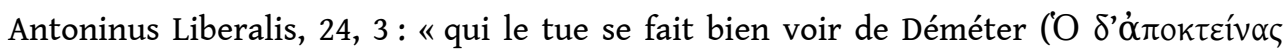

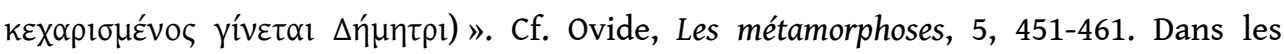
savoirs naturalistes, le gecko est considéré comme un poison: Nicandre, Thériaques, 483-487, cf. M. Waegeman, « The gecko, the hoopoe... and lice».

46. Galien, Les médicaments simples, Préambule du livre 6 [Kühn, 11, p. 792-794]. Cf. J. Jouanna, « Médecine rationnelle et magie : le statut des amulettes et des incantations chez Galien ». 
47. PGM IV, 285-295 ; Alexandre de Tralles, 12 [Puschmann, II, p. 585]; Traité sur la pivoine : CCAG 8, 1, p. 187-193 et 8, 2, p. 167-171.

48. PGM IV, 2967-3006 ; S. H. Aufrère, « Le rituel de cueillette des herbes médicinales du magicien égyptien traditionnel d'après le Papyrus magique de Paris ».

49. D. Kaimakis, Die Kyraniden; K. Alpers, «Untersuchungen zum griechischen Physiologus und den Kyraniden », suivi par D. Bain, " "Trading Birds": an unnoticed use of $\pi \alpha \tau \varepsilon \dot{\omega} \omega$ (Cyranides, 1. 10.27, 1.19.9)».

50. Cyranides, 3, 1.6-36.

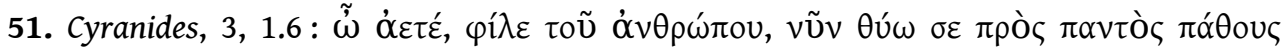

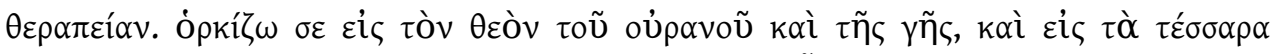

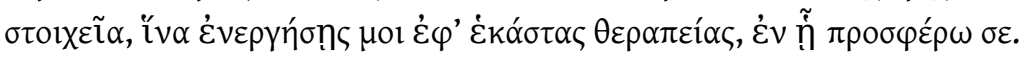

52. Lapidaire " orphique», 724-730.

53. PGM XII, 30-35. A. Zografou, «Des sacrifices qui donnent des ailes : PGM XII, 15-95 », repris dans A. Zografou, Papyrus Magiques Grecs : le mot et le rite, p. 101-121.

54. G. Verbeke, L'évolution de la doctrine du pneuma, p. 321-337; J. Dieleman et I. Moyer, "Miniaturization and the Opening of the Mouth in a Greek Magical Text (PGM XII. 270-350)».

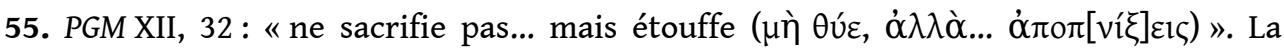
strangulation est en Égypte le mode courant de mise à mort des volatiles avant leur dépôt pour offrande, S. Ikram, Choice Cuts, p. 57-61. Ici, cette mise à mort a été chargée d'une pertinence rituelle propre.

\section{RÉSUMÉS}

À partir de prescriptions rituelles d'époque romaine, communément considérées comme «magiques», il est possible de proposer une approche de la mise à mort des animaux indépendamment de la notion de "sacrifice ». Les documents de la pratique témoignent d'une modalité de cuisine, proche des cueillettes rituelles de plantes, dans laquelle la mise à mort d'un animal, participe pleinement de la fabrique d'une puissance divine en prélude à l'élaboration de recettes qui nécessitent des ingrédients animaux. Cette approche méthodologique permet d'aborder le pouvoir rituel des corps animaux.

\section{AUTEUR}

\section{THOMAS GALOPPIN}

Docteur en histoire des religions dans le monde romain 


\title{
Entre hommes et dieux : le statut de l'animal et la notion d'hybride dans l'Égypte ancienne
}

\author{
Nadine Guilhou
}

1 On connaît la place de l'animal dans l'Égypte ancienne. Nombre d'espèces ont été observées et représentées avec beaucoup de finesse, témoignant d'une parfaite connaissance du milieu. Signalons tout de suite que, comme cela a été noté à maintes reprises, il n'existe pas en égyptien de terme générique pour désigner les animaux comme il en existe pour les dieux (netjerou) et les hommes (remetj). Les diverses listes évoquant les êtres vivants mettent en effet souvent en regard des hommes et des dieux plusieurs catégories d'animaux, distinguées tant par leurs caractéristiques essentielles que par leur habitat. Par exemple, sur le papyrus magique connu sous le nom de Ruse d'Isis, Rê se désigne lui-même comme celui :

«Qui a fait le ciel, la terre, l'eau, le souffle de vie, la flamme/le feu, les dieux, les hommes, les hardes du désert, les troupeaux, êtres rampants, les oiseaux et les poissons. $»^{1}$

2 C'est cependant ce terme âout, ici traduit par « hardes du désert » par opposition aux «troupeaux », animaux domestiques, qui suivent, qui est le plus proche équivalent de notre terme générique pour «animaux $»^{2}$. Dans la graphie, l'élément commun, susceptible d'être utilisé pour l'ensemble de la gent animale, est le déterminatif de la peau de mammifère, que l'on pourra trouver pour les différents êtres vivants, des mammifères aux insectes et êtres minuscules tels que puce, pou ou scarabée, à l'exclusion des hommes'.

3 Les listes qui constituent nos sources principales pour cette réflexion proviennent d'hymnes religieux, de textes magiques, funéraires, cosmogoniques, rituels, évoquant plus ou moins explicitement la création par le démiurge. Si l'on s'en tient aux êtres vivants, on peut espérer y trouver trois informations : qui est créé, selon quel mode et dans quel ordre, ces deux dernières données devant permettre de définir le statut des différentes créatures. 


\section{La création des êtres vivants}

$4 \quad$ Il ressort des réflexions faites en introduction à propos des termes génériques que les listes se limitent rarement aux trois qui nous intéressent, à savoir hommes, dieux, animaux, mais énumèrent toute une série d'êtres, distingués en fonction de différents critères, comme dans l'exemple donné ci-dessus. De même :

«Il a façonné homme, petit et gros bétail, ce qui vole et se pose, poissons et tout reptile. $»^{4}$

Ces listes complexes permettent d'esquisser une, ou plutôt des, classification(s) du vivant, comme l'ont fait P. Vernus et J. Yoyotte et en dernier lieu D. Meeks ${ }^{5}$. Inversement, nombre de textes cosmogoniques se bornent à la création des dieux et des hommes, plus souvent dans l'ordre inverse, des hommes et des dieux ${ }^{6}$. Hommes et dieux sont présentés au même titre comme des émanations (théologie héliopolitaine) ou des créations (Khnoum modeleur dans son temple d'Esna) du démiurge :

«C'est de ses yeux que les hommes sont sortis, (tandis que) les dieux venaient à

l'existence sur sa bouche.»

Un autre hymne présente une légère variante :

«C'est de ses yeux divins que les hommes sont sortis, et les dieux de sur sa bouche. $»^{7}$

Ou encore :

"Il a fait les hommes de ses deux yeux divins, il a vomi les dieux de sa bouche. ${ }^{8}$

Quelques documents mentionnent cependant à leurs côtés, et toujours après eux, les animaux, comme le naos d'Ismaïlia, à trois reprises :

« Ne peuvent y entrer (dans le temple que vient de bâtir Chou) ni dieux, ni déesses, ni hommes ni animaux pour voir ses secrets. »

«Ses plans n'ont pas été vus ni décidés par les dieux, les déesses, les hommes, les animaux. »

«Cependant, la Majesté de Geb apparut (...) sur le trône de son père Chou, en tant que roi des dieux, des déesses, des hommes et des animaux, seigneur du ciel, de la terre, de la Douat, du Noun, des montagnes, des vents, du Grand-Vert (= la mer), des pierres. $»^{9}$

Ou encore à Esna, célèbre pour son temple :

« Tu (Khnoum) es le maître d'Esna (...) qui a tourné les dieux et façonné les hommes et les animaux. $»^{10}$

Ici, hommes et animaux semblent être regroupés par rapport aux dieux, mais ce n'est pas le cas dans cet autre passage :

«Tu as tourné les hommes, tu as fait les dieux, tu as façonné petit et gros bétail. »11

11 L'ordre ne semble donc pas être un critère pertinent, la seule constante étant la place des animaux en troisième position dans les rares listes qui se bornent à ces trois catégories d'êtres, tandis que les listes complexes vont, pour les animaux, du plus gros au plus petit, soit decrescendo.

\section{Modes de création}

12 Les modes de création pourraient constituer un critère supplémentaire. Ils dépendent, au moins à l'origine, du système théologique dans lequel ils s'insèrent, même si les images sont aussi utilisées à propos d'autres dieux créateurs, comme autant de 
métaphores. L'apparition des hommes est basée sur un jeu de mots créateur, fondé sur l'assonance entre remetj, hommes, et remy, pleurer/larmes, alors que celle des dieux ne repose sur aucune similitude. Les uns comme les autres sont issus du liquide créateur, fondement de toute vie dans la pensée égyptienne. Il en est de même pour des créations secondaires, comme les végétaux et les minéraux, dont certains sont nés du sang, de la sueur ou de la salive du démiurge, mais, curieusement, pas pour les animaux, dont le mode de création n'est pas véritablement explicité. Au-delà de la variété des termes employés (pleurer, vomir, cracher et expectorer ${ }^{12}$ ), prime ce qui est issu de la bouche du démiurge, " ce qui est sur sa bouche ", c'est-à-dire la parole, ailleurs personnifiée par Hou, le Verbe créateur ${ }^{13}$.

Ce liquide peut être aussi le sperme du démiurge qu'il obtient par masturbation, expression de la bisexualité originelle du créateur, au point que Neith, à Esna, est qualifiée de "Taureau féminin $»^{14}$, même si son mode de création est l'énoncé par la parole, produit de la pensée et de la connaissance. L'identité de ces modes de création, qui ne sont qu'autant de métaphores transcrivant une même réalité, est d'ailleurs clairement exprimée sur la Pierre de Chabaka ${ }^{15}$, qui développe la cosmogonie memphite, selon laquelle « l'Ennéade (de Ptah) est devant lui, dents et lèvres, (c'est-àdire) semence et mains d'Atoum ». À Esna également, en raison de son apparence de bélier, incarnant la force génésique, on pourra dire de Khnoum qu'il est «celui qui a enfanté les dieux et engendré les déesses ${ }^{16}$.

Cependant, Khnoum est aussi le dieu potier qui modèle l'embryon dans la matrice. Le mode de création, à Esna, va donc souvent renvoyer à son instrument de prédilection, le tour de potier, et au travail de l'argile, modelage ou façonnage, comme dans les exemples précédemment cités. Quelques passages laisseraient pourtant penser qu'hommes, dieux et animaux ne font pas l'objet d'un traitement identique. Ainsi, il est dit qu' « il a tourné les hommes et mis au monde les dieux » ${ }^{17}$. Ailleurs, il est celui « qui a engendré dieux et déesses, (...) qui a tourné les hommes et les dieux $»^{18}$, ce qui pourrait signifier que les dieux peuvent être tournés comme les hommes mais que, inversement, ces derniers ne sont pas engendrés par le créateur, à la différence des dieux et déesses. De même, deux des passages cités ci-dessus (Esna III, 378, 9-10), qui sont en fait consécutifs, font état d'un mode de création différencié comparable :

«Tu es le maître d'Esna (...) qui a tourné les dieux et façonné les hommes et les animaux (...), le bélier (...) qui a mis au monde les dieux et engendré les déesses. »

Cependant, plus qu'un traitement différent réservé aux dieux, aux hommes et aux animaux, ce passage évoque deux apparences différentes de la divinité, potier d'une part, qui tourne et façonne, bélier d'autre part, qui engendre, la mise au monde renvoyant à la bisexualité originelle du démiurge. Cette analyse est confirmée par un autre passage, selon lequel Khnoum est celui :

"Qui a tourné les hommes, mis au monde les dieux, engendré l'Ennéade, engendré tout être (litt. : chose) vivant. $»^{19}$

En conclusion, le plus souvent, à Esna, les hommes sont faits au tour, selon un mode de création spécifique à Khnoum, les dieux enfantés ou engendrés, les animaux façonnés. Mais les dieux peuvent être tournés et les hommes façonnés ; hommes et dieux peuvent être tournés. Et le dernier exemple semble prouver que tout être vivant, ce qui comprendrait aussi les animaux, est susceptible d'être engendré. En d'autres termes, même si les actes d'engendrer et d'enfanter concernent le plus souvent dieux et déesses, il ne semble pas y avoir de traitement spécifique à une catégorie donnée. 


\section{Le troupeau de Dieu} hiérarchie entre dieux, hommes et animaux. Une donnée complémentaire est fournie par une série de documents, qui présentent les hommes comme "troupeau » ou «bétail $»^{20}$, situant hommes et animaux par rapport au divin. Ils remontent pour l'essentiel au Nouvel Empire, mais le thème apparait déjà à l'Ancien Empire à travers le célèbre passage du papyrus Westcar $(8,12-17)^{21}$ : à Khéops, qui propose au magicien Djédi de montrer son savoir-faire - remettre en place une tête coupée - sur un prisonnier, celui-ci fait la réponse suivante :

«Non, souverain mon maitre, car il n'est pas permis de faire pareille chose au précieux troupeau.»

L'image est reprise au Moyen Empire dans les Instructions pour Mérykarê, au Nouvel Empire dans différents hymnes à Rê, les hymnes à Amon du papyrus Boulaq $\mathrm{n}^{\circ} 17$ et Chester Beatty IV, et dans la cinquième heure du Livre des Portes ${ }^{22}$. Dans ce dernier recueil, ce «troupeau de Rê qui est dans la Douat, dans la terre fertile et le désert " regroupe même vivants, bien identifiés comme hommes, et morts :

«Gloire à toi, troupeau de Rê, venu à l'existence du Grand (dieu) qui préside au ciel ! Que le souffle soit à vos nez (...) ! Car vous êtes les larmes de mon œil akhet, en votre nom d'hommes!»

La même thématique est développée à l'époque ptolémaïque et romaine dans le Grand Hymne à Khnoum d'Esna. Ainsi, les hommes constituent le troupeau de Dieu à l'image des animaux, troupeau des hommes, ce qui peut être considéré comme une hiérarchisation des différents règnes. Cela ressort également d'un passage, dit « Hymne au créateur ", qui clôt l'Enseignement pour Mérykarê, selon lequel l'homme, issu du créateur, est bénéficiaire de l'ensemble de la création :

«Bien pourvus sont les hommes, le troupeau du dieu,

à l'intention desquels il a fait le ciel et la terre,

après avoir repoussé l'avidité de l'eau.

Pour que vivent leurs narines, il a fait le souffle.

(Car) ce sont ses répliques (litt. « seconds », sn-nw), issues de son corps.

C'est à leur intention qu'il se lève dans le ciel.

Et c'est pour qu'ils se nourrissent qu'il a fait pour eux les végétaux, le bétail, les oiseaux, les poissons. ${ }^{23}$

Ce schéma trouve un écho dans la Genèse (26-31), selon laquelle l'ensemble du monde créé, animal et végétal, est placé sous la domination de l'homme. Le même procédé de création pour l'homme - l'argile - y est également développé par la suite, comparable au modelage et tournage par Khnoum. Cependant, l'ordre de création proposé par la Genèse est fondamentalement différent de celui des textes égyptiens. L'homme y est créé en dernier lieu, présenté comme le parachèvement de cette création, alors qu'elle est régulièrement placée en premier lieu par rapport aux autres êtres vivants dans les listes égyptiennes ${ }^{24}$. Dans la Genèse, le fait que l'homme est créé à l'image de Dieu, selon sa ressemblance, le différencie des animaux et le positionne par rapport à eux (25-27) :

«Puis Dieu dit: "Faisons l'homme à notre image, selon notre ressemblance, et qu'il domine sur les poissons de la mer, sur les oiseaux du ciel, sur les animaux domestiques et sur toute la terre, et sur les reptiles qui rampent sur la terre". Et Dieu créa l'homme à son image; il le créa à l'image de Dieu: il les créa mâle et femelle.» 
21

D’où nous pouvons déduire que Dieu a une apparence humaine.

\section{L'image de Dieu} de l'apparence divine dans les représentations égyptiennes. La divinité peut être en effet figurée tantôt comme un homme, tantôt comme un animal, tantôt sous la forme hybride d'un homme à tête d'animal, rarement l'inverse. La raison en est que la nature de Dieu, sa "forme véritable ", selon la phraséologie égyptienne, étant inconnaissable, comme le répètent à l'envi les textes religieux égyptiens, il n'est possible d'en rendre compte que par une accumulation d'images ${ }^{25}$. Le propre du divin est donc sa capacité à conjuguer différents règnes, en combinant homme et animal : «Ce dieu dont la face est (celle d')un chien et la peau (i. e. l'aspect extérieur) (celle d')un homme, son nom est Avaleur de million(s), le coutilier, c'est le portier de l'occident », peut-on lire dans le chapitre 335 des Textes des Sarcophages (=CT IV, 315a-316a), illustré, quelque six cents ans plus tard, par la représentation d'un des « dieux de l'Ennéade, maîtres de la Douat (l'Au-delà) » dans la tombe de Khâemouaset, fils de Ramsès III (fig. 1).

Fig. 1. - Divinité à tête de chien.

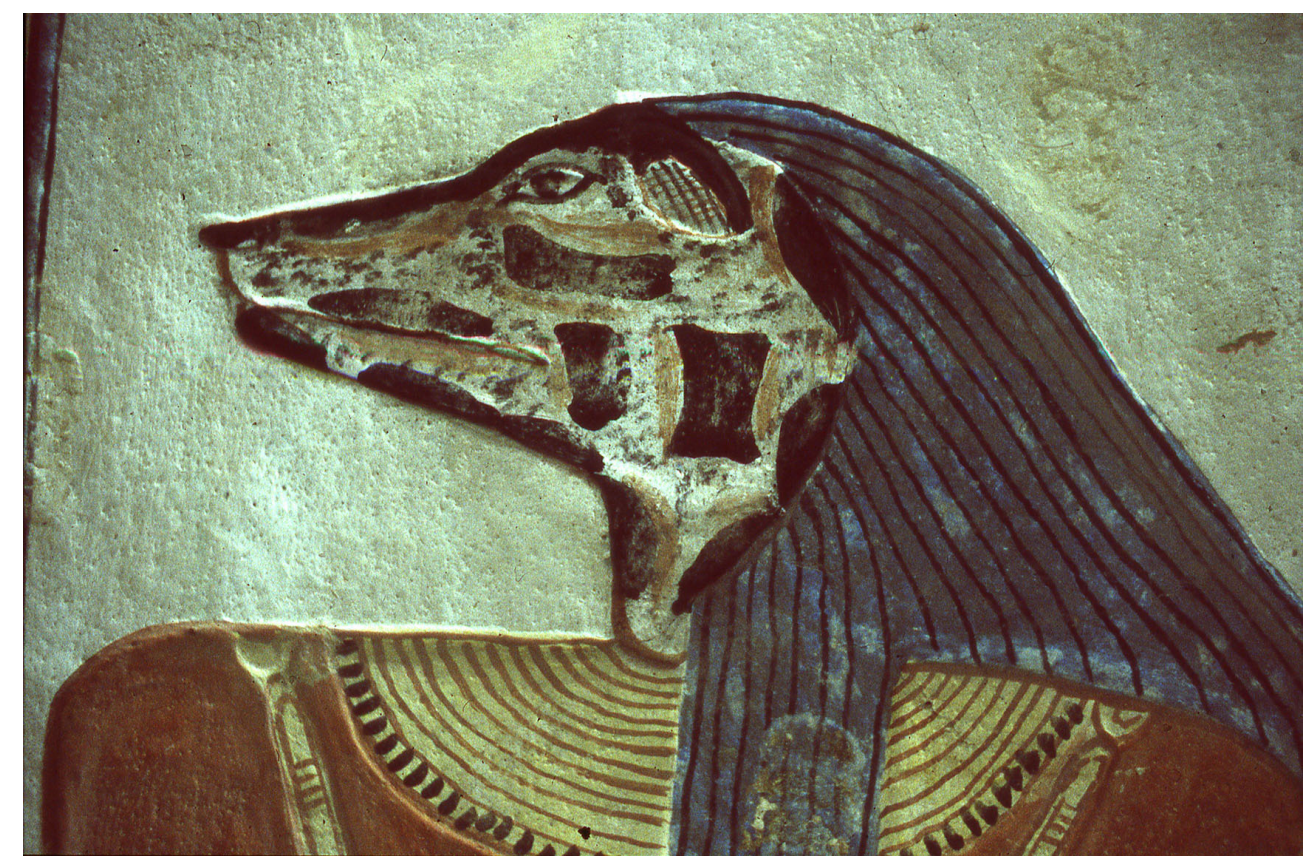

Elle représente l'ensemble des dieux de la Douat qui accueillent le défunt, tombe de Khâemouaset, Vallée des Reines 44, salle du sarcophage.

(c) Cliché Serge Blanc.

Bien loin de l'incompréhension grecque, pour qui l'hybride est, à de rares exceptions près, l'expression de la monstruosité, et la forme animale grotesque, comme l'exprime la quinzième satire de Juvénal ${ }^{26}$, l'aspect animal de la divinité est en Égypte aussi bien une métaphore explicitant certaines de ses caractéristiques essentielles ${ }^{27}$ qu'une manière de mieux révéler, tout en la dissimulant, sa nature. Le corollaire en est qu'homme et animal apparaissent comme complémentaires pour définir une autre dimension de l'être. Il faudrait illustrer ici les différentes relations entre divinité et 
animal: forme hybride, mais aussi incarnation dans son $b a^{28}$, c'est-à-dire, paradoxalement, sa forme mobile et immatérielle, ou encore dans son animal sacré. Ainsi, le taureau Apis est le ba vivant de Ptah; à Edfou, un rapace, prélevé dans la volière du temple, représente Horus pour une année. Le nom même d'Horus, qui signifie "le Lointain", peut s'écrire avec un faucon, l'une de ses apparences les plus courantes. Le faucon sur le pavois (signe G 7 dans la liste Gardiner) est d'ailleurs le déterminatif courant du mot «dieu » en hiératique. Il est d'autre part fréquent, à l'époque ptolémaïque et romaine, d'utiliser un groupe de trois oiseaux différents pour écrire le pluriel «dieux $»^{29}$. Plus extraordinaire est la graphie du passage, déjà cité, d'Esna (III, 319, 16-17) (fig. 2) :

«Tu as tourné les hommes, tu as fait les dieux. »

Fig. 2. - Inscription du temple d'Esna.

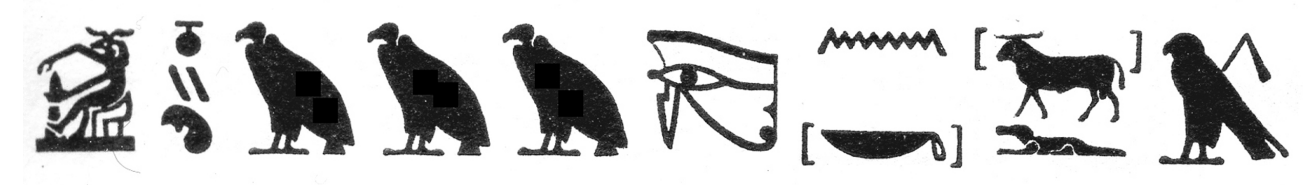

D'après Sauneron, Esna III, 319, 16-17. et les trois vautours pour le mot « hommes ", graphie courante à l'époque ptolémaïque et romaine. Moins banale est l'utilisation de l'œil oudjat au lieu de l'œil ordinaire pour «faire ", sans doute pour ajouter une fonction de protection ou une dimension sacrée ; peut-être aussi pour distinguer graphiquement les dieux des hommes, issus des larmes du créateur ${ }^{30}$. Pour le mot "dieux", le rédacteur a choisi trois animaux différents : bélier, crocodile, faucon, soit trois animaux appartenant à trois milieux, la terre, l'eau et l'air. Trois êtres, en même temps, qui véhiculent une idée de puissance : la vigueur génésique $\mathrm{du}$ bélier qui renvoie aussi à Khnoum; la force du crocodile, traditionnellement utilisé, en outre, pour écrire le mot "souverain »; l'élan du faucon, qui s'élève au plus haut du ciel, doté du flagellum qui l'identifie comme un être sacré. Sarcophages et de l'Enseignement pour Mérykarê, que pouvons-nous conclure de ces deux documents? Selon le premier, le dieu dont il est question a l'aspect extérieur, la peau (inem), c'est-à-dire son enveloppe, d'un homme. Selon le deuxième, les hommes sont des «seconds » de Dieu, issus de son corps, renvoyant au temps (faits dans un deuxième temps), mais signifiant aussi «égal », " pareil » (comme dans l'expression « sans égal »). On en revient à l'apparence, et en même temps, au mode de création de l'homme comme émanation du démiurge développé plus haut. L'Hymne au créateur de l'Enseignement pour Mérykarê ne se distingue guère du récit de la Genèse. Ce qui en rend l'analyse différente, c'est qu'il se juxtapose à des documents comme celui du chapitre 335 des Textes des Sarcophages : les deux assertions ne sont pas exclusives.

C'est ce qui fait toute la différence avec la vision judéo-chrétienne de la Genèse, qui présente une vision univoque de Dieu, même s'il est susceptible d'être également représenté par une main, un rayon de lumière, une colombe, un vieillard (le Dieu de l'Ancien Testament) ou un homme jeune (le Christ). Ces représentations, limitées, illustrent des modes d'action et de relation avec l'homme, non des apparences du créateur. La différence essentielle avec la conception égyptienne réside précisément 
dans cette notion d'apparence, d'image. La divinité égyptienne est susceptible d'en avoir plusieurs, voire "de nombreuses", selon une phraséologie courante, tout en demeurant cachée. L'homme est une réplique de Dieu, mais l'inverse n'est pas forcément vrai: il peut prendre cette apparence, ou celle d'un animal, voire de plusieurs, ou combiner les deux. C'est ce seul dernier point qui constitue un fossé entre vision égyptienne et vision grecque du divin, car le dieu grec, malgré une conception anthropocentrique, ne répugne pas à la métamorphose : en témoignent les multiples formes de Zeus.

En d'autres termes, en Égypte, il n'y a pas de relation exclusive entre dieux et hommes dans le domaine de l'image, et il n'est pas conçu comme réducteur de donner à la divinité une ou des forme(s) animale(s), ni une forme hybride. Comment mieux exprimer le fait que le divin transcende non seulement la nature des êtres, mais aussi l'espace ${ }^{31}$ ? En même temps, un tel emprunt au monde animal démontre qu'il n'y a pas réellement de barrières dans le domaine du vivant et qu'hommes et animaux sont susceptibles, au même titre et souvent ensemble, d'être le support du divin.

\section{BIBLIOGRAPHIE}

BICKEL Susanne, La cosmogonie égyptienne. Avant le Nouvel Empire, Fribourg-Göttingen (Orbis Biblicus et Orientalis 134), 1994.

Breasted James, «The Philosophy of a Memphite Priest », Zeitschrift für Ägyptische Sprache und Altertumskunde 39, 1901, p. 39-54 et pl. I-II.

DAUMAS François, BARUCQ André, Hymnes et prières de l'Égypte ancienne, Paris, Éd. du Cerf (Littératures anciennes du Proche-Orient 10), 1980.

Esna III : voir SAUNERON.

GOYON Georges « Les travaux de Chou et les tribulations de Geb d'après le naos 2248 d'Ismaïlia », Kêmi VI, 1936.

GuILHou Nadine, La vieillesse des dieux, Montpellier, université Paul-Valéry (Orientalia Monspeliensia V), 1989.

GUILHOU Nadine, « La naissance du soleil et ses voyages d'Esna à Saïs : une lecture astronomique de la cosmogonie d'Esna ", dans E. KORMYSCHEVA, Cultural Heritage of Egypt and Christian Orient 4, Moscou, 2007, p. 13-24 (Actes du colloque de Moscou, 15 au 20 mai 2006).

GUTBUB Adolphe, « Jeux de signes dans quelques inscriptions des grands temples de Dendérah et d'Edfou », BIFAO LII, 1953, p. 57-101.

HORNUNG Erik, Das Buch von den Pforten des Jenseit, Bâle-Genève, (Aegyptiaca Helvetica 7), 1979, et 8, 1980.

JUVÉNAL, Satires, par LABRIOLle (de) Pierre, Villeneuve François, $5^{e}$ éd., Paris, Les Belles Lettres, 1951. 
LEFEBVRE Gustave, Romans et contes égyptiens de l'époque pharaonique, Paris, Maisonneuve, 1949.

MEEKS Dimitri, « De quelques insectes' égyptiens. Entre lexique et paléographie », dans Z. HAWASS, P. Der MANUELIAN, Perspectives on Ancient Egypt, Studies in Honor of Edward Brovarski, Supplément aux Annales du Service des Antiquités de l'Égypte, Cahier nº 40, Le Caire, 2010, p. 273-304.

MEEKS Dimitri, «La hiérarchie des êtres vivants selon la conception égyptienne ", dans A. GASSE, Fr. SERVAJEAN, Chr. THIERS, Et in Ægypto et ad Ægyptum, Recueil d'études dédiées à J.-Cl. Grenier, CENiM 5 , Montpellier, 2012, p. 517-543.

RocCATI Alessandro, Magica Taurinensia. Il grande papiro magico di Torino e i suoi duplicati, Rome, Gregorian \& Biblical Press, 2011.

ROCCATI Alessandro, « Connaissance des animaux dans l'Ancienne Égypte », dans M. MASSIERA, B. MATHIEU, Fr. RoufFET (éd.), Apprivoiser le sauvage-Taming the Wild, CENiM 11, Montpellier, 2015, p. 293-296.

SAUNERON Serge, YOYOTTE Jean, La naissance du monde, Paris, Éditions du Seuil (Sources Orientales 1), 1959, p. 17-91.

SAUNERON Serge, Le temple d'Esna III, Textes hiéroglyphiques nos 194-398, Le Caire, Ifao, 1968.

VERnUS Pascal, YOYOTTE Jean, Bestiaire des pharaons, Paris, Perrin 2005.

VERnus Pascal, Sagesses de l'Égypte pharaonique, Arles, Actes Sud (« Thesaurus »), 2 éd., 2010.

\section{NOTES}

1. Rt 1, 3-4 ; jr(w) (...) nTr.w rmT aw.t mnmn.t Ddf.t Apd.w rmw.w. Voir A. Roccati, Magica Taurinensia, p. 135, 222-223. Sauf mention contraire, toutes les traductions sont de N. Guilhou.

2. Mais dans le contexte de l'étable, on pourrait opposer «petit bétail » (les caprinés venant de la savane) et "gros bétail " (les bovins). En fait, le terme âout possède un champ sémantique étendu et ce n'est que lorsqu'il s'oppose aux hommes qu'il prend le sens général de « animaux ».

3. Usage systématique en hiératique. À propos de ce déterminatif pour les insectes, voir D. Meeks, « De quelques “insectes” égyptiens », p. 296.

4. od.n=f rmT aw.t kA.w pAw $x n n(w)$ rmw.w Hrr nb; hymne à Amon d'Hibis (Fr. Daumas, A. Barucq, Hymnes et Prières, 89, p. 15-16). Le terme Hrr, qui clôt la liste, désigne plus précisément la vermine, ce qui grouille.

5. P. Vernus, J. Yoyotte, Bestiaire des pharaons, p. 15-19; la création des animaux est développée p. 20-21. D. Meeks, «La hiérarchie des êtres vivants selon la conception égyptienne », p. 518. Aux sources qu'il donne dans sa note 6, on ajoutera Esna III, 319, $16-17 ; 378,9-10 ; 387,2 ; 388,9 ; 394,27$, moins complètes, mais plus pertinentes pour notre propos, ainsi que le naos d'Ismaïlia. Voir également A. Roccati. «Connaissance des animaux dans l'Ancienne Égypte », p. 293-296.

6. Ceci est à relativiser : outre le fait qu'il y a des variations en fonction des documents, le démiurge commence dans tous les cas par créer ses différentes hypostases, soit d'autres dieux. Cet ordre dépend aussi du mode de création, comme développé ci-après. 
7. Respectivement Grand hymne à Amon du Caire, papyrus Boulaq 17 (A. Barucq, Fr. Daumas, Hymnes et prières, $\left.n^{\circ} 69\right)$, VI, 3 : prr.n rmT $m$ jr.ty=fy xpr nTr.w tp r(A)=f; et hymne à Amon du décret de Nesikhonsou (ibid. $n^{\circ}$ 79), 1. 19-20: pr.n rmT $m$ nTr.ty=f nTr.w $m$ tp(y).w r(A)=f.

8. jr.n=f rmT m nTr.ty=f oAa.n=f nTr.w m r(A)=f ; hymne à Amon d'Hibis (ibid.89), 7-8.

9. Naos d'Ismaïlia, paroi A et $C: n n$ ao nTr.w nTr.wt rmT jwaa.w; nn mAA nn xtm sxr.w=f jn nTr.w nTr.wt rmT jwaa.w ; jsk rf wn\{n\} Hm n(y) Gb xa (...) Hr s.t (jt=f) Sw m n(y)-sw.t nTr.w nTr.wt rmT jwaa.w. Voir G. Goyon, «Les travaux de Chou et les tribulations de Geb d'après le naos 2248 d'Ismaïlia ", p. 9-10, 18. Pour " animaux ", on utilise ici une variante graphique du terme habituel ; voir D. Meeks, « La hiérarchie des êtres vivants selon la conception égyptienne », 2012, p. 527.

10. Esna III, 378 , $9: \mathrm{nHp}(\mathrm{w})$ nTr.w nb(y) Xnmm.t aw.t.

11. Esna III, 319, 16-17 : nHp.n=k rmT jr.n=k nTr.w nb.n=k aw.t mnmn $t$.

12. Ces deux derniers termes, utilisés lors de la création du premier couple, principe masculin et principe féminin, incarnés par Chou et Tefnout, hypostases du démiurge, sont eux aussi à la base d'un jeu de mots avec le nom des deux divinités : le créateur crache (chou) Chou et expectore ( $t f n)$ Tefnout.

13. En particulier dans la cosmogonie memphite, telle qu'elle est présentée sur la Pierre de Chabaka. Pour un exposé sur les différentes cosmogonies égyptiennes, voir S. Sauneron, J. Yoyotte, La naissance du monde, p. 17-91.

14. Esna III, 206, $3^{\mathrm{e}}$ paragraphe selon le découpage de S. Sauneron (p. 28-34; = col. 2); pour une traduction de cette cosmogonie d'Esna et les références, voir N. Guilhou, « La naissance du soleil et ses voyages d'Esna à Saïs: une lecture astronomique de la cosmogonie d'Esna », p. 20-24.

15. J. Breasted, «The Philosophy of a Memphite Priest », p. 29-54 et pl. I-II.

16. Esna III, 378, 10 ; nHp(w) nTr.w nb(y) Xnmm.t aw.t (...) ms(w) nTr.w wtt(w) nTr.wt. On notera l'emploi, en chiasme, des termes enfanter, mettre au monde, à propos des dieux et engendrer à propos des déesses.

17. Esna III, 394, $27:$ nHp.n=f rmT ms.n=f nTr.w.

18. Esna III, 388, 9 : wtt(w) nTr.w nTr.wt (...) nHpw rmT nTr.w.

19. Esna III, 387, 2 ; nHp(w) rmT ms(w) nTr.w wtt(w) psD.t wtt(w) x.t nb anx.

20. Traduction choisie par D. Meeks, «La hiérarchie des êtres vivants », p. 526.

21. Ou du moins attribué à cette période, puisque la rédaction du papyrus Westcar (Berlin 3033) se situe un peu plus tard, au Moyen Empire ou à la Deuxième Période intermédiaire. Pour la traduction et les références, voir G. Lefebvre, Romans et contes égyptiens de l'époque pharaonique, p. 70-90, en particulier p. 83. De même, la datation au Moyen Empire de l'Enseignement pour Mérykarê (ci-après) est contestée, certains la situant à la XVIII ${ }^{e}$ dynastie.

22. Pour les différents hymnes à Rê et à Amon, voir A. Barucq, Fr. Daumas, Hymnes et prières, p. 133, 166, 170, 193, 196, 198, 242, 248. Pour le Livre des Portes, il s'agit de la scène 30, dite « les quatre races »; voir E. Hornung, Das Buch von den Pforten des Jenseit 7, p. 176-177 et 8, p. 135-136.

23. Ma traduction s'inspire de celles de P. Vernus, Sagesses de l'Égypte pharaonique, p. 194 et de S. Bickel, La cosmogonie égyptienne, p. 215 (texte 198). 
24. Dans les cosmogonies, l'espace est bien évidemment défini en premier, avec l'émergence de la butte primitive hors des eaux comme préalable à la manifestation du démiurge, qui a besoin d'un endroit où se poser. À partir de là, il va d'abord fixer cette butte puis la consolider par apports de terres successives afin qu'elle serve d'assise au monde créé. Viennent ensuite la séparation de la lumière et des ténèbres, puis la création du monde avec les différents êtres qui le peuplent.

25. De même que son nom, qui est secret : c'est tout le propos du texte connu sous le nom de «Ruse d'Isis ».

26. «Qui ne sait (...) à quels monstres l'Égyptien adresse son culte insensé ? Les uns adorent un crocodile, les autres se sentent saisis d'effroi devant l'ibis gorgé de serpents" (traduction P. de Labriolle et Fr.Villeneuve, p. 189). Les hybrides appartiennent au domaine du sauvage, comme les centaures, à l'exception de Chiron, ou encore du monstrueux, comme le Minotaure, issu d'une relation contre nature.

27. Comme le bélier incarnant la puissance génésique, pour rester dans le domaine de la création.

28. Cet aspect est développé dans un des épisodes du Livre de la Vache céleste; voir N. Guilhou, La vieillesse des dieux, p. 21-22, 98-104.

29. Voir A. Gutbub, «Jeux de signes dans quelques inscriptions des grands temples de Dendérah et d'Edfou », p. 78-97.

30. Le mot remtj, «hommes », peut être écrit à l'époque ptolémaïque et romaine par l'idéogramme de l'œil qui pleure.

31. Il transcende aussi le temps, mais cela n'apparaît pas dans la présente réflexion.

\section{RÉSUMÉS}

L'animal est omniprésent dans l'Égypte ancienne, que ce soit dans le monde domestique ou dans le monde sauvage, dans le monde réel ou dans le monde imaginaire. Il occupe une place importante dans l'art et la culture et a fait l'objet d'observations attentives de la part des Égyptiens. Tout ceci a conduit à un emploi métaphorique de l'animal, dont les formes hybrides d'homme à tête d'animal, revêtues par les dieux, sont l'expression la plus connue et la plus spectaculaire. L'article s'interroge sur le statut de l'animal: quelle place lui est faite dans la création? Comment peut-on le définir par rapport aux hommes et aux dieux? La division en règnes humain et animal - on pourrait ajouter végétal -, héritée de l'Antiquité classique et de la tradition chrétienne est-elle pertinente? Et comme corollaire, que peut-on conclure de ces différents statuts pour la notion du divin?

\section{AUTEUR}

\section{NADINE GUILHOU}

Institut d'égyptologie François-Daumas, université Paul-Valéry, Montpellier III 


\title{
La bête dans l'homme : péché originel ou origine de la moralité ?
}

\author{
Antonello La Vergata
}

1 Dans une page des carnets où le jeune Darwin (il avait alors 28 ans) notait ses réflexions sur la transformation des espèces on trouve cette phrase, écrite en 1837 :

« Notre descendance (descent) est l'origine (origin) de nos mauvaises passions! Le

Diable, sous forme de babouin, est notre grand-père. $"^{1}$

2 Cela n'est pas très poli envers les babouins, mais, pour leur rendre justice ainsi qu'à Darwin, il faut ajouter que trente-quatre ans après, dans La Descendance de l'homme (1871) on lit tout autre chose. Le naturaliste anglais évoque un babouin courageux qui redescendit de la montagne où il était en toute sécurité, grimpa sur un bloc de rocher où se trouvait un jeune congénère de six mois entouré par des chiens, le rassura et l'emmena fièrement. Le commentaire de Darwin est un peu trop victorien et en rien politiquement correct pour notre sensibilité, mais il est clair en ce qui concerne son appréciation d'un pareil comportement :

«J'aimerais autant pour ma part descendre [...] de ce vieux babouin qui emporta triomphalement son jeune camarade après l'avoir arraché à une meute de chiens étonnés, que d'un sauvage qui se plaît à torturer ses ennemis, offre des sacrifices sanglants, pratique l'infanticide sans remords, traite ses femmes comme des esclaves, ignore toute décence, et reste le jouet des superstitions les plus grossières. $»^{2}$

Ce n'est qu'un des innombrables exemples que Darwin présente pour soutenir sa thèse : tout comme les «facultés intellectuelles », les «facultés morales » de l'homme se sont développées graduellement à partir de celles des animaux ; la moralité dérive, à travers la sympathie, des instincts sociaux dont on trouve trace chez nombre d'espèces animales. Chez l'homme, ces instincts se sont accompagnés d'un accroissement lent et graduel de la capacité de raisonner, mais ils furent initialement développés par la sélection naturelle, car ils donnaient aux individus qui les possédaient, et surtout au groupe dont ils faisaient partie, un avantage reproductif dans la lutte pour la vie.

Darwin admettait donc la possibilité de ce qu'on a ensuite appelé la sélection de groupe, et qui est aujourd'hui encore un sujet sur lequel il n'y a pas d'accord chez les 
biologistes. Mais laissons ce problème de côté et arrêtons-nous sur l'idée darwinienne de l'animal pourvu d'une sorte de "morale». C'est une idée qui va décidément à l'encontre de toute une tradition dont on trouve déjà des traces chez Platon, auquel on doit l'expression "la bête dans l'homme». Christianisée, pour ainsi dire, par les premiers Pères de l'Église, elle est arrivée jusqu'à nos jours: est-il nécessaire de rappeler combien de traits animaux ont été attribués au Diable : barbe de bouc, cornes, sabots, queue, dents de loup, corps de reptile, malice de serpent... ? L'homme moral se doit donc de lutter contre sa partie animale, responsable des tentations de la chair. En 1850, moins de dix ans avant la parution de l'Origine des espèces (1859), le poète anglais Alfred Tennyson, réfléchissant aux extinctions innombrables dont témoignait l'histoire géologique, lançait cette exhortation à l'homme qui, face à l'indifférence de la nature qui détruit tout, cherche un sens à sa vie et une source d'espoir :

«Avance vers le haut, expulse la bête,/et fais mourir le singe et le tigre [qui habitent au fond de ton âme].»

5 Autrement dit : supprime ta partie animale et élève ton esprit ${ }^{3}$. Malgré Darwin et les études sur le comportement animal que déclencha La Descendance de l'homme, l'idée de la bête comme personnification du mal, et de l'animalité comme origine de nos mauvaises tendances, persista longtemps dans toute sa force. Il y a plus : par un des paradoxes dont l'histoire des idées est si riche, et qui ne semblent tels qu'a posteriori, une interprétation particulière d'une partie des idées de Darwin favorisa cette persistance et lui donna un soutien scientifique. Opération très facile, d'ailleurs : il ne s'agissait que de traduire en langage évolutionniste une image ancienne de l'animalité et la doctrine de la lutte contre l'animalité. Dans L'Origine des espèces (1859) Darwin avait soigneusement précisé qu'il employait l'expression « lutte pour l'existence » dans « un sens large et métaphorique ", mais l'image d'une nature cruelle, livrée à un combat sans répit devint populaire chez beaucoup de scientifiques comme chez les lecteurs moins spécialisés. D'autre part, pourquoi renoncer à tirer une morale des découvertes scientifiques? Tant mieux si elle confirmait des croyances enracinées depuis longtemps. L'évolution ne pouvait être que la préparation dans la nature du progrès de l'histoire ; la souffrance, la destruction, la concurrence vitale en seraient les moyens, terribles mais efficaces, le prix à payer pour l'avènement de l'homme et de l'esprit. L'enseignement moral resterait le même qu'avant Darwin. En 1883, le poète et écrivain anglais George Meredith relançait le message de Tennyson : il faut lutter contre « notre propre Dragon (our old Dragon Self) $»^{4}$.

6 La littérature de l'époque nous présente un grand nombre de variations sur le thème de la bête dans l'homme. Tout le monde connaît le conte de Robert Louis Stevenson The strange case of Dr Jekyll and M. Hyde (1886). Le crime du protagoniste, c'est d'avoir voulu séparer physiquement la partie animale de la partie spirituelle de l'homme, le bien du mal. M. Hyde est donc "le mal à l'état pur»: il est nain, boiteux, d'une agilité surprenante, dégingandé, sensuel, taquin, narquois ; ses mains sont maigres, noueuses, toutes tendons et poils; il a quelque chose en soi de troglodytique ; il est animé d'une " férocité primitive ». C'est " la bête sauvage qui dort» au fond de Jekyll et qui prend force quand « la partie spirituelle sommeille ", un " démon qui sort rugissant de la cage où il a été enfermé trop longtemps ». Bref, ce mélange de singe et de tigre, c'est notre origine animale. Faudra-t-il rappeler que l'ouvrage de Stevenson est paru dans un climat déjà imprégné de darwinisme? Il faut cependant se demander: quel darwinisme? Celui du Diable sous forme de babouin ou celui de l'animal capable d'un rudiment de moralité ? Nous avons dans cette œuvre un exemple frappant de ce qu'on 
écrivait plus haut : une part de Darwin fut opposée à l'autre. Tout le monde connait aussi La Bête humaine de Zola (1890), mais voici comment l'américain Frank Norris décrit dans son roman McTeague (1899) le surgissement du désir sexuel chez le protagoniste, un dentiste sans diplôme, un homme lourd, élémentaire, primitif, devant la belle patiente anesthésiée.

«Soudain, dans l'homme s'agita et se réveilla la bête; les mauvais instincts qui étaient chez lui si près de la surface jaillirent à la vie en poussant des cris [...] Il lutta, aveuglément, sans savoir pourquoi, contre [la crise qui se manifestait si rapidement], mû par un instinct non prémédité de résistance. Au fond de lui-même, un second moi, un autre et meilleur McTeague, se dressa, en même temps que la brute ; les deux étaient forts, avaient la même force immense et lourde de l'homme qui les contenait. Là-bas, dans le modeste, misérablecabinet de dentiste, une lutte terrible commença. C'était l'ancienne bataille, aussi ancienne que le monde, et aussi grande: le bond soudain, comme d'une panthère, de la bête sauvage, les lèvres tendues, les pattes foudroyantes, horrible, monstrueuse, qui n'admet pas de résistance, et, en même temps, la révolte de l'autre homme, sa meilleure partie, qui s'écrie "Bas, bas" sans savoir pourquoi, qui saisit le monstre et lutte pour l'étrangler, pour l'abattre et le pousser en arrière. $\rrbracket^{5}$

Dans un autre roman du même auteur, dont le titre est tout un programme - Vandover and the brute (1914) -, la dégénérescence physique et morale du protagoniste est accompagnée de crises de lycanthropie: un véritable retour à la condition animale. Mais il n'y eut pas que la littérature. L'image de la bête fut projetée sur celle de l'homme primitif et devint un lieu commun pour les anthropologues, mais aussi pour bien des historiens. Voici Ernest Renan :

«Il faut se figurer la primitive humanité comme très méchante. Ce qui caractérisa l'homme durant des siècles, ce fut la ruse, le raffinement qu'il porta dans la malice, et aussi cette lubricité de singequi, sans distinction de dates, faisait de toute l'année pour lui un rut perpétuel. Mais, dans cette foule de satyres éhontés, il y avait des groupes portant en eux des germes meilleurs. $»^{6}$

8 De l'homme primitif ainsi caractérisé au sauvage décrit comme un fossile vivant il n'y avait qu'un pas, ainsi que de l'homme-bête au criminel vu comme un atavisme, une survivance du passé évolutif, ou comme un retour pathologique à ce passé. On sait quel usage Cesare Lombroso et l'école italienne d'anthropologie criminelle firent de cette idée. Mais ses applications furent multiples. Hippolyte Taine, par exemple, s'en servit pour décrire la violence des «bandes » révolutionnaires déchaînées. Laissons-lui la parole, c'est un passage très éloquent :

«Par la dissolution de la société et par l'isolement des individus, chaque homme est retombé dans sa faiblesse originelle, et tout pouvoir appartient aux rassemblements temporaires qui, dans la poussière humaine, se soulèvent comme des tourbillons [...]. En pareil cas, les blancs ne valent guère mieux que les noirs : car non seulement la bande, ayant pour objet une action violente, se compose des plus misérables, des plus exaltés, des plus enclins à la destruction et à la licence, mais encore, comme elle exécute tumultueusement une action violente, chaque individu, le plus brut, le plus déraisonnable et le plus perverti, y descend encore au-dessous de lui-même, jusque dans les ténèbres, la démence et la férocité de ses derniers bas-fonds [...] Tous [les] freins, intérieurs et extérieurs, manquent à l'homme lancé dans l'émeute [...] L'action commencée l'entraîne au-delà de ce qu'il a voulu. Sa colère est exaspérée par le péril et la résistance. La fièvre lui vient au contact des enfiévrés, et il suit des bandits qui sont devenus ses camarades. Ajoutez à cela les clameurs, l'ivrognerie, le spectacle de la destruction, le tressaillement physique de la machine nerveuse tendue au-delà de ce qu'elle peut supporter, et vous comprendrez comment, du paysan, de l'ouvrier, du bourgeois, pacifiés et apprivoisés par une 
civilisation ancienne, on voit tout d'un coup sortir le barbare; bien pis, l'animal primitif, le singe grimaçant, sanguinaire et lubrique, qui tue en ricanant et gambade sur les dégâts qu'il fait [...] Les Huns, les Hérules, les Vandales et les Goths ne viendront ni du Nord ni de la mer Noire, ils sont au milieu de nous. $»^{7}$

Les psychologues des foules expliqueront tout ça aussi par la force de l'« imitation ", typique des animaux grégaires, et de la "contagion » qui se propage d'un individu à l'autre, et qui fait qu'une foule revient dans son comportement à un stade plus primitif, plus animal. On le voit bien déjà chez Taine: animalité, criminalité, barbarie, sauvagerie, le tout fusionné grâce à une naturalisation qui coïncide avec une moralisation des faits sociaux. Le mal, c'est l'« autre», naturel ou social. Il n'est pas dans notre société civilisée, mais dans ceux qui, à proprement parler, n'y appartiennent pas : les populations «sauvages » réelles ou les homme-bêtes vivant abusivement parmi nous. Il faut les soumettre aux règles de la civilisation, et s'ils ne s'y conforment pas... Eh bien, ce ne sera pas notre faute à nous, les civilisés. En évoquant la bête noire, on se rassure. Dans cette tentative d'exorciser le mal en le confinant dans l'espace d'un passé qui ne veut pas mourir, une téléologie évolutive joue un rôle décisif: ce n'est plus l'homme en tant que tel qui est le sommet de la nature, c'est l'homme civilisé et moral nous, les blancs, respectueux de la loi, respectables...

Le mythe de la bête dans l'Homme remplit une fonction importante dans la substitution de la religion par la science comme autorité morale, mais respectueuse de la moralité conventionnelle. Il n'y a pas à s'étonner de voir cette religion laïque se doter d'une version scientifique du péché originel. Francis Galton, cousin de Darwin et fondateur de l'eugénisme, qu'il définit comme " une religion », et dont le but était d'éliminer par des mesures législatives «la tare héréditaire due à la barbarie de nos origines ", écrivit en 1865 :

"C'est un thème commun aux moralistes de tout credo que l'homme naît avec une nature imparfaite. Ses aspirations se dirigent en haut, mais dans ses facultés il y a une faiblesse qui ne lui permet pas d'atteindre ses nobles fins. La nature humaine toute entière est tachée par le péché, qui l'empêche de faire ce qu'il sait être juste [...] Le sens du péché originel consiste, selon ma théorie, non dans une chute de l'homme d'une condition supérieure, mais dans sa rapide montée à partir d'une condition inférieure. $»^{8}$

11 Galton n'en croyait pas moins à la possibilité de soustraire l'évolution aux mains de la nature et de la confier à celles de l'homme pour assurer le progrès par une sélection rationnelle plus rapide et efficace. D'autres ne partageaient pas cette confiance, tout en s'appuyant sur la même réinterprétation du péché originel. "La "théorie de la descendance" - affirma Ferdinand Brunetière - a discrédité pour longtemps et ruiné, je l'espère, la dangereuse hypothèse de la "bonté naturelle de l'homme" [...], l'idée, typique des Lumières, de sa perfectibilité indéfinie ", qui était «la source première de nos utopies socialistes », mais aussi de "l'optimisme positiviste ».

«Nos mauvais instincts sont en nous l'héritage de nos premiers ancêtres [...] Oui, nous avons en nous, dans notre sang, et, pour ainsi parler, nous avons tous au plus profond de nos veines, quelque chose de la brutalité, de la lubricité, de la férocité $\mathrm{du}$ gorille ou de l'orang-outan! [...] La "théorie de la descendance" est venue donner en quelque sorte une base physiologique au dogme du péché originel ; et la principale difficulté qui suspendît encore l'assentiment des incrédules ou de quelques croyants même, c'est vraiment Darwin et Haeckel qui l'ont levée [...] Le "règne humain" ne s'est réalisé qu'à mesure, et dans la mesure où nous nous dégagions de l'antique animalité [...]; et nous-mêmes, enfin, nous ne vivons qu'au prix du combat qu'il nous faut quotidiennement soutenir conte l'humiliante fatalité 
de notre première origine. Ce que nous nous devons, c'est de dompter, de soumettre, et de dominer ce que nous trouvons en nous d'instincts qui nous rapprochent de l'animalité. ${ }^{9}$

$$
\begin{aligned}
& \text { l'homme naturel à suivre son cours amoral » agissent même dans la société la plus } \\
& \text { civilisée. Et lutter contre la nature, n'est-ce pas lutter contre un Diable naturalisé ? La }
\end{aligned}
$$
réinterprétation du péché originel montre, aussi chez Huxley, toute sa force :

\begin{abstract}
«Les doctrines de la prédestination, du péché originel, de la dépravation innée de l'homme, du destin funeste de la plupart de notre race, de la suprématie de Satan dans ce monde, de l'abjection essentielle de la matière, d'un Démiurge malin subordonné à un Être tout-puissant et bienveillant qui ne s'est révélé que tardivement; ces doctrines, aussi imparfaites soient-elles, me semblent infiniment plus proches du vrai que ne le sont toutes les illusions populaires "libérales" pour lesquelles tous les enfants naissent bons et ne le restent pas par la faute de l'exemple que leur offre cette société corrompue. $»^{12}$

«Avant que l'héritage transmis à l'homme par ses ancêtres [...] - notre dose de péché originel - ne soit éradiqué par quelque système encore inconnu, du moins pour celui qui ne croit pas au surnaturel, tout enfant né en ce monde portera toujours avec lui l'instinct de l'auto-affirmation illimitée et devra apprendre la leçon de l'auto-limitation et du renoncement. $»^{13}$
\end{abstract}

15 Tous ces débats ont laissé une trace profonde dans la psychanalyse. « Le diable, dira Freud en 1908, n'est que la personnification de la vie pulsionnelle inconsciente refoulée $»^{14}$. Comme on l'a remarqué, l'instinct de mort introduit dans Par-delà le 
principe du plaisir (1920) « ressemble de façon sinistre au péché originel » ${ }^{15}$. Le « ça » (Es) est l'aspect de l'inconscient qui est enraciné dans notre passé phylogénétique : ce qu'il $\mathrm{y}$ a de plus animal dans notre nature psychique :

"Quand par exemple les forces morales qui s'opposaient à ses manifestations et jusque-là les inhibaient ont été mises hors d'action, l'agressivité se manifeste aussi de façon spontanée, démasque sous l'homme la bête sauvage qui perd alors tout égard pour sa propre espèce. $»^{16}$

Homo homini lupus, donc, comme pour Hobbes : diagnostic confirmé par la tragédie de la guerre mondiale, qui a montré la fragilité de la civilisation, croûte subtile surimposée aux descendants de la «bande d'assassins » qui tua le père dominateur de Totem et tabou (1913). D'ailleurs, à part Freud, on sait trop bien qu'en guerre on animalise l'ennemi (les « singes noirs » ou « jaunes », la « violence bestiale des rouges »), tout comme on fit des animaux nos premiers ennemis. Jung ira plus loin que Freud, et parlera en $1942 \mathrm{du}$ « dogme salutaire du péché originel, si profondément, extraordinairement vrai». L'« Ombre ", le " côté obscur » de la personnalité est " une bête qui a une âme de bête, un système vivant qui obéit inconditionnellement à l'instinct ». " La morale ascétique du Christianisme a précisément le but de nous libérer du danger de réveiller la nature animale enfouie dans les couches les plus éloignées de l'homme $»^{17}$.

Cependant, une troupe composite de naturalistes, surtout en Russie et chez les biologistes néo-lamarckiens français, s'était élevée contre cette image «criminalisante » de l'animalité. Si la moralité ne dérive pas de l'évolution, d'où vientelle ? À moins de croire qu'elle ne soit d'origine divine, il faut admettre que non seulement elle n'est pas antagoniste au processus cosmique, mais en est un résultat. Mais il y a plus : elle possède une solide base biologique, et est elle-même un facteur de l'évolution. À côté de la lutte pour la vie, il y a la loi, bien plus importante, du « secours mutuel » (ou " aide réciproque »). Elle est à la base du phénomène de l'« association » qui caractérise la vie animale dès ses formes les moins développées (comme le polypier et les coraux, qui sont de véritables "colonies animales»). Pour Kropotkine, l'aide réciproque se développe au fur et à mesure que l'on gravit les marches de l'échelle de l'intelligence animale. Il y a de l'aide réciproque aussi pour des groupes entiers d'organismes différents contre d'autres groupes et contre la rudesse des conditions de vie (le climat, la pénurie de vivres, etc.). Kropotkine retourne la formule de Huxley : la conflictualité humaine n'est pas un héritage naturel, mais l'effet du (mauvais) développement social ; l'évolution éthique se fonde sur l'évolution organique, elle est la cause, non l'effet, de l'évolution sociale. Bref, il y a déjà une moralité dans la nature. Darwin avait compris ce que ses disciples semblent avoir oublié. Mais Darwin lui-même n'avait pas traité le thème de la sociabilité des animaux avec l'ampleur que méritait un tel sujet. Sur certaines questions, il avait été trop prudent et même hésitant. Par exemple, il avait parfois laissé entendre que l'instinct social avait son origine dans l'instinct parental et n'en était qu'une extension, parfois il en avait parlé comme d'un instinct séparé des autres, et quelquefois même en opposition avec eux, lorsqu'il entrait en conflit avec l'instinct de conservation. Pour Kropotkine, il était " plus correct de considérer les instincts sociaux et parentaux comme deux instincts étroitement liés, le premier étant peut-être le plus ancien et donc le plus fort ». On le trouvait chez des animaux inférieurs, comme certains crabes et certains poissons, qui ne manifestent pas d'instincts parentaux ${ }^{18}$. La leçon de l'évolution était donc évidente : la nature humaine n'est pas mauvaise, les hommes laissés à eux-mêmes ne sont pas des bêtes qu'il faut brider soit par la prédication des prêtres, soit par la violence de la police. 

pas le royaume du mal. Konrad Lorenz a soutenu que l'agressivité elle-même est non seulement utile à l'espèce, mais est intimement liée à des aspects du comportement animal qu'on ne considère généralement pas comme «mauvais » et que Lorenz définit comme des «formes de comportement analogues à la morale». Au fur et à mesure que l'agressivité tend à devenir plus destructive, des contre-mesures et des mécanismes de compensation se sont développés par sélection naturelle, et c'est précisément chez les animaux les plus agressifs, tels que l'homme, que nous trouvons la liaison personnelle et même l'amour. L'agressivité - écrit Lorenz empruntant les mots au Méphistophélès du Faust de Goethe - est une partie « de cette force qui poursuit toujours le mal, mais qui toujours crée le bien ». Les penchants naturels de l'homme ne sont donc pas si mauvais qu'on le croit. Ni les impératifs moraux ni les interdits «ne découlent de la raison, mais d'une poussée dans l'obscurité dans laquelle notre conscience ne pénètre pas [...] L'homme privé de toute son animalité, de cette poussée obscure, l'homme en tant qu'être purement rationnel ne serait point du tout un ange: il serait plutôt bien plus proche $d u$ contraire! [...] L'irrationalité dérive $d u$ fonctionnement erroné d'un instinct $»^{19}$. Lorenz l'a répété dans une grande quantité d'ouvrages populaires : c'est la faute à la mauvaise organisation sociale, aux aspects négatifs, anti-biologiques de la civilisation industrielle, d'autant plus que ceux-ci se sont produits trop rapidement pour que notre patrimoine psychique, formé lentement par sélection naturelle, s'y adapte.

Quoi qu'il en soit, la théorie de Lorenz sur l'agressivité et sa notion du «bien de l'espèce » ont été profondément révisées, voire généralement abandonnées, par les éthologues des générations suivantes, surtout après l'essor de la sociobiologie et la floraison des études sur les bases génétiques du comportement animal et sur la psychologie animale. On n'exagère pas si l'on dit que, somme toute, la tendance a été de réduire la distance entre l'homme et l'animal, soit en étendant à l'homme des résultats obtenus chez les animaux, soit en repérant chez les animaux des éléments fondamentaux de la moralité humaine. D'une part, Richard Dawkins a affirmé dans son best-seller Le Gène égoïste (1976) que nos gènes (réincarnation ultérieure de l'animalité méchante) tendraient à faire de nous des "gangsters de Chicago " s'ils n'étaient pas contrôlés par la raison et la société (sur l'origine mystérieuse desquelles au milieu d'une évolution dirigée par l'égoïsme reproductif il ne dit rien). D'autre part, l'éthologue Frans De Waal a rejeté tout récemment dans ses livres, et notamment dans Le bonobo, Dieu et nous (2013), ce qu'il appelle la «théorie du vernis (veneer) ", c'est-àdire la thèse, qu'il attribue à Huxley, selon laquelle la moralité humaine n'est qu'une écorce ou un vernis subtil qui couvre à grand-peine un bouillonnement irréductible de tendances odieuses. Selon De Waal, les mammifères possèdent une impulsion altruiste : ils répondent activement aux messages de souffrance, sont capables de se réconcilier après une dispute, recherchent la manière de vivre en accord les uns avec les autres et de contrôler leur agressivité. Ils ont des règles, dont la valeur pour la survie du groupe est indiscutable. Il y a donc une continuité émotionnelle entre les animaux et l'homme. L'existence d'un sens de la justice et de l'équité chez des singes comme les capucins et les bonobos démontre que ces sentiments chez nous, loin d'être un produit de notre rationalité si célébrée, sont enracinés dans des émotions élémentaires et très anciennes. 

recherches sur le comportement animal et humain suivront leur cours, sans être influencées, espérons-le, par nos préjugés moraux, tels que l'image de la bête en l'homme à cause de laquelle « on projette les vices de la bête qui est en nous sur les animaux réels $»^{20}$. Cette bête - humaine, trop humaine - n'est qu'un mythe, tout comme celui du « bon sauvage » ou celui de la nature-mère sage et généreuse.

\section{BIBLIOGRAPHIE}

BARRETt Paul H., GAUTRey Peter J., HERBERT Sandra, KoHn David et SMITH Sydney (dir.), Charles Darwin's Notebooks, 1836-1844. Geology, transmutation of species, metaphysical enquiries, London, British Museum (Natural History), Cambridge, Cambridge University Press, 1987.

BERKE J., The Tyranny of Malice, London, Simon and Schuster, 1989.

BRUNETIÈRE Ferdinand, La Moralité de la doctrine évolutive, Paris, Didot, 1896.

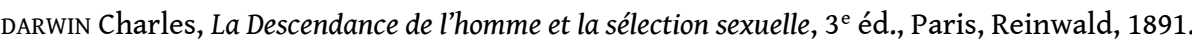

DAWKINS Richard, The Selfish Gene, $2^{\mathrm{e}}$ éd., Oxford, Oxford University Press, 1986.

DE WAAL Frans, Le bonobo, Dieu et nous, Paris, Les Liens qui libèrent, 2013.

FREUD Sigmund, Le Malaise dans la civilisation, Paris, PUF, 1971.

FREUD Sigmund, «Caractère et érotisme anal », dans FREUD Sigmund, Névrose, psychose, perversion, Paris, PUF, 1973.

GALTON Francis, « Hereditary Talent and Character », Macmillan's Magazine, vol. XII, 1865, p. $157-166,318-327$

HUXLEY Thomas Henry, « An Apologetic Irenicon », Fortnightly Review, vol. LII (nouvelle série), 1892, p. 557-571.

HUXLEY Thomas Henry, « Evolution and Ethics. Prolegomena », dans HUXLEY Thomas Henry, Collected essays, London, Macmillan, 1894, 9 vol., T. IX, p. 1-45.

HUXLEY Thomas Henry, «The Struggle for Existence in Human Society ", dans HUXLEY Thomas Henry, Collected essays, London, Macmillan, 1894, 9 vol., T. IX, p. 195-236.

JUNG Carl Gustav, Über die Psychologie des Unbewussten, Zurich, Rascher Verlag, 1943.

KROPOTKINE Pëtr Alekseevič, L'Entr'aide. Un facteur de l'évolution, Paris, Hachette, 1904.

LORENZ Konrad, Das sogenannte Böse. Zur Naturgeschichte der Aggression, Wien, Borotha-Schoeler, 1964.

MEREDITH George, «The Woods of Westermain », dans BARTLETT Phyllis B. (dir.), The poems of George Meredith, New Haven and London, 1978.

MIDGLEY Mary, Beast and Man. The Roots of Human Nature, $2^{\mathrm{e}}$ éd., London, Methuen, 1980.

NORRIS Frank, McTeague. A Story of San Francisco, New York, Doubleday and McClure, 1899. 
RENAN Ernest, Histoire du peuple d'Israël, 2e éd., Paris, Calmann Lévy, 1887, 5 vol.

TAINE Hippolyte, Les Origines de la France contemporaine. Deuxième partie : La Révolution, Paris, Hachette, 1878-1885, 3 vol.

TENNYSON Alfred, « In Memoriam A.H.H. », dans WARREN T. H. (dir.), Poems of Tennyson, Oxford, Oxford University Press, 1913.

\section{NOTES}

1. P. H. Barrett, P. J. Gautrey, S. Herbert, D. Kohn et S. Smith (dir.), Charles Darwin's Notebooks, p. 123.

2. C. Darwin, La Descendance de l'homme, p. 108, 678.

3. A. Tennyson, « In Memoriam A.H.H. », stanza CXVII.

4. G. Meredith, « The Woods of Westermain », p. 219.

5. F. Norris, McTeague. A story of San Francisco, p. 46.

6. E. Renan, Histoire du peuple d'Israël, t. I, p. 4.

7. H. Taine, Les Origines de la France contemporaine, t. III. 1, p. 70.

8. F. Galton, « Hereditary Talent and Character », p. 327.

9. F. Brunetière, La Moralité de la doctrine évolutive, p. 9, 13, 16, 18, 21, 26-27.

10. T. H. Huxley, « The Struggle for Existence in Human Society », p. 197, 199-200.

11. Ibid., p. 203.

12. T. H. Huxley, « An Apologetic Irenicon », pp. 567-569.

13. T. H. Huxley, « Evolution and ethics. Prolegomena », p. 44.

14. S. Freud, « Caractère et érotisme anal », p. 147.

15. J. Berke, The tyranny of malice, p. 73.

16. S. Freud, Le Malaise dans la civilisation, p. 64-65.

17. C. G. Jung, «Über die Psychologie des Unbewussten », p. 55.

18. P. Kropotkine, L'Entr'aide, p. 39-40, 58, 63, 139, 322.

19. K. Lorenz, L'agression, p. 63.

20. M. Midgley, Beast and Man, p. 5, 40.

\section{RÉSUMÉS}

L'éthologiste Frans De Waal a relancé récemment la thèse selon laquelle les éléments fondamentaux de la moralité dérivent des façons d'agir et même de sentir qu'on constate, à différents niveaux, chez les mammifères. C'est une idée qu'on trouve déjà dans Darwin et qui fut reprise par plusieurs auteurs, notamment par Kropotkine. Elle s'oppose non seulement aux doctrines de l'origine surnaturelle de la morale, mais aussi à la thèse, elle aussi issue de 
l'évolutionnisme, selon laquelle l'animalité de l'homme est le fardeau héréditaire, encombrant et dangereux, que l'homme doit maîtriser pour devenir moral. De Galton à Brunetière, de Taine à Zola, aux psychologues des foules, c'est une réinterprétation évolutionniste du péché originel et de l'idée ancienne de la «bête dans l'homme». Mais les traits qu'on attribue à cette bête qui menace constamment de remonter à la surface sont décidément « humains, trop humains »

\section{AUTEUR}

ANTONELLO LA VERGATA

Professeur d'Histoire de la philosophie, dipartimento di Studi linguistici e culturali, università di Modena e Reggio Emilia 


\title{
«Ce sont les principaux maîtres des maîtres du monde » (Pline l'Ancien $\mathrm{X}, 24)$ : le coq dans les religions romaine, grecque et gauloise
}

\author{
Michaël Seigle
}

1 Au début de l'opérette d'Offenbach « La Belle Hélène », le devin Calchas s'exclame :

«De piètres offrandes, en vérité... deux tourterelles, une amphore de laitage, trois petits fromages, des fruits très peu, et des fleurs beaucoup. Toutes ces guirlandes nous encombrent en pure perte [...] Il est passé, le temps des troupeaux de bœufs et de moutons [...] Voilà où en sont les sacrifices! [...] Les dieux s'en vont ! Les dieux s'en vont ! ${ }^{1}$

2 Cette citation est révélatrice de la vision que nous avons du sacrifice grec et antique en général, née de la lecture d'Homère, d'Hésiode ou encore de Virgile, à savoir l'offrande en grand nombre de certains mammifères domestiques spécifiquement choisis en fonction de la divinité à honorer. Si, dans la réalité, la plupart d'entre elles recevaient effectivement le sacrifice d'animaux sélectionnés selon leur espèce, leur sexe et leur couleur (à l'instar de Déméter recevant surtout des truies en offrande ou Jupiter des taureaux blancs), l'archéozoologie a montré que d'autres espèces supplétives apparaissaient, souvent en petite quantité. La poule, par exemple, totalement absente des épopées, de la mythologie et en grande partie des prescriptions rituelles s'avère pourtant présente dans de nombreux contextes rituels et cultuels.

Cependant, si pour la Grèce et Rome, les pratiques religieuses et rituelles nous sont aussi bien connues par la littérature que par l'archéozoologie et l'épigraphie, en Gaule ce domaine est essentiellement appréhendé par le biais des seules découvertes archéologiques. Par ailleurs, la place de la poule dans les pratiques religieuses antiques va bien au-delà du seul sacrifice sanglant et communautaire, comme c'est le cas pour la triade domestique (bœuf, porc et caprinés), car ce volatile y joue un rôle actif de son vivant. 


\section{Le coq vivant : devin ou oiseau sacré ?}

\section{L'oiseau chanteur et divinatoire}

4 En effet, les Hommes de l'Antiquité considéraient la poule, et surtout le coq, liés en tant qu'oiseaux au monde céleste, comme des annonciateurs vivants des volontés divines et attachaient beaucoup d'importance à l'observation de leur comportement, révélateur du destin et de l'avis divin sur les actions humaines.

5 Ainsi, le chant du coq est le premier élément que mettent en avant les textes anciens ${ }^{2}$. La première inscription égyptienne et le premier texte grec à évoquer l'espèce nous décrivent d'abord son cri précédant le lever du jour ${ }^{3}$. L'animal est le héraut solaire par excellence, qui prédit chaque matin la venue d'un nouveau jour aux hommes et les éveille dès l'aube pour leurs activités quotidiennes ${ }^{4}$. Cette aptitude unique l'a fait considérer par les Grecs, les Romains et bien d'autres peuples anciens comme un devin ou un messager des dieux. Dans le récit de la bataille de Leuctres, opposant Spartiates et Thébains, Cicéron et Callisthène rapportent qu'avant l'engagement du combat, plusieurs signes annonçaient la défaite spartiate, parmi lesquels le fait que tous les coqs de Trophonius, au cours d'un sacrifice précédant la bataille, se mirent à chanter en même temps et sans s'arrêter, ce que les prêtres béotiens accueillirent comme l'annonce de la victoire des Thébains ${ }^{5}$. Par ailleurs, Pétrone, dans son Satiricon, nous montre un Trimalcion paniqué par le chant d'un coq survenu au cours de son repas et le traduit comme une annonce de mauvais augure. Il propose alors à ses convives de s'emparer de l'oiseau chanteur pour le faire rôtir et ainsi détourner le mauvais sort ${ }^{6}$.

6 Ce chant annonciateur du dieu solaire et du destin a fait du coq un oiseau-devin consulté par les hommes de diverses manières. À Rome, la prise d'augures par l'observation du vol des oiseaux a peu à peu été remplacée par le tripudium, c'est-à-dire l'observation du comportement de coqs à qui l'on présentait de la nourriture. Suivant leur appétit on en déduisait les arrêts du destin qui influençaient les actions publiques de la Cité et de ses représentants ${ }^{7}$. Une nouvelle catégorie d'augures vit le jour, les pullaires, chargés d'interpréter le comportement de ces coqs tant pour les généraux en campagne, tels Papirius ${ }^{8}$, au IV siècle av. J.-C. ou Caius Flaminius, au siècle suivant ${ }^{9}$, que pour des sénateurs et dignitaires, tout acte public nécessitant l'approbation divine.

7 Un autre mode de divination faisant appel au coq, plus difficile à dater car seulement attesté par des auteurs tardifs, comme Jean Zonaras, au XII siècle, est l'alectryomancie. Cette pratique consiste à tracer un cercle ou un carré divisé en cases contenant les lettres de l'alphabet sur lesquelles sont placés des grains de blé. En fonction des grains que l'oiseau vient picorer, il devient possible de reconstituer la réponse des dieux ${ }^{10}$.

8 Ces consultations d'augures spécialisés n'excluent pas l'interprétation du comportement de l'oiseau par les profanes. Ainsi, nous rapporte Suétone, d'un coq qui vint se percher sur l'épaule puis la tête de Vitellius, lors de sa marche vers Rome, il en conclut, a posteriori, qu'il serait piétiné par un Gaulois (rappelons l'homonymie entre gallus, le coq, et Gallus, le Gaulois), ce qui fut le cas puisqu'il fut tué par un général né à Toulouse, Antonius Primus ${ }^{11}$.

9 Bien entendu, les entrailles du poulet, comme celles des autres animaux sacrifiés, étaient auscultées pour prédire l'avenir. L'hépatoscopie et l'haruspicine étrusques étaient ainsi conviées, à Rome, lors de chaque sacrifice public (et peut-être privé, chez 
les plus riches) afin de connaître l'avis des dieux sur les grandes actions publiques ${ }^{12}$. Les haruspices vérifiaient les entrailles de la victime ainsi que leurs éventuelles déformations pour savoir si les dieux agréaient ou non le sacrifice qui leur avait été fait et s'ils seraient donc favorables au dédicant. Dès lors, plusieurs poulets pouvaient être sacrifiés avant d'obtenir l'autorisation des divinités.

\section{Le coq est-il un oiseau sacré en Gaule?}

Le coq semble arriver en Gaule au premier âge du Fer et s'y répand peu à peu en commençant par des sites économiquement importants, car situés sur de grands axes d'échanges, tels Lyon (Rhône) ${ }^{13}$, Illfurth (Haut Rhin) ${ }^{14}$ et Basly (Calvados) ${ }^{15}$. Jusque vers 500-450 av. J.-C., les rares individus recensés ne portent pas de traces de consommation ${ }^{16}$. Ces éléments laissent supposer que l'espèce a d'abord été réservée à une élite, sans doute pour le plaisir de l'élevage et l'aspect exotique de l'animal ${ }^{17}$, peutêtre pour le combat de $\operatorname{coq}^{18}$ mais aussi pour des motifs religieux ${ }^{19}$.

11 Toutefois, l'allégation de César concernant l'interdit alimentaire posé sur la poule par les peuples bretons ne semble pas pouvoir être appliquée à la Gaule de la fin du premier âge du Fer ${ }^{20}$. En effet, l'interdit breton ne se porte pas seulement sur la poule mais aussi sur l'oie et le lièvre, deux espèces consommées en Gaule avant l'introduction de notre oiseau. En revanche, il est tout à fait plausible que le coq, en annonciateur du lever du soleil et en "devin», ait d'abord été élevé en tant que curiosité et qu'animal divinatoire, avant de se démocratiser. Nous ignorons toutefois les modalités pratiques de son utilisation dans les pratiques divinatoires gauloises. D'une certaine manière, il est possible d'envisager que l'espèce ait été «sacrée » au sens latin du terme sacer, à savoir « consacrée aux dieux, mise à part ».

\section{L'oiseau sacrifié}

\section{Le coq dans les sacrifices « classiques »}

En Grèce comme à Rome, où les sacrifices sont régis par des codes et des pratiques précises, certaines espèces sacrifiées sont spécifiquement associées à certaines divinités ${ }^{21}$. Ainsi, le sacrifice du porc était-il essentiellement réservé au culte de Déméter ${ }^{22}$, tandis que l'on préférait offrir à Zeus et à Jupiter des bœufs ${ }^{23}$ et des colombes à Aphrodite et à Vénus ${ }^{24}$. La place des gallinacés demeure plus difficile à estimer, les textes mentionnant rarement leur emploi dans le cadre des sacrifices antiques.

Quelques récits nous rappellent tout de même l'importance du coq dans le culte rendu à Asclépios. Socrate, qui vient de boire la cigüe, dit ainsi à son disciple Criton: «nous devons un coq à Asclépios $»^{25}$. Dans le Mime IV d'Hérondas, deux femmes viennent offrir un coq au dieu guérisseur ${ }^{26}$. Ces exemples littéraires et épigraphiques abondent dans le sens d'un lien entre le dieu de la médecine, fils d'Apollon, et l'oiseau qui annonce le jour ${ }^{27}$. Dès lors, faut-il voir ici le coq comme un annonciateur du jour de la guérison? Ou encore comme celui qui réveille les malades qui ont été invités à dormir dans le sanctuaire pour recevoir, en songe, les conseils guérisseurs du dieu et les invite donc à mettre en pratique les paroles divines ? 
14 Mais Asclépios n'est pas le seul dieu dont les textes nous disent qu'il recevait des coqs en sacrifice. En effet, une tradition spartiate rapportée par Plutarque mentionne un tel don destiné à Arès. Selon cet auteur, le dieu de la guerre se voyait offrir un coq blanc en remerciement d'une victoire militaire parfaite, tandis qu'un bœuf lui était consacré si la victoire avait été remportée par ruse ${ }^{28}$. Le coq est ici mis sur un pied d'égalité avec la victime sacrificielle la plus prestigieuse de la religion grecque et sa combativité est rapprochée de la nature belliqueuse d'Arès ${ }^{29}$. Cependant, quoique cette pugnacité soit très souvent exaltée par les Grecs puis les Romains, nous avons ici l'un des très rares exemples d'offrande de cet oiseau à une divinité guerrière. En effet, le coq est absent des sacrifices et du culte d'Athéna, pourtant déesse guerrière, bien qu'il figure sur le casque de la grande statue d'Athéna Erganè, à Elis, décrite par Pausanias. Cette épiclèse «Erganè » (ouvrière) renvoie cependant à l'aspect artisanal de la déesse plus qu'à son aspect combatif ${ }^{30}$. Par ailleurs, de nombreuses amphores panathénaïques présentent pour motif Athéna entourée de deux colonnes surmontées par des coqs, symboles de sa nature guerrière ${ }^{31}$.

L'archéozoologie révèle une réalité quelque peu différente puisque la poule et le coq, bien qu'ils ne soient représentés que par un petit nombre de restes dans quelques temples, sont associés à presque toutes les grandes divinités du panthéon antique. On les retrouve ainsi sur l'autel de la Stoa Poikilé, à Athènes, dédiés à Aphrodite dès le début du v $v^{\mathrm{e}}$ siècle av. J.-C..$^{32}$, auprès d'Héra à peu près à la même époque à Poséidonia ${ }^{33}$, de Déméter durant la période hellénistique à Mythilène ${ }^{34}$, d'Apollon au $\mathrm{IV}^{\mathrm{e}}$-III ${ }^{\mathrm{e}}$ siècle av. J.C. à Halasarna... ${ }^{35}$ Cette pratique d'offrande de gallinacés finit même par se généraliser à tous les cultes, à partir du $\mathrm{I}^{\mathrm{er}}$ siècle de notre ère, en particulier dans nombre de sanctuaires romains et celto-romains dédiés à Mercure. Un tel lien entre Mercure et l'oiseau se retrouve dans les très nombreuses représentations occidentales du dieu, qui est généralement accompagné d'un bouc, d'un chien, d'une tortue, d'un coq ou de plusieurs de ces animaux ${ }^{36}$. Cela est particulièrement vrai en Gaule et en Bretagne, où le dieu romain du commerce est associé à Lug, également dieu de la communication ${ }^{37}$. Il s'explique sans doute par leur fonction commune de messagers divins, Mercure étant principalement celui de Zeus/Jupiter ${ }^{38}$. En outre, peut-être faut-il chercher un lien entre le nom de Lug, que de nombreux chercheurs font dériver du nom de la lumière ${ }^{39}$, et l'annonce quotidienne de l'aube par le coq. Cependant, dans tous les cas présentés précédemment, le coq demeure une offrande dont les restes sont marginaux face aux mammifères domestiques, en particulier ceux appartenant à la triade domestique, soit qu'il soit peu offert aux dieux, soit que la consommation de sa chair, après le sacrifice, en ait fait disparaître la majeure partie des os.

\section{L'oiseau dans les cultes « orientaux »}

16 Si la poule occupe une place réelle mais anecdotique dans tous les types de cultes grecs et romains, privés ou publics, elle devient beaucoup plus présente, voire omniprésente, dans les cultes dits « orientaux » ou " à mystères » et notamment ceux d'Isis, de Mithra et, dans une moindre mesure, de Cybèle. Le culte de ces trois divinités se caractérise en effet par un grand nombre d'offrandes de poules, coqs et poulets, généralement consommés par la suite par les célébrants et les assistants. Sur les sites associés à ces cultes, le nombre de restes et le nombre minimum d'individus sont très largement supérieurs à ceux des autres espèces. Ainsi, dans le temple d'Isis et Magna Mater, à 
Mayence, l'espèce représente $90 \%$ des restes osseux appartenant aux rejets de bûchers sacrificiels ${ }^{40}$. Dans le sanctuaire isiaque de Bélo, en Espagne, ce sont $73 \%$ des restes osseux qui appartiennent à la poule ${ }^{41}$, et encore entre 70 et $90 \%$ de ceux retrouvés dans les dépôts de l'autel d'Isis et Sarapis à Délos ${ }^{42}$. Le culte isiaque, qui, en Égypte, se caractérise plutôt par le sacrifice de jeunes bœufs et d'oies, semble donc s'être adapté, en Occident et en Grèce, et avoir très largement privilégié la poule et le $\operatorname{coq}^{43}$.

Dans le cadre du culte mithriaque, l'importance du dieu Soleil offre une place de choix au héraut solaire qu'est le $\operatorname{coq}^{44}$. Cependant, il n'intervient que dans une partie bien spécifique du rituel : le banquet. Après l'immolation du taureau, en souvenir de l'acte fondateur de Mithra, les initiés étaient conviés à partager un banquet rituel au cours duquel la poule était abondamment représentée ${ }^{45}$. Dans le mithraeum de Septeuil (Yvelines), plus de 6000 restes lui sont attribués ${ }^{46}$, de même que la grande majorité des restes d'animaux de ceux de Londres ${ }^{47}$ ou de Kunzing (Allemagne) ${ }^{48}$. Si tous les mithraea ne se caractérisent pas par une telle surabondance de restes de poulets, l'espèce $y$ demeure toujours mieux représentée que dans les dépotoirs domestiques des quartiers alentour. Ainsi, dans le mithraeum de la Crypta Balbi, à Rome, $20 \%$ des restes correspondent à des ossements de poule, tandis que l'espèce ne représente que $7 \%$ de la faune dans les quartiers proches ${ }^{49}$. De même, à Martigny (Suisse), où ont été retrouvés plus de 10000 restes dans le sanctuaire et presque autant dans l'habitat, le mithraeum a livré $31 \%$ de restes de volailles contre $2 \%$ au sein de la zone d'habitation ${ }^{50}$. Les exemples de ce genre ne manquent pas, qui mettent également en avant une présence de la poule plus importante dans les sanctuaires de Mithra que dans les temples de divinités « classiques».

Si les temples de Cybèle livrent moins de restes de gallinacés que ceux dédiés à Isis ou Mithra, ces trois cultes à mystères partagent certaines caractéristiques comme l'initiation individuelle des assistants, la croyance en une vie après la mort et, souvent, la tenue d'un banquet rituel réunissant tous les participants au sacrifice ${ }^{51}$. La présence et l'abondance de la poule dans un tel contexte nous permettent d'entrevoir les valeurs probablement attribuées au coq dans ces cultes. Outre son rôle symbolique d'éveilleur des hommes du sommeil de la mort, il devient également l'offrande individuelle par excellence, beaucoup plus pratique et abordable qu'un taureau ou un porc entier. En ce sens, le sacrifice du coq pourrait être perçu comme un symbole d'individualité et une volonté de créer un lien direct avec les dieux, comme une offrande personnelle de qualité de l'initié à sa divinité, suivie d'un partage entre eux.

Par ailleurs, la poule se retrouve également dans d'autres sanctuaires occidentaux de divinités « orientales ", à l'instar du temple de Jupiter Héliopolitain, à Mühlacker, en Autriche. Une fosse du sanctuaire, riche en faune, a ainsi livré 833 restes d'au moins 121 poulet $^{52}$. Cela s'avère en réalité assez faible, comparé à l'immense quantité de restes de bœufs identifiés et montre bien la spécificité des gallinacés, y compris au sein des cultes orientaux, des cultes à mystères, où cette espèce joue un rôle important et pas seulement par son aspect culinaire.

\section{La situation en Gaule}

Les sanctuaires des âges du Fer découverts en Gaule ont, pour la plupart, livré des restes osseux qui s'avèrent être la seule manière d'approcher le sacrifice gaulois, ce dernier ne faisant l'objet que de très rares mentions dans les textes latins, ceux-ci 
visant avant tout à montrer les Gaulois comme des barbares sacrifiant des humains à leurs divinités ${ }^{53}$. En outre, la méconnaissance des divinités honorées dans les sanctuaires retrouvés par l'archéologie, pour cette époque, empêche le moindre rapprochement entre le sacrifice d'un animal en particulier et la présence d'un culte spécifique.

21 Dans les sacrifices gaulois, le poulet semble tenir une place similaire à celle qu'il occupe dans les sanctuaires grecs et latins. L'espèce, absente de certains sanctuaires, n'est que faiblement représentée au sein du cortège faunique des espèces consommées, ne dépassant que très rarement $2 \%$ des restes déterminés ${ }^{54}$, dans des proportions identiques à celles constatées sur les sites d'habitats gaulois ${ }^{55}$. À notre connaissance, ce fait ne semble pas connaître d'exception et la poule apparaît ainsi comme une espèce en marge des sacrifices gaulois, notamment par rapport aux espèces de la triade domestique, au chien ou même au cheval.

La période romaine ne semble pas marquer de changement radical dans l'utilisation rituelle de la poule en Gaule, alors même que l'espèce occupe une place de plus en plus importante dans la consommation domestique, aux côtés de la triade domestique. Sur le temple de Mercure, au sommet du Puy de Dôme, où le dieu et l'oiseau sont étroitement liés par la tradition, la poule ne représente que $3 \%$ environ des restes de l'amas d'ossements déposé dans le temple au $\mathrm{II}^{\mathrm{e}}$ siècle de notre ère ${ }^{56}$. Il existe néanmoins quelques rares exceptions, comme le sanctuaire d'Ognon, dans l'Oise, où les gallinacés occupent la troisième place parmi les offrandes, avec $20 \%$ des restes identifiés ${ }^{57}$.

23 À l'époque gauloise, le seul domaine où elle s'avère légèrement mieux représentée est celui du banquet communautaire. Cependant, même dans ce cas précis, l'espèce n'est jamais majoritaire, quoiqu'elle dépasse parfois les $2 \%$ de représentation ${ }^{58}$. Cette abondance relative semble alors surtout liée au statut de viande de qualité dont jouit la poule, la qualité du repas étant essentielle dans ce genre de rassemblement de la communautés ${ }^{5}$.

\section{L'oiseau consommé et offert : la place de la poule dans les tombes}

Les pratiques funéraires nous éclairent également sur la place de la poule dans l'univers religieux. Les rites funéraires grecs ne semblent jamais faire appel aux gallinacés ou alors en amont de l'incinération du corps, pratique hautement destructive pour les os d'oiseaux. Aussi nous attarderons-nous davantage sur ceux des Gaulois, avant et après la conquête.

L'espèce ne semble apparaître dans les tombes gauloises qu'à l'époque de La Tène et, dans un premier temps, au sein des tombes à char assez riches, comme celles de Châlons-en-Champagne (Marne) ${ }^{60}$ ou de Somme-Tourbe (Marne) ${ }^{61}$. On la retrouve rapidement, en petite quantité, dans quelques tombes de certaines nécropoles, mais sans égard particulier envers le statut social, le mode d'inhumation ou le sexe de l'individu ${ }^{62}$. À partir de la conquête romaine, l'espèce va progressivement occuper une place de plus en plus importante parmi les offrandes funéraires, devenant rapidement la deuxième espèce rencontrée dans ce contexte juste après le porc ${ }^{63}$. Durant l'Antiquité tardive, la poule et le coq deviennent, généralement, les seules offrandes carnées déposées avec le corps du défunt, dans un plat situé sur ou près des jambes de ce dernier. Le fort développement du christianisme, dans les siècles suivants, va peu à peu 
faire disparaitre ces pratiques rituelles normalisées, qui demeurent néanmoins encore prégnantes dans les régions païennes du nord-est de la Gaule jusqu'au viI ${ }^{\mathrm{e}}$ siècle de notre ère $e^{64}$.

L'analyse de ces dépôts de viande révèle, en général, la bonne qualité de cette nourriture destinée au défunt, privilégiant, pour les mammifères, des animaux jeunes. Dans ce contexte, la poule est quelquefois déposée entière mais, le plus souvent, elle est placée dans un plat à un stade plus ou moins avancé de préparation, souvent sans la tête ni les extrémités des pattes, ou bien avec les différentes parties du corps découpées avant d'être reconstituées ${ }^{65}$. Ces éléments sont autant de preuves d'une cuisine faite pour le défunt, qui partageait de la sorte, symboliquement, un dernier repas avec les vivants, en recevant sa part des victuailles. Une part parfois assez importante, puisqu'elle pouvait consister, du moins jusqu'à l'Antiquité tardive, en un demi-porc et d'autres pièces de viande, comme dans la nécropole de Lamadeleine (Luxembourg) ${ }^{66}$.

Cette viande de qualité, souvent mise en scène dans la tombe ${ }^{67}$, et ce partage avec les vivants évoquent fortement l'univers du banquet, la plus belle part étant réservée au défunt, auquel la communauté consentait à fournir une nourriture si abondante qu'il n'aurait pu la consommer à lui seul au cours d'un seul repas. La poule joue donc, dans ce cadre, le rôle d'un mets de choix mais représente aussi l'un des rares animaux qu'un homme seul pourrait manger en intégralité en un seul repas. Ce dernier point explique peut-être la généralisation des dépôts de poulets dans les tombes gallo-romaines, par la suite, l'oiseau constituant à la fois une nourriture de qualité et une viande accessible à toutes les classes sociales, de par son prix, tout en permettant d'offrir au mort un repas correct et consistant.

\section{Rituels domestiques, privés et magiques}

\section{Sacrifices et offrandes domestiques}

Le coq se retrouve également dans la sphère de la religion privée. Plusieurs laraires publics et privés de Pompéi, et un autre à Empuries (Catalogne), comportent l'image d'un coq au-dessus de l'autel ${ }^{68}$. À Mandeure (Doubs), un groupe laraire présente un Lare entouré d'un côté par un petit autel et un porcelet et, de l'autre, par un serpent et un $\operatorname{coq}^{69}$. Les données archéozoologiques sont plus rares, mais un autel dédié aux Lares Compitales, les divinités protectrices des carrefours, à Pompéi, a livré les restes d'une moitié de poulet sacrifié sur l'autel peu avant l'éruption du Vésuve, l'autre moitié ayant sans doute été consommée par le dédicant ${ }^{70}$. De la même manière, une fosse accolée au laraire domestique de la maison d'Amaranthus a livré de très nombreux restes de poules et de coqs. Les restes retrouvés dans cette fosse attestent parfaitement de ce partage de l'animal sacrifié entre les divinités domestiques et les habitants de la maison puisque nous y retrouvons essentiellement des extrémités de pattes, part réservée aux Lares et aux Pénates, avec la tête ${ }^{71}$. Par ailleurs, Juvénal, dans sa $13^{\mathrm{e}}$ satire, évoque l'offrande d'une crête de coq aux divinités domestiques pour écarter la maladie ${ }^{72}$.

En définitive, les gallinacés devaient fréquemment être offerts en sacrifice dans le cadre des rituels privés, du fait de la qualité de la chair partagée entre divinités et dédicants et de la praticité de leur emploi pour un tel usage. 


\section{Pratiques magiques et rites de protection}

30 La littérature antique nous fournit quelques rares exemples de rites de protection faisant appel aux gallinacés. Selon Pausanias, un rituel effectué à Méthana, en Argolide, pour protéger les vignes du vent du sud-est, impliquait le sacrifice d'un coq blanc qui était ensuite coupé en deux. Deux hommes, tenant chacun une moitié de l'oiseau, faisaient le tour des plantations avant d'enterrer le cadavre sur le lieu de départ ${ }^{73}$. Pourrait-on y voir une volonté d'enfermer la violence du vent destructeur dans le corps $\mathrm{du}$ coq dont la blancheur peut rappeler l'akousmaton de Pythagore, qui le lie à Zeus ${ }^{74}$ ? Rien n'est moins sûr puisqu'il semble que cette pratique soit apparue à Pausanias comme assez étrange et pittoresque pour qu'il la mentionne.

D'autres rites de protection difficiles à interpréter sont livrés par l'archéologie. En Gaule méridionale, on trouve ainsi des dépôts d'oiseaux en vases, placés au sein des maisons, entre le III ${ }^{\mathrm{e}}$ siècle av. J.-C. et le III ${ }^{\mathrm{e}}$ siècle apr. J.-C..$^{75}$. Toutefois, l'absence d'étude spécifique des restes aviaires, dans un grand nombre de cas, ne nous permet pas de connaître l'espèce utilisée, à l'exception du dépôt de la ferme de Caramany (PyrénéesOrientales), dont la chronologie s'étend du $\mathrm{I}^{\mathrm{er}}$ au milieu du $\mathrm{III}^{\mathrm{e}}$ siècle de notre ère. Ce site a livré quatre vases, enterrés devant la porte d'une pièce. Chacun d'eux a livré une tête de poule (ou de coq, dans un cas) accompagnée du reste du corps entier et non découpé, signe que les oiseaux ont sans doute été égorgés et leur sang récupéré dans les vases puis mélangé, dans un cas, à un œuf. Il faut sans doute voir là un rituel magique ou de protection visant à se concilier des divinités inférieures, voire les Mânes et les Lémures ${ }^{76}$, vivant au niveau du sol, dans les croyances romaines, et se nourrissant des aliments qui y tombent. À moins qu'il ne faille y voir, comme dans tous les dépôts de ce type, en Catalogne et en Languedoc, un rituel de protection gallo-ibère.

Enfin, la poule et le coq sont fréquemment convoqués lors de rituels magiques consignés sur des papyri. Le coq est privilégié dans la plupart de recettes retrouvées, en particulier pour les questions amoureuses, l'oiseau étant considéré, depuis Aristote ${ }^{77}$, mais aussi chez Varron $^{78}$, comme sexuellement actif voire agressif. Les seuls autres oiseaux à être utilisés dans ce genre de rituel sont le pigeon et l'oie. Les rituels décrits par ces papyri peuvent prendre plusieurs formes plus ou moins développées, mais supposent toujours la mise à mort de l'oiseau par un sacrifice sanglant, par étouffement ou par décapitation. La plupart du temps, l'animal est intégralement offert à la divinité, souvent par holocauste. Plus rarement, l'officiant peut être invité à consommer seul l'oiseau, en secret, étant entendu que c'est d'abord le souffle de vie de la victime qui revient au dieu invoqué ${ }^{79}$. Le choix du coq s'explique assez facilement par sa petite taille, son faible coût mais aussi par son statut, en tant qu'oiseau, de messager des dieux et porteur de présages ${ }^{80}$.

Ces différentes utilisations des gallinacés, morts ou vifs, nous permettent d'identifier les valeurs attribuées à l'espèce dans le domaine religieux mais aussi profane. Par son association avec Arès/Mars, que les mythographes tardifs présentent comme le créateur de l'oiseau par la métamorphose de son ami Alektryon ${ }^{81}$, ou encore avec Athéna, le coq est un symbole du combat et du courage. Son agressivité sexuelle, mise en avant par de nombreux auteurs antiques, est exploitée dans les rites magiques, 
notamment, où il est associé à $\operatorname{Eros}^{82}$. Mais c'est surtout par son chant que le coq a marqué les esprits, l'identifiant ainsi à une figure solaire annonciatrice de l'avenir et des arrêts divins. Ce statut de devin aboutit à la création, à Rome, d'une charge augurale spécifique, celle des pullaires, chargés d'observer des coqs en train de manger (pour en extraire des présages). L'animal devient même le «maître des maîtres du monde ", selon le mot de Pline l'Ancien ${ }^{83}$, car, à Rome du moins, aucune grande action publique ne pouvait se faire sans consultation des coqs. En tant que messager des dieux, le coq s'est vu associé à Hermès/Mercure, messager de Zeus/Jupiter, et par acculturation à Lug, le dieu lumineux, équivalent de Mercure. Cette association de l'oiseau à Mercure a pu faire naître une autre symbolique du coq, l'aspect psychopompe du dieu se superposant à l'image du gallinacé "rédempteur" - au sens où il accompagne le passage de la mort à la vie.

D'autre part, sa présence au sein des sanctuaires et, notamment, dans ceux impliquant un culte à mystères nous rappelle que cet oiseau devait tout simplement incarner l'offrande individuelle par excellence, à l'opposé du sacrifice du bœuf des cultes "classiques", symbole majeur de l'offrande communautaire. Aussi constitue-t-il logiquement l'une des offrandes principales à Asclépios/Esculape, invoqué directement par les malades, mais aussi à Isis, Cybèle ou Mithra, dont le culte reposait sur un engagement personnel. En outre, ces cultes évoquent tous l'idée d'une vie après la mort et le coq annonciateur de la renaissance perpétuelle du soleil devient, en quelque sorte, le héraut du réveil des morts.

Dans le même ordre d'idée, la progression des dépôts de gallinacés parmi les offrandes alimentaires met en avant ce symbole d'individualité. Le mort reçoit, au cours d'un dernier repas symbolique, partagé avec les siens, la meilleure part de la nourriture consommée et en quantité conforme à ses besoins quotidiens. Ainsi, tandis que le bœuf sacrifié aux dieux représente une forme d'abondance et un partage impliquant toute la communauté, le coq apparaît comme l'oiseau offert aux dieux par un petit nombre, voire par un seul individu soit dans une logique de partage étroit soit comme don total du mortel à l'immortel.

\section{BIBLIOGRAPHIE}

Aristote, Histoire des animaux, tome III, livres VIII-X, texte établi et traduit par LouIs P., Les Belles Lettres, Paris, 1969.

AUXIETTE G. 1995, L'évolution du rituel funéraire à travers les offrandes animales des nécropoles gauloises de Bucy-le-Long (450/100 avant J.-C.), Anthropozoologica, $n^{\circ} 21$, p. 245-252.

BAUDRY A. 2005, Approvisionnement et alimentation carnée sur les sites de l'âge du Fer en Bretagne et en Normandie. L'exemple du site de « la campagne » à Basly, Calvados, Revue Archéologique de l'Ouest, 22. BELLON C. 1997, 2-6 rue de la Fraternelle - 29-31 rue de Gorge de Loup 69009 Lyon : DFS de sauvetage urgent. 
BRUNEAU P. 1965, Le motif des coqs affrontés dans l'imagerie antique, Bulletin de correspondance hellénique, $\mathrm{n}^{\circ} 89$, pp. 90-121.

César, Commentarii de Bello Gallico, tome II, texte établi et traduit par consTANS L.-A., $14^{\mathrm{e}}$ édition revue et corrigée, Les Belles Lettres, 2014.

Cicéron, De divinatione, traduction de KANY-TURPIN J., Flammarion, Paris, 2004.

Cicéron, De legibus, (Traité des lois) texte établi et traduit par DE PLINVAL G., Les Belles Lettres, Paris, 1968.

(Collectif) Thescra, Thesaurus cultus et rituum antiquorum (ThesCRA). I. Processions, sacrifices, libations, fumigations, dedications, Jean-Paul Getty Museum et fondation pour le LIMC, Los Angeles, 2004.

CUMONT F. 1942, Le coq blanc des Mazdéens et des Pythagoriciens, Comptes rendus de l'Académie des Inscriptions et Belles-Lettres, volume 86.

Diogène Laërce, Doctrines, Vies et sentences des philosophes illustres, texte traduit par GENAILLE R., Garnier-Flammarion, Paris, 1965.

DOHERTY S. 2013, New Perspectives on Urban Cockfighting in Roman Britain, Archaeological Review from Cambridge, 28, Cambridge.

Élien, Histoire variée, traduit et commenté par LUKINOVITCH A. et MORAND A.-F., Les Belles Lettres, la Roue à Livres, Paris, 1991.

FABRE V., FOREST V., KOTARBA J. 1999, Dépôts cultuels domestiques dans la ferme d'époque romaine du Pla de l'Aïgo (Caramany, Pyrénées-Orientales), Revue Archéologique de Narbonnaise, vol. 32, issue 1, pp. 271-292.

Festus Grammaticus, De la signification des mots, traduit par SAVAGNER M. A., Panckoucke, 1846. FEUGÈRE M. 2007, Cultes domestiques en Languedoc préromain : magie ou religion ?, Ephesia Grammata, 1-2007, pp. 1-10.

FOSTER G. V. 1984, The bones from the altar west of the painted stoa, Hesperia: The Journal of the American School of Classical Studies at Athens, vol. 53, $\mathrm{n}^{\circ} 1$.

FOURDRIGUIER E. 1876, Double sépulture gauloise de la Gorge Meillet, Mémoires de la Société d'Agriculture, Commerce, Sciences et Arts du Département de la Marne, 1875-1876.

GAIDON-BUNUEL M.-A. et CAILlat P. 2008, « Honorer Mithra en mangeant : la cuisine du mithraeum de Septeuil », dans LEPETZ S. et VAN ANDRINGA W., Archéologie du sacrifice animal en Gaule romaine : rituels et pratiques alimentaires, Archéologie des plantes et des animaux 2, Monique Mergoil, Montagnac, pp. 255-266.

GÁL E., KUNST G. K. 2014, Offered to Gods, Eaten by People: Bird Bones from the Sanctuary of Jupiter Heliopolitanus in Carnuntum-Mühläcker (Austria), International Journal of Osteoarchaeology, $\mathrm{n}^{\circ} 24$, pp. 336-346.

GARCIA-PETIT L. 2002, « La migration du coq, de l'Extrême-Orient à la Méditerranée », dans GARDEISEN A. (ed.) Mouvements ou déplacements de populations animales en Méditerranée au cours de l'Holocène, BAR International Series 1017.

GARCIA-PETIT L. 2005, "Recent studies on prehistoric to medieval bird bones remains from Catalonia and Southeast France", dans GRUPE G. et PETERS J., Feathers, Grit and Symbolism: birds and humans in the ancient old and new worlds, Documenta Archaeobiologiae, $\mathrm{n}^{\circ} 3$. 
HAAK M.-L. 2003, Les haruspices dans le monde romain, Ausonius, Scripta antiqua 6, De Boccard, Paris, 2003.

Hérondas, Mimes, texte établi par ARBUTHNOT NAIRN J., traduit par LALOY L., Les Belles Lettres, Parsi, 1960.

Hésiode, Théogonie, texte établi et traduit par MAzon P., Les Belles Lettres, Paris, 2012.

HILY G. 2012, Le dieu celtique Lugus, Publication du Centre de recherche bretonne et celtique de l'Université Rennes 2, Rennes.

HOCHMUTH M. et WITTEYER M. 2008, « Holocaustes et autres offrandes alimentaires dans le sanctuaire d'Isis et Magna Mater à Mayence ", dans LEPETZ S. et Van ANDRINGA W., Archéologie du sacrifice animal en Gaule romaine : rituels et pratiques alimentaires, Archéologie des plantes et des animaux 2, Monique Mergoil, Montagnac, pp. 119-124.

Homère, Odyssée, texte traduit par Dufour M. et RAISON J., Garnier-Flammarion, Paris, 1965.

Jean Zonaras, Epitomè historion, Lipsiae, Bibliotheca Teubneriana.

Juvénal, Satires, texte établi et traduit par de LABRiolle P. et villeneuve F., Les Belles Lettres, Paris, 1983.

LAFORGE M.-O. 2009, La religion privée à Pompéi, Études - Centre Jean Bérard 7, Naples.

LEGUILLOUX M. et BRUN H. 2013, « Rituels sacrificiels et offrandes animales dans le Sarapieion C de Délos ", dans EKROTH G. et WALLENSTEN J., Bones, behaviour and belief : the zooarchaeological evidence as a source for ritual practice in ancient Greece and beyond, Svenska Institutet I Athen, Stockholm, pp. 167-179.

LEGUILLOUX M., BRUN J.-P., CAVASSA L., MUNZI P. 2015, « Banquets rituels à Cumes au IV siècle av. J.C. », dans ROURE R. (ed.), Contacts et acculturations en Méditerranée occidentale, Arles, 15, pp. 81-97. LEMOINE R. 1905, Sépulture à char, découverte le 10 mars 1904 à Châlon-sur-Marne, Mémoires de la Société d'Agriculture, Commerce, Sciences et Arts du Département de la Marne, T. 8, pp. 123-150. LENTACKER A., ERVYNCK A., VAN NEER W., 2004, “Gastronomy or religion? The animal remains from the mithraeum at Tienen (Belgium)”, dans JONES O'DAY S., VAN NEER W. et ERVYNCK A., Behaviour behind bones: the zooacrhaeology of ritual, religion, status and identity. Proceedings of the $9^{\text {th }}$ conference of the International Council of Archaeozoology, Durham, august 2002, Oxbow books, Oxford, pp. 77-94.

LEPETZ S. 2000, Les restes osseux animaux du sanctuaire gallo-romain de la forêt d'Halatte (commune d'Ognon, Oise). Vestiges sacrificiels et reliefs de repas ?, Revue Archéologique de Picardie, $\mathrm{n}^{\circ}$ spécial 18, pp. 197-200.

LIGNEREUX Y., PETERS J. 2008, Annexe II : Les ossements d'oiseaux recueillis dans le foyer du sanctuaire d'Isis, dans DARDAINE S., FINCKER M., LANCHAJ., SILLIÈRES P., Belo VIII. Le sanctuaire d'Isis, volume I, Collection de la Casa de Velázquez, Madrid.

LIMET H. 1994, Le chat, les poules et les autres : le relais mésopotamien vers l'Occident, dans BODSON L. (ed.) Des animaux introduits par l'homme dans la faune de l'Europe, Université de Liège, Liège.

Lucien de Samosate, Le songe ou le coq, dans Euvres, tome III, opuscules 21-25, texte établi et traduit par BOMPAIRE J., Les Belles Lettres, Paris, 2003.

MÉNIEL P. 1992, Les sacrifices d'animaux chez les Gaulois, Collection des Hespérides, Éditions Errance, Paris. 
MÉNIEL P. 1999, « Les offrandes animales », dans METZLER-ZENS N. et J., Lamadeleine : une nécropole de l'oppidum trévire du Titelberg, Dossiers d'archéologie du Musée d'Histoire et d'Art, $\mathrm{n}^{\circ} 6$, Luxembourg pp. 258-281.

MÉNIEL P. 2001, Les Gaulois et les animaux. Élevage, repas et sacrifice, Collection des Hespérides, Éditions Errance, Paris.

MÉNIEL P. 2008, Manuel d'archéozoologie funéraire et sacrificielle, âge du Fer, Éditions Infolio, Paris.

MÉNIEL P. 2014, «Une favissa dans le sanctuaire de Mercure au sommet du Puy de Dôme », dans ALBERTI G., FÉLIU C., PIERREVELCIN G. (textes réunis par), Transalpinare : mélanges offerts à Anne-Marie Adam, Ausonius, Mémoires, $\mathrm{n}^{\circ}$ 36, Bordeaux, pp. 235-245.

OFFENBACH J., MEILHAC H., HALEVY L., La Belle Hélène, Opéra bouffe en trois actes, Représenté pour la première fois à Paris, au Théâtre des Variétés, le 17 décembre 1864. Musique de Jacques Offenbach, livret de Meilhac H. et Halévy L.

OLIVE O. 2008, «Honorer Mithra en mangeant : le menu des mithriastes d'Orbe et de Martigny », dans LEPETZ S. et VAN ANDRINGA W., Archéologie du sacrifice animal en Gaule romaine : rituels et pratiques alimentaires, Archéologie des plantes et des animaux 2, Monique Mergoil, Montagnac, pp. 267-272. PAUL S. 2013, Cultes et sanctuaires de l'île de Cos, Kernos, supplément 28, Presses Universitaires de Liège, Liège.

Pausanias, Description de la Grèce, texte établi et traduit par ROCHA-PEREIRA M. H., Bibliotheca Teubneriana, Leipzig, 1973.

Pétrone, Satiricon, texte établi et traduit par ERNOUT A., Les Belles Lettres, Paris, 1982.

Platon, Phédon, texte établi et traduit par RoBin L., Les Belles Lettres, Paris, 1970.

Pline l'Ancien, Histoire Naturelle, livre X, texte établi et traduit par de SAINT DENIS E., Les Belles Lettres, Paris, 1961.

Plutarque, Apophtegmes des Lacédémoniens, dans « Euvres morales de Plutarque », texte traduit par RICARD, Chez Lefèvre, Paris, 1844.

POLLARD J. 1977, Birds in Greek life and myth. (Aspects of Greek and Roman life), Thames and Hudson, Londres.

POOLE K. 2010, “Bird introductions", dans O'CONNOR T. et SYKES N. (eds.) Extinctions and Invasions: A Social History of British Fauna, Oxford, Windgather Press, pp. 156-65.

PUTELAT O., CHÂTELET M., LATRON-COLECCHIA A., RÉVEILLAS H. 2014, « Les dépôts alimentaires animaux de la nécropole mérovingienne d'Eckwersheim « Burgweg Links » (Bas-Rhin) », dans BEDE I. et DETANTE M. (dir.), Rencontre autour de l'animal en contexte funéraire : Actes de la Rencontre de SaintGermain-en-Laye des 30 et 31 mars 2012. IV Rencontre du Groupe d'anthropologie et d'archéologie funéraire, Saint-Germain-en-Laye, pp. 165-181.

ROTH-ZEHNER M. 2007, Illfurth Lieu-dit Buergelen, Lotissement « les Hauts de Buergelen » (Alsace - HautRhin), SRA Alsace.

SEIGLE M. 2014, Poules et coqs en Gaule durant les deux âges du Fer, Mémoire de Master 2, université Lumière - Lyon 2.

SERJEANTSON D. 2009, Birds, Cambridge University Press, Cambridge. 
STAFFORD E. 2008, Cocks for Asklepios : sacrificial practice and healing cult, dans MEHL V. et BRULÉ P. (dir.), Le sacrifice antique, Vestiges, procédures et stratégies, Collection « Histoire », Presses Universitaires de Rennes, Rennes, pp. 205-221.

Suérone, De vita duodecim Caesarum, texte traduit et établi par AILLOUD H., tome III, Les Belles Lettres, Paris, 1964.

SYKES N. 2012, A social perspective on the introduction of exotic animals: the case of the chicken, World Archaeology, 44.

Tite-Live, $A b$ urbe condita, texte établi et traduit par BLOCH R. et GUITTARD C., Les Belles Lettres, tome VIII, livre VIII, Paris, 1987.

TURCAN R. 1993, Mithra et le mithriacisme, Les Belles Lettres, collection Histoire, $2^{\mathrm{e}}$ édition, Paris. VAN ANDRINGA W. 2009, Quotidien des dieux et des hommes, la vie religieuse dans les cités du Vésuve à l'époque romaine, Bibliothèque des écoles françaises d'Athènes et de Rome, fasc. 337, Rome.

Varron, De Re Rustica, livre III, texte établi et traduit par GUIRAUD C., Les Belles Lettres, Paris, 1997.

ZAVARONI A. 2008, Les dieux gaulois à la bourse, Gerión 26, vol. 1, pp. 327-347.

ZOGRAFOU A. 2011, « Des sacrifices qui donnent des ailes : PGM XII, 15-95 » dans PIRENNE-DELFORGE Vinciane et PRESCENDI Francesca (eds.), Nourrir les dieux ? Sacrifice et représentation du divin, Kernos, supplément 26, Liège, pp. 149-163.

\section{NOTES}

1. Offenbach et Meilhac 1864 .

2. Serjeantson 2009. Cumont 1942.

3. Limet 1994.

4. Cumont 1942.

5. Cicéron, De div. I, 34.

6. Pétrone, Satiricon LXXIV.

7. Cicéron, De div. I, 15.

8. Tite-Live, Ab urbe condita VIII, 30, 1-2.

9. Ibid. I, 35.

10. Jean Zonaras, Epit. Hist. «Sur Valens ».

11. Suétone, Vita Vitellii IX.

12. Haak 2003.

13. Bellon 1997.

14. Roth-Zehner 2007.

15. Baudry 2005.

16. Seigle 2014.

17. Garcia-Petit 2002 ; Seigle 2014.

18. Poole 2010 ; Sykes 2012 ; Doherty 2013.

19. Garcia-Petit 2005.

20. César, De Bello Gallico V, 12. 
21. Cicéron, De leg. II, 12 ; (Collectif) Thescra 2004.

22. (Collectif) Thescra 2004.

23. Ibid.

24. Foster 1984 ; Ibid.

25. Platon, Phédon 114d.

26. Hérondas, Mimes IV.

27. Stafford 2008.

28. Plutarque, Apopht. des Lac. $238 \mathrm{f}$.

29. Pollard 1977.

30. Pausanias, Description VI, 26.

31. Bruneau 1965.

32. Foster 1984

33. Leguilloux 2000 ; Leguilloux et alii 2015.

34. (Collectif) Thescra 2004.

35. Paul 2013.

36. Zavaroni 2008.

37. Ibid. ; Hilly 2012.

38. Homère, Odyssée V, 28-43 ; Hésiode, Théog. 938-939.

39. Hilly 2012.

40. Hochmuth M., Witteyer M. 2008.

41. Lignereux et Peters 2008.

42. Leguilloux et Brun 2013.

43. Lignereux et Peters 2008.

44. Turcan 1993 ; Lentacker et alii 2004.

45. Turcan 1993.

46. Gaidon-Bunuel et Caillat 2008.

47. Lentacker et alii 2004.

48. Ibid.

49. Ibid.

50. Lentacker et alii 2004 ; Olive 2008.

51. Turcan 1993.

52. Gál et Kunst 2014.

53. Méniel 1992.

54. Méniel 2001, 2008.

55. Méniel 2001.

56. Méniel 2014.

57. Lepetz 2000.

58. Méniel 2001.

59. Méniel 2008.

60. Lemoine 1905. 
61. Fourdriguier 1875.

62. Auxiette 1995.

63. Méniel 2008.

64. Putelat et alii 2014.

65. Méniel 1992, 2008.

66. Méniel 2001.

67. Méniel 1992.

68. Laforge 2009.

69. Feugère 2007.

70. Laforge 2009 ; Van Andringa 2009.

71. Serjeantson 2009 ; Van Andringa 2009.

72. Juvénal, Sat. XIII, 233.

73. Pausanias, Description II, 34, 2.

74. Diogène Laërce, Vies des philosophes illustres VIII, 1.

75. Fabre et alii 1999 ; Feugère 2007.

76. Fabre et alii 1999.

77. Aristote, Hist. des anim. IX, 9, 614a.

78. Varron, De Re Rust. III, 9.

79. Zografou 2011.

80. Ibid.

81. Lucien, Le songe ou le coq, 3 .

82. Bruneau 1965.

83. Pline l'Ancien, Hist. Nat. X, 24.

\section{RÉSUMÉS}

Nous connaissons bien les colombes de Vénus/Aphrodite ou les taureaux de Jupiter/Zeus, que ce soit dans les mythes ou dans les rites sacrificiels des religions romaine et grecque, mais la place de la volaille dans les religions du pourtour de la Méditerranée nous échappe. En réalité, l'espèce s'avère bien présente, quoiqu'en petite quantité, dans les rites, y compris en Gaule avant et après la conquête. Mais son importance semble être davantage marquée au sein des cultes à mystères, où elle occupe une place de premier plan. Par ailleurs, ses utilisations lors de rites magiques ou de protection, ainsi que dans le cadre de la religion privée, nous indiquent que la poule et le coq sont d'abord perçus comme les offrandes religieuses individuelles et individualistes par excellence, tout en ayant une réelle valeur gustative susceptible de plaire aux divinités et aux défunts. 
AUTEUR

MICHAËL SEIGLE

Doctorant en archéozoologie, laboratoire Hisoma (UMR 5189), université Lumière - Lyon II 


\title{
Animaux du désert et moines en Égypte au IV ${ }^{\mathrm{e}}$ siècle : une sociabilité ambiguë
}

\author{
Françoise Thelamon
}

1 Les animaux sauvages sont nombreux dans les déserts d'Égypte où depuis la fin du $\mathrm{III}^{\mathrm{e}}$ siècle, voire avant, des hommes qui cherchent dans la vie anachorétique un lieu pour être seuls avec Dieu se retirent en marge des villages, puis dans le désert profond, plus ou moins loin de la vallée du Nil. Animaux et moines se rencontrent dans cet espace de tous les dangers, dans ce lieu fondamentalement ambivalent qu'est le désert ${ }^{1}$. Entre danger et familiarité, entre peur et hostilité réciproques mais aussi parfois entraide, entre diabolisation et sociabilité réconciliée, les relations entre les animaux et les moines dans les déserts d'Égypte au IV siècle donnent lieu à toute une gamme de comportements dotés de valeurs symboliques.

2 Nous prendrons en compte quelques textes fondateurs d'une littérature qui a connu ensuite un grand rayonnement. La première biographie d'un moine est la Vie d'Antoine (VA) écrite en grec par Athanase d'Alexandrie ${ }^{2}$, à la demande, dit-il, de moines « venus d'ailleurs »- occidentaux ou syriaques ${ }^{3}$ - après la mort, peu avant février 356 , de celui qui était le modèle par excellence : «Pour des moines en effet la vie d'Antoine suffit comme modèle d'ascèse » écrit Athanase ${ }^{4}$; elle connut rapidement une diffusion en latin dans la partie occidentale de l'Empire romain ${ }^{5}$.

3 L'Enquête sur les moines d'Égypte (HMg) est le récit, en grec, d'un voyage en Égypte, du Delta à la Thébaïde, à la fin du IV siècle, d'un groupe de sept moines d'un monastère du Mont des Oliviers à Jérusalem, venus visiter les moines les plus renommés pour s'instruire auprès d'eux et découvrir les exploits d'ascèse et les charismes d'hommes qui, au désert, connaissent déjà la " vie angélique » en paix avec les animaux et assistés par les anges ${ }^{6}$. Le texte, traduit en latin par Rufin d'Aquilée au début du $v^{\mathrm{e}}$ siècle, fut largement diffusé en Occident ${ }^{7}$. Nous prendrons en compte également le chapitre emblématique que Rufin consacre dans l'Histoire ecclésiastique (H.E., écrite en 402-403) au célèbre moine Macaire qu'il a connu\& . 
Il s'agit donc de documents hagiographiques où les animaux sont présentés soit comme des êtres réels, soit comme des êtres diaboliques qui ont pris une forme animale. $\mathrm{Ce}$ sont presque toujours des bêtes sauvages: serpents, scorpions, reptiles sont les plus nombreux, mais aussi onagres, chamelles et antilopes plus proches de l'homme, chiens sauvages, lions, hyènes qui sont les plus dangereux; crocodiles et hippopotames présents dans les zones humides. Tout le bestiaire des déserts d'Égypte est là. Suppôts de Satan déchaînés contre Antoine, animaux fantasmés que le moine combat avec succès, mais aussi voisine confiante - cette hyène qui amène à Macaire ses petits aveugles pour qu'il les guérisse et qui lui manifeste ensuite sa reconnaissance par un cadeau - autant d'exemples où l'on retrouve la tradition égyptienne millénaire de familiarité entre l'animal et l'homme', mais aussi cette incompatibilité fondamentale entre l'homme et le serpent inscrite dans la Bible. Les serpents sont également agents de la punition divine quand, au peuple qu'il a fait sortir d'Égypte et qui récrimine contre lui, Dieu «dans le désert grand et redoutable, pays des serpents brûlants, des scorpions et de la soif » envoie contre le peuple ces serpents brûlants dont la morsure est mortelle ${ }^{10}$. La sociabilité réconciliée entre l'animal et le moine, quand elle advient, est alors figure de cette vie angélique (bios aggelikos) à laquelle il accède par l'ascèse ${ }^{11}$ et qui fait de lui un nouvel Adam auquel il est dit :

« Les bêtes sauvages seront en paix avec toi. " ${ }^{12}$

Ces textes sont empreints de merveilleux, langage qui vise à rendre sensible au lecteur ce que peut une foi hors de pair vécue au désert. C'est un langage concret qui parle aux sens, à l'imagination et au cœur, qui manie le pittoresque, l'exotique, l'insolite voire l'incroyable et le fantastique, où les relations avec les animaux permettent de décliner les situations qu'affrontent ces hommes extraordinaires, ces « hommes de Dieu » que sont les moines exemplaires dont Rufin écrit :

«On les considérait comme des hommes qui partageaient non pas la vie des autres

mortels mais des anges d'en haut. ${ }^{13}$

\section{Les animaux : des êtres dangereux rusés ou dénués de raison}

\section{Les animaux : des êtres sans raison divinisés par les païens}

6 La critique du zoomorphisme des divinités en usage en Égypte est fréquente, ainsi Antoine dit-il qu'il est scandaleux d'" assimiler Dieu à des êtres sans raison (cf. Ac 17, 29) et par suite, de vénérer des quadrupèdes et des reptiles ${ }^{14}$. Même critique par le moine Apollô :

«Jadis en Égypte, c'est, énorme et dégoûtante que l'idolâtrie a abondé... Ils rendaient un culte en effet à chiens, singes et autres bêtes. $»^{15}$

7 Et de se livrer à une critique de type évhémériste pour expliquer la divinisation « au temps de Pharaon » d'animaux ou de choses utiles à la vie : le bœuf, l'eau du Nil mais aussi des légumes. 


\section{Les animaux : figures des hérétiques ariens}

8 Parce que dénués de raison, les animaux peuvent figurer les hérétiques du moment, c'est-à-dire, au milieu du IV ${ }^{\mathrm{e}}$ siècle, les ariens. Athanase prête à Antoine une vision à valeur de présage :

«J'ai vu la table de la maison du Seigneur et, tout autour, se tenaient des mulets qui donnaient des coups de pied à ceux qui se trouvaient à l'intérieur comme feraient des bêtes bondissant en désordre. ${ }^{16}$

Une vision prémonitoire qui se révèle exacte :

« Nous le reconnûmes tous, les coups de pied de ces mulets annonçaient à Antoine ce que les ariens font actuellement sans raison comme des bêtes. »

Quant à la doctrine des ariens :

«(elle) est privée de raison et stérile (comme les mulets) et le fruit d'une pensée qui n'est pas droite : comme les mulets ils sont privés de raison. $»^{17}$

Mais la perfidia des ariens est stigmatisée de manière pire encore par une autre comparaison animale :

«Des sectateurs d'Arius vinrent à lui (Antoine). Il les interrogea, reconnut que c'étaient des impies et les chassa de la montagne en disant que leurs paroles étaient pires que des serpents. $»^{18}$

\section{Le Serpent rusé et maudit et les serpents dangereux}

Très fréquents sont les serpents auxquels les moines sont confrontés ; mais bien audelà du danger réel qu'ils peuvent représenter, c'est la figure emblématique du serpent qui sous-tend tous les textes où il en est question. De la Genèse à l'Apocalypse, la référence au serpent, figure de Satan, figure du mal, est constante. Dans la Genèse il est " le plus rusé de tous les animaux des champs que Dieu avait faits », il est le suborneur par excellence qui séduit la femme, la pousse à la désobéissance en suscitant le désir de s'approprier la connaissance au-delà de ce qui est conforme à la condition humaine, et le désir d'être « comme des dieux $»^{19}$. Mais la malédiction pèse sur lui désormais :

«Maudit sois-tu parce que tu as fait cela, maudit sois-tu entre tous les bestiaux et toutes les bêtes sauvages. Tu marcheras sur ton ventre et tu mangeras de la terre. $»^{20}$ Telle est la malédiction qui pèse sur le serpent. " Menteur et père du mensonge ${ }^{21}$, « le Dragon, l'antique Serpent, le Diable ou le Satan, le séducteur du monde entier » sera vaincu définitivement à la fin des temps comme il est dit dans l'Apocalypse ${ }^{22}$.

Mais en attendant, les serpents sont présents au désert. Les moines, Antoine en particulier, ont à les combattre, comme jadis les Hébreux dans le désert avaient subi leurs morsures et certains en étaient morts ${ }^{23}$. S'enfonçant dans un désert profond, Antoine arrive à la montagne où il va vivre reclus près de vingt ans :

« Il trouva, au-delà du fleuve, un fort, désert et, avec le temps, plein de reptiles. Il s'y établit et en fit sa demeure. Les reptiles battirent aussitôt en retraite comme si quelqu'un les poursuivait. $»^{24}$

De son côté Macaire, mordu par un aspic - « animal qui peut donner la mort » précise Pallade :

«Après l'avoir saisi et maitrisé en le tenant à deux mains par les mâchoires, le mit en pièces en disant : “Comment as-tu osé venir puisque Dieu ne t'a pas envoyé ?" "25 
Les moines visiteurs de l'Historia monachorum (HMg), qui découvrent dans le désert la trace d'un énorme serpent et sont saisis d'une grande frayeur, nous invitent à une autre lecture. Les frères égyptiens qui les guident leur expliquent, non sans prétention :

«Vous allez voir notre foi, car nous allons le tuer. Nombreux déjà sont les serpents, aspics et cérastes que nous avons détruits de nos mains, en sorte que s'est accompli à leur sujet ce qui est écrit: "Je vous ai donné le pouvoir de fouler aux pieds serpents, scorpions, et toute l'armée de l'Ennemi" $(L c 10,19)$. ${ }^{26}$

17 En fait, les étrangers ne surmontent pas leur frayeur et les moines égyptiens, trop présomptueux, sont ramenés à la raison par un Ancien; mieux vaut ne pas aller affronter ce serpent monstrueux dans son repaire. Pour vaincre les reptiles dangereux, il faut avoir atteint un degré de sainteté qui n'est pas le fait de tous. Poursuivant leur « enquête » chez les moines de Nitrie, les voyageurs racontent :

«Nous avons vu là-bas un homme du nom de Didyme, vieillard quant à l'âge, agréable d'aspect, qui écrasait de ses pieds scorpions, cérastes et aspics, alors que nul autre n'osait le faire ; bien plutôt, beaucoup d'autres qui avaient cru y réussir ont été tués par ces bêtes, pour les avoir seulement frôlées. $»^{27}$

Le grand âge et l'aspect même du vieillard sont les signes d'une sanctification qu'atteste son pouvoir sur ces animaux dangereux, des betes que l'on foule aux pieds. Mais le combat n'est pas aisé et le pouvoir n'est pas donné à tous, d'où l'exemple d'un moine anonyme qui a une relation particulière avec le/les serpent(s). Alors qu'un serpent énorme ravage leurs terres, les paysans des alentours viennent le chercher pour expulser la bête. C'est par la prière qu'il l'affronte dans un combat singulier : le moine prie à genoux, le serpent monstrueux se jette sur lui :

«Émettant un râle terrible, soufflant, sifflant, exhalant une haleine infecte ; lui sans frayeur aucune, tourné vers le serpent lui dit: "Christ va te tuer, le Fils du Dieu vivant, lui qui doit tuer le grand monstre des mers." À ces mots le serpent creva. ${ }^{28}$

19 Les animaux dangereux, en particulier les serpents, sont donc toujours dans ce contexte figures du mal et de Satan. La protection divine permet de s'en défendre, de les écraser ou de les battre ; ainsi se réalise la promesse du Ps 90 :

«Dieu donne mission à ses anges de te protéger. Tu marcheras sur la vipère et le scorpion, tu écraseras le lion et le Dragon.»

\section{Quand les démons se présentent sous l'aspect de bêtes sauvages}

21 Ce sont de multiples bêtes sauvages qui assaillent Antoine avec une extrême violence, manifestations démoniaques qui se déclinent sous l'aspect de toute la faune du désert.

\section{Les attaques de bêtes sauvages : des ruses du Démon}

22 L'Ennemi convoque ses chiens (kunais) - on y a vu une référence à la divinité à tête de chien ou de chacal: Anubis -; puis viennent les démons métamorphosés en bêtes sauvages et reptiles (thèrion kai herpretôn) : lions, ours, léopards, taureaux, serpents, vipères, scorpions, loups, cortège en somme du dieu Seth, frère ennemi d'Osiris, dieu du mal qui règne sur le désert. Dans un vacarme épouvantable, ils attaquent Antoine qui 
vivait alors dans un tombeau et qui, déjà molesté par le démon lors d'un premier combat, priait étendu sur le sol ${ }^{29}$.

«Le lion rugissait dans l'intention d'attaquer, le taureau semblait donner de la corne, le serpent rampait mais sans l'atteindre, le loup s'élançait mais son élan était suspendu. Absolument terrible était la fureur de toutes ces apparitions, jointe au hurlement de leurs cris [...] Ils grinçaient des dents contre lui, furieux de s'être joués d'eux-mêmes plutôt que de lui. ॥"

\section{démons :}

«Ils façonnent des apparences trompeuses et tâchent d'effrayer en se métamorphosant $(2$ Co 11, 13) et en prenant l'allure de femmes, de bêtes sauvages, de serpents, de géants ou d'une grande troupe de soldats. $»^{34}$

\section{Le combat sans peur du moine}

«Seul en tel désert, il n'avait pas peur quand les démons l'attaquaient, ni ne redoutait la férocité de tant de bêtes sauvages, quadrupèdes et reptiles (cf. $A c, 10$, 12) qui se trouvaient là [...] Mais comme il est écrit il avait vraiment confiance dans le Seigneur. $\|^{35}$

Et pourtant le combat est effrayant et dangereux, notamment quand Antoine doit affronter les bêtes réputées les plus féroces : les hyènes :

"Comme il veillait la nuit, le diable lança contre lui des bêtes sauvages (thèria), et presque toutes les hyènes de ce désert sorties de leurs tanières l'entourèrent : il se trouvait au milieu d'elles. Chaque bête ouvrait la gueule et menaçait de le mordre. Lui, comprenant l'artifice de l'Ennemi, leur dit à toutes: "Si vous avez reçu pouvoir contre moi $(c f . M t 10,1)$ je suis prêt à me laisser dévorer par vous ; mais si vous avez été subornées par des démons, ne vous attardez pas, retirez-vous, car je suis serviteur du Christ (cf. Rm 1, 1; Gal 1,10; Phil 1, 1)". À ces mots d'Antoine, elles prirent la fuite, chassées par sa parole comme par un fouet $(J b 5,21) . »^{36}$

Efficacité donc de la parole de celui qui proclame son appartenance au Christ.

\section{Phantasmes tentateurs et métamorphoses}

Mais il arrive que le démon use de phantasmes d'autant plus pernicieux qu'ils sont moins effrayants. Alors que Macaire est épuisé de fatigue et de privations :

«Le diable crée pour lui le mirage d'une chamelle de bât errant par le désert avec toutes les provisions nécessaires. Elle voit Macaire et vient s'asseoir devant lui. Mais le saint avait compris que c'était un phantasme, ce qu'elle était bien : il se dressa en prière, et la chamelle aussitôt fut engloutie dans le sol. $»^{37}$ 
Il arrive aussi qu'un être humain soit transformé en animal par les sortilèges d'un magicien. On fait alors appel à un moine réputé pour ses pouvoirs et sa sainteté, tel Macaire. Ainsi :

«Comme un vaurien avait un jour, par de certains sortilèges, changé en jument une fille vouée à la virginité, et que ses parents l'avaient amenée au saint, lui demandant s'il consentirait par ses prières à la changer de nouveau en femme, il l'avait donc enfermée pendant sept jours à part, ses parents demeurant à côté, tandis que dans une autre cellule il vaquait lui-même à la prière. Le septième jour il entra dans la cellule avec les parents, lui frotta d'huile tout le corps et, ayant fléchi les genoux, pria avec les parents : quand ils se furent relevés, ils la trouvèrent changée en fille. ${ }^{38}$

\section{La victoire sur la bête hybride}

31 Ayant épuisé en vain contre Antoine toutes les formes d'animaux les plus féroces possibles, le Diable lui-même se manifeste sous une forme hybride, mi-homme mi-bête, Athanase commente alors ${ }^{39}$ :

«Il vit une bête (thérion) d'apparence humaine jusqu'aux cuisses mais ayant des jambes et des pieds comme ceux d'un âne. Antoine se contenta de se signer et dit: "Je suis serviteur du Christ $(R m$ 1,1). Si tu as été envoyé contre moi, me voici." La bête (thérion) avec ses démons s'enfuit, si rapidement qu'elle tomba et mourut. La mort de la bête était la chute des démons. Ils s'efforçaient par tous les moyens possibles de lui faire quitter le désert, mais ils n'y réussirent pas. $»^{40}$

De même que, au désert, le diable avait épuisé différentes tentations face à Jésus avant de reconnaître sa défaite ${ }^{41}$, face à Antoine il a eu recours à tout le bestiaire du désert pour tenter de le faire renoncer à sa vocation : sévices, apparitions terrifiantes n'ont pas eu raison du serviteur du Christ qui, en finissant par chasser les hyènes furieuses puis l'onocentaure immonde, manifeste un triomphe continu sur le diable par le nécessaire discernement des esprits auquel il accède, par l'oraison et l'ascèse. Il acquiert ainsi - et d'autres moines également - le pouvoir que Dieu avait donné à Adam avant la faute ${ }^{42}$, créant au désert une sociabilité réconciliée entre les animaux et les hommes, en une sorte de retour au Paradis perdu.

\section{"Les bêtes sauvages seront en paix avec toi » (Jb 5, 23) : une sociabilité réconciliée}

C'est Jésus lui-même qui en est le modèle : vainqueur de Satan « il était avec les bêtes sauvages et les anges le servaient» (Mc 1,13). Et cette bonne entente peut prendre diverses formes.

\section{Des animaux obéissants}

C'est souvent le cas des crocodiles et même d'un hippopotame. Ainsi Abba Bès "qui dépassait tout le monde par sa douceur ", dont on reconnaît la " profonde sérénité, les manières affables et le maintien tout angélique », en use pour délivrer la région de certains animaux dangereux :

« Il se trouva un jour qu'un hippopotame dévastait la région voisine. Sur l'invite des paysans, il se rendit auprès du lieu et, ayant aperçu la bête, qui était énorme, il lui 
commanda d'une voix douce: "Au nom de Jésus-Christ, je t'ordonne de ne plus dévaster le pays." L'autre, comme chassé par un ange, disparut entièrement du lieu. C'est de la même manière qu'il expulsa une autre fois un crocodile. $»^{43}$

En effet, les crocodiles suscitent la frayeur; c'est ce qui arrive aux moines de l'Enquête dans leur inexpérience, tant de la crue du Nil que de la faune locale :

"Comme nous allions vers la Nitrie, nous passâmes par un certain lieu où il y avait un creux plein d'eau; beaucoup de crocodiles s'y tenaient à demeure, car l'eau s'était retirée de la campagne voisine. Trois grands crocodiles étaient donc étendus là sur le bord de la fosse, et nous nous approchâmes pour regarder ces bêtes, les croyant mortes. Mais elles, aussitôt, se jetèrent sur nous, et nous voilà invoquant le Christ à voix forte, clamant: “Christ, au secours !” Les bêtes alors, comme chassées en arrière par un ange, piquèrent vers l'eau. ${ }^{44}$

Tandis que les moines s'enfuient à toutes jambes. Antoine aussi échappe, indemne, aux crocodiles :

«Il dut un jour franchir le canal d'Arsinoë - c'était pour aller visiter des frères. Ce canal était rempli de crocodiles. Il se contenta de dire une prière, entra dans l'eau, lui et tous ceux qui l'accompagnaient, et ils traversèrent indemnes. $»^{45}$

\section{Animaux serviables et animaux coupables}

7 Mieux encore, un crocodile peut rendre service à un moine. Ainsi abba Hellê, allant visiter des moines un dimanche, leur demanda pourquoi la synaxe n'a pas été célébrée ; on lui expliqua que le prêtre n'avait pas pu venir de l'autre rive à cause d'un crocodile dangereux qui semait la terreur dans la région pour avoir dévoré des hommes. Hellê, sans hésiter, se lève et va au passage.

« Aussitôt la bête le reçut sur son dos et le remit à terre sur l'autre rive. »

Hellê va chercher le prêtre et, faute de barque :

«Poussant un grand cri, appela le crocodile. Celui-ci obéit aussitôt et se montra, lui faisant un lit de son dos. Le père invita le prêtre à y monter avec lui. »

À nouveau, il traverse le passage sur le dos de la bête et aborde à la terre ferme :

« Il y tira aussi la bête : mieux valait qu'elle mourût, lui dit-il, et récoltât sa punition pour les gens qu'elle avait tués. Sur-le-champ le crocodile s'affaissa et rendit l'âme. $»^{46}$

La convivialité avec les animaux sauvages et dangereux n'est pas possible pour tous, comme le montre la terreur sacrée qui s'empare des assistants. Seul le moine qui a atteint un haut degré de sainteté peut communiquer avec l'animal jusqu'à lui faire comprendre le sens de sa mort : l'animal coupable n'est pas sauvé. Abba Hellê pouvait avoir une relation moins tragique avec des bêtes moins dangereuses. Rentrant à sa grotte, chargé de quelques provisions :

«Il vit des ânesses sauvages qui paissaient et leur dit : "Au nom du Christ, qu'une de vous vienne à moi, elle portera mon fardeau". Aussitôt l'ânesse vint à lui. Il lui mit dessus son bagage, s'assit sur elle et, en un seul jour, arriva à la grotte. »

41 Cependant à nouveau l'ambiguité des relations se manifeste :

"Comme il avait exposé au soleil les pains et les fruits, les bêtes qui selon leur habitude allaient à l'eau, s'en rapprochèrent; mais à peine eurent-elles touché au pain qu'elles expirèrent. $»^{47}$

Cette fois encore pour les animaux coupables, il n'est point de salut. Même les serpents peuvent être obéissants et serviables. Ammoûn avait déjà été victime de voleurs : 
"Or un jour qu'il était sorti dans le désert, il attira à lui deux grands serpents et leur commanda de rester sur la place et de garder sa porte. »

«Voyez combien vous êtes plus sauvages que les bêtes. Elles, à cause de Dieu, obéissent à nos volontés. Mais vous, vous n'avez même pas eu peur de Dieu. \} ^ { 4 8 }

Ce qui laisse entendre que les serpents éprouvent, fut-ce à travers le moine, une certaine crainte de Dieu et que des animaux - même des plus pernicieux - peuvent être meilleurs que certains humains.

\section{Des animaux dotés de discernement, agents de la justice divine}

Ils peuvent même avoir un rôle de justiciers. Ainsi trouvons-nous dans l'Enquête un conflit armé entre villageois païens et chrétiens pour une affaire de bornage. Abba Apollô intervient pour rétablir la paix.

«Mais le champion des païens, homme redoutable et féroce, lui résistait, affirmant avec force qu'il refuserait la paix jusqu'à la mort. Apollô lui dit : «Eh bien qu'il en soit comme tu l'as choisi. Nul autre ne périra que toi. Et, une fois mort, ta tombe ne sera pas la terre, mais les ventres des bêtes sauvages et des vautours se rempliront de ta chair. $»^{49}$ Et c'est bien ce qui arrive : « Aussitôt dit, aussitôt fait : nul autre ne périt que le champion. Ils l'enterrèrent dans le sable, mais le lendemain ils le trouvèrent déchiqueté par les vautours et les hyènes. Quand ils eurent vu ce prodige et l'accomplissement de l'oracle, tous crurent dans le Sauveur et ils proclamaient Apollô un prophète. $»^{50}$

Ici, l'homme se conduit comme une bête féroce rejetant la paix ; il prononce lui-même l'omen déterminant qui, explicité par le moine, s'accomplit par l'action des charognards sans merci que sont les hyènes et les vautours, agents de la justice divine pour la pire des punitions : la privation de sépulture.

4 Un animal peut aussi discerner la doctrine. Ce que fit le cheval d'un officier de haut grade, le dux Balacios qui, acquis aux ariens, persécute les chrétiens nicéens, en particuliers les moines et les vierges consacrées. Antoine lui écrit :

«Cesse de persécuter les chrétiens si tu ne veux pas que la colère divine te saisisse."

Balacios s'en moque et menace Antoine :

«C'est à toi maintenant que je m'en prendrai.»

Il se met en route avec le préfet d'Égypte Nestorios; tous deux montaient des chevaux de Balacios :

«Les plus doux de ses écuries. Pourtant avant d'arriver à l'étape, les chevaux se mirent à jouer entre eux, comme à l'habitude. Soudain, le plus doux, celui que montait Nestorios, mordit Balacios, le désarçonna et se jeta sur lui. De ses dents, il lui déchira si bien la cuisse, qu'il fallut le transporter à la ville où, en trois jours, il mourut. Tous admiraient que la prédiction d'Antoine se fût réalisée. $»^{51}$

Pour qu'il n'y ait pas de doute sur le sens surnaturel de l'événement, Athanase insiste sur la douceur de ce cheval justicier qui ne reconnaît plus son maître.

\section{Des bêtes apprivoisées : une sociabilité réussie}

$51 \mathrm{Au}$ début de son séjour dans la montagne intérieure, les bêtes sauvages endommageaient les cultures d'Antoine. 
«Il captura alors tout doucement une de ces bêtes et dit à toutes: "Pourquoi me faites-vous du tort, puisque moi je ne vous en fais pas? Allez-vous-en et au nom du Seigneur n'approchez plus d'ici." Dès lors, comme par crainte de la défense, elles n'approchèrent plus de l'endroit. $»^{52}$

d'une véritable clairvoyance spirituelle, elle reconnait le charisme thaumaturgique du moine et lui amène ses petits pour qu'ils soient guéris, posant ainsi un acte de foi sinon en Dieu du moins en son serviteur. Humanisée, l'hyène ne peut cependant pas prier Dieu, mais sa démarche est une supplication et elle s'en remet à la médiation du saint homme qui comprend et se tourne vers Dieu pour obtenir le miracle. Exaucée, elle exprime sa gratitude par un cadeau en associant ses petits à sa démarche. Une authentique communication s'établit entre l'animal et le moine. Dans la version de l'Enquête, on peut lire :

" Macaire lui sourit comme à une personne pleine de gentillesse et de sensibilité. »"0

Le pouvoir sur les animaux est toujours exercé au nom du Seigneur et ceux-ci font preuve d'obéissance et de crainte envers Dieu. C'est en somme une certaine spiritualisation des animaux qui transparait.

Théon, lui, est un véritable ami des bêtes et jouit de leur compagnie, alors même qu'il se nourrit comme elles puisqu'il ne mange que des légumes crus :

«Il sortait la nuit de sa cellule, se mêlait aux troupeaux et les abreuvait de ce qu'il avait d'eau. De fait on pouvait voir près de son ermitage des traces de boubales, d'onagres, de gazelles et d'autres bandes d'animaux dont il faisait ses délices. " $^{53}$ moines les plus réputés par leur haut degré de sainteté :

«On les considérait comme des hommes qui partageaient les activités non d'autres mortels mais des anges d'en-haut. $\|^{54}$ avec des animaux eux-mêmes humanisés ${ }^{55}$. Alors qu'il allait mourir d'épuisement dans le désert :

«Apparut un troupeau d'antilopes qui sont nombreuses dans ces contrées. Une femelle accompagnée de son petit s'arrêta. De sa mamelle le lait ruisselait. Macaire se mit sous elle, la téta et ses forces furent reconstituées. L'animal l'accompagna jusqu'à sa cellule, l'allaitant lui et son petit. $»^{56}$ une bonne mère jusqu'à ce qu'il soit en sécurité, Macaire parait parvenu à cette vie paradisiaque dont le lait ruisselant est le signe. Or il est une autre bête, pourtant réputée des plus féroces, qui entretient avec lui des rapports de bon voisinage: une hyène ${ }^{58}$. Rufin raconte :

«Macaire avait la caverne d'une hyène proche de sa cellule. Un jour, la bête lui apporta ses petits aveugles et les déposa à ses pieds. Et comme il avait compris que la bête le suppliait à cause de la cécité de ses petits, il demanda au Seigneur de leur rendre la vue. L'ayant recouvrée, ils rentrent à la caverne en suivant leur mère. Peu de temps après, celle-ci revenant avec ses petits, apporte en présent à l'Ancien, pour le bienfait reçu, nombre de toisons de mouton laineuses qu'elle tient dans sa gueule et, après les avoir déposées devant la porte, s'en va. ${ }^{59}$

ette histoire symbolique prête à l'animal des sentiments et des conduites humaines alors que l'hyène est emblématique de la sauvagerie. Au-delà du motif fréquent de l'animal reconnaissant, on voit abolie la distance entre l'animal le plus sauvage et 
l'homme qui, parvenu à un haut degré de sainteté, atteint le bios aggelikos, qui mène dès cette terre la uita caelestis.

À terme, au désert d'Égypte, animaux et moines peuvent vivre en paix. Sans parler des
traditions populaires égyptiennes de familiarité entre les animaux du désert et les
humains, cette littérature montre que peut se réaliser la promesse : «Je conclurai avec
eux une alliance de paix, je ferai disparaître du pays les bêtes féroces. Ils habiteront en
sécurité dans le désert » $(\mathrm{Ez} 34,25)^{61}$, restauration du Paradis perdu, avant-goût du
Royaume à venir.

À terme, au désert d'Égypte, animaux et moines peuvent vivre en paix. Sans parler des
traditions populaires égyptiennes de familiarité entre les animaux du désert et les
humains, cette littérature montre que peut se réaliser la promesse : «Je conclurai avec
eux une alliance de paix, je ferai disparaître du pays les bêtes féroces. Ils habiteront en
sécurité dans le désert » $(\mathrm{Ez} 34,25)^{61}$, restauration du Paradis perdu, avant-goût du
Royaume à venir.

À terme, au désert d'Égypte, animaux et moines peuvent vivre en paix. Sans parler des
traditions populaires égyptiennes de familiarité entre les animaux du désert et les
humains, cette littérature montre que peut se réaliser la promesse : «Je conclurai avec
eux une alliance de paix, je ferai disparaître du pays les bêtes féroces. Ils habiteront en
sécurité dans le désert » $(\mathrm{Ez} 34,25)^{61}$, restauration du Paradis perdu, avant-goût du
Royaume à venir.

À terme, au désert d'Égypte, animaux et moines peuvent vivre en paix. Sans parler des
traditions populaires égyptiennes de familiarité entre les animaux du désert et les
humains, cette littérature montre que peut se réaliser la promesse : «Je conclurai avec
eux une alliance de paix, je ferai disparaître du pays les bêtes féroces. Ils habiteront en
sécurité dans le désert » $(\mathrm{Ez} 34,25)^{61}$, restauration du Paradis perdu, avant-goût du
Royaume à venir.

À terme, au désert d'Égypte, animaux et moines peuvent vivre en paix. Sans parler des
traditions populaires égyptiennes de familiarité entre les animaux du désert et les
humains, cette littérature montre que peut se réaliser la promesse : «Je conclurai avec
eux une alliance de paix, je ferai disparaître du pays les bêtes féroces. Ils habiteront en
sécurité dans le désert » $(\mathrm{Ez} 34,25)^{61}$, restauration du Paradis perdu, avant-goût du
Royaume à venir. c'est tout un éventail de comportements des animaux que l'on peut découvrir dans cette littérature hagiographique qui fonctionne, d'une certaine manière, comme les contes; en humanisant les animaux, elle en fait des interlocuteurs, voire des amis. Attaques, relations d'hostilité, comportements féroces poussés à l'extrême sont aussi présentés comme manifestations des démons ; mais le Démon n'a pas le dernier mot. Il manipule les animaux sur lesquels il a prise ou simplement suscite des phantasmes, mais il est vaincu.

De la violence féroce des uns au comportement plein de douceur des autres, des dommages causés aux humains aux aides et services rendus, de l'effroi à la confiance Royaume à venir.

\section{BIBLIOGRAPHIE}

Athanase d'Alexandrie, Vie d'Antoine, introduction, texte critique, traduction, notes et index par G. J. M. Bartelink, Paris, Les Éditions du Cerf (Sources chrétiennes 400), 2004 (citée VA).

FESTUGIÈRE André-Jean, Les moines d'Orient, I, Culture et sainteté, Paris, Les Éditions du Cerf, 1961.

GUILLAUMONT Antoine, « La conception du désert chez les moines d'Égypte », Revue d'Histoire des Religions, 188, 1, juillet 1975, p. 3-21.

Historia monachorum in Ægypto, traduction d'après le texte grec par A.-J. Festugière, Les moines d'Orient, IV/1, Enquête sur les moines d'Égypte, Paris, Les Éditions du Cerf, 1964 (citée HMg).

MARTIN Annick, Athanase d'Alexandrie et l'Église d'Égypte au IV siècle (328-373), École française de Rome, Palais Farnèse (Collection de l'École française de Rome 216), 1996.

LEFEBVRE Georges, Romans et contes égyptiens de l'époque pharaonique, Paris, 1949.

Pallade d'Héllénopolis, Histoire Lausiaque, introduction, traduction et notes par N. Molinier, Abbaye de Bellefontaine (Spiritualité orientale 75), 1999 (citée Pallade, HL).

Rufin d'Aquilée, Histoire ecclésiastique, éd. Th. Mommsen, GCS 9, 2, Leipzig, 1909, p. 951-1040, traduction partielle dans F. Thelamon, Païens et chrétiens au IV siècle (v. infra) (citée Rufin, HE). THELAMON Françoise, « Modèles de monachisme oriental selon Rufin d'Aquilée », Antichità Alto Adriatiche, 12, 1977, p. 323-352. 
THELAMON Françoise, Païens et chrétiens au IV siècle. L'apport de l'« Histoire ecclésiastique » de Rufin d'Aquilée, Paris, Institut d'Études Augustiniennes (collection des Études Augustiniennes - Série Antiquité 86), 1981.

THELAMON Françoise, « Ascèse et sociabilité : les conduites alimentaires des moines d'Égypte au IV siècle ", Revue des Études Augustiniennes, 38, 2, 1992, p. 295-321.

THELAMON Françoise, « Présence du monachisme dans l'Histoire ecclésiastique de Rufin d'Aquilée », Adamantius, 17, 2011, p. 23-38.

VOGÜÉ Adalbert (de), Histoire littéraire du mouvement monastique dans l'Antiquité, Paris, Les Éditions du Cerf (Patrimoines - christianisme), 1991, t. I.

\section{NOTES}

1. A. Guillaumont, «La conception du désert », p. 3-21 montre que le désert est un lieu où il est dangereux de s'aventurer et difficile de cheminer mais aussi un lieu où l'on peut rencontrer Dieu aussi bien que des animaux sauvages.

2. Athanase d'Alexandrie, Vie d'Antoine, passim (citée VA). La paternité athanasienne de l'œuvre, déjà affirmée par Grégoire de Nazianze en 380, n'est plus discutée de nos jours, A. Martin, Athanase, p. 481, n. 113.

3. Pour des moines occidentaux de l'avis de G.J.M. Bartelink, VA, introduction p. 46 et A. de Vogüé, Histoire littéraire, p.17, mais plutôt pour des moines de Syrie ou de Palestine où les monastères étaient nombreux à cette date pour A. Martin, Athanase, p. 481-484.

4. VA, Prologue.

5. Elle connut une première traduction anonyme de peu postérieure à l'original, dont l'auteur serait un familier d'Antoine, puis une seconde par Évagre d'Antioche rédigée sans doute en Italie, avant son retour en Orient fin 372. Écrivant à Aquilée en 402, Rufin fait état de "ce petit livre écrit par Athanase et même publié en latin " (Histoire ecclésiastique, citée HE, I, 8) qui semble largement diffusé, et y renvoie ses auditeurslecteurs, préférant traiter de faits moins connus des Occidentaux.

6. F. Thelamon, « Modèles de monachisme », p. 323-352.

7. Rentré en Italie peu après la Pentecôte 397, Rufin qui avait dirigé le monastère latin du Mont des Oliviers adapta en latin, peu après 403 , ce récit désormais connu sous le titre d'Historia monachorum in Ægypto.

8. Rufin, HE, II, 4, traduction dans F. Thelamon, Païens et chrétiens, p. 480. Arrivé à Alexandrie au printemps 373, Rufin avait vécu huit ans en Égypte au cours de deux séjours; il avait visité les moines les plus célèbres, v. F. Thelamon, "Présence du monachisme », p. 23-38.

9. On la trouve, par exemple, dans les contes, où le magicien-sage peut par ses connaissances magiques communiquer avec les animaux, ainsi Bata, dans le Conte des deux frères, comprend le langage des animaux, v. G. Lefebvre, Romans et contes, p. 137-158; Païens et chrétiens, p. 389, n. 49 et 50.

10. Dt 8,$15 ; \mathrm{Nb} 21,6 ; 1$ Co 10, 24.

11. F. Thelamon, « Ascèse et sociabilité », p. 295-321; Païens et chrétiens, p. 378-379. 
12. Jb 5, 23.

13. Rufin, HE, II, 4 ; Païens et chrétiens, p. 378.

14. VA 74, 5 cf. Rm 1, 23.

15. $\mathrm{HMg}, 8$ (MO IV/1, p. 53).

16. VA 82, 7 cité par Sozomène, HE, 6,5 .

17. Ibid. 82, 10 se référant au Ps 31, 9 ; A. Martin, Athanase, p. 488.

18. VA 68, 3 cf. Athanase, Hist. Ar. 65.

19. Gn 3, 1-13 ; cf. Job 8, 44.

20. Ibid. 14.

21. Jn 8,44 .

22. Ap 12, 9-10.

23. $\mathrm{Nb} 21,6$; cf. 1 Co $10,9$.

24. VA 12, 3-4.

25. Histoire lausiaque (HL), 18, 10.

26. $\operatorname{HMg} 9$ (p. 64).

27. $\operatorname{HMg} 20,12$ (p. 113)

28. $\operatorname{HMg} 9,9-10$ (p. 66).

29. VA, $9,4$.

30. VA, 9, 7 et 11 .

31. VA, 7, 2 cf. I P 5, 8 : « Votre partie adverse, le Diable, comme un lion rugissant, rôde, cherchant qui dévorer. Résistez- lui, fermes dans la foi ».

32. Ps $22,13-14 ; 17$.

33. VA, $39,3$.

34. VA, 23, 3.

35. VA, 51, 5 .

36. VA, 52, 2-3.

37. $\mathrm{HMg}, 21,4$ (p. 116).

38. $\mathrm{HMg}, 21,17$ (p. 119).

39. On ne peut pas manquer de faire le rapprochement avec les divinités égyptiennes souvent représentées sous des formes hybrides mi humaines mi animales.

40. VA, 53, 1-3.

41. LC $4,1-13$.

42. Gn2, 18-20 ; cf. Jb 5, 21-23.

43. HMg IV, 3 (p. 36-37).

44. HMg, Épilogue, 14 (p. 132).

45. VA, 15,1 .

46. $\operatorname{HMg~12,~6-9~(p.~82-83).~}$

47. Ibid. 12, 5 (p. 82).

48. HMg, 9, 7 (p. 65). 
49. Ibid. 8, 36 (p. 56) : menace terrible quand on sait ce que la privation de sépulture, en Égypte plus qu'ailleurs, représente ; le corps livré aux chiens et aux vautours subit la pire ignominie qui prive le mort de toute survie dans l'au-delà.

50. Ibid. 8, 37 (p. 56-57).

51. VA, 86, 1-7 ; A. Martin, Athanase, p. 488-489.

52. VA, 50, 8-9 et n. 2 (p. 273).

53. HMg 6, 4 (p. 43) ; sur l'anachorète ami des bêtes, v. A.-J. Festugière, Moines d'Orient, I, p. 53-57.

54. Rufin, Histoire ecclésiastique, II, 4 ; Païens et chrétiens, p. 378.

55. Il s'agit chez Rufin de Macaire l'Égyptien, encore appelé l'Ancien ou le Grand qui vivait surtout à Scété, mais il règne une certaine confusion avec Macaire d'Alexandrie qui vivait aux Cellules. Rufin a connu les deux Macaire.

56. Pallade, HL, 18, 9.

57. Sur les animaux femelles nourrices de dieux et de héros, voir la communication dans le présent volume de Liliane Régent-Romy: L'animal nourricier d'enfants dans la mythologie grecque.

58. Voir supra les hyènes lancées contre Antoine VA, 52, 2-3.

59. Rufin, HE, II, 4 ; Païens et chrétiens, p. 380 ; cf. à quelques détails près, on trouve le même récit dans HMg, 21, (p. 118-119) et dans Pallade, HL, 18, 27-28 qui dit tenir l'anecdote d'un disciple de Macaire, Paphnuce.

60. HMg, 21, 16 (p. 119).

61. Sur le parallélisme et la complémentarité entre sociabilité amicale du moine avec les animaux et commerce des anges, Païens et Chrétiens, p. 389-390; F. Thelamon, « Ascèse et sociabilité », p. 295-321.

\section{RÉSUMÉS}

Entre danger et familiarité, entre peur et hostilité réciproques mais parfois entre-aide, entre diabolisation et sociabilité réconciliée, les relations entre les animaux et les moines dans les déserts d'Égypte au Iv siècle donnent lieu à toute une gamme de comportements. La Vie d'Antoine par Athanase d'Alexandrie, l'Enquête sur les moines d'Égypte, l'Histoire lausiaque de Pallade et le chapitre que leur consacre Rufin d'Aquilée dans l'Histoire ecclésiastique constituent une riche documentation. Suppôts de Satan déchaînés contre Antoine, animaux fantasmés que le moine combat avec succès, mais aussi, voisine confiante, cette hyène qui amène à Macaire ses petits aveugles pour qu'il les guérisse, autant d'exemples où l'on retrouve la tradition égyptienne millénaire de familiarité avec les animaux. La sociabilité réconciliée entre l'animal et le moine figure cette vie angélique (bios aggelikos) à laquelle il aspire accéder par l'ascèse. 
AUTEUR

FRANÇOISE THELAMON

Professeur d'Histoire ancienne honoraire, université de Rouen-Normandie, membre de

l'Académie des Sciences, Belles-Lettres et Arts de Rouen 


\title{
Le sanglier et le bœuf entre hommes et dieux : chasser l'animal sauvage, sacrifier l'animal domestique en Grèce ancienne
}

\author{
Françoise Thelamon
}

\begin{abstract}
En Grèce ancienne, le sanglier et le bœuf dans leur relation à l'homme, sont au cœur de deux pratiques sociales opposées et complémentaires : la chasse et le sacrifice ${ }^{1}$. Dans l'un et l'autre cas, l'animal est mis à mort, mais selon des processus différents plus ou moins empreints de violence. Si le meurtre rituel du bœuf dans le sacrifice médiatise la communication entre les hommes et les dieux et délimite le corps politique par la consommation «à parts égales » de la viande cuite, la mise à mort violente du sanglier repousse la sauvagerie hors de l'espace humain et contribue à délimiter l'espace de la cité. Le sanglier monstrueux envoyé par la déesse Artémis pour ravager la terre de Calydon, comme on le voit sur le vase du peintre de Rouen (fig. 1) ${ }^{2}$, signifie en effet l'intrusion de la sauvagerie dans la terre cultivée. Il faut l'exploit cynégétique de jeunes hommes pour établir une barrière radicale entre animaux sauvages et humains.
\end{abstract}


Fig. 1. - Chasse de Calydon, amphore attique à figures rouges, 560-550 av. J.-C., attribué au peintre de Rouen, Rouen, musée des Antiquités 531.

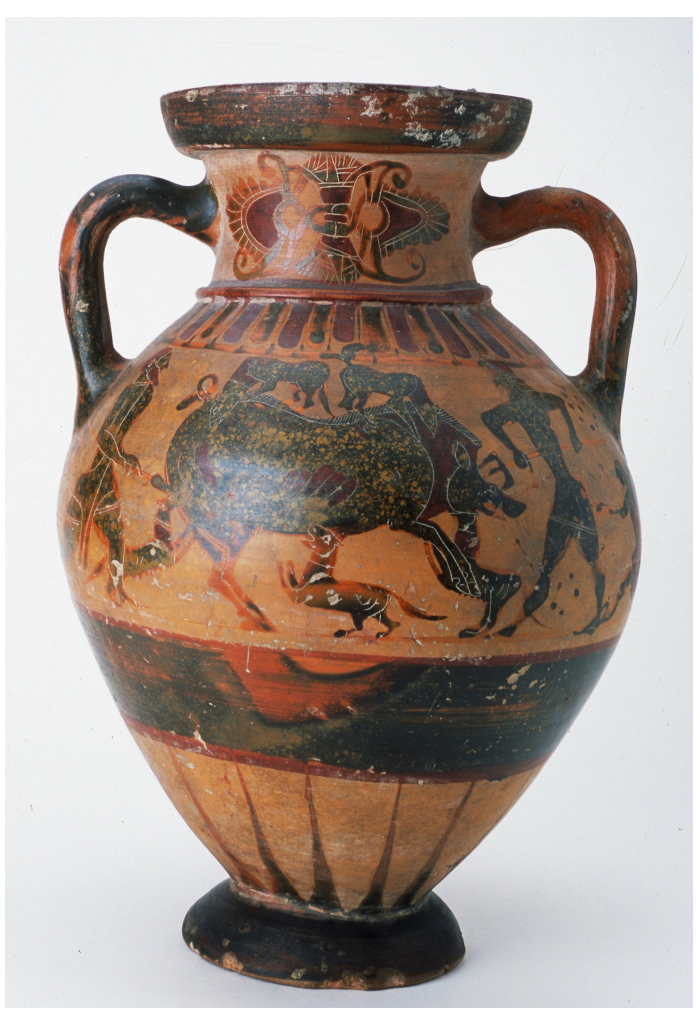

(c) Musée - Métropole - Rouen - Normandie, Cliché Yohann Deslandes.

2 En revanche l'animal domestique par excellence, le bœuf de labour, considéré comme consentant, est conduit au sacrifice sans violence, alors même que le couteau est caché dans une corbeille. On offre aux dieux le sang de l'animal égorgé et les parties brûlées dont ils apprécient le fumet, aux hommes sont distribuées les parts de viande dûment découpées et cuites, mais hommes et dieux ne partagent pas la même table. Il s'agit de les conjoindre dans l'acte même qui les sépare.

\section{Le sanglier et le bœuf : animal sauvage, animal domestique}

\section{Le sanglier de Calydon : une bête monstrueuse (fig. 2) ${ }^{3}$}


Fig. 2. - Chasse de Calydon, peintre de Rouen, détail.

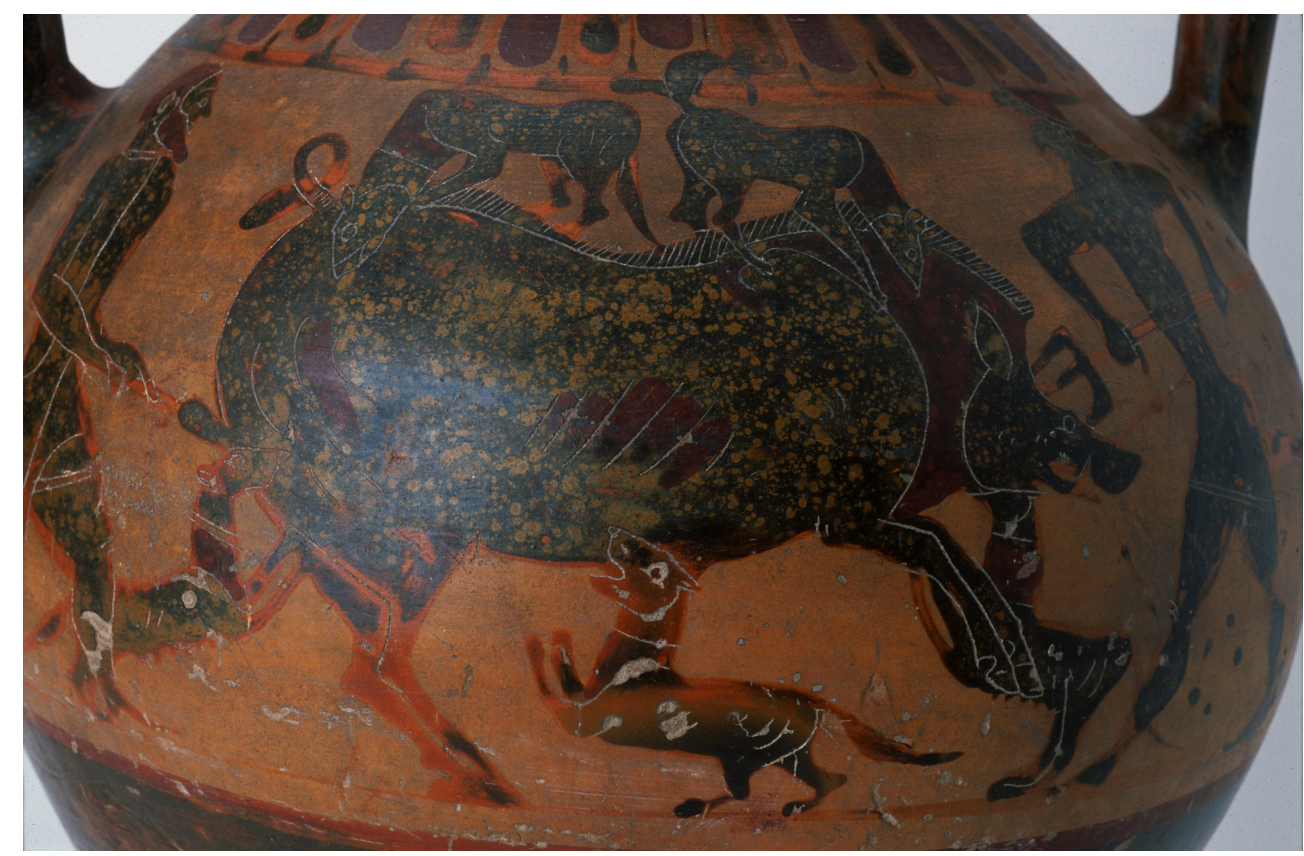

(c) Musée - Métropole - Rouen - Normandie, Cliché Yohann Deslandes.

3 Ce mythe très ancien est raconté dans l'Iliade 4 dans la description du bouclier d'Achille. Artémis, patronne de la nature sauvage, maîtresse des fauves, chasseresse, « en voulait à Oineus qui ne lui avait pas offert de prémices sur les pentes de son vignoble... ». Homme du vignoble et des plantations arbustives, Oineus, roi de Calydon, a « oublié » de rendre à la déesse les honneurs qui lui sont dus, sa timè, car Artémis est aussi la protectrice de toute croissance : des plantes, des animaux et des humains. Et les fautes d'oubli se paient.

«Elle avait donc déchaîné contre eux un sanglier sauvage, un solitaire aux dents blanches, qui sans répit faisait de grands ravages au milieu des vignes d'Oineus et avait déjà sur le sol fait choir de grands arbres avec leurs racines et leurs fruits épanouis. »

Il en va de même, selon Hérodote, du temps de Crésus, en Mysie :

« Apparut [...] sur le mont Olympe, un sanglier de grande taille. Il descendait de la montagne pour ravager les terres cultivées et les Mysiens lui donnaient la chasse, mais loin de lui faire du mal, eux-mêmes en éprouvaient de son fait. »

5 Aussi demandent-ils au roi d'envoyer son fils « avec des jeunes gens valeureux et des chiens pour, avec eux, en délivrer le pays $»^{5}$. Il s'agit là encore d'une "créature monstrueuse »; c'est l'irruption de la sauvagerie dans la terre des plantations, dans l'espace humanisé, civilisé. L'invasion des Barbares sur une terre grecque est du même ordre, dans les deux cas c'est la guerre, car le retour de la sauvagerie est perçu comme une menace permanente à combattre. Dans les scènes de chasse ordinaire, le sanglier demeure la bête sauvage par excellence, il est souvent figuré de grande taille par rapport à l'homme. Même si la chasse peut avoir une fonction alimentaire complémentaire, l'animal sauvage n'est jamais sacrifié ; la chasse est toujours perçue comme un moyen de défendre la terre cultivée contre les déprédations des bêtes sauvages; elle établit une barricade radicale entre elles et les hommes. 


\section{Le bœuf laboureur au contraire est l'animal domestique par excellence}

6 Proche de l'homme, il est son auxiliaire indispensable pour cultiver la terre des blés, celle qui fournit son bios aux hommes «mangeurs de pain ». Hésiode conseille donc:

"Ayez d'abord une maison, une femme et un bœuf - une femme achetée mais pas épousée qui puisse suivre les bœufs. $\rrbracket^{6}$

7 Il précise :

«Procurez-vous une paire de bœufs mâles de neuf ans, à cet âge leur force est difficile à abattre car c'est pour eux la plénitude de la jeunesse et ils sont excellents au travail [...] Qu'ils soient suivis d'un homme robuste de quarante ans [...] le cœur tout à son ouvrage. $»^{7}$

Ensemble ils vont labourer la terre :

« Au moment où, commençant les labourages et tenant la poignée qui termine le mancheron, vous toucherez le dos des bœufs qui tirent sur la clef du joug. $»^{8}$

9 L'animal et l'homme sont ainsi complémentaires, unissent leurs efforts dans ce ponos nécessaire pour que, après d'autres travaux, et avec la protection des dieux, l'homme qui a engrangé son blé ait de quoi vivre avec sa maisonnée, puisse prendre du repos mais aussi prendre soin de ses animaux :

"À l'automne, c'est le moment de nourrir chez soi des bœufs aux cornes recourbées. $»^{9}$

Entre le bœuf de labour et le paysan, c'est un véritable compagnonnage qui s'établit, d'où l'interdit de tuer le bœuf :

«Un bœuf de labour et qui a peiné sous le joug, attelé à la charrue, ou encore au chariot, il est interdit de le sacrifier, car il est bien paysan lui aussi et partage les peines que connaissent les hommes. ${ }^{10}$

11 La question est soulevée par des philosophes et différents courants - orphisme, pythagorisme - qui refusent le sacrifice et la consommation de la viande. Ce n'est pas un choix diététique :

«C'est décider de ne pas accomplir l'acte le plus important de la religion politique $»^{11}$.

12 Ami de l'homme, voire quasiment son double dans le labeur, le bœuf, animal lié à la terre cultivée, est néanmoins mangé, car les hommes "mangeurs de pain » sont aussi des mangeurs de viande. Mais il faut que le bœuf soit mis à mort par le sacrifice qui conjoint rituellement les hommes et les dieux par son entremise, tout en fixant la distance qui les sépare. Et dans la cité, l'alimentation carnée coïncide avec la pratique sacrificielle ${ }^{12}$.

\section{Encore faut-il ne pas confondre animal sauvage, animal domestique, animal consacré ${ }^{13}$}

13 Ce sont des erreurs que commettent les compagnons d'Ulysse, qui pourtant les avait mis en garde :

« Amis, dans le croiseur on a boisson et vivres; laissons donc ces troupeaux; nous en aurions malheur! C'est un terrible dieu qui possède ces bœufs et ces grasses brebis : le Soleil qui voit tout. » 

d'Ulysse, «ils se mettent en chasse et cernent les meilleures des vaches du Soleil », s'en prenant aux bêtes qui paissaient paisiblement et procèdent à un sacrifice perverti. Le Soleil furieux du « meurtre de ses vaches » obtient de Zeus la punition de ces « impies » frappés par la foudre au milieu d'une violente tempête ${ }^{14}$. Or, immortelles, les vaches du Soleil ne sont ni sauvages, ni domestiques; elles vivent en troupeaux paisiblement, ne sont ni attelées, ni mangées. Les compagnons d'Ulysse, après les avoir chassées comme des bêtes sauvages, opèrent une subversion du sacrifice et les bêtes elles-mêmes protestent :

"Les dépouilles marchaient; les chairs cuites et crues meuglaient autour des broches ; on aurait dit la voix des bêtes elles-mêmes. $»^{15}$

Dans ces deux modes de rapport entre les animaux et les hommes que sont la chasse et le sacrifice, il y a mise à mort de l'animal, violente dans un cas, en douceur - ou du moins le prétend-on - dans l'autre.

\section{Montrer ou occulter la violence}

\section{Combattre et tuer la bête dangereuse : une mise à mort violente et difficile}

Pour Isocrate :

«La plus nécessaire et la plus juste des guerres est celle que les hommes mènent dans leur ensemble contre la sauvagerie des bêtes, la seconde étant celle que les Grecs mènent contre les Barbares. ${ }^{16}$

17 La chasse permet aux hommes de s'affranchir de la menace des animaux. S'il est plusieurs sortes de chasse, la plus noble est la chasse aux quadrupèdes, cerfs, daims, et surtout la chasse au sanglier. Écartant certaines pratiques peu dignes, chasse de nuit, chasse avec filets et pièges, selon Platon :

"Seule demeure celle que l'on fait aux quadrupèdes, en s'aidant de chevaux et de chiens et de son propre corps; toutes les proies, soit qu'on les course ou qu'on les frappe de près ou de loin, on ne les capture que de ses propres mains, si l'on est de ceux qui cultivent la divine bravoure."

C'est ainsi que :

«Par la victoire d'une âme vaillante est domptée la force sauvage des bêtes ${ }^{17}$.

Nombre de héros grecs sont des chasseurs qui affrontent un sanglier monstrueux. À Calydon, il fallait tuer le sanglier pour défendre la terre cultivée :

"Ce fut le fils d'Oineus qui le tua. Il avait pour cela convoqué les chasseurs, les chiens de maintes villes: la bête n'eût pas succombé sous un petit nombre d'hommes ; elle était énorme et elle fit monter bien des mortels au bûcher. $»^{18}$

Méléagre avait convoqué en effet les plus renommés des héros de la Grèce dont les noms sont parfois indiqués sur les vases ${ }^{19}$. La violence du combat est signifiée par le nombre des chasseurs qui encerclent la bête, les chiens, les javelots fichés sur la bête, les traces de sang, un chasseur blessé ou mort sous le sanglier. Méléagre armé d'un trident comme on le voit sur le vase de Rouen - ou sur d'autres images d'un épieu affronte l'animal de face ${ }^{20}$. Xénophon consacre le chapitre $\mathrm{X}$ du traité De la chasse, à la chasse au sanglier. Une fois la bauge découverte par les chiens, il faudra tendre les rets 
et le chasseur le plus expérimenté pressera la meute tandis que les autres se placeront autour à bonne distance.

«Quand les chiens sont près de la bauge, ils s'élancent vers lui. Le sanglier troublé se dressera, et tout chien qui s'approchera de son groin, il le lancera en l'air. »

morceaux comestibles sont camouflés sous la peau et l'estomac (gaster), mais en mangeant la viande, les hommes se comportent comme des ventres (gasteres oion) insatiables ${ }^{25}$. Cette fraude initiale, sorte de péché originel, a de lourdes conséquences, mais fonde les règles du partage inégal, entre les dieux et les hommes, des animaux domestiques rituellement tués. À cette condition les hommes peuvent en consommer la chair cuite, dûment partagée. Si les hommes prennent plaisir à se repaître de la chair d'une bête morte, c'est pour assouvir un besoin : la faim, qui sans cesse les tenaille, liée des pierres, en se gardant de ses mouvements, et le cerner par-derrière et à bonne distance jusqu'à ce que, poussant en avant, il tende le tirant du filet. Puis le plus expérimenté et le plus fort des chasseurs présents le frappera de face avec son épieu, au moment où il s'avancera. $»^{21}$

Cette chasse est violente et dangereuse pour les chasseurs. Xénophon explique ce qu'il faut faire : si le chasseur doit prendre des risques, voire être jeté à terre et piétiné, un autre chasseur doit exciter le sanglier pour le détourner, en colère et furieux, de l'homme à terre qui ainsi va pouvoir se relever.

«Qu'il saute sur ses pieds aussitôt, sans oublier, en se relevant, de prendre son épieu; car il ne peut honnêtement se sauver que par la victoire. Il présentera de nouveau l'épieu de la même manière et l'enfoncera entre les omoplates, à l'endroit de la gorge, en appuyant de toutes ses forces. L'animal en fureur s'élancera, et, si les dents de la lame ne l'arrêtaient pas, il arriverait en poussant en avant le long de la hampe jusqu'à l'homme qui tient l'épieu. $»^{22}$

La violence et le danger sont des deux côtés; chasseurs et chiens peuvent être mis à mal, c'est néanmoins une sorte de combat à la loyale pour vaincre le sanglier.

\section{Le meurtre du bœuf : une mort douce consentie}

Dans le sacrifice de «l'ami de l'homme », le bœuf, au contraire, la violence est en partie occultée. Lors du premier sacrifice dont Hésiode fait état dans $L a$ Théogonie ${ }^{23}$, la mise à mort du bœuf est sous-entendue ; le récit commence après :

« Prométhée avait d'un cœur empressé partagé un bœuf énorme, qu'il avait ensuite placé devant tous. Il cherchait à tromper la pensée de Zeus : pour l'un des deux partis, il avait mis sous la peau les chairs et les entrailles lourdes de graisse puis recouvert le tout du ventre du bœuf; pour l'autre, il avait par une ruse perfide disposé en un tas les os nus de la bête, puis recouvert le tout de graisse blanche. »

«Comprit la ruse et sut la reconnaître... En ses deux mains il souleva la graisse blanche et la colère emplit son âme, tandis que la bile montait à son cœur à la vue des os nus de la bête trahissant la ruse perfide. »

«Et aussi bien est-ce pourquoi, sur la terre, les fils des hommes brûlent aux Immortels les os nus des victimes sur les autels odorants. ${ }^{24}$ 
à l'usure de leurs forces, au vieillissement, à la mort. Les dieux, eux, prennent plaisir à humer le fumet, les odeurs, les parfums: Immortels toujours vivants, ils demeurent jeunes; il n'y a en eux aucun élément périssable. Les hommes au contraire ont en commun avec les animaux leur condition mortelle. Néanmoins il faut bien assumer que le sacrifice est une mise à mort, même si celle-ci est occultée.

«Les problèmes que la mort animale peut poser dans le cadre du sacrifice sont à Athènes ancrés dans la pratique sacrificielle de la cité elle-même. La fête très officielle des Bouphonia, célébrée le quatorze Skirophorion, empêche d'éluder le fait que pour sacrifier il faut faire mourir. C'est parce que le premier bœuf a été immolé sur l'Acropole que tous les ans on rappelle le souvenir de cette mort au cours de la fête ainsi dénommée : bouphonia, tuerie du bœuf. $»^{26}$

Mais ce n'est pas sur la mise à mort du bœuf que se fonde la cité, aussi la violence estelle le plus possible occultée.

«Lorsque sous la contrainte, il faut sacrifier le bœuf de labour, il faut du même coup porter à l'extrême la mise à distance de l'acte violent inhérent au sacrifice. $»^{27}$

\section{Qu'en est-il dans le rituel ?}

Celui-ci, la thusia, est assez bien connu par les textes et les images; même si d'autres victimes, mouton, porc sont sacrifiées, c'est le sacrifice du bœuf qui est le plus noble. Un passage de l'odyssée ${ }^{28}$ décrit ce sacrifice alimentaire sanglant dont le rituel demeure ensuite à peu près le même dans la cité. C'est l'acte religieux qui permet aux hommes de consommer la chair des bêtes sous le regard des dieux sans se bestialiser ${ }^{29}$. Le sacrifice est décidé par Nestor, roi de Lacédémone, pour fêter l'arrivée de Télémaque. La victime (une vache en l'occurrence) a été soigneusement choisie et embellie: on dore les cornes, on l'orne de bandelettes. On prépare l'eau lustrale, le bassin, la hache et le vase pour le sang. Puis viennent les rites préliminaires :

« Nestor répandit l'eau lustrale et les orges, puis il fit à Pallas (Athéna) une longue prière et, comme il prélevait quelques poils de la tête qu'il lançait dans le feu, l'assistance en priant jeta les pincées d'orge. »

Cette offrande des poils vaut consécration complète de la victime et les céréales manifestent la conjonction entre le sacrifice et la terre cultivée. Recevant l'aspersion d'eau et les orges, la bête réagit et bouge la tête; ce mouvement est interprété comme signe d'acquiescement. La mise à mort est décrite dans le texte alors qu'elle n'est jamais représentée ou presque sur les vases ou autres supports. Un fils de Nestor :

«A frappé, et la hache a tranché les tendons cervicaux : la bête tombe inerte, sous les clameurs sacrées des filles et des brus et de la vieille reine Eurydice... Fils et gendres alors saisissent la victime, qu'on soulève au-dessus du sol... ${ }^{30}$ Pisistrate l'égorge, dans le flot de sang noir l'âme quitte les os. " $^{31}$

31 Les femmes participent en poussant l'ololugê. Ce cri des femmes exprime la charge émotionnelle que provoquent l'égorgement de la victime et l'écoulement du sang; le geste n'est pas représenté mais évoqué par la présence sur les images du vase destiné à recueillir le sang (sphageion) ou par des traces du sang qui a éclaboussé l'autel ${ }^{32}$. Puis viennent le dépeçage et la découpe :

« On dépèce à la hâte, en détachant tous les cuisseaux, selon le rite. »

Nestor les brûle pour les dieux en faisant une libation de vin ; les autres enfilent sur des broches les viscères nobles (cœur, poumons, foie) et les font griller : 
«Puis les cuisses brûlées, on goûte les grillades et découpant le reste de la bête, on

le met à rôtir le long des longues broches. ${ }^{33}$ texte comme sur les images, il s'agit d'une cérémonie collective avec de nombreux participants, majoritairement des hommes portant des couronnes. Ainsi voit-on sur un cratère du musée de Ferrare ${ }^{34}$, vers Apollon représenté à Delphes (colonnes, trépieds, arc et instruments de musique dans le champ) la procession (pompè) qui avance calmement ; un prêtre, sorte de maitre des cérémonies, l'accueille. En tête une femme richement parée porte sur la tête le panier (kanoun) qui contient différentes graines produit des cultures auxquels le bœuf a participé - sous lesquelles est caché le couteau (makhaira); un brûle-parfum est représenté pour les fumigations. Viennent ensuite plusieurs bœufs guidés en douceur. La scène est paisible, pleine de retenue; les participants couronnés sont soigneusement drapés. Les victimes sont censées être consentantes.

sacrifice en tant que meurtre rituel de l'animal domestique permet la consommation de la viande cuite dans la cité, grillée ou bouillie dans un chaudron, forme de coction à cœur plus raffinée. Sur l'hydrie de Caeré, sur une frise continue sur l'épaule du vase, on montre différentes opérations qui suivent l'immolation de la bête non représentée. Ces scènes relèvent de la boucherie et de la cuisine, tandis que sous une treille qui couvre l'ensemble des scènes, un prêtre figuré au centre fait une libation sur un autel sur lequel brûle le feu. Le bœuf est maintenant une carcasse ; dépeçage et découpe en font de la viande consommable. Le nom de mageiros désigne à la fois le sacrificateur et le boucher, mais il n'y a pas de boucherie en dehors du sacrifice, car «l'alimentation carnée coïncide avec la pratique sacrificielle $»^{35}$. Des morceaux de viande sont enfilés sur de longues broches (obeloi) pour être transportés et distribués plus tard ; ils peuvent aussi être bouillis dans un chaudron comme on le voit sur ce vase ${ }^{36}$.

\section{Le sanglier et le bœuf : deux animaux symboliques pour délimiter la place des humains dans le monde}

\section{Chasser le sanglier permet de délimiter l'espace de la cité dont la protection relève de la responsabilité des hommes et des jeunes gens}

C'est ce que représente l'exploit cynégétique qui vient à bout du sanglier monstrueux de Calydon. Méléagre convoque des héros jeunes et adultes, souvent figurés barbus mais pas toujours ; les Courètes, ses oncles maternels, participent à la chasse. Lui-même est un jeune homme, qui plus est le fils du roi dont la fonction est de protéger son peuple, qui se doit de mener la chasse; d'ailleurs son nom, «Celui qui donne tous ses soins à la Chasse ", l'y prédestine. Mais dans cette chasse particulière se trouve une jeune fille chasseresse, équipée d'un arc, Atalante ${ }^{37}$. C'est elle en réalité qui atteint le sanglier d'une flèche à l'œil et fait couler le premier sang, coup mortel qui permet ensuite à Méléagre d'achever la bête. Atalante est ainsi décrite par Ovide :

«Une fibule agrafait le haut de son vêtement ; rien ne parait ses cheveux [...] À son épaule gauche résonnait le carquois d'ivoire, gardien de ses flèches, et, de la main gauche aussi elle tenait son arc ; quant à ses traits on eût pu dire, en vérité, qu'ils étaient ceux d'une jeune fille chez un jeune garçon, ceux d'un jeune garçon chez 
une jeune fille [...] Elle ajusta sur la corde une flèche rapide et, courbant son arc, la décocha. Le roseau se fixa sous l'oreille de la bête [...] C'est Méléagre qui, le premier croit-on, vit couler le sang et le montra à ses compagnons et dit "Tu as mérité et on te décernera le prix de la valeur". $»^{38}$

Les femmes grecques ne sont jamais chasseresses, mais Atalante, jeune fille qui a été abandonnée bébé dans une forêt, allaitée par une ourse, vit dans la nature sauvage, jointe au cortège d'Artémis chasseresse. Elle est une sorte de double de l'Archère :

« La bruyante Artémis aux flèches d'or qui de ses traits frappe les cerfs [...] celle qui par les montagnes ombreuses et les pics battus des vents bande son arc d'or pur, toute à la joie de la chasse, et lance des flèches qui font gémir [...]. La déesse au cœur vaillant se lance de tous côtés, et sème la mort parmi la race des bêtes sauvages. $\|^{39}$

Elle intervient dans la chasse de Calydon, cette chasse de jeunes gens auxquels elle ressemble, elle, la vierge qui fuit les hommes, comme si le sanglier monstrueux envoyé par la déesse ne pouvait être mis à mort que par la déesse elle-même ou par son double. Mais la pratique de cette chasse est dangereuse, l'homme peut basculer dans la sauvagerie. C'est ce qui arrive: Méléagre a décerné les dépouilles de la bête à Atalante au grand dam de ses oncles, les Courètes; Artémis suscite une violente querelle entre les chasseurs; ensauvagés ils s'entretuent. De même quand, à Crésus, ses sujets qui ne peuvent venir à bout du sanglier, demandent :

« Nous te prions d'envoyer avec nous ton fils accompagné de jeunes gens choisis et

de chiens pour que nous en débarrassions le pays. »

Le roi, qui redoute le pire à la suite d'un songe, commence par refuser ; il finit par céder aux instances du jeune homme, qui se sent déshonoré par ce refus, de le laisser aller à la guerre et à la chasse. La troupe « de jeunes gens choisis et de chiens » atteint le mont Olympe: "Ils se mirent en quête de la bête, la débusquèrent, l'encerclèrent et l'assaillirent à coups de javelots "; c'est alors que le malheur a lieu: l'homme que Crésus avait chargé de protéger son fils lance son javelot, manque la bête, «le jeune homme est atteint par la pointe de l'arme ", chasseur chassé à mort, tandis que l'auteur de ce meurtre involontaire se donne à son tour la mort sur le tombeau du jeune homme ${ }^{40}$. Quoi qu'il en soit, chasser et tuer un sanglier est toujours perçu comme un exploit. Dans l'Odyssée, il est raconté que, tout jeune encore, Ulysse est allé séjourner chez son grand-père maternel; il participe à une chasse au sanglier avec ses oncles maternels et affronte « un sanglier géant » qui bondit furieux hors des fourrés :

« Ulysse le premier bondit en élevant [...] sa lance. La bête le devance et le boute à la cuisse [...] Mais Ulysse d'un heureux coup l'avait frappée en pleine épaule droite : la pointe était sortie [...] à l'autre flanc, et la bête, en grognant, roulait dans la poussière : son âme s'envolait. " $^{41}$

Exploit cynégétique à valeur initiatique dont le jeune homme garde la cicatrice inscrite dans sa chair toute sa vie. C'est cette cicatrice que reconnait sa vieille nourrice quand il rentre à Ithaque au terme de ses longues pérégrinations après la guerre de Troie. Exploit, rite de passage à l'âge adulte dans l'épopée, la victoire sur le sanglier demeure emblématique de la défense de la terre cultivée par les jeunes gens quand à Athènes, dans la seconde année du service militaire, les éphèbes sont en garnison dans les forts aux marges du territoire de la cité. Dans le serment qu'ils prononcent, ils prennent à témoin, outre les divinités, « les frontières de la patrie, ses blés, orges, vignes, olives et figues " qu'ils s'engagent à défendre. Il s'agit bien de la défense de la terre cultivée, celle des blés et des plantations, contre la sauvagerie, celle des bêtes et celle des ennemis. Il s'agit de la défense de la terre de la cité. Xénophon ne manque pas de 
terminer son traité sur la chasse en en montrant l'utilité comme préparation à la guerre des citoyens soldats :

«Dans les attaques contre l'ennemi, ils seront capables à la fois de marcher sur lui et d'exécuter les ordres... parce qu'ils sont habitués à le faire pour prendre les fauves; placés en première ligne, ils n'abandonneront pas leurs rangs, parce qu'ils sont endurcis. $»^{42}$

Et la chasse est toujours perçue comme la meilleure école de vertu pour les jeunes gens, car c'est le seul plaisir de la jeunesse qui « rend les jeunes gens tempérants et justes, en les élevant à l'école de la vérité ${ }^{43}$. De ce fait, symboliquement la chasse au sanglier, en définissant les rapports des hommes avec la nature sauvage, permet de délimiter l'espace civique mais aussi le corps politique.

\section{Le partage du bœuf définit la place de l'homme dans le monde}

41 Par l'offrande aux dieux de la partie non comestible de la victime qui est brûlée, il est établi que les dieux et les hommes ne consomment pas les mêmes nourritures. Dans l'hymne homérique A Hermès, sont racontées les expériences de ce jeune dieu fugueur. Après avoir volé cinquante vaches du troupeau de son frère Apollon dont il est jaloux, et trouvé tout seul comment faire du feu, dans un pseudo-sacrifice, il tue deux vaches dont il découpe les chairs qu'il fait rôtir, en faisant douze lots pour les douze dieux de l'olympe :

«Hermès eut envie de goûter aux viandes consacrées: leur odeur agréable le troublait, tout Immortel qu'il fût ; mais, malgré la force de ce désir, [...] il ne put se résoudre à les faire passer par son gosier sacré. $\rangle^{44}$

Autant dire que les Immortels peuvent savourer le fumet, l'odeur délicieuse et subtile des os brûlés du bœuf, mais ne mangent pas sa chair; les humains, mortels comme l'animal sacrifié, la consomment. Entre les Immortels bienheureux et les hommes mortels il n'y a pas de commensalité possible. Par la médiation du bœuf s'établit une relation verticale qui certes les conjoint, mais en même temps délimite la place des hommes dans le monde, entre bêtes et dieux. On observera que, a contrario, les bêtes sauvages, dont le sanglier, ne sont pas sacrifiées et que, si leur chair est consommée, c'est lors du « repas des chasseurs » ou dans l'espace domestique.

\section{Le partage de la viande du bœuf s'inscrit dans la vie de la cité démocratique}

Déjà dans l'épopée le « repas des égaux » implique le «partage à parts égales ». Il en va de même dans la cité où les citoyens, semblables et égaux, participent aux repas en commun qui suivent les sacrifices. C'est le seul moment et le seul mode de consommation de viande. La participation à ces repas est un acte politique analogue à la participation aux autres obligations et privilèges de la vie du citoyen. La viande est découpée au carré en morceaux égaux. Des parts d'honneur sont attribuées aux magistrats, prêtres, vainqueurs aux jeux, hôtes etc. Lors de certaines fêtes un grand nombre de victimes sont sacrifiées : cent bœufs pour une hécatombe. Certaines viandes sont réservées pour une consommation différée ; une partie est distribuée aux citoyens pour nourrir leur famille; les morceaux de viande sont enfilés sur les obeloi pour être transportés. Jean-Louis Durand et Alain Schnapp le résument ainsi : 
«La cuisine du sacrifice, c'est d'abord l'accès égal aux viandes communes, c'est la démocratie. »

Ou encore :

«Ce qui fonde la société civique c'est le fait de manger ensemble l'animal sacrifié, la commensalité autour des parts de viande. $»^{45}$

Sauvage ou domestique, chassé ou sacrifié, l'animal est au centre de la relation vécue par l'homme dans son rapport à l'au-delà ; ainsi se définit l'espace de l'humain entre bêtes et dieux. Ainsi se définit aussi le territoire de la cité. Le bœuf est emblématique de la terre cultivée : auxiliaire de l'homme pour la production des orges et des blés, mais aussi nourriture par sa chair consommée. Le sanglier, symbole de cette sauvagerie toujours présente aux confins, doit être affronté et chassé pour assurer la protection de la cité.

\section{BIBLIOGRAPHIE}

BONNEFOY Yves (dir.), Dictionnaire des mythologies et des religions des sociétés traditionnelles et du monde antique, Paris, Flammarion, 1981, 2 vol.

(Collectif) La cité des images. Religion et société en Grèce Ancienne, Paris, Flammarion, 1984. DETIENNE Marcel et VERNANT Jean-Pierre, La cuisine du sacrifice en pays grec, Paris, Éditions Gallimard, 1979.

DURAND Jean-Louis, « Bêtes grecques. Propositions pour une topologie des corps à manger ", dans La cuisine du sacrifice, p. 167-182.

DURAND Jean-Louis, « Sacrifice. Les mythes grecs, II. Mythes d'Argos et d'Athènes », dans Dictionnaire des mythologies, p. 410-414.

DURAND Jean-Louis, Sacrifice et labour en Grèce ancienne. Essai d'anthropologie religieuse, Paris-Rome, Éditions de la Découverte/École française de Rome, 1986.

ELLINGER Pierre, « Artémis », dans Dictionnaire des mythologies, p. 70-73.

Hommes, dieux et héros de la Grèce, Catalogue de l'exposition 23 octobre 1982-31 janvier 1983, Musée départemental des Antiquités, Rouen, 1982.

Hérodote, L'Enquête, texte présenté, traduit et annoté par Andrée BARGUET, Bibliothèque de La Pléiade, Paris, Gallimard, 1964.

Hésiode, Théogonie. Les Travaux et les Jours, texte établi et traduit par Paul MAZoN, Collection des Universités de France, Paris, « Les Belles Lettres », 1967.

Homère, Hymnes, texte établi et traduit par Jean HUMBERT, Collection des Universités de France, Paris, «Les Belles Lettres », 1967.

Homère, Iliade, traduction, introduction et notes de Robert FLACELIÈRE. Odyssée, traduction de Victor BÉRARD, introduction et notes de Jean BÉRARD, Bibliothèque de La Pléiade, Paris, Gallimard, 1955. 
LISSARRAGUE François, Vases grecs. Les Athéniens et leurs images, Paris, Éditions Hazan, 1999.

SCHNAPP Alain, «Chasse. Ses héros et ses mythes en Grèce ancienne », dans Dictionnaire des mythologies, p. 156-158.

VERNANT Jean-Pierre, «À la table des hommes. Mythe de fondation du sacrifice chez Hésiode », dans La cuisine du sacrifice, p. 37-132.

VERNANT Jean-Pierre, « Sacrifice. Les mythes grecs, I. Prométhée », dans Dictionnaire des mythologies, p. 408-410.

VIDAL-NAQUET Pierre, "Chasse et sacrifice dans l' "Orestie d'Eschyle" ", dans VERNANT Jean-Pierre et VIDAL-NAQUET Pierre, Mythe et tragédie en Grèce ancienne, Paris, Maspero, 1972, p. 133-158.

Xénophon, Traité De la Chasse, traduction, notices et notes par Pierre CHAMBRY, Euvres complètes II, Paris, Garnier-Flammarion, 1967, p. 383-427.

\section{NOTES}

1. P. Vidal-Naquet, "Chasse et sacrifice dans l'“Orestie d'Eschyle" ", dans J.-P. Vernant et P. Vidal-Naquet, Mythe et tragédie en Grèce ancienne, p. 133-158.

2. Rouen, Musée départemental des Antiquités, 531 (9820029) dans Hommes, dieux et héros, fig. 84a, p. 200.

3. Id. détail, ibid. 84c, p. 202.

4. Iliade, IX, 530-547.

5. Hérodote, L'Enquête, I, 36.

6. Hésiode, Les Travaux et les Jours, 405.

7. Ibid. 437-439.

8. Ibid. 466-468.

9. Ibid. 439.

10. Élien, Var. hist., V, 14 cité par J.-L. Durand, Sacrifice et labour, p. 176.

11. M. Detienne, dans M. Detienne et J.-P. Vernant, La cuisine du sacrifice, p. 14.

12. M. Detienne, ibid., p. 7-21.

13. A. Schnapp, s.v. Chasse, dans Dictionnaire des mythologies, p. 156.

14. Odyssée, XII, 325-418 passim.

15. Ibid., 395-396 ; J.-P. Vernant, « Manger au pays du Soleil », dans La cuisine du sacrifice, p. 239-249.

16. Isocrate, Panathénaïques, 163.

17. Platon, Lois, VII, 823 b-824 a.

18. Iliade, IX, 545-547.

19. Ainsi sur le vase François, cratère à figures noires signé Clitias et Ergotimos, 570 av. J.-C., Florence, Musée archéologique ; v. F. Lissarrague, Vases grecs, p. 10-21, face A p. 11 et détail p. 15.

20. Dans Hommes, dieux et héros, "La chasse ", p. 189-190 ; "La chasse de Calydon", p. 200-205. 
21. Xénophon, De la chasse, X, 4 ; 9.

22. Ibid., 15-16.

23. J.-P. Vernant, "Sacrifice. Les mythes grecs. I. Prométhée ", Dictionnaire des mythologies, II, p. 408-410, qui souligne qu'il s'agit du «mythe de référence pour comprendre la place, la fonction, les significations du sacrifice dans la vie religieuse des Grecs » et comment le sacrifice est au cœur de la relation entre les hommes et les puissances surnaturelles. Pour une analyse plus développée, voir J.-P. Vernant, «À la table des hommes. Mythe de fondation du sacrifice chez Hésiode », dans La cuisine du sacrifice, p. 37-132.

24. Hésiode, Théogonie, 535-616.

25. Ibid., 26 : vous « qui n'êtes rien que ventres !», c'est ainsi que les Muses définissent les hommes en s'adressant à Hésiode au début du poème.

26. J.-L. Durand, Sacrifice et labour, p. 13-14.

27. Ibid., p. 198.

28. Odyssée, III, 418-472.

29. J.-L. Durand et A. Schnapp, «Boucherie sacrificielle et chasses initiatiques », dans La Cité des Images, p. 48-56 ; M. Detienne et J.-P. Vernant, La cuisine du sacrifice, passim.

30. On voit le bœuf ainsi soulevé sur une amphore à figures noires du musée de Viterbe reproduite dans Cité des images, p. 55, fig. 85.

31. Odyssée, III, 460-472.

32. J.-L. Durand, Sacrifice et labour, p. 10-12.

33. J.-L. Durand, «Bêtes grecques; Propositions pour une topologique des corps à manger ", La cuisine du sacrifice, p.133-166, voir en particulier le déroulement des scènes figurées sur l'épaule de la très belle hydrie ionienne de Caeré publiée par G. Ricci, «Una hydria ionica da Caere », ASAA, 24-26, 1946-1948, p. 47-57, reproduite dans La cuisine, planches hors texte I à IV, entre les p. 144 et 145 ; elle est également reproduite en partie dans Cité des images, p. 51, fig. 74.

34. Ferrare, Museo Nazionale, T 316 B V P, reproduit dans Cité des Images, p. 48.

35. M. Detienne, La cuisine du sacrifice, p. 10.

36. Cité des images, p. 51, fig. 74.

37. On la voit bandant son arc sur le vase du peintre de Rouen, dans Hommes, dieux et héros, p. 203, fig. 84d.

38. Ovide, Métamorphoses, VIII, 317-319; 384-390.

39. Hymne homérique à Artémis, II, 1-10 ; P. Ellinger, sv Artémis, dans Dictionnaire des mythologies, p. 70-73.

40. Hérodote, L'Enquête, I, 43-44.

41. Odyssée, XIX, 429-455.

42. Xénophon, De la chasse, XII, 3.

43. Ibid., XII, 6 .

44. Hymne homérique à Hermès, 130-134.

45. J.-L. Durand et A. Schnapp, "Boucheries sacrificielles et chasses initiatiques », Cité des Images, p. 52. 


\section{RÉSUMÉS}

Le sanglier monstrueux envoyé par Artémis pour ravager la terre de Calydon marque l'intrusion de la sauvagerie dans la terre cultivée. L'exploit cynégétique de jeunes hommes établit une barrière radicale entre animaux sauvages et hommes et délimite l'espace de la cité. Le meurtre de l'animal domestique le plus proche de l'homme, le bœuf, considéré comme consentant, conduit au sacrifice sans violence, constitue la médiation nécessaire entre les hommes et les dieux. Il s'agit de les conjoindre dans l'acte même qui les sépare : aux dieux le sang de l'animal égorgé et les parties brûlées dont ils apprécient le fumet, aux hommes les parts de viande rituellement découpées et cuites, mais hommes et dieux ne partagent pas la même table. Sauvage ou domestique, chassé ou sacrifié, l'animal est au centre de la relation vécue par l'homme dans son rapport à l'au-delà ; ainsi se définit l'espace de l'humain. Il est aussi un catalyseur qui soude le corps politique inscrit dans un territoire.

\section{AUTEUR}

\section{FRANÇOISE THELAMON}

Professeur d'Histoire ancienne honoraire, université de Rouen-Normandie, membre de

l'Académie des Sciences, Belles-Lettres et Arts de Rouen 


\title{
Les manifestations des animaux
} dans les espaces propres à l'homme comme signe augural dans les collections de présages de Mésopotamie ( ${ }^{\mathrm{er}}$ millénaire av. J.-C.)

\author{
Andréa Vilela
}

1 Les animaux, qu'ils soient vivants ou morts, ont souvent été considérés comme un support particulier pour les techniques divinatoires. Les méthodes ne manquent pas pour tenter de déceler les anomalies éventuelles et d'en deviner le sens, tout du moins sur le plan « prophétique ». En Mésopotamie, où le corpus divinatoire est riche et divisé en différentes techniques, les animaux jouent un rôle majeur. Ils sont susceptibles d'apparaître dans diverses collections de présages, répertoriées sur des tablettes d'argile rédigées en langue akkadienne et en caractères cunéiformes. C'est notamment le cas dans la collection shumma âlu ina mêlê shakin ${ }^{1}$, dont le texte de référence date du $\mathrm{I}^{\mathrm{er}}$ millénaire av. J.-C. Bien que cette collection n'ait pas encore été totalement reconstituée, on estime que le nombre total de présages qu'elle contenait devait avoisiner les dix mille, répartis sur plus d'une centaine de tablettes, dont plusieurs étaient consacrées entièrement aux animaux. Chaque espèce ou groupe d'espèces était ainsi présenté sur une ou plusieurs tablettes. Sont mentionnés divers types d'animaux, domestiques ou sauvages. Il peut être question de mammifères, d'oiseaux, de reptiles, d'insectes... Aussi bien la morphologie que le comportement aident à définir la valeur augurale, ils sont donc décrits avec minutie. Mais d'autres éléments affectent également la valeur du signe comme le moment et, surtout, le lieu où il est observé.

Les manifestations animales sont donc souvent situées dans l'espace et c'est sur cet aspect de la question que porte notre étude. L'organisation de l'espace sur le plan symbolique apparaît comme extrêmement complexe en Mésopotamie et certaines de ses subdivisions citées dans les textes étudiés sont clairement considérées comme «propres à l'homme». Bien évidemment, cela ne signifie pas que les animaux n'y 
soient pas admis et la présence de certaines espèces dans l'espace urbain ou même domestique est présentée comme normale. Mais chacune a son espace propre, qui peut être situé en dehors de la ville, à l'intérieur, ou même dans les maisons. Qu'un animal fasse irruption dans un lieu où il ne devrait pas être confère à sa manifestation une valeur augurale potentielle. Il en va de même lorsque les animaux se comportent d'une manière qui ne serait pas en adéquation avec le lieu, en faisant preuve d'agressivité par exemple.

3 Au cours de notre étude nous avons également pu observer une corrélation entre le lieu où l'animal se manifeste et la portée collective ou individuelle du signe divinatoire. Certes, ce constat peut être nuancé par certains cas particuliers, mais une tendance générale se dégage tout de même. Nous avons donc décidé de traiter des manifestations animales et du lieu où elles se produisent selon la portée collective ou individuelle du signe. Après avoir abordé la question de la structuration de l'espace, nous verrons ainsi dans un premier temps les irruptions animales pouvant concerner la collectivité, puis celles relatives à l'individu.

\section{La structuration de l'espace et ses subdivisions}

4 Les différentes manières de structurer l'espace dans les sociétés humaines varient en fonction de la culture. Ces disparités sont également observables dans les rapports entretenus avec le monde animal. Néanmoins, certains aspects de ce type de raisonnement sont des manifestations particulières d'un besoin instinctif de défense, qui ont ensuite été mises en forme par le cadre mental de chaque société. Dans la nature, chaque espèce peut être amenée à se défendre contre des prédateurs. Une trop grande proximité avec une autre espèce peut ainsi, selon les cas, déclencher un comportement de fuite ou de défense.

5 Chez l'homme, ces réactions, bien que rationalisées et formatées par des moules culturels, n'ont pas totalement disparu. C'est ainsi que toute proximité avec des animaux pouvant constituer une menace pour les ressources, et surtout pour les individus, provoquera un certain malaise et que, d'une manière générale, la présence rapprochée d'un prédateur sera source d'inquiétude. Dans le cas présent, nous verrons comment se manifestent les interactions d'un groupe humain spécifique, les populations vivant en Babylonie et en Assyrie au I ${ }^{\text {er }}$ millénaire av. J.-C., avec les espèces venant à s'approcher et à pénétrer dans ce qu'ils considèrent être « leur espace ».

6 En Mésopotamie, la production scribale se fait dans le cadre urbain, c'est donc la vision des choses d'une population sédentaire et vivant dans les villes qui nous est transmise par les sources écrites dont nous disposons. Dans ces dernières, nous pouvons observer une opposition entre le monde urbain et tout ce qui se trouve à l'extérieur, souvent désigné par les logogrammes sumériens KUR (la montagne) et EDIN (la plaine). Cette opposition n'est pas propre à la civilisation mésopotamienne et se retrouve aussi ailleurs. Ainsi, au Japon actuel, une distinction existe entre sato (le lieu habité) et son opposé désigné par le terme yama (la montagne). Mais si en Mésopotamie KUR et EDIN servent à désigner un environnement hostile, ce n'est pas le cas de yama dans l'imaginaire japonais où ce lieu échappant au contrôle des hommes n'est pas vu comme une source d'inquiétude ${ }^{2}$. Les habitants des villes de Mésopotamie ne font donc pas seulement la distinction entre la ville et l'environnement extérieur, mais présentent également le lieu non habité comme une menace potentielle. 
7 Il n'est donc guère étonnant de voir que l'opposition entre sauvage et domestique est aussi très présente, et les textes font souvent la distinction entre les variétés domestiques et sauvages d'animaux. Les sources écrites montrent clairement que la présence d'un animal sauvage dans l'espace urbain est vue comme une intrusion extrêmement grave, constituant une violation de l'espace de la communauté par un élément extérieur, qui peut annoncer sur le plan symbolique la prise de la ville par une armée ennemie ou son abandon. Pour mieux comprendre la gravité de ces intrusions, nous pouvons citer ici un extrait d'un texte mythologique, le Poème d'Erra, où le dieu s'exprime en ces termes :

«Je fais pénétrer les bêtes sauvages dans les sanctuaires, j'empêche l'accès à toute ville où elles sont apparues. Je fais descendre les bêtes de la montagne. Où qu'elles aillent, elles apportent le silence de la mort dans les places publiques. Je fais quitter la plaine aux bêtes de la plaine, et leur fais traverser les rues de la ville. (Ainsi) je rends les présages défavorables, je change les lieux sacrés en pâtures. » ${ }^{3}$

8 Un cas de figure similaire se retrouve dans un texte rassemblant des signes néfastes, la tablette K2848, sur laquelle nous trouvons parmi les diverses protases à la ligne $19 \mathrm{du}$ verso :

«Si des animaux de la montagne sont vus dans la plaine et des animaux de la plaine sont vus dans la ville... $»^{4}$

Ces deux exemples décrivent le transfert des espèces d'un milieu à un autre. Elles semblent être poussées hors de leur habitat naturel par une force surnaturelle, ce qui a pour résultat de rendre caduque la division de l'espace. Nous comprenons alors que, dans leurs rapports avec les animaux, les populations de Mésopotamie établissent une division de l'espace fondée à la fois sur une conception mentale inhérente à leur culture et sur l'environnement naturel des espèces concernées. Toute irruption constitue donc une grave infraction à l'ordre du monde, aussi bien naturel que mental, et peut être interprétée comme signe révélateur de la colère divine ${ }^{5}$.

10 Cette division de l'espace attire ainsi l'attention par une première opposition entre l'espace urbain et l'espace extérieur, sauvage, échappant au contrôle des hommes (tout du moins de ceux qui vivent dans l'environnement urbain). Toutefois, envisager les choses uniquement sous cet angle serait réducteur, car il existe de nombreuses autres nuances et subdivisions de l'espace urbain qui sont répertoriées dans les textes. Ce dernier comprend la ville en général, avec ses rues, ses places, ses carrefours, ainsi que les espaces faisant office de transition avec le monde extérieur comme les murailles et les portes. Il intègre également certains édifices ayant un statut particulier, comme les temples et le palais. Enfin, il inclut aussi les habitations qui, bien que situées à l'intérieur de la ville, sont un cas à part et incarnent une autre subdivision : l'espace domestique.

11 Il existe aussi certains cas particuliers, des endroits que l'on peut considérer comme des prolongements temporaires du monde des hommes dans l'espace sauvage. Nous avons donc des "prolongements mentaux", à valeur symbolique, qui se manifestent temporairement de manière physique. Ainsi un campement militaire peut être perçu comme une extension provisoire du monde « urbain » et si, par exemple, des rapaces le survolent, cette observation sera considérée comme néfaste exactement comme elle le serait au-dessus d'une ville. Nous pouvons ainsi comparer certains présages relatifs à ces deux lieux, comme ceux des tablettes MS 1687 et W 22729/10. La première se 
consacre aux rapaces survolant un camp militaire et à tous les malheurs qu'ils peuvent annoncer. À titre d'exemple, les lignes i 20'-21' du verso :

«Si le roi a installé le camp et que des faucons ont crié au-dessus des tentes:

l'ennemi s'abattra sur la tente du roi durant la nuit. $»^{6}$

12 La seconde quant à elle compile différents signes relatifs aux oiseaux, dont certains présentent clairement l'apparition de rapaces au-dessus d'une ville comme annonciatrice de troubles pour cette dernière, voire de son abandon. Il peut être question de faucons, comme c'était le cas dans l'exemple précédent, mais d'autres espèces peuvent intervenir. C'est notamment le cas de la chouette à la ligne $19 \mathrm{du}$ verso:

«Si une chouette a crié sans arrêt au-dessus d'un lieu, cette ville sera abandonnée. $»^{7}$

Le lieu où les animaux sont observés est donc extrêmement important pour définir la valeur augurale d'un signe. Certes, d'autres éléments entrent également en jeu: l'espèce concernée, son apparence, son comportement, sa position par rapport à l'observateur (à droite ou à gauche par exemple), le moment où a lieu la manifestation... Mais la localisation reste centrale et certaines compilations de présages faites par les scribes se soucient davantage du lieu où est observé le phénomène que de l'animal concerné. Ainsi la tablette W. $22310^{8}$ est consacrée à des irruptions animales dans le temple. Bien qu'étant très endommagée, elle révèle la nécessité de faire des compilations de signes relatives à ce qui serait susceptible de se produire dans le cadre très particulier de l'espace religieux. Cette préoccupation se perçoit aussi dans la tablette $\mathrm{n}^{\circ} 5$ de la collection shumma âlu, mais cette fois-ci avec tout ce qui pouvait être observé dans une maison en construction, y compris les irruptions animales ${ }^{9}$.

\section{Les irruptions animales à valeur augurale collective}

D'une manière générale, les signes observés dans l'espace public auront une portée collective, par opposition à ce qui se produit dans l'espace domestique, à portée individuelle ou familiale. Néanmoins, certains cas particuliers existent, notamment dans l'espace public. Si plusieurs individus ont assisté à la scène, alors la prédiction concernera bien évidemment la collectivité alors que s'il n'y a qu'un seul témoin, c'est lui et éventuellement son entourage proche qui seront affectés.

Les lieux concernés par les prédictions relatives à l'avenir d'une communauté en particulier sont ceux occupés par cette dernière. Il s'agit donc dans la plupart des cas de l'espace urbain et de ses subdivisions. La mention « dans la ville » n'apparaîtra que dans le cadre de l'irruption d'animaux sauvages. En effet, que certaines espèces domestiques soient à l'intérieur de l'espace urbain est de toute évidence perçu comme normal. Leur présence en elle-même ne fait pas office de signe et d'autres éléments doivent être observés : le comportement, la morphologie... Parfois, l'endroit de la ville peut être précisé, ce genre de détail étant susceptible d'affecter la prédiction, ce qui est plus rarement le cas pour les animaux sauvages : leur irruption à elle seule suffit. Pour ces derniers, les limites de l'espace urbain, comme les murailles ou les portes de la ville, sont également citées. Le simple fait que les animaux sauvages se manifestent à proximité des portes est source d'inquiétude et il en va de même si certains oiseaux se posent sur les remparts ou survolent le lieu. 

C'est le cas notamment des temples, où la colère aussi bien que la satisfaction de divinités peuvent se manifester. Quant au palais, il est sans surprise un lieu hautement symbolique. Car le roi est lié de très près à l'avenir des territoires sous sa domination : son décès, une défaite ou une victoire militaire peuvent affecter le quotidien de toute une population, que ce soit en bien ou en mal. De même, l'espèce à laquelle appartiennent les animaux intervenant dans l'espace lié à la communauté compte énormément. Ils peuvent être classés en trois catégories. Nous avons déjà mentionné les animaux sauvages et domestiques, mais il est aussi bien souvent question de certaines espèces qui, bien que non domestiquées, se sont installées dans l'espace urbain et partagent cet environnement avec les hommes. bovins et bien sûr les chiens. Si leur présence en soi est tout à fait anodine, certains types de comportements observés dans l'espace urbain peuvent se voir attribuer un caractère néfaste. C'est notamment le cas des marques d'agitation ou d'agressivité, comme dans CT 38,46.

"Si des porcs sautent sans arrêt sur la place, malheur sur la ville. $»^{10}$

Sont parfois citées des espèces non-domestiquées, mais vivant à proximité des hommes. Il s'agit dans la plupart des cas d'animaux de taille relativement réduite. Aucune de ces espèces n'est utile à l'homme, elles vivent près de lui soit parce qu'elles profitent des ressources présentes telles que les déchets (corbeaux et autres charognards) ou les réserves de nourriture (rongeurs), soit parce que leurs proies naturelles se sont adaptées à l'environnement urbain (serpents et chouettes). La cohabitation est donc endurée par l'homme, mais d'une certaine manière acceptée. Leur présence peut certes être parfois présentée comme une gêne, mais ne provoquera pas un malaise comparable à celui lié à l'irruption des espèces sauvages.

19 Nous pouvons le voir dans la tablette VAT 10116 et 10145 (KAR 384-385) ${ }^{11}$, associée à la collection shumma âlu, où l'on distingue le serpent de la ville du serpent de la campagne. Il est probablement ici question de deux espèces différentes, dont l'une est associée au milieu urbain. Sur le plan symbolique le serpent de la ville représente la population de cette dernière, tandis que celui de la campagne, venant de l'extérieur, annonce l'arrivée d'une armée ennemie. Ainsi :

«Si un serpent de la ville est sorti dans la campagne, cette ville sera abandonnée. $»^{12}$

«Si un serpent de la campagne est entré dans la ville, cette ville sera brûlée par

l'ennemi. $»^{13}$

20 Cette tendance générale néfaste se retrouve avec toutes les espèces sauvages pouvant s'approcher de la ville ou y pénétrer et ce, même s'il ne s'agit pas de prédateurs ou d'animaux menaçants. Ainsi, dans CT 40,41f à la ligne 6 du verso :

"Si une gazelle est entrée à l'intérieur, cette ville sera abandonnée. ${ }^{14}$

Et dans CT 40,41, si un aurochs se trouve devant la porte de la ville:

«L'ennemi détruira cette porte. $»^{15}$

Cette thématique de la chute de la ville se retrouve avec diverses espèces sauvages faisant irruption à proximité ou à l'intérieur de cette dernière. Bien que la plupart des présages à portée collective soient néfastes, on peut observer des variations en fonction du comportement de l'animal, de son espèce et du lieu où il a été observé. Certains types de comportements sont par exemple mauvais signe et ce, où qu'ils soient 
observés : c'est ainsi que, dans les espaces publics, agitation, marques d'agressivité et affrontements annoncent troubles et malheurs. Il en va de même si un oiseau fait son nid ou qu'un autre animal a ses petits dans un édifice à forte valeur symbolique, comme les murailles, les temples, les palais... Ainsi dans la première ligne de la tablette 34 de la collection shumma âlu :

«Si une mangouste a mis bas dans les fondations de la porte de la ville : dispersion de la ville. $»^{16}$

Dans la tablette MS 1687 au recto colonne II ligne 30' nous avons aussi :

«Si un faucon a fait son nid dans le palais : le roi mourra et le palais sera déserté. »"17

Comme mentionné plus haut, le palais est un lieu particulier, où la plupart des irruptions animales sont néfastes. Si un faucon y pénètre, la prédiction sera bien souvent relative à des soucis sur le plan militaire, comme cela se voit aux lignes $33^{\prime}-34^{\prime}$ du même texte :

«Si un faucon est entré dans le palais du roi et en est ressorti par une fenêtre, un ennemi puissant se répandra sur le pays et le détruira. $»^{18}$

Quant au chien, certaines prédictions vont même jusqu'à l'associer à l'annonce d'un futur incendie :

«Si un chien entre dans le palais, le feu frappera ce palais. $»^{19}$

Le temple est un autre lieu à forte valeur symbolique. Certaines espèces comme les scorpions ou les faucons y annoncent divers malheurs, pouvant aller de la dispersion du temple ${ }^{20}$ à l'arrivée d'un ennemi. D'autres présages peuvent être fastes, même avec des animaux à connotation globalement négative. Ainsi, la ligne 23 du texte K17+K4046 stipule que :

«Si un chien blanc est entré dans le temple, ses fondations seront stables. »21

Bien sûr, la tendance s'inverse si le comportement est agressif ou si les animaux sont présents en trop grand nombre. Notons dans SU51/49+, un texte associé à la collection shumma âlu le cas d'un serpent se redressant près de la statue du dieu (ce qui, pour ces reptiles, peut être un comportement menaçant, précédant une réaction violente de défense) :

«Si un serpent dans un temple s'est redressé plusieurs fois devant le dieu ${ }^{22}$, le pays

du roi se révoltera. $»^{23}$

\section{Les irruptions animales à valeur augurale individuelle ou familiale}

Bien qu'en certains cas elles puissent être observées dans un lieu public par un individu isolé, nous nous concentrerons ici sur les prédictions à portée individuelle relatives aux irruptions animales dans l'espace domestique, par opposition à la ville et ses autres subdivisions que nous venons d'étudier. Cet espace intime, de sécurité, est nettement séparé du reste de l'espace propre aux hommes et doté d'une forte valeur symbolique. Nous pouvons d'emblée remarquer que le lieu sera ici toujours précisé: on aura toujours la mention « dans la maison d'un homme », même s'il est question d'un animal domestique ou familier. Nous voyons bien la différence avec l'espace "public », où, même si ses subdivisions étaient citées, on ne retrouvait la mention « dans la ville » que dans certains cas bien particuliers. Ici, au contraire, même si le phénomène est observé dans une partie spécifique de l'espace domestique, la "maison» sera toujours citée 
dans le présage. Tout comme pour l'espace urbain, nous pouvons relever de nombreuses subdivisions de l'espace domestique. Divers éléments sont mentionnés par les textes tels que le toit, la cour, la porte d'entrée, la fenêtre, la chambre et même du mobilier, comme le lit ou les chaises.

Tout signe observé à l'intérieur d'une maison affecte en priorité le propriétaire de cette dernière. Mais les prédictions peuvent aussi concerner la maitresse de maison, l'avenir du couple, leurs enfants, et parfois même tous les habitants de la maisonnée. Elles sont particulièrement variées et, tandis que la plupart des manifestations animales dans la ville étaient néfastes, nous pouvons trouver ici bon nombre d'éléments favorables. Dans ce qui est positif, nous avons donc la richesse, la santé, la longévité, la naissance d'un héritier ou de nombreux enfants, le succès (notamment dans des affaires juridiques)... Mais les mauvais signes sont bien sûr eux aussi présents : nous retrouvons la mort du propriétaire ou d'un des membres de la famille, des pertes économiques, la maladie, l'abandon de la maison...

Divers détails servent à évaluer la valeur du signe comme la localisation des animaux dans l'habitation. Dans la plupart des cas, les espèces citées sont celles dont la présence est normale, ou tout du moins attendue dans une habitation. Cela peut concerner les animaux domestiques ou apprivoisés (chiens, chats, mangoustes) mais aussi ceux dont la présence est inévitable (rongeurs, lézards, insectes). Certaines espèces, comme la mangouste et le chat, sont admises dans la maison car ce sont les prédateurs naturels des rongeurs et des serpents. Ces derniers pouvant représenter une menace réelle pour les habitants de la maison, ils ne sont bien évidemment pas les bienvenus, tout comme d'autres animaux venimeux, notamment le scorpion. Ces deux espèces se voient d'ailleurs consacrer plusieurs tablettes de la collection shumma âlu, sans doute à cause du danger qu'elles peuvent représenter. Quant aux rongeurs, bien que souvent associés à des prédictions néfastes, ils n'attirent de toute évidence pas autant l'attention. Les oiseaux sont peu cités, mais on constate tout de même qu'il n'est guère souhaitable qu'ils fassent leur nid sur le toit d'une maison.

31 Mais, quelles que soient les espèces concernées, il existe des règles générales à l'intérieur d'une maison. Ainsi, on n'apprécie guère que les animaux s'approchent de lieux intimes, comme le lit et c'est encore plus vrai s'ils y font preuve d'un comportement inconvenant, comme c'est le cas dans K17+K4046 ligne 13 :

«Si un chien urine sur le lit d'un homme, cet homme sera atteint d'une maladie grave. ${ }^{24}$

Dans d'autres présages, si le chien urine en d'autres endroits de la maison cela peut aussi annoncer la mort d'un des enfants qui y vivent. Néanmoins, pour certaines espèces, on peut noter des variables selon les situations. Dans le présage 110 de la tablette 23 de shumma âlu, Si un serpent tombe sur le lit d'un couple, ce sera mauvais, mais sur le lit d'un homme seul, cela sera bon pour lui :

«Si un serpent s'étend sur le lit d'un homme, le dieu de cet homme sera reconnu. ${ }^{25}$

33 Tandis que dans le présage 111:

«Si un serpent tombe sur le lit d'un homme et d'une femme, une terrible insurrection aura lieu; sa maison sera dispersée. $»^{26}$

34 D'autres éléments peuvent contribuer au caractère néfaste de certains signes. C'est le cas si les animaux sont trop nombreux et ce, quelle que soit l'espèce ${ }^{27}$. Ainsi dans la ligne 20 de la tablette 22 de la collection shumma âlu : 
«Si entre le $1^{\text {er }}$ et le $30^{\mathrm{e}}$ jour du mois de Nisan, des serpents se sont enroulés les uns sur les autres dans la maison d'un homme, cet homme mourra. ${ }^{28}$ (fig. 1 ; transcription $n^{\circ} 18$ ) où elle a été observée, compte. Mais il existe encore certains cas particuliers : celui des espaces domestiques en puissance, pour ainsi dire. Il s'agit des maisons abandonnées ou en construction. Bien qu'inoccupées, elles sont potentiellement habitables. Tout ce qui s'y produit peut donc donner des indications sur une future occupation. Cela explique l'intérêt que ces espaces au statut bien particulier peuvent susciter et pourquoi la cinquième tablette du recueil de présages shumma âlu est consacrée à tout ce qui peut avoir lieu dans une maison en construction ${ }^{35}$. Dans ce cas, presque toutes les mentions d'animaux sont néfastes, annonçant divers malheurs pour les futurs occupants: difficultés d'ordre économique, décès, abandon de la maison... C'est le cas notamment dans la ligne 32 de cette tablette : 
«Si un chat ou un renard a été aperçu dans les fondations, abandon de la maison. $\|^{36}$ phénomènes et nous avons pu voir que chaque élément joue un rôle dans la définition de leur valeur divinatoire. L'endroit où le signe est observé est alors non seulement étroitement lié à la prédiction elle-même, mais aussi au destinataire de cette dernière : ce sont les occupants du lieu cité qui seront les premiers concernés. Ainsi, pour les prédictions qui sont relatives à la collectivité dans son ensemble, la plupart des observations auront lieu dans l'espace urbain. Diverses sortes d'animaux peuvent être citées, et la connotation néfaste des irruptions d'animaux sauvages montre clairement que, sur le plan de l'organisation spatiale, leur place est située à l'extérieur. Quant aux animaux domestiques, s'ils sont tolérés dans la ville, tous ne sont pas admis dans l'espace domestique et la présence de certaines espèces y est même très mal perçue. Mais, même lorsqu'un animal est accepté dans les diverses subdivisions de l'espace "propre aux hommes", son comportement ne doit en aucun cas constituer une menace ou une gêne pour les individus et leurs activités. Si cela venait à se produire, s'ajoute alors à l'inconvénient concret et immédiat une interprétation symbolique, à portée divinatoire, affectant l'avenir des occupants du lieu (habitants de la ville ou, dans le cas de l'espace domestique, de la maison). Ainsi, par l'interprétation divinatoire qu'elles donnent des manifestations animales, les populations de Mésopotamie laissent transparaître dans ces textes non seulement leur perception de l'espace, mais aussi, à travers elle, la manière dont étaient régulés les rapports de proximité ou de distance avec les différentes espèces animales. 


\section{BIBLIOGRAPHIE}

ABRAHAMI Philippe, « Le cochon dans les collections d'oracles de la Mésopotamie », dans MICHEL Cécile et uIon Brigitte (dir.), De la domestication au tabou. Le cas des suidés dans le Proche-Orient ancien, Paris, Éd. De Boccard (Travaux de la Maison René Ginouvès, 1), 2006, p. 237-282.

BEAULIEU Paul-Alain, « Les animaux dans la divination en Mésopotamie », dans PARAYRE Dominique, Les animaux et les Hommes dans le monde syro-mésopotamien aux époques historiques, Actes du colloque de Lille, décembre 1998, Lyon, Éd. Marie-Françoise Boussac (Topoï Supplément 2), 2000, p. 351-365.

DESCOLA Philippe, «Le sauvage et le domestique » dans Communication, 76, 2004, p. 17-31.

FREEDMAN Sally M., If a City is Set on a Height: the Akkadian Omen Series shumma alu ina mêlê shakin, Philadelphia, University Museum of Archaeology and Anthropology, University of Pennsylvania (Occasional Publications of the Samuel Noah Kramer Fund, 17 et 19), 1998 et 2006, 2 vol.

GEORGE Andrew R., Babylonian Divinatory Texts Chiefly in the Schoyen Collection, Bethesda, CDL Press (CUSAS [Cornell University Studies in Assyriology and Sumerology], 18), 2013.

HUNGER Hermann, Spätbabylonische Texte aus Uruk I, Berlin, Gebr. Mann Verlag (Ausgrabungen der deutschen Forschungsgemeinschaft in Uruk-Warka, 9), 1976.

NÖTSCHER Friedrich, « Die Omen Serie Shumma Alu ina Mele Shakin I », Orientalia, vol. 39-42, 1929.

NÖTSCHER Friedrich, « Die Omen Serie Shumma Alu ina Mele Shakin II », Orientalia, vol. 51-54, 1930.

opPENHEIM Adolf Leo, « A Babylonian Diviner's Manual », Journal of Near Eastern Studies, 33, 1974, p. $197-220$.

VON WEIHER Egbert, Spätbabylonische Texte aus Uruk II, Berlin, Gebr. Mann Verlag (Ausgrabungen der deutschen Forschungsgemeinschaft in Uruk-Warka, 12), 1988.

\section{NOTES}

1. «Si une ville est située sur une hauteur ». Il s'agit là du titre de cette collection établi d'après son incipit, que l'on trouve référencé dans les catalogues d'œuvres compilés par les lettrés mésopotamiens. Notons qu'en Mésopotamie les textes, qu'il s'agisse de mythes, d'épopées ou de recueils de présages n'ont pas de véritable titre au sens où nous l'entendons aujourd'hui. Les différents textes sont ainsi désignés par le début de la première ligne.

2. P. Descola, «Le sauvage et le domestique », p. 29.

3. P.-A. Beaulieu, « Les animaux dans la divination en Mésopotamie », p. 360.

4. A.L. Oppenheim, « A Babylonian Diviner's Manual », p. 203.

5. Il faut néanmoins être conscient que les prédictions de Mésopotamie annoncent un avenir possible, mais non inéluctable. Dans cette optique, un mauvais présage doit être interprété comme un avertissement envoyé par les divinités, lesquelles peuvent, via des rituels, être apaisées, ce qui a pour effet d'annuler la valeur néfaste du signe.

6. A.R. George, Babylonian Divinatory Texts Chiefly in the Schoyen Collection, p. 264. 
7. E. von Weiher, Spätbabylonische Texte aus Uruk II, p. 143.

8. H. Hunger, Spätbabylonische Texte aus Uruk I, p. 77.

9. S.M. Freedman, If a City is Set on a Height: the Akkadian Omen Series shumma alu ina mêlê shakin I, p. 88-108.

10. P. Abrahami, « Le cochon dans les collections d'oracles de la Mésopotamie », p. 272.

11. S. M. Freedman, If a City is Set on a Height: the Akkadian Omen Series shumma alu ina mêlê shakin, II, p. 120-121.

12. Ibid.

13. Ibid.

14. F. Nötscher, « Die Omen Serie Shumma Alu ina Mele Shakin II », p. 34.

15. Ibid., p. 29-30.

16. S.M. Freedman, If a City is Set on a Height: the Akkadian Omen Series shumma alu ina mêlê shakin II, p. 224-225.

17. A.R. George, Babylonian Divinatory Texts Chiefly in the Schoyen Collection, p. 266.

18. Ibid.

19. P. Abrahami, « Le cochon dans les collections d'oracles de la Mésopotamie », p. 279.

20. C'est-à-dire du personnel, des biens, voire même des divinités du temple.

21. F. Nötscher, « Die Omen Serie Shumma Alu ina Mele Shakin II », p. 68.

22. À comprendre ici : devant sa statue.

23. S.M. Freedman, If a City is Set on a Height: the Akkadian Omen Series shumma alu ina mêlê shakin II, p. 114-115.

24. P. Abrahami, « Le cochon dans les collections d'oracles de la Mésopotamie », p. 280.

25. S.M. Freedman, If a City is Set on a Height: the Akkadian Omen Series shumma alu ina mêlê shakin II, p. 48-49.

26. Ibid.

27. Notons ici le parallèle avec les animaux dans la ville. Il existe en effet certaines constantes dans le caractère faste ou néfaste d'un signe, quel que soit le lieu où il est observé. La localisation n'est que l'un des éléments permettant de définir la valeur d'un signe, et parfois d'autres aspects sont prioritaires.

28. S.M. Freedman, If a City is Set on a Height: the Akkadian Omen Series shumma alu ina mêlê shakin II, p. 11.

29. F. Nötscher, « Die Omen Serie Shumma Alu ina Mele Shakin I », p. 192.

30. Ibid.

31. Ibid.

32. S.M. Freedman, If a City is Set on a Height: the Akkadian Omen Series shumma alu ina mêlê shakin I, p. 314-315.

33. H. Hunger, Spätbabylonische Texte aus Uruk I, p. 76-77.

34. F. Nötscher, « Die Omen Serie Shumma Alu ina Mele Shakin II », p. 16-17.

35. S.M. Freedman, If a City is Set on a Height: the Akkadian Omen Series shumma alu ina mêlê shakin I, p. 88-108.

36. Ibid., p. 91. 
37. S. M. Freedman, If a City is Set on a Height: the Akkadian Omen Series shumma alu ina mêlê shakin II, p. 47.

\section{RÉSUMÉS}

Les animaux jouent un rôle important dans les textes divinatoires de Mésopotamie, où leurs manifestations fortuites sont interprétées grâce à divers éléments, comme leur morphologie et leur comportement. Le lieu où ils sont observés entre également en considération et nos sources mettent en évidence le statut particulier de l'espace occupé par les hommes. L'irruption d'animaux dans l'espace urbain ou domestique est présentée dans notre corpus comme susceptible d'avoir un impact sur l'avenir de ceux qui y vivent, que ce soit sur le plan collectif ou individuel. Le but de cette étude est de comprendre comment ces manifestations étaient perçues et interprétées par les populations de Mésopotamie au I ${ }^{\mathrm{er}}$ millénaire, notamment par le biais du recueil de présages shumma âlu ina mêlê shakin. Nous nous interrogerons sur leur caractère néfaste ou non et verrons les variations possibles en fonction des lieux et des animaux concernés, que ces derniers soient domestiques, familiers ou sauvages.

\section{AUTEUR}

\section{ANDRÉA VILELA}

Doctorante en histoire ancienne au laboratoire Archéorient, maison de l'Orient et de la Méditerranée, université Lumière - Lyon II 
Imitations et appropriations symboliques : I'animal comique et l'animal-signe 


\title{
Le déni des apparences : bestiaire et
} dérision dans l'illustration marginale d'un pontifical de Guillaume Durand (Paris, Bibliothèque Sainte-Geneviève, ms. 143)

\author{
Marianne Besseyre
}

1 Selon M. Andrieu, qui consacrait en 1940 une étude fondatrice au Pontifical de Guillaume Durand ${ }^{1}$, l'évêque de Mende (1285-1296), en rédigeant vers 1292-1295 une version nouvelle des sacrements et rituels réservés aux titulaires des sièges cathédraux, n'a pas dû ni voulu croire que son ouvrage resterait confiné dans les montagnes du Gévaudan. La preuve en est qu'il décrit des cérémonies comme l'ordination du souverain pontife, ou le couronnement de l'empereur par le pape. Les copies de son œuvre se multiplièrent effectivement sans tarder. Même si l'on n'en connaît pas d'exemplaire illustré avant le milieu du XIv siècle, elles rivalisèrent bientôt en Avignon avec la version romaine du Pontifical, qui avait suivi la curie sur les bords du Rhône. Au moment du grand Schisme d'Occident qui divisa pendant quarante ans la chrétienté2, c'est l'ouvrage de Guillaume Durand qui paraît le plus en faveur dans l'entourage de Clément VII (1378-1394) et Benoît XIII (1394-1423) : il mêle à l'héritage des pontificaux romains des $\mathrm{XII}^{\mathrm{e}}$-XIII ${ }^{\mathrm{e}}$ siècles des usages locaux bien vivaces, découlant parfois d'antiques rituels gallicans - ce qui ne pouvait déplaire aux adversaires de Rome. Les liturgistes finissent par lui donner la préférence pour la première édition imprimée du Pontificale romanum,commandée par Innocent VIII (1484-1492) en 1485.

2 Presque tous les manuscrits conservés du Pontifical de Guillaume Durand ont d'abord été copiés dans le centre-sud de la France, en Languedoc, Provence et Guyenne ${ }^{3}$. Ils reprennent à l'origine la décoration et le programme iconographique du Pontifical de la Curie romaine ${ }^{4}$, auquel s'ajoutent de nouvelles images inspirées par la révision de 
l'évêque de Mende. Bon exemple de ce qui se fait à Rome à la fin du XIII ${ }^{\mathrm{e}}$ siècle, le manuscrit BnF latin $960^{5}$ décline sous nos yeux la trame d'un canevas illustré, rapidement diffusée de l'autre côté des Alpes ${ }^{6}$ - comme dans un pontifical enluminé à Avignon vers 1320-1330 par le dénommé Maître du codex de saint Georges ${ }^{7}$, miniaturiste au service du cardinal Jacopo Stefaneschi qu'il suivit dans la cité rhodanienne. Si le style de ce brillant artiste dénote sans conteste une obédience toscane, on remarque en début d'ouvrage trois petites figures animales (lapins, écureuil) représentées avec un grand réalisme sur la baguette ornementale inférieure du fol. 2 - emprunt possible au répertoire des drôleries alors en vogue dans les marges des manuscrits gothiques septentrionaux. Ce type de décor est au demeurant déjà bien attesté dans les codices produits sur place, tant il est vrai qu'Avignon est devenue, dès ce premier quart du XIV ${ }^{e}$ siècle, un foyer d'expérimentations artistiques au carrefour d'influences multiples ${ }^{8}$. Il faut mentionner encore un pontifical copié à Avignon vers 1330 dans une écriture italienne mais illustré par des mains françaises, dont le travail fut complété à la fin du siècle par un miniaturiste d'origine probablement espagnole, Sancho Gonthier, qui est cité en fin d'ouvrage ${ }^{9}$ : Éric Palazzo a relevé l'ampleur exceptionnelle donnée aux lettrines historiées - cent quarante - où plusieurs saynètes illustrent le même thème, "donnant ainsi l'impression de doubler le texte liturgique par un "pontifical visuel" $»^{10}$. Selon toute vraisemblance, cette édition augmentée du pontifical a subi l'influence du livre de l'évêque de Mende; il trahit l'escalade de la concurrence entre les deux textes en Avignon par l'inflation d'un cycle peint qui intègre après coup à la copie du Pontifical de la Curie romaine des images liées à la rédaction de nouveaux chapitres dus à Guillaume Durand.

3 L'exemplaire de Guillaume Durand qui sera étudié ici, le manuscrit 143 de la Bibliothèque Sainte-Geneviève à Paris ${ }^{11}$, témoigne à sa façon de cette surenchère d'illustrations envahissant aussi, dans ce cas précis, les marges du codex. Le phénomène est surprenant à double titre: d'une part les marginalia ou drôleries ${ }^{12}$, fréquentes dans les psautiers, bréviaires, livres d'heures et de dévotion laïques, sont en revanche rarissimes dans les pontificaux ${ }^{13}$. D'autre part, si la facture des marginalia du manuscrit de Sainte-Geneviève est à n'en pas douter méridionale, l'esprit qui les anime remonte au début du XIII ${ }^{e}$ siècle et trouve sa source plus au nord (Paris, Flandres et Angleterre). Le genre gagna ensuite du terrain en Europe (Italie, Espagne, Allemagne) puis passa progressivement de mode au cours du XIv siècle, cédant la place à la prolifération des feuillages dans les marges. Le manuscrit de Sainte-Geneviève, daté aux alentours de l'an $1357^{14}$, est donc atypique par l'étendue et la cohérence de son décor secondaire, qui fait contrepoint au classicisme du programme iconographique des initiales.

4 Le codex étant armorié, nous avons misé sur l'enquête prosopographique menée autour de l'ancien possesseur et commanditaire pour questionner davantage les raisons d'être d'une illustration marginale aussi particulière dans un pontifical. Le chanoine Leroquais signalait, dans son inventaire détaillé des pontificaux publié en $1937^{15}$, que l'exemplaire conservé à la bibliothèque Sainte-Geneviève avait appartenu à Pierre de Saint-Martial, successivement évêque de Rieux en 1357 puis de Carcassonne en 1372, avant d'être nommé archevêque de Toulouse en 1391 par l'antipape Clément VII. Le blason «d'argent, au lion de gueules, à la bordure de sable chargée de huit besants d'or» ne porte pas la croix archiépiscopale mais une simple crosse, ce qui laisse entendre une confection de l'œuvre antérieure à cette dernière date ${ }^{16}$. Cette attribution 
fut un temps battue en brèche par Marguerite Pecqueur, qui crut reconnaître dans les armes peintes à huit reprises en marge inférieure celles de Jean de Cardaillac, docteur ès lois à l'université de Toulouse et administrateur de plusieurs diocèses dans le sudouest de la France ${ }^{17}$. L'hypothèse de Mme Pecqueur s'avéra toutefois intenable après comparaison avec un Commentaire sur l'Apocalyps $\mathrm{e}^{18}$, dédicacé sans ambiguïté par son auteur à Jean de Cardaillac, et dont le blason porte "d'or, au lion d'azur, dressé, couronné et armé de gueules, orlé d'azur à 8 besants d'or ». Mais l'attribution à Pierre de Saint-Martial ne va pas pour autant absolument de soi, car les sources héraldiques compilées par les érudits du XvII ${ }^{\mathrm{e}}$ siècle, et vraisemblablement reprises par les armoriaux du XIX ${ }^{e}$ siècle, comportent nombre de contradictions et d'inexactitudes. L'essentiel pour notre étude est, surtout, de retrouver les éléments permettant d'ancrer fermement le commanditaire dans une zone géographique déterminée, en l'arrimant à un groupe bien identifié de détenteurs de charges ecclésiastiques liés de près, en ce troisième quart du XIv ${ }^{e}$ siècle, à la Curie avignonnaise.

5 Pierre de Saint-Martial et son frère Hugues, nommé cardinal en 1361, sont nés à Tulle, dans l'actuel département de la Corrèze. La Gallia Christiana livre des compléments d'information sur le parcours de l'évêque : conservateur des privilèges du collège de Saint-Martial de Limoges en 1394, il est désigné comme l'un des exécuteurs testamentaires du cardinal Guillaume d'Aigrefeuille le Jeune en 1401. Pierre de SaintMartial souhaitait pour sa part être enterré dans l'église Saint-Étienne de Toulouse, aux côtés de son compatriote Jean de Cardaillac ${ }^{19}$. L'un et l'autre avaient servi Clément VI en Italie en suivant les opérations de reconquête de la Sicile menées par la reine Jeanne $I^{\text {ère }}$ de Naples, en 1351. Cardaillac fut ensuite rapidement promu évêque d'Orense, puis archevêque de Braga, avant d'investir le siège de Toulouse (1379) où le remplacera à sa mort (1390) Pierre de Saint-Martial.

6

Les travaux fondateurs de Mollat ${ }^{20}$ et Guillemain ${ }^{21}$ ont depuis longtemps mis en lumière l'importance du lobby limousin à la curie pontificale $d^{\prime}$ Avignon $^{22}$. La famille d'Aigrefeuille y fut aussi particulièrement bien en cour dès le milieu du siècle, où Guillaume l'Ancien (1326-1369) fut créé cardinal en 1350. Son frère, Pierre d'Aigrefeuille, né comme lui à la Font, en Corrèze, accéda au siège épiscopal d'Avignon en 1368, après avoir été à la tête de plusieurs évêchés dans le centre-sud de la France. Un autre frère, Faydit, devint évêque d'Avignon à la mort de Pierre, en 1371, avant d'être à son tour créé cardinal en $1383^{23}$. Quant à Aymar, l'aîné de la fratrie, il fut élevé à la charge de Maréchal de la cour pontificale par Urbain $\mathrm{V}$, en signe de reconnaissance envers la famille d'Aigrefeuille qui avait favorisé son accession au trône. Le blason des Aigrefeuille, conservé dans un manuscrit de la bibliothèque Vaticane (Città del Vaticano, BAV Biblioteca Apostolica Vaticana, Vat. Lat. 14 701), a été identifié par Francesca Manzari malgré des surpeints postérieurs (les armes du pape Martin V) ${ }^{24}$.

Il s'agit d'un Bréviaire ${ }^{25}$ dont la provenance avignonnaise est attestée par le calendrier. Exécuté selon toute probabilité pour l'un des deux frères évêques, Pierre ou Faydit, son style mêle à des éléments français et italiens une influence bohémienne nouvelle. Il révèle ainsi l'activité d'un atelier jusqu'alors non documenté dans la cité rhodanienne, et comble partiellement le vide des années 1370 dont a pâti longtemps notre connaissance de l'enluminure avignonnaise ${ }^{26}$. Les drôleries qui emplissent les marges présentent une grande variété de thèmes, parmi lesquels s'ajoutent aux traditionnels hybrides, grotesques et scènes humoristiques mettant en scène des animaux travestis en Mendiants, quelques emprunts à des sources littéraires comme le Roman de 
Renart $^{27}$. Or la seule autre occurrence du motif représentant Renard tiré dans un attelage (conduit par un singe, fol. 28) que nous avons pu repérer parmi les marginalia ornant les livres liturgiques du Moyen Âge central se trouve au bas du fol. $168 \mathrm{v} d u$ manuscrit de Sainte-Geneviève (tracté ici par un rapace, fol. 168v). Le combat de béliers figurant au fol. 2 du codex de la Vaticane rappelle aussi celui du manuscrit de Paris (fol. 160). Enluminés l'un et l'autre à une quinzaine d'années de distance ${ }^{28}$ pour de hauts prélats dont nous avons souligné les accointances multiples, rien n'empêche de supposer que les volumes aient circulé dans le milieu culturellement privilégié de la Curie avignonnaise, où ces dignitaires possédaient souvent une bibliothèque et où il leur était facile de commander pour leurs livres illustrés quelques suppléments puisés à des œuvres goûtées alors par ces élites d'origine française ${ }^{29}$.

8 Ce préambule historique s'imposait pour appréhender à leur juste valeur la saveur et l'intention des drôleries peintes en marge de l'œuvre de Guillaume Durand dans le manuscrit 143 de la Bibliothèque Sainte-Geneviève, dont la moitié des feuillets sont illustrés (140 sur 284). Car, n'était leur présence exceptionnelle dans un pontifical, la majorité des éléments du décor secondaire ne présentent pas d'originalité foncière; ils se rangent aisément dans les catégories thématiques coutumières au genre que sont, d'une part, les monstres et autres grylles (visages sur pattes), hérités de l'Antiquité ou du bestiaire roman; d'autre part les distractions courtoises telles que la chasse sous toutes ses formes, les jeux et tournois, la musique et la danse; enfin le registre de l'inversion des rôles et des lois, humaines (charivari) ou naturelles, qui conduit à la profusion des motifs et à la prolifération du non-sens - le tout sans doute dans le but de distraire ou de provoquer le rire, et d'abord en parodiant l'institution monastique. Mais la critique sarcastique des professionnels du sacré ainsi que de leur morale jugée parfois douteuse a statut de lieu commun dans l'illustration des drôleries depuis les origines, il ne faut donc pas en surestimer la portée subversive. Si, pour un lecteur d'aujourd'hui, le contraste est fort entre l'irrévérence de certaines scènes et le texte liturgique que ces images jouxtent, il faut se garder aussi d'un réflexe moderne consistant à présupposer d'emblée un rapport direct et univoque entre le texte et l'ensemble du décor qui l'entoure, au profit de l'observation des « rapports qui se tissent entre les marges et les images principales $»^{30}$.

De fait, il n'y a de grotesques en marge que si figure sur la même page une lettrine historiée. La cohérence interne du codex est magnifiquement orchestrée par sa mise en page, laquelle hiérarchise différents niveaux de lecture, et même différentes strates visuelles: les vignettes historiées incluses dans les lettrines se présentent naturellement comme des narrations en abîme qui «creusent » le feuillet à l'orée du chapitre et en lien direct avec son contenu, tandis que les baguettes ornementales supportent les drôleries en surface. Le rapport dynamique d'opposition, ou quelquefois de complétude, qui existe entre les deux systèmes d'illustration est bien visible au fol. 176, où un hybride d'homme à arrière-train de lion tourne ses prières vers l'évêque occupé à bénir une croix d'autel dans l'initiale.

10 Davantage, le sentiment d'avoir affaire à des jeux d'échos entre les pages, et globalement à une structure rythmique basée sur l'alternance (l'illustration suit la distribution des chapitres) et la répétition (motifs récurrents des grands singes humanisés, des oiseaux/hybrides ailés à long bec et long cou, des grylles à têtes barbues et oreilles de lapin), mérite l'attention. 
11 Le décor est planté dès la première page du volume ${ }^{31}:$ le portrait de saint Pierre, coiffé de la tiare pontificale à triple couronne, occupe la boucle de la lettrine. Un lévrier poursuit un lapin dans la marge supérieure, un âne joue de la lyre dans celle de droite. Plus bas, un singe armé d'une arbalète vise un papillon au-dessus d'un étang où pêche un compère: est-ce une allusion à Simon Pierre représenté en pape à l'initiale, cet ancien pêcheur (et pécheur) de Gennésareth appelé à suivre le Christ pour devenir un "pêcheur d'hommes " (Luc 5, 10 ; Marc 1,17) bientôt à la tête de son Église ? Dans l'angle inférieur gauche, d'autres hominoïdes (de grands singes sans queue) sont occupés à battre la semelle (jeu de la plantée).

Une tension indéniable occupe les marges du pontifical de Paris. Elle se traduit par une composition syntaxique récurrente, faite de diverses figures affrontées : (singe/oiseau hybride, fol. 9 ; sagittaire/lapin, fol. 52 ; grand échassier griffu/singe soldat, fol. 56v ; singe à l'arbalète/ «escargot » cornu et barbichu, fol. 92; sanglier/singe, fol. 98 ; béliers, fol. 160 ; poisson vomissant un canidé/rat, fol.161v; singes, fol. 169 ; âne en armure/escargot armé, fol. 179v ; singe/sanglier, fol. 211 ; licorne/singe, fol. 232 ; rat/ chat, fol. 238 ; singe/hybride à long bec et long cou, fol. 255), avec quelques occurrences ou l'affrontement donne lieu à un contact direct entre protagonistes (singe abattant son épée sur un rat, fol. 251 ; aigle couronné terrassant un lapin, fol. 62v).

13 Nombreux sont aussi les couples chasseur/chassé (singe/papillon, fol. 1, 208v; singe soldat/sanglier ailé, fol. 91v; singe et lévrier/porc-épic, fol. 95 ; lévrier/lapin, fol. 1, $158 \mathrm{v}, 180$; singe nu portant heaume, gantelets, lance et bouclier/quadrupède à tête d'oiseau et queue bifide, fol. 159 ; singe armé d'une pierre/lapin hybride, fol. 163 ; rat/ papillon, fol. 165 ; sagittaire/papillon, fol. 247v).

14 Le canevas narratif des marges se nourrit donc pour une grande part de luttes armées entre singes et créatures hybrides. Au service de ces dernières, un répertoire d'éléments morphologiques somme toute limité offre un large éventail de combinaisons formelles. Les corps «non naturels» obéissent aussi à des règles de construction $^{32}:$ l'hybride est composé de deux ou trois sections dont chacune provient d'un règne différent, mais l'empilement tête-tronc-membres respecte habituellement la hiérarchie humain-animal lorsqu'un segment humain entre en jeu, d'où le malaise ressenti quand il y a inversion séquentielle du dispositif comme c'est le cas au fol. 9v, où une tête barbue emmanchée sur un corps de volatile à queue de poisson se fait picorer l'œil par une autre tête d'oiseau qui sort de son crâne.

Les hybrides du manuscrit de Sainte-Geneviève sont des fantaisies drôles ou inquiétantes, nées à la fois d'une longue tradition et de l'imagination (oiseaux à tête barbue et oreilles de lapin, fol. $3 \mathrm{v}, 122,157 \mathrm{v}, 179$; monstres hybrides à deux têtes, fol. $9 \mathrm{v}, 156,163,180 \mathrm{v}-181$; à têtes de fesses, fol. 145, 156v, 159v ; etc.). Mais on trouve à leur côté plus monstrueux encore; il existe en effet dans le règne des espèces voulues par Dieu une créature qui, par sa nature même, défie celle de l'homme en la reflétant comme en un miroir déformant: le singe est l'incarnation de la duplicité et du mensonge, une contrefaçon trompeuse si l'on en croit l'étymologie d'Isidore de Séville qui fait dériver simia de similitudo. Figure du diable dans la littérature patristique et le Bestiaire, l'animal est devenu dans l'art l'image du pécheur, aussi éloigné de son modèle humain que l'homme l'est de son Créateur depuis la Chute. De fait, les «hommes-singes » velus qui mènent la danse dans le manuscrit de Sainte-Geneviève sont souvent nus (comme Adam et Ève chassés du Paradis), ou vêtus d'un simple capuchon sur les épaules. Quand ils sont habillés, ils revêtent presque toujours la tenue 
monastique pour tourner en ridicule la dévotion ou la prière facile, de même que la pédanterie et l'hypocrisie de l'homme d'Église : au fol. 145v, la bénédiction du cimetière par l'évêque, représentée à l'initiale, s'accompagne en marge d'une parodie de prière où un pleurant récite ses litanies, livre en main, à un hybride à long bec pourvu d'une impressionnante gueule de fesses.

Aux fol. 172 et $172 \mathrm{v}$, la bénédiction des offrandes pratiquées lors des fêtes de l'Assomption et de l'Ascension (évêque bénissant des pains) trouve un contrepoint ironique dans l'évocation des plaisirs de la boisson et de la table en marge inférieure : un singe tire du vin et fait signe à un confrère encagoulé d'approcher. Un sacramentaire est ouvert sur le tonneau à côté du calice, comme s'il venait de consacrer les saintes espèces. Au verso, le moine s'est mis à table et un serviteur lui tend une coupe.

Plus acerbe encore, la prise d'habit d'un novice est l'occasion d'un jeu visuel sur le vêtudévêtu entre la lettrine peinte qui reflète la solennité du moment, et son gauchissement en bas de page (fol. 53). L'investiture de l'impétrant est parodiée par la vision des coules retroussées de deux singes qui dévoilent leur arrière-train, prétexte de surcroît à la suggestion d'une scène d'agression anale puisque l'un vise les fesses de l'autre avec son arc. Au fol. 181v, la flèche a atteint son but tandis qu'il est question, plus haut dans le chapitre à l'initiale peinte, de la bénédiction des épées, hallebardes et armes de jet.

18 Ce théâtre humoristique ou satirique, à fonction divertissante et cathartique, ouvre également une fenêtre sur le mode de vie de l'aristocratie médiévale et de la société courtoise avec, par exemple, l'évocation malicieuse de la fauconnerie (singe au faucon monté sur un oiseau et accompagné d'un singe piquier, fol. $8 \mathrm{v}$; rat au faucon monté sur un chat, fol.76v ; lapin portant un escargot sur son gant, à cheval sur un lévrier, fol. 165).

Les marginalia du codex de Sainte-Geneviève ne reprennent pas que des babouineries à l'honneur dans les manuscrits gothiques du siècle précédent, elles puisent à d'autres sources iconographiques et littéraires en vogue comme le Bestiaire ${ }^{33}$, d'où est issue la figure de sirène couronnée représentée au fol.63v. La femme poisson attire les navigateurs avant de mettre à mort ceux qui se laissent abuser par les plaisirs ${ }^{34}$, et sa queue bifide peut être interprétée comme le symbole de sa duplicité foncière. Audessus, les deux initiales historiées montrent les rites de bénédiction des diaconesses et de consécration des vierges. Celles-ci, vouées à l'abstinence, ont opté au contraire pour un choix de vie radicalement opposé à celui de la tentatrice marine et qui leur assure le salut de l'âme. Autre motif sorti tout droit du Bestiaire, celui de l'autruche avec un fer à cheval dans le bec, et tenue en laisse par un Maure, c'est-à-dire un Infidèle, qui porte un paquet de clous à la main au fol.12. L'autruche a mauvaise réputation, car son corps trop lourd l'empêche de voler. Elle fait semblant de dresser les ailes mais ne quitte jamais le sol. La leçon du Bestiaire est sans appel :

«Tels sont évidemment les hypocrites qui, tout en simulant une vie pieuse, donnent

l'apparence de la sainteté, alors qu'ils n'en ont pas la réalité ! »35

Nous avons vu plus haut que les acteurs principaux des marges du manuscrit de SainteGeneviève étaient les grands singes et les « échassiers » ou hybrides ailés à long bec et long cou. Or l'étude de l'antagonisme singe/oiseau dans l'art et la pensée du Moyen Âge central est éclairante pour notre propos. Selon Honorius Augustodunensis ${ }^{36}$, moine et théologien chrétien du $\mathrm{XII}^{\mathrm{e}}$ siècle, les grands volatiles «aquatiques» symbolisent les 
Gentils tandis que les petits oiseaux renvoient aux âmes chrétiennes, appelées un jour à quitter leur corps pour rejoindre le séjour céleste. Les oisillons du fol. 17 semblent sous la coupe d'un haleur de barque simiesque qui cherche peut-être à détourner le cours de leur embarcation tandis qu'à l'initiale l'ordination du portier veut garantir au contraire la bonne garde, et marche, de l'Église terrestre, en empêchant les infidèles d'y entrer, de troubler les offices ou de profaner les mystères. L'inimitié jalouse du singe envers les habitants des airs est commentée par Hildegarde de Bingen (1098-1179) au VI livre de sa Physica ${ }^{37}$. Elle l'explique comme le résultat d'une nature particulièrement imparfaite et instable qui, déchirée entre humanité et animalité, cherche sans cesse à dépasser sa condition. Hildegarde rapporte l'anecdote suivante: quand un singe voit voler un oiseau, il a le réflexe de bondir lui aussi pour quitter le sol, mais n'y parvenant pas, il a tôt fait de se mettre en rage. Son dépit se transforme alors en haine. Cette légende dont l'abbesse nous transmet l'écho trouve une traduction visuelle dans les miniatures marginales du pontifical de Sainte-Geneviève où les singes décochent souvent leurs traits sur des créatures des airs, en particulier des papillons.

21 Il reste à souligner la parenté que ce décor secondaire entretient avec les drôleries des manuscrits enluminés à Naples durant le second tiers du xive siècle. L'atelier de Cristoforo Orimina ${ }^{38}$ a livré, entre les années 1330 et 1365 environ, plusieurs bibles de très grand luxe ${ }^{39}$ destinées aux souverains et hauts dignitaires de la cour angevine. On y trouve un répertoire de figures marginales qui partagent des similitudes avec celles du pontifical d'Avignon, ce qui n'a rien d'étonnant au vu de l'histoire : la reine Jeanne I ère de Naples (vers 1326-1382) a vendu en 1348 la ville d'Avignon au pape Clément VI, mais elle reste la suzeraine de la Provence et conserve des liens politiques étroits avec le souverain pontife, en même temps que des rapports d'émulation artistique avec la cité des bords du Rhône. La cour de Naples demeure par ailleurs un foyer culturel où le livre conserve le prestige qu'il a connu sous le règne de son grand-père Robert le Sage, célèbre mécène et bibliophile. Vers 1340 , ce dernier avait commandé pour Jeanne, choisie pour lui succéder sur le trône, et son fiancé André de Hongrie, une Bible ${ }^{40}$ au riche décor ponctué en marge d'allusions à la dynastie régnante, en plus d'un foisonnant décor de grylles, lapins, canidés, sirène, échassiers, perroquets verts affrontés à longue queue bifide (qui semblent bien être une des signatures de l'atelier Orimina ${ }^{41}$ ), figures de combattants à cheval, hommes nus montés sur divers animaux/ hybrides et armés de lances ou d'arcs, chasseurs sonnant du cor, musiciens, têtes de feuilles ou de lune... La femme couronnée à corps hybride et ailes de paon qui parade au bas du fol. 262 de la Bible de Louvain est une allusion probable à la princesse de Naples, destinataire du manuscrit, et trouve un écho surprenant dans la femme-paon couronnée représentée à la fin du pontifical de Paris ${ }^{42}$. À la différence du manuscrit de Sainte-Geneviève cependant, ce décor secondaire n'entretient pas avec les illustrations principales du texte un antagonisme dynamique du type de celui qui forge l'originalité réelle du codex avignonnais.

La carrière de Pierre de Saint-Martial n'a guère laissé de traces dans les archives. Quant au pontifical qui lui a été attribué, il n'est personnalisé que par son blason. Le texte est une copie proche de la version originale de Guillaume Durand, entachée toutefois de nombreuses fautes qui furent corrigées ultérieurement, et même d'un «lapsus » iconographique où, pour la cérémonie du sacre, le peintre a représenté la couronne impériale sous la forme du trirègne ${ }^{43}$ : est-ce une maladresse d'artiste ou une manière d'affirmer que, malgré la proclamation de la Bulle d'or par l'empereur Charles IV 
l'année précédente ${ }^{44}$, le pape Innocent VI (1352-1362) entend bien garder la main sur la confirmation de l'élection du candidat désigné pour être le chef du Saint Empire romain germanique? Qui, de l'un ou de l'autre, mène désormais les destinées du monde, dont on peut lire une allégorie ironique dans la représentation d'une barque conduite par des rats en bas du même feuillet?

Au final, cet exemplaire du pontifical de l'évêque de Mende fut probablement exécuté pour un dignitaire ecclésiastique à la fois cosmopolite par ses relations et ses missions, mais que l'on soupçonne aussi d'être resté foncièrement "pro-français ", attaché à la défense des intérêts de la caste limousine à la Curie - et par conséquent non mécontent de la « captivité » forcée des papes en Avignon. Ce qui ne l'empêchait pas d'adhérer au projet d'une milice épiscopale universelle renouvelée, à l'image du manuel de Guillaume Durand, et raffermie dans ses valeurs comme dans ses fonctions.

\section{BIBLIOGRAPHIE}

ANDRIEU Michel, Le Pontifical romain au Moyen Âge, II, Le Pontifical de la Curie romaine au XIII ${ }^{e}$ siècle, Città del Vaticano, Biblioteca apostolica vaticana (Studi e testi, 87), 1940.

ANDRIEU Michel, Le Pontifical romain au Moyen Âge, III, Le Pontifical de Guillaume Durand, Città del Vaticano, Biblioteca apostolica vaticana (Studi e testi, 88), 1940.

BESSEYRE Marianne, «Le pontifical d'Autun et la production de pontificaux romains enluminés entre 1300 et $1330 "$, dans Bologne et le Pontifical d'Autun. Chef-d'œuvre inconnu du premier Trecento, Langres, Éd. Dominique Guéniot (Les rendez-vous du Louvre à Autun), 2012, p. 132-138.

BRÄM Andreas, Neapolitanische Bilderbibeln des Trecento: Anjou-Buchmalerei von Robert dem Weisen bis zu Johanna I, Wiesbaden, Reichert, 2007, 2 vol.

CAMILLE Michael, Images dans les marges. Aux limites de l'art médiéval, trad. de l'anglais par Béatrice et Jean-Claude BONNE, Paris, Gallimard (Le Temps des images), 1997 (éd. anglaise 1992).

Dictionnaire des auteurs grecs et latins de l'Antiquité et du Moyen Âge, Paris, Brepols, 1991 (éd. allemande 1982).

DUPUIS Marie-France et LOUIS Sylvain, Le Bestiaire. Texte intégral traduit en français moderne. Reproduction en fac-similé des miniatures du manuscrit du Bestiaire Ashmole 1511 de la Bodleian Library d'Oxford. Présentation et commentaires de Xénia Muratova et Daniel Poirion, Paris, Philippe Lebaud, 1988.

ENGUAMARRE Isabelle, « Les processus d'hybridation dans les marges à drôleries des manuscrits gothiques ", dans Il mondo animale e la società degli uomini, Sismel, Edizioni del Galluzo (Micrologus VIII), 2000, p. 445-461.

GUILLEMAIN Bernard, La cour pontificale d'Avignon (1309-1376) : étude d'une société, Paris, de Boccard, 1962.

LEROQUAIS Victor, Les pontificaux manuscrits des bibliothèques publiques de France, Paris, [S. N.], 1937, 4 vol. 
MANZARI Francesca, «La miniatura ad Avignone nel XIV secolo », dans TOMEI Alessandro, Roma, Napoli, Avignone. Arte di curia, arte di corte. 1300-1377, Torino, Seat, 1996, p. 201-223.

MANZARI Francesca, La miniatura ad Avignone al tempo dei Papi (1310-1410), Modena, Franco Cosimo Panini Editore, 2006.

MOLLAT Guillaume, «Jean de Cardaillac. Prélat, orateur et diplomate », dans Histoire littéraire de la France (XL), Paris, imprimerie nationale, 1967, p. 187-210.

MOLLAT Guillaume, Les papes d'Avignon (1305-1378), Paris, J. Gabalda (Bibliothèque de l'enseignement de l'histoire ecclésiastique), 1912.

MONFRIN Jacques et JULLIEN de POMMEROL Marie-Henriette, Bibliothèques ecclésiastiques au temps de la papauté d'Avignon, II, Paris, CNRS éditions (Histoire des bibliothèques médiévales 12), 2001.

MOULINIER-BROGI Laurence, «Les merveilles de la Nature vues par Hildegarde de Bingen (XII ${ }^{\mathrm{e}}$ siècle) ", dans Miracles, prodiges et merveilles au Moyen Âge. Actes des congrès de la Société des historiens médiévistes de l'enseignement supérieur public, 25e congrès, Orléans, 1994, p. 115-131. PALAzzo Éric, L'évêque et son image. L'illustration du pontifical au Moyen Âge, Turnhout, Brepols, 1999. PAYAN Paul, Entre Rome et Avignon : une histoire du Grand Schisme, 1378-1417, Paris, Flammarion, 2009. PECQUEUR Marguerite, «Répertoire des manuscrits de la Bibliothèque Sainte-Geneviève peints aux armes de leur premier possesseur (XIII ${ }^{e}-\mathrm{XVII}{ }^{e}$ siècle) ", dans Bulletin d'information de l'Institut de Recherche et d'Histoire des Textes, bulletin n 10, (1961), [1962], p. 73-96.

PERRICCIOLI SAGGESE Alessandra, « Orimina, Cristoforo », dans Enciclopedia dell'Arte medieval, 8, Rome, Istituto della enciclopedia italiana, 1997, p. 870-871.

RANDALL Lilian M. C., Images in the Margins of Gothic Manuscripts, Los Angeles, University of California Press, 1966.

VAN DEN ABEELE Baudoin, Bestiaires médiévaux. Nouvelles perspectives sur les manuscrits et les traditions textuelles, Louvain-la-Neuve, Institut d'études médiévales de l'Université Catholique de Louvain (Textes, Études, Congrès, vol. 21), 2005.

WATTEEUW Lieve et VAN DER STOCK Jan (dir.), The Anjou Bible. A royal manuscript revealed. Naples 1340, Louvain, Peeters, 2010.

WIRTH Jean (dir.), Les marges à drôleries des manuscrits gothiques (1250-1350), avec la collaboration d'Isabelle ENGAMMARE et des contributions de Andreas BRÄM, Herman BRAET, Frédéric ELSIG, Isabelle ENGAMMARE, Adriana FISCH HARTLEy et Céline FRESSAT, Genève, Droz (Matériaux pour l'histoire), 2008.

\section{NOTES}

1. M. Andrieu, Le Pontifical romain au Moyen Âge. T. III, Le Pontifical de Guillaume Durand.

2. P. Payan, Entre Rome et Avignon : une histoire du Grand Schisme, 1378-1417.

3. V. Leroquais, Les pontificaux manuscrits des bibliothèques publiques de France, vol. I, p. XXVII.

4. M. Andrieu, Le Pontifical romain au Moyen Âge. T. II, Le Pontifical de la Curie romaine au XIII siècle. 
5. Paris, BnF, latin 960. En ligne sur Gallica, http://gallica.bnf.fr/ark:/12148/ btv1b9066906d

6. M. Besseyre, «Le pontifical d'Autun et la production de pontificaux romains enluminés entre 1300 et $1330 »$.

7. Paris, BnF, latin 15619. En ligne sur Gallica, http://gallica.bnf.fr/ark:/12148/ btv1b9067236f

8. F. Manzari, La miniatura ad Avignone al tempo dei Papi (1310-1410), p. 3-12.

9. Paris, BnF, latin 968.

10. E. Palazzo, L'évêque et son image, p. 173.

11. Paris, Bibliothèque Sainte-Geneviève, ms. 143, consultable en ligne sur https:// archive.org/details/BSGMS143, ainsi que sur la Bibliothèque virtuelle des manuscrits médiévaux : http://bvmm.irht.cnrs.fr/consult/consult.php?reproductionId=13225.

12. Les ouvrages de référence sur le sujet sont L.M.C. Randall, Images in the Margins of Gothic Manuscripts; M. Camille, Images dans les marges. Aux limites de l'art médiéval et plus récemment J. Wirth (dir.), Les marges à drôleries des manuscrits gothiques (1250-1350).

13. L.M.C. Randall, ibid., recense seulement deux pontificaux romains illustrés de drôleries pour le Continent, et aucun pour l'Angleterre.

14. F. Manzari, La miniatura ad Avignone al tempo dei Papi (1310-1410), p. 159, pense que le pontifical a été commandé à l'occasion de l'élection de Pierre de Saint-Martial à l'évêché de Rieux, en 1357.

15. V. Leroquais, Les pontificaux manuscrits des bibliothèques publiques de France, vol. II, $\mathrm{n}^{\circ} 172$, p. 241-245.

16. Voir supra n. 14.

17. M. Pecqueur, Répertoire des manuscrits de la Bibliothèque Sainte-Geneviève peints aux armes de leur premier possesseur (XIII ${ }^{e}$-XVII ${ }^{e}$ siècle), n. 143, p. 75.

18. Toulouse, Bibliothèque municipale, ms. 57 , fol. 5 , reproduit sur le site en ligne de la Bibliothèque virtuelle des manuscrits médiévaux.

19. G. Mollat, « Jean de Cardaillac. Prélat, orateur et diplomate », p. 187-210.

20. G. Mollat, Les papes d'Avignon.

21. B. Guillemain, La cour pontificale d'Avignon (1309-1376).

22. B. Guillemain, Ibid., p. 116 : « Les pontificats successifs de Clément VI et Innocent VI avaient eu pour effet la centralisation, à la cour d'Avignon, d'un parti limousin qui, naturellement, n'aspirait qu'à conserver le plus longtemps possible les avantages dont il avait joui jusque-là ».

23. Voir la "Maison épiscopale d'Avignon ", J. Monfrin et M.-H. Jullien de Pommerol, Bibliothèques ecclésiastiques au temps de la papauté d'Avignon, II, $\mathrm{n}^{\circ} 369.8$.

24. F. Manzari, « La miniatura ad Avignone nel XIV secolo », p. 215.

25. Vatican, Biblioteca apostolica vaticana, Vat. lat. 14701.

26. F. Manzari, La miniatura ad Avignone al tempo dei Papi (1310-1410), p. 188-195.

27. F. Manzari, Ibid., p. 194.

28. À moins de supposer que le pontifical de Sainte-Geneviève ne date de l'accession de Pierre de Saint-Martial au siège épiscopal de Carcassonne, auquel cas les deux codices seraient quasiment contemporains. 
29. J. Monfrin et M. H. Jullien de Pommerol, Bibliothèques ecclésiastiques au temps de la papauté d'Avignon.

30. J. Wirth (dir.), Les marges à drôleries des manuscrits gothiques (1250-1350), p. 32.

31. Paris, Bibliothèque Sainte-Geneviève, ms. 143, fol. 1.

32. I. Enguammare, «Les processus d'hybridation dans les marges à drôleries des manuscrits gothiques».

33. B. Van den Abeele (dir.), Bestiaires médiévaux.

34. M. F. Dupuis et S. Louis (trad.), Le Bestiaire, p. 132-133.

35. M. F. Dupuis et S. Louis (trad.), Le Bestiaire, p. 118.

36. Dictionnaire des auteurs grecs et latins de l'Antiquité et du Moyen Âge, p. 420-421.

37. Sur la vision du merveilleux et du monstrueux chez Hildegarde de Bingen, voir L. Moulinier-Brogi, « Les merveilles de la Nature vues par Hildegarde de Bingen (XII ${ }^{\mathrm{e}}$ siècle) », en part. p. 116, 119-121.

38. A. Perriccioli Saggese, " Orimina, Cristoforo », p. 870-871.

39. A. Bräm, Neapolitanische Bilderbibeln des Trecento: Anjou-Buchmalerei von Robert dem Weisen bis zu Johanna I.

40. Louvain, Faculté de Théologie, Bibliothèque Maurits Sabbe, Ms. 1.

41. Idem, fol. 102, 120v, 123, 126, 157v. Le motif se retrouve au fol. 253v du pontifical de Sainte-Geneviève.

42. Paris, Bibliothèque Sainte-Geneviève, ms. 143, fol. 251v.

43. Idem, fol. 77v.

44. Si l'on s'en tient, selon l'hypothèse de $\mathrm{F}$. Manzari, à une commande du pontifical en 1357, voir supra n. 14.

\section{RÉSUMÉS}

L'évêque de Mende Guillaume Durand est l'auteur, vers 1295, d'une nouvelle version du pontifical (ou manuel liturgique réservé au service de l'évêque). Cette édition locale et « gallicane » connaît une fortune rapide, au point de concurrencer bientôt sa rivale romaine, dont elle reprend cependant la trame illustrative. L'étude a pour objet un exemplaire richement enluminé du pontifical de Guillaume Durand, le manuscrit 143 de la Bibliothèque Sainte-Geneviève, vraisemblablement copié au milieu du XIV ${ }^{\mathrm{e}}$ siècle pour un haut dignitaire limousin proche de la curie avignonnaise. Elle s'attarde sur l'originalité de son décor secondaire de marginalia, exceptionnel dans un pontifical: les drôleries dominées par la figure du singe semblent entretenir à dessein un antagonisme dynamique avec les hystoires représentées dans les initiales. 
AUTEUR

MARIANNE BESSEYRE

Conservatrice des bibliothèques, Ciham UMR 5648 


\title{
Les animaux imitateurs au
}

\section{XVIII ${ }^{\mathrm{e}}$ siècle : miroir d'une animalité humaine ou d'une humanité conquérante?}

\author{
Clotilde Boitard
}

1 Un singe qui peint dans un atelier (fig. 1)... Voilà un bien curieux tableau! Jean-Baptiste Deshays, l'auteur de cette œuvre conservée au Musée des Beaux-Arts de Rouen, ridiculise ici les artistes médiocres par la simple utilisation de l'image du singe, imitateur par excellence. Ce type de représentation des primates est la signature du genre artistique des «singeries » dont l'apogée se situe au cœur du xviII ${ }^{e}$ siècle. Les murs du château de Chantilly, ornés de singes brossés dans un style rococo par le peintre Christophe Huet, semblent emblématiques à cet égard. Les primates y évoluent dans toutes sortes de postures humaines (fig. 2). Au-delà de ce mouvement artistique où animaux et imitation s'imbriquent, cette communication portera sur la présence auprès des hommes d'animaux vivants, possédés pour leur talent à imiter, et ce dans les limites de l'espace francophone européen du XvIII ${ }^{e}$ siècle. Bien entendu, cette pratique est loin d'être spécifique à ce périmètre. On trouve actuellement sur des sites internet nombre de vidéos de perroquets parlants. Ces scènes plaisent et provoquent instantanément le rire du spectateur amusé et troublé. Cependant, il semble que l'aptitude à l'imitation de certains animaux ait fait l'objet d'un engouement particulier au XVIII ${ }^{\mathrm{e}}$ siècle, tout comme son utilisation métaphorique dans l'art. 
Fig. 1. - Le singe peintre de Jean-Baptiste-Henri Deshays.

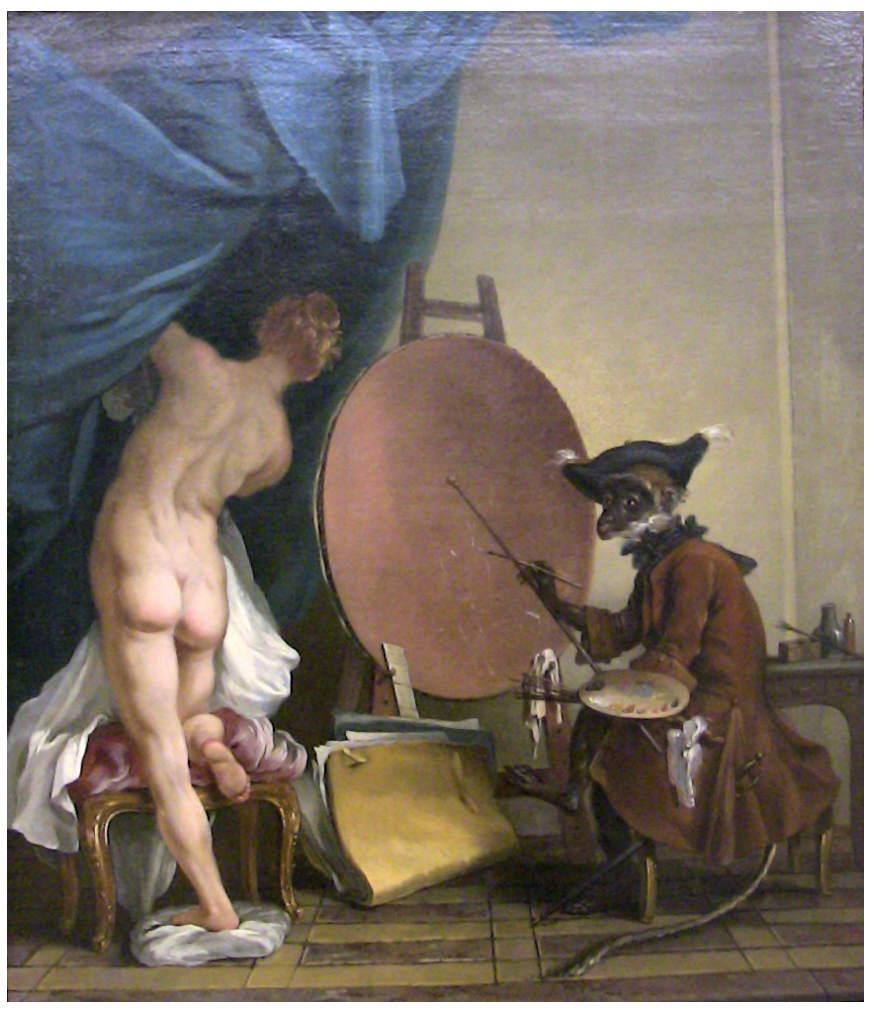

(c) Musée des Beaux-Arts de Rouen.

Fig. 2. - La Grande Singerie du château de Chantilly.

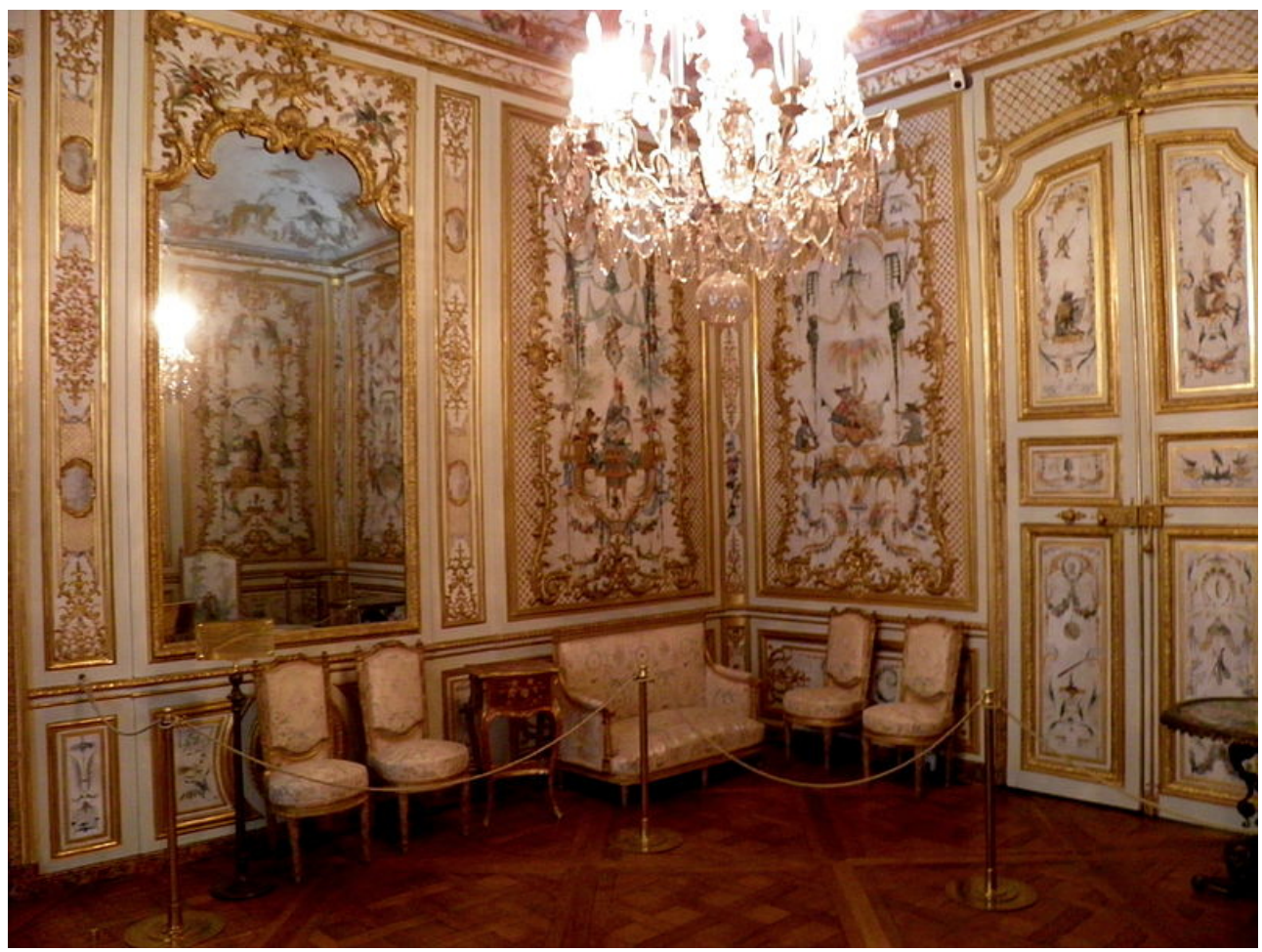

Article Wikipédia « Musée Condé ». 
Mes recherches de doctorat portant sur l'apprivoisement en général au XVIII siècle m'ont amené à noter de façon anecdotique ce phénomène amusant. On est frappé par son importance révélant des tendances et des évolutions sociales. Ces pratiques de dressage questionnent ainsi en retour les fondements d'une recherche sur les animaux apprivoisés : pourquoi ces hommes ont-ils domestiqué des animaux sauvages pour les modeler à leur image ? Ces animaux sont-ils hissés au rang d'humains ou mécanisés tels des automates? Les hommes souhaitent-ils recréer à leur côté une nature artificielle, miroir animal marquant leur supériorité ? Et ces pratiques ne conduisent-elles pas à une interrogation sur le propre de l'homme?

3 Nous allons donc voir à quoi correspond cette réalité animale, principalement dans les villes, puis nous reviendrons sur les méthodes de dressage de ces différents types d'animaux aux aptitudes diverses. Enfin nous interrogerons ces pratiques, miroirs de la société du XVIII ${ }^{\mathrm{e}}$ siècle en pleine métamorphose.

\section{Une réalité diverse, un amusement multiforme}

\section{Des bêtes de foires}

Un Parisien ou un provincial du siècle des Lumières se promenant le long des étals des foires peut y admirer des bêtes spectaculaires, tels des phoques, des rhinocéros ou des fauves, mais également des animaux dressés et accoutrés comme des hommes tel un singe virtuose jouant de la vièle, ancien instrument de musique ${ }^{1}$. Autre exemple : au travers de la presse, nous pouvons suivre le parcours du « sieur Lemoine », accompagné d'un serin savant qui calcule et donne l'heure. Ils sont annoncés à la foire SaintGermain de Paris en $1760^{2}$, à Bordeaux en $1771^{3}$. Le duo retourne à Paris en $1774^{4}$ : il est probable que le dénommé Lemoine ait eu plusieurs canaris, l'espérance de vie de ces oiseaux étant limitée à quelques années. L'année suivante, le tandem fait son numéro en compagnie d'un chien ${ }^{5}$. Il arrive que ces spectacles soient de véritables tromperies. Mais il est possible que les animaux soient réellement instruits à des gestes et des sons, les métamorphosant en des pantomimes humaines. Sans être factices, ces comportements ne sont pas réellement spontanés. Les gestes de l'animal sont plutôt induits par une forte connivence affective avec son maître, comme le cheval Hans le Malin. Cet équidé a provoqué l'émoi de scientifiques au début $d u x^{e}$ siècle par son talent à compter. Il s'est avéré que son propriétaire influençait inconsciemment et involontairement les mouvements de l'animal.

\section{Dans l'intimité des familles}

5 À côté de cette imagerie saltimbanque connue, de nombreux «imitateurs » vivent également au cœur des foyers. Si notre Parisien ou provincial ouvre un journal d'annonces, on peut lui proposer à la vente qui un perroquet bavard, qui une linotte, star à la mode. Ainsi, en 1788, on peut se procurer un perroquet parlant français et espagnol à La Rochelle 6 . En 1761, à Bordeaux, on propose un canari sifflant La Retraite, air de guerre ${ }^{7}$ et trente-deux ans plus tard, en 1793, une alouette chantant Ça ira est à céder dans cette même ville ${ }^{8}$. Ainsi, à travers ces animaux, nous suivons la mode et l'évolution des goûts. Mais gare à celui qui n'imite pas au bon moment ou au bon endroit ! Dans la presse orléanaise de 1792, il est écrit : 
«Londres, le 20 octobre Un oiseleur patriote s'occupe en ce moment de dresser un serin à chanter Ça ira. Les juges du quartier l'ont appris, \& [...], ils déclarent que s'il ne renonce à donner de pareilles leçons, ils tueront tous ses oiseaux, \& feront un petit bûcher des cages. "

6 Le sort final de ces patriotes ailés exilés n'est pas précisé... Toutes sortes d'animaux sont en effet citées dans la presse d'annonces prenant son essor dans la seconde moitié du XVIII ${ }^{e}$ siècle depuis Paris jusque dans les villes de province. J'ai recensé, à ce jour (juin 2016), de manière non exhaustive, 1074 annonces d'animaux apprivoisés, écureuils, oiseaux, singes, entre 1750 et $1815^{10}$. Or, parmi ces annonces de vente ou de perte ou de demandes d'achat, beaucoup mettent en avant la capacité à imiter de certains animaux, en particulier le langage et le sifflement d'airs de musique, comme il est indiqué sur le graphique représentant les différents éléments de descriptions de ces animaux (fig. 3). Ces caractéristiques sont principalement des arguments de vente et plus rarement des moyens d'identifier l'animal. Si, la plupart du temps, les animaux égarés sont distingués par des caractéristiques physiques, ils sont parfois décrits par leur talent de virtuose ou d'orateur. Ainsi, un oiseau lyonnais perdu est signalé de la sorte :

«Un Serin privé, qui siffle l'air du Roi de Sardaigne en passant par Namur. »"11

7 Trois livres de récompense sont promises. Ces usages étant recherchés et ces animaux difficiles à dresser, certains d'entre eux ont une valeur astronomique. Alors que les prix de ces animaux sont rarement énoncés, laissant toute la place à la négociation orale, il existe quelques annonces affichant des prix très conséquents. Or ces dernières annonces concernent systématiquement des animaux imitateurs. Par exemple, un perroquet " parlant bien \& fort doux » est à vendre à 350 livres à Lyon ${ }^{12}$. Toujours dans cette même ville, un « fort joli Sansonnet, âgé de 18 mois, qui parle très bien \& qui siffle un air $»^{13}$ est proposé à 48 livres. En 1789, à Bordeaux cette fois, un serin " parlant bien, \& sifflant supérieurement des airs de serinette ${ }^{14}$ est à céder à 6 louis. En 1794, à Nantes, une citoyenne propose une récompense de 12 livres à qui retrouvera sa perruche " parlant très-bien $»^{15}$. En revanche, le prix des animaux à l'état sauvage est beaucoup moins onéreux. Les animaux exotiques sont souvent acquis à vil prix dans leur pays d'origine. Ceci tient en partie à la loi de l'offre et de la demande avec des animaux plus abondants dans leur milieu naturel. En Europe, ils deviennent, comme toutes les denrées exotiques, un bien rare et luxueux. L'éducation renforce cette tendance. Peu nombreux sont ceux qui survivent aux traversées. Rares sont ceux qui sont dressés à des numéros d'imitateurs... 
Fig. 3. - Les caractéristiques des animaux imitateurs dans les annonces de presse.
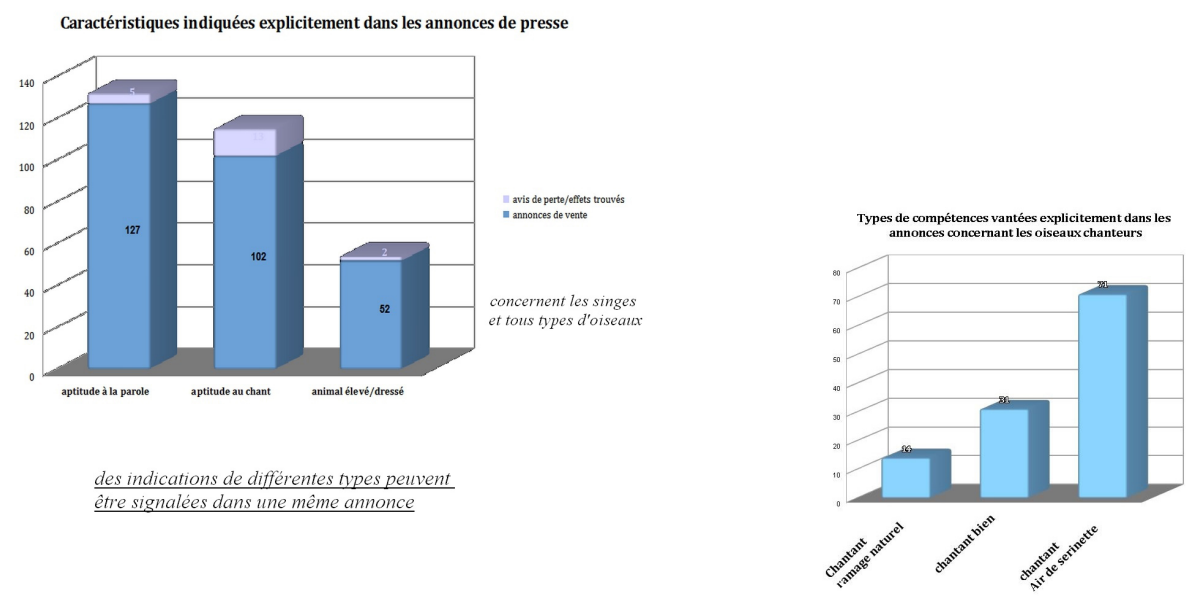

Presse d'annonces consultées par l'auteur (juin 2016) : Bordeaux, Caen, Grenoble, La Rochelle, Lausanne, Lyon, Metz, Montpellier, Nantes, Orléans, Neufchâtel, Paris, Poitiers, Reims, Rouen, Strasbourg et Toulouse.

\section{Un panel étendu d'espèces}

Les oiseaux constituent la majorité des animaux recensés dans le corpus d'annonces, comme il est montré dans le graphique qui illustre les différentes espèces présentes dans le recensement d'annonces (fig. 4). Parmi elles, les oiseaux chanteurs, serin en tête, sont les favoris. Ces oiseaux souvent originaires des bois proches, sont plus faciles à capturer et à élever. Les serins ont, dans ce paysage, une histoire et une place particulière. Ces petits passereaux sont originaires du milieu arboré de l'archipel des îles Canaries. Découverts par les Espagnols au début $\mathrm{xV}^{\mathrm{e}}$ siècle, ils font d'abord l'objet d'un monopole mis en place par les moines. Ces derniers ne cèdent en effet que les mâles pour en empêcher l'élevage. Néanmoins, suite à l'échappée d'une cargaison au large de l'île d'Elbe et probablement en raison du commerce de contrebande des femelles, la prérogative des moines ibériques s'éteint. Le serin devient alors l'objet d'un trafic européen ayant pour centre la région du Tyrol. Cet oiseau se trouve au sommet de sa gloire au $\mathrm{XVIII}^{\mathrm{e}}$ siècle, alors qu'il est particulièrement apprécié pour sa voix et son chant, avec un élevage et une reproduction accessibles à tout un chacun, comme en témoignent les nombreuses éditions du traité d'élevage des serins ${ }^{16}$. Cet élevage effectué par des particuliers, en concurrence du trafic transfrontalier, se développe tout comme l'éducation musicale de ces oiseaux, particulièrement sensibles à la musique. L'apprentissage est en effet plus facile avec l'essor des serinettes, instrument de musique mécanique, sur lequel nous allons revenir.

Durant le $\mathrm{XVIII}^{\mathrm{e}}$ siècle, les singes et les perroquets, tous deux animaux exotiques, sont souvent mis en miroir, les premiers imitant l'homme par les gestes et les seconds par les sons. Par exemple, Georges Christian Raff dénomme le perroquet le «singe de la gent emplumée $»^{17}$. Cette symétrie est en fait déséquilibrée, les singes occupant une place majeure dans l'art pictural tout en étant plus rares dans les foyers. À L'inverse, les perroquets, bien que leur reproduction et leur élevage soient problématiques, sont bien plus nombreux, Gris du Gabon ou perroquets « amazone » d'Amérique. La présence des babouins, macaques ou autres singes d'Afrique est certes ancienne, depuis l'Antiquité, 
avec un trafic méditerranéen ${ }^{18}$. La période moderne voit en revanche la découverte des plus proches cousins de l'homme, les grands singes, avec l'arrivée en Europe, depuis le Nouveau Monde et à partir $\mathrm{du} \mathrm{XVII}^{\mathrm{e}}$ siècle, de quelques rares spécimens vivants succombant rapidement au froid et au stress. En 1738, une femelle chimpanzé est présentée au public londonien, déguisée et buvant le thé. Elle provoque un engouement sans précédent. Un an après, un autre chimpanzé, Jocko, fait également sensation à Paris dans une même mise en scène renforçant à outrance sa ressemblance avec les hommes. Toutefois, les singes vendus dans les annonces de presse ne concernent pas ces singes anthropoïdes rarissimes mais des singes à queue. L'importance relative des primates peut s'expliquer en partie par la difficulté de capture de ces agiles acrobates vivant en bande, et par leur fragilité une fois en cage. Leur comportement agité posant problème en captivité, les annonces de ventes insistent habituellement non sur leur capacité d'imitation mais sur leur docilité. Pourtant, ils sont les rois de l'évasion. Dans les quelques annonces de perte, il est précisé fréquemment que ces animaux sont attachés, comme à Bordeaux, dans une annonce où l'on recherche :

«[...] un Singe, de la plus petite espèce, ayant un cordon attaché au milieu du corps. $\aleph^{19}$

10 Malgré tous ces désagréments, le singe est finalement remarquablement présent, y compris dans des demeures bourgeoises simples. Les perroquets, bien que pouvant causer des désagréments (bruits, malpropreté...) sont plus faciles à vivre. Ce constat vaut encore aujourd'hui : le commerce et la possession des singes sont interdits dans de multiples pays. Quand cela n'est pas le cas, les singes sont rares et souvent abandonnés. À l'inverse, nombre d'espèces de perroquets font l'objet de commerces légaux ou malheureusement de trafics interdits. L'élevage et la reproduction en captivité de ces oiseaux se sont grandement améliorés depuis le XIX ${ }^{\mathrm{e}}$ siècle.

11 Nous avons donc vu le prestige de ces animaux imitateurs. Ces divertissements axés autour de multiples animaux, les oiseaux chanteurs et les perroquets en premier lieu, révèlent un rapport particulier aux animaux sauvages. Ils sont aussi indirectement un témoignage des goûts artistiques, musicaux et politiques de l'époque. Maintenant, nous allons voir comment cette éducation est faite. 
Fig. 4. - Les différentes espèces recensées dans la presse d'annonces consultée par l'auteur.

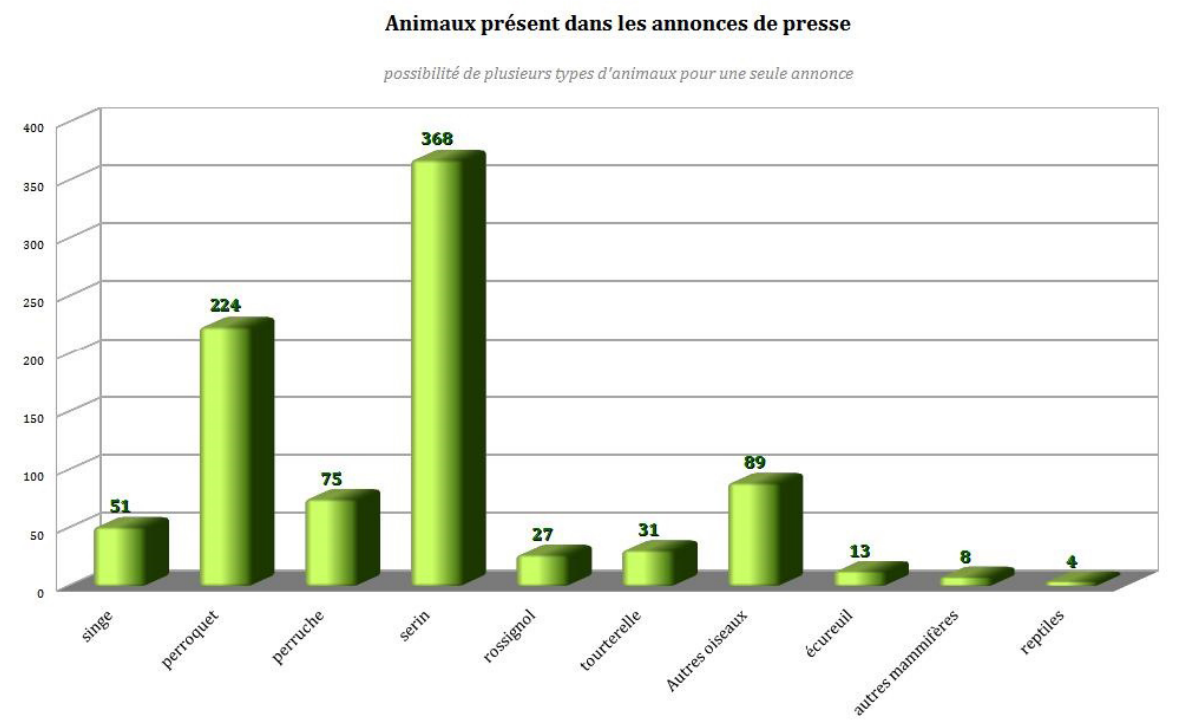

\section{Le double mouvement de l'imitation : entre aptitude naturelle et dressage}

\section{Le singe : une diva ingérable}

12 Comme nous l'avons dit, à l'école de la caricature des hommes, le singe a une place particulière. Georges-Louis Leclerc de Buffon écrit :

«[...] le singe nous imite-t-il, parce qu'il le veut, ou bien parce que sans le vouloir il le peut ? [...] ; le singe ayant des bras et des mains s'en sert comme nous, mais sans songer à nous : la similitude des membres et des organes produit nécessairement des mouvemens et quelquefois même des suites de mouvemens qui ressemblent aux nôtres $[\ldots] »^{20}$

Or, au XVIII siècle, les hommes accentuent fréquemment ces traits communs, par exemple en travestissant les singes avec des vêtements, tels ceux conservés au Musée des Arts Décoratifs de Paris ${ }^{21}$. Paradoxalement, les singes sont rares dans les traités d'élevage. Si un chapitre leur est consacré dans le traité de Pierre-Joseph Buc'hoz ${ }^{22}$, des conseils précis manquent concernant leur éducation. L'auteur énumère seulement pêle-mêle leurs talents sans préciser les méthodes pour les améliorer :

«Le génie du singe ne se flétrit pas par la captivité, car on le voit dans les maisons également rusé, audacieux, voluptueux, frippon \& moqueur ; [...]. On leur apprend facilement à danser sur la corde \& y faire des entrechats, à faire une toilette, à faire la roue, à attiser le feu; à laver la vaisselle, à pousser la brouette, à battre du tambour, à embrasser, à rincer des verres, et même à donner à boire [...] $»^{23}$

Ces lignes étonnantes peuvent être corroborées, en partie, par les tentatives effectuées au $\mathrm{Xx}^{\mathrm{e}}$ siècle de dresser des singes capucins à aider les handicapés. Il est avéré qu'ils ont la capacité d'accomplir plus de 50 tâches mais avec des résultats inégaux et moins satisfaisants que ceux des chiens, à l'espérance de vie pourtant plus courte ${ }^{24}$. Avec une faible concentration, des pulsions sexuelles pas toujours canalisées, un comportement remuant, les singes se démotivent souvent et peuvent poser problème. Durant le siècle des Lumières, le singe est en fait apprécié pour les mêmes raisons qu'il est redouté, 
voire détesté : pour ses facéties et sa turbulence! La baronne d'Oberkirch évoque dans ses mémoires les dégâts du singe de la princesse de Chimay, chez qui elle soupait. Le primate, en fugue à l'insu de tous, trouve refuge dans le cabinet de toilette de la maison... La baronne raconte :

« Il se roula dans la poudre, se regarda au miroir, et apparemment satisfait de cette transformation, il la rendit complète en s'appliquant du rouge et des mouches, ainsi qu'il avait vu faire sa maîtresse ; seulement il se mit le rouge sur le nez et la mouche au milieu du front. $»^{25}$

Il surgit ainsi durant le repas, provoquant l'effroi puis les rires des convives. La baronne, qui n'apprécie pas particulièrement ces animaux remuants, est pourtant, elle aussi, amusée. Notons un détail, la narratrice indique incidemment que le singe se mire dans une glace quand il se maquille. Elle reconstitue nécessairement ce fait, n'étant pas présente dans le cabinet... Il est avéré d'ailleurs, suite à nombre d'expériences scientifiques, que très peu d'espèces de singes réussissent «le test du miroir ». L'expérience consiste à mettre une tache de peinture sur l'animal, qui l'efface ou non en se regardant dans la glace. Ce geste induit une conscience de soi. Or, seuls quelques grands singes, bonobos et chimpanzés passent cette épreuve... Par cette invention, la baronne humanise encore plus le primate.

\section{Les oiseaux, brillants virtuoses travailleurs}

Loin des malices simiesques, des oiseaux sont dressés au chant. Après une période d'adaptation à la captivité pour certains, les cours ont lieu plusieurs fois par jour et à heures régulières, sur un temps bref. L'élève est isolé, parfois dans le noir ou les yeux mutilés (provisoirement selon les dires de Louis Arnault de Nobleville, auteur d'un traité d'élevage du rossignol26). Le dresseur joue alors un air de trente secondes devant l'oiseau avec une petite flûte, appelée flageolet, au son très aigu, similaire à celui des oiseaux chanteurs.

Un instrument de musique voit le jour au XviII ${ }^{e}$ siècle, appelé serinette pour les serins, pionne pour les bouvreuils, perroquette ou merline et ainsi de suite selon les oiseaux à instruire, le premier étant le plus répandu (tout comme le type d'oiseau). Cet instrument (fig. 5) est un petit orgue fonctionnant avec une manivelle actionnant un soufflet et un cylindre où se trouvent des picots. Ces derniers font basculer les touches reliées aux tuyaux par des soupapes qui laissent passer l'air du soufflet. Simple à utiliser et ne nécessitant pas de formation musicale, cet instrument facilite le dressage des oiseaux, a fortiori pour des leçons répétitives. Il trouve son origine dans l'Est de la France, à Mirecourt, dans la première moitié $d u x \mathrm{XIII}^{\mathrm{e}}$ siècle $^{27}$. La fabrication s'étend ensuite au reste du territoire: dans la presse, des serinettes sont à vendre avec pas moins de 114 annonces recensées en France ou en Suisse. Leur fabrication est maîtrisée par les facteurs d'orgues et luthiers. L'instrument précis de la figure 5, disposant de 10 airs ${ }^{28}$, conservé actuellement au Musée Auguste Grasset à Varzy, est à la fois une serinette et une pionne, car il est pourvu de deux rangées de tuyaux à l'arrière permettant de jouer le même air avec un ton aigu ou grave : l'homme tente ainsi de se rapprocher de la voix de l'apprenti. L'homme imite l'oiseau, pour que l'oiseau l'imite ! Pour soumettre l'animal, il s'adapte ainsi à ses capacités. 
Fig. 5. - Serinette, 1763, Varzy.

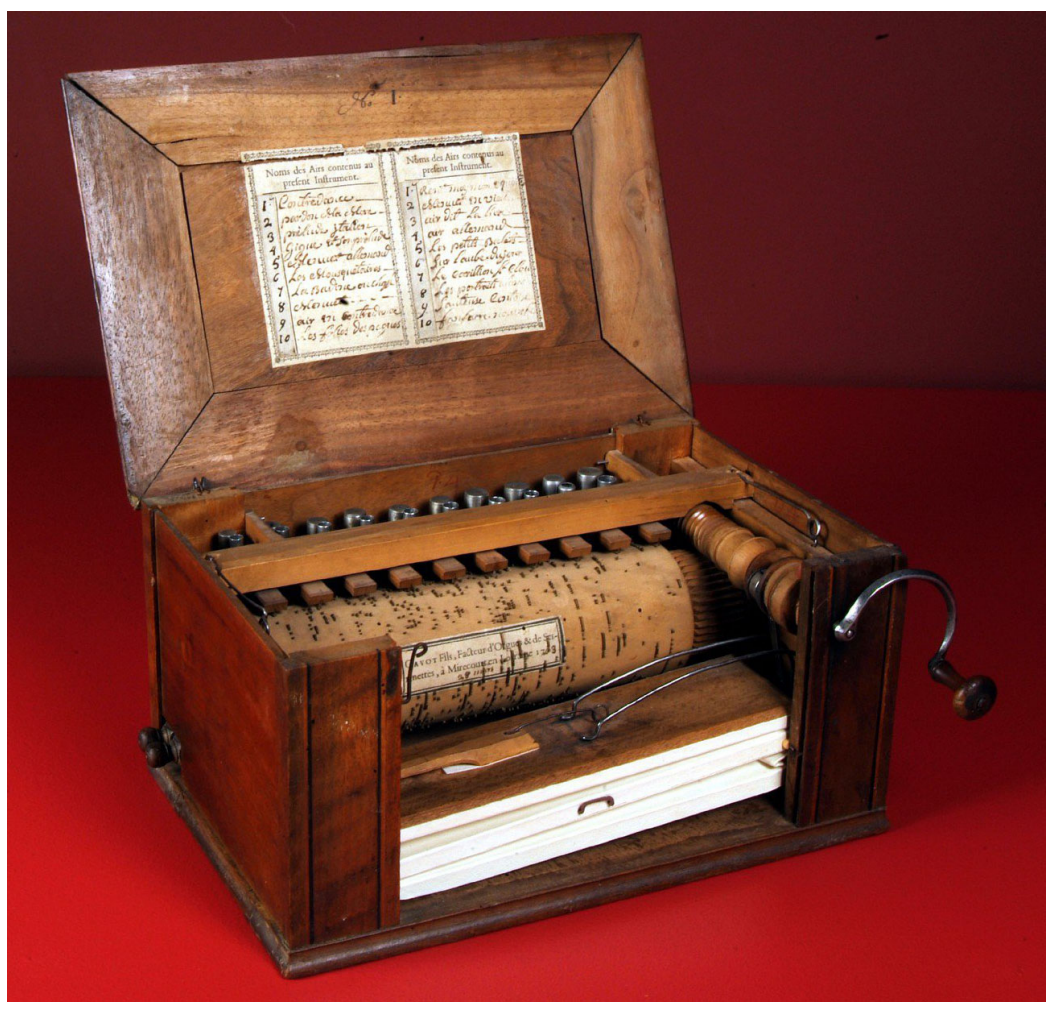

(c) Musée Auguste Grasset, Varzy.

\section{Entre nature et culture}

Ce dressage est-il vraiment efficient? Les traités d'élevage préviennent souvent l'amateur des difficultés auxquelles il devra faire face. Si la fréquence des leçons diminue, leurs résultats s'amenuisent immanquablement. Gageons que beaucoup d'oiseaux sont comme le petit serin perdu à Grenoble en 1787. Son maittre écrit dans les Affiches du Dauphiné:

« On a perdu samedi dernier un canari [...] disant un air de serinette, qu'il mele avec son chant naturel. $»^{29}$

19 Il est avéré néanmoins que cette aptitude à imiter les sons est naturelle chez les oiseaux apprenant à chanter. Dans un récent Dictionnaire du comportement animal, il est expliqué :

«Bien entendu, nombre d'oiseaux sont d'excellents imitateurs des sons étrangers [...]. La raison n'est pas claire, mais contrairement au chant des insectes, le chant des oiseaux est rarement monotone et ils sont à même d'y ajouter de nouveaux éléments. Cette habileté est importante pour la sélection du partenaire. $»^{30}$

Les méthodes pour apprendre aux oiseaux à parler comportent des aspects similaires. Voici un extrait d'un traité d'élevage :

«[...] on couvre leur cage avec un morceau d'etoffe, \& on leur répete plusieurs fois la même parole qu'on veut qu'ils apprennent, ayant soin de tenir la lumière cachée : on leur mettra quelquefois un miroir devant eux avec de la lumière quand on leur parle, parce qu'ils s'imaginent que ce sont leurs semblables qui forment cette voix. $»^{31}$ 
Ces éleves ont aussi des aptitudes naturelles, comme le perroquet qui, vivant dans la cacophonie de la forêt tropicale, a développé une ouïe fine pour reconnaître les cris de ses semblables et de son partenaire. Il imite des bruits pour tromper les prédateurs ou pour ébahir son/sa partenaire. Sa langue épaisse et molle peut bouger dans tous les sens, lui permettant de moduler des sons alors que son bec s'ouvre indépendamment de la position de la langue. Toutefois, ces oiseaux parleurs ne sont pas des communicants similaires aux humains. Ils n'utilisent pas le langage défini comme un système structuré de transmission des pensées et d'information. Konrad Lorenz explique :

"Même les oiseaux qui "parlent" le mieux et sont [...] capables de relier les sons qu'ils émettent à certains événements par des associations très déterminées, n'apprennent jamais à utiliser leurs connaissances en vue d'un but précis, même le plus simple. $»^{32}$

Le lien affectif avec les hommes imités semble prééminent. Malgré tout, certains perroquets nous troublent par leur mémoire phénoménale, l'utilisation à bon escient des mots et surtout une interaction indéniable.

Pour conclure, ce type de dressage suppose une forte familiarité entre l'homme et l'animal, animé d'une volonté constante de vouloir éduquer l'oiseau. Appartenant tout simplement au milieu ambiant de l'oiseau, l'homme devient aussi par là même un des repères sonores $\mathrm{du}$ volatile. Nous avons donc vu que les animaux imitateurs correspondent à une scénarisation consciente des hommes avec des animaux pantomimes, ou à un long conditionnement aux résultats inégaux, les hommes utilisant un comportement naturel alors qu'hommes et animaux vivent dans une forme d'intimité. Il convient donc maintenant de se questionner sur le sens de ces pratiques en lien avec l'évolution de la société.

\section{Un reflet de l'homme ou une marque de différence? Double mouvement de fascination et domination de la nature}

\section{Arts du reflet et reflets de l'art}

Il semble bien que l'imitation et la nature appartiennent à l'air du XVIII siècle. L'usage du mot imitateur culmine d'ailleurs en $1780^{33}$. Ce climat transparait dans les arts. Imitation de la nature avec des paysagistes tel Hubert Robert, contrefaisant la nature dans un décor de carton-pâte. Imitation de l'homme: les singes des Singeries déjà évoquées sont des métaphores, des fables humaines, avec une réflexion satirique sur l'humanité. L'art plagie la nature et l'animal singe les actions des hommes devenues grotesques. Or, peut-on observer des points de rencontre entre ces mouvements artistiques et ces pratiques vis-à-vis des animaux ? Les relations entre art et réalité sont complexes et il serait hasardeux d'établir des liens directs. Les singes des singeries n'ont rien de réel. Peut-être, à l'inverse, existe-t-il une volonté d'incarner ces Singeries tant appréciées avec des singes vivants déguisés en de véritables petits aristocrates dans un tableau vivant, miroir réel de fictions.

Ces animaux familiers deviennent en retour des figures typiques dans les arts, comme dans le poème tragi-comique sur le perroquet de Nevers écrit par Jean-Baptiste Gresset $^{34}$. Cette œuvre a connu un succès et une postérité remarquable ${ }^{35}$, avec nombre 
d'adaptations et de représentations le siècle suivant (fig. 6) : Vair-vert, perroquet, demeurant chez les visitandines de Nevers et donc riche d'un langage dévot, est envoyé dans un couvent à Nantes, fort d'une large renommée. Mais pendant son voyage, il apprend le vocabulaire familier du batelier qui le transporte. Son changement de registre provoque son renvoi de la ville bretonne. Cependant, de retour à Nevers, il est pardonné par les nonnes attendries. Il meurt quelque temps plus tard... gavé de sucreries dont il est si friand. Ce perroquet est irrévérencieux sans être réellement dangereux. Étant hors de l'humanité, il peut passer d'un milieu humain à l'autre au sein d'une société en plein mouvement mais qui demeure stratifiée et cloisonnée.

Fig. 6. - Vair-Vert de Fleury-Richard, 1804.

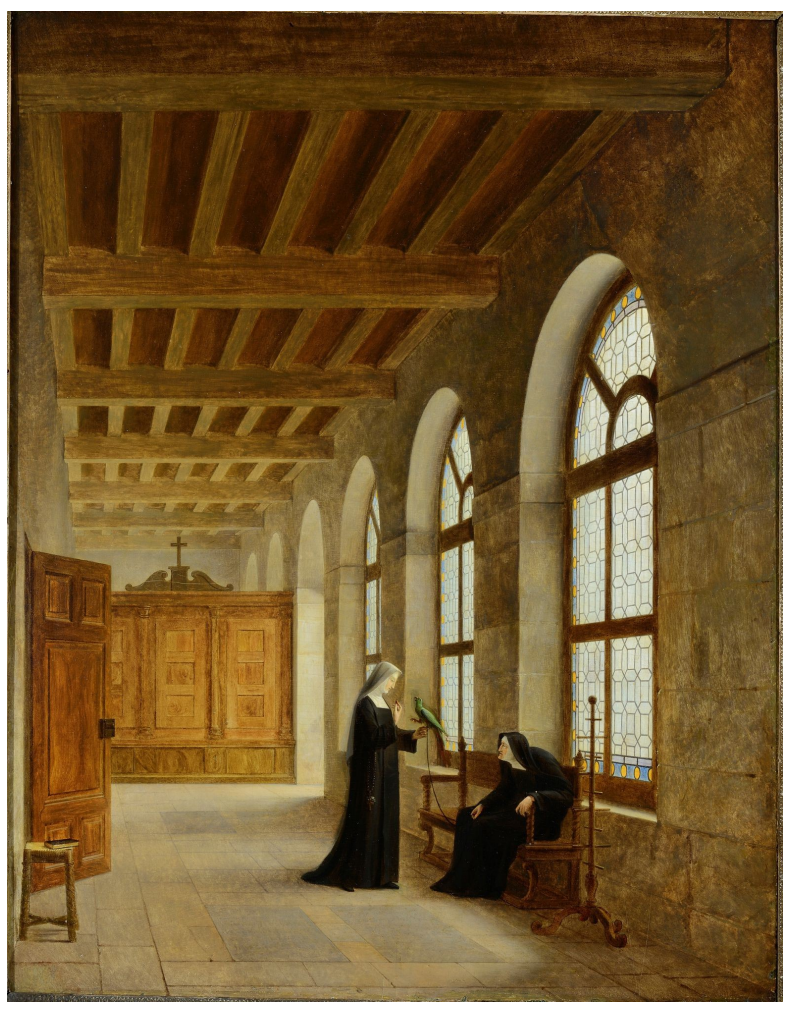

(c) Musée des Beaux-Arts, Lyon.

\section{Ressemblances et dissemblances : animalités et humanité}

Les perroquets et autres oiseaux réels font aussi écho aux croyances des hommes, avec par exemple des perroquets ânonnant des prières ou des oiseaux chantant des airs politiques. Ils deviennent ainsi des étendards. Le contraste entre la familiarité des paroles et l'altérité de l'animal provoque le rire. L'ornithologue François Levaillant évoque un perroquet pavouane :

«[...] chez un capitaine de vaisseau, qui récitait le pater tout entier en Hollandois, en se couchant sur le dos, et en joignant les doigts des deux pieds comme nous joignons les mains en priant $[. ..] »^{36}$

La ressemblance du geste accentue le décalage avec la dissemblance du corps, marquant la séparation entre l'homme et l'animal. Cette pratique permet finalement à l'homme de se démarquer et de se valoriser. Les animaux deviennent un reflet narcissique de l'homme. Cette imitation est recherchée mais l'animal imitateur souvent 
déconsidéré. Le regard de Georges-Louis Leclerc de Buffon est éloquent. Fasciné par la nature toute puissante et glorifiant la domestication c'est-à-dire l'empreinte de l'homme sur les animaux, il différencie et caractérise fréquemment les animaux par leur aptitude ou non à imiter les hommes notamment parmi les animaux familiers ou ceux des foires, références récurrentes dans ses écrits. Il constate que ce comportement est le fruit d'un apprentissage, mais bien moins élaboré que l'éducation des hommes. Une imitation :

«[...] qu'on doit regarder comme artificielle, ne peut, ni se répartir ni se communiquer à l'espèce; elle n'appartient qu'à l'individu qui la reçoit, qui la possède sans pouvoir la donner : le perroquet le mieux instruit ne transmettra pas le talent de la parole à ses petits. $»^{37}$

Cet apprentissage, produit par l'homme sur les animaux, ne concerne tout de même que « des espèces distinguées dans l'ordre des êtres organisés " ${ }^{38}$. L'homme hisse vers le haut certains animaux. Cependant, ce comportement imitatif est pour Buffon une marque de bêtise. Parmi de nombreux extraits, en voici un :

«[...] c'est par les rapports de figure que le singe contrefait les gestes humains, c'est par les rapports d'organisation que le serin répète des airs de musique, et que le perroquet imite le signe le moins équivoque de la pensée, la parole, [...] $\aleph^{39}$

Le savant, réunissant les animaux imitateurs, reprend ainsi l'argumentaire des cartésiens adeptes de la théorie de l'animal-machine, dans une perception du monde désenchantée et mécanique. Se combinent donc familiarité et rapport de domination, analogie et divergence, dissemblance et similarité entre hommes et animaux.

Les animaux imitateurs font partie intégrante de la société du XVIII ${ }^{\mathrm{e}}$ siècle, tant dans les spectacles comiques que dans l'intimité des maisons. Ces pratiques correspondent à la fois à une fiction humaine et à une réalité éthologique. Au-delà du divertissement, elles marquent la volonté des hommes de dominer le monde à découvrir et de l'éduquer. Dans un jeu paradoxal, les hommes s'amusent de ces animaux leur renvoyant un miroir rassurant, familier et pourtant troublant.

31 Si les évolutions de la science font voir ces aptitudes comme des preuves d'intelligence et d'évolution de certaines espèces, ces comportements font encore rire de nos jours. L'éthologue Konrad Lorenz affirmait pourtant il y a plusieurs décennies :

«Je ris très rarement d'une bête et, si je ris, il apparaît généralement, en y regardant de plus près, que c'est de moi que j'ai ri, de l'homme dont l'animal m'a présenté une caricature plus ou moins impitoyable. $»^{40}$ 


\section{BIBLIOGRAPHIE}

ALLETZ Pons-Augustin, Histoire des singes, et autres animaux curieux, dont l'instinct et l'industrie excitent l'admiration des hommes..., Paris, Duchesne, coll. « Bibliothèque de campagne, ou les amusements du cœur et de l'esprit », n 9, 1752.

BRETAGnolle Vincent, Pourquoi les oiseaux chantent-ils? Paris, Éd. le Pommier, coll. « Les petites pommes du savoir », $\mathrm{n}^{\circ} 70,2005$.

BUC'HOz Pierre-Joseph, Traité de l'éducation des animaux qui servent d'amusement à l'homme : savoir : le singe, le chien, le chat, l'écureuil, le perroquet... : la manière de les élever, de les nourrir, de les traiter dans leurs maladies, d'en tirer du profit \& de l'amusement, Paris, Lamy, 1780.

BUC'HOZ Pierre-Joseph, Les amusemens innocens : contenant le traité des oiseaux de volière, ou le parfait oiseleur..., Paris, Chez P. Fr. Didot le jeune..., 1774.

BUFFON Georges-Louis Leclerc et DAUBENTON Louis-Jean-Marie, Histoire naturelle générale et particulière : avec la description du Cabinet du Roy, t. IV, Paris, Impr. royale, 1749. http:// gallica.bnf.fr/ark:/12148/bpt6k97493f BUFFON Georges-Louis Leclerc et DAUBENTON Louis-Jean-Marie, Histoire naturelle générale et particulière : avec la description du Cabinet du Roy, t. XIV, Impr. royale, 1749. http://gallica.bnf.fr/ ark:/12148/bpt6k97503x

BUFFON Georges-Louis Leclerc, Histoire naturelle des oiseaux. Tome VI, de l'Impr. royale (Paris), 1770. http://gallica.bnf.fr/ark:/12148/bpt6k975106

CAMPARDON Émile, Les spectacles de la foire : théâtres, acteurs, sauteurs et danseurs de corde, monstres, géants, nains, animaux curieux ou savants, marionnettes, automates, figures de cire et jeux mécaniques des foires Saint-Germain et Saint-Laurent, des boulevards et du Palais-Royal, depuis 1595 jusqu'à 1791, t. 2, Documents inédits recueillis aux Archives nationales, Paris, 1877.

CLOUZOT Martine et ВЕСК Corinne (eds.), Les oiseaux chanteurs : sciences, pratiques sociales et représentations dans les sociétés et le temps long, Dijon, Éditions universitaires de Dijon, 2014.

GRESSET Jean-Baptiste, Vair-vert ou les voyages du perroquet de la visitation de Nevers. Poème héroïcomique, La Haye, Chez Guillaume Niegard, 1734.

HERVIEUX de CHANTELOUP J.- C., Nouveau Traité des Serins de Carnarie, contenant la manière de les élever, de les appareiller pour en avoir de belles races [Stances par Philémon Trotet], Paris, 1709, nouvelles éditions en 1713, 1745, 1766 et 1785.

HERZFELD Chris, Petite histoire des grands singes, Paris, Ed. du Seuil, coll. « Science ouverte », 2012. LEVAILLANT François, Histoire naturelle des perroquets. Paris, Levrault, Schoell, 1804, 2 vol. http:// gallica.bnf.fr/ark:/12148/bpt6k97063d.

LORENZ Konrad, Il parlait avec les Mammiferes, les Oiseaux et les Poissons, traduit par Denise VAN MOPPÈs, Paris, Flammarion, 1970.

MARRET Bertrand, Portraits de l'artiste en singe : les singeries dans la peinture, Paris, Somogy éd. d'art, 2001.

NOBLEVILLE Louis Daniel Arnault de, Aedologie ou traité du rossignol franc. ou chanteur, Paris, 1751. 
OBERKIRCH Henriette-Louise de Waldner de Freundstein, Mémoires de la baronne d'Oberkirch sur la cour de Louis XVI et la société française avant 1789, Paris, Mercure de France, 2000.

PIN Bernard, « L'atelier de Nicolas Gavot, facteur de serinettes à Mirecourt à la fin du XVIII ${ }^{\mathrm{e}}$ siècle ", Musique. Images. Instruments. Revue française d'organologie et d'iconographie musicale, vol. 6, Écoles et traditions régionales ( $1^{\text {re }}$ partie), 2004, p. 2-18.

PIN Bernard, « La plus ancienne serinette française conservée ? », Musique. Images. Instruments.

Revue française d'organologie et d'iconographie musicale, vol. 4, Nouveaux timbres, nouvelle sensibilité au XVIII ${ }^{e}$ siècle (2 ${ }^{\mathrm{e}}$ partie), 1999, p. 132-145.

RAFF Georg Christian, Abrégé d'histoire naturelle pour l'instruction de la jeunesse. Imité de l'allemand de M. Raff, $\ldots 1^{\text {re }}\left[-2^{\mathrm{e}}\right]$ partie, traduit par PERRAULT, Strasbourg, A. Koenig, 1786.

ROUDIER Jean-Michel et GRESSET Jean-Baptiste-Louis, Ver-Vert : étude d'un phénomène littéraire \& artistique, Nevers, Musées de la Nièvre, 1998.

UNIVERSITY OF OXFORD, Dictionnaire du comportement animal, traduit par Guy SCHOELLER, Paris, R. Laffont, coll. «Bouquins », 1990.

\section{NOTES}

1. E. Campardon, Les spectacles de la foire : théâtres, acteurs, sauteurs et danseurs de corde, monstres, géants, nains, animaux curieux ou savants, marionnettes, automates, figures de cire et jeux mécaniques des foires Saint-Germain et Saint-Laurent, des boulevards et du Palais-Royal, depuis 1595 jusqu'à 1791, p. 400.

2. Annonces, affiches, nouvelles et avis divers pour la ville de Nantes, 15 février 1760 , $\mathrm{n}^{\circ}$ 7, B.M. Nantes, cote : 60578 .

3. Annonces, affiches et avis divers pour la ville de Bordeaux, 31 janvier 1771, $\mathrm{n}^{\circ}$ 5, B.M. Bordeaux, cote : H 3440/5 Rés.

4. E. Campardon, Les spectacles de la foire, ibid., p. 394. (L'auteur se réfère à l'almanach forain de 1775).

5. Annonces, affiches et avis divers de la Haute et Basse Normandie, 10 novembre 1775, $n^{\circ} 45$, A.D Seine-maritime, Cote : BMR 260_3.

6. Affiches de la Rochelle, 3 octobre 1788, B.M. La Rochelle, Per. 549.

7. Annonces, affiches, nouvelles et avis divers pour la ville de Bordeaux, 29 janvier 1761, nº 5, B. M Bordeaux, cote : DU 23073/1 Rés.

8. Le Journal de Commerce, de Politique et de Littérature, 10 avril 1793, $\mathrm{n}^{\circ} 100$, B.M. Bordeaux, cote : H 3442/18 Rés.

9. Le journal du Loiret, 27 octobre 1792, nº 247, B.M. Orléans, cote : E5129 (1792).

10. Les journaux proviennent des villes suivantes: Bordeaux, Caen, Grenoble, La Rochelle, Lausanne, Lyon, Metz, Montpellier, Nantes, Orléans, Paris, Poitiers, Reims, Rouen, Strasbourg, Toulouse.

11. Les Affiches de Lyon, le 26 juin $1766, \mathrm{n}^{\circ} 26, \mathrm{~B} . \mathrm{M}$. Lyon, cote : 951.000 .

12. Ibid., le 14 août $1771, \mathrm{n}^{\circ} 33$.

13. Ibid., le 22 janvier $1772, \mathrm{n}^{\circ} 4$. 
14. Le Journal de Guienne, le 30 octobre 1789, $n^{\circ}$ 303, B.M. Bordeaux, cote H 3442/11 Rés.

15. Affiches de Nantes et du département de la Loire-Inférieure, le 12 janvier $1794, \mathrm{n}^{\circ} 5$, B.M. Nantes, cote : 97036

16. J.-C. Hervieux de Chanteloup, Nouveau traité des serins de canarie...

17. G. C. Raff, Abrégé d'histoire naturelle pour l'instruction de la jeunesse... $1^{\text {ére }}\left[-2^{e}\right]$ partie, p. 60.

18. C. Herzfeld, Petite histoire des grands singes, chapitre 1 (p. 12-17).

19. Le journal de Guienne, le 4 février 1786, $n^{\circ} 35$, B.M. Bordeaux, cote : H 3442/4 Rés.

20. G.-L. Leclerc de Buffon et L.-J.-M. Daubenton, Histoire naturelle générale et particulière : avec la description du Cabinet du Roy. t. XIV, p. 38-39.

21. Musée des Arts Décoratifs de Paris, Habit de singe, manteau, 1720-70, $\mathrm{n}^{\circ}$ d'inventaire

22. 15316 et Habit de singe, vers $1760, \mathrm{n}^{\circ}$ d'inventaire 56580, photographies de ces habits consultables sur le site $:$ https///madparis.fr/

P.-J. Buc'hoz, Traité de l'éducation des animaux qui servent d'amusement à l'homme : savoir : le singe, le chien, le chat, l'écureuil, le perroquet... : la manière de les élever, de les nourrir, de les traiter dans leurs maladies, d'en tirer du profit \& de l'amusement, p. 1-75.

23. Ibid., p. 51-52.

24. Aide simienne - Wikipédia.

25. H-L de Waldner de Freundstein Oberkirch, Mémoires de la baronne d'Oberkirch sur la cour de Louis XVI et la société française avant 1789, p. 159-160.

26. L. D. Arnault de Nobleville, Aedologie ou traité du rossignol franc ou chanteur, p. 85, puis 94 à 100. L'auteur explique comment aveugler le rossignol : « On cassera en deux par le milieu le tuyau d'une pipe à fumer ordinaire : on chauffera bien au feu sur un réchaud le gros bout du tuyau cassé, \& lorsque qu'il sera bien chaud \& presque rouge, on l'approchera si près de la prunelle de l'œil de l'oiseau, qu'il soit obligé de le fermer sans plus oser l'ouvrir » p. 99. Plus loin, il affirme que l'oiseau pourrait recouvrer la vue, « [...] on se réserve le plaisir de lui rendre la vue quand on le veut [...]» p. 100.

27. B. PIN, « La plus ancienne serinette française conservée?».

28. Ces airs sont: Contredanse, Pardon ma mère, Prélude italien, Gigue et son prélude, Menuet allemand, Les Mousquetaires, La Badine en Chasse, Menuet, Air en contredanse, Les Folies d'Espagne.

29. Les Affiches du Dauphiné, 22 juin $1787, \mathrm{n}^{\circ} 8$, BNF, cote 4-LC9-68 (6).

30. University of Oxford, Dictionnaire du comportement animal, traduit par G. Schoeller, p. 164 (article Chant).

31. P-J. Buc'hoz, Les amusemens innocens: contenant le traité des oiseaux de voliere, ou le parfait oiseleur ..., p. 176-177.

32. K. Lorenz, Il parlait avec les Mammiferes, les Oiseaux et les Poissons, p. 97.

33. Ce point culminant est particulièrement évident dans le graphique en ligne sur le site du Dictionnaire vivant de la langue française (DVLF) à l'adresse http:// dvlf.uchicago.edu/mot/imitateur: il est représenté un graphique de l'occurrence du mot « imitateur » dans les textes. 
34. J.-B.-L. Gresset, Vair-Vert, ou Les Voyages du perroquet de la visitation de Nevers. Poème héroï-comique.

35. J.-M. Roudier et J.-B.-L. Gresset, Vert-Vert : étude d'un phénomène littéraire \& artistique.

36. F. Levaillant, Histoire naturelle des perroquets, t. I, p. 37.

37. G-L. Leclerc de Buffon, Histoire naturelle des oiseaux, t. VI, p. 71-72.

38. Ibid., p. 72.

39. G-L. Leclerc de Buffon et L.-J.-M. Daubenton, Histoire naturelle générale et particulière : avec la description du Cabinet du Roy, t. IV, p. 87-88.

40. K. Lorenz, Il parlait avec les Mammiferes, les Oiseaux et les Poissons, p. 170.

\section{RÉSUMÉS}

Cet article repose sur un constat: le goût pour les animaux dit imitateurs, singes, oiseaux parleurs ou chanteurs culmine durant le siècle des Lumières. Cette présence ne concerne pas uniquement les foires mais aussi les demeures urbaines. En témoignent les multiples annonces de presse. Oiseaux chanteurs, oiseaux parleurs, singes parfois, y sont proposés à la vente, recherchés suite à leur fugue. Pour " goûter » aux talents de ces animaux, les hommes les mettent en scène tels les singes naturellement proches de l'homme. Ils dressent également des animaux par un apprentissage long et difficile, souvent à l'aide d'instruments de musique telle la serinette, et par la lecture de nombreux traités d'élevage d'animaux d'amusements. Cette éducation renvoie à de réelles aptitudes naturelles à imiter des sons, paroles ou musiques de nombreux types d'oiseaux et celle à imiter des gestes des singes. Ces pratiques plus ou moins efficaces révèlent le climat du $\mathrm{XVIII}^{\mathrm{e}}$ siècle et sont un élément important de son paysage culturel. Elles mettent au jour également une fascination de la nature imbriquée à une volonté de l'assujettir et donc de s'en démarquer.

\section{AUTEUR}

\section{CLOTILDE BOITARD}

Doctorante, laboratoire GRHIs (Groupe de Recherche d'Histoire) sous la direction de Michel Biard - université de Rouen - Normandie 


\section{Les jetons « au lion attaquant un loup » en France (fin XVI ${ }^{\mathrm{e}}$-début XVII ${ }^{\mathrm{e}}$ siècle)}

Jérôme Jambu

De rares jetons ${ }^{1}$ frappés dans le royaume de France à la fin du $\mathrm{XVI}^{\mathrm{e}}$ et au début du $\mathrm{XVII}^{\mathrm{e}}$ siècle, dont les plus nombreux et les plus beaux exemplaires sont conservés au Département des Monnaies, médailles et antiques de la Bibliothèque nationale de France, présentent sur un côté - le revers - une très belle scène de combat animal entre un fauve et un canidé (fig. 1), réalisé par un graveur habile mais inconnu, toujours reprise à l'identique ${ }^{2}$. Ils constituent une série de onze pièces qui n'a jamais été cataloguée et dont l'original motif n'a pas été expliqué, ou alors de façon plus ou moins fantaisiste. Pourtant, neuf entités institutionnelles et personnages publics ont utilisé cette représentation entre 1586 et 1635 - à savoir la Cour des monnaies, les trésoriers de France et la municipalité de Rouen, les rois Henri III, Henri IV et Louis XIII, ainsi que les officiers Nicolas Le Camus, Nicolas de Harlay et un certain Guinot (cf. catalogue). Pourquoi chacun d'entre eux a-t-il utilisé, à des moments et dans des circonstances différentes, cette scène si particulière pour illustrer un jeton? 
Fig. 1. - Détail d'un jeton « au lion attaquant un loup. »

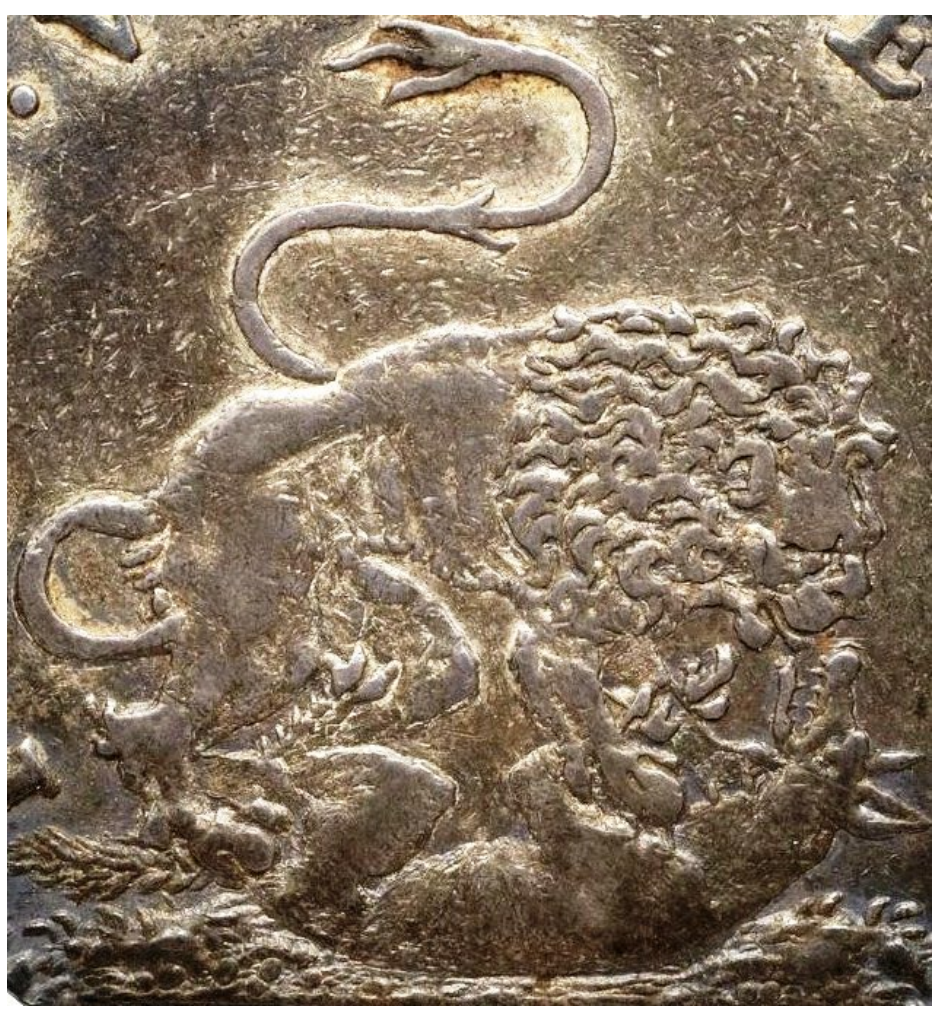

BNF, MMA, Jet 2636

\section{La lecture de la scène}

2 Pour répondre à cette question il convient, dans un premier temps, de bien décrire la scène et de la comprendre. Les numismates qui s'y sont essayés n'y ont pas vu la même chose, se contredisant parfois eux-mêmes. Sur le revers du jeton des trésoriers de France $\left(n^{\circ} 6\right)$, Félix Feuardent, grand collectionneur jetonophile du début du siècle dernier, voyait un «lion à droite, dévorant un renard ». S'il considérait cette scène comme satirique - nous reviendrons plus loin sur l'explication qu'il y apportait - il ne la décrivait pas de la même façon sur les autres jetons qui la présentent. Ainsi le lion figurait-il «terrassant un renard ou un loup » sur celui de la Cour des monnaies $\left(n^{\circ} 1\right)$ puis «égorgeant un renard» sur celui de Nicolas Le Camus $\left(n^{\circ} 3\right)$ mais «égorgeant un loup » sur celui de Nicolas de Harlay $\left(n^{\circ} 4\right)$. Il était encore «tenant sous lui un loup terrassé » $\left(n^{\circ} 10\right)$ ou « terrassant et dévorant un loup » $\left(n^{\circ} 11\right)$. C'est donc finalement, en nombre d'occurrences, le loup qui l'emportait sur le renard chez cet auteur. Le docteur érudit Pierre Corre, reprenant largement les descriptions de Feuardent près d'un siècle plus tard, était quant à lui partagé entre "lion dévorant un renard » ( $\left.n^{\circ} 11\right)$, «lion égorgeant un loup » $\left(n^{\circ} 4\right)$ ou « lion égorgeant un renard » $\left(n^{\circ} 3\right)$. Hésitant entre loup et renard, il optait cependant pour une scène de mise à mort. Henri de La Tour, bibliothécaire ayant rédigé plusieurs catalogues des jetons du Cabinet des médailles à l'articulation des $\mathrm{XIX}^{\mathrm{e}}$ et $\mathrm{XX}^{\mathrm{e}}$ siècles, avait vu soit un «lion tenant sous lui un loup terrassé » $\left(n^{\circ} 10\right)$, soit un "lion terrassant un renard» $\left(n^{\circ} 2\right)$ : il ne tuait donc pas le canidé, mais était incapable de trancher pour savoir duquel il s'agissait. Récemment 
MM. Sarmant et Ploton-Nicollet étaient plus affirmatifs en décrivant un renard terrassé (n 1 et 4$)$.

3 L'identification de l'animal victime du lion à un loup est selon nous certaine. La taille et la musculature de l'animal, ainsi que la forme et l'ouverture de sa gueule, plaident en faveur de cette lecture. On dispose en fait ici d'une représentation assez proche du loup héraldique, telle que celle qui figure, par exemple, sur les armoiries d'un Foulques d'Agoust $^{3}$ (fig. 2), bien qu'en la circonstance il ne soit pas lampassé mais montre les crocs. Pour un renard, on aurait attendu une figure plus courte et trapue, avec un ventre moins creusé et une queue plus large. De plus, la confrontation entre le loup et le lion, dans une scène de combat manichéenne, est ancienne et traditionnelle. C'est ainsi par exemple que l'on a représenté l'assassinat du duc Louis d'Orléans par le duc de Bourgogne Jean Sans Peur dans la Justification de Jean Petit ${ }^{4}$ (fig. 3). Van Clève et Raon offriront plus tard, à la fin du XvII ${ }^{e}$ siècle, une superbe interprétation de lion terrassant un loup pour une fontaine des jardins du château de Versailles (fig. 4). On peut préciser que le lion terrasse le loup, mais que la scène n'est pas encore entrée dans la phase suivante de mise à mort : les gueules sont ouvertes et les griffes sorties mais point de coup de patte fatal ou de morsure procédant d'un égorgement. C'est ainsi la première description connue, la plus ancienne et pratiquement contemporaine qui nous satisfait le mieux, celle de Jacques de $\mathrm{Bie}^{5}$ :

«Le corps est d'un grand et puissant lion, qui attire sous soi un loup lequel il déchire avec ses griffes, en intention et comme dans l'action de le vouloir dévorer, quelque résistance qu'il puisse faire. $»^{6}$

On ajoute que l'époque se prête à l'identification de ce nuisible: l'animal était alors particulièrement dangereux et mortifère?

Fig. 2. - Loup héraldique au $x \mathrm{Vl}^{\mathrm{e}}$ siècle.

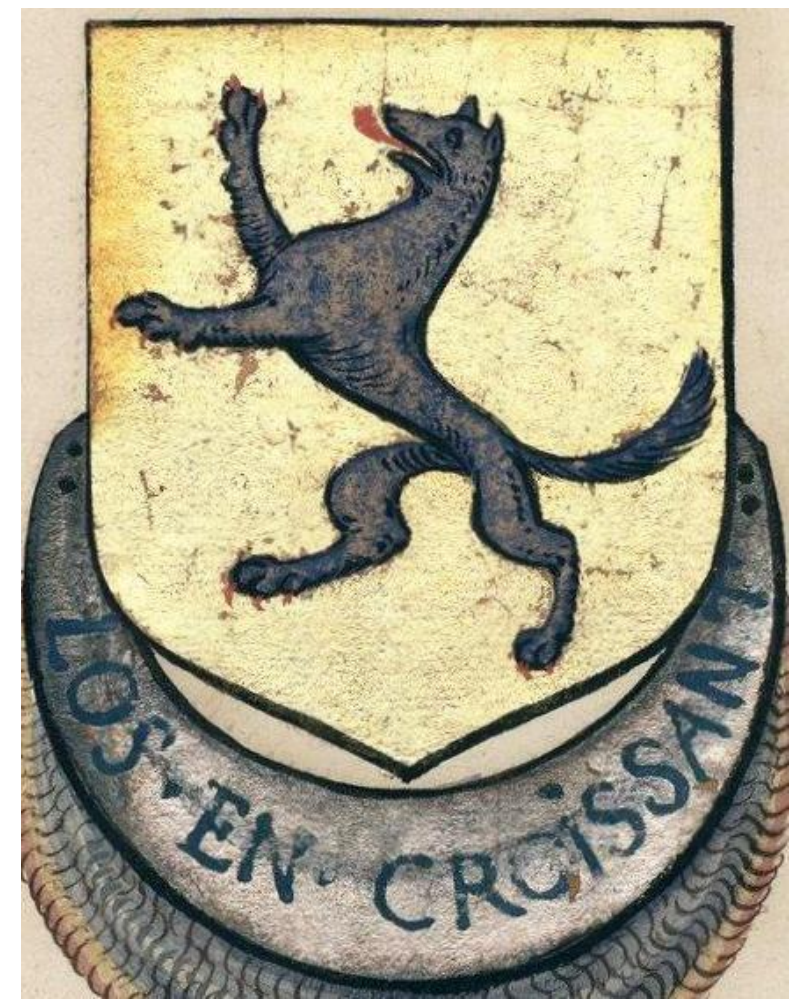

BNF ms. fr. 5225 
Fig. 3. - Scène de combat entre un lion et un loup - Enluminure, $x V^{e}$ siècle.

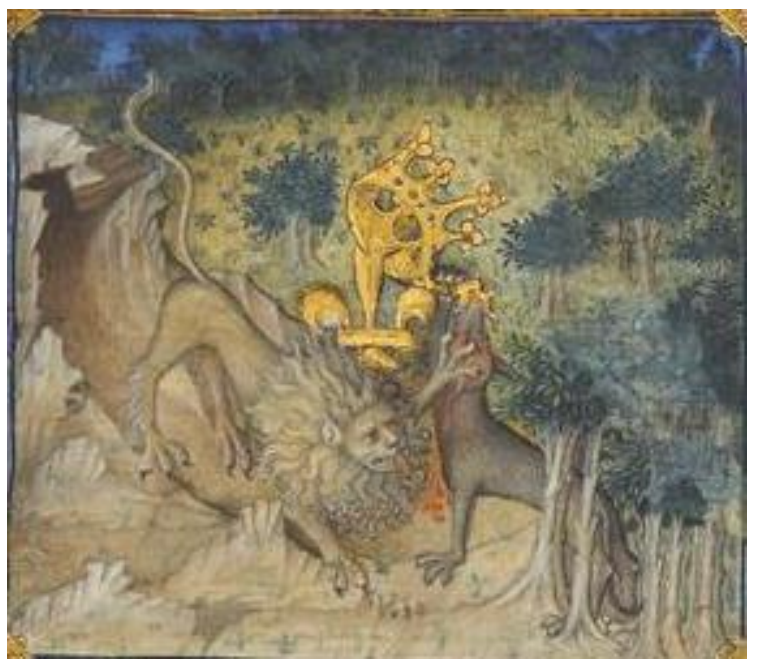

Musée Condé, ms. 878.

Fig. 4. - Scène de combat entre un lion et un loup - Sculpture, XVII siècle.

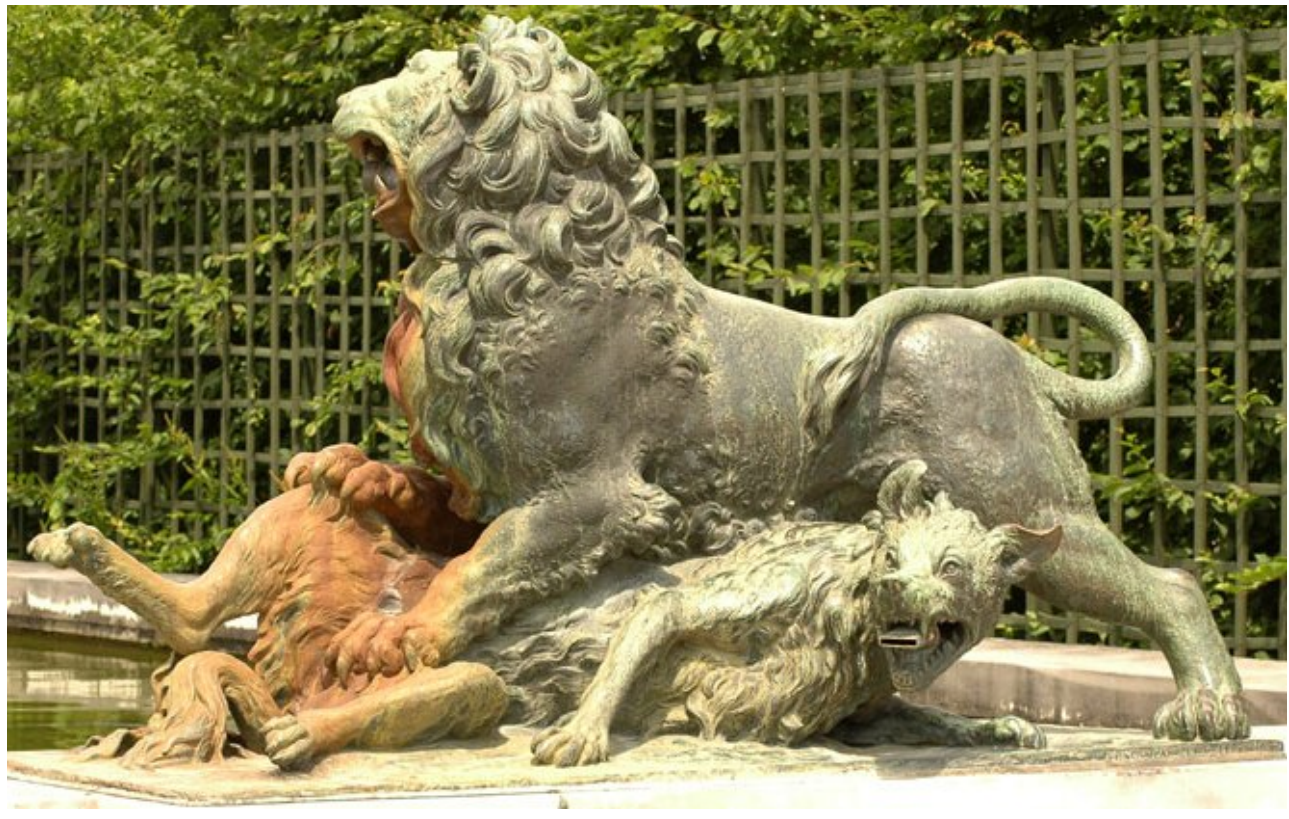

Versailles, Fontaine du Soir.

5 Le second aspect sur lequel nous devons nous arrêter pour comprendre cette scène est sa légende. Quel que soit l'émetteur ou la date du jeton, elle demeure invariablement la même, n'étant jamais modifiée, ni remplacée. Elle est constituée de trois mots : FRAVS VIRTVTE PERIT. MM. Sarmant et Ploton-Nicollet rappellent que cet "hémistiche de pentamètre» est inspiré d'« un détournement d'Ovide»: FRAVDE PERIT VIRTVS (Fastes, 2, 227), «la ruse triomphe de la vaillance $»^{8}$. Ils traduisent en conséquence la devise des jetons par «la ruse est mise à mort par la vaillance.» Proche est la traduction de MM. Broder et Desnier : « la ruse est vaincue par la bravoure $»^{9}$. C'est sans doute cette notion de ruse qui les a fait adhérer à l'idée que l'animal vaincu était forcément un renard ${ }^{10}$, bien que les deux canidés puissent y être associés à l'époque 
moderne. Dès lors l'association de la scène et de la légende fait sens : il s'agit d'illustrer un combat où le courage l'emporte sur la machination. Une autre traduction, celle de l'héraldiste Henri de Limiers, au début du XviII ${ }^{\mathrm{e}}$ siècle, permet d'envisager un autre cadre d'utilisation. Selon lui, on doit comprendre « la valeur victorieuse de la fraude $»^{11}$. Cette traduction éloignée témoigne des glissements de sens que l'on avait l'habitude d'opérer afin de faire correspondre des mots intelligibles à des expressions savantes, mais difficilement compréhensibles. Ainsi FRAVS, la ruse en latin, glisse-t-elle pour devenir, grâce à sa forme visuelle, «la fraude » en français et VIRTVTE, la force en latin, devient «la vertu» en français. Notre scène peut donc également illustrer une lutte morale.

\section{Plusieurs utilisations, plusieurs interprétations}

\section{La première série de 1586 : un discours fiscal et moral}

6 Les premiers jetons frappés au motif du « lion attaquant un loup » datent de 1586. Selon toute logique et une pratique rodée de réutilisation des carrés et des poinçons à des destinations différentes, le premier des cinq qui furent frappés cette année-là est très certainement celui de la Cour des monnaies $\left(n^{\circ} 1\right)$, pour laquelle ce motif a été créé ; puis ce revers remarquable et remarqué a été utilisé pour le roi $\left(n^{\circ} 2\right)$; enfin, deux officiers $\left(n^{\circ} 3\right.$ et 4$)$ et une ville $\left(n^{\circ} 5\right)$ ont pu choisir de l'utiliser. Selon Feuardent qui tente de l'expliquer, la scène, sur le jeton de la Cour des monnaies, renvoie à la situation en Flandre et plus particulièrement à Breda, sans argumentation. On a plusieurs raisons de s'opposer à cette interprétation. D'abord parce que l'on voit mal pourquoi un haut fait d'armes ayant eu lieu en 1581 serait célébré seulement en 1586 . Si des événements ayant opposé victorieusement les Espagnols catholiques aux Néerlandais protestants en 1585-1586 avaient dû l'être, il se serait plutôt agi du siège d'Anvers ou des batailles de Boksum et de Zutphen. Ensuite, si le parti ligueur et ultracatholique l'emportait alors dans la capitale, laissant envisager une certaine liesse à l'annonce de ces victoires, on comprend mal pourquoi la Cour des monnaies serait allée jusqu'à célébrer des événements étrangers. Il suffit, pour comprendre son choix, de regarder son histoire propre. L'institution était la garante de la «bonne monnaie ", à un moment où les troubles politico-religieux conduisaient à sa déliquescence. Fin 1585début 1586, la Cour instruit les poursuites qui mènent - mesure exceptionnelle - à la fermeture de la Monnaie de Montpellier pour avoir produit de la fausse monnaie sous la férule du duc de Montmorency, gouverneur du Languedoc en rupture de ban ${ }^{12}$. Par ailleurs, au cours de l'automne 1586, elle participe à l'interdiction des monnaies rognées et à la poursuite des rogneurs, plaie récurrente ${ }^{13}$. Voilà deux dossiers de «fraude ", s'il en est, à laquelle sa "vertu » s'est attaquée : les officiers de la Cour des monnaies incarnés par le lion comptent bien écraser, comme c'est leur rôle judiciaire, les faux-monnayeurs et/ou billonneurs incarnés par le loup.

7 Présenter au roi un tel rendu est habituel et c'est l'objet de son jeton $\left(n^{\circ} 2\right) . V u$ les difficultés que connaissait Henri III à cette époque, tiraillé entre les partis, un revers agressif pour affirmer sa puissance n'était pas malvenu. Nicolas Le Camus fut reçu conseiller de la Cour des monnaies sur résignation de Jacques Colas le 12 septembre $1585^{14}$. Il est manifeste qu'il eut le désir de faire frapper un jeton à son nom pour célébrer sa nouvelle fonction. Sa fabrication eut lieu dans les mois qui suivirent, au 
cours de l'année 1586, comme en témoigne l'utilisation du revers à ce millésime. Il en est de même pour Nicolas de Harlay, peut-être nouvellement magistrat à la Chambre des comptes ${ }^{15}$. Cette scène a enfin été choisie par la ville de Rouen pour son jeton annuel. C'est plus difficile à comprendre. Sans doute la municipalité lui octroyait-elle un sens particulier, mais lequel? Dans son histoire, on relève que l'année 1586 fut marquée par une crise de subsistance. À cette occasion, plusieurs boulangers et marchands furent punis pour avoir spéculé ${ }^{16}$. Cette année-là également, plusieurs fauxmonnayeurs furent pendus ${ }^{17}$. Que ce soit pour illustrer l'une ou l'autre affaire, la scène et sa légende peuvent trouver tout leur sens, un sens très proche de celui de la Cour des monnaies, qui explique que ce revers ait été proposé aux échevins décideurs.

\section{La seconde série de 1598 : célébrer la victoire d'un roi belliqueux}

8 La scène du «lion attaquant un loup » est abandonnée puis utilisée une douzaine d'années plus tard par les trésoriers de France $\left(n^{\circ} 6\right)$ et pour Henri IV $\left(n^{\circ} 7\right.$ à 9$)$. Nous pensons que c'est une commande des premiers qui l'a faite exhumer, ce corps d'officiers de finances étant certainement à la recherche, cette année-là, d'une composition illustrant la répression de la fraude dont il était acteur. Selon Feuardent, le choix de ce motif par les trésoriers serait lié «à l'impopularité de Robert Dudley, duc de Leicester, qui est représenté par le renard ${ }^{18} »$; il ne l'explique pas et se contente de reprendre une attribution fantaisiste belge du $\mathrm{XIX}^{\mathrm{e}}$ siècle $^{19}$. Que le lord fut vilipendé outre-Manche, c'est incontestable, d'autant que cet amant de la reine Élisabeth I ${ }^{\text {ère }}$ avait participé à la campagne des Pays-Bas aux côtés de Provinces-Unies en 1585 et commandé l'escouade anglaise contre l'Invincible Armada en 1588. Mais, là encore, pourquoi les trésoriers de France l'auraient-ils moqué sur leur jeton dix ans après sa mort? C'est à nouveau donner trop d'écho au parti espagnol. Et c'est à nouveau l'histoire de l'institution, chargée de remplir le Trésor royal, qui nous éclaire. La paix revenue, débutent des inspections en 1598, pilotées par des commissaires enquêteurs, afin de faire entrer l'argent des impôts dans les caisses. Il s'agit de les «égaliser, poursuivre les exactions, concussions et malversations de toutes sortes $»^{20}$. En quelque sorte, faire rendre gorge aux fraudeurs. On reste donc dans le même registre de la morale opposant fraude et vertu dans la matière économico-financière. Le lion représente le fisc et le loup les fraudeurs fiscaux.

9 Les trois jetons d'Henri IV font en revanche l'unanimité chez tous les auteurs et nous croyons qu'il faut les rejoindre. La scène prend désormais un tout autre sens et une tout autre dimension, plus politique. C'est le roi qui y joue le rôle du lion tandis que l'Espagnol y fait celui du loup. Selon Feuardent, le droit du $n^{\circ} 9$ "a été frappé en mémoire de la reprise de la ville d'Amiens par Henri IV $»^{21}$, à quoi on ajoute que ce fut fort probablement après la paix de Vervins (2 mai 1598). Il reprend en cela La Tour ${ }^{22}$, qui cite Jacques de Bie au sujet du ${ }^{\circ} 8$ :

"Sous l'exergue: M. D XC VIII (1598). Qui fait voir clairement que le monument a esté donné à la postérité pour un second ressouvenir de la prise d'Amiens, et pour marquer qu'ayant esté surpris par un stratagème et ruse de guerre, il fut reconquis à force ouverte par l'invincible courage et magnanimité du monarque. ${ }^{23}$

Près d'un siècle plus tard, Limiers faisait le même rapprochement : 
« Rarement la ruse réussit-elle contre la véritable valeur. L’Espagnol avait agi en loup dans le stratagème qui le rendit maître d'Amiens. Henri IV en usa en lion pour le reprendre. Il serra le loup de si près, qu'il ne put lui échapper. C'est ce que l'on voit sur la médaille ${ }^{24}(.$.$) , où ce prince est représenté sous la figure d'un lion, tenant$ un loup terrassé entre ses griffes. $»^{25}$

11 C'est effectivement par "ruse », par "stratagème » que l'armée espagnole se rendit maîtresse de la ville d'Amiens le 11 mars 1597 : des soldats déguisés en paysans venus y vendre des noix y avaient pénétré. D'ailleurs, les historiens ne nomment-ils pas cet épisode « la surprise d'Amiens » ? Le roi y répondit par un effort de guerre considérable à la hauteur de la menace et obtint la capitulation de la ville le 19 septembre ${ }^{26}$. C'est la force - du lion - qui écrasa la vilénie - du loup. C'est cette interprétation qui a dû faire songer a posteriori Feuardent et ses suiveurs à une utilisation politique et ciblée de la scène en 1586, avec une lecture exclusivement pro-espagnole et antiprotestante; lecture qui se serait inversée 12 ans plus tard en raison de l'évolution du contexte politique.

12 La réapparition du loup dans une série datée de 1598-1599, au-delà de sa dimension symbolique, trouve un écho dans l'histoire même de la bête. C'est justement à cette extrême fin de $\mathrm{XVI}^{\mathrm{e}}$ siècle que les attaques de canis lupus sont en recrudescence, le conflit ensanglantant le royaume ayant favorisé son anthropophagie, au point que « le quinquennat 1596-1600 s'affirme comme l'un des plus sombres que tout l'Ancien Régime ait connu ${ }^{27}$ ». Ainsi le roi accorde-t-il de nombreux brevets de chasse au moment même où sont frappés ces jetons. L'apparition de la scène, en 1586, n'est sans doute pas un hasard non plus : le loup inquiétait déjà sérieusement et le roi prenait des dispositions pour le détruire dans un édit de 1583. Les graveurs et les commanditaires de jetons devaient être sensibilisés à ce douloureux contexte.

Pourtant, si l'interprétation du thème ne fait guère de doute, c'est bien la seule série où le canidé pourrait être identifié à un renard! En effet, le roi d'Espagne était alors Philippe II. Or c'est bien du surnom de «vieil renard», parmi d'autres, qu'il était affublé en France. Cette appellation est par exemple avérée dans le célèbre libelle la Satyre Ménipée, écrit et diffusé à Paris en 1593-1594 afin de dénoncer les excès de la Ligue et les prétentions des Espagnols, alors que la guerre faisait rage. Dans ces circonstances, c'est bien à l'animal rusé qu'il était fait référence, comme c'est en prince de Machiavel qu'il était dépeint ${ }^{28}$.

\section{La dernière série de 1635 : une incantation}

La scène est à nouveau mise à l'honneur, 37 ans plus tard, pour le roi Louis XIII, dans un jeton non daté mais millésimé 1598 puisqu'il en reprend le revers sans modification $\left(\mathrm{n}^{\circ} 10\right)$. La mémoire de la série précédente a été conservée, car le jeton $\mathrm{n}^{\circ} 8$ est publié par Jacques de Bie en 1636. C'est de cette époque que nous proposons donc de dater le $\mathrm{n}^{\circ} 10$, c'est-à-dire du début de la guerre ouverte avec l'Espagne, commencée en 1635 . C'est ainsi sur le souvenir du dernier grand fait d'armes victorieux de la dernière guerre avec le Roi Catholique que s'ouvre le nouveau conflit, avec une résonance particulière puisqu'Amiens est à nouveau immédiatement et directement menacée par la prise de Corbie. Aucun élément ne nous permet en revanche d'expliquer le choix de cette scène, au même moment, par le sieur Guinot, de Champagne $\left(n^{\circ} 11\right)$; mais la situation de ses fiefs à proximité du front et sa vraisemblable participation au ban doit 
induire une motivation comparable. On note que, là encore, la corrélation entre réutilisation de cette thématique et reprise des attaques de loups est manifeste. Après une trentaine d'années de calme relatif, c'est bien au milieu des années 1630 qu'elles enflent à nouveau, liées à la guerre qui a suscité la fabrication de ces nouveaux jetons ${ }^{29}$.

La conception de jetons nouveaux passait souvent par la réutilisation de poinçons et de carrés anciens qui avaient eu leur succès ou n'étaient pas trop usés pour être réutilisés. C'était tant mieux, car la réalisation d'un nouveau motif par un graveur chevronné et la fabrication de matériel de frappe était coûteuse, tandis que la demande était importante et le renouvellement difficile. Ce motif esthétique et original de scène animalière et violente révèle qu'une même scène pouvait revêtir un sens différent selon son commanditaire, fût-il de plus en plus éloigné de son sens initial. On envisage dès lors un monde où, sensibilisé par un contexte singulier, l'on commandait son jeton selon son goût et l'on choisissait parmi les modèles présentés par les graveurs, ou qui avaient été vus et plaisaient. La datation, l'association à une institution ou à un personnage particulier et la distribution dans un certain cercle devaient le rendre intelligible aux récipiendaires. Les sources relatant les réflexions présidant au choix d'un jeton ont très souvent disparu, mais l'observation et l'analyse d'un tel corpus permet de les aborder et de les comprendre un peu.

\section{Catalogue}

Fig. 5. - Jeton 1 droit et revers.
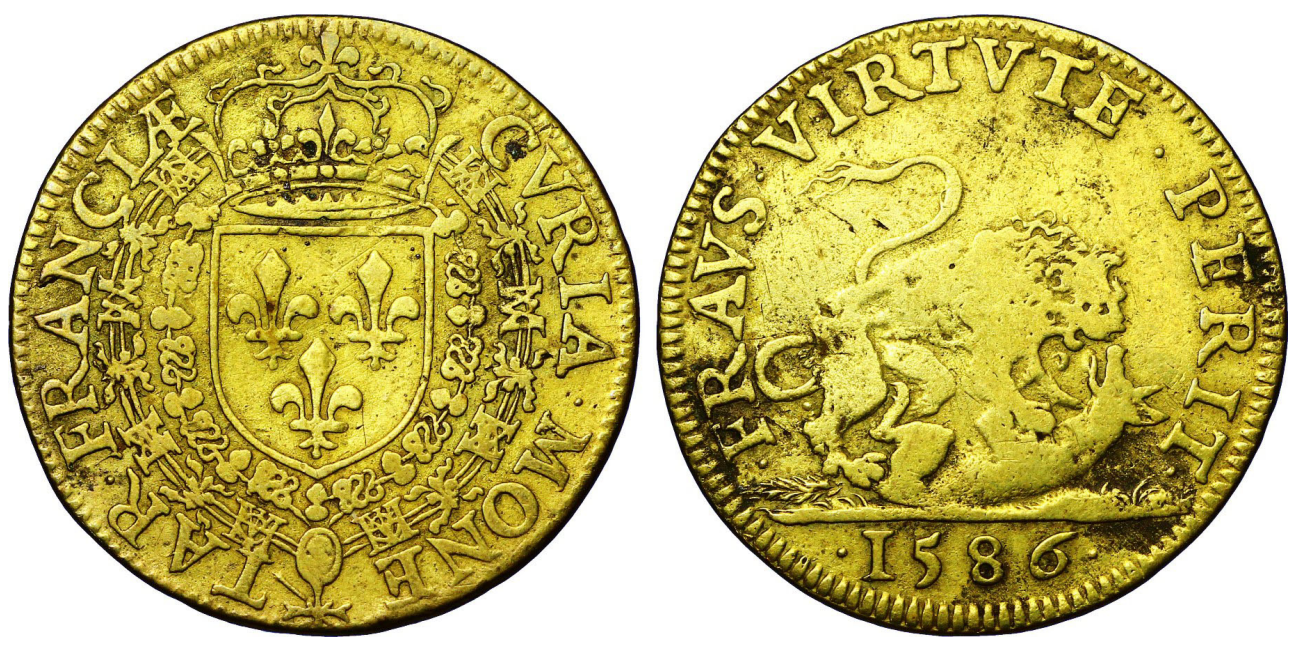

\section{Cour des monnaies, 1586 (fig. 5)}

D/CVRIA • MONE TAR - FRANCIAE (légende débutant à 12 heures) (Cour des monnaies de France) Ecu de France couronné et entouré des colliers des Ordres de Saint-Michel et du Saint-Esprit.

$\mathrm{R} / \cdot \mathrm{FRAVS} \cdot \mathrm{VIRTVTE} \cdot \mathrm{PERIT} \cdot$ Un lion s'attaquant à un loup couché sur le dos. $・ 1586 \cdot a ̀$ l'exergue. 
18 - Bimétallique cuivre/laiton, 5,84 g, $28 \mathrm{~mm}$. Feuardent 2166 var. $^{30}$; Sarmant PlotonNicollet 2443. 2 ex. connus, BNF, MMA, Rouyer 2875 et Musée de la Monnaie (cf. Broder, Desnier).

19 - Laiton ${ }^{31}$, 4,47-5, 28 g, 28 mm. Feuardent 2166 ${ }^{32}$; Sarmant, Ploton-Nicollet 2444-2446B. 4 ex. BNF, MMA, dont Rouyer 2876 ; 1 ex. CGB E-auction 112-59977 (fjt_299695) (illustré).

Fig. 6. - Jeton 2 droit et revers.
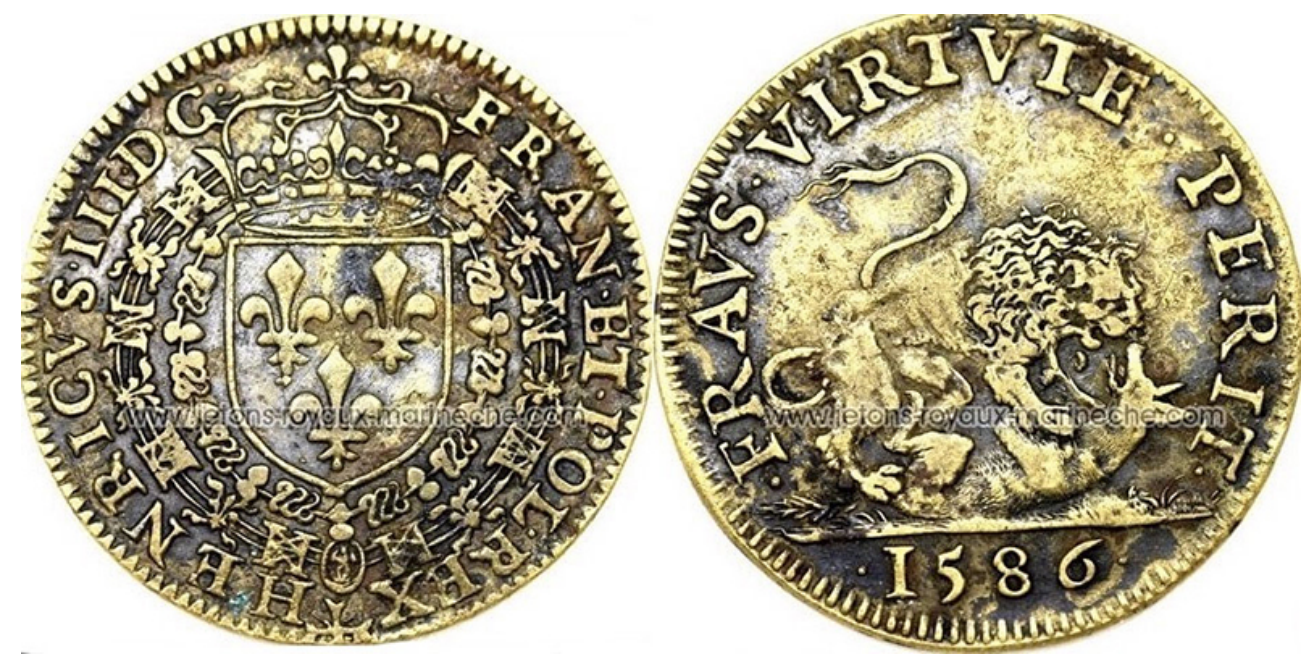

\section{Henri III, 1586 (fig. 6)}

$\mathrm{D} / \mathrm{HENRICVS} \cdot \mathrm{III} \cdot \mathrm{D} \cdot \mathrm{G} \bullet \mathrm{FRAN} \cdot \mathrm{ET} \cdot \mathrm{POL} \cdot \mathrm{REX}$ (légende débutant à 6 heures) (Henri III par la grâce de Dieu roi de France et de Pologne) Ecu de France couronné et entouré des colliers des Ordres de Saint-Michel et du Saint-Esprit.

R/• FRAVS • VIRTVTE • PERIT • Un lion s'attaquant à un loup couché sur le dos. • 1586 • à l'exergue.

22 - Laiton, $\pm 5 \mathrm{~g}, 28 \mathrm{~mm}$. Manque aux ouvrages de référence hors catalogue. $1 \mathrm{ex}$. BNF, MMA, Rouyer $1969 ; 1$ ex. coll. Marineche (illustré).

Fig. 7. - Jeton 3 droit et revers.

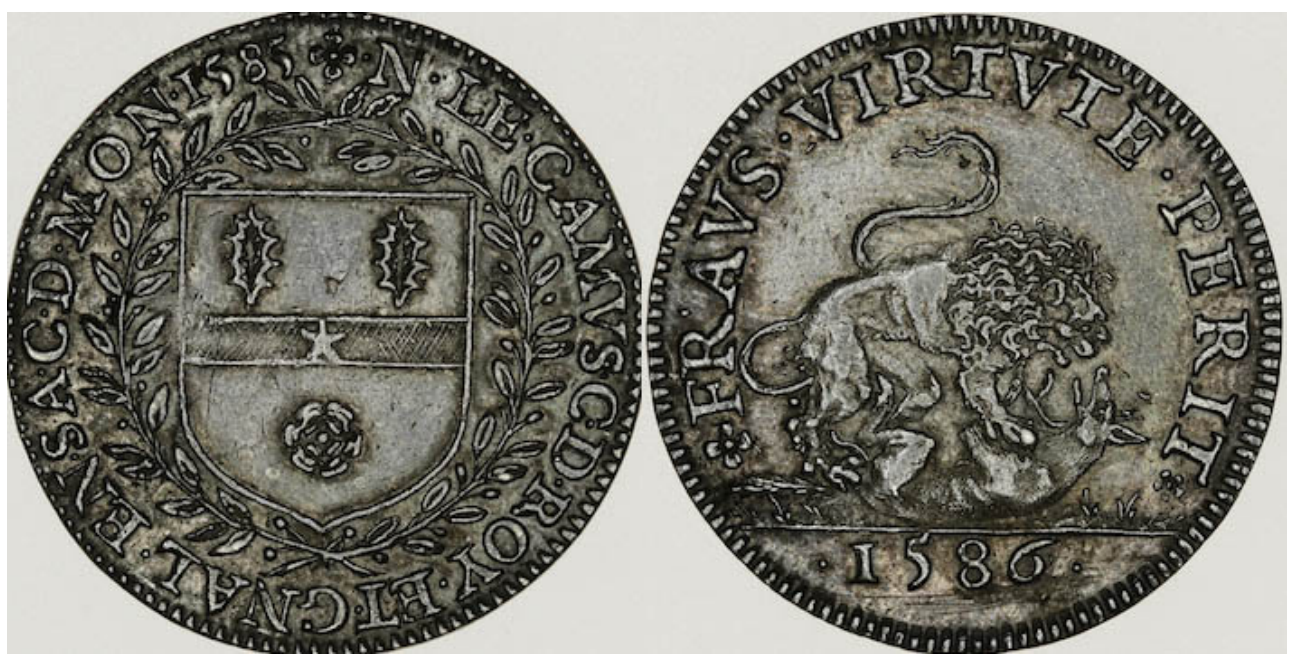




\section{Nicolas Le Camus, conseiller de la Cour des monnaies, (1585)} 1586 (fig. 7)

$\mathrm{D} /($ Fleur) $\mathrm{N} \cdot \mathrm{LE} \cdot \mathrm{CAMVS} \cdot \mathrm{C} \cdot \mathrm{D} \cdot \mathrm{ROY} \cdot \mathrm{ET} \cdot \mathrm{GNAL} \cdot \mathrm{EN} \cdot \mathrm{SA} \cdot \mathrm{C} \cdot \mathrm{DE} \cdot \mathrm{MON} \cdot 1585$ (légende débutant à 12 heures) (Nicolas Le Camus conseiller du roi et général en sa Cour des monnaies) Ecu à ses armes, entouré de deux palmes. R/(Fleur) FRAVS • VIRTVTE • PERIT (fleur) Un lion s'attaquant à un loup couché sur le dos. 1586 à l'exergue.

24 - Argent, 4,66 g, $28 \mathrm{~mm}$. Feuardent 2251 var. ; Corre 2809 var. ${ }^{33} 1$ seul ex. connu, BNF, MMA, JF 1088 (illustré).

25 - Laiton ${ }^{34}$, pds ? $28 \mathrm{~mm}$. Feuardent 2251; Corre 2809. NB : alors que les jetons précédents et suivants font usage d'un poinçon identique, celui-ci est légèrement différent, peutêtre simplement retouché : la queue du lion est plus courte et plus fine, sa crinière plus touffue et plus haute.

Fig. 8. - Jeton 4 droit et revers.
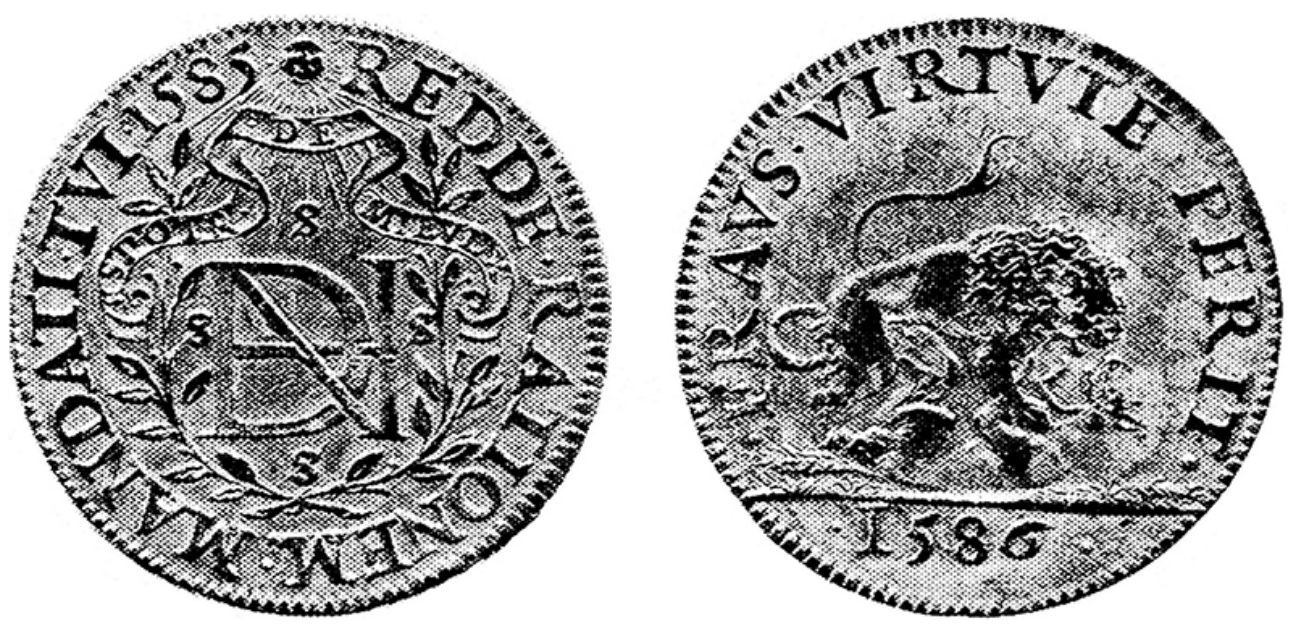

\section{Nicolas de Harlay ${ }^{35}$, conseiller de la Chambre des comptes ${ }^{36}$, Ile- de-France ${ }^{37}$, (1585) 1586 (fig. 8).}

D/REDDE • RATIONEM • MANDATI • TVI • 1585 • (légende débutant à 12 heures) (Rends compte de ta mission) Monogramme, entouré d'une couronne de laurier et de plusieurs $\mathrm{S}$ barrés, surmonté d'un phylactère avec inscrit ESPOIR DE MIEULX. $\mathrm{R} / \bullet$ FRAVS $•$ VIRTVTE $\bullet$ PERIT •Un lion s'attaquant à un loup couché sur le dos. • 1586 •à l'exergue.

- Laiton ${ }^{38}$, 6,45 g, 28 mm. Feuardent 5549 ; Corre 2314 ; Sarmant Ploton-Nicollet 2106. 1 ex. BNF, MMA, 96 bis-13 (illustré). 
Fig. 9. - Jeton 5 droit et revers.
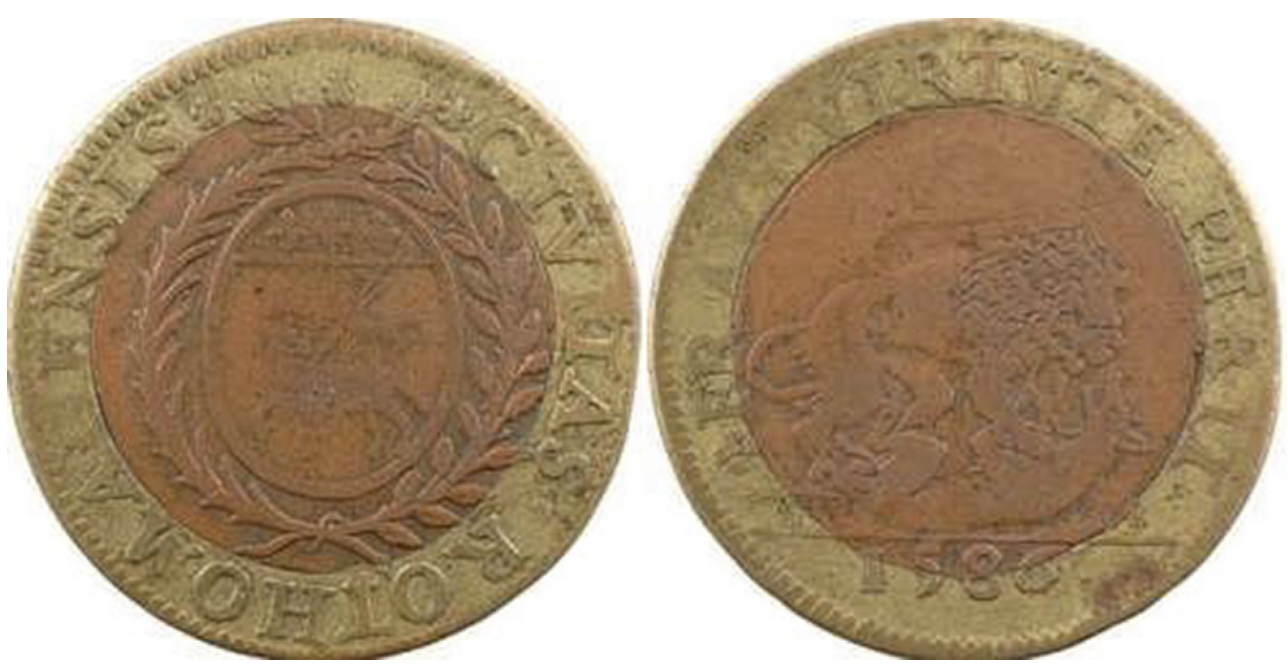

\section{Ville de Rouen, 1586 (fig. 9)}

D/(Fleur) CIVITAS • ROTHOMAGENSIS (fleur) (légende débutant à 12 heures) (La Cité des Rouennais) Ecu aux armes de Rouen, entouré d'une couronne formée d'une palme à gauche et d'un rameau de laurier ou d'olivier à droite.

R/FRAVS • VIRTVTE • PERIT Un lion s'attaquant à un loup couché sur le dos. • 1586 • à l'exergue.

31 - Bimétallique, cuivre/laiton, 4,85 g, $28 \mathrm{~mm}$. Manque à tous les ouvrages de référence (cf. Weil, Pastoureau). 2 ex. connus, BNF, MMA (non vidi, non coté ? ${ }^{39}$ ) et Inumis, VSO 30 , 14 octobre $2015, \mathrm{n}^{\circ} 1352$ (illustré).

Fig. 10. - Jeton 6 droit et revers.

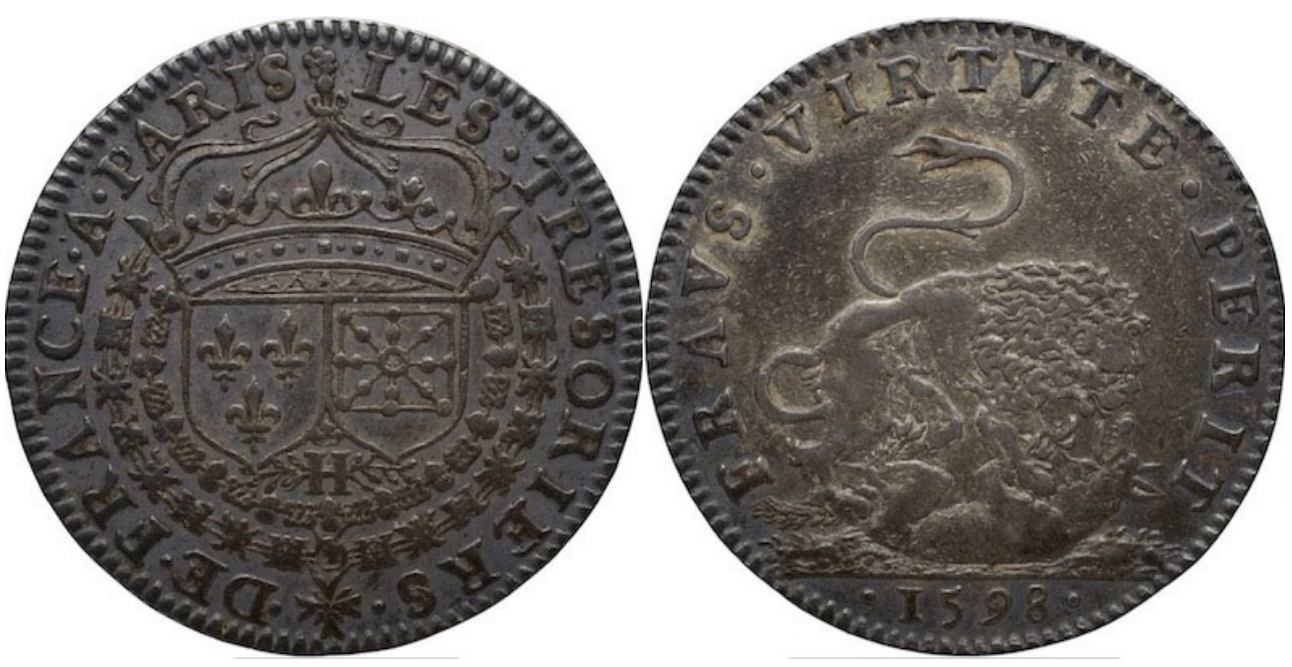




\section{Trésoriers de France, 1598 (fig. 10)}

D/(fleur) LES • TRÉSORIERS $・ \mathrm{DE} \cdot \mathrm{FRANCE} \cdot \mathrm{A} \cdot \mathrm{PARIS}$ (légende débutant à 12 heures) Deux écus de France et de Navarre accolés, un $\mathrm{H}$ en dessous, couronnés, entourés des colliers des Ordres de Saint-Michel et du Saint-Esprit.

R/FRAVS • VIRTVTE • PERIT Un lion s'attaquant à un loup couché sur le dos. • 1598 • à l'exergue.

34 - Argent, 5,06 g, $28 \mathrm{~mm}$. Feuardent 2015 var. ${ }^{40} 1$ seul ex. connu, BNF, MMA, Jet 2636 (illustré).

35 - Laiton ${ }^{41}$, 5,92 g, 28 mm. Feuardent 2015. 1 ex. CGB fjt_223678 ; 1 ex. coll. privée.

Fig. 11. - Jeton 7 droit et revers.
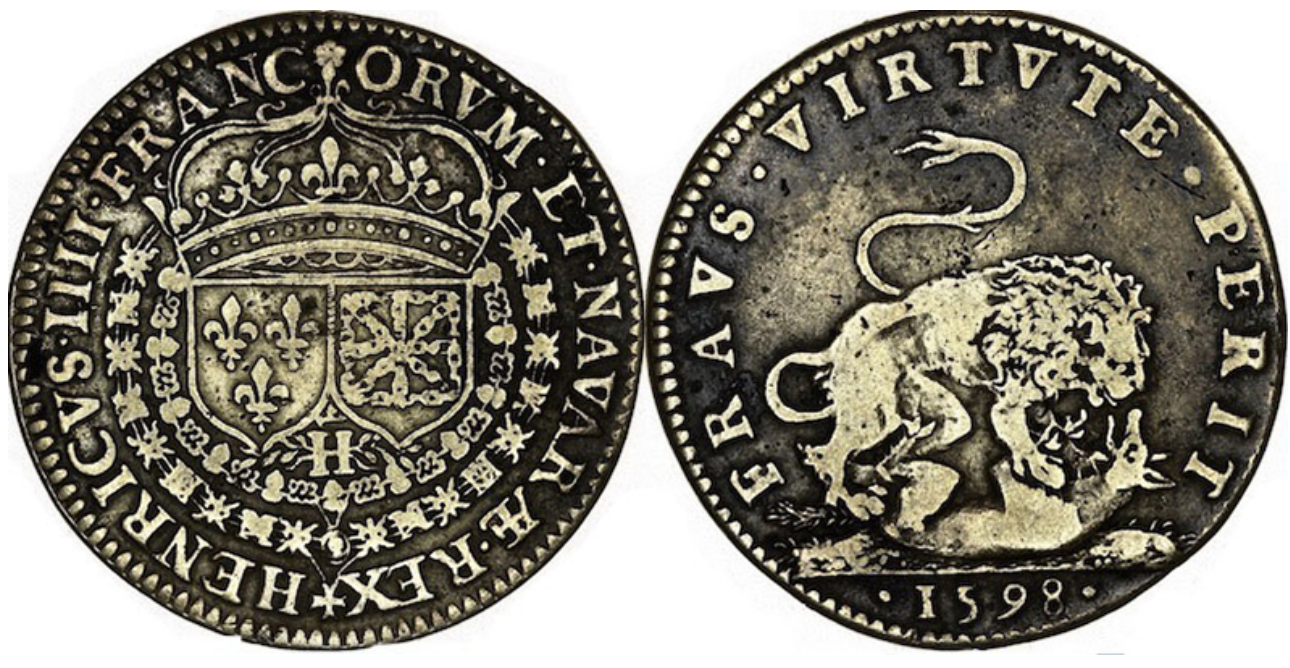

\section{Henri IV, Prise d'Amiens, 1598 (fig. 11)}

D/(Croix) HENRICVS ・ IIII • FRANCORVM • ET • NAVARAE • REX (légende débutant à 6 heures) (Henri IV roi des Francs et de Navarre) Écus de France et de Navarre accolés, un $\mathrm{H}$ en dessous, couronnés, entourés des colliers des Ordres de Saint-Michel et du SaintEsprit.

R/FRAVS • VIRTVTE • PERIT. Un lion s'attaquant à un loup couché sur le dos. • 1598 •à l'exergue.

- Laiton, 5,61 g, 27,5 mm. Manque aux ouvrages de référence hors catalogue. 1 seul ex. connu, BNF, MMA, Rouyer 2013-201442 (illustré). NB : le droit de ce jeton présente le même motif que le précédent dont il ne diffère que par la légende.

\section{Henri IV, Prise d'Amiens, 1598}

$\mathrm{D} / \mathrm{HENRICVS} \cdot \mathrm{IIII} \cdot \mathrm{D} \cdot \mathrm{G} \cdot \mathrm{FRANC} \cdot \mathrm{ET} \cdot \mathrm{NAV} \cdot \mathrm{REX} \cdot \mathrm{CHRISTIANISS} \cdot$ (légende débutant à 12 heures ?) (Henri IV par la grâce de Dieu roi très chrétien de France et de Navarre). Buste du roi à droite lauré et cuirassé.

R/FRAVS • VIRTVTE • PERIT. Un lion s'attaquant à un loup couché sur le dos. • 1598 • à l'exergue. 
41 - Cuivre ou laiton? pds? diam.? De Bie, 259-260, XXIII-XXV; cf. Limiers p. 21 et 20, XXVII (seul le revers est illustré). Aucun exemplaire vu.

Fig. 12. - Jeton 8 droit et revers.
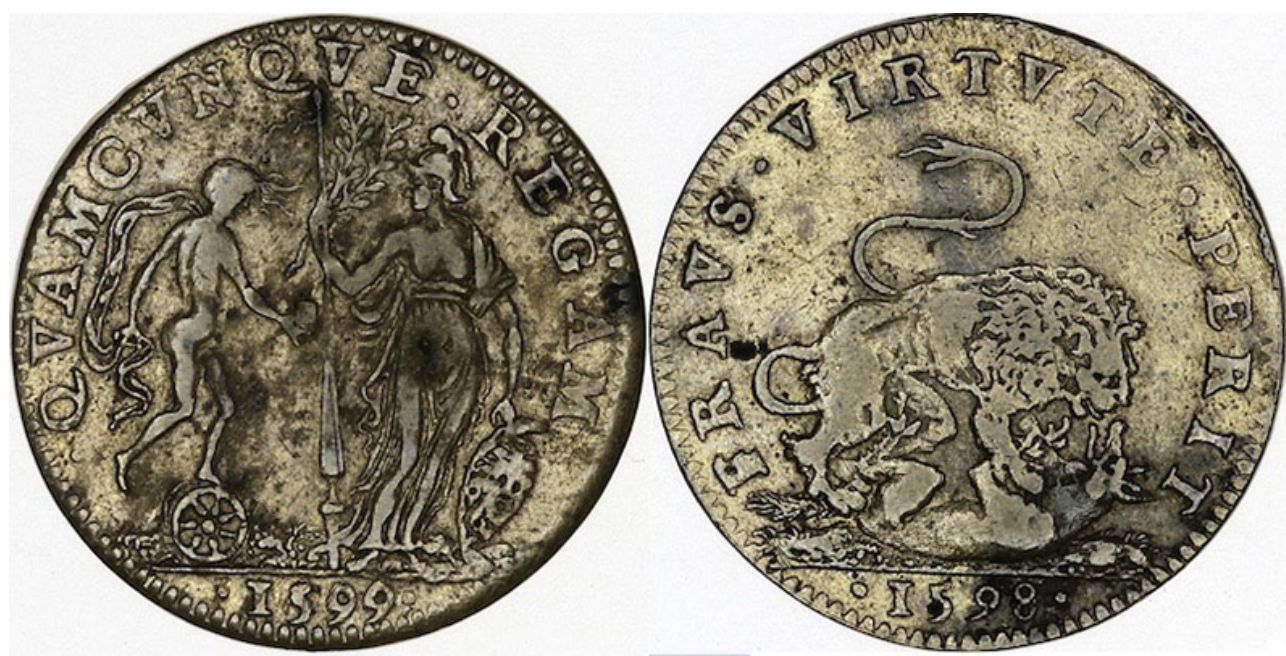

\section{Henri IV ${ }^{43}$ ou Marquisat de Vervins ${ }^{44}$, Prise d'Amiens et Paix de Vervins, (1598) $1599^{45}$ (fig. 12)}

D/QVACVMQUE $\cdot \operatorname{REGAM} \cdot 1599 \cdot$ (légende débutant à 6 heures) (Je conduirai tout) La fortune à droite debout sur une roue, présentant une palme à Minerve debout de face.

R/FRAVS • VIRTVTE • PERIT. Un lion s'attaquant à un loup couché sur le dos. • 1598 à l'exergue.

44 - Laiton, 9,45 g, 28 mm. Cf. Limiers p. 21 et 20, XXVII ; Feuardent 6676a. 1 seul ex. connu, BNF, MMA, LT 510 (illustré).

\section{Louis XIII, (1598) V. 1635-1636}

D/LVDOVICVS $\cdot \mathrm{XIII} \cdot \mathrm{D} \cdot \mathrm{G} \cdot \mathrm{FRANCORVM} \cdot \mathrm{ET} \cdot \mathrm{NAV} \cdot \mathrm{REX} \cdot$ (légende débutant à 12 heures ?) (Louis XIII par la grâce de Dieux roi des Francs et de Navarre) Écus de France et de Navarre accolés, entourés des colliers des Ordres de Saint-Michel et du SaintEsprit.

R/FRAVS • VIRTVTE • PERIT. Un lion s'attaquant à un loup couché sur le dos. • 1598 à l'exergue.

47 - Cuivre ou laiton, pds? $28 \mathrm{~mm}$. Feuardent 12 041. Aucun exemplaire vu depuis celui décrit par Feuardent.

\section{Guinot (Champagne), 1635}

D/Anépigraphe. Ecu à ses armes, entouré de deux palmes.

R/FRAVS • VIRTVTE • PERIT. Un lion s'attaquant à un loup couché sur le dos. 1635 à l'exergue. 

depuis celui décrit par Feuardent.

\section{BIBLIOGRAPHIE}

BABELON Jean-Pierre, Henri IV, Paris, Fayard, 1982.

BARRACHINA M.-A. et GÉRAUD M.-C., « L'esprit national », dans LESTRINGANT Franck et MÉNAGER Daniel, Études sur la Satyre Ménipée, Genève, Droz (Études de Philologie et d'Histoire 41), 1987, p. 227.

BIE (de) Jacques, La France métallique, contenant les actions célèbres tant publique que privées des rois et reynes, Paris, chez Jean Camusat, 1636.

BRODER M. et DESNIER Jean-Luc, « Contribution à l'étude des jetons bimétalliques, de Charles IX à Louis XIV », Bulletin de la Société Française de Numismatique, 50 année, nº 5, mai 1995, p. 1054-1058. DUGNIOLLE Jean-François, Le jeton historique des dix-sept provinces des Pays-Bas. Tome III : XVI et XVII siècles, Bruxelles, Fr. Gobbaerts, 1877.

CONSTANS Germain, Traité de la Cour des monnoyes et de l'estendue de sa jurisdiction, Paris, chez Sébastien Cramoisy, 1658.

CORRE Pierre, Corpus de jetons armoriés de personnages français, $2^{\mathrm{e}}$ éd., Paris, Le Léopard d'or, 1986. FEUARDENT Félix, Jetons et méreaux depuis Louis XI jusqu'à la fin du consulat de Bonaparte, Paris, Rollin et Feuardent éditeurs, 1907-1915, 4 vol.

LA TOUR Henri (de), Catalogue des jetons de la Bibliothèque nationale. Rois et reines de France, Paris, chez C. Rollin et Feuardent, $1897^{46}$.

LA TOUR Henri (de), Catalogue de la collection Rouyer. Deuxième partie : jetons \& méreaux de la Renaissance et des temps modernes, Paris, Ernest Leroux éditeur, $1910^{47}$.

LIMIERS Henri (de), Annales de la monarchie françoise depuis son établissement jusqu'à présent où l'on trouve [...] les médailles authentiques..., Amsterdam, chez L'Honoré et Châtelain, 1724.

MORICEAU Jean-Marc, Histoire du méchant loup. La question des attaques sur l'homme, $\mathrm{XV}^{e}-\mathrm{XX}^{e}$ siècle, Paris, Pluriel, 2016.

PASTOUREAU Michel, Traité d'héraldique, Paris, Picard, 2007.

PERIAUX Nicolas, Histoire sommaire et chronologique de la ville de Rouen, Rouen, Lanctin-Ch. Métérie, 1874.

SARMANT Thierry et PLOTON-NICOLLET François, Jetons des institutions centrales de l'Ancien Régime. 2. Juridictions, Paris, Bibliothèque nationale de France, 2012.

Satyre Menippee, de la Vertu du Catholicon d'Espagne et de la tenue des Estats de Paris, Martin Martial (édition critique de), Paris, H. Champion (Textes de la Renaissance, 117), 2007.

SCHRENCK Gilbert, Nicolas de Harlay, sieur de Sancy (1546-1629), l'antagoniste d'Agrippa d'Aubigné, Paris, Champion, 2000. 
WEIL Alain et PASTOUREAU Michel, «Les jetons bimétalliques français de XVI et XVII ${ }^{\mathrm{e}}$ siècles ", Numismatics witness to history, Wetteren, Moneta (IAPN, 8), 1986, p. 171-181 + pl. 34-35.

\section{NOTES}

1. Les jetons étaient des objets monétiformes destinés à servir pour le compte, le jeu, comme marque de présence et même comme carte de visite. En métal précieux, ils sont devenus des gratifications, offerts aux étrennes notamment. Ceux de la qualité de la série présentée étaient généralement produits à la Monnaie de Paris.

2. Il est remarquable que le même poinçon ait été utilisé pour chacun des jetons.

3. Armoiries des chevaliers de l'ordre du Croissant, institué par René d'Anjou (...) $\left(\mathrm{xVI} \mathrm{e}^{\mathrm{e}}\right.$ siècle). Bibliothèque nationale de France, ms. fr. 5225.

4. Plusieurs versions et copies sont connues ( $x v^{e}$ siècle). Citons parmi d'autres deux exemplaires conservés dans des collections publiques françaises: La Justification du duc de Bourgogne par Jean le Petit, Chantilly, musée Condé, ms.878 et Paris, Bibliothèque nationale de France, ms. fr. 5733.

5. Donnée pour le jeton $n^{\circ} 7$.

6. J. de Bie, La France métallique, p. 260.

7. Voir le chapitre « les loups : un quatrième fléau de l'Apocalypse (1570-1660) » de J.-

M. Moriceau, Histoire du méchant loup, p. 110-128.

8. T. Sarmant et F. Ploton-Nicollet, Jetons des institutions centrales de l'Ancien Régime, II, p. 192.

9. M. Broder et J.-L. Desnier, "Contribution à l'étude des jetons bimétalliques, de Charles IX à Louis XIV », p. 1056.

10. Cf. les Romans de renart des $\mathrm{XII}^{\mathrm{e}}$ et XIII ${ }^{\mathrm{e}}$ siècles.

11. Donnée pour le jeton $n^{\circ} 8$. H. de Limiers, Annales de la monarchie françoise, p. 21.

12. Lettres patentes pour la clôture de la Monoye de Montpellier et pour informer contre les officiers et monoyers qui y ont malversé, 7 octobre 1585 (CAEF, MdP, ms $4^{\circ} 146$ ) ; Ordonnance du roy sur le descry des doubles sols parisis faulx, nouvellement forgez en la Monnoye de Montpellier, Paris, 15 novembre 1585 (CAEF, MdP, ms $4^{\circ} 146$ et Paris, Vve N. Roffet, 1585); Lettres patentes qui décrient les doubles et simples parisis faux nouvellement forgez es Monoyes de Montpellier et Beaucaire, ouvertes de l'ordonnance du duc de Montmorency, maréchal de France, 23 mars 1586 (CAEF, MdP, ms $4^{\circ}$ 146).

13. Ordonnance du roy sur le descry des espèces d'or et d'argent légères et rongnées, Paris, 23 septembre 1586 (CAEF, MdP, ms $4^{\circ} 146$ et Paris, Vve N. Roffet, 1586); Déclaration du roy sur son édict du 23 septembre dernier, contenant le descry des monnoyes rongnées, SaintGermain-en-Laye, 13 octobre (CAEF, MdP, ms $4^{\circ} 146$ et Paris, Vve N. Roffet, 1586); Lettres patentes du roy contenant les défences de transporter hors le royaume de France ou esloigner de la plus prochaine Monnoye les espèces rongnées et descriées ny autres espèces et matières d'or, d'argent et de billon, Saint-Germain-en-Laye, 10 novembre 1586 (CAEF, MdP, ms $4^{\circ} 146$, ms $4^{\circ} 148$ et Paris, Vve N. Roffet, 1586).

14. G. Constans, Traité de la Cour des monnoyes, « liste des officiers », non paginée.

15. Voir G. Schrenk, Nicolas de Harlay, sieur de Sancy (1546-1629). 
16. N. Périaux, Histoire sommaire et chronologique de la ville de Rouen, p. 338.

17. Ibid., p. 339.

18. F. Feuardent, Jetons et méreaux, I, p. 164.

19. C'est étonnement comme jeton «des Pays-Bas» qu'est classé le $n^{\circ} 3134$ du catalogue de docteur Dugniolle, qui décrit pourtant la même scène et la même légende au droit, avec comme titre non justifié : «Impopularité du duc de Leicester.» La description du revers, incomplète, ne fait référence à aucun des jetons de notre catalogue mais sa légende (NIL NISI CONSILIO) renvoie sans aucun doute possible au Conseil du roi de France. Ce jeton n'est hélas pas illustré. On peut supposer qu'il s'agit d'une variante du jeton royal d'Henri III, ${ }^{\circ} 2$ 2. J.-F. Dugniolle, Le jeton historique des dixsept provinces des Pays-Bas, III, p. 75.

20. J.-P. Babelon, Henri IV, p. 748.

21. F. Feuardent, Jetons et méreaux, II, p. 55.

22. H. de La Tour, Catalogue des jetons de la Bibliothèque nationale, p. 102.

23. J. de Bie, La France métallique, p. 260, n XXV.

24. Appellation généraliste qui recouvre les jetons.

25. H. de Limiers, Annales de la monarchie françoise, p. 21.

26. J.-P. Babelon, Henri IV, p. 618-622.

27. J.-M. Moriceau, Histoire du méchant loup, p. 114-116.

28. M.-A. Barrachina et M.-C. Gomez-Géraud, « L'esprit national », p. 241-242.

29. J.-M. Moriceau, Histoire du méchant loup, p. 117-119.

30. Cet auteur ne connait pas la variété bimétallique, mais seulement celle en laiton.

31. Contrairement à ce qu'indique Feuardent, ces jetons sont en laiton plutôt qu'en cuivre.

32. Classé dans «Chambre des monnaies » alors qu'elle est devenue «Cour » en 1552.

33. Ces deux auteurs ne connaissent pas la variété en argent mais seulement celle en laiton.

34. Contrairement à ce qu'indique Feuardent, ces jetons sont en laiton plutôt qu'en cuivre.

35. Jeton attribué à Nicolas du Châtelet dans la vente de la collection Monnier. VE Rollin et Feuardent, collection de feu M. Monnier, Paris, 7-11 avril 1874, n $^{\circ} 1581$.

36. Classement institutionnel retenu par la BNF mais, comme le font judicieusement observer MM. Sarmant et Ploton-Nicollet, il « aurait sa vraie place parmi les jetons des particuliers » (T. Sarmant et F. Ploton-Nicollet, Jetons des institutions centrales de l'Ancien Régime, II, p. 161), proposition que nous retenons.

37. Classement retenu dans P. Corre, Corpus de jetons armoriés de personnages français, p. 216-217. Nicolas de Harlay, si ce jeton lui appartient, est effectivement membre d'une famille alors implantée en Île-de-France (mais peut-être issue de Bourgogne), né et mort à Maule (actuelles Yvelines).

38. Contrairement à ce qu'indique Feuardent, ces jetons sont en laiton plutôt qu'en cuivre.

39. Jeton inaccessible au moment de la rédaction de l'article en raison du déménagement des collections. Sa présence dans les collections de la BNF est 
mentionnée par A. Weil et M. Pastoureau, «Les jetons bimétalliques français des $\mathrm{XVI}^{\mathrm{e}}$ et XVII ${ }^{\mathrm{e}}$ siècles ", p. 76.

40. Cet auteur ne connait pas la variété en argent, mais seulement celle en laiton.

41. Contrairement à ce qu'indique Feuardent, ces jetons sont en laiton plutôt qu'en cuivre.

42. Un seul jeton demeure pour ces deux cotes.

43. Selon La Tour.

44. Selon Feuardent, sans plus d'explication. Dire que ce jeton célèbre la paix de Vervins serait plus juste.

45. Droit et revers sont inversés dans les ouvrages de La Tour et de Feuardent. Nous pensons plus juste de remettre la scène animalière au revers, comme pour l'ensemble de la série.

46. « LT » dans le catalogue.

47. « Rouyer » dans le catalogue.

\section{RÉSUMÉS}

De rares jetons diffusés dans le royaume de France entre 1586 et 1635, frappés pour différentes institutions, le roi et quelques particuliers, montrent une très belle scène de combat animal entre un fauve et un canidé. Précisément, un lion s'attaque à un loup qu'il terrasse et s'apprête à dévorer. Autour figure la légende FRAVS VIRTVTE PERIT, détournée d'un vers d'Ovide et signifiant que «la ruse est mise à mort par la vaillance». Les numismates n'ont pas su inventorier ces jetons et les ont toujours décrits différemment. Seuls quelques auteurs anciens ont tenté d'en interpréter quelques-uns, sans suite ni succès. Pourtant, le catalogage, la lecture et la confrontation de ces petits objets métalliques destinés à véhiculer un message permettent aujourd'hui de les comprendre : selon les commanditaires, les lieux et les époques, le lion et le loup représentent des groupes ou des autorités et symbolisent des vertus ou des vices opposés. Leur combat représente à chaque fois une lutte réelle et manichéenne, mais différente, que se mènent des hommes.

\section{AUTEUR}

JÉRÔME JAMBU

Conservateur au département des Monnaies, médailles et antiques de la Bibliothèque nationale de France, IRHiS UMR CNRS 8529 


\title{
La revanche des animaux couards. Lièvres, lapins et escargots dans l'art médiéval : aspects moraux et comiques
}

\author{
Florian Meunier
}

L'auteur tient à remercier M. Pierre-Yves Le Pogam pour l'aide précieuse et les exemples qu'il lui a fournis.

Face aux animaux puissants qui forment la matière principale des études d'histoire, d'histoire de l'art, de l'onomastique et de l'héraldique du Moyen Âge ${ }^{1}$, les animaux couards et peureux, en particulier le lapin, le lièvre et l'escargot ont été peu représentés et peu cités. Ils apparaissent d'autant plus fortement dans les scènes de monde inversé et l'on peut mieux saisir à cette occasion le caractère symbolique de la couardise, selon un mode qui apparaît aujourd'hui tantôt inquiétant, tantôt comique.

2 Est-il utile de rappeler que le lapin sauvage et le lièvre sont difficilement reconnaissables dans les représentations médiévales, mais ont de tout temps symbolisé la peur et la fuite sous deux formes très proches? Le lapin de garenne vit dans des terriers où il se hâte de se réfugier par bonds successifs. Le lièvre incarne davantage encore la fuite devant l'ennemi, car son gîte est un simple renfoncement naturel du terrain, d'où il est contraint de partir lorsque l'homme ou le prédateur arrive, et semble courir sans but devant son ennemi. On peut ajouter que les racines des mots français «lièvre " et « lapin » seraient liées ${ }^{2}$ et que l'un des rares titres de gloire du lièvre est d'avoir donné son nom français à un chien de course spécialisé dans sa chasse, le lévrier, avec la levrette sa femelle.

Peu de représentations sont centrées sur le lapin ou le lièvre et leur présence même au sein de groupes d'animaux est rare dans l'art roman ${ }^{3}$ : on en trouve un rare exemple au sommet du portail de Saint-Ours de Loches. On peut avoir l'impression qu'à la fin du Moyen Âge, ces animaux sont un peu plus souvent pris pour thème dans les émaux translucides de l'orfèvrerie princière disparue ${ }^{4}$, les rinceaux des portails flamboyants, 
les tapisseries millefleurs dont la célèbre tenture de la Dame à la Licorne du musée de Cluny et exceptionnellement sur les clefs de voûtes (dont un exemple à l'hôtel de Cluny) et dans les fenestrages avec le motif giratoire des trois lièvres aux deux oreilles chacun (Dreihasenfenster du cloître de la cathédrale de Paderborn). Dans la plupart des cas cependant, ces animaux semblent représentés d'un point de vue purement décoratif au même titre que la flore, comme en témoigne aussi le plat du Louvre du XIV siècle dont le centre représente un lapin poursuivi par un chien au sein d'une scène dans les bois dont l'émail vert a disparu ${ }^{5}$. Il est difficile de suivre le thème du lapin et du lièvre avant les $\mathrm{XIII}^{\mathrm{e}}$ et XIV ${ }^{\mathrm{e}}$ siècles où le thème de la nature est particulièrement bien illustré, sans parler de l'Antiquité où les représentations en sont rares ${ }^{6}$.

\section{Le chasseur ligoté par deux lièvres à Königslutter am Elm}

4 L'abbatiale impériale ou Kaiserdom de Königslutter am Elm, située dans la partie orientale du Land de Basse-Saxe, présente une frise sculptée romane relativement méconnue en France. Son sens n'a pu véritablement être précisé avec certitude. En revanche, le contexte du commanditaire et de l'artiste est bien défini : il s'agit d'une construction royale et impériale de Lothaire III, mort en 1137, poursuivie sous le duc de Saxe Henri le Lion, qui fit de Brunswick, principale ville de la région, sa capitale avant d'être déchu par Frédéric Barberousse. L'architecture est exceptionnelle par sa qualité et ses dimensions qui sont celles d'une grande abbaye ou d'une cathédrale ; l'équilibre parfait des masses, la perfection géométrique renforcée par la mise en œuvre des pierres sont remarquables dans l'art roman germanique; ce sont des qualités que Königslutter partage avec le Neuwerk de la ville impériale voisine de Goslar. Quant au style des reliefs de la chasse de Königslutter, ils ont été rapprochés à juste titre de ceux du tympan de Saint-Zénon de Vérone, signé par maître Niccolò (Nicholaus) en 1138 : les mêmes reliefs d'animaux qu'à Königslutter s'y trouvent sculptés, mais indépendamment les uns des autres et sans ordre discernable ${ }^{7}$.

5 La scène de chasse du chevet de Königslutter (fig. 1) apparaît remarquablement hiérarchisée et organisée en deux moitiés symétriques, les personnages et animaux courant des extrémités de l'abside vers le centre de la composition, associant de chaque côté quatre reliefs d'une scène de chasse normale à l'unique scène de chasse à l'homme, au centre. Placés sous les arcatures, les reliefs sont séparés entre eux par des rosaces décoratives. 
Fig. 1. - Königslutter (Basse-Saxe), chevet de l'abbatiale, vue d'ensemble.

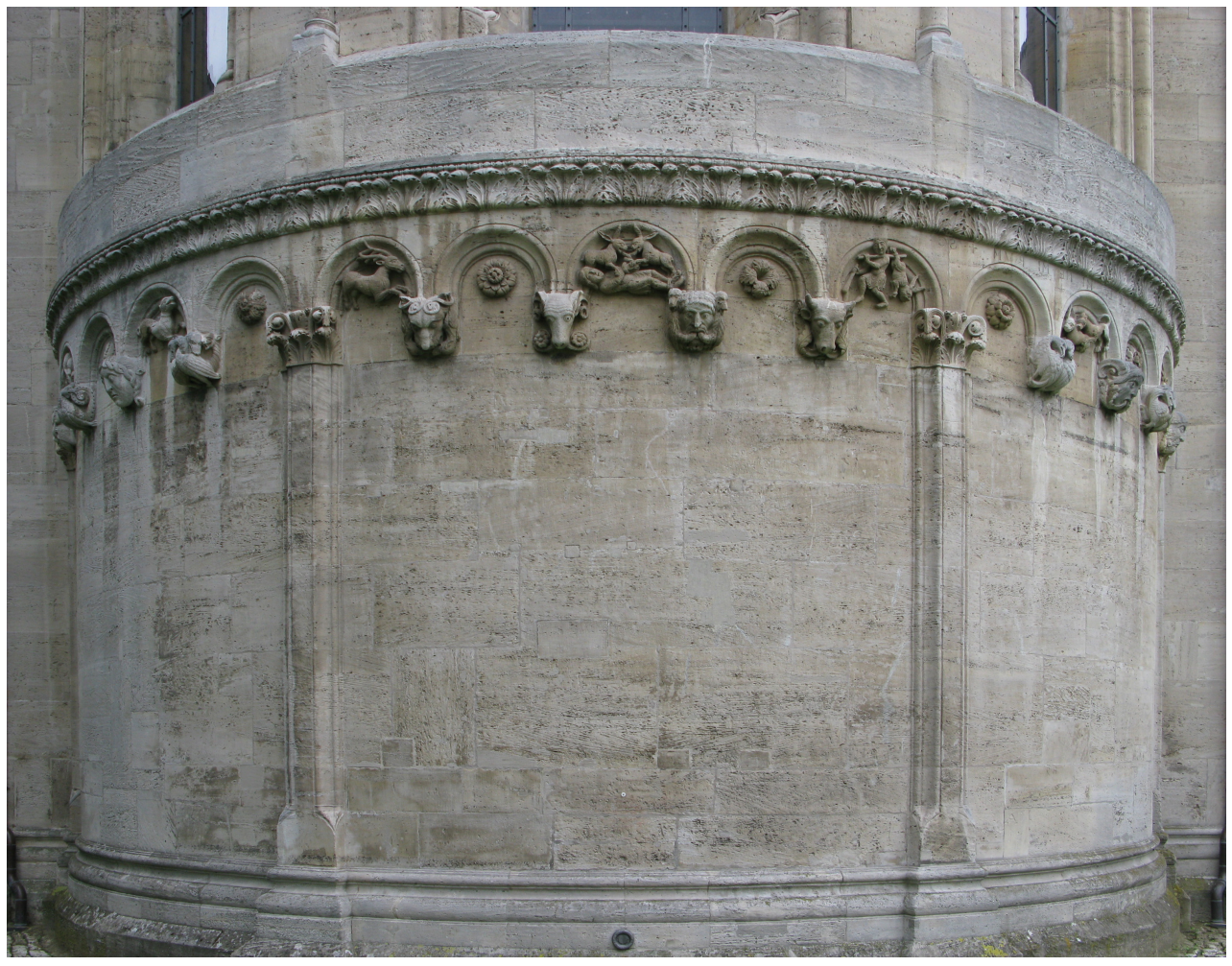

(c) Cliché F. Meunier.

6 En partant de la gauche (ou de dextre) vers le centre, on trouve : un chasseur sonnant de la trompe, un chien mordant un sanglier au col, un chien de chasse seul, un cerf. De l'autre côté, de la droite vers le centre, sont représentés : un autre chasseur sonnant de la trompe, un chien seul, un chien saisissant un lièvre au col, un chasseur tenant un bâton auquel est suspendu un lièvre (fig. 2). 
Fig. 2. - Königslutter, détail de la scène de chasse.

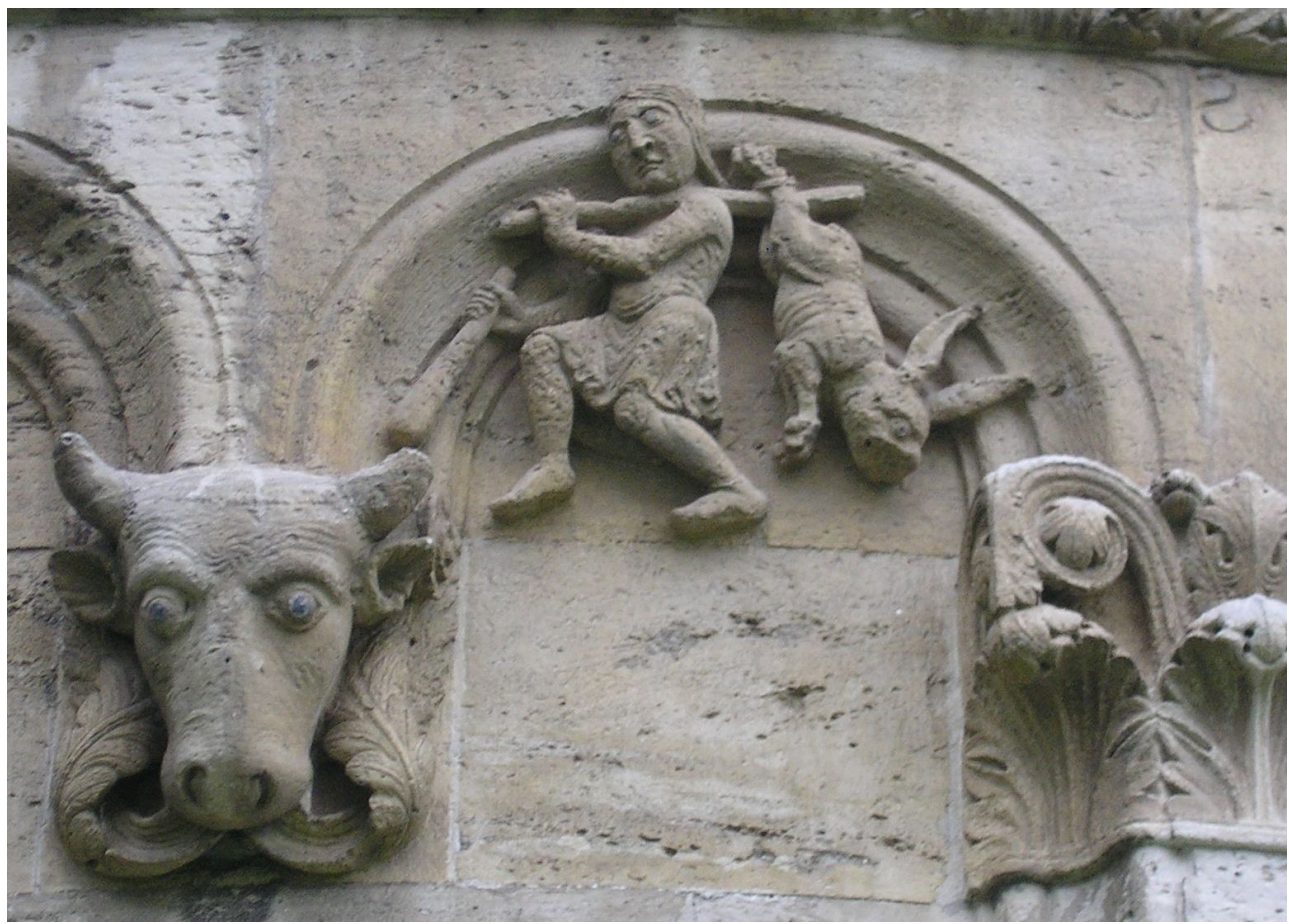

(c) Cliché F. Meunier.

7 Au centre (fig. 3), un homme est allongé, pieds liés, et ligoté par deux lièvres qui enroulent des liens autour de ses poignets en les serrant entre leurs dents. Cette scène est le pendant inversé de celle qui la précède à droite (fig. 2). La position centrale et axiale au chevet de l'église impériale de cette représentation d'un homme capturé par des lièvres incite à y voir bien davantage qu'une drôlerie de marge comme on en trouve ensuite dans les manuscrits de la fin du Moyen Âge. Parmi les interprétations avancées, un sens moral pu être interprété : l'homme représenterait l'âme humaine prisonnière de ses vices représentés par les lièvres. Loin d'être univoque, cette scène de captivité, qui clôt de façon inversée et donc tragique l'ensemble de la scène de chasse, doit être rapprochée des lions qui supportent les colonnes du porche nord (le Löwenportal) ${ }^{8}:$ l'un d'eux tient sous ses pattes antérieures un homme barbu qui tente en vain de s'en extraire. Ce thème, remontant sans aucun doute à une lointaine tradition antique, se retrouve ailleurs en Europe; il est spécialement bien illustré sous les colonnes du portail de l'abbatiale de Saint-Gilles-du-Gard, sans que l'on puisse se prononcer sur la répartition symbolique entre le bien et le mal: si le mal est du côté animal à Königslutter, l'écart serait grand avec les représentations du lion emblématique du duc de Saxe Henri à la même époque. Pour rester dans le domaine germanique médiéval, les sculptures et les reliefs de l'abbaye d'Andlau (Bas-Rhin) présentent au $\mathrm{XI}^{\mathrm{e}}$ siècle un thème proche, où monstres et animaux sauvages luttent avec des hommes. Quant aux reliefs en grande partie disparus de l'église de Marienhafe, dans la région allemande de la Frise, elles mettent en scène des animaux qui se substituent aux hommes dans une scène d'enterrement ou de veillée mortuaire, incitant là encore le fidèle à craindre l'idée d'un monde inversé9. 
Fig. 3. - Königslutter, détail de la scène du chasseur et des deux lièvres, dans l'axe du chevet.

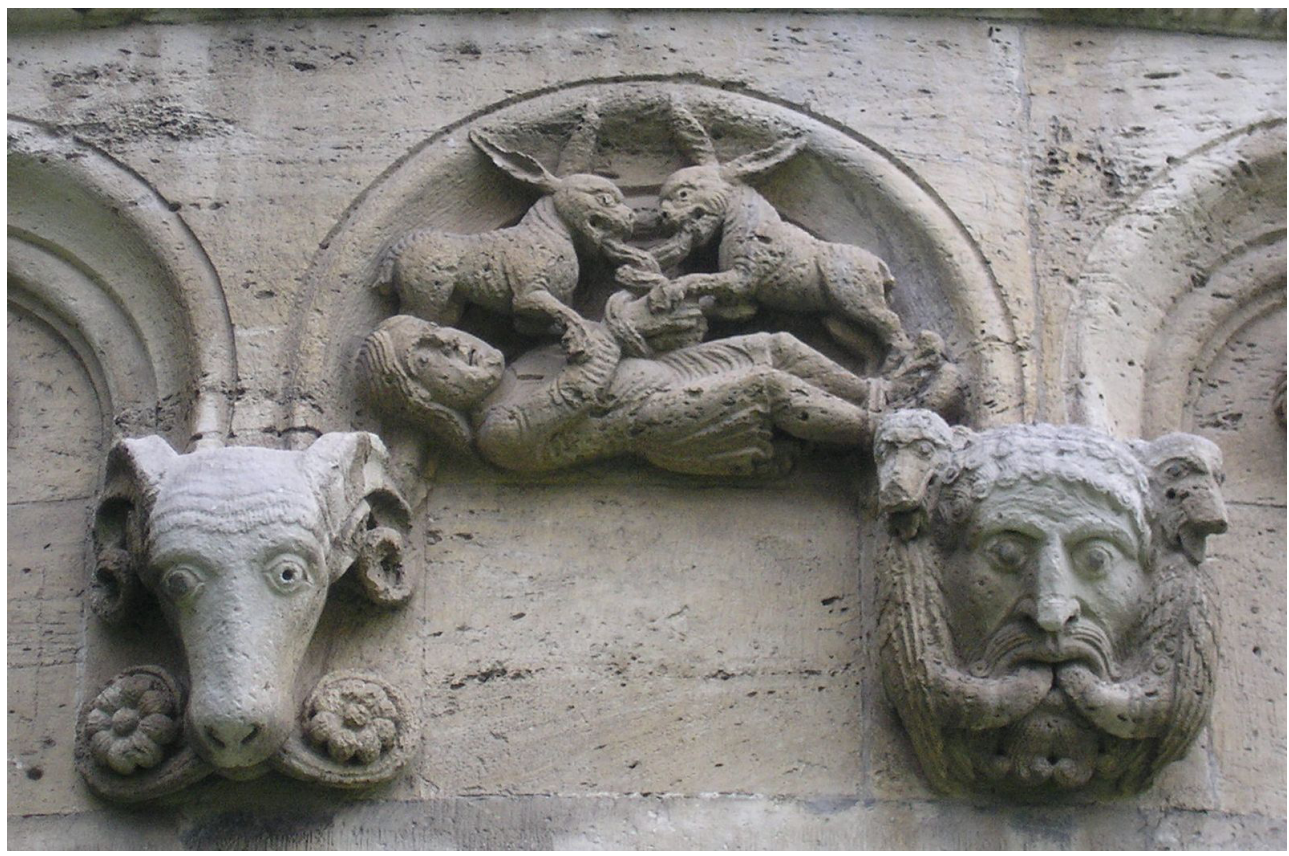

(C) Cliché F. Meunier.

Pour compliquer encore la situation, le maître d'ouvrage, l'architecte ou le sculpteur identifiable à un proche collaborateur de l'artiste italien Niccolò ou au maître lui-même - s'est targué de l'audacieuse singularité de cette réalisation dans une grande inscription, visible au-dessus des scènes en caractères latins inversés en miroir et à lire lettre à lettre de droite à gauche. Il y indique Hoc opus eximium vario celamine mirum sc(ulpsi) [ou] sc(ulptum est), ce qui peut se traduire par: "J'ai admirablement sculpté cette œuvre extraordinaire d'une ciselure variée ». Cette écriture spéculaire, qui précède celle de Léonard de Vinci, insiste sans doute encore sur le caractère inversé de la représentation de la chasse; elle a aussi été interprétée comme une énigme dont la représentation de l'homme ligoté serait la solution (le prénom Nicolaus codé) ${ }^{10}$. Il reste que le sens théologique ou moral en reste obscur, mais ne semble pas dénué d'une gravité et d'une menace qu'on ne retrouve plus dans les scènes similaires des siècles suivants.

\section{Les reliefs des cathédrales, du lapin à l'escargot}

9 Vices et vertus sont, depuis l'Antiquité, une source riche de représentations allégoriques, dont certaines mettent en scène des animaux. Aux médaillons des soubassements de portails occidentaux des cathédrales de Notre-Dame de Paris (fig. 4) et de Notre-Dame d'Amiens (fig. 5), vers 1210 et 1200, se retrouvent deux scènes très proches issues d'un même modèle, qui montrent un chevalier fuyant des animaux inoffensifs (lapin ou lièvre et oiseau) en abandonnant son épée, soit qu'il l'ait lâchée de frayeur, soit qu'il veuille courir plus rapidement. À la même époque, un fragment du jubé de Chartres propose, dans un écoinçon du signe zodiacal du Lion, symbole de force et de la terre, un autre chevalier abandonnant son bouclier, sa lance et son épée pour fuir, avec tous les autres animaux de la création, et même un dragon volant, devant un 
escargot ${ }^{11}$, animal davantage apprécié encore par les enlumineurs que par les sculpteurs ${ }^{12}$.

Fig. 4. - Notre-Dame de Paris, médaillon du soubassement du portail central de la façade.

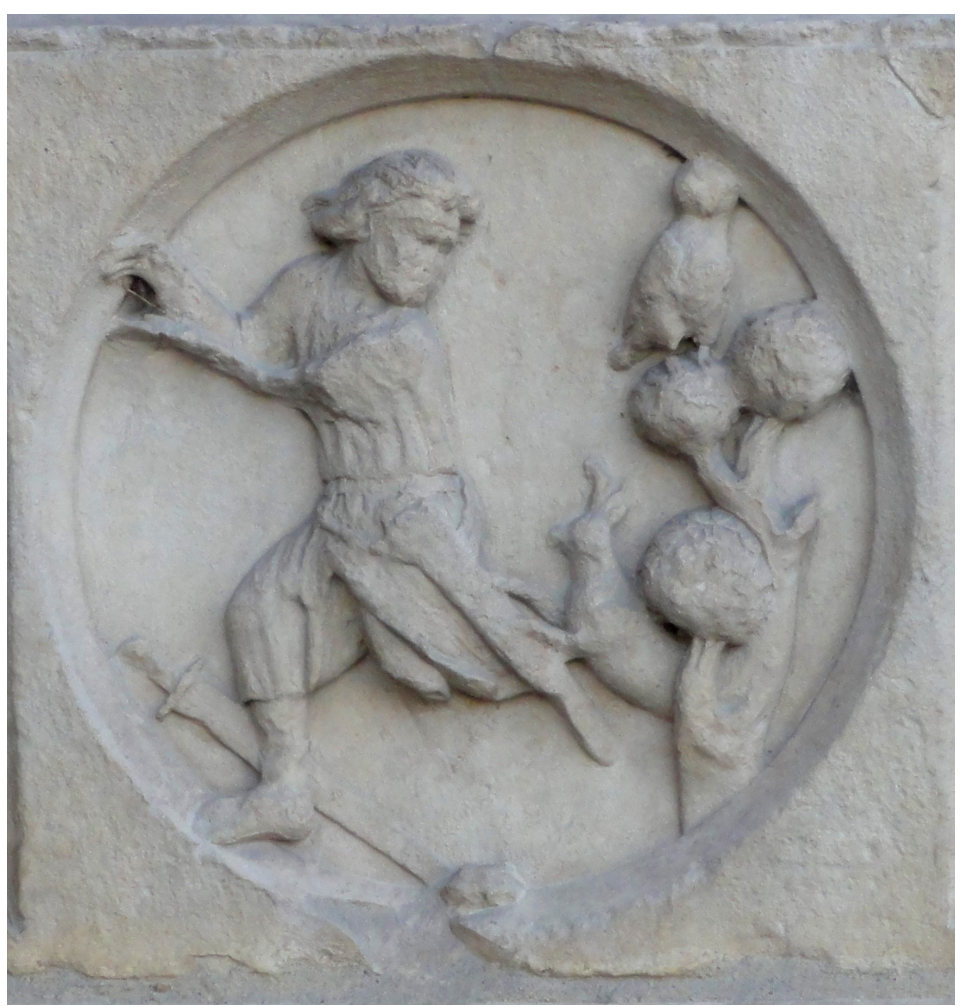

(C) Cliché F. Meunier. 
Fig. 5. - Cathédrale d'Amiens, médaillon du soubassement du portail Saint-Firmin.

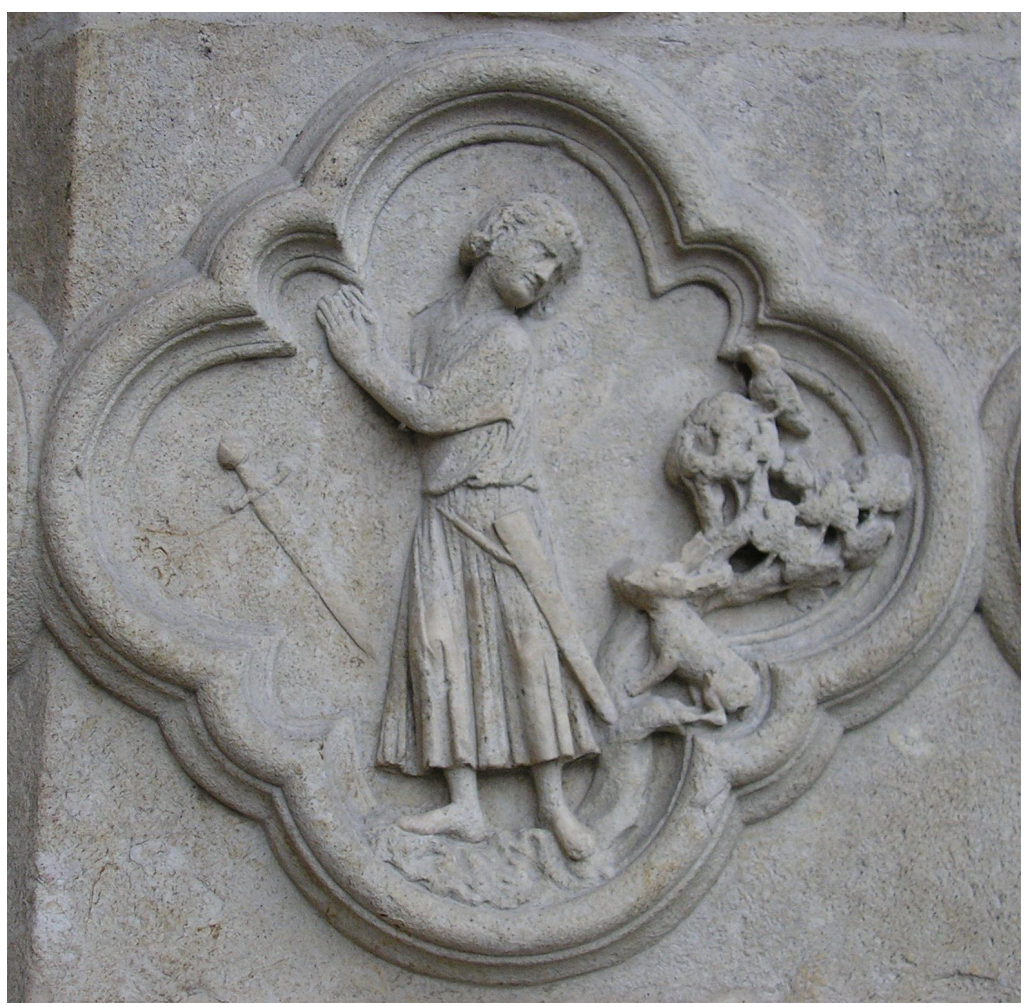

(c) Cliché F. Meunier.

10 Les médaillons des portails de Paris et d'Amiens semblent tirés d'un même modèle dessiné; le même type de composition se retrouve dans un médaillon de Rouen où le chevalier est remplacé par un bûcheron en fuite et les animaux par un arbre qui a retenu la cognée que l'homme y avait enfoncée. Dans les manuscrits, plusieurs scènes montrent le même schéma d'un homme lâchant ses armes devant un lièvre ${ }^{13}$.

11 Popularisées par Michael Camille ${ }^{14}$, les scènes drolatiques des «marges " des cathédrales, au sens figuré, et celles des manuscrits, au sens propre, couvrent un vaste domaine aux XIII et $\mathrm{XIV}^{\mathrm{e}}$ siècles. Propices aux représentations animales et au monde inversé, les marges sont riches en illustrations de chasses. Ce monde plaisant et subversif en même temps n'a sans doute pas nécessairement de portée morale ni religieuse et semble éloigné de la théologie que l'on devine sous-jacente au chevet roman de Königslutter. La forme des chasses, en revanche, reste stable avec les représentations de profil d'un lapin sautant sur l'échine d'un lévrier dans une Somme de droit canon attribuable au Midi et provenant de Clairvaux ${ }^{15}$.

Lièvre et escargot se trouvent réunis pour renforcer le caractère comique du monde inversé dans la marge d'un manuscrit. Dans le Pontifical avignonnais du XIV siècle, publié à l'occasion de l'exposition de Troyes de 2004, le lièvre est devenu chasseur tandis que son chasseur habituel, le lévrier, lui sert de monture. Il tient sur son poing ganté, en guise de redoutable faucon, un escargot dressé sur sa coquille et qui sort ses antennes ${ }^{16}$. 


\section{Loi salique et exempla}

13 La loi salique et un exemplum illustrent, à deux époques éloignées, la force symbolique des animaux couards. La loi salique, en usage sous Clovis puis mise en forme sous Charlemagne, recensait les amendes infligées en cas d'insulte qui sont au nombre de sept, en un latin calqué sur la langue franque: la première insulte est l'insulte de cinitum ou cenitum interprétée comme Keinnutz, homme de rien, suivie de concatum ou conchagatum, la merde, puis de meretrix, la putain, vulpes ou vulpicula le renard, puis arrive lepus, le lièvre, parfois transcrit sous sa forme lebus, leboris :

Si quis alterum leporem clamaverit, CCXL denariis qui faciunt solidos VI culpabilis judicetur (si quelqu'un a traité autrui de lièvre, il sera condamné à verser deux cent quarante

deniers qui font six sous).

Suit une autre insulte de couardise :

Si quis alteri imputaverit quod scutum suum projecisset in hoste vel fugiendo prae timore, CXX denariis qui faciunt solidos III, culpabilis judicetur (si quelqu'un a dit d'autrui qu'il a jeté son bouclier devant l'ennemi ou en s'enfuyant à cause de la peur, il sera condamné à verser cent vingt deniers qui font trois sous). ${ }^{17}$

La dernière insulte concerne les fausses accusations de dilator et falsator (délateur et faussaire). Les médaillons des cathédrales de Paris et d'Amiens semblent donc suivre au mot deux des insultes de cette liste. En ce qui concerne l'escargot qui fait fuir l'ensemble des autres créatures, un exemplum ou prêche espagnol indique la raison de l'association de l'escargot à la couardise :

«De même qu'au contact d'une paille ou d'une épine, les cornes de l'escargot se rétractent, de même un évêque s'enfuit et se cache au moindre danger.» (Fables d'Eudes de Cheriton, clerc anglais du XIII ${ }^{\mathrm{e}}$ siècle) ${ }^{18}$

16 Cette importance des antennes dans le symbole du caractère craintif de l'escargot permet de comprendre pourquoi le jubé de Chartres met ce détail en valeur et, dans le même ordre d'esprit, pourquoi les lapins ou lièvres ont les oreilles si dressées lorsqu'ils font peur aux chevaliers de Paris et d'Amiens: les oreilles que les lapins et lièvres tiennent couchées lorsqu'ils ont peur ou courent se trouvent être comme les seules parties menaçantes de l'animal employé de façon comique.

17 L'inversion des rôles entre l'animal et l'homme dans les scènes de chasse ou de représentation de la nature peut avoir dans l'art roman, à Königslutter, une portée symbolique menaçante dont la portée morale reste sujette à plusieurs interprétations. Aux portails et jubés de cathédrales gothiques au contraire, la position en marge de la composition principale permet d'instruire par le rire, en utilisant l'animal et en mettant en image des types de défauts humains de portée plus universelle que les proverbes, les fables et les fabliaux. 


\section{BIBLIOGRAPHIE}

BESSEYRE Marianne, «L'alphabet de la Création : l'animal dans la Bible », Bestiaire du Moyen Âge. Les animaux dans les manuscrits, Paris, Somogy, 2004.

CAMILLE Michael, Images dans les marges, Paris, Gallimard, 1997.

DEBIDOUR Victor-Henry, Le bestiaire sculpté du Moyen Âge en France, Paris, Arthaud, 1961.

ECKHARDT Karl August (éd.), Lex Salica (Monumenta Germaniae Historica, Leges nationum

Germanicarum, T. 4, partie II), Hanovre, Hahnschen Buchhandlung, 1969.

ERNOUT Alfred et MEILLET Alfred, Dictionnaire étymologique de la langue latine, histoire des mots, Paris, Klincksieck, 2001.

GABORIT Jean-René, « Niccolo, maître (première moitié XII ${ }^{\mathrm{e}}$ siècle) », Encyclopcedia Universalis [en

ligne], consulté le 4 décembre 2018. URL : http://www.universalis.fr/encyclopedie/niccolomaitre/

GOSEBRUCH Martin et GROTE Hans-Henning, Königslutter und Oberitalien, Kunst des 12. Jahrhunderts in Sachsen, Brunswick, éd. Limbach, 1980.

KUCK Jürgen Bernhard, Nikolaus, Lothar und der Teufel. Der Jagdfries am Dom zu Königslutter als kosmisches Rätsel, Königslutter, 2007.

LABORDE Léon de, Glossaire français du Moyen Âge à l'usage de l'archéologue et de l'amateur des arts précédé de l'inventaire des bijoux de Louis, duc d'Anjou, dressé vers 1360, p. 222, renvoyant à l'inventaire publié p. 1 à 114 .

LÜDERS Adolf, Der Kaiserdom zu Stift Königslutter, 1904.

MOORE HUNT Elizabeth, Illuminating the Borders of Northern French and Flemish Manuscripts, 1270-1310, New York, Routledge, 2006.

PASTOUREAU Michel, L'ours, histoire d'un roi déchu, Paris, Seuil (La Librairie du XXI ${ }^{\mathrm{e}}$ siècle), 2007.

REY Alain, TOMI Marianne, HORDÉ Tristan, TANET Chantal, Dictionnaire historique de la langue française, Paris, Le Robert, 1998.

RITZ-GUILBERT Anne, Des drôleries gothiques au bestiaire de Pisanello, le Bréviaire de Marie de Savoie, CTHS/INHA (L'art et l'essai, t. 8), 2010.

TESNIÈRE Marie-Hélène et DELCOURT Thierry (dir.), Bestiaire du Moyen Âge, les animaux dans les manuscrits, Paris, Somogy, 2004.

TUBACH Frederic C., Index exemplorum, a handbook of medieval religious tales, Helsinki, Academia scientiarum Fennica, 1981.

WIRTH Jean (dir.), Les marges à drôleries des manuscrits gothiques, 1250-1350, Genève, Droz, 2008.

\section{NOTES}

1. Cf. M. Pastoureau, L'ours, histoire d'un roi déchu.

2. Pour le lièvre, le mot viendrait de l'ibère avant de passer en latin en lepus, leporis ; pour le lapin, il tirerait son origine de l'espagnol, après abandon de l'ancien français 
« connil » ou «connin » (lui-même issu du latin coniculus qui est devenu coniglio en italien et correspond aussi à l'allemand Kanninchen et au néerlandais konijn). Le mot lapin serait d'abord venu de l'espagnol lapereau, peut-être dérivé de levraut (de leporellus, jeune ou petit lièvre) puis aurait été transformé en lapin par attraction de l'ancien vocable "connin » qu'il a finalement supplanté, cf. A. Ernout et A. Meillet, Dictionnaire étymologique de la langue latine, histoire des mots ; A. Rey, M. Tomi, T. Hordé, Ch. Tanet, Dictionnaire historique de la langue française, t. 2, p. 1976 et 2022.

3. Cf. V. H. Debidour, Le bestiaire sculpté du Moyen Âge en France, exemples gothiques de Lyon p. 41, Amiens p. 266 (commenté ici, à la fig. 5), et notice p. 392.

4. Léon de Laborde a relevé vingt-cinq occurrences de lapins (connins) décoratifs dans l'inventaire du duc d'Anjou de 1360 (L. de Laborde, Glossaire français du Moyen Âge, p. 222, renvoyant à l'inventaire publié p. 1 à 114).

5. Musée du Louvre, département des Objets d'art, coupe ou hanap à ombilic, Paris, vers 1350, inv. OA 11380.

6. Pour l'Antiquité : Bec de fontaine en bronze représentant un lapin, musée archéologique de Naples, provenance indéterminée, inv. 124912. Sur les représentations de lapins dans les manuscrits à la fin du Moyen Âge et en particulier en Italie du Nord, voir A. Ritz-Guilbert, Des drôleries gothiques au bestiaire de Pisanello, le Bréviaire de Marie de Savoie, p. 190, 232-233, 250, 258-260, et pl. XXII, XXIV, XXV, XXVI.

7. Sur maître Niccolò : J.-R. Gaborit, "Niccolo, maître (première moitié $\mathrm{xII}^{\mathrm{e}}$ siècle) ", Encyclopaedia Universalis [en ligne], consulté le 4 décembre 2018. URL : http:// www.universalis.fr/encyclopedie/niccolo-maitre/. Sur les liens stylistiques entre Königslutter et l'Italie du Nord et l'analyse précise des sculptures : M. Gosebruch et H.H. Grote, Königslutter und Oberitalien, Kunst des 12. Jahrhunderts in Sachsen, en particulier p. 36 sur la chasse inversée et p. 56-63 pour la contribution de Hans Gerhard Meyer intitulée « Der Jagdfries von Königslutter ».

8. Ces sculptures, malgré l'érosion qui semble leur conférer une ancienneté, auraient été refaites à l'identique en 1880 d'après A. Lüders, Der Kaiserdom zu Stift Königslutter, 1904. Les lions qui se trouvent à l'intérieur de l'église seraient les originaux de ces copies sensiblement différentes.

9. Sur la chasse inversée dans l'enluminure au XIV siècle, voir J. Wirth, «Problèmes de méthode " et A. Fisch Hartley, "La chasse », dans J. Wirth, Les marges à drôleries des manuscrits gothiques, p. 11-43 et 201-206, en particulier la fig. 4.1.9 (British Library, ms Y.T 8, « lièvre et chien se battant à l'épée », fol. 181).

10. J. B. Kuck, Nikolaus, Lothar und der Teufel. Der Jagdfries am Dom zu Königslutter als kosmisches Rätsel.

11. Relief reproduit et commenté par M. Camille, Images dans les marges, p. 51, fig. 15 et par V. H. Debidour, Le bestiaire sculpté du Moyen Âge en France, p. 289.

12. Sur l'histoire de l'escargot en rapport avec les vices et la couardise, $c f$. l'analyse très complète d'E. Moore Hunt, Illuminating the Borders, p. 139-143, en particulier fig. 37, p. 140 (Bruxelles, BRB, ms 9543, fol. 117).

13. J. Wirth, "Problèmes de méthode", dans J. Wirth, Les marges à drôleries des manuscrits gothiques, p. 11-43, en particulier p. 14 (manuscrit Latin 14284 de la BNF, vers 1280, en marge inférieure : un chevalier lâche épée et bouclier devant un lapin blanc qui bondit vers lui, fol. 1v). 
14. M. Camille, Images dans les marges.

15. Somme de droit canon d'Innocent IV, Troyes, Médiathèque de l'agglomération troyenne, ms. 89, fol. 216, enluminure publiée dans M.-H. Tesnière et T. Delcourt (dir.), Bestiaire du Moyen Âge, les animaux dans les manuscrits, fig. 68.

16. Pontifical de G. Durand, Paris, Bibliothèque Sainte-Geneviève, ms. 143, fol. 165, publié par M.-H. Tesnière et T. Delcourt (dir.), Bestiaire du Moyen Âge, les animaux dans les manuscrits, fig. 67.

17. K. A. Eckhardt (éd.), Lex Salica, p. 228, (titre LXX, de convitiis).

18. Odo de Ceritona (nom latin d'Eudes de Cheriton), Fabulae et parabolae, cité par F. C. Tubach, Index exemplorum, $\mathrm{n}^{\circ} 4923$.

\section{RÉSUMÉS}

À travers les exemples des reliefs romans du chevet de l'abbatiale impériale (Kaiserdom) de Königslutter près de Brunswick (Basse-Saxe), des reliefs des cathédrales gothiques de Chartres, Paris et Amiens ainsi que de manuscrits enluminés, on peut s'interroger sur le thème de l'inversion des valeurs chevaleresques lorsque lièvres et escargots capturent le chasseur ou mettent en déroute le guerrier. Parmi les explications possibles, celle des vices et des vertus semble primer, et l'on peut penser que la vis comica sert l'exemplum moral à partir d'un substrat remontant à l'époque de la loi salique.

\section{AUTEUR}

\section{FLORIAN MEUNIER}

Conservateur en chef département des Objets d'art du musée du Louvre 


\title{
Essai sur la valeur symbolique de la genette dans la littérature et l'art médiéval occidental
}

\author{
Virginie Muxart
}

Remerciements très sincères à David Camps, Rachida Mallogi et à Christian Parsy pour avoir donné leur aimable autorisation de publier leurs photos.

1 S'aventurer sur les traces de la genette, c'est-à-dire mettre à jour les savoirs et les représentations qui concernent ce petit animal a été (et est toujours, car la recherche continue) une tâche ardue qui a exigé des connaissances relevant de nombreux domaines, très différents, voire souvent opposés « académiquement ». En outre, pour mener à bien cette recherche, il a été nécessaire de mobiliser non seulement des sources textuelles mais aussi archéologiques et iconographiques pour ce petit carnivore dont le poids ne varie qu'entre 1,8 à $2,0 \mathrm{~kg}$.

2 La genette européenne (Genetta genetta Linné, 1758) est un animal atypique, car non seulement elle est l'unique représentant de la famille des viverridés en Europe ${ }^{2}$ mais elle rassemble aussi les caractéristiques morphologiques de différents animaux : elle ressemble à un chat, avec des oreilles de fennec ou de renard, des taches de panthère et une queue qui ressemble à celle des lémuriens ${ }^{3}$. Elle est singulière mais aussi discrète et donc très rare à observer dans le milieu naturel. Elle grimpe dans les arbres avec beaucoup d'agilité, saute de branche en branche en se servant de sa queue comme d'un balancier et descend la tête en bas, ce que peu d'animaux peuvent faire (fig. 1). 
Fig. 1. - Genette, région de Barcelone (Catalogne).

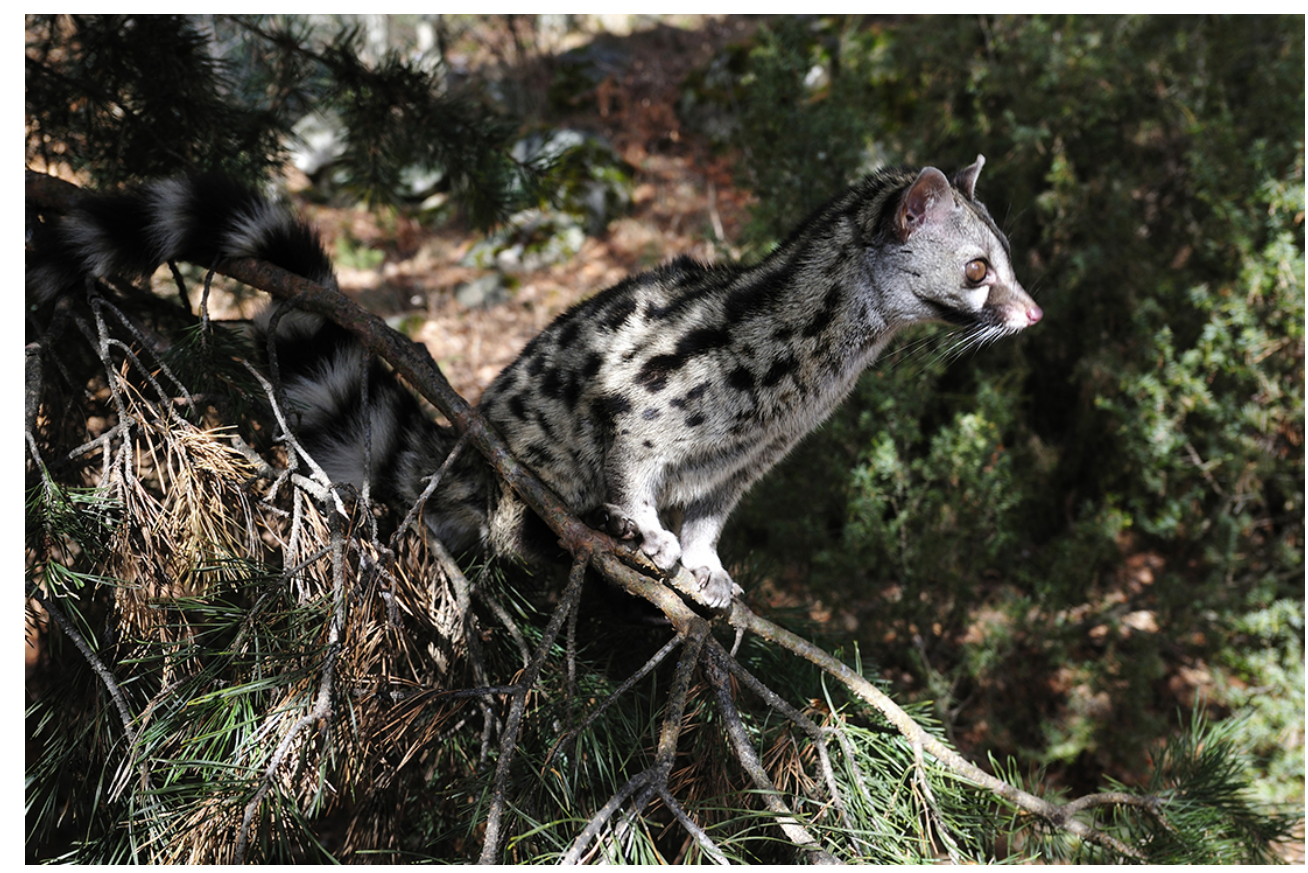

(C) David Camps

3 Sa discrétion dans les textes est à l'égal de sa discrétion naturelle ${ }^{4}$ : elle est rarement présente dans les textes occidentaux et orientaux de l'Antiquité au Moyen Âge ${ }^{5}$. Seul le passage du roman Perceforest $\left(\mathrm{xv}^{\mathrm{e}}\right.$ siècle) offre une piste sérieuse pour percer à jour la valeur symbolique de la genette ${ }^{6}$. Camille, l'une des petites-filles de Pergamon, fait envoyer à son preux Chevalier aux Trois Papegaux un nouvel écu qu'il devra porter sans qu'il en connaisse la provenance: une genette blanche ${ }^{7}$. Le chevalier accepte, d'autant qu'il ne voulait pas porter ses propres armes au cas où il ne pourrait pas relever le défi de battre tous ses adversaires, et gagner ainsi la jeune fille dont il est épris, qui n'est autre que Camille elle-même. Après avoir remporté le turpinoy et le tournoi, il est appelé un court moment le «Chevalier à la Genette », avant que tous ne le reconnaissent lorsqu'il se désarme.

4 Le choix, par Camille, de la genette et de sa fourrure blanche n'est pas fortuit. La genette albinos a l'avantage d'être blanche du museau à la pointe de la queue, alors que l'hermine garde le bout de la queue noir, même en période hivernale. Camille s'apparente à la genette blanche, car elle est aussi virginale qu'elle. En cela, la genette blanche la représente, c'est son animal-emblème. Son chevalier porte sa couleur et est défini d'abord par le pouvoir symbolique que lui confère cette genette blanche, avant même son propre nom ${ }^{8}$. Si la genette représente Camille, elle pourrait aussi symboliser l'Amour vrai, pur, celui qui inspira à l'un des amoureux de se mutiler afin de donner à l'autre le temps de guérir et de rendre possible leur union ${ }^{9}$ ou le protecteur de cet Amour. Mais comment vérifier cette piste?

5 C'est ici que les sources iconographiques se révèlent précieuses. C'est à partir du $\mathrm{XV}^{\mathrm{e}}$ siècle que la genette commence à être représentée, notamment dans les marginalia de manuscrits, sur des tapisseries, sur des vitraux et des estampes. Elle est utilisée dans l'héraldique comme emblèmede plusieurs princesses prénommées Jeanne du $\mathrm{Xv}^{\mathrm{e}}$ et $\mathrm{XVI}^{\mathrm{e}}$, 
seule $^{10}$, ou avec l'initiale «I $\mathrm{I}$ et la fleur de janette (formant un double rébus), ainsi que pour certains hommes prénommés Jean ${ }^{11}$ (fig. 2).

Fig. 2. - Tapisserie dite aux armes de Louis Bâtard de Bourbon, genette et fleurs de janette, détail.

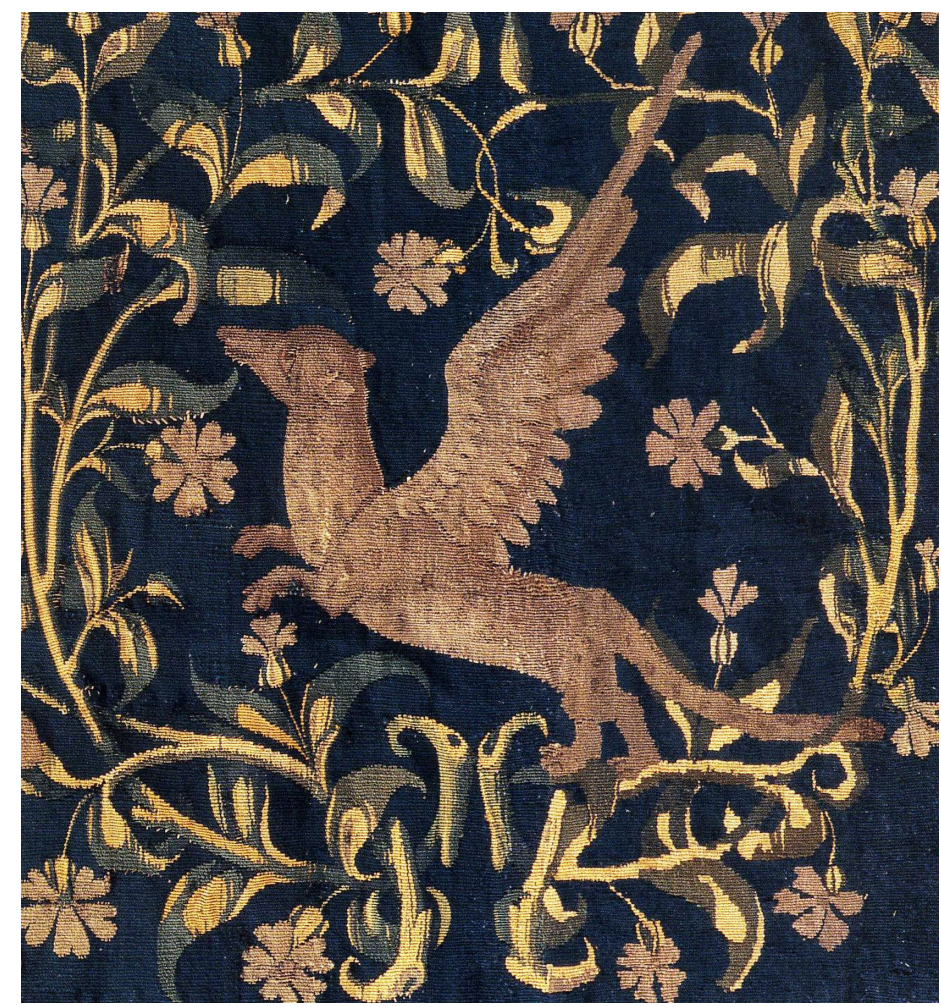

(c) Rachida Mallogi

La genette est donc choisie comme emblème par des nobles se prénommant Jean et Jeanne et se voit alors arborée sur des blasons dans les marges des manuscrits occidentaux, des estampes, sur des sceaux, sur des tapisseries ${ }^{12}$. Mais sa seule fortune s'arrête-t-elle là ? Se pourrait-il qu'enfin, après bien des siècles de retard par rapport à d'autres petits carnivores (l'hermine par exemple), elle ait une valeur symbolique qui lui est propre?

7 La seule étude qui avait apporté des hypothèses sérieuses sur la valeur symbolique de la genette au Moyen Âge est celle de Margaret Beam Freeman ${ }^{13}$. Son premier objet étant d'étudier la seconde tapisserie de la Chasse à la Licorne "The Unicorn is Found », elle analyse le groupe d'animaux formé au premier plan dans lequel une genette est parfaitement reconnaissable. Confrontant cette représentation iconographique à d'autres où apparaît le viverridé ${ }^{14}$, elle en vient à la conclusion que si la genette est confondue avec la belette ${ }^{15}$, alors elle aura la même signification symbolique que celleci :

«[...] courageuse comme le lion, [...] ennemie des serpents comme le cerf, la panthère et la licorne.»

Mais si l'artiste connaissait l'animal :

«Elle constitue une adjonction intéressante au groupe d'animaux qui se trouvent près du ruisseau.»

Dans cette seconde éventualité, elle ajoute : 
« Il se peut que l'artiste qui a dessiné les cartons des tapisseries ait eu un faible pour cet animal, pour son long corps souple et sa queue élégamment ornée d'anneaux, et qu'il lui ait attribué un peu de la signification symbolique de la belette (Mustela), bête qui pour un œil non prévenu scientifiquement ressemble à la genette et qui, elle, joue un rôle important dans les bestiaires. ${ }^{16}$ mais aussi en Europe du Nord (les Flandres), du Sud (Espagne, Portugal) et centrale (tout au moins en Allemagne pour sa fourrure) ${ }^{17}$. Lors de ces deux siècles, une partie de l'Europe intègre tout à coup dans son bestiaire un animal dont les seules connaissances écrites recensées à son sujet étaient naturalistes et qui jusque-là, était resté dans l'ombre. Afin de vérifier si la genette a la signification symbolique de la belette, le corpus de Margaret B. Freeman qui comportait des supports datés de la fin du Xve siècle a été repris et enrichi d'une enluminure présente au folio 87 du ms. BNF Fr. 1537 (1530) et d'une tapisserie " aux feuilles de choux » datée du Xvi ${ }^{\mathrm{e}}$ siècle $^{18}$. Sur un total de huit supports (en comptant «La vue» de la Dame à la Licorne) s'échelonnant sur une période de près d'un siècle, la genette est présentée six fois auprès de la licorne. Par conséquent, cette association n'est pas due au hasard.

11 La genette est présente sur deux des six tapisseries «La Vue » et «Le Goût » qui composent la tenture de La Dame à la licorne. Cependant, les deux genettes ne portent pas de collier et ne sont pas reliées à un «I»; elles ne sont donc pas emblématiques. Si ces deux tapisseries de la Dame à la Licorne ne peuvent aider à identifier la valeur symbolique de la genette, c'est celle qui a été analysée par Margaret B. Freeman qui donne le plus d'indices ${ }^{19}$. Celle-ci «combine une scène typique d'une grande chasse médiévale avec le «rite» de la purification d'un cours d'eau par la licorne ${ }^{20}$. Les chasseurs viennent de trouver la licorne, animal qui représente le plus souvent le $\mathrm{Christ}^{21}$, et s'immobilisent car ils assistent à cet acte noble et merveilleux. Les animaux en font autant et ces derniers ne boiront que lorsqu'elle aura fini son acte purificateur ${ }^{22}$. La genette, reconnaissable à sa silhouette, sa robe marron clair aux taches marron foncé et à sa queue annelée fait partie d'un groupe de trois animaux et est située entre deux grands carnassiers dont la symbolique est déjà bien connue, la panthère et la hyène. Au Moyen Âge, il faut rappeler qu'un animal ne prend son sens " que pour autant qu'il est opposé ou associé à un ou plusieurs autres animaux »"

À sa gauche se trouve la panthère à laquelle la genette tourne le dos en toute confiance. En effet, la panthère a la réputation depuis le Physiologus d'être entièrement tournée vers le bien ${ }^{24}$. En revanche, l'animal que regarde fixement la genette est la hyène, plutôt connotée négativement. Cette dernière, dans la tradition des bestiaires, « vit dans les sépulcres des morts et dévore leurs corps $»^{25}$. Elle fait partie des animaux conspués au Moyen Âge, notamment pour son hermaphrodisme et son changement annuel de $\operatorname{sexe}^{26}$. La genette semble fixer paisiblement cet animal à connotation maléfique et ne semble pas le craindre. Au contraire, elle soutient son regard. Toute proche de la Licorne, elle semble la protéger de la hyène.

scène est proche symboliquement de celle représentée sur le folio 155 du ms. 776 (Chantilly, Bibliothèque du château) intitulé La guerre des Juif $\mathrm{s}^{27}$. Comme l'indique son décor héraldique, ce manuscrit a été commandé entre 1480 et $1485^{28}$ par Antoine de Chourses (1453-1484), conseiller et chambellan du roi Louis XI et sa femme, Catherine de Coëtivy. Sur le folio 155, en marge inférieure, la genette est très reconnaissable : tête fuselée, robe grise et queue annelée. Dans cette configuration triangulaire, la genette défie une créature diabolique qui guette, la mine réjouie et avide, la licorne paisible, 
couchée sur un tertre. Cette licorne emblématique ${ }^{29}$ est tournée vers la genette. Son regard est plein de confiance, comme si elle se savait protégée par cette dernière. Pour la deuxième fois, la genette semble protéger la licorne.

Trois autres scènes, combinant entre autres la genette et la licorne, se déroulent au jardin d'Éden. Le folio 2 de la Bible historiale, premier incunable produit par Antoine Vérard en 1498 présente au premier plan, au pied de l'Arbre de la connaissance du Bien et du Mal, une genette dont la queue tachetée semble prolonger le bout de la queue du serpent, lui-même tacheté. Le serpent représente la tentation et la mort finale, «le caractère irrépressible et "sauvage » de l'instinct et enfin l'aspect répugnant de cette conduite $»^{30}$. De part et d'autre de l'Arbre autour duquel s'est entortillé le serpent au buste de femme, Adam et Ève ont déjà pourvu à leur nudité. Au fond se distingue une représentation bien caractéristique de la fontaine de vie auprès de laquelle courent la licorne ainsi qu'un cerf, qui la suit. Entre les deux scènes, un singe assis mange un fruit, à proximité d'Ève.

15 La licorne est représentée, comme souvent, à côté du cerf, qui a bénéficié d'une classification favorable aux yeux de l'homme depuis les Écritures (qui louent sa douceur, son désir pour les eaux vives, son indépendance, son absence d'agressivité) et des légendes de l'Antiquité dans lesquelles son inimitié avec le serpent en fait l'image du Christ combattant le démon.

La présence de la genette au pied de l'Arbre de Vie prolongeant de sa queue celle du serpent rappelle à Adam et Ève qu'ils viennent de perdre l'Âge d'or et qu'à leurs yeux à présent, distinction est faite entre le Bien et le Mal. La genette et le singe semblent symboliser tous deux, l'un le Bien, l'autre le Mal. En effet, ce dernier qui croque un fruit non loin d'Ève a une connotation négative ; dès le Haut Moyen Âge, il est l'image :

«Soit du démon en raison de sa difformité et de son manque d'harmonie qui est la conséquence plus ou moins explicite d'une punition, soit du pécheur, évoquant principalement la tromperie car il s'agit d'une bête qui ose prétendre au statut humain. $»^{31}$

17 Ce même singe et cette même genette ont dû inspirer l'illustrateur du folio 87 du ms. BNF Fr. 1537 (vers 1530); les deux animaux ont été repris et ce, exactement dans la même attitude ${ }^{32}$. Ils font partie d'une scène illustrant un chant royal qui célèbre le jardin d'Éden aux folios $87 \mathrm{v}, 88$ et $88 \mathrm{v}$ dont l'adaptation est libre puisqu'après vérification, aucun animal n'y est cité, à part le serpent qui n'a pas droit d'y pénétrer ${ }^{33}$. La genette regarde dans la direction du singe (qui mange le fruit) et tous deux sont au premier plan. Ils préfigurent sans doute le choix que fera le couple Adam et Ève car derrière eux, les animaux sont paisibles, rassemblés autour de la fontaine de vie d'où jaillit le fleuve qui se divise en trois bras (le quatrième doit être derrière) et qui leur procure eau et herbe verdoyante. Sur les rives du bras central du fleuve où se baignent canards et cygnes, le cerf et la licorne sont couchés, tournés l'un vers l'autre ${ }^{34}$. Si cette scène a été décrite - quoique sommairement - mettant en exergue «le bébé singe qui croque une pomme» qui «annonce la Faute»-, la genette n'avait pas été encore identifiée ${ }^{35}$.

Enfin, la genette fait partie du décor d'une miniature du folio $17 \mathrm{du}$ ms. BNF Fr. 64, dans le jardin d'Éden, derrière les personnages de Dieu, Adam et Ève $^{36}$. Cette représentation de la genette peinte par le Maître de Coëtivy est sans doute la plus ancienne de tout ce corpus puisque le manuscrit est daté entre 1460 et 1465 . Elle fait partie d'un groupe de 
trois animaux qui entourent la fontaine de Vie et composé du cerf et d'un faisan, celuilà même qui se trouve sur la deuxième tapisserie de la Chasse à la Licorne.

Comme l'a bien souligné Margaret B. Freeman, l'estampe de la Bible historiale ainsi que le folio 17 du ms. BNF Fr. 64 présentent des similitudes avec la seconde tapisserie de la Chasse à la licorne puisque la fontaine, élément symbolique de l'Éden, la genette, le cerf et la licorne sont associés ${ }^{37}$. Ces parentés, fort justes, ont été corroborées depuis par les études de Nicole Reynaud en 2003 : l'artiste des cartons de la Chasse à la Licorne a été identifié à Jean d'Ypres, appelé aussi le Maître des Très Petites Heures d'Anne de Bretagne, fils de Colin d'Amiens (ce dernier étant le Maître de Coëtivy, qui a dessiné le folio $17 \mathrm{du}$ ms. 64) et sa production pour le moins spectaculaire ${ }^{38}$ met en lumière les occurrences de la genette dans au moins quatre des représentations étudiées précédemment. Il se pourrait donc que la genette associée à la licorne pour le couple Chourses-Coëtivy (peinte par le Maître de Cardinal de Bourbon, quoique plus probablement par un artiste de son atelier, comme vu précédemment), puis associée à la fontaine par le Maître de Coëtivy, ait été associée logiquement à la licorne et à la fontaine, dans la continuité, par le propre fils du Maître de Coëtivy, Jean d'Ypres. C'est donc la raison pour laquelle cette triade est représentée non seulement sur la deuxième tapisserie de la Chasse à la licorne, mais aussi sur l'estampe du folio 2 de la Bible Historiale, puisqu'il a été démontré que le matériel iconographique de Jean d'Ypres ${ }^{39}$ a été utilisé jusqu'au siècle suivant notamment par le libraire Antoine Vérard (qui travaillait aussi avec Simon Vostre, libraire qui a pris pour emblème la genette ${ }^{40}$ ). La genette, protectrice de la licorne aurait été ainsi diffusée dans un laps de temps assez court (fin $\mathrm{XV}^{\mathrm{e}}$ - début $\mathrm{XVI}^{\mathrm{e}}$ ) mais suffisant et dans plusieurs domaines (enluminure, tapisserie, vitrail) pour qu'elle puisse connaître du même coup le succès et ce, même représentée seule.

Une dernière représentation de la genette, très originale, la montrant en confrontation directe avec un serpent ${ }^{41}$, pourrait soulever d'autres questions et apporter d'autres pistes pour la valeur symbolique de la genette. Il s'agit d'une scène qui se trouve sur une tapisserie (d'une série de trois dites "à feuilles de choux" du $\mathrm{xvI}^{\mathrm{e}}$ siècle), probablement tissée dans les ateliers d'Adenarde ou de Grammont en Flandre ${ }^{42}$ (fig. 3). Dans son article de 1997, Xénia Muratova étudie notamment cette tapisserie et montre combien l'apparition des premières éditions gravées des Bestiaires et du Physiologus au $\mathrm{XV}^{\mathrm{e}}$ siècle a pu servir de sources aux créateurs des cartons de tapisseries ${ }^{43}$. Les deux animaux sont campés sur la balustrade qui "peut bien symboliser l'enclos de l'Amour $~^{44}$, l'un, sur la rampe, et l'autre, enserrant les barreaux de ses anneaux. La genette défie le serpent. L'identification du quadrupède n'est pas discutable : même si le cliché est en noir et blanc, la genette est bien cet animal aux vibrisses très développées, tacheté à la queue annelée (même si trop courte et évasée à la fin) et dont le museau est effilé. Cette scène est placée à droite de la scène centrale qui présente un lion terrassant un cheval. 
Fig. 3. - Tapisserie franco-flamande du xvie siècle, genette et serpent, détail.

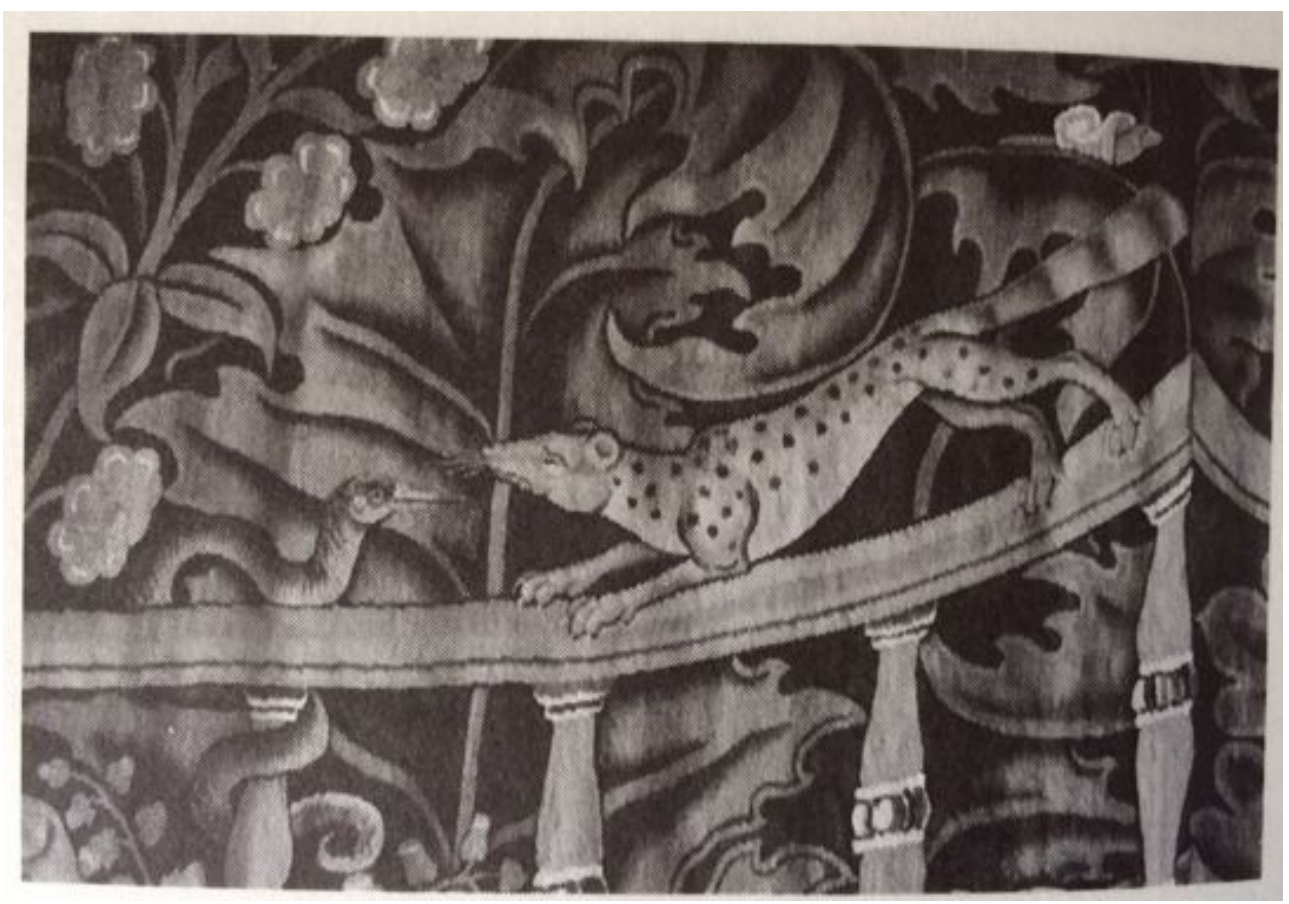

(C) Xenia Muratova

Partant du principe que la scène représentée est « la confrontation de la belette et du serpent ", "thème ancien du Physiologus ", l'auteur de l'article reconnaît que "la belette a une peau tachetée et une longue queue avec des anneaux, ressemblant ainsi plutôt à un animal qu'on définirait aujourd'hui comme une genette ». Cependant, elle poursuit en écrivant que «le Moyen Âge ne distinguait pas ces deux espèces » et que "les genettes ont été souvent domestiquées avant d'être supplantées par le chat actuel $\aleph^{45}$. Enfin, elle ajoute que cette représentation tachetée de la belette avec la queue annelée est très proche des représentations de celle des ouvrages zoologiques, notamment de ceux de Conrad Gesner.

Or, après vérification, le Moyen Âge distinguait bien ces deux espèces, la belette n'est pas représentée ainsi chez Gesner ${ }^{46}$ et la genette est populaire et bien connue (notamment grâce à sa fourrure), sans toutefois être "domestiquée " aux $\mathrm{Xv}^{\mathrm{e}}$ et $\mathrm{XVI}^{\mathrm{e}}$ siècles ${ }^{47}$, période à laquelle toutes ces représentations ont été analysées. De toute évidence, la genette, à prendre soudainement la place de la belette, déstabilise et embarrasse.

Si avant le $\mathrm{XI}^{\mathrm{e}}$ siècle, la belette était reconnue comme un animal rampant et donc impur, c'est à partir du xIII ${ }^{e}$ siècle que son statut change, grâce en partie aux bestiaires : elle devient soit «l'emblème des fidèles de Dieu qui reçoivent la semence de sa parole et qui luttent contre le serpent diabolique (très souvent le basilic) $»^{48}$, soit " l'image de la résurrection, partagée avec d'autres animaux (le lion, le pélican) ou de la purification $»^{49}$. Un glissement de la symbolique de la belette s'est-il réellement opéré sur la genette ? Et si oui, pour quelles raisons ${ }^{50}$ ? Motif utilisé dans l'art du Xv au début $\mathrm{du} \mathrm{XVI}^{\mathrm{e}}$ siècle, choisie et considérée tout au long $\mathrm{du} \mathrm{Xv}^{\mathrm{e}}$ pour représenter des nobles prénommés Jeanne et Jean, elle est dotée, très probablement d'une signification symbolique qui lui est propre. Plus proche aussi physiquement de l'homme à cette 
période ${ }^{51}$, ce dernier a probablement ressenti le besoin de lui attribuer la valeur symbolique d'un animal à connotation positive.

De la plupart de ces représentations où la genette défie un être symboliquement maléfique ou négatif, qu'il soit hyène, chimère, serpent ou singe, il est déduit que la genette est toujours proche de la licorne et la protège. Et en étant proche de la licorne, elle l'est aussi de la fontaine de vie, avec ou sans la licorne. Ainsi l'est-elle sur la tapisserie de Narcisse ${ }^{52}$ et il ne serait pas impossible que son carton ait pu servir à celui des deux genettes représentées sur la scène du «Baptême du Christ » dans l'église de Saint-Étienne-du-Mont à Paris et celle de Saint-Jean-Baptiste à Nemours ${ }^{53}$. Si la licorne représente le plus souvent la figure christique, la fontaine, celle qui reflète parfaitement, représente la Vierge et la bien-aimée sur terre ${ }^{54}$. La genette, indépendamment du fait qu'elle est liée à la fontaine de vie est liée à l'élément eau, indubitablement ${ }^{55}$.

Fig. 4 - Vitrail de l'église de Saint-Étienne du Mont (1541), Paris, genette, détail.

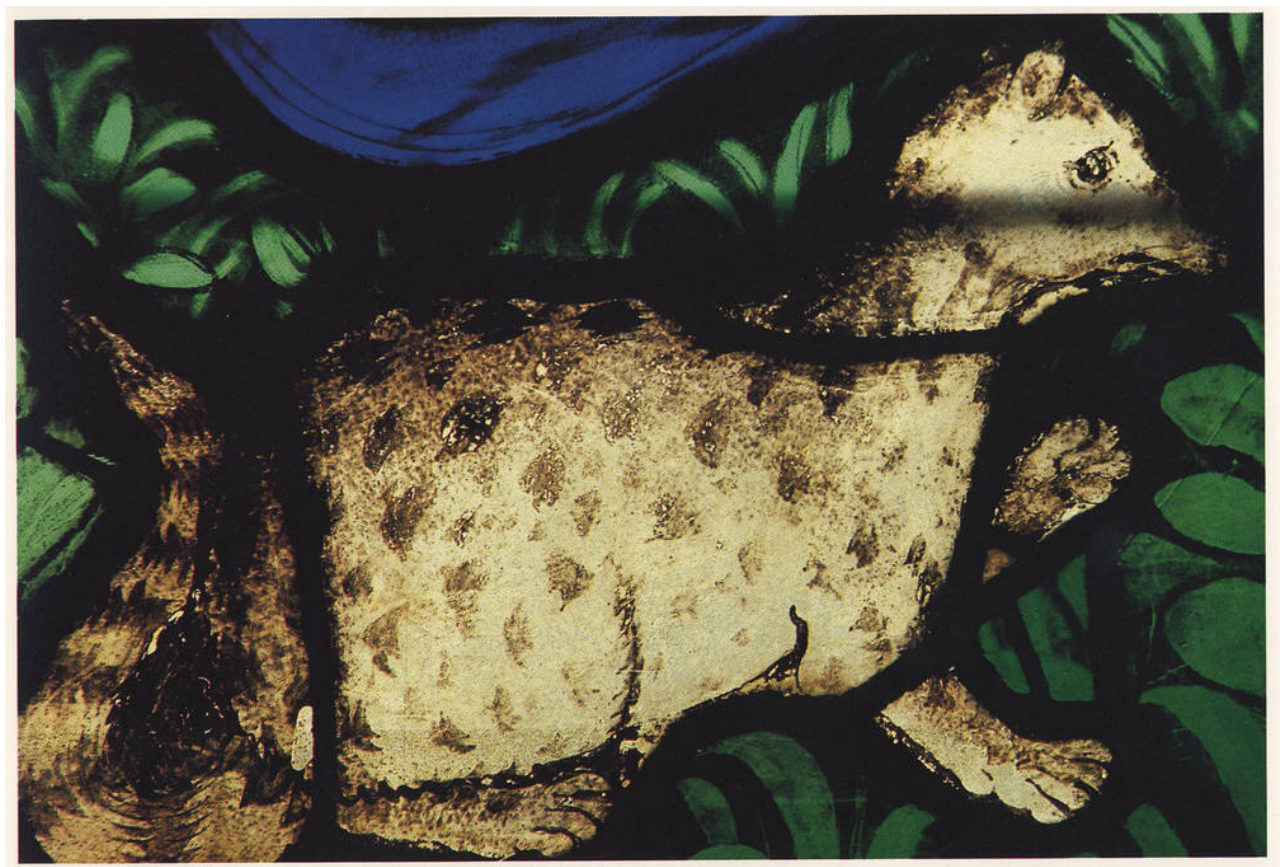

(C) Christian Parsy

Très souvent à leur côté, et à côté de figures bibliques, le Christ, dans les deux vitraux déjà cités, et des anges, notamment dans la troisième tapisserie de la série nommée Anges porteurs des instruments de la Passion (1512-1514) ${ }^{56}$, elle rejoint le cortège des animaux dont la tâche est de se confronter au Mal, tel le cerf depuis l'Antiquité. Cependant, si la belette affronte le serpent, elle l'affronte seule, pour elle-même. La genette, elle, affronte le mal pour protéger un être qui symbolise lui-même le Bien; autrement dit, elle n'intervient que si la figure du Bien qu'elle doit protéger est en péril. Dans la tapisserie dite " aux feuilles de choux " ( $\mathrm{xvI}^{\mathrm{e}}$ siècle) où la genette défie un serpent, elle le fait car Amour est en danger. Mais sa protection ne dure qu'un temps et pour un moment précis : si la genette fait en sorte que la licorne puisse mener à terme son acte purificateur parmi les animaux qui auraient pu lui nuire, elle ne peut rien 
contre les hommes qui eux, attendent que la licorne ait terminé son acte bienveillant pour la blesser et la capturer.

La genette protège la licorne (ou l'agneau pascal ${ }^{57}$ ) ou ce sentiment vertueux qu'est l'Amour. Elle conduit, accompagne en protégeant un temps, pour une étape bien définie dans la vie du protégé : dans le roman Perceforest, elle représente et protège Camille, la pucelle c'est-à-dire une Licorne incarnée, sur les armoiries que porte Pallidès afin de permettre au couple d'être réuni ; elle permet à la licorne de purifier l'eau afin que tous, animaux comme humains puissent s'abreuver; elle permet à Ève de choisir ne serait-ce qu'un temps. Si elle guide en protégeant, elle le fait par amour ; aussi, est-ce sans doute la raison pour laquelle la devise du libraire Jehan Janot autour des deux genettes est :

« Tout par amour, Amour par tout, Par tout amour.»

Ainsi la genette paraît-elle avoir la signification symbolique amplifiée de la belette. Son essence même protège ce qui doit être protégé. Elle accomplit sa tâche, comme le passeur, pour un temps. En cela, la genette de l'Occident médiéval (des $\mathrm{xv}^{\mathrm{e}}$ et $\mathrm{XVI}^{\mathrm{e}}$ siècles) est liée intrinsèquement à l'antique Mafdet ${ }^{58}$.

Son absence des bestiaires des clercs du $\mathrm{v}^{\mathrm{e}}$ au XII ${ }^{\mathrm{e}}$ siècle l'a préservée de l'attribution d'un caractère ambivalent, les rapports qu'entretient l'homme avec la faune étant très nombreux à cette période, mêlant sentiments contradictoires comme l'admiration, l'amour ou la peur, la méfiance, voire l'hostilité et la haine. La réalité du contact quotidien conditionne les relations affectives que l'homme tisse avec l'animal mais " celles-ci sont renforcées par l'exploitation symbolique, propre à chaque société, de l'animal et de ses comportements » ${ }^{59}$. Un même animal peut être méprisé à une époque puis estimé à une autre ${ }^{60}$. La genette ne sera donc entachée d'aucun opprobre par les auteurs ecclésiastiques, privilège que tous les grands et petits carnivores n'auront pas eu.

Il reste à savoir, tout en considérant avec prudence les interprétations et hypothèses proposées ici, depuis quand et pourquoi la genette a acquis cette valeur symbolique. Dans la période perturbée qu'est le $\mathrm{xv}^{\mathrm{e}}$ siècle par la guerre de cent ans opposant la France et l'Angleterre et la fin de la Reconquista espagnole, il était nécessaire de croire en un monde où le Bien triompherait. La genette était cet animal musqué, au pelage exotique, officieuse auxiliaire contre souris et rats, capable de réenchanter ce monde, si instable. Sa valeur symbolique est-elle liée à sa longue queue présentant des analogies dans ses représentations avec la corne de la licorne ${ }^{61}$ ou est-elle une conséquence logique de sa popularité incontestable puis de son anoblissement tout au long du $\mathrm{xv}^{\mathrm{e}}$ siècle par le double rébus, la promouvant ainsi aux côtés de la Vierge Marie que Jeanne de France, épouse de Jean II et sainte Jeanne, sa nièce, vénéraient tant ${ }^{62}$ ? 


\section{BIBLIOGRAPHIE}

AVRIL François et REYNAUD Nicole, Les manuscrits à peinture en France 1440-1520, Paris, FlammarionBibliothèque Nationale, 1993, 440 pages.

DELIBES Miguel, Virginie MÉZAN-MUXART et CALZADA Javier, « Albino and melanistic genets (Genetta genetta) in Europe ", Acta Theriologica, Volume 58, 2013, p. 94-99.

DRAELANTS Isabelle, « De la compilation au Centon. Les emprunts à Arnold de Saxe dans l'Hortus Sanitatis : quels intermédiaires ?», Kentron, n² 29, p. 19-68.

GIRBEA Catalina, « Pratiques héraldiques dans Perceforest » dans Perceforest, un roman arthurien et sa réception, textes réunis par Christine FERLAMPIN-ACHER, Presses Universitaires de Rennes,

«Interférences », Rennes, 2012, p. 163-177.

FREEMAN MARGARET B., La Chasse à la licorne : prestigieuse tenture française des Cloisters, adapté en français par Pierre Alexandre, Edita S.A. Lausanne, 1983, 247 pages.

HABLOT Laurent, La devise, mise en signe du prince, mise en scène du pouvoir, Les devises et l'emblématique des princes en France et en Europe à la fin du Moyen Âge, thèse de doctorat en Histoire médiévale, sous la direction de Martin Aurell et Michel PASTOUREAU, université de Poitiers, 2001, 787 pages.

MÉZAN-MUXART Virginie, « Genette et janette : devises de Jeanne de France au Xve siècle », dans VAN DEN ABEELE Baudouin and WACKERS Paul (eds.), Reinardus : Yearbook of the International Reynard Society, volume XXII, 2010, p. 104-125.

MURATOVA Xénia, «La fortune des bestiaires au XVI ${ }^{\mathrm{e}}$ siècle : une série inconnue de tapisseries flamandes ", L'animal dans la littérature, actes du colloque de Tokyo de la Société Internationale Renardienne du 22 au 24 juillet 1996 à l'université Keio, édités par Hideichi MATSUBARA, Satoru SUZUKI, Naoyuki fUKUMOTO et Noboru HARANO, Keio University Press, Tokyo, p. 201-237.

MUXART Virginie, Savoirs et représentations de la genette (Genetta genetta) dans le bassin méditerranéen de la préhistoire à nos jours. Histoire d'une belle méconnue, thèse de doctorat en littérature générale et comparée, dirigée par Mesdames les professeurs Corinne BECK et Juliette VION-DURY, Université Paris 13-Paris Sorbonne Cité, 2016, tome I, 549 pages et tome II, 159 pages.

PASTOUREAU Michel, Figures et couleurs. Étude sur la symbolique et la sensibilité médiévales, Paris, Le Léopard d'or, 1986, 244 pages.

STIRNEMANN Patricia, L'enluminure en France au temps de Jean Fouquet : [exposition, Chantilly, musée Condé, 26 mars-22 juin 2003], Somogy, Paris 2003, 93 pages.

STIRNEMANN Patricia, « Histoire d'amour sans paroles », Art de l'enluminure, ${ }^{\circ}{ }^{\circ}$, Hors-série de l'Art et métiers du livre, Paris, juin/juillet/août 2003, p. 4-57.

TESNIÈRE Marie-Hélène, Bestiaire médiéval, enluminures, Paris, Bibliothèque nationale de France, 2005, 240 pages.

VOISENET Jacques, Bêtes et Hommes dans le monde médiéval. Le bestiaire des clercs du ve au XII siècle, Turnhout, Préface de Jacques LE GOFF, Brepols, 2000, 552 pages.

ZUCKER Arnaud, Physiologos : bestiaire des bestiaires, Éditions Jérôme Millon, Paris, 2004, 325 pages. 


\section{NOTES}

1. V. Muxart, Savoirs et représentations de la genette (Genetta genetta) dans le bassin méditerranéen de la préhistoire à nos jours, t. 1 et 2.

2. Dans le bassin méditerranéen, elle est présente essentiellement en Afrique du Nord, en Espagne, au Portugal, en France, jusqu'à la Loire, et en Italie où elle a été observée dans la vallée d'Aoste.

3. Son pelage gris fauve est tacheté de noir sur le corps et sa longue queue annelée est composée de 8 à 9 anneaux noirs. Son museau pointu est bordé de part et d'autre par une bande noire, ses yeux sont de couleur rouge foncé à brun, ses oreilles sont relativement grandes, ses vibrisses développées peuvent atteindre jusqu'à $9 \mathrm{~cm}$. La longueur totale de l'animal est en moyenne de $95 \mathrm{~cm}$ dont une longueur moyenne de queue de $44 \mathrm{~cm}$.

4. Les sources archéozoologiques concernant la présence de la genette en Europe ne sont guère plus loquaces : trois sites seulement, tous situés en Europe du sud, attestent sa présence au Moyen Âge. Cf. V. Muxart, Savoirs et représentations de la genette (Genetta genetta) dans le bassin méditerranéen de la préhistoire à nos jours, t. 1, p. 156-157, 196-197 et t. 2, « Carte des ossements de genette dans le bassin méditerranéen de la préhistoire à nos jours », p. 148.

5. La recherche a été étendue dans les textes orientaux, en procédant par sondages. Cf. V. Muxart, Savoirs et représentations de la genette (Genetta genetta) dans le bassin méditerranéen de la préhistoire à nos jours, t. 1, 4.1.3. «Piste sans indices », p. 161-171.

6. Perceforest, troisième partie, t. II, édition critique par Gilles Roussineau, ouvrage publié avec le concours du Centre national de la recherche scientifique, p.130-161, «XXXVII. Comment le septième tournoy fut prolongé pour l'amour que le chevalier aux papegais estoit navré ; comment la pucelle Camille se navra de son gré et comment après leur garison le chevalier gaigna le pris du tournoy et eut sa dame ».

7. Au Turpinoy, surgit « hors de la forest ung chevalier bien monté, qui portait ung escu d'asur a une blanche jenette " in Perceforest, troisième partie, t. II, p. 146. Cette genette blanche est très probablement une genette albinos. M. Delibes, V. Mézan-Muxart \& J. Calzada, «Albino and melanistic genets (Genetta genetta) in Europe », p. 94-99.

8. Dans le roman arthurien, le nom est important. Dans Perceforest, «ce sont les armoiries et non les noms qui définissent les preux chevaliers»: "la sémiologie iconique remplace l'onomastique» (C. Girbea, «Pratiques héraldiques dans Perceforest », p. 174). Ainsi, le "Chevalier à la Genette » est-il acclamé et félicité et peu importe son nom.

9. Pour l'analyse entière du passage: V. Muxart, Savoirs et représentations de la genette (Genetta genetta) dans le bassin méditerranéen de la préhistoire à nos jours, t. 1, p. 229-234.

10. Comme nous l'a appris la thèse de Laurent Hablot, grâce aussi aux recherches de Nicole Reynaud, François Avril et Patricia Stirnemann. L._Hablot, La devise, mise en signe du prince, mise en scène du pouvoir, Les devises et l'emblématique des princes en France et en Europe à la fin du Moyen Âge, p. 96, 138, 255, 669 et 734 .

11. V. Mézan-Muxart, «Genette et janette : devises de Jeanne de France au Xve siècle ", p. 104-125 et thèse, vol. 1, p. 258-259. 
12. V. Muxart, Savoirs et représentations de la genette (Genetta genetta) dans le bassin méditerranéen de la préhistoire à nos jours, t. 1, 1.3.3, "Les sources iconographiques ", «1.3.3.4. Moyen Âge », p. 69-75.

13. M. B. Freeman, La Chasse à la licorne, adapté en français par Pierre Alexandre, Edita S.A. Lausanne, 1983, chapitre intitulé « La genette, la belette et l'hermine », p. 78-79.

14. Son corpus est constitué du folio 155 du ms. Chantilly 776 (1460), de la tapisserie de «La vue » de La Dame à la Licorne (elle ne mentionne pas la tapisserie intitulée «Le goût » sans doute parce que la genette n'est pas située sur lî̂lot, au côté de la licorne), du folio 17 du ms. Paris BNF Fr 64, Histoire ancienne jusqu'à César et Faits des Romains (1460-1465 ?) peint par le Maître de Coëtivy et du folio 2, une estampe représentant "La tentation d'Adam et Ève », créée pour l'édition d'Antoine Vérard en 1498, utilisée pour illustrer sa Bible historiée.

15. M. B. Freeman revient sur les caractéristiques de la belette citées le plus souvent dans les bestiaires : recevoir la semence par la bouche, mettre bas par l'oreille (ou inversement, selon les versions), ressusciter ses petits par de la rue si elle les trouve morts (dans l'Ortus Sanitatis), chasser souris et serpents et vaincre le Basilic. Ibid., p. 79.

16. Ibid., p. 78.

17. V. Muxart, Savoirs et représentations de la genette (Genetta genetta) dans le bassin méditerranéen de la préhistoire à nos jours, t. 1, 4.2.1. "À la fourrure recherchée", p. 171-178, 4.3.1 « Une fourrure inestimable », p. 217-234.

18. Il s'agit de l'une des tapisseries "aux feuilles de choux» d'une collection particulière étudiée par X. Muratova, "La fortune des bestiaires au XvI siècle: une série inconnue de tapisseries flamandes ", L'animal dans la littérature, p. 201-237.

19. Voir vol. 2, p. 73. Voici le lien vers la tapisserie "The Unicorn is Found", seconde tapisserie de la Chasse à la Licorne (1495-1505), sur le site du Metropolitan Museum of Arts de New York : https://www.metmuseum.org/art/collection/search/467638.

20. M. B. Freeman, La Chasse à la licorne, p. 96.

21. J. Voisenet, Bêtes et Hommes dans le monde médiéval. Le bestiaire des clercs du ve au VII siècle, p. 309.

22. Le pouvoir prophylactique de la corne de la licorne est très connu au Moyen Âge. Cf.

A. Zucker, Physiologos : bestiaire des bestiaires, p. 157.

23. M. Pastoureau, Figures et couleurs, p. 9.

24. J. Voisenet, Bêtes et Hommes dans le monde médiéval. Le bestiaire des clercs du ve au $\mathrm{VII}^{e}$ siècle, ibid., p. 60 : « elle ne présente aucune cruauté (laissée au léopard) mais une grande douceur qui en fait l'image du Christ ».

25. M. B. Freeman, La Chasse à la licorne, ibid., p. 79.

26. J. Voisenet, Bêtes et Hommes dans le monde médiéval. Le bestiaire des clercs du VII au XII siècle, ibid., p. 359.

27. Ce manuscrit (1460) renferme la traduction française de Guillaume Coquillart du De bello judaico, de Flavius Josèphe. Voici le lien vers le folio 155 du ms 776 de la bibliothèque du musée Condé, mis en ligne sur la BVMM : https://iiif.irht.cnrs.fr/iiif/ Chantilly/M601415401_MS0776/jp2/M601415401_MS0776_0159/full/full/0/default.jpg

28. P. Stirnemann, L'enluminure en France au temps de Jean Fouquet, p. 73. 
29. Cette licorne devait sans doute faire allusion à son titre de "Seigneur de Malicorne » qu'il détenait de son propre père, Guy de Chourses. Elle constitue avec la rose les emblèmes du couple (cf. http://initiale.irht.cnrs.fr/ouvrages/ouvrages.php? $\mathrm{id}=9198 \& i n d e x$ Courant $=0$ ). Les initiales « $\mathrm{A}$ » et « $\mathrm{K}$ » sont placés à droite de la licorne et de la tige de roses.

30. J. Voisenet, Bêtes et Hommes dans le monde médiéval. Le bestiaire des clercs du ve au XII siècle, p. 359.

31. Ibid., p. 67. Voir aussi p. 65 et 66.

32. M.-H. Tesnière, Bestiaire médiéval, enluminures, p. 34. L'enlumineur est Étienne Collaut. Voici le lien vers le folio $87 \mathrm{du}$ ms. BNF Fr. 1537 (Auber et al., Chants royaux sur la Conception couronnés au Puy de Rouen de 1519 à 1528, vers 1530) : https://gallica.bnf.fr/ ark:/12148/btv1b8539706t/f179.image

33. Ms. Paris BNF Fr. 1537, folio 87v, troisième vers de la deuxième strophe : « Les ords serpents sont du lieu interdits («ord»: «sale, rempli de malpropreté, de souillures $[\ldots] »$.

34. Sur la seconde tapisserie de la "Chasse à la Licorne », le cerf est aussi représenté face à la licorne. Ils sont cependant disposés inversement et la licorne accomplit son acte purificateur.

35. M.-H. Tesnière, Bestiaire médiéval, enluminures, p. 35.

36. Voici le lien vers le folio 17 du ms. BNF 64 (Histoire ancienne jusqu'à César et Faits des Romains, 1460-1465 ?) : https://gallica.bnf.fr/ark:/12148/btv1b85624763/f37.item

37. Dans le folio $17 \mathrm{du} \mathrm{ms}$. BNF 64, la licorne n'apparaît pas, mais la genette est peinte dans la même attitude que celle de la deuxième tapisserie de la "Chasse à la licorne ", et le cerf ressemble très fortement à celui qui court derrière la licorne sur l'estampe (folio 2 de la Bible Historiée). La licorne de l'estampe ressemble aussi à celle de la tapisserie. Si la fontaine, la genette et l'oiseau semblent être repris de la seconde tapisserie de La Chasse à la Licorne, c'est que peut-être, le dessinateur du folio 17 et le maquettiste de la tapisserie sont de la même école ou sont une seule et même personne.

38. Nicole Reynaud consacre une page à ce «dernier des trois artistes de la seconde triade parisienne ", " successeur et héritier du Maître de Coëtivy, avec qui les frontières sont parfois délicates à établir ». Peintre de métier, il «a surtout fourni en abondance des cartons pour le vitrail et la tapisserie, domaine où son rôle a été de premier plan à la fin du siècle et où il a dominé le marché de façon écrasante : en effet, non seulement il a donné les grands patrons originaux pour plusieurs vitraux d'origine parisienne [...] mais il a animé un atelier dont les modèles et les pratiques lui ont survécu (SaintEtienne-du-Mont, Saint-Merry, Saint-Gervais) et se sont diffusés jusque vers 1520, et particulièrement en Normandie autour de Rouen. De même, on lui doit les patrons ou les modèles de plusieurs tentures célèbres (Chasse à la licorne, New York, Cloisters; Femmes vertueuses, Boston, Museum of Fine Arts ; Persée, coll. part.; Dame à la licorne, Paris, musée de Cluny), certaines exécutées pour de hauts magistrats parisiens (Le Viste, Guillard).» Cf. François Avril et Nicole Reynaud, Les manuscrits à peinture en France, p. 265.

39. Jean d'Ypres avait bien compris l'enjeu de la nouvelle technique de l'imprimerie. Cf. François Avril et Nicole Reynaud, Les manuscrits à peinture en France, p. 268. 
40. Sur la genette, emblème des libraires parisiens : V. Muxart, Savoirs et représentations de la genette (Genetta genetta) dans le bassin méditerranéen de la préhistoire à nos jours, t. 1 , p. 272-273.

41. Scène reproduite d'après l'article: X. Muratova, «La fortune des bestiaires au $\mathrm{xVI}^{\mathrm{e}}$ siècle : une série inconnue de tapisseries flamandes ", L'animal dans la littérature, p. 222, fig. II. 3.b.

42. Ibid., p. 205. L'auteur mentionne aussi que ces tapisseries ont des points communs avec la production des ateliers de la Marche (Felletin ou Aubusson).

43. Ibid., p. 203. Cette démonstration fort juste vient tout à propos pour soutenir ce qui a été précédemment écrit, à savoir que les enluminures ou estampes étudiées ont pu servir de source aux tapisseries, notamment la deuxième de La Chasse à la Licorne.

44. Ibid., p. 209.

45. Ibid., p. 207. L'auteur cite en note 21 p. 207, L’Encyclopédie des animaux du monde, p. 110-119.

46. Ni à la p. 851 d'Historiae animalium. Libri I: de quadrupedibus viviparis de Conrad Gesner, ni à la p. 100 du Icones animalium quadrupedum viviparorum et oviparorum. Il est à noter que Gesner puis Aldrovandi rapportent tous les deux la critique de Scaliger à l'encontre de la classification de la genette dans la famille des belettes de Jérôme Cardan (Cf. Conrad Gesner, d'Historiae animalium. Libri I : de quadrupedibus viviparis, ibid., p. 619 et Icones animalium quadrupedum viviparorum et oviparorum, ibid., p. 70-71). Depuis au moins Pline, deux sortes de belettes sont différenciées; la sauvage, plus grande et l'autre, plus petite, qui erre dans les maisons. Reste que Thomas de Cantimpré n'a jamais classé la genette dans la famille des belettes (mais Gesner et Aldrovandi ne mentionnent qu'Isidore de Séville, Vincent de Beauvais et Albert le Grand). Xenia Muratova écrit donc en légende du détail « serpent-genette » : fig. II. 3.b : «Belette et serpents (détail de la tapisserie 1) dans X. Muratova, «La fortune des bestiaires au $\mathrm{XVI}^{\mathrm{e}}$ siècle : une série inconnue de tapisseries flamandes ", p. 232.

47. V. Muxart, Savoirs et représentations de la genette (Genetta genetta) dans le bassin méditerranéen de la préhistoire à nos jours, t. 1, p. 462-463.

48. J. Voisenet, Bêtes et Hommes dans le monde médiéval. Le bestiaire des clercs du $v^{e}$ au $\mathrm{XII}^{e}$ siècle, ibid., p. 91 et note 31. Voir aussi p. 92, note 32. Jacques Voisenet cite le Bestiaire de Pierre de Beauvais, le Bestiaire Divin de Guillaume le Clerc de Normandie et Li Livres dou Tresor de Brunetto Latini.

49. Ibid., p. 92, notes 33 et 34. L'auteur cite Li Livres dou Tresor de Brunetto Latini ainsi que Louis Charbonneau-Lassay, Le Bestiaire du Christ, Bruges, 1940, p. 322.

50. Serait-ce la conséquence dans ce cas du rapprochement textuel des articles de la belette et de la genette dans l'encyclopédie de Vincent de Beauvais qui perdure dans l'Ortus Sanitatis? L'article « Gala et genetha » (in BC ms. Res 13-Fol, Ortus Sanitatis) a été rédigé à partir de trois sources, parmi lesquelles la principale, le Speculum naturale de Vincent de Beauvais, les Pandectesde Mattheus Silvaticus et l'Encyclopédie d'Albert le Grand (Cf. Isabelle Draelants, « De la compilation au Centon. Les emprunts à Arnold de Saxe dans l'Hortus Sanitatis : quels intermédiaires? », p. 19-68).

51. V. Muxart, Savoirs et représentations de la genette (Genetta genetta) dans le bassin méditerranéen de la préhistoire à nos jours, t. 1, 4.3.2. "La genette dans l'espace social ", p. 234-246. 
52. Tapisserie conservée au Museum of Fine Arts de Boston, aux mille-fleurs, reprend les animaux sauvages classiques du genre: faisan sur la margelle de la fontaine de vie, lapins, perdrix, hérons. Elle compte aussi deux petits carnivores: la genette, se trouvant à gauche de la fontaine et occupant seule le quart gauche inférieur de la tapisserie, sur le fond floral et un mustélidé à droite de la fontaine qui pourrait être identifié à un furet. Ce dernier qui se retrouve aussi sur la Tapisserie de Persée avait été injustement identifié à une genette (cf. M. B. Freeman, La Chasse à la licorne, ibid., p. 206) alors qu'il est l'exacte copie, à l'envers, de celui qui figure sur la tapisserie de Narcisse. La genette est d'une très grande qualité (même si le profil ressemble davantage à celui d'un chien à cause du museau): courte sur pattes, corps tacheté et longue queue annelée. Voici le lien vers la tapisserie: http://www.mfa.org/collections/object/ tapestry-narcissus-37423)

53. V. Muxart, Savoirs et représentations de la genette (Genetta genetta) dans le bassin méditerranéen de la préhistoire à nos jours, t. 1, p. 278, note 1130.

54. M. B. Freeman, La Chasse à la licorne, p.119-120. De plus, "nombre d'hymnes médiévaux louent la Vierge en l'appelant fontaine », dans le Stabat Mater, Marie est « la fontaine d'Amour ".

55. Il est à rappeler aussi que les naturalistes eux-mêmes, reprenant à leur tour ce qu'avaient écrit les encyclopédistes (sans jamais citer - regrettablement - Thomas de Cantimpré, mais Isidore et Vincent de Beauvais) ont établi une relation entre la genette et les milieux humides (Cf. Ulysse Aldrovandi, De quadrupedibus digitatis viviparis, libri tres et De quadrupedibus digitatis oviparis libri duo, p. 340).

56. V. Muxart, Savoirs et représentations de la genette (Genetta genetta) dans le bassin méditerranéen de la préhistoire à nos jours, t. 1, p. 273-274.

57. Sur le folio 1 du ms. Aix-en-Provence 1552 (1511).

58. V. Muxart, Savoirs et représentations de la genette (Genetta genetta) dans le bassin méditerranéen de la préhistoire à nos jours, t. 1, 3.1.2. « Déesse Mafdet », p. 126-134.

59. J. Voisenet, Bêtes et Hommes dans le monde médiéval. Le bestiaire des clercs $d u X^{e} a u$ XII siècle, p. 91 et 239.

60. Ibid., p. 239 et p. 92 , note 35 . Cependant, certains animaux parviennent à se doter d'une face positive après le $\mathrm{XI}^{\mathrm{e}}$ siècle comme la belette, déclarée impure car faisant partie des animaux "rampants", qui a réussi à échapper à une présentation entièrement dégradante, "probablement en raison de son état de bête quasidomestique au service de l'homme » (alors que, paradoxalement, le chat qui remplissait les mêmes fonctions et s'utilisait dans tout l'Occident, s'infernalisait).

61. Il est à noter que sur le folio 259 du ms. BNF 20124, le r7v. du BC Res. 1270-12 (Heures de Vostre), la queue des genettes est torsadée et s'apparente à la représentation classique de la corne de la licorne.

62. Cf. Passage p. 257 : « Enfin, par-delà le jeu de mots, la genette aurait-elle sa propre symbolique pour ces femmes dénommées Jeanne? Révélerait-elle implicitement une référence religieuse à la Vierge que Jeanne vénérait tant ? Est-ce une coïncidence si la fleur de janette est appelée aussi «fleur de la Vierge », « Marienrösslein » (" petite rose de Marie ») ou encore « slzičky panny Marie » (« larmes de Sainte-Marie ») ? ». 


\section{RÉSUMÉS}

Animal originaire d'Afrique du nord, atypique sous nos latitudes, la genette européenne (Genetta genetta) est très singulière tant par sa physionomie (tête fuselée, oreilles de renard, taches de panthère et longue queue annelée de lémurien) que par sa discrétion. Alors qu'elle a été représentée notamment sur deux des tentures de la Dame à la Licorne et que sa fourrure était très prisée tout au long des $\mathrm{Xv}^{\mathrm{e}}$ et $\mathrm{XVI}^{\mathrm{e}}$ siècles, il faut se rendre à l'évidence : elle est absente des bestiaires médiévaux. La genette est-elle pour autant dénuée de toute signification symbolique dans la société médiévale? Dans cet article nous nous proposons de présenter les résultats de notre recherche de doctorat qui a mobilisé notamment quelques sources textuelles, mais surtout des sources iconographiques variées telles qu'enluminures de manuscrits, tapisseries, vitraux et estampes.

\section{AUTEUR}

\section{VIRGINIE MUXART}

Docteur en Littérature générale et comparée, membre associé au laboratoire PLEIADE de Paris 13-

Sorbonne Paris Cité 